Itzamkanac y Acalan Tímpos de crisis anticipando el futuro

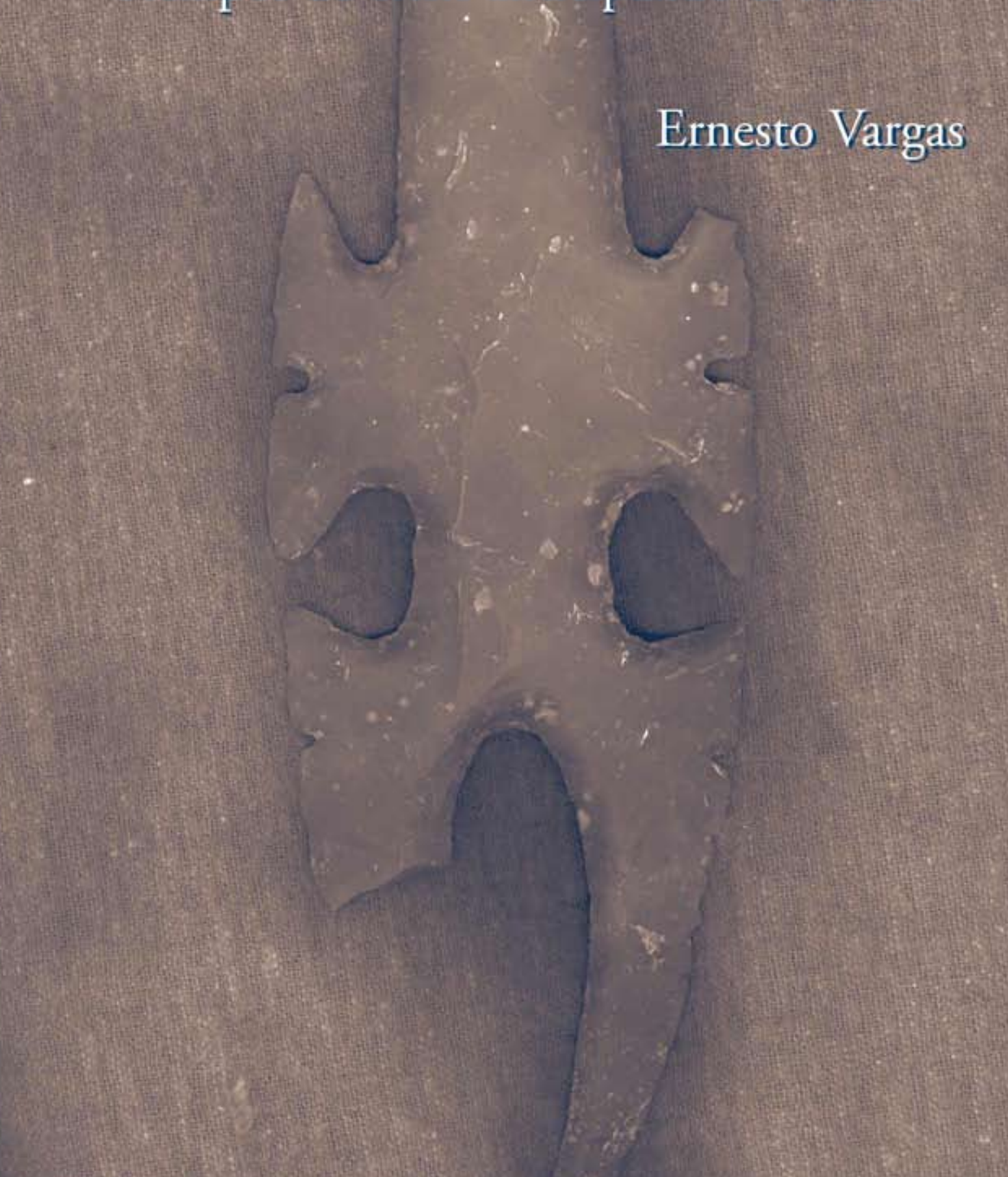


Itzamkanac y Acalan

Tiempos de crisis anticipando el futuro 
Diseño de portada: Martha González S.

Cuchillo de pedernal procedente de la Estructura 1. El Tigre.

Primera edición impresa 2001

Primera edición electrónica 2015

(C) Instituto de Investigaciones Antropológicas

Universidad Nacional Autónoma de México

Ciudad Universitaria, 04510, México, D. F.

ISBN 968-36-9345-8 versión impresa

ISBN 978-607-02-6648-5 versión electrónica

D. R. Derechos reservados conforme a la ley.

Hecho en México/Made in Mexico 


\title{
Itzamkanac y Acalan Tiempos de crisis anticipando el futuro
}

\author{
Ernesto Vargas
}





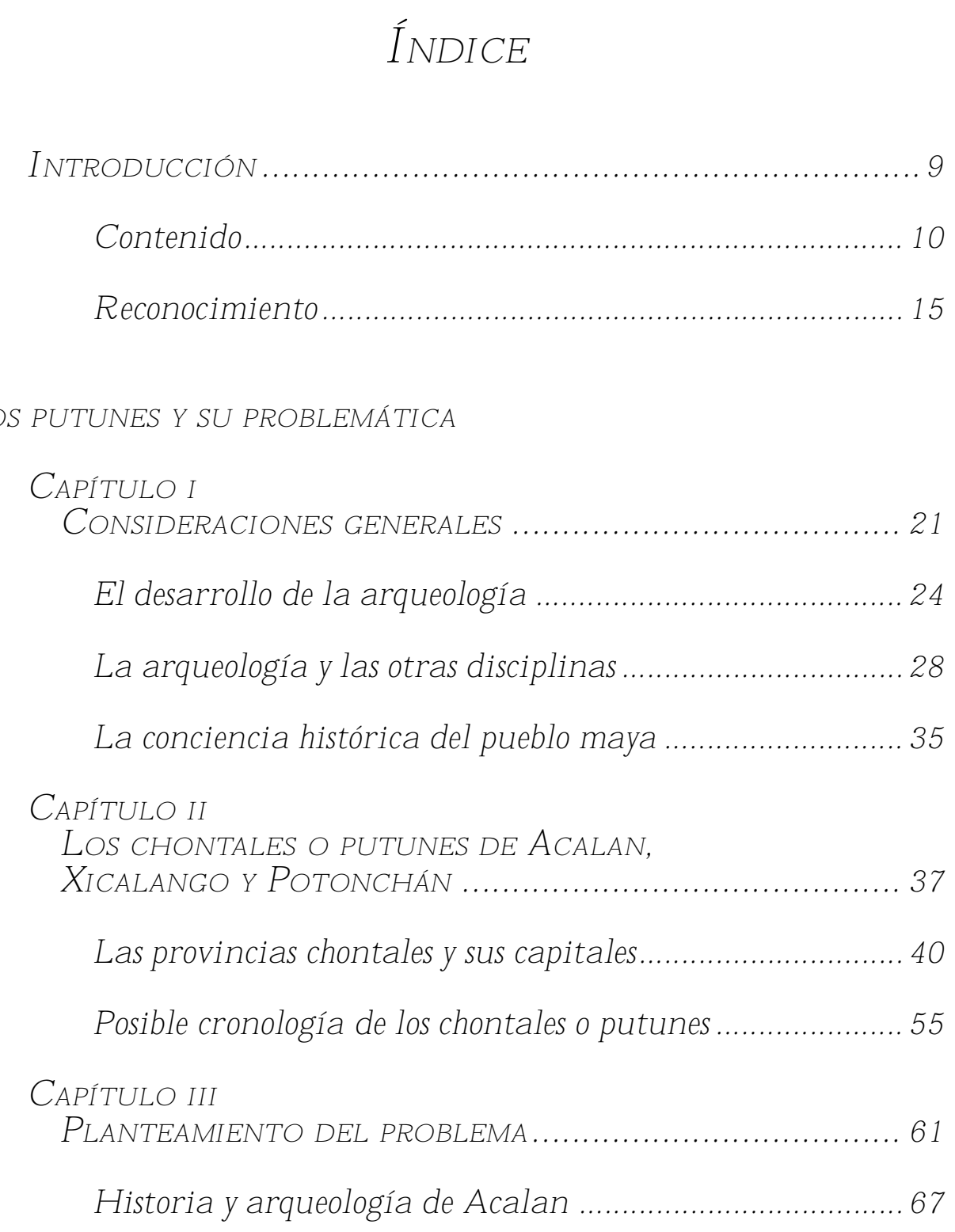


Historia y arqueología de Acalan

Capítulo I

La PROVINCIA DE ACALAN-TIXChEL

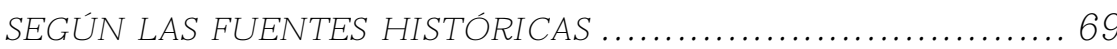

U bicación y límites de la provincia .....................................69

I tzamkanac cabecera de la provincia ..................................74

Los pobladores de la provincia

de A calan según lasfuentes ............................................... 81

R econstruccion del área a partir de las fuentes.................90

Capítulo II

La PROVINCIA de ACALAN-TixCheL

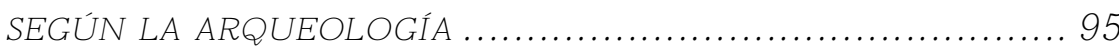

A nteceden tes a rqu eol ógi cos................................................ 95

EI Preclásico. Primeras ocupaci ones ...................................98

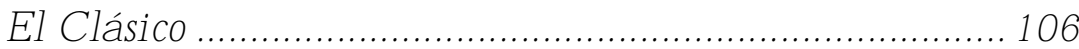

EI C lásico terminal. El auge de la región chontal ...........110

El Postclásico ...................................................................

Síntesis de la arqueología de la provincia de A calan ......115

El Río y la PROVINCIA de ACALAN

Capítulo I

El río Candelaria, ordenamiento y Planeación ..... 121

Ordenami ento del espacio y planeación de los poblados... 121

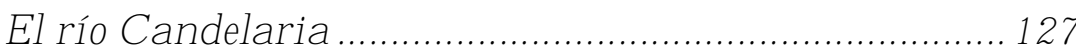

El agua en la cosmovisión maya-chontal .........................147 
ITZAM KANAC Y ACALAN, Tiempos de crisis anticipando el futuro

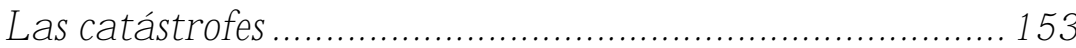

Capítulo II

Itzamkanac cabecera de la Provincia de Acalan ... 157

La Provincia de A calan ................................................ 157

La cabecera dela provincia. I tzamkanac ........................ 162

Capítulo III

Los putunes de Acalan y los itzaes ........................ 195

Los itzaes y los putunes.................................................. 195

Presencia yucateca en la región chontal.

Evidencias históricas y a rqueológicas................................ 197

Presencia putún en la Península de Yucatán.

Eviden cias históricas y arqueológi cas...............................20 20

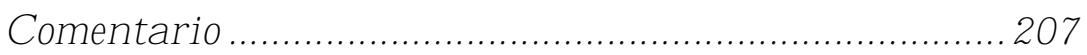

TIEMPOS DE CRISIS ANTICIPANDO EL FUTURO

Capítulo I

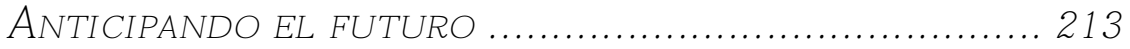

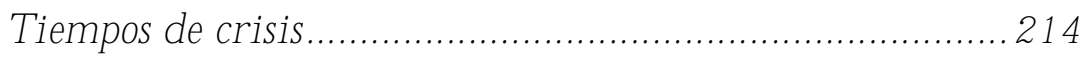

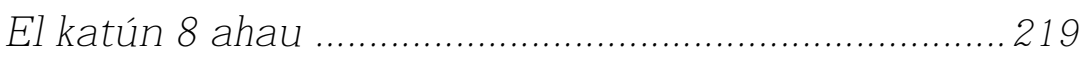

Capítulo il

LA GEOGRAFÍA POLITITA Y EL ESPACIO

SAGRADO EN ACALAN .............................................. 227

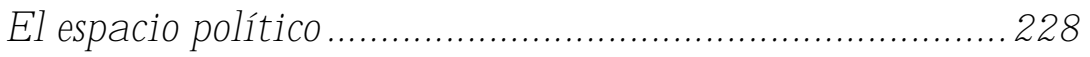

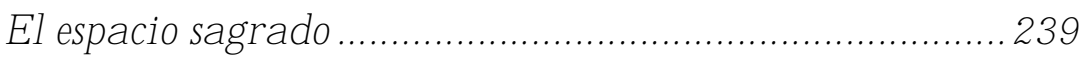

Capítulo III

COMENTARIO FINAL ................................................ 243 
ERNESTO VARGAS

A calan el tzamkanac..................................................... 243

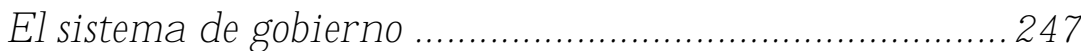

El ti empo y el espacio sagrado .......................................... 249

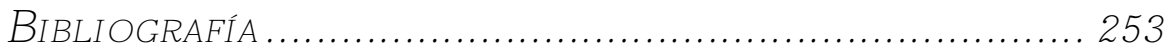




\section{INTRODUCCIÓN}

Campeche, al nacer como estado en el siglo pasado, realiza varios intentos por afirmar la existencia de una identidad campechana diferenciada de la yucateca. En el intento, ha logrado «recrear» la historia peninsular desde los tiempos prehispánicos hasta la separación de Yucatán.

Sin embargo, el sur de Campeche es de gran importancia para la entidad en particular y para la península de Yucatán, G uatemala y el centro de M éxico, dado que los itzaes, cocomes, xiues, canules, dicen venir de esa región, lo mismo que los quichés y cakchiqueles de Guatemala. EI centro de M éxico también tiene que ver mucho con la zona, pues se habla de la presencia tanto de olmecas xicalancas como toltecas en dicho lugar; la muerte de C uauhtémoc, último tlatoani de M éxico Tenochtitlan, se dio en la rica provincia de Acalan, precisamente en lo que hoy es $C$ andelaria y EI C armen.

D entro de la historiografía campechana, El C armen desempeña un papel importante; éste radica primero en la piratería y después en el auge del corte del palo de tinte, el cual hizo que se incorporara rápidamente al mercado mundial y prácticamente soportara el peso de la economía de Campeche durante el siglo $x I x$.

EI C armen y $C$ andelaria tienen una historia propia. En la primera mitad de ese siglo, EI Carmen dependió políticamente no sólo de Yucatán, sino también de Puebla y Tabasco, y entre 1853 y 1856 fue convertido en territorio federal. Con anterioridad había sido tierra y refugio de piratas, tema por demás interesante y del cual existen magníficos trabajos. D urante la época prehispánica perteneció a uno de los cacicazgos más importantes del área maya, la provincia de Acalan.

Los estudios arqueológicos realizados en esta zona son escasos y generalmente corresponden a reconocimientos de superficie parciales, en los cuales se describen al gunos sitios y las estructuras principal es con lostiestos ahí encontrados.

Andrews, Blom, Ruz L., Ball, Piña Chan y Pavón Abreu, etcétera, de una u otra manera han pretendido dar importancia arqueológica a la región, pues según las fuentes históricas ahí se localizaban C hakamputún, T ixchel, I tzamkanac, Xicalango y Potonchán. A pesar de que estos grandes arqueólogos se interesaron por esa región, todavía se desconoce casi en su totalidad la información y nunca se ha llevado a cabo un proyecto de investigación sistemático, que plantee el problema arqueológico de la provincia de Acalan; por ello la importancia de estudiar I tzamkanac como la gran capital de dicho cuchcabal. 
Por las fuentes históricas y los restos arqueológicos reportados, se sabe que ésta fue una región relevante para el comercio, como ruta de entrada a la zona maya en la que convivieron diversos grupos humanos y de donde dicen venir otros. Ahí habitaron chontales, cehaches, mayas yucatecos y hacia el sur, en Tabasco, los zoques y nahuas.

L os chontales desempeñaron un papel relevante en la región de TabascoC ampeche; las evidencias arqueológicas existentes muestran una ocupación importante, la cual deja entrever que fueron los dominadores de una ruta de comercio a través de ríos, lagunas y litoral marino.

Además, por su localización geográfica especial, los chontales entraron en contacto con diversos grupos de M esoamérica; esta área constituyó una entrada estratégica a la zona maya. D esde allí pudieron llegar por mar a toda la península de Yucatán y Centroamérica, y por el norte hasta la $\mathrm{H}$ uaxteca; asimismo, por vía fluvial arribaron a Chiapas y al Petén guatemalteco.

L as fuentes históricas son importantes para entender el pasado prehispánico, pues muchas de ellas narran hechos relacionados con la región. Baste recordar las referencias que existen en fuentes históricas del centro de M éxico, las cuales hablan de los nonoualcas y los olmecas xicalancas (cfr. Jiménez M oreno 1976, Foncerrada 1983). A su vez los principales grupos que se establecieron en Yucatán: xiues, itzaes, cocomes, cupules, canules, etcétera, dicen provenir de ahí ( cfr. Chilam Balam, L anda, López de Cogolludo). L osquichés y cakchiqueles de Guatemala también dicen ser de una región de ríos y lagunas, que bien pudiera identificarse como parte del territorio tabasqueño-campechano (cfr. Popol Vuh, A nales de los C akchiqueles, Carmack 1976).

E stas citas señalan la importancia de la región durante ese momento de perturbación en M esoamérica, conocida con el nombre de Epiclásico para el centro de M éxico y Clásico terminal para la zona maya, donde al parecer el grupo chontal desempeñó un papel más importante del que comúnmente se le atribuye. La mayor parte del territorio chontal sigue en espera de exploraciones indispensables para precisar sus rasgos esenciales.

Para entender el desarrollo histórico de este grupo es de vital importancia conocer el origen de los chontales y la visión cíclica que determinaba sus actividades políticas, religiosas y sociales y su organización político- territorial. Además, es necesario reunir más datos respecto a sus relaciones interétnicas y lingüísticas.

\section{CONTENIDO}

Anticipar el futuro en función del pasado. Este trabajo trata en gran parte sobre el manejo del tiempo, del tiempo cíclico en el cual el pasado viene a ser el futuro, el eterno retorno en el que el futuro es pasado. Todo está íntimamente relacionado con el río: alrededor de él, las ciudades y los pue- 
blos chontales se desarrollaron y desaparecieron. El katún* 8 ahau es el paradigma para lograr los objetivos de este ensayo. EI tiempo encierra dos tipos diferentes de experiencias, que son lógicamente distintas y aun contradictorias: en primer lugar tenemos la noción de repetición (recurrencia de los días, de la luna o de las estaciones), y en segundo la de no repetición (los seres vivientes nacen, envejecen y mueren); Ios fenómenos de la natural eza se repiten, pero en cambio los de la vida son irreversibles.

Pretendo realizar el análisis primero desde la perspectiva de los conocimientos que se tienen, posteriormente me referiré a los aspectos de la naturaleza, al medio geográfico y sobre todo al río, para pasar después al análisis de su organización político territorial y llegar, finalmente, al aspecto ideológico, a su cosmovisión.

Creo que ni la arqueología ni las fuentes históricas tienen por sí solas la verdad, pero tampoco están equivocadas: ambas aportan conocimiento, se complementan. Por lo tanto, trataré de explicar el desarrollo de la provincia de Acalan por medio de las fuentes históricas y la arqueología, aunque en algunos momentos parezcan contradictorias. A mi juicio, lo que nos ofrecen son puntos de vista diferentes.

La mayor parte de lo que se ha escrito sobre los chontales trata aspectos generales como la región que dominaban y sus características comunes; también se ha descrito a los chontales como un grupo muy importante durante el Postclásico tardío; de manera uniforme se han basado en fuentes históricas para afirmar que fueron los dominadores de una ruta fluvial durante el Postclásico tardío.

L as pocas exploraciones arqueo lógicas realizadas en esa región parecen confirmar que los chontales de Tabasco-Campeche son del Postclásico tardío. Con la información aportada por los reconocimientos de superficie y algunas exploraciones preliminares, ahora se puede sostener que el gran florecimiento de los chontales fue durante el Clásico terminal; sin embargo, esta afirmación no pretende nulificar las fuentes históricas, ni tampoco decir que los chontales no existían durante el Postclásico tardío.

Este problema nos plantea el que tengamos que explicar el papel de los chontales en la región desde mucho antes; por ello debemos recurrir tanto a la arqueo logía como a las fuentes históricas y, aún más, a la visión cosmogónica que tenían del universo. No podemos negar que Xicalango, Potonchán e I tzamkanac fueron ciudades importantes durante el Posclásico tardío.

A continuación se explicarán cada una de las partes y cada uno de los capítulos. EI trabajo está dividido en cuatro partes que muestran diferentes

\footnotetext{
* Baktún y katún se han puesto en cursivas sólo en los casos en que se refieren a una fecha específica. Siendo palabras mayas deberían escribirse en cursivas y sin acento, pero dada la popularización que se ha dado a la nomenclatura del calendario maya las mantendremos con acento y en redondas, salvo en los casos ya descritos (nota de los editores).
} 
aspectos del tema por tratar. La primera se refiere a los putunes en general y a la problemática de los acalanes en particular, de allí se generan los problemas que trataremos en este trabajo; la segunda parte trata de la historia y de la arqueología de la región, abarcando desde el Preclásico hasta la Conquista; la tercera parte se centra en la descripción del río Candelaria y la Provincia de Acalan y la aportación hecha por el Proyecto A rqueológico EI Tigre. Se presentan algunos resultados de gran importancia como son los mapas que reconstruyen la provincia y la cabecera de Acalan, y también tratamos con cierta amplitud el problema de los chontales y de los itzaes; y en la cuarta parte nos centramos específicamente en la organización política, el tiempo cíclico y en el espacio sagrado manejado por los mayas.

En la introducción se habla de la importancia que tienen EI Carmen y C andelaria, donde se localiza la provincia de Acalan, para la historia de Campeche. También se describe de manera breve el contenido del libro; por último se habla de las personas e instituciones que hicieron posible el trabajo.

En el capítulo । de la primera parte se analizan aquellos aspectos que tienen que ver con la arqueología y las fuentes históricas de la provincia de Acalan; en primer lugar se plantea la relación de la arqueología con las fuentes históricas, la lingüística, la iconografía y la epigrafía, para terminar aseverando que los mayas sí poseían una conciencia histórica de su pasado. Se presenta, desde el punto de vista teórico, la cercanía que debe guardar la arqueología con las otras disciplinas, historia, lingüística, iconografía y epigrafía. E n muchas ocasiones se les toma como auxiliares y no como verdaderas fuentes que sirven para resolver el problema planteado; juntas se complementan.

El capítulo II de esta primera parte trata del grupo chontal y de la posible extensión de su territorio. Posteriormente se señalan las provincias 0 cuchcabalob* mayas chontales o putunes, y se determinan tres: Tabasco, Xicalango y Acalan, cada una con su capital o cabecera y su halach uinic 0 jefes principales. Se definen para las dos primeras los principales pueblos que las componían y se delimita en general el área de cada provincia. Es importante describir Acalan, y ponerlo dentro del contexto putún; por tal motivo me interesa mostrar las otras provincias.

O tra subdivisión es la cronología del grupo maya chontal, ya que, si leemos las fuentes históricas y a los historiadores, veremos que se les identifica como del Postclásico tardío; sin embargo, por los trabajos que se han hecho a nivel arqueológico vemos que el florecimiento de dicho grupo quizás se dio durante el Clásico terminal. Esto parecería contradictorio, pero lo que intentamos es complementar la información de la arqueología con la de fuentes históricas para solucionar dichas divergencias.

* El plural en maya es agregando la partícula ob al final de la palabra. Así, el plural de cuchcabal es cuchcabalob (nota de los editores). 
En el capítulo ॥I de «L os putunes y su problemática», planteamos los principales problemas que trataremos en este trabajo y delineamos varios temas que nos interesan con respecto a los chontales; básicamente su relación con el río, sus posibles límites geográficos, algo de su cosmovisión. El problema que voy a estudiar se delimitará gracias a toda la información anterior; se plantearán al gunas hipótesis por resolver; se tratará de explicar quiénes fueron los chontales, el papel que desempeñaron en una región de ríos y lagunas, los contactos que tuvieron con otros grupos y, específicamente, su relación con los itzaes, y cómo éstos influyeron en su cosmogonía.

El capítulo I de la segunda parte trata específicamente de la provincia de Acalan, vista sólo a través de las fuentes históricas, pues de esa manera hemos definido nuestro universo de estudio. Lo hemos dividido en varios incisos, en los que se analizan las fuentes históricas indígenas, coloniales de origen hispano y documentos de archivo. Con ese legajo se pretende reconstruir el área que ocupó la provincia de Acalan; ese trabajo, lógicamente, parte de los fundamentales estudios de Scholes y Roys.

El capítulo ॥ analiza también la provincia de Acalan, que se definió gracias a las fuentes históricas, pero aquí se añade toda la información arqueológica existente. L a ocupación de la región de los ríos y lagunas data de, por lo menos, el Preclásico medio hasta la conquista española, con ocupaciones y desocupaciones en diferentes momentos; su auge se dio durante el Clásico terminal.

La tercera parte constituye el meollo del trabajo, pues nos habla de la íntima relación que tuvo la provincia de Acalan con el río. En el capítulo I nos abocamos específicamente al río $C$ andelaria; en primer lugar nos interesa ver su funcionamiento como un todo que tiene sus partes perfectamente bien distribuidas, las cuales fueron utilizadas por los acalanes para aprovechar el ordenamiento del espacio y la planeación de los poblados. Dividimos el río en Alto, M edio y Bajo C andelaria, y analizamos brevemente las modificaciones hechas para sacar mayor provecho de esa extraordinaria vía de comunicación, columna vertebral de la provincia. El agua fue fundamental para los chontales; medio esencial para la vida; gran benefactor, pero también causante de destrucción y pánico; al tratar esta dualidad hablamos brevemente de la cosmovisión de ese grupo. Al parecer, el agua provocó ocupaciones y deso cupaciones en la región; de ahí que introduzcamos estos factores de sequía o sobreabundancia de agua como elementos de destrucción importantes para los cambios que se presentan en la región.

En el capítulo ॥ de «El río y la provincia de Acalan» delimitamos primero la provincia de Acalan con sus fronteras y posible extensión, presentamos un plano topográfico con la localización de casi 150 sitios arqueológicos en gran parte ubicados por el Proyecto Arqueológico de EI Tigre y analizamos cuál pudo ser la estructura de la misma. En este mismo capítulo 
describimos EI Tigre o Itzamkanac, cabecera de la provincia de Acalan; asimismo, señalamos las principales estructuras del centro ceremonial y la extensión del sitio. Se aborda especificamente la provincia de Acalan y su cabecera I tzamkanac. Para ello se señalan todos los sitios arqueológicos localizados en los recorridos hechos durante varios años y se determina el lugar donde estuvo EI Tigre, mostrando los levantamientos topográficos y los resultad os de las excavaciones y análisis del material cerámico, producto de nuestras investigaciones de campo.

E n el capítulo III de esta tercera parte se plantea que las fuentes históricas indígenas, a pesar de que tienen una gran cantidad de mitos, bien analizadas pueden mostrar la base histórica que las sustenta; lo cual se puede comprobar a través de la arqueología. Así, presentamos brevemente la información arqueológica, lingüística, epigráfica e histórica de la presencia itzá en la región chontal y de la presencia chontal en la región de Yucatán. Participamos en todo momento de los comentarios hechos por especialistas sobre los mayas como Tozzer, Barrera Vásquez, Thompson y Piña Chan entre otros, en cuanto a que los itzaes fueron una rama de los putunes acalanes, que sin lugar a duda estuvieron ahí en la rueda katúnica, correspondiente a los años 700-950 dC, de donde salieron hacia C hichén I tzá, lugar que abandonaron en el ciclo katúnico anterior para conquistar C hakamputún. Sostenemos también que los Papeles de Paxbolom $\mathrm{M}$ aldonado narran la llegada de los magtunes desde Cozumel, y que ese hecho corresponde aproximadamente a los años de 1200 dC, al finalizar el baktún 11.0.0.0.0., y coincide con el katún 8 ahau que es catastrófico, pues C hichén I tzá es destruida por la guerra de $\mathrm{H}$ unac $\mathrm{C}$ eel $\mathrm{C}$ auich.

La cuarta parte, «Tiempos de crisis anticipando el futuro», aborda la concepción cíclica del tiempo que tenían los mayas y cómo el katún 8 ahau fue tiempo de guerra y cambio para algunos grupos. Además, el manejo del tiempo no puede ser solamente mítico, como algunos han pretendido, sino que existen registros en estelas, fuentes históricas tanto indígenas como españolas y hay también coincidencias con fenómenos naturales, por lo tanto, creo que tiene una base histórica.

El capítulo II considera los aspectos teóricos sobre el término «unidad política» y las diferentes nomenclaturas que se han utilizado para explicar la organización político-territorial de la región, que fue una unidad política dependiente, después llegó a ser un gobierno centralizado, más tarde fue un gobierno confederado y por último se formaron los cuchcabalob o provincias. $\mathrm{H}$ ablamos, entre otras cosas, de las características principales de los itzaes en la península de Yucatán, porque estamos de acuerdo con varios de los autores en aceptar que ese grupo es de raigambre chontal y por lo tanto proviene de la región que tratamos; que utilizando el tiempo cíclico de los katunes impusieron diferentes formas de gobierno en los lugares en donde se asentaron. 
O tro aspecto importante de este capítulo । es el inciso que trata acerca del espacio sagrado, pues creo que los itzaes sacralizan el tiempo y el espacio, el tiempo cíclico manifestado por la rueda katúnica representa el orden cósmico mismo, porque el cosmos necesita renovar periódicamente su propia vida. El ciclo cósmico tiene necesariamente una creación, una existencia y un retorno al caos, para dar lugar a un nuevo orden, a otro periodo del mundo. La región de Acalan es una región localizada al poniente (Zuyúa), lugar de entrada al inframundo, lugar de muerte y renacimiento, lugar de donde salen varios grupos: itzaes, cocomes, canules, quichés y cakchiqueles, entre otros.

En el capítulo III se presenta un comentario final y las conclusiones a las que llego con este trabajo. Se interpreta brevemente la cosmovisión de los chontales-acalanes y su go bierno cuatripartido, los conceptos que compartieron con el resto de los grupos mayas, especialmente los itzaes, dejando a un lado a los xiues y a otros grupos que se establecieron en Yucatán durante el Postclásico y que dicen venir de esta región.

Por último presentamos la bibliografía consultada y citada para la elaboración de este trabajo; no pretendemos de ninguna manera agotarla.

\section{RECONOCIMIENTO}

En primer lugar al doctor Piña C han que ya desde Teotenango, E stado de M éxico, nos hablaba del sitio arqueológico de EI Tigre, en donde había sido muerto C uauhtémoc, zona en que quería trabajar y retirarse, espacio en el cual yo definitivamente nunca pensé que trabajaría, pues en mis planes e intereses no entraba la posibilidad de hacerlo. Piña $C$ han ha escrito trabajos importantes sobre los itzaes y los xiues, a los cuales localiza en la región de ríos y lagunas de Tabasco y Campeche; inspirado en sus análisis retomo parte de esos trabajos; sin embargo dejo a un lado sus trabajos sobre los xiues, pues creo que no se refieren específicamente a la provincia de Acalan.

En 1978, al finalizar una temporada de campo en el proyecto Tierras Bajas $\mathrm{N}$ oroccidentales del área maya, dirigido por Lorenzo O choa y dependiente del Centro de Estudios M ayas de la UNAM, fuimos a visitar el sitio arqueológico de EI Tigre y anduvimos por primera vez en el río Candelaria, bajo la guía de Julián Soler, conocedor como ninguno de la región y con quien posteriormente he vivido momentos buenos y malos en el río $C$ andelaria y sus al rededores.

Lorenzo O choa y yo, por parte del Centro de Estudios M ayas de la unAm y con la asistencia de Sofía Pincemín, llevamos a cabo un reconocimiento arqueológico en la cuenca del río $C$ andelaria y sobre los ríos $C$ aribe y San Pedro en noviembre de 1983, con el propósito de obtener una visión general de la distribución de los asentamientos prehispánicos y la relación 
que guardaban con el paisaje; se localizaron puntos estratégicos utilizados en el tráfico comercial y se corroboró la existencia de camellones usados en la práctica de la agricultura intensiva.

Por iniciativa del doctor Román Piña C han se iniciaron varios proyectos arqueológicos en el estado de C ampeche en 1984; uno de ellos fue EI Tigre. Por invitación personal del doctor Piña Chan trabajé cuatro meses en el sitio; se intervinieron las estructuras 1, 2 y una estructura habitacional que se excavó cerca del poblado. El proyecto, por diversas causas, no tuvo continuidad y no se siguieron posteriormente los trabajos.

Sin embargo, en el mes de noviembre de 1994, con un grupo de alumnos de la ENAH y con la autorización del Consejo de Arqueología, realizamos los levantamientos topográficos de las estructuras $1,2,3$ y 4, y de dos estructuras habitacionales. Se hicieron algunos reconocimientos preliminares de superficie en el sitio para realizar un croquis y una posible delimitación del mismo. Los alumnos que participaron en el trabajo de campo fueron Ios siguientes: Vladimira Palma, Leonardo Santoyo, Tobías García, O laf J aime, Adriana H ernández, M iguel Roberto Guevara, Angélica D elgado, C uauhtémoc Sentíes, Blanca E stela M artínez. Además, participó la pasante en Arqueología Kimiyo Teramoto, de la U niversidad de Veracruz.

En 1995, con financiamiento del IIA de la UNAM y CONACYT y los permisos correspondientes del INAH, se cubrió parte de lo planteado en el proyecto general, que comprendía la realización de los reconocimientos de superficie y los levantamientos topográficos. Se contó con la participación eficiente de los arqueólogos y pasantes de arqueología: Kimiyo Teramoto, J acobo M ugarte M 00 y Dolores Ballesteros. Además, colaboraron en los trabajos de campo los habitantes del ejido EI Tigre, que en todo momento nos ayudaron eficientemente y con gran entusiasmo.

Un agradecimiento especial a las autoridades del Consejo de Arqueología INAH, al doctor Enrique $\mathrm{N}$ alda, entonces secretario técnico del INAH, quien despertó nuevamente el interés por el sitio al invitarme; al doctor Alejandro M artínez, Coordinador N acional de Arqueología quién supervisa desde su dependencia el Proyecto Arqueológico de EI Tigre; y al maestro Norberto González y al ingeniero Joaquín García Bárcenas, quienes me dieron las facilidades para terminar esta parte del proyecto, planteado en varios años, pues es una región poco trabajada que con el tiempo ofrecerá posibilidades de entender mejor una parte de la región maya. También al licenciado Carlos Vidal, director del Centro Regional de Campeche INAH, quien en todo momento apoyó con su entusiasmo los trabajos que se hicieron en EI Tigre.

Así mismo se realizaron durante la penúltima temporada de campo trabajos de reconocimiento subacuático en el río Candelaria, con la participación del arqueólogo Paul Pettennude (qepd) del Instituto de Estudios M ayas de Florida, y la Subdirección de A rqueología Subacuática del INAH, bajo la 
dirección de la arqueóloga Pilar L una, quien comisionó con gran acierto al arqueólogo Santiago Analco Ramírez.

En los trabajos de la última temporada de campo 1997-98 se hicieron labores de consolidación en la Estructura 1; participaron en la exploración y consolidación el arqueólogo Andrés Brizuela $C$. y las pasantes de arqueología Angélica D elgado Salgado, Adriana H ernández Granada y Kimiyo Teramoto 0 .

Por ser el Proyecto Arqueológico de EI Tigre interinstitucional, se pudo integrar a investigadores que se han dedicado por varios años al estudio de un tema o una región. E $n$ el caso de este proyecto, el Centro Regional del INAH Campeche tenía los recursos otorgados por el Convenio PEM Ex-Gobierno del Estado de Campeche, y la UnAM por medio del IIA proporcionó al personal encargado, más el equipo especializado para realizar tales investigaciones. Este tipo de convenios son muy interesantes porque se aprovechan al máximo los recursos tanto humanos como económicos de las instituciones.

Finalmente quiero expresar mi agradecimiento a la doctora Johanna Broda, quien me apoyó en todo momento para que escribiera este trabajo como tesis de doctorado; me dio todas las facilidades e ideas nuevas sobre la cosmovisión necesarias para entender el pasado maya, reconozco que me falta mucho. En la U NAM, a los doctores Luis A. Alberto Vargas G. entonces director del ı A y J esús González Balandrano exsecretario académico, al doctor Ramón Arzápalo por sus comentarios y puntos de vista sobre algunas palabras mayas. A $O$ tto Schumann, Tsubasa $O$ koshi, José M anuel Chávez, Fidencio Briceño, integrantes del Proyecto «Estudio inter y multidisciplinario de los itzaes, chontales y grupos circunvecinos» (4003585-2506H ), les agradezco su apoyo y ayuda, con ellos he aprendido mucho, tanto de historia como de lingüística, pues me han ayudado a entender muchos aspectos de los mayas. A conACYT que me otorgó una beca para que terminara de escribir la tesis; y finalmente muchas gracias por las correcciones y sugerencias que me hicieron los doctores Román Piña C han, L inda M anzanilla, N oemí Q uezada, Alejandro M artínez, Stanislaw I waniszewski y T subasa O koshi, lectores del manuscrito.

Agradezco al Departamento de Publicaciones por el trabajo realizado, en especial a Adriana Incháustegui y O mar M arín por la corrección del texto y a L ourdes Aznavwrian por la formación. También a $R$ afael R eyes el invaluable apoyo en la fotografía que ilustra este trabajo y a Rubén Gómez por el entintado de los dibujos.

Por último, un reconocimiento a mi familia: Rosa M aría Ramos, quien en todo momento me ha apoyado para que haga mi trabajo de campo; a Rodrigo, con quien viví momentos interesantes en $\mathrm{EI}$ T igre y en los «rápidos del C andelaria», y a M ónica, quien soportó pláticas interminables de los magtunes o putunes de Acalan, tal vez sin interesarle; a todos ellos gracias por soportarme y por la paciencia de oírme hablar del katún 8 ahau y del tiempo cíclico de los mayas. 



\section{LOS PUTUNESY SU PROBLEMÁTICA}





\section{Capítulo I CONSIDERACIONES GENERALES}

Para el arqueólogo que enfoca su interés en los últimos años de la época prehispánica y primeros de la conquista española, los documentos tienen un fondo riquísimo que puede ampliar la comprensión sobre los eventos de la vida de los pueblos. Estos documentos sirven, en los casos más afortunados, para explicar el registro arqueológico de una manera que sería imposible sólo con base en la arqueología. Así mismo, existen situaciones en las cuales lo verdadero y lo falso en los documentos pueden identificarse mediante datos arqueológicos.

Los estudios mayistas de los últimos años se han caracterizado por un desarrollo muy marcado en la utilización e interpretación de textosindígenas y crónicas españolas, para reconstruir la historia a partir de relatos considerados como mitológicose históricos. U no de los resultadosmás fructíferos de esa tendencia han sido los estudios realizados tanto en Guatemala ( $C$ armack 1981, Fox 1987) como en Yucatán (Farriss 1984) y C hiapas (García de León 1985, Wasserston 1989) por diferentes investigadores.

M etodológicamente es difícil ligarlas. Sin embargo, la relación pluridisciplinaria es indispensable, los textos poseen un potencial informativo que no debe descuidarse, y su interpretación puede ser factible con la ayuda de la etnología, la lingüística y la arqueología.

$L a$ «historia» no es simplemente la descripción de una serie de acontecimientos, implica ante todo una explicación dentro del paradigma de la historia universal, en donde, al decir de algunos autores, el historiador debe permanecer fuera de los acontecimientos. O tros, como H odder (1991: 91-96), opinan que la historia debe introducirse en los sucesos, en las intenciones y pensamientos de los actores; el papel de la historia es comprender las acciones humanas, no los eventos.

Trigger (1978) ha mostrado que la historia implica generalización. Sin embargo, tanto en los análisis arqueológicos como en los no arqueológicos han sido los estudios particularistas, combinados con un interés por lo «interior» de los acontecimientos, los que han dado pie a los enunciados más profundos y de mayor alcance acerca de la naturaleza de las relaciones entre significado y práctica (H odder 1991: 98). 
Collingwood (1946) y muchos otros historiadores rechazaron con pasión los conceptos de la teoría de la historia universal y la de progreso; fueron partidarios de una distinción definitiva entre ciencias sociales y naturales. En estas últimas se clasifican hechos objetivos, se descubren relaciones entre categorías y se elaboran leyes. En las ciencias humanas se pretende sistematizar a partir de un análisis cada vez más profundo del hecho concreto dentro de su propio contexto, en función de otros hechos relacionados estructuralmente con él.

Estudiar historia es intentar explicar finalidad y pensamiento. Este concepto alcanzó gran difusión en el medio arqueológico antes de los años sesenta y sigue predominando en gran parte de los arqueólogos. Piggott (1959) decía que la arqueología es historia, con la única diferencia de que la información no se registra intencionadamente como historia: es inconsciente.

El estudio de la etnohistoria de M éxico (C arrasco 1978, B roda 1991, Piña Chan 1980, Jiménez M oreno 1976, entre otros) plantea necesariamente la colaboración entre la historia y la antropología en general. La arqueología en contacto con la antropología, la lingüística y la historia ha enriquecido el estudio de la época prehispánica. En los últimos años se ha apoyado en teorías más sólidas so bre el desarrollo de la civilización, las cuales a su vez condujeron la investigación a la búsqueda sistemática de datos abundantes, que se prolongan en el tiempo, son representativos de regiones amplias y reflejan los diversos tipos de organización sociopolítica que se dieron en el mundo prehispánico.

La metodología para recuperar el pasado mexicano ha variado a lo largo del tiempo. Durante las últimas décadas han surgido diversos fenómenos que repercutieron en la manera de escribir la historia. El marxismo favo reció los estudios sobre historia económica y social; la estadística impulsó la historia cuantitativa; los movimientos feministas despertaron el interés por la historia de la mujer y de género; la microhistoria resaltó la importancia del estudio de caso; y así podríamos seguir nombrando otros movimientos intelectuales que se han puesto de moda.

A pesar de este revuelo intelectual, perdura uno de los logros mayores de la antropología mexicana: haber creado una concepción antropológica e histórica que reconoció el carácter original de las diversas culturas mesoamericanas, y a partir de este reconocimiento realiza enfoques concretos para comprender su desarrollo dentro de sus propios marcos históricos y culturales.

Esta necesidad de integrar la arqueología con la historia, y ésta con la antropología, ha sido enmarcada con diferentes nombres por diversos autores: etnoarqueología, arqueología histórica, arqueohistoria, etnohistoria, etcétera; otros, en cambio, con mayores conocimientos, realizan trabajos en ese sentido sin pretender etiquetarlos, están más a gusto haciendo investigación «etnohistórica» que discutiendo o desarrollando una teoría dis- 
ciplinaria. Lo importante de toda esta preocupación es que tanto el historiador como el antropólogo interesado en un determinado problema, reconocen la necesidad de auxiliarse de otras disciplinas, pues en el fondo la diferencia que existe entre unos y otros es el enfoque teórico de los autores.

La aplicación de estos enfoques al periodo inmediatamente anterior a la invasión española y las décadas siguientes ha permitido comprender, con mayor profundidad, los cambios dramáticos que la Conquista impulsó en el mundo indígena: la fractura de estructuras fundamentales de la organización indígena y la continuidad y capacidad de adaptación de las culturas indígenas a la situación colonial. En lugar de la imagen que se tenía de un mundo indígena inerte, estos estudios muestran pueblos e individuos en constante transformación, plenos de iniciativas y empeñados en la afirmación de sus identidades.

El contacto de la historia con la arqueología, la etnología y la lingüística ha enriquecido sus enfoques y aumentado sus recursos metodológicos. E sta es una escuela rica y fructífera en $M$ éxico. En una valoración rápida, lo importante no es tratar a las otras disciplinas como auxiliares, sino plantear un problema determinado en donde converjan las diversas disciplinas para resolverlo, el mérito no será de tal o cual disciplina sino del manejo de ellas; es decir, lo importante es la complementación de las disciplinas para entender el problema planteado.

L a investigación histórica no es más que un continuo debate y una constante aproximación al tema: «E I conocimiento histórico es el conocimiento de lo que la mente hizo en el pasado y es, al mismo tiempo un rehacer, un perpetrar los actos pasados en el presente» (Collingwood 1946: 218); es por lo tanto una experiencia que hay que volver a vivir, y este «revivir» el pasado se consigue gracias al método de pregunta y respuesta. No podemos sentarnos y observar los datos, debemos ponerlos en acción haciendo preguntas definidas y concretas.

En la actualidad parecería que el historiador, arqueólogo y etnólogo están más preocupados por regalar y mostrar al pasado sus modelos, ideas, lenguaje y avances tecnológicos, que en comprender a través del presente ese pasado tan difícil de entender. Con el paso del tiempo la producción historiográfica del siglo xx indicará más de éste que de los siglos anteriores que pretende estudiar (Z avala 1992).

Tenemos que ir más allá de las modas pasajeras; este contacto entre disciplinas enriquece los enfoques y aumenta los recursos metodológicos, pero «disuelve» las disciplinas. L a arqueología utiliza argumentaciones flexibles, fácilmente «adecuables»; no tiene más opciones viables. No se puede conseguir certeza alguna, pero el conocimiento del pasado es acumulable mediante una aplicación crítica.

La «nueva arqueología» pretendió romper con la «vieja arqueología», por ser ésta normativa, descriptiva, especulativa e inadecuada, para empe- 
zar de nuevo; así se condenaron los objetivos histórico-culturales y los métodos interpretativos; es evidente que se había hecho mucha historia cultural y demasiada mala arqueología, pero lo mismo ocurriría luego con la nueva arqueología y seguirá ocurriendo con to da la arqueología futura; de allí lo interesante de ir un poco hacia atrás para avanzar, pues debe recuperarse la historia cultural y un enfoque filosófico coherente.

\section{EL DESARROLLO DE LA ARQUEOLOGÍA}

Cada día más, los arqueólogos han ido abandonando la seguridad positivista de sus investigaciones y han empezado a abrigar algunas dudas sobre la objetividad de las mismas. Binford (citado en Trigger 1992) dice que en la interpretación arqueológica se puede distinguir entre un diálogo interno, a través del cual los arqueólogos han intentado desarrollar métodos para inferir el comportamiento humano a partir de los datos arqueológicos, y un diálogo externo, en el que utilizan estos hallazgos para referirse a problemas más generales, concernientes al comportamiento y a la historia de los seres humanos.

L a historia del pensamiento arqueológico ha variado considerablemente en el transcurso del tiempo, pues ha recibido influencias de las diferentes teorías sobre el comportamiento humano, expuestas por las ciencias sociales; pero los lazos más estrechos los ha mantenido y los sigue manteniendo con la etnología y la historia, y otros conceptos teóricos que utiliza proceden de la geografía, la sociología, la economía y las ciencias políticas.

L a arqueología es una ciencia social en el sentido de que intenta explicar el pasado de seres humanos y los procesos de cambio cultural. A diferencia de las demás ciencias sociales, los arqueólogos no pueden observar el comportamiento de la gente a la que estudian, ni tienen acceso directo a su pensamiento a través de sus fuentes escritas. En su lugar, los arqueólogos deben inferir el comportamiento y las ideas humanas a partir de los restos materiales de to do aquello que los hombres han creado y utilizado, y también a partir del impacto medioambiental de sus actuaciones. A pesar de todo, los arqueólogos están lejos de ponerse de acuerdo en cómo estos conocimientos deben ser aplicados de una manera legítima y global que permita la comprensión del comportamiento humano pasado a través de sus datos (Binford 1967).

Para que la arqueología al canzara su estado actual se ha pasado por un largo proceso, desde la arqueología clásica y el anticuarismo hasta los comienzos de la arqueología científica, en donde se utilizó la datación relativa y la estratigrafía, para llegar posteriormente a la gran etapa de la arqueología histórico-cultural. $\mathrm{H}$ acia finales del siglo XIX la arqueología se asoció con el nacionalismo y uno de sus objetivos principales fue determinar, con criterios bastantes caprichosos, a qué grupos étnicos se pertenecía, de ma- 
nera que las naciones emergentes pudiesen conocer mejor sus orígenes y saber cómo habían vivido sus ancestros; con esto trató de reafirmar sus vínculos con el estudio de las historias nacionales.

Boas se opuso a la doctrina del evolucionismo cultural y afirmó que cada cultura era una entidad única que tenía que ser entendida en sus propios términos; esto implicaba aceptar dos ideas: el relativismo cultural, que negaba la existencia de cualquier modelo universal, y el particularismo histórico, que consideraba cada cultura como el producto de una secuencia única de desarrollo, en la cual la intervención, en gran parte casual, de la difusión desempeñaba un papel principal en el desencadenamiento del cambio (Trigger 1992: 147).

M ontelius (1843-1921) se interesó por la elaboración de una cronología; así fue como desarrolló una tipología en la que observó variaciones a lo largo del tiempo y el espacio. La aceptación de la interpretación de este autor sobre el desarrollo de la civilización requería creer, no sólo en el difusionismo, sino también en que los cambios ocurrieron en determinadas áreas y se difundieron de ese núcleo hacia las periferias.

A finales del siglo xıx existió una preocupación creciente por la etnicidad, que fomentó el desarrollo del concepto de cultura y de enfoque históricocultural. Kossinna, inspirado por un patriotismo fanático, llegó a declarar que la arqueología era la más nacional de las ciencias y los antiguos alemanes el sujeto más noble, digno de estudio arqueológico. A pesar de todo lo anterior, con Kossinna terminó el enfoque evolucionista en la prehistoria y se inició el enfoque histórico. Él ordenó los datos arqueológicos de cada periodo según un mosaico de culturas arqueológicas, buscó documentos sobre cómo vivieron en el pasado y qué les había ocurrido a lo largo del tiempo. Su enfoque ofrecía un medio para explicar la creciente evidencia arqueológica.

Childe adoptó el concepto básico de Kossinna y lo combinó con el cronológico de Montelius; puso de manifiesto que cada cultura debía ser delineada individualmente según sus artefactos constituyentes, y que éstas no podían definirse simplemente subdividiéndolas en periodos; por el contrario, se tenían que establecer la duración y los límites geográficos de cada cultura, además de situarse cronológicamente mediante la estratigrafía y la seriación. Childe interpretó la prehistoria de Europa como si se tratase de un complejo mosaico de culturas. Fue más allá, pues los arqueólogos habían tratado los artefactos como fósiles muertos y no como la expresión de sociedades vivas.

El enfoque histórico-cultural tuvo como resultado inmediato un avance significativo de las técnicas arqueológicas, sobre todo en lo referente a la estratigrafía, la seriación, la clasificación y el conocimiento del modo de vida de los pueblos en el pasado.

EI marxismo también tiene una presencia muy fuerte dentro de la arqueología, pues desde 1930 se empieza a poner un gran énfasis sobre la 
producción como base de la sociedad. Childe continuó desarrollando y refinando su enfoque marxista sobre el cambio social.

O tro gran innovador de la arqueología fue Clark (1939), quien sostenía que la arqueología tenía que ser «el estudio de cómo los seres humanos vivían en el pasado», y para lograrlo los artefactos debían ser examinados desde un punto de vista funcionalista. Argumentaba que los arqueólogos debían reconstruir cómo vivían los seres humanos en la antigüedad, sus economías, su organización política y social, y sus sistemas de creencias y valores. Destacó el papel de la cultura como un sistema adaptativo, al mismo tiempo que afirmó que su objetivo era documentar la vida social. Sus excavaciones tenían la finalidad de recuperar materiales orgánicos, así como instrumentos que revelasen el modelo de subsistencia. Clark se auxiliaba de paleobotánicos y zoólogos para reconstruir el pasado.

D espués de la Segunda Guerra M undial se tomó conciencia de la importancia del enfoque ecológico. Así surgieron grandes proyectos de investigación llevados a cabo por equipos interdisciplinarios (arqueólogos, botánicos, zoólogos, geólogos, químicos, etcétera) que estudiaban el origen de la producción de los alimentos y formaban una secuencia cultural ininterrumpida.

Gordon Willey (1953) inició el desarrollo de la arqueología de los patrones de asentamiento. Afirmó que los modelos de asentamiento: «reflejaban el ambiente natural, el nivel de tecnología que poseían los constructores y las variadas instituciones de control e interacción social que esa cultura mantenía».

D entro del contexto de la arqueología del patrón de asentamiento, los sitios individuales dejaron de ser estudiados como fines en sí mismos, o considerados representativos de una cultura o de una región en particular. Se empezaron a ver como redes en las que cada uno desempeñaba un papel diferente y complementario, de ahí que todos hayan adquirido una dimensión importante. Muchos arqueólogos vieron en estos modelos de asentamiento una importante fuente de información sobre las tendencias demográficas y las instituciones so ciales, políticas y religiosas de las so ciedades. L os asentamientos se analizaron en términos de jerarquía de niveles: las estructuras individuales reflejaban la organización familiar; los asentamientos, la estructura de la comunidad; y las distribuciones espaciales, el impacto del comercio, de la administración y la defensa regional.

Las investigaciones de Willey en el valle del Virú inspiraron a muchos arqueólogos para realizar estudios en diversas partes del mundo; sin embargo, éste es un paso preliminar necesario para las interpretaciones sociales y políticas; para muchos investigado res ésta es la finalidad de sus investigaciones, para otros es tan sólo un paso previo a estudios futuros.

Con la aparición de la nueva arqueología se pensó que su llegada significaba una ruptura dramática con el pasado, sin considerarse que era la 
continuación e intensificación de las tendencias funcional istas y procesuales que habían estado desarrollán do se en la arqueo logía desde la década de los treinta. El objetivo principal de los arqueólogos debía ser explicar los cambios producidos en las culturas en términos de procesos culturales.

Binford consideraba las culturas como medios extrasomáticos de adaptación de la humanidad; por consiguiente, los cambios culturales eran interpretados como respuestas adaptativas a alteraciones ocurridas en el medio ambiente 0 en los sistemas culturales adyacentes y competidores; los cambios que causaban perturbaciones se iniciaban por factores externos o no culturales.

L os nuevos arqueólogos creían firmemente que los sistemas culturales se caracterizaban por una fuerte regularidad y, por lo tanto, pensaban que una pequeña parte del sistema podía ser representativa del todo. Se idearon estrategias de muestreo que guiasen los reconocimientos de superficie y las excavaciones para ahorrar tiempo y trabajo.

Los críticos han afirmado que la «nueva arqueología» representó una revolución más en las esferas metodológicas y técnicas que en la teoría arqueológica; sin embargo, su influencia ha sido grande, utilizó datos concernientes al patrimonio de los nativos para formular generalizaciones que se decían aplicables al conocimiento de la sociedad euroamericana. También se han utilizado las técnicas introducidas por la «nueva arqueología» para tratar problemas de comercio, desarrollo político y cambios de la organización social en los tiempos prehispánicos.

$\mathrm{H}$ acia los años setenta los arqueólogos empezaron a expresar reservas sobre las teorías neo evolucionistas, que analizaban el cambio como si ocurriese según trayectorias lentas y graduales. Adams (1974: 248-249) observó que en las primeras civilizaciones existían rupturas abruptas, separadas a veces por grandes periodos en los que ocurrían muy pocos cambios. $L a$ teoría de las catástrofes, inventada por el matemático francés R ené Thom trata la cuestión de cómo un conjunto de variables fluctuantes pueden producir efectos discontinuos como resultado de una conjunción particular de estados internos. Independientemente de la aceptación o no de estas teorías, los arqueólogos han reforzado la creencia de que las culturas son más frágiles y el cambio cultural más cargado de peligros de lo que ellos mismos habían creído hasta ahora.

U n número cada vez mayor de arqueólogos entienden las culturas prehipánicas como entes con una gran diversidad que hay que explicar; J oyce $M$ arcus (1983: 360) nos dice que no podemos ignorar la complejidad cultural de los mayas ni sus capacidades adaptativas, tampoco debemos olvidar la intensificación agrícola, el crecimiento de la población, la guerra y el comercio interregional; es decir, estos factores por sí mismos son insuficientes para explicar la diversidad de las culturas, hay que ver a la sociedad que estudiamos como un todo. 
En la actualidad se está volviendo al enfoque de que las sociedades o las culturas son unidades cerradas, fuertemente cohesionadas, que deben estudiarse de manera independiente unas de otras, y a prestar más atención a los estímulos externos en el desencadenamiento del cambio cultural.

L os arqueólogos cada día se convencen más de la necesidad de examinar todos los aspectos posibles de una cultura arqueológica, para poder comprender el significado de cada una de las partes que la componen. En el discurso arqueológico la palabra «contexto» adquiere cada día más vigencia, a pesar de que Flannery (1972) se opuso y trató de destacar la «sistemidad», como un enfoque más flexible que tomara en consideración las relaciones concretas. En cierto sentido, la arqueología puede definirse por la importancia que otorga al contexto; interesarse por objetos desprovistos de información contextual es propio de anticuarios, extraer objetos fuera de su contexto es la antítesis de la arqueología.

H odder (1991: 136) nos dice que los arqueólogos han estudiado dos tipos fundamentales de significado:

[...] el sistema estructurado de interrelaciones funcionales y el contenido estructurado de las ideas y los símbolos. Así pues, si buscamos el primer tipo de significado, analizaremos el entorno humano y físico, los procesos de deposición, la organización del trabajo, el tamaño del asentamiento y los intercambios de materia, energía e información. Si descubrimos cómo funciona el objeto en relación con estos otros factores y procesos, y en relación con la estructura económica y social, le daremos sentido, significado.

L os arqueólogos, cada día más, aceptan haber aprendido a utilizar sus datos contextuales para interpretar las interrelaciones funcionales. D esde hace muchos años se considera al registro arqueológico como un «texto» que hay que leer; sin embargo, para muchos arqueólogos los objetos son mudos; pero lo interesante de la arqueología es que los datos no se estudian aislados, sino dentro de un contexto, y lo que inferimos son conceptos públicos y sociales, reproducidos en la práctica de la vida cotidiana que queda plasmada en la cultura material.

\section{LA ARQUEOLOGÍA Y LAS OTRAS DISCIPLINAS}

En M éxico, el pasado fue objeto de manipulación política incluso antes de la Conquista (Carrasco 1978). En la Colonia se trató por todos los medios desalentar el interés por la historia y cultura mesoamericana. D urante los conflictos de la independencia se continuó desaprobando el estudio del periodo prehispánico, aunque los criollos se aferraron a él como fuente de inspiración de la identidad nacional. En el siglo xıx los conservadores no le prestaron mayor atención, mientras que los liberal es veían a esa época como un periodo significativo de la historia nacional. La R evolución de 1910 se 
apoyó en gran medida en los indígenas que fueron el grueso de los ejércitos; se les prometieron reformas económicas y sociales para remediar en parte las grandes injusticias a que habían sido sometidos. Entre los programas realizados por el gobierno estuvo el estudio sobre el riquísimo patrimonio del M éxico prehispánico, como parte principal de la historia mexicana; se destinaron grandes sumas de dinero para la formación de investigadores y para realizar las excavaciones; entre las grandes metas todavía sigue pensándose que los arqueólogos tienen el deber de proporcionar a los mexicanos un pasado propio.

Con el surgimiento de la arqueología se propone el estudio de la cultura material indígena, y uno de sus primeros objetivos fue establecer la cronología relativa de las culturas y monumentos con la ayuda de la estratigrafía y la cerámica.

Su rasgo principal ha sido reconstruir la cultura de las sociedades desaparecidas, la conducta del hombre del pasado, y para lograrlo necesita excavar, recoger materiales y observar, para luego analizar y ordenar, describir, explicar, integrar y sintetizar, procedimientos que constituyen su metodología.

Con la conquista española la sociedad prehispánica sufrió un descalabro tremendo; sin embargo, muchos elementos de la cultura indígena tradicional sobrevivieron en la época colonial, pero se articularon de otra manera en una sociedad radicalmente diferente. La organización social prehispánica sufrió profundas transformaciones en su estructura social, en la explotación económica y en la dominación política.

La conquista española enfrentó a dos grupos humanos culturalmente distintos, provistos cada uno de una concepción diferente del mundo y de la vida, de una capacidad desigual en el manejo de la técnica y de un sistema de valores divergentes. En consecuencia, cada grupo en particular contaba con su propia organización social, económica y política. El choque inicial dio como resultado la victoria militar española y el consiguiente sometimiento del elemento autóctono. De este hecho violento nacieron relaciones que ya no fueron más patrimonio de cada uno de los grupos, sino que los envolvieron a ambos, acercándolos y separándolos simultáneamente. A partir de entonces, las mutuas relaciones descansaron sobre la fuerza del vencedor, quien trató de imponer sus maneras de actuar y pensar, sobre todo, con el afán de justificar el sistema desigual creado por él (Guzmán Bockler 1970).

Así, tanto la arqueología como la historia tratan de reconstruir el pasado del hombre; ambas con técnicas diferentes pueden apoyarse para brindar un mejor y más completo conocimiento del pasado, interrelacionándose y rebasando sus límites.

Con frecuencia se han utilizado las fuentes históricas como base para realizar reconocimientos de superficie por tierra, agua y aire, auxiliándose con fotografía aérea y mapas; ésta, creo, es la mejor manera de abordar ciertos problemas, pues se visitan los lugares en donde se llevaron a cabo 
Ios acontecimientos descritos en las fuentes históricas y se trata de comprobar, por medio de la arqueología, la veracidad de la fuente. Estamos seguros de que solamente con la información de primera mano es posible entender y obtener una correcta ubicación de un pueblo y/ o ciudad, o de las características físicas de una región (Vargas 1987: 130-45).

O tros arqueólogos han afrontado problemas sobre la organización político-territorial de una región utilizando fuentes históricas y contrastándolas con la arqueología, básicamente para el Postclásico tardío. En estos trabajos se intenta reconstruir una provincia prehispánica (cfr. Benavides y Andrews 1979, Andrews 1984, Vargas y Teramoto 1997a) que fue descrita en diferentes fuentes históricas; lo que hace el arqueólogo es tratar de conocer la forma en que pudo estar organizada el área, como primer paso, y posteriormente con el estudio interno de los sitios se conocerán los procesos de desarrollo de una región. "Los que estudian el pasado maya son extraordinariamente afortunados por poder contar con esta abundancia de datos etnohistóricos; los arqueólogos hacen mal en desdeñarla» (Thompson 1975: 72).

\section{La lingüística y las fuentes históricas}

EI análisis de las fuentes históricas y de los términos mayas aporta información de primera mano para el entendimiento de la geografía política y social de los mayas. Este tipo de análisis nos ofrece, como antropólogos y arqueólogos, marcos de referencia para aplicar todas aquellas técnicas arqueológicas disponibles para entender, por ejemplo, una región determinada.

Cuando los españoles invadieron la península de Yucatán, encontraron esta tierra subdividida en varias entidades políticas que ellos denominaron «provincias». Ralph L. Roys (1957) hizo un estudio extenso y exhaustivo del tema utilizando numerosos documentos inéditos encontrados en el Archivo General de Indias, así como las R elaciones históricogeográficas de la gobernación de Y ucatán. Concluyó que a principios del siglo xvı los mayas yucatecos mantenían tres tipos de jurisdicciones: enumera en total 16 jurisdicciones en las tierras bajas mayas del norte, y cada una de ellas, según este investigador, tenía sus propios límites territoriales definidos (mapa 1).

Este modelo planteado por Roys ha sido aceptado a tal grado, que los estudiosos reproducen, sin crítica alguna, en sus obras su concepción sobre la geografía política de los mayas yucatecos. En el mejor de los casos se han propuesto modificaciones de los límites territoriales de algunas jurisdicciones, como Benavides y Andrews (1979), que dan un magnífico ejemplo del manejo de la arqueología y la etnohistoria. Y el caso de J. M arcus (1993), quien analiza minuciosamente los términos mayas concernientes a la geografía política y, sin alejarse de las ideas roysianas, establece un modelo «dinámico» que es aplicable para el Clásico maya. 


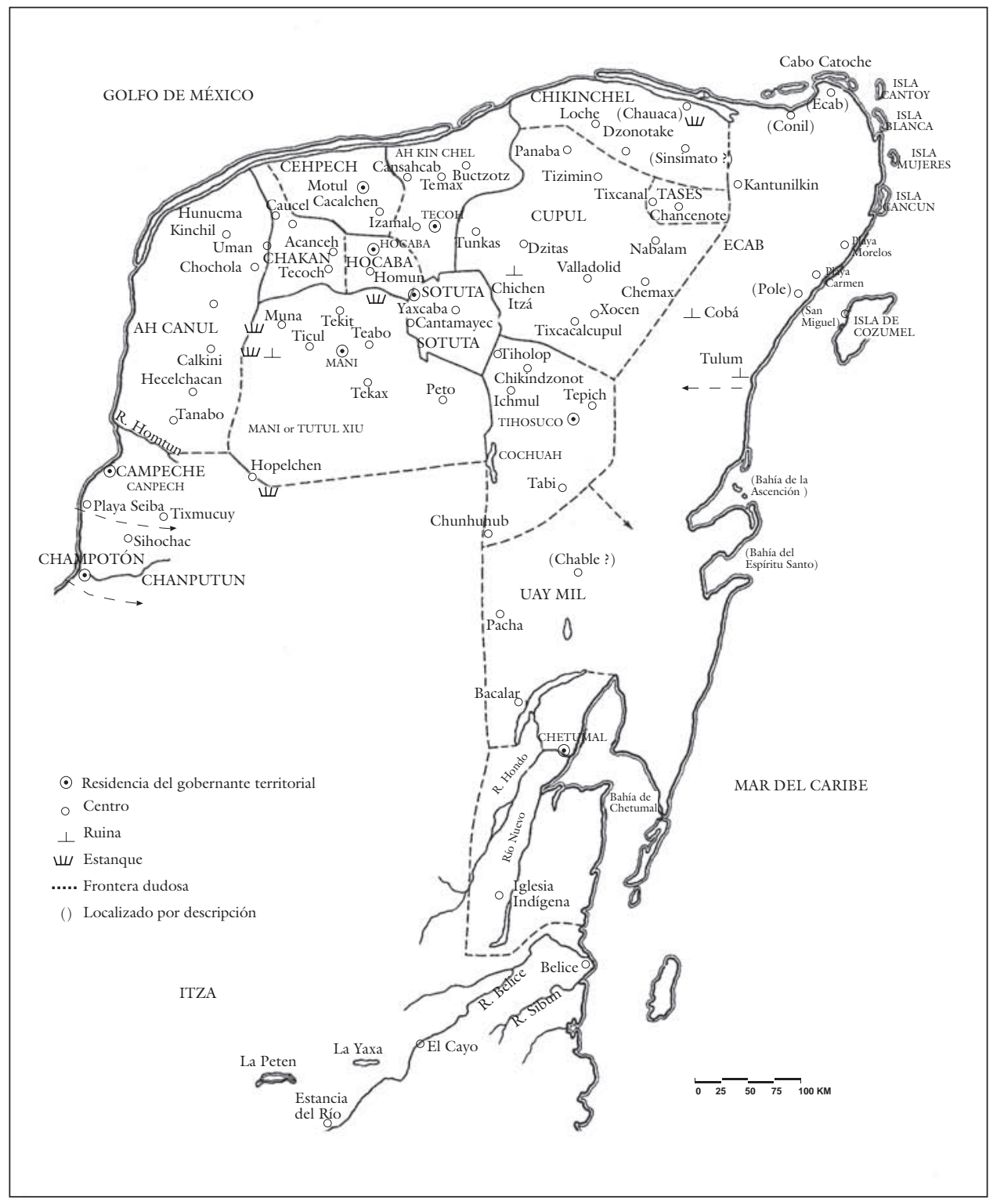

Mapa 1. Provincias de Yucatán (Roys 1957).

En la actualidad existen otras propuestas basadas en el análisis lingüístico de los términos mayas yucatecos relativos a «barrios», "pueblo» y «jurisdicción», que intentan esclarecer el campo semántico de estos términos para definir los conceptos autóctonos de los mayas sobre su propia organización político territorial. De hecho, según estos autores (Quezada 1993, Okoshi 1994), en la propuesta roysiana, así como en las obras académicas de sus seguidores, se refleja claramente la visión occidental, la cual distor- 
sionó considerablemente el entendimiento de las características de las entidades políticas prehispánicas.

Roys decía que las jurisdicciones prehispánicas fueron llamadas por los mayas yucatecos cuchcabal, que significa literalmente «jurisdicción» (1957: 3). Sin embargo, el campo semántico de este término, clave para comprender la realidad de la organización político territorial maya, es mucho más rico de lo que se piensa. De acuerdo con O koshi y Q uezada, el término cuchcabal se refiere a: 1) los go bernantes y oficiales que el señor supremo tiene a su cargo en un territorio, y 2) un territorio en que están los gobernantes y oficiales que el señor supremo tiene a su cargo. En el primer caso, este término estaría antepuesto al patronímico del gobernante supremo y en el segundo le seguiría el topónimo de su capital. A pesar de que Roys señalaba la presencia de los cuchcabalob o jurisdicciones que no contaban con un solo gobernante supremo (halach uinic), sino con un conjunto de varios gobernantes secundarios (batabob) pertenecientes al mismo linaje, el análisis minucioso de las fuentes históricas apunta que estos cuchcabalob también tenían un representante (batab) que era la cabeza del linaje dominante de su territorio. Asimismo, estos dos estudiosos proponen que a principios del siglo XVI en las tierras bajas mayas del norte existían tierras que no pertenecían a nadie y, además, varios pueblos (batabilob) independientes que no establecían ningún lazo político religioso con algún cuchcabal cercano.

Ahora bien, para comprender la geografía política prehispánica no es suficiente esclarecer los conceptos mayas concernientes a las entidades políticas de diversos niveles, sino también habría que saber las ideas autóctonas en torno al fundamento del poder político que ejercían los gobernantes mayas sobre sus gobernados, específicamente sobre la tenencia de la tierra.

D e ahí que el gobernante de una jurisdicción prehispánica (halach uinic) no solamente desempeñaba el papel de intermediario entre los dioses y los hombres como un ahau a través del árbol sagrado, sino que también prometía la fertilidad de la tierra a todos los habitantes del territorio, legitimaba el linaje dominante y, por lo tanto, también el poder de los oficiales pertenecientes a esa estirpe; ésa es una justificación del poder con base en la cosmovisión del grupo que aseguraba mantener, en primer lugar, la cohesión de todos los miembros de los grupos gubernamentales subordinados y, en segundo lugar, el poder sobre el común del pueblo al cual garantizaba la armonía y la fertilidad (O koshi 1995b: 23-24).

$\mathrm{N}$ o se ha registrado un gran avance con respecto a la comprensión de las funciones de cada uno de los cargos en el gobierno indígena prehispánico. E sto se debe a que después de la C onquista los españoles hicieron desaparecer del plano político indígena los poderes centrales (halach uinicob) de los cuchcabalob, sobreviviendo únicamente los batabilob que se transformaron en los pueblos indígenas coloniales, por lo que muy pocas fuentes históricas hablan con detalle sobre la organización política prehispánica. 
Esta situación no cambiará en el futuro, razón por la cual, en vez de enfocarnos en las funciones de los cargos políticos, deberíamos discutir ampliamente cuál sería el mecanismo por el cual los gobernantes mantenían su sociedad. Al respecto, se propone que los gobernantes mayas tenían como principio no ejercer el poder político despóticamente, sino más bien procurar mantener la armonía con la gente del común; mientras ésta participaba, a través de sus representantes, en la toma de decisión del gobierno indígena, y si su gobernante llegaba al extremo de abusar de su poder, la gente común podía manifestar su inconformidad, sublevándose contra el grupo gubernamental (O koshi 1995a). O bviamente, el problema del sistema de redistribución y de reciprocidad sería el tema principal por investigar para entender la forma del gobierno en la sociedad maya.

\section{La importancia de la iconografía y la epigrafía}

Sin duda al guna, uno de los avances académicos más notables dentro de los estudios mayas es la epigrafía, la cual empezó a hacer comprensible la historia de las dinastías de las tierras bajas mayas del sur. Los textos glíficos del norte han sido más difíciles de traducir que los del sur; quizá esto se deba a que los textos tienen más alto porcentaje de signos fonéticos y la caligrafía es mucho más difícil de leer. Pese a dichas dificultades, en esta región la mayor parte de los esfuerzos de estudios epigráficos se ha concentrado en dos sitios: C hichén I tzá y U xmal. Ya se han identificado el glifo emblema de C hichén Itzá (Fox 1984, Schele y Freidel 1990: 496) y algunos términos de parentesco (Kelly 1968, 1976, 1982). D e tal manera, ya contamos con una reconstrucción hipotética y parcial de la dinastía de Chichén I tzá (D avoust 1980, Kelly 1982, G rube y Stuart 1987, Schele y Freidel 1990), así como de U xmal (Kowalski 1985, 1989). Además, entre los personajes de la dinastía de C hichén I tzá se han identificado Kakupacal (Kelly 1968), Cocón (Grube y Stuart 1987) y H un-Pic-T oc (Stuart citado en Schele y Freidel 1990: 498), los cuales son mencionados en los documentos coloniales. Q uizás en el futuro el resultado del desciframiento de los glifos de estos dos importantes sitios nos dará un panorama mucho más concreto de la poca historia conocida y confusa de las tierras bajas mayas del norte.

Pese al hecho de que los epigrafistas se preocupan por concordar sus lecturas con los datos arqueológicos e iconográficos (su principal disciplina de apoyo), han prestado poca atención a las fuentes históricas coloniales, las cuales tienen dos procedencias distintas. El primer grupo de documentos fue escrito por los mismos mayas con caracteres latinos después de la invasión española y el segundo por los invasores europeos. Algunos de estos últimos recurrieron a los informantes mayas para obtener datos más detallados sobre la sociedad prehispánica. $\mathrm{H}$ asta la fecha todos 
estos documentos históricos fueron interpretados «literalmente» por la mayoría de los historiadores y los epigrafistas. Sin embargo, en las últimas décadas comenzaron a aparecer algunos trabajos que ponen en duda este ingenuo manejo de los documentos mayas coloniales, lo cual obliga también a los epigrafistas a la revisión crítica de la interpretación literaria de sus lecturas, así como de los datos glíficos.

El primero de estos trabajos es el de Victoria Bricker (1981), en el cual, utilizando tanto documentos indígenas como datos etnográficos, demuestra que la estructura básica del mito y ritual maya incorpora y asocia indistintamente los eventos históricos separados por siglos o por una distancia de miles de kilómetros, sin importar su procedencia geográfica y/ o temporal.

L a postura de Bricker, quien trató de encontrar el mensaje estructurado en el substrato mitológico de la historia narrada por los mayas, fue aplicada por Charles Lincoln $(1990,1993)$ para el análisis de la organización político territorial de Chichén Itzá. Lincoln, con base en el análisis filológico y estructuralista de las fuentes históricas, así como en los datos arqueológicos e iconográficos, hizo una reconstrucción detallada de la organización político territorial de Chichén I tzá, dividiéndola en tres sistemas: el dual, el tripartita y el cuatripartita. Pero una de las aportaciones más importantes de este investigador sería su planteamiento con respecto al manejo de los documentos coloniales. De acuerdo con este autor, la información histórica que ofrecen tanto las fuentes indígenas coloniales como las españolas, quienes usaron a los indígenas mayas como informantes, no pueden ser interpretadas literalmente, puesto que se trata del «mito estructurado». Dicho de otra manera, no podemos analizar la «historia» indígena con el concepto histórico occidental, porque la «historia» narrada en estos documentos es una manifestación del patrón mítico o cosmológico de los mayas. D e manera que, al utilizar estas fuentes, se debe tomar en cuenta el patrón autóctono de la relación que existe entre el mito y la historia. Esta postura coincide con la de J oyce M arcus (1992), quien dice que los textos mesoamericanos son producto de las manipulaciones hechas por los go bernantes, relacionando sus actividades con los eventos del pasado y de la mitología. En la «historia» indígena, por lo tanto, no existía la división entre el tiempo mítico y real, lo cual exige a los estudiosos el manejo no literal de la información contenida en estos documentos.

L a colaboración entre antropología, historia, arqueología y lingüística es fundamental para que el estudio de la sociedad y cultura preshipánicas mexicanas adquiera un valor explicativo. Este estudio así enfocado, nos permite plantear procesos de larga duración que, a pesar de la ruptura violenta de la conquista y colonización, permiten vislumbrar la persistencia de elementos culturales y conceptos religiosos que tienen su raíz en el remoto pasado prehispánico. Sólo con una rigurosa metodología es posible rastrear estos procesos a través del tiempo y lograr un nivel explicativo de las instituciones culturales. 
Conjuntar fuentes históricas, lingüística y arqueología es muy importante para entender el pasado prehispánico; conjuntarlas nos ayuda a ver algo de lo mucho que sucedió en ese pasado difícil de enfocar; sabemos también lo peligroso que resulta adjudicar determinados restos arqueológicos a un grupo étnico-lingüístico, pero a pesar de ello no deja de ser interesante intentarlo, siempre y cuando nos apoyemos en datos confiables.

El gran valor de esta metodología está precisamente en la confrontación de estos enfoques que, conjuntándose de una manera inteligente y bien estructurada, genera hipótesis sujetas a corroboración.

\section{LA CONCIENCIA HISTÓRICA DEL PUEBLO MAYA}

Por muchos años se repitieron las palabras de Spinden, Morley y Thompson de que los mayas nunca registraron en sus inscripciones hechos históricos o nombres de individuos. Sin embargo, Tatiana Proskouriakoff, $\mathrm{H}$ einrich Berlin y David Kelley fueron los primeros mayistas que descubrieron que los mayas sí registraban hechos humanos antiguos, como eran los nacimientos, matrimonios, ascensiones al trono, conquistas y muertes. En las inscripciones empezaron a aparecer nombres de personas, de dinastías y de lugares (glifo emblema), cambiando la imagen de un hombre preocupado sólo por el devenir del tiempo y lo divino.

Berlin (1953 y 1956), con el descubrimiento del glifo emblema y posteriormente con los glifos nominales del sarcófago de Palenque, abrió las puertas a la búsqueda del acontecer maya, y en la actualidad se sabe que no fueron ajenos a su propia trayectoria histórica. Proskouriakoff (1963), interesada en el posible contenido histórico de las inscripciones, hizo investigaciones en Piedras N egras y en Yaxchilán, mostrando un nuevo camino en la interpretación de las inscripciones mayas. En las estelas del Clásico se presentan los personajes principales enmarcad os por textos jeroglíficos que hablan de su pasado, de sus hazañas y, lógicamente, con representaciones astronómicas y el cómputo del tiempo.

Los mayas destacaron entre las culturas mesoamericanas por sus conocimientos matemáticos y astronómicos; estos conceptos fueron resultado de una conciencia del devenir que parece ser el aspecto medular de su cultura. El maya captó el carácter divino y temporal del cosmos, el devenir de to do cuanto existe, y trató de hacerlo comprensible ordenándolo y registrándolo (D e la G arza 1975: 98). Así desarrolló la Cuenta L arga, la Cuenta Corta y la Rueda Calendárica. El tiempo constituyó un motivo de interés absorbente para el maya, no sólo como algo útil para la vida humana material, sino también como una conciencia más profunda de la temporalidad. Le interesó comprender y precisar su propio sitio dentro de este cosmos dinámico, planeó su propio devenir. 
Para el Postclásico tardío la mayoría de los investigadores aceptan que las fuentes, y específicamente los códices, sí tienen contenido histórico, eran algo más que el medio de conservar sus conocimientos y tradiciones, eran el símbolo de lo sagrado; allí se conservaba la clave para comprender el espacio y el tiempo, y para situarse en ellos. L anda y el padre A vendaño dicen que los mayas tenían muchos analtes o libros sagrados, y se sugiere que el recuerdo del pasado y los mitos se unifican en una sola tradición en manos de los sacerdotes, pues ningún aspecto de la vida se desligaba de la religión; esto no quiere decir que no existieran documentos específicamente destinados a registrar el pasado.

L os mayas de Yucatán tenían un conocimiento muy notable de la historia, un saber muy completo de su pasado, poseían gran número de libros (Landa 1978: 105) y, al decir de López de Cogolludo (1957: 498-499), se juntaron todos los libros y caracteres antiguos que los indios tenían y se quemaron públicamente, pues allí se conservaban las tradiciones y los antiguos ritos. Ese fue uno de los primeros actos de los evangelizadores, pero después dirigieron sus ataques hacia los sacerdotes indígenas; como sabían que ellos eran los guías del pueblo, al desaparecerlos habría una pérdida de identidad, un desamparo ante el futuro y no existiría la posibilidad de prepararse para lo que trajera la carga divina de los katunes.

Al ser destruidos los códices, los sacerdotes perseguidos y muertos, la conciencia histórica del maya no pudo ser eliminada y, gracias a ello, tenemos noticias de su historia, mitos y costumbres, pues conservaron ese pasado en la memoria y algunos de esos indios aprendieron a escribir con el alfabeto latino e hicieron nuevos libros basándo se en los viejos códices y en las tradiciones orales. Así surgieron valiosos textos, como el Popol Vuh, los A nales de los $C$ akchiqueles y Los Libros de C hilam Balam, que contienen una gran riqueza de información histórica, religiosa y costumbres de los mayas, dado que esta cultura no murió con la conquista española, sino que se siguieron conservando su pasado y sus tradiciones.

Los acontecimientos registrados en algunos textos mayas están situados en una sucesión temporal, lo que refleja una conciencia del devenir; y además no se documentaron todos los sucesos, sino algunos que consideraron significativos para la comunidad, lo cual implica una reflexión sobre el acontecer del pasado del hombre.

Esta necesidad de registrar sólo algunos hechos surgió por su concepción cíclica de la historia, según la cual, los acontecimientos han de repetirse como los ciclos de la naturaleza, lo que era necesario registrar para saber qué había pasado y prever lo que ocurriría. C reían en la reiteración de la historia, en que los acontecimientos de un ciclo se repetían en todos los ciclos sucesivos y, por lo tanto, el calendario podía usarse para predecir hechos futuros. 


\section{Capítulo II \\ Los chontales o putunes de Acalan, XiCALANGO Y POTONCHÁN}

Es difícil saber lo que fue este grupo en la antigüedad, pero puede asegurarse que en tiempos del descubrimiento y conquista del $\mathrm{N}$ uevo $\mathrm{M}$ undo los chontales habían perdido ya su grandeza y poderío, y en medio de otros grupos apenas llamaba la atención de los cronistas de la época. Potonchán, Xicalango, I tzamkanac y T ixchel parecen ser de gran importancia durante el Postclásico tardío, según las fuentes históricas; hecho que llama poderosamente la atención, pues los restos arqueológicos llevan a pensar que fueron importantes durante el Clásico terminal y aun desde antes.

Las evidencias arqueológicas existentes en la región muestran una ocupación significativa, manifiesta en los rasgos arquitectónicos, la escultura, cerámica y restos líticos; lo que permite entrever que fueron los dominadores de una ruta de comercio a través de los ríos, laguna y litoral marino. N o sin razón, Thompson (1975) Ilamó a los chontales o putunes de T abasco-Campeche los fenicios de América.

$\mathrm{H}$ oy en día los chontales son un grupo lingüístico relativamente pequeño, habitan los municipios tabasqueños de $\mathrm{N}$ acajuca, Centro, Centla, M acuspana y Jonuta, aunque el área que antiguamente ocuparon era mucho mayor, como lo veremos posteriormente.

L os chontales no se autodenominaban de ese modo: el término significa extraño o extranjero, algo desconocido o raro (Schumann 1985: 117); así los llamaron los nahuas del centro de M éxico. Sin embargo ellos se autodenominan yoko yinik o yoko winik, 'hombre verdadero', según la variante de este idioma, y a su lengua la llaman yoko t'aan, 'palabra verdadera'. Lo más probable es que los chontales antiguamente se llamaran putunes, como lo registra Ciudad Real y posteriormente lo cita Thompson. En la región de Acalan se autodenominaron magtun o tagmactun, y así aparecen registrados en los Papeles de Paxbolom M aldonado. En general se les conoce como mayas chontales-putunes.

Tres fueron los grupos principales que se encontraban en Tabasco: 1) mixezoque; 2) mayas, representados por los chontales; y 3) nahuas. En Campeche se registran a los mayas chontales o acalanes, los cehaches y los dzulob. 
Al tratar de situar los restos arqueológicos de los chontales dentro del conjunto de la civilización maya, hemos de tener presente que aunque se localizan en el actual estado de Tabasco, con anterioridad abarcaron parte de otros estados como Campeche y Chiapas.

$\mathrm{H}$ a sido una preocupación de diferentes investigadores definir directa o indirectamente el área chontal (cfr. Gate, M endizábal y Jiménez M oreno, y J ohnson citados en Ruz L. 1945; Vargas 1983). En términos generales, el territorio chontal o putún se extendía desde el río Copilco, cerca de Comalcalco, limitado por grupos nahuas y mixe-zoques; hacia la costa se ampliaba a través de los deltas de los ríos G rijalva, San Pedro y San Pablo hasta la $L$ aguna de $T$ érminos, la cuenca del río $C$ andelaria y posiblemente hasta Champotón. Por el interior su poderío llegaba, por lo menos, hasta Tenosique y las estribaciones de la sierra, en donde limitaba con los grupos chol, zoque y lacandón. Por el lado del río Candelaria limitaba con los mayas yucatecos y cehaches.

Thompson sugiere, además, que dominaban las cuencas de los ríos Chixoy y Cancuén, en donde se localizan los sitios de Altar de Sacrificios, Seibal y C ancuén, entre otros, y los puertos de $\mathrm{N}$ aco sobre el río C hamalecón en $\mathrm{H}$ onduras y $\mathrm{N}$ ito en el Golfo Dulce (mapa 2).

En esta simple descripción puede apreciarse que la extensión del área de acción de los chontales era impresionante, pues se extendía por toda la costa hasta $\mathrm{H}$ onduras y por el territorio de los actuales estados de Tabasco, C hiapas, Campeche e interior de la zona maya (Thompson 1975: 24-25).

La situación geográfica estratégica de los chontales les permitió aprovechar un vasto sistema de rutas fluviales a través de los ríos $G$ rijalva, U sumacinta, Chacamax, San Pedro y San Pablo, San Pedro Mártir, Palizada y $C$ and elaria, hasta la $L$ aguna de T érminos; esta ubicación fue de vital importancia para su expansión e intercambios comerciales y culturales con otras partes del área maya, convirtiéndose en los comerciantes por excelencia.

Los límites de la provincia de Tabasco seguramente variaron con el tiempo; es más, como dijimos anteriormente, para la época de la conquista los chontales ya habían decaído, su esplendor había pasado, como lo atestiguan algunas fuentes históricas, aunque algunas otras afirman lo contrario al describir grandes ciudades y mucha población.

En las R elaciones H istórico-geográficas de la Gobernación de Y ucatán (1983 [1898]: 319) se dice que la provincia de Tabasco: «Es de mui poca población y jente. Es toda ella tierra mui caliente y mui umida abundantes de aguas de rríos grandes y pequeños, esteros, lagunas, ciénagas y tembladeras».

Juan López de Velasco (1994: 131-32), quien hace la D escripción U niversal de las Indias y define geográficamente cada una de las provincias, nos ha dejado el siguiente relato de Tabasco: 
H ay sólo un pueblo pequeño de españoles y como dos mil indios no más en esta provincia, la cual anda por la cercanía con la gobernación y obispado de Yucatán desde el año de 50.

La villa de nuestra Señora de la Victoria, ochenta leguas de la ciudad de M érida, junto a unas lagunas grandes abundantes de pescado y cerca de la mar; hay en ella cincuenta vecinos españoles, los treinta y seis encomenderos y pobres, porque el mayor repartimiento no pasa de trescientos indios, y los demás tratantes.

Antonio de Ciudad Real (1976: 357) también describe la provincia casi como los otros autores: «C incuenta leguas adelante de Tixchel está otra villa de españoles llamada Tabasco, de poca vecindad del mesmo obispado de Yucatán, en cuyo distrito está la chontalpa, provincia muy rica de cacao y no menos poblada de mosquitos».

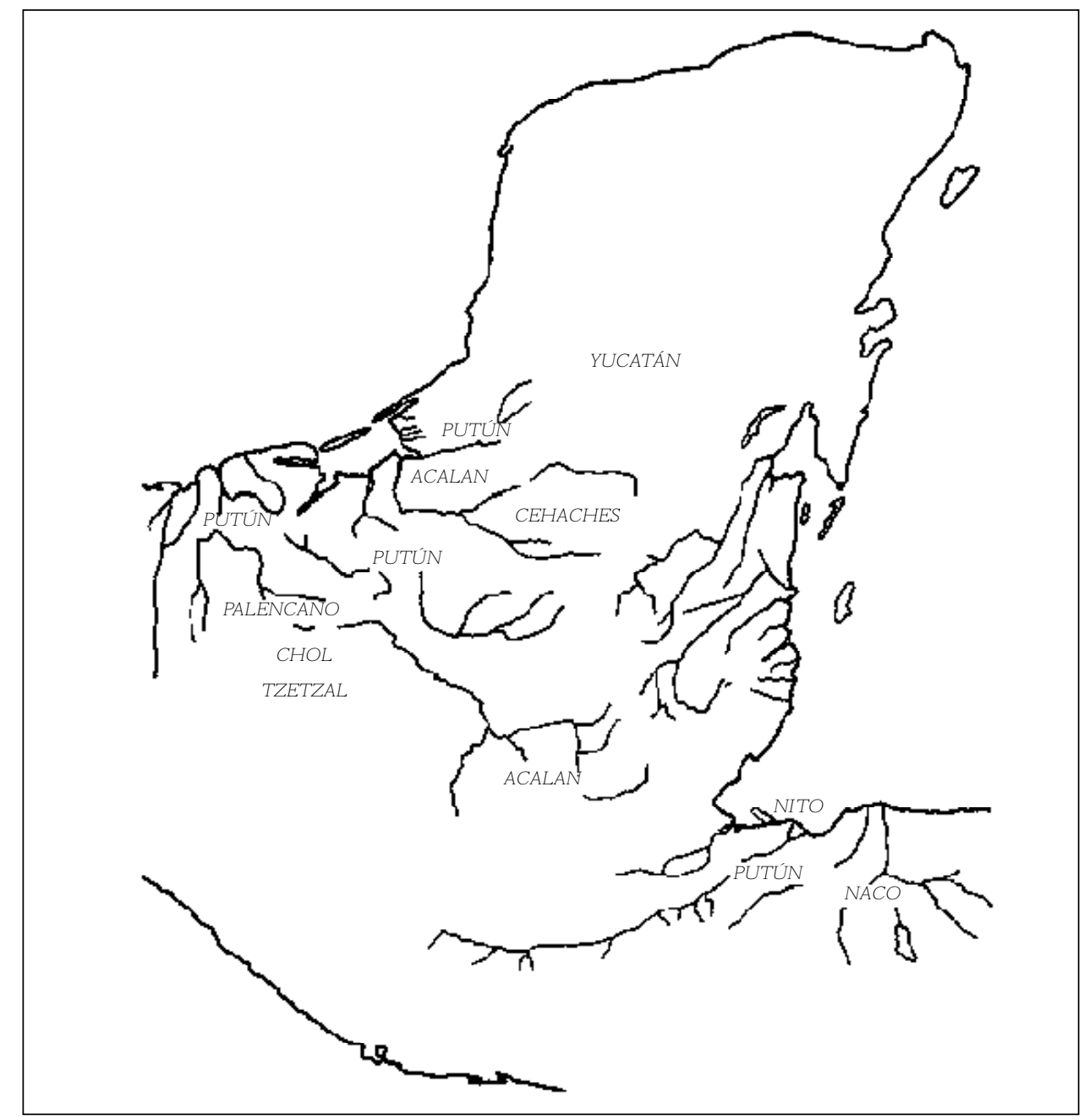

M apa 2. Área de dominio de los chontales según E. Thompson (1975). 
L os límites de los chontales hacia la península de Yucatán quedan marcados en una cita de Antonio de Ciudad Real (1976: 336), quien recorre gran parte del territorio de la N ueva España y Audiencia de Guatemala.

\footnotetext{
O tras catorce leguas poco más, hacia el mesmo M éxico está, en la mesma ribera de la mar, otro pueblo llamado Tixchel, de indios mejor agestados y un poco más polidos y curiosos que los de maya, los cuales hablan una lengua diferente llamada putunthan, y por otro nombre chontal, aunque en muchos vocablos se encuentra con la de $M$ aya, y así sabida la una, fácilmente se sabrá la otra.
}

Por las fuentes históricas se podría pensar que los chontal es Ilegaron hasta Tixchel, sin embargo, por otras se concluye que llegaron hasta el actual Champotón, ya que López de Cogolludo lo identifica con C hakamputún, la 'sabana de los putunes'.

La provincia o cacicazgo de Acalan, como aparece en algunas de las fuentes históricas, pertenecía también a los chontales; abarcaba posiblemente desde Tixchel y $L$ aguna de Términos hasta Tenosique, con su capital I tzamkanac o Acalan, junto al actual río de $C$ andelaria.

Scholes y Roys (1968: 24-5) establecen que estos grupos se extendían desde la costa hasta Tenosique, donde aún habían hablantes de chontal en los siglos XVI y XVII; su mayor concentración, al parecer, se dio hacia el C andelaria y la costa en general; sin embargo, los límites de la lengua chontal llegaron hasta Tenosique y las estribaciones de la sierra.

Todo ello nos revela que la provincia lingüística chontal coincide casi exactamente con una zona que forma una entidad geográfico-cultural caracterizada por tierras bajas pantanosas, anegadas una gran parte del año y con un sistema hidrográfico único, compuesto por multitud de ríos y estuarios, abundantes lagunas y salidas al litoral marino.

En términos generales, tanto cultural como geográficamente, se pueden reconocer siete divisiones en el área de estudio: 1 ) las sierras bajas con sitios del Clásico y localizadas sobre los 800 metros snm; 2) las llanuras intermedias situadas entre las sierras bajas y el U sumacinta medio; 3) el U sumacinta medio, que comprende, como su nombre lo indica, la parte central del río, es decir, la zona de Zapata-U sumacinta; 4) el área del río San Pedro M ártir; 5) el bajo U sumacinta, que consiste en terrenos bajos, pantanosos, inundados gran parte del año y atravesado por ríos y lagunas, desde J onuta-C hontalpa hasta la costa; 6) la del río Candelaria; y por último, 7) la península deXicalango, que en sí forma un conjunto geográfico y cultural (Vargas 1983).

\section{LAS PROVINCIAS CHONTALES Y SUS CAPITALES}

El conocimiento de la organización político territorial de una región es de gran importancia, pues por medio de ella podemos comprender no so- 
lamente la división política y su organización social, sino también establecer las relaciones internas y externas que se dieron.

En las fuentes históricas se citan varias provincias para la región de Tabasco, y sin lugar a duda me atrevería a decir que funcionaban como el cuchcabal en Yucatán, ya que se nombran una cabecera o capital y un territorio determinado que debió estar gobernado por un halach uinic o un batab, según el caso.

Izquierdo (1997) nos dice en su trabajo que por medio del patrón de asentamiento de la Chontalpa, y con base en las fuentes históricas, ha podido delimitar siete entidades políticas en el Postclásico tardío, a las que llama provincias.

L as provincias que identifica como de la Chontal pa son: A calan, I ztapaU sumacinta y Xicalango, y a estas dos últimas las Ilama «provincias occidentales»; las cuatro provincias orientales son C opilco, Z ahuatán, C hilapan y Potonchán.

Es interesante comparar esta división en provincias de I zquierdo con las que se hicieron a partir de la información arqueológica, tomando en cuenta las características del medio ambiente y los sistemas constructivos de los restos arqueológicos localizados en la región de la Chontalpa (cfr. Berlin 1956, Rands 1967, Vargas 1983). Con base en toda esa información recopilada se realizaron siete subdivisiones; en algunos casos no se encontró el sitio rector por lo cual no se pudo hablar de capitales.

A bordar esta problemática para to da la C hontalpa es to davía muy difícil y, por lo tanto, el trabajo desarrollado por I zquierdo me parece de gran valor; pienso que algunas de estas provincias no son chontales, algunas posiblemente tengan otra filiación lingüística y étnica, pues se cita con frecuencia a los dzulob y los problemas internos de la región.

Por otro lado, creo que a pesar de la poca información arqueológica existente, sí puede hablarse de una región chontal que abarcaba parte del U sumacinta bajo y medio, las costas y el río Candelaria, llegando posiblemente hasta Champotón y hacia el interior hasta las estribaciones de la sierra. En toda esa región se localizan, además de otros poblados, tres grandes cabeceras o capitales: Potonchán, Xicalango e Itzamkanac; seguramente todos los autores que se han dedicado a la región chontal estarán de acuerdo con aceptarlas como chontales o putunes.

Estas tres provincias chontales que se reconocen sin mayores problemas son: T abasco, Xicalango y Acalan; cada una con su capital: Potonchán, Xicalango e I tzamkanac, y cada una con su gobernante principal: T avasco para la primera provincia, el cacique Francisco para Xicalango y Paxbolom A cha para I tzamkanac.

\section{La provincia de T abasco}

Juan Díaz, en el Itinerario de la A rmada, dice lo siguiente: «Llámase esta provincia Potonchán»; sin embargo, la R elación de la villa de Santa 
M aría de la Victoria (R elaciones H istórico-geográficas... 1983, II: 385-432) apunta lo siguiente:

[...] que esta provincia se dice la provincia de Tabasco a causa de que el señor de este pueblo se decía Potonchán, que en la lengua castellana dice lengua chontal [...] y así este pueblo se decía Potonchán, que es la lengua mas común de esta provincia, y como se llamaba el señor de este pueblo Tabasco, dice la provincia de Tavasco (Tabasco).

Algunos autores han Ilamado a esta provincia Potonchán; pero el nombre fue Tavasco y su capital Potonchán. La cita anterior es clara al respecto pues J uan Díaz debió registrar el nombre de la cabecera o capital de la provincia y por extensión la llamó así; empero, la relación es clara al diferenciar la provincia de la capital o cabecera. La misma relación nos dice que tomó su nombre del pueblo que está en la misma tierra y sitio, que se llamaba Tabasquillo.

I gual que muchas demarcaciones prehispánicas, la provincia de T abasco parece no tener fronteras precisas; se sabe que estaba delimitada al poniente por la provincia de Copilco, al sur llegaba hasta lo que hoy se conoce como Villahermosa, al norte se delimitaba por la costa y al oriente debió llegar hasta el río San Pedro y San Pablo.

La provincia de Tabasco tuvo diferentes límites. Comprendía la costa desde la barra de Tupilco (C opilco) hasta la barra de San Pedro y San Pablo, las Ilanuras fluviales formadas por el curso inferior de los ríos G rijalva y U sumacinta y sus tributarios, y las estribaciones de la sierra norte de Chiapas. En los primeros años de la Colonia también incluyó en su territorio la L aguna de Términos; pero seguramente no perteneció con anterioridad, porque Xicalango fue un territorio que funcionó independientemente para el comercio, y según Bernal Díaz del Castillo era un santuario hacia el final del Postclásico tardío.

Gerhard (1991: 29) señal a que esta provincia se conformaba por la C hontalpa, así llamada por los españoles; hacia el noroeste estaba dividida en quizás 30 comunidades diminutas pero autónomas. Sobre el delta del G rijalva-U sumacinta se local izaban Potonchán y algunos otros pueblos.

En el M emorial de pueblos de la provincia de Tabasco (R elaciones H istóricogeográficas... 1983: 351), recopilado hacia 1580, se consigna que existe la dicha villa de españoles refiriéndose a la villa de T avasco y 71 pueblos de indios, aunque se nombran otros en la ribera de ese río (mapa 3). En relación con la provincia de Tabasco también se numeran 71 pueblos y se añade que es de muy poca población y gente:

Esta provincia es de tierra llana y montosa, excepto las sierras que están en la parte del este, que es donde están los pueblos que llaman de la sierra. En el mismo río existen tres pueblos que Ilaman los tres Zaguatanes; más abajo está el primer pueblo de naguatatos; son ocho pueblos de naguatatos, que es lengua mexicana, y los de tierra zoque. M ás adentro en la tierra son treinta y tres pueblos de la Chontalpa; estos son 


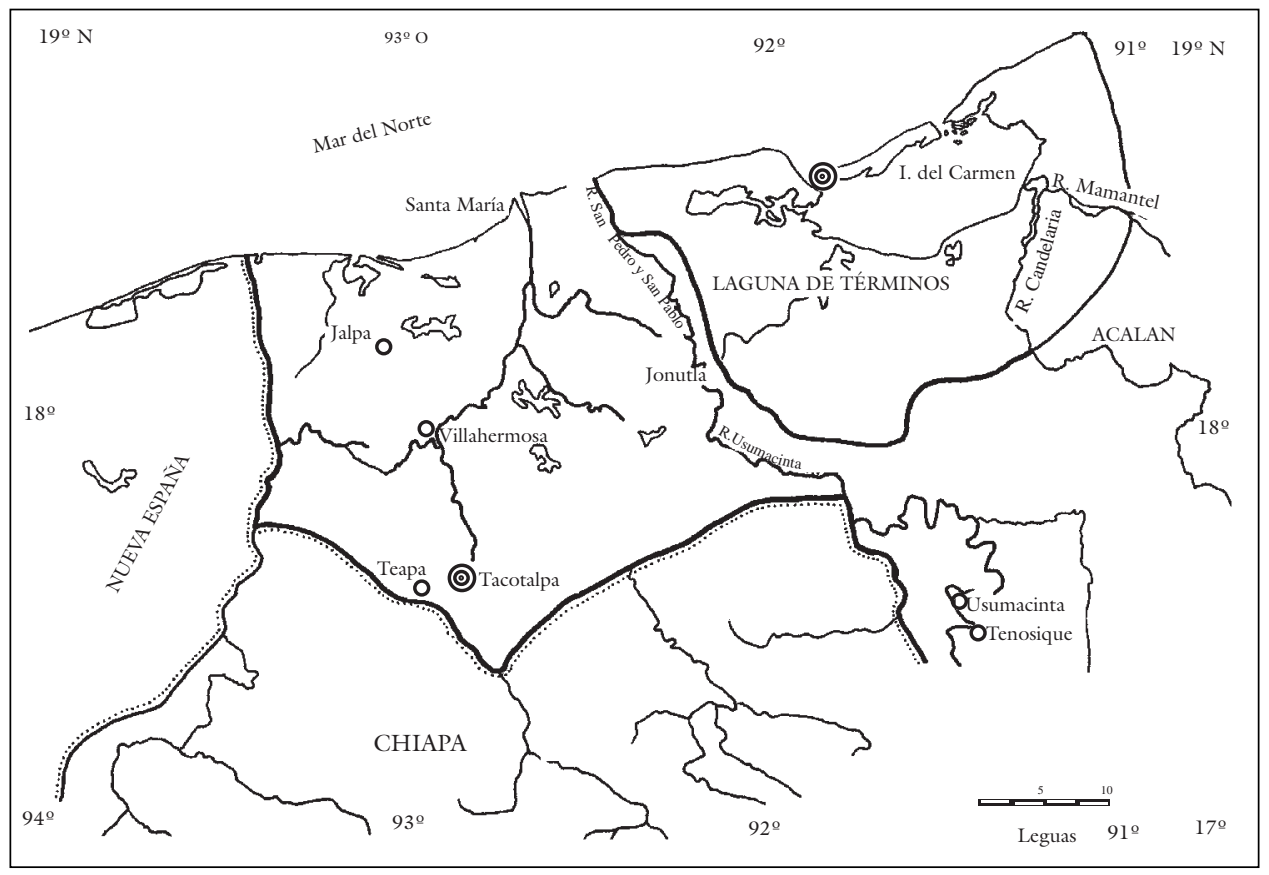

Mapa 3. Pueblos de la provincia de Tabasco (Gerhard 1991).

de otra lengua; son éstos de muy poquita población; tierra muy anegadiza toda por causa de los muchos ríos que tiene (Relaciones Histórico-geográficas... 1983: 368).

Se sabe que, generalmente, las encomiendas guardan cierto tipo de relación con la organización sociopolítica de la región durante la época prehispánica; por lo tanto, esto podría ser un buen indicador para entender el pasado prehispánico de una región.

La provincia de Tabasco se dividió en tres: a) los nueve pueblos cercanos al de Tabasquillo, b) la Chontalpa con 36 pueblos, y c) Tepetitán con diez pueblos (ibidem: 373-8).

Pueblos cercanos a Tabasquillo

Izquierdo (1997: 171-85) habla de cinco pueblos que formaban la colindancia entre las provincias de Potonchán (Tabasco) y Copilco, localizados a orillas del río Nuevo o González: Olcuatitán (1), parece ser la población mayor y pudo tener 1174 habitantes; Ociacaque (2), al parecer fue una aldea; Guatacalca (3), una villa; Guavicalco (4), posiblemente un barrio de Guatacalca; y Jalupa (5), en las márgenes del río Vainilla.

A estos cinco poblados hace referencia el Memorial de los pueblos de la provincia de Tabasco, y también están registrados en el mapa de Alfaro Santa Cruz (Izquierdo 1997: 172): Apaztla o Atasta (6), que se ubicaba a 
orillas del río Plátano, cercano a Villahermosa y podría ser la actual A tasta, una colonia de la ciudad capital del estado y se le calcula una población de 1212 habitantes (I zquierdo 1997: 173).

Tamulté de la Barranca (7) aparece también registrado en el M emorial de los pueblos..., en M emoria de los conventos y en el mapa de Alfaro de Santa Cruz; parece que hoy es un barrio de Villahermosa. En la R elación de Santa M aría de la Victoria se explica lo siguiente con respecto a Tamulté de la Barranca: «EI río arriba de G rijalva, a doce leguas de esta villa, sobre una barranca de él, está asentado un pueblo de ciento y tantos vecinos que se dice Tamulté, y de allí adel ante, desde a tres leguas, van los demás pueblos» (Relaciones H istórico-geográficas, II: 426). Este poblado es al parecer el segundo más importantes de la provincia de Tabasco, se calcula que tenía una población de 3240 habitantes.

Tamulté de la Sabana (8). Allí existen restos arqueológicos como en los dos sitios anterio res y está registrado en fuentes históricas del siglo xvı. Se localiza sobre terrenos elevados que los preservaban de las inundaciones. E stá relativamente cerca del río aunque rodeado de pantanos y lagunas. $\mathrm{La}$ población de este lugar se calcula en 2430 habitantes.

O cuilzapotlán (9) sólo aparece citado en el M emorial de los pueblos... y en la R elación de la Provincia...; no se tiene ninguna información adicional sobre el lugar, pero lo que sí se sabe es que era de la Chontalpa.

Potonchán (10) fue descrito en el momento del contacto (1518) como una ciudad entre 15 mil y 25 mil casas, aunque se vieron asentamientos aún mayores (Anglería 1964-65: 408, 420). R elatos de españoles presentes en la batalla de $C$ entla estiman que el ejército que luchó contra ellos fue de 40 mil. Es posible que esta cifra sea exagerada, pero de to dos modos da una idea de lo importante de la región. Díaz del Castillo (1974) escribió con respecto a Potonchán: «Porque en aquella sazón aquel pueblo era de mucho trato, y estaban sujetos a él otros grandes pueblos».

Se localizaba a media legua de la costa, río arriba en la orilla oeste del Grijalva. Thompson ha pretendido localizar al Potonchán de las fuentes históricas frente a Frontera; sin embargo, durante nuestros reconocimientos de superficie que hicimos en la región no se encontró ningún sitio importante en dicha ribera, de no ser uno relativamente pequeño que se conoce con el nombre de San Román, y otro más importante en lo que hoy es Frontera: Los Í dolos. Cerca de la desembocadura y en tierra firme se ubican dos sitios importantes por los restos arqueológicos, EI Pájaro (figura 1) y Allende (fotografía 1); alguno de los dos bien podría ser Potonchán, porque a mi juicio no necesariamente debía estar localizado a orillas del río Grijalva, aunque sí relativamente cerca.

Todos estos sitios desde C omalcalco hasta el Grijalva, y posiblemente de la costa hasta J onuta y E miliano Z apata, están construidos con ladrillo y se caracterizan por tener en gran abundancia la cerámica anaranjada fina de 
LOS CHONTALES O PUTUNES DE ACALAN, XICALANGO Y POTONCHÁN

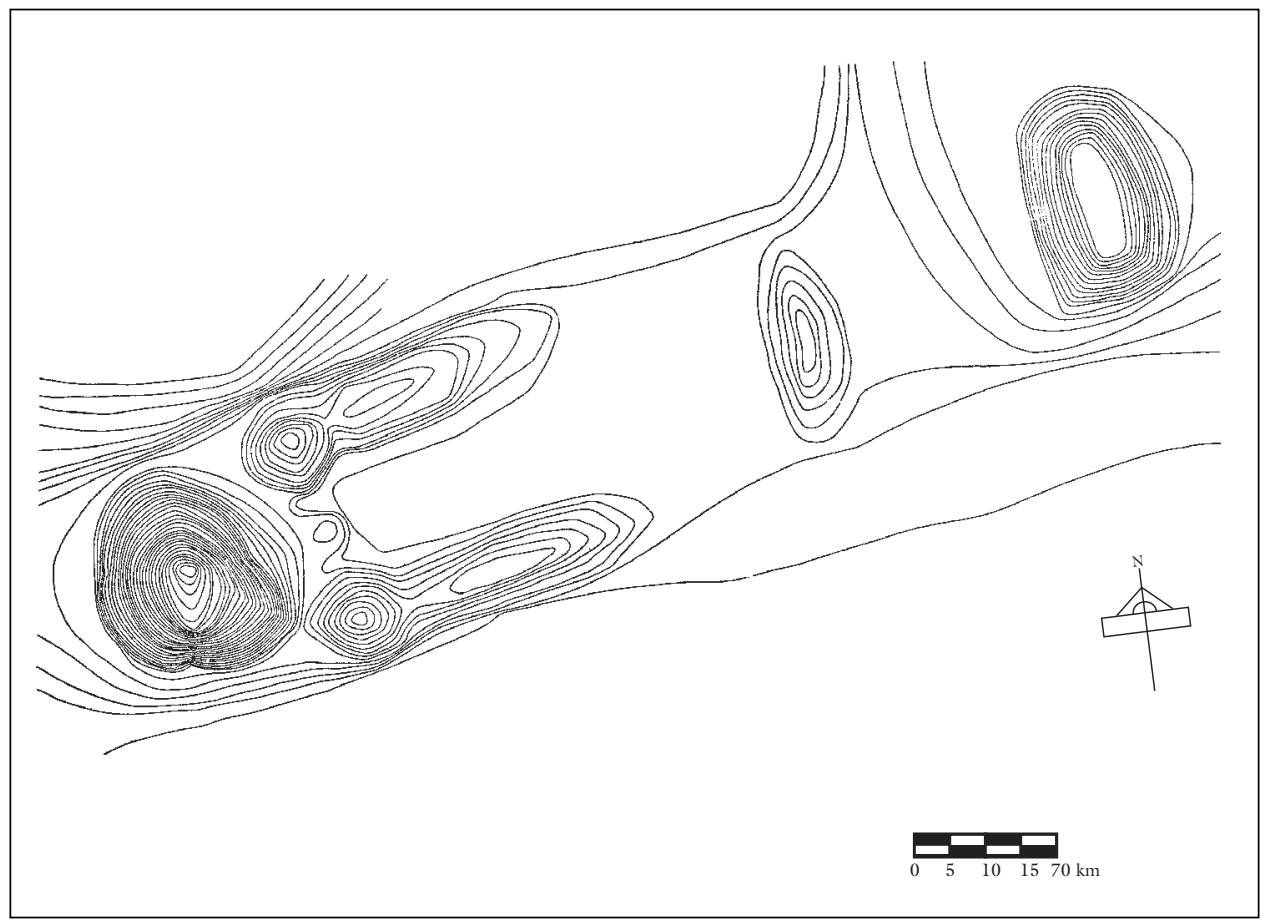

Figura 1. Estructuras del sitio: El Pájaro.

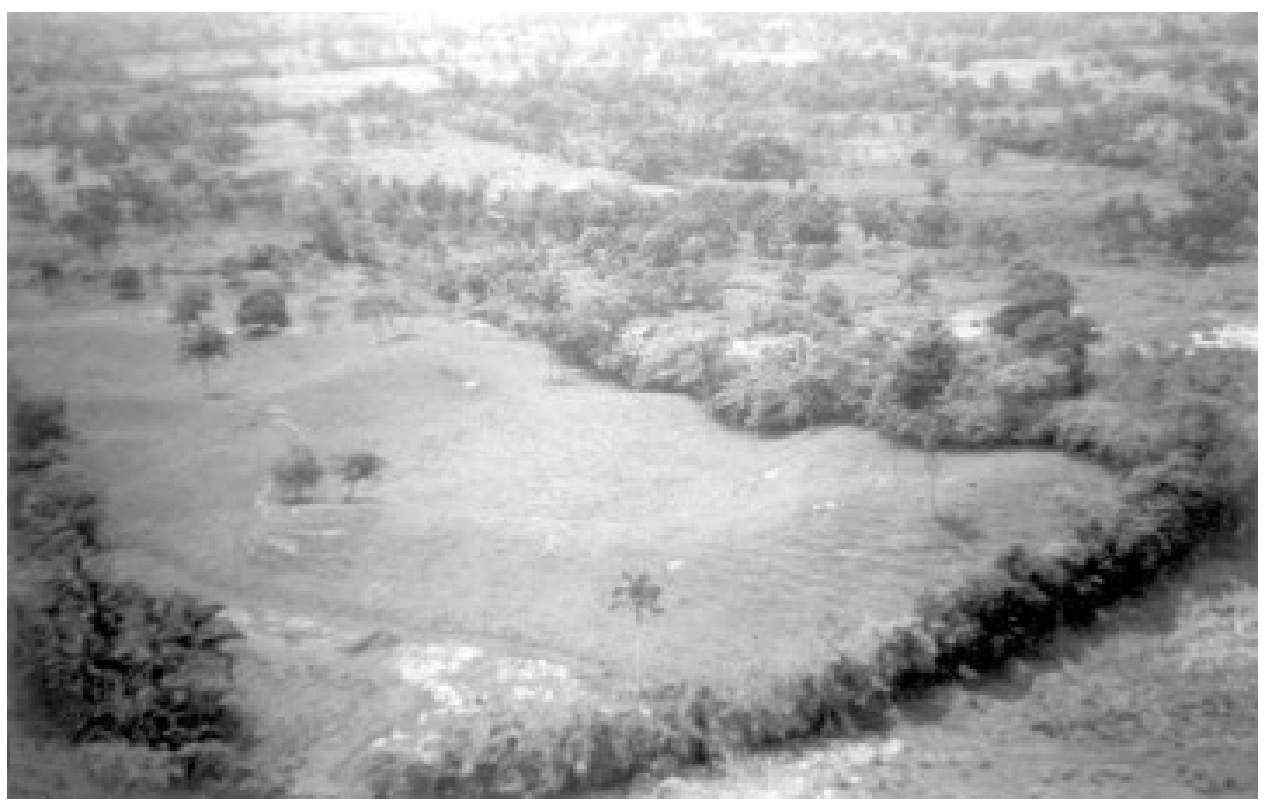

Fotografía 1. Sitio arqueológico de Allende. 
los grupos Altar, Balancán, $\mathrm{M}$ atillas y Tres $\mathrm{N}$ aciones, entre otros; en esa provincia se asentaron los mayas chontales o putunes durante el Clásico terminal (800-1100 dC) y también durante el Postclásico.

Potonchán desempeñó un papel preponderante como capital o cabecera; además, según las fuentes históricas, fue un lugar importante de comercio a larga distancia y coexistió con Xicalango e I tzamkanac en el momento del contacto, porque los españoles quisieron utilizarlos en el proceso colonizador.

No debemos olvidar tampoco que ahí, a orillas del río Grijalva, se fundó la primera población en M éxico, Santa M aría de la Victoria, como agradecimiento a la $V$ irgen por la victoria obtenida contra los chontales, que a decir de los conquistadores presentaron un frente de batalla bien ordenado, lo cual hace pensar en una organización político-territorial de cierta importancia, en donde debió existir un poder centralizado con una cabecera Potonchán; seguramente las alianzas sólo se hacían para evitar ser sometidos y no eran muy fuertes.

Centla (11). La primera información que se tiene del lugar es por G rijalva en 1518 y la mejor información es sobre la batalla de C entla en1519, cuando Cortés está en dicho lugar. Al parecer C entla se localizaba a orillas del G rijalva en el lugar en donde se encuentra Frontera, y en donde está el sitio arqueológico de Los Ídolos. Bernal Díaz del Castillo (1974) nos habla de Zintla, pueblo sujeto al mismo Tabasco. Fray Bernardino Pérez en 1581 menciona a Z intla como una visita de la Chontalpa y nos dice que tenía 50 habitantes (I zquierdo 1997: 181).

Taxahual (12). Parece ser uno de los pueblos que estaban en las cercanías de Santa M aría de la Victoria y aparece dibujado en el mapa de Alfaro de Santa Cruz y en la lista de los pueblos encomendados como poblado con 15 indios tributarios. I zquierdo (1997: 182) calcula que debió tener 67 cabezas de familia en 1579; dice que existen varias referencias sobre esta población pero muchas de ellas muy confusas y piensa que la más clara es la siguiente cita: «Y a tres leguas de esta villa, poco más o menos se aparta un camino que entra la vuelta del noreste-suroeste y apartase en una cruz que está en la playa por señal y a la legua y media de ella está el dicho pueblo de Taxagual (Taxahual) antes referido»(Relaciones H istórico-geográficas... 1983, 11:423).

\section{La Chontalpa}

La arqueología, como dijimos, no muestra una ocupación importante para el Postclásico tardío; sin embargo, las fuentes históricas citan algunos pueblos localizados a orillas del río y en la región de la C hontalpa.

En este caso particular vemos que las fuentes históricas aportan información sobre el número de pueblos registrados en ellas; la arqueología 
consigna un gran número de sitios construidos de ladrillo a orillas del río, todos con cerámica de pasta fina; la lingüística y el medio ambiente ayudan a entender el momento histórico de una región determinada, porque allí viven los chontales y seguramente lo hicieron con anterioridad.

Es interesante señalar la multietnicidad de la provincia de Tabasco, pues en las fuentes se menciona que había nahuas, zoques y chontales. De 71 pueblos nombrados en las Relaciones Histórico-geográficas..., sólo 33 son chontales, el resto de los otros grupos. A Potonchán se le refiere en otros documentos con diez pueblos cercanos, que seguramente dependían directamente de él, más 36 pueblos autónomos que constituían la Chontalpa (mapa 4).

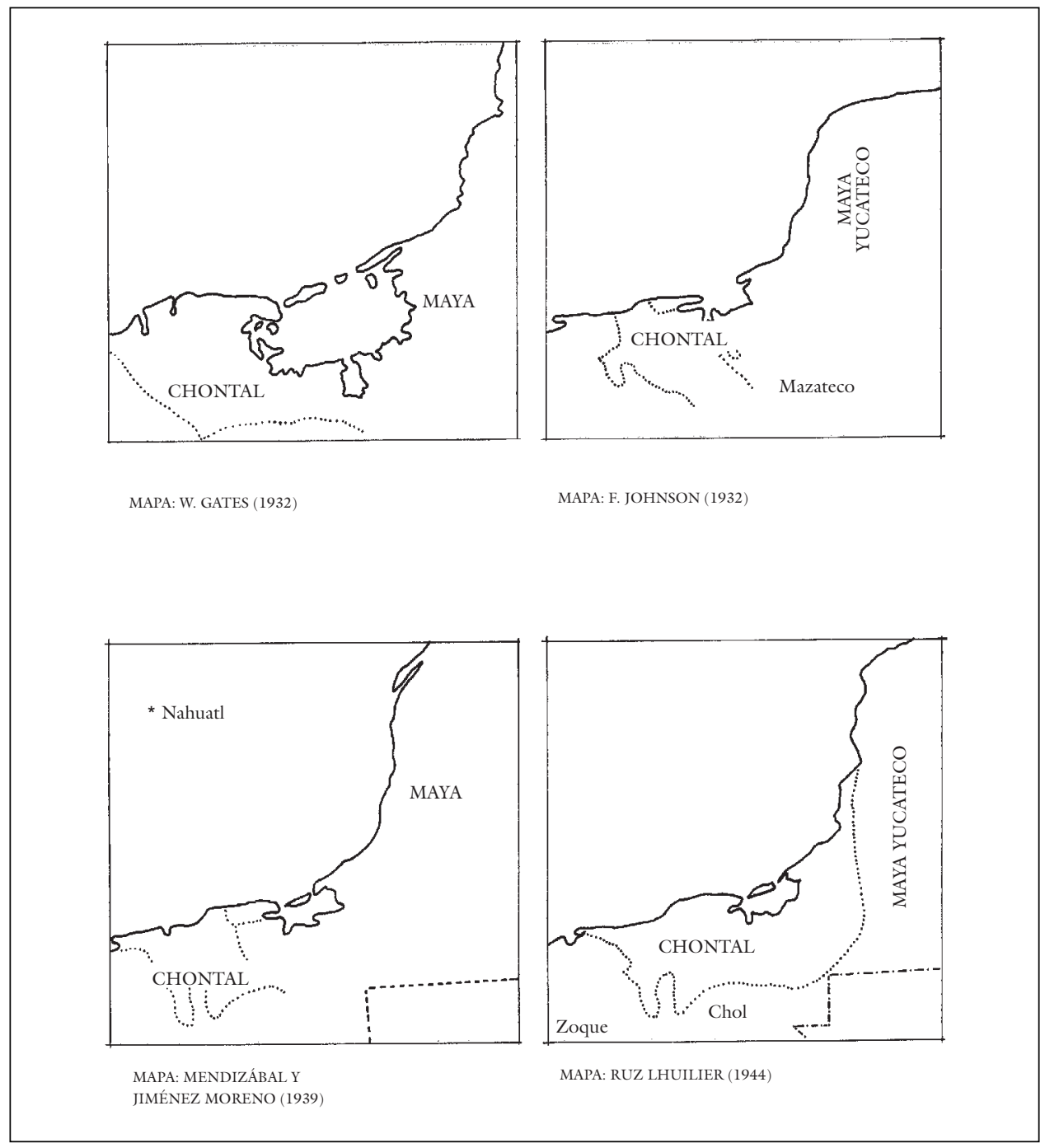

Mapa 4. Ocupación chontal. 
Por lo tanto la Chontal pa no se conformaba con los pueblos citados en las fuentes históricas, sino que por lo menos serían 33 pueblos chontales de acuerdo con algunas fuentes, y según otras 46: diez pueblos dependiendo de Potonchán y 36 autónomos; citaré a continuación los nombres de algunos pueblos chontales: 1) Boquiapa, Chichicapa, I cnuapa (I quinuapa), Copilcozacualco, U lapa. 2) A pastla (Cipastla), Guavicalco, O celoteapa, O mitlán (O mitán). 3) Partido de Jalpa, Amatitán, Ayapa, Cupilco, M ecoacán, Soyataco. 4) C hontalpa O riental, N acajuca (cabecera), C hilatempa, Guatacalca, Guaytalpa, M azateupa, O culzapotlán, O Icuatitán, O xiacaque, T amulté de la Sabana, T apocingo, T ecoluta, T ucta (Tuptla). 5) Potonchán - Tabasco, Centla, Chayala, T axagual, T amulté de la Barranca. 6) H acia el sur, Zahuatanes o C ihuatanes, A stapa, Xaguacapa, Xalapa. 7) Partido de U sumacinta (L os Ríos), J onuta, I ztapa (E stampilla), Balancán, Cihuatecpan, T atahuital pa, Popame (M ulté), Petenecté, U sumacinta, T enosique.

Lo que podemos apreciar por esta simple enumeración de pueblos chontales es que alrededor de Potonchán, la cabecera de la provincia de Tabasco, existían por lo menos diez pueblos dependientes de ella; los otros chontales parece que sí estaban más concentrados en lo que hoy conocemos como la Chontalpa pero no había un po der central que los aglutinara.

Por otra parte, los chontales eran vecinos de los nahuas y de los zoques, pues en estas mismas relaciones se les cita como tales.

Con base en la información presentada podemos decir que sí existió una provincia o cuchcabal Ilamado T abasco, la cual tenía por capital o cabecera Potonchán, y por halach uinic o señor a Tavasco, en el momento de la C onquista. Sin embargo, también es importante señalar que había otros 30 pueblos que no dependían de Potonchán, eran autónomos.

Al hablar de los cuchcabalob o provincias, generalmente se piensa que es una unidad político territorial; aunque, por la información que se tiene de esta parte de la C hontalpa, vemos que existían dos sistemas diferentes de gobierno. El primero se define como el espacio territorial gobernado por un poder central que reside en un lugar determinado, caracterizado en este caso por Potonchán. Y el segundo tipo de organización política es aquel en donde no existe un poder central, sino más bien era un conjunto de batabilob confederados pertenecientes a un mismo linaje, que reproducían en su interior la organización política del primer tipo y se aliaban para evitar ser sometidos por sus vecinos mejor organizados.

\section{La provincia de Xicalango}

Xicalango parece ser otra provincia chontal, pues se habla de un territorio dominado por un poder central que residía en un lugar determinado, que denominamos cabecera o capital, que bien podría ser Santa Rita. 
Xicalango formaba un gran asentamiento junto con Atasta; dominaban posiblemente lo que hoy es la península de Xicalango hasta el río San Pedro y San Pablo, controlando además el río Palizada, parte de la L aguna de T érminos y la I sla del C armen. L a lengua común era el chontal, aunque posiblemente el grupo dirigente hablaba el náhuatl y muchos los entendían.

La capital o cabecera de la provincia o cuchcabal debió ser Xicalango, que pudo localizarse en el sitio arqueoló gico de Santa R ita o en L os Cerritos según el autor que sigamos (cfr. M atheny 1970, Blom en prólogo de Torres 1945, O choa y Vargas 1979). El único cacique que se conoce en el sitio llevaba el nombre de Francisco (I zquierdo 1992).

Como hemos dicho, no existía una frontera precisa; además, en momentos diferentes pudo pertenecer a otra provincia o tomar otro nombre, como L aguna de Términos, de acuerdo con algunas fuentes, y según otras, provincias de Tabasco y Xicalango.

En 1529, el adelantado M ontejo dominó a los indígenas de Xicalango y Atasta; a final de 1530 y comienzos de 1531 el Adelantado y algunos españoles pasaron varios meses en Xicalango. En una anotación que aparece en el mapa de Alfaro Santa Cruz de 1579 se dice que Atasta tenía 18000 habitantes; es posible que dicho número correspondiera al total de la comunidad de Atasta y Xicalango cuando se hizo el primer censo de tributarios.

Diezmada primero por la viruela en 1519 ó 1520, la población de Xicalango y Atasta sufrió ulteriores pérdidas por enfermedades, y al final de la década de 1550 los tributarios sobrevivientes de Xicalango fueron congregados en Jonuta. Con esto Atasta quedó como la única población de la península de Xicalango.

En la información documental Xicalango aparece como una zona económica de gran importancia que desempeñó un papel sobresaliente durante el Postclásico tardío. Sin embargo, se sabe que esta área fue habitada desde épocas tempranas, Preclásico Superior, hasta la Conquista (cfr. Ruz 1969, M atheny 1970, O choa y Vargas 1979, J iménez 1984).

En los reconocimientos arqueológicos de superficie hechos en 1978 se localizaron más de 40 sitios (mapa 5); el ambiente que prevalece es aparentemente inhóspito, pues la franja de tierra es estrecha y llena de pantanos, ciénagas y gran cantidad de mosquitos que hacen casi imposible la vida de esas comunidades.

EI sistema constructivo se caracteriza, fundamentalmente, por utilizar como materia prima la concha de ostión para construir algunas plataformas y hacer ciertas nivelaciones sobre los pantanos. También observamos durante nuestros reconocimientos que se hicieron ladrillos con ese material, mientras que las construcciones de Comalcalco, Allende, O axaca y Jonuta, entre otras, se trabajaron con ladrillos construidos de arcilla.

Destacan en esta zona los sitios: El Aguacatal, Los Cerritos, La Veleta, Atasta y Santa Rita. 


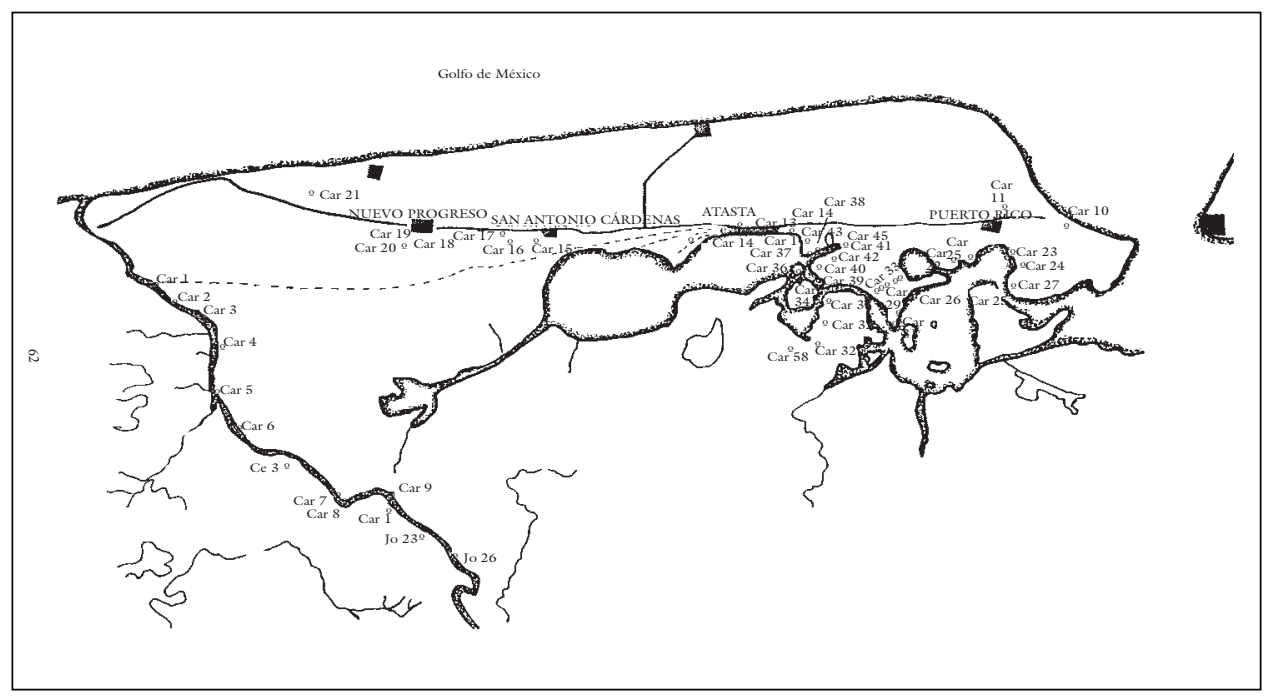

Mapa 5. Sitios arqueológicos de la península de Xicalango.

El primero es uno de los más visitados por los arqueólogos y donde se han hecho estudios particulares. Según los reportes, su ocupación data del Formativo superior, pero sus construcciones más importantes corresponden al momento de la intrusión de un nuevo grupo, que nosotros hemos identificado como el chontal, el cual llega hacia finales del Clásico y tiene su apogeo durante el Clásico terminal (700-100 dC).

La documentación que se refiere a Xicalango como uno de los mayores puertos de comercio es numerosa (Scholes y Roys 1968, Cardós de Méndez 1959, Chapman 1957, Thompson 1975), y se dice que llegaban allí los comerciantes desde Yucatán, Honduras, Chiapas y el Golfo de México: «[...] la otra mitad entraba por allá por la costa de Xicalanco. Los que entraban a Xicalanco llevaban mercancía del rey Ahuízotl, para comerciar con ella» (Sahagún citado en Ochoa y Vargas 1979: 78).

Xicalango cobró gran importancia como puerto de intercambio, y más tarde desempeñó un papel relevante en el comercio no sólo de la región, sino de Mesoamérica. Por ahora no se sabe si su relevancia decayó a raíz de la conquista de Tenochtitlan, cuando se cortaron prácticamente las rutas de comercio a larga distancia, o si su florecimiento correspondió a un periodo anterior. Por dos fechas de Carbono 14 se puede afirmar que la ocupación mayor corresponde al periodo Clásico terminal, y que durante el Postclásico tardío siguió funcionando pero a menor escala, como un gran sitio de épocas pasadas; así lo atestiguan los restos arqueológicos. Sabemos que ahí floreció uno de los más poderosos centros comerciales y que fue una puerta de entrada de los mayas chontales o putunes a las tierras bajas.

Los reconocimientos de superficie realizados en la península de $\mathrm{Xi}$ calango aportaron datos interesantes con respecto a la localización del si- 
tio. Varios investigadores han trabajado en la ubicación de estas grandes capitales, apoyados en fuentes históricas y datos arqueológicos; Berlin (1953) dice que en la península existían dos poblaciones principales: Xicalango y Atasta; la ubicación de la primera es difícil de determinar, mientras que la segunda se encontraba a orillas de la laguna del mismo nombre. Fernández (1939: 20), en el Atlas arqueológico, sitúa Xicalango cerca del actual faro, lo mismo que Ruz L. (1969). Roys (1943: 101) afirma que dicho sitio estuvo localizado en el lugar conocido como Los Cerritos.

Durante los trabajos de campo realizados en 1978 recorrimos el área después de haber leído el Diario de fray Tomás de la Torre. Las descripciones del paisaje, de las distancias y de las características del medio fueron importantes en la ubicación del sitio; gracias a sus imágenes hemos creído identificar el sitio de Santa Rita (mapa 6) con Xicalango (Ochoa y Vargas 1979).

$\mathrm{Al}$ mencionarlo, las fuentes históricas lo citan como un lugar muy importante. López de Gómara (1965, LIV: 78) dice: «También había grandísima feria en Xicalango, donde venían muchos mercaderes de muchas y lejos tierras a tratar, y así era muy mentado lugar». Sahagún (1975) no habla de Xicalango como de un pueblo, sino de Anáhuac Xicalango como una provincia. Landa, por su parte, señala que Xicalango y Tabasco conformaban una misma provincia, aunque seguramente se refiera a esa situación para los primeros años después de la conquista.

El sitio debió ser de gran importancia estratégica, pues dominaba el área de lagunas que servía de puente hacia la península de Yucatán, controlaba el tráfico marítimo-fluvial y, seguramente, era la base de los mercade-

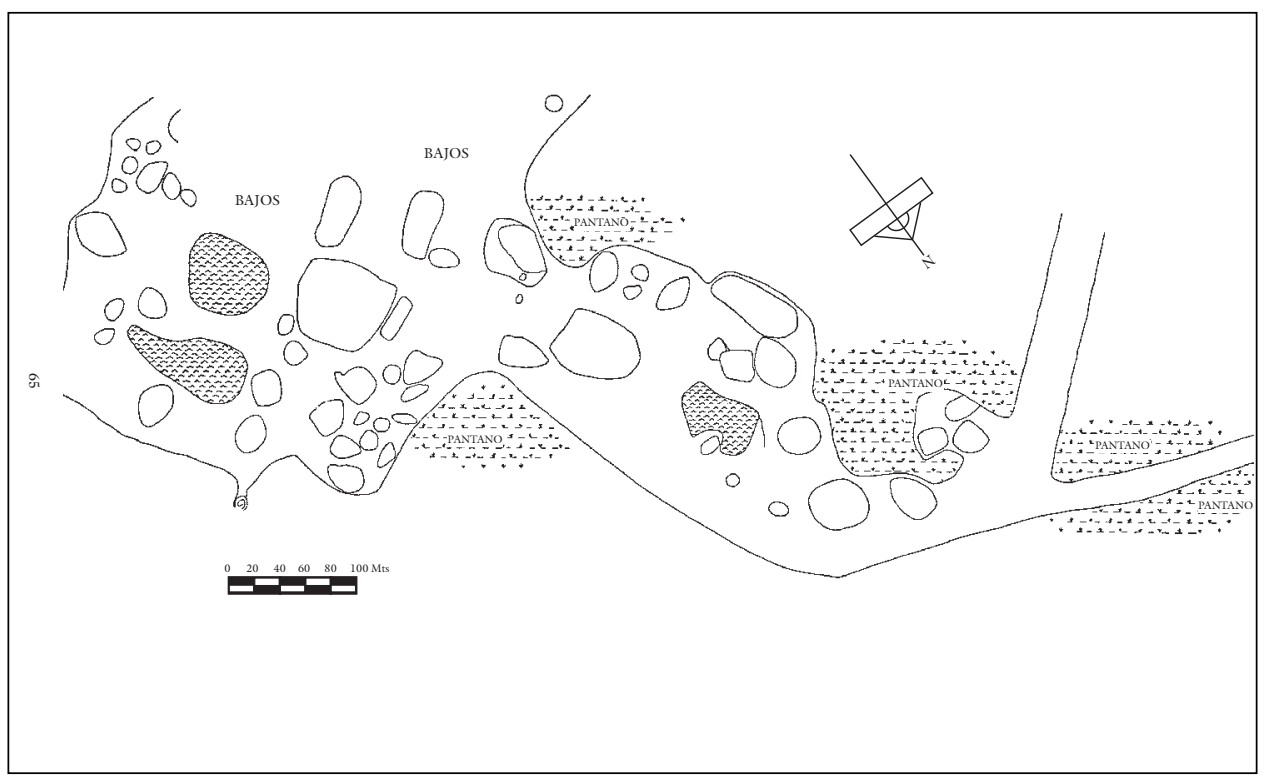

Mapa 6. Santa Rita, posiblemente Xicalango de las fuentes históricas. 
res que controlaban la vía más corta terrestre entre Tabasco y Yucatán; además, estaba protegido de los huracanes. Por su posición estratégica fue habitado desde el Preclásico, llegó a su máximo apogeo durante el Clásico terminal y perduró hasta la C onquista. Por ser un puerto de larga distancia, su fin llegó rápidamente durante la conquista española, al cortarse el tráfico marítimo-fluvial-terrestre con la toma de otros grandes centros mesoamericanos.

Para 1550 aquella próspera y populosa Xicalango sólo tenía edificios abandonados y el ganado salvaje pastaba en los páramos y pantanos. Los pocos habitantes que sobrevivieron a las epidemias fueron trasladados a J onuta; de este modo concentraron la población indígena en pocos centros para facilitar su control y administración, dejando desocupado y sin protección aquel magnífico puerto, base ideal para bucaneros y piratas.

Así es como Xicalango, capital de otra provincia chontal decayó y pocos años después de la Conquista desapareció fundamentalmente por el cese del comercio a larga distancia.

\section{La provincia de A calan}

Scholes y Roys (1968) hicieron una exhaustiva investigación acerca de Acalan, para la cual consultaron gran cantidad de documentos que dieron a conocer y pusieron a la disposición de los investigadores. H oy en día contamos con toda esa documentación histórica de gran importancia que nos servirá para entender el mundo prehispánico de Acalan; gran parte de ese trabajo nos será útil cuando tratemos con amplitud la provincia de Acalan.

Sobre esta provincia o cuchcabal tenemos mayor información histórica; sin embargo, la información arqueológica es poca pues no hay trabajos de excavación ni de reconocimientos de superficie. Se sabe de su existencia y que la capital o cabecera de dicha provincia fue I tzamkanac, que el rey principal o halach uinic fue Paxbolom Acha y además se conoce el nombre de los principales de la región.

Según las fuentes históricas, la provincia de Acalan abarcaría desde T ixchel, a orillas del mar, parte de la L aguna de Términos y toda la cuenca del río Candelaria hasta Tenosique. I tzamkanac fue la capital o cabecera de la provincia y ha sido identificada con el sitio arqueológico de EI Tigre (Scholes y Roys 1968, Piña Chan y Pavón Abreu 1959, O choa y Vargas 1986).

Los $P$ apeles de $P$ axbolom $M$ aldonado es el escrito chontal que fue publicado por Scholes y R oys en 1948, contiene información histórica sobre los chontales de Acalan, y trata sobre la historia de los magtunes, desde su arribo a la región que se nombró luego Tamagtún, M agtún o Acalan, hasta el gobierno de don Pablo Paxbolom Maldonado.

El escrito sugiere una gran inestabilidad política en la región, la cual se disputan constantemente diversos grupos. $\mathrm{N}$ arra hechos históricos acaeci- 
dos en la región y el evento más temprano al cual se refiere es la llegada de Cozumel a Tenosique, que bien podría situarse hacia 1200 dC. L os otros hechos atribuidos a determinados reyes son la fundación de Tagmatún, la conquista de Términos, las guerras contra los de Champotón, Xicalango, Tabasco y finalmente la conquista de Chetumal y Balancán.

En la segunda parte del documento se hace una relación de los 76 pueblos de los magtunes.

EI principio que empezó, estando en sus pueblos los Tamagtún, que se llama chontal, y Acalan en mexicano, los indios magtunes, como parece por sus pueblos en que asistían, que la cabecera se llamaba Yxamhanac, y allí está el R ey Paxbolom Acha, que así se llamaba, que éste era su reino, teniendo sus gobernadores, principales, M tuzin, rey, $\mathrm{H}$ inzuti, Pazayatomal y Cixun, que así se llamaban.

L a descripción es muy interesante pues se habla de un principal que era el rey Paxbolom A cha, que existía una cabecera I tzamkanac, así como gobernadores y principales. Todo esto nos indica que la organización políticoterritorial de la región debió parecerse mucho al cuchcabal descrito por Roys para Yucatán.

En la tercera parte del texto se refiere al paso de Cortés por la zona, la muerte de Cuauhtémoc acaecida cerca de Itzamkanac, la llegada de los frailes y el inicio de la evangelización, la tasación del tributo y el traslado de los pueblos de tamagtún Acalan a Tixchel.

Itzamkanac fue la capital de la provincia de Acalan; H ernán Cortés pasó por allí en su expedición hacia las H ibueras y más tarde Alonso D ávila fundó la población de Salamanca de Itzamkanac que rápidamente fue abandonada.

$\mathrm{N}$ inguno de los dos llegó al lugar por las rutas conocidas. Sin embargo, sabemos que a la provincia de Acalan llegaban diversas rutas fluviales y terrestres; la principal era el río Candelaria, desde donde se podía comerciar hacia el exterior llegando a T ixchel, Xicalango, Potonchán y hasta N ito y $\mathrm{N}$ aco, en $\mathrm{H}$ onduras.

EI enclave estratégico de EI Tigre es claro, al localizarse sobre unas lomas que dominan parte importante del río Candelaria. Destacan en el asentamiento: un centro principal con estructuras que sobrepasan los $20 \mathrm{~m}$ de altura (fotografía 2), el área habitacional, una cal zada y los campos levantados para realizar agricultura intensiva, to do lo cual apunta a identificarlo con I tzamkanac, la gran capital de Acalan.

Cortés (1969: 126) dice lo siguiente con respecto a Acalan: «E sta provincia de Acalan es muy gran cosa, porque hay en ella muchos pueblos y mucha gente, $[. .$.$] todos ellos salen a la bahía o puerto que llaman de$ Términos, [...] Xicalango y Tabasco».

Los mayas chontales tuvieron varios centros de comercio, localizados en lugares muy bien protegidos, como para ofrecer la seguridad necesaria a 


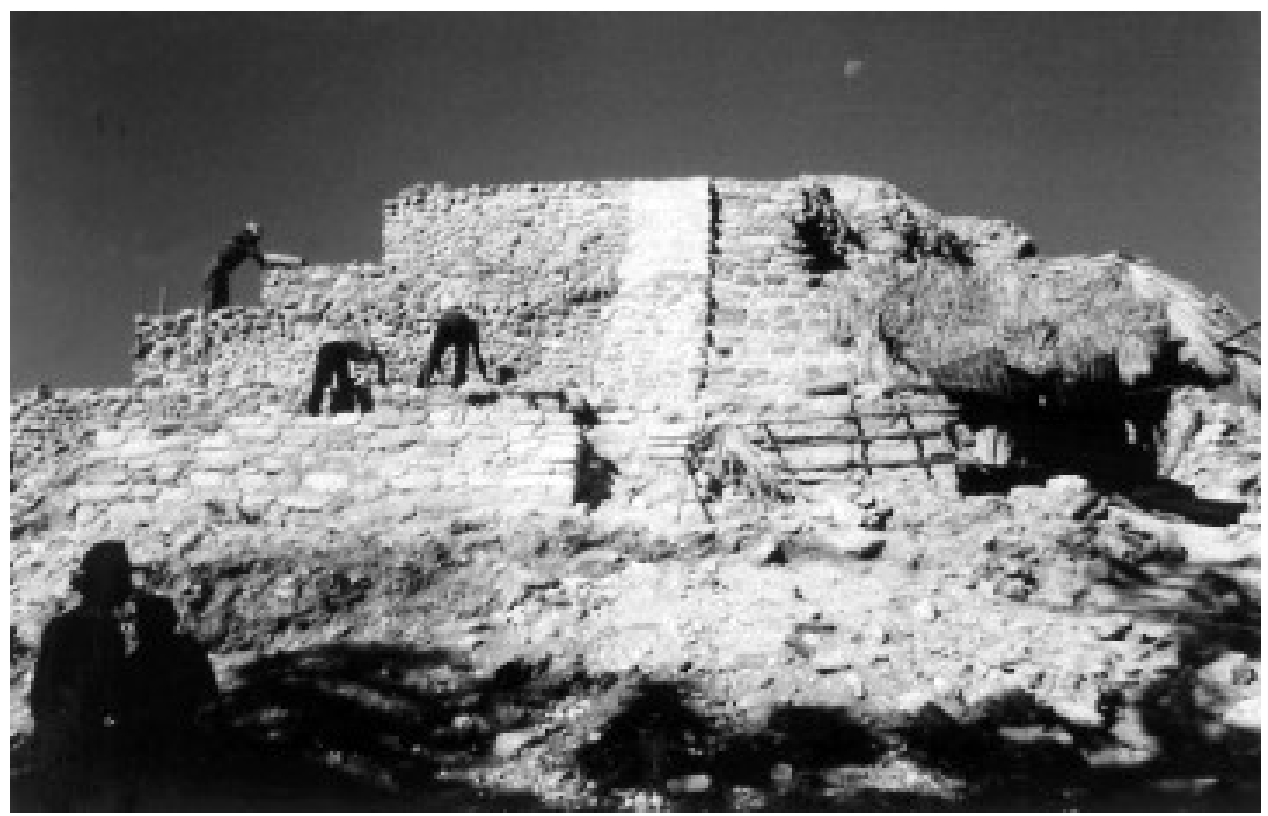

Fotografía 2. Estructura 2 de EI Tigre.

un puerto de intercambio; ellos fueron: Potonchán, Xicalango, Tixchel e I tzamkanac. D e éstos partían los mercaderes hacia diversos puntos del sur, norte y centro de M esoamérica, rutas que sirvieron para transportar mercancías locales e importadas. E stas tres unidades políticas de los chontales, que por el momento no sabemos cómo se interrelacionaban, fueron las que dominaron por varios siglos el comercio de los mayas a través de los ríos y costa hasta $\mathrm{N}$ ito y $\mathrm{N}$ aco, en $\mathrm{H}$ onduras.

$L$ a región del río $C$ andelaria, en donde se ubica según las fuentes históricas la provincia de Acalan y su capital I tzamkanac, es un área importante para investigar, no sólo por ser desconocida, sino también porque existen restos arqueológicos de gran importancia y porque algunos grupos como los itzaes, los xiues, los quichés y cakchiqueles, entre otros, dicen venir de esa región de ríos y lagunas, lo cual siempre ha intrigado a los investigadores.

Poco se sabe de I tzamkanac, se cree que estaba en la provincia de Acalan (cfr. Piña C han y Pavón A breu 1959, Scholes y R oys 1968, O choa y Vargas 1986) y se le ha identificado con el sitio arqueológico de EI Tigre. Pretender localizarlo no es una mera curiosidad, sería de gran importancia para entender las relaciones que guardó con otras áreas de la zona maya, específicamente con las otras grandes capitales chontales: Xicalango y Potonchán. Tenía comunicación con Xicalango, Tixchel, $\mathrm{N}$ aco y $\mathrm{N}$ ito en $\mathrm{H}$ onduras; pero seguramente también fue una magnífica ruta de comunicación hacia el Petén y Calakmul. 


\section{Posible CRONOLOGÍA de LOS CHONTALES O PUTUNES}

Con base en las fuentes históricas se sostiene que los chontales o putunes tuvieron su máximo florecimiento durante el Postclásico mesoamericano. Sin embargo, éstas nos dicen que los chontal es en el momento del descubrimiento y conquista del $\mathrm{N}$ uevo M undo ya habían perdido su grandeza y poderío, y que en medio de otros grupos apenas llamaban la atención de los cronistas de la época.

En varios de los trabajos publicados ( O choa y Vargas 1979 y 1989 , Casasola 1979 y 1987, H ernández 1981) se afirma que su máximo esplendor fue durante el Clásico terminal (700-1000 dC) y que con anterioridad a esas fechas no podemos hablar del grupo maya chontal, porque de acuerdo con la lingüística los datos arqueológicos y las mismas fuentes históricas, los chontales provienen de la separación del grupo cholano, del cual derivaron el chol, el chontal y el chortí (Schumann 1985).

Para entender este planteamiento podrían existir varias explicaciones que sería importante investigar y trataremos de analizar en nuestro trabajo.

1. Los chontales existieron desde mucho antes del Clásico terminal en enclaves específicos de la región, baste citar a Xicalango y EI Tigre.

2. Antes de la caída de Palenque el grupo cholano se había diversificado y en esos momentos se estaba formando el chontal como una separación del anterior, con su propia lengua y sus características específicas como construcciones de ladrillos, cerámica fina y dominio de las rutas fluviales, marítimas y terrestres.

3. Llegaron al área provenientes de otras partes y se remontan a los siglos vII-VIII, fechas que coinciden con la época de esplendor y probablemente de expansión de los ocupantes de Palenque.

D urante los siglos vII-VIII se siente su auge en un gran número de sitios alrededor de Palenque conocidos con el nombre de L lanuras I ntermedias, y ese momento coincide con el establecimiento de más grupos chontales en las Ilanuras costeras y en las orillas de los ríos y lagunas. EI C hilam Balam también describe el establecimiento de lositzaes en Chakamputún para esos años.

U na explicación de este fenómeno podría ser que los grupos mayas menos favorecidos, provenientes del abandono de las grandes ciudades, se dirigieran a las orillas de los ríos para dominar las rutas de comunicación y el comercio. El colapso maya, por lo tanto, se explicaría como un cambio de orientación en el patrón de asentamiento, por la migración masiva de su población hacia los ríos para dominar las rutas fluviales; también, se ha planteado que esa región por ser baja y pantanosa, llena de mosquitos y alimañas, fuera una zona de refugio o hasta la mítica región de Suyúa.

Thompson (1975: 44) dice que los itzaes Ilegaron a Chichén I tzá en cuatro secciones que tenían el nombre de los cuatro rumbos del cielo, de los cuales estaban encargados, y uno fue holtun zuiua. 
El del oeste se llama Holtún Zuiua. H oltún resulta ser una palabra putún que significa «puerto» [...] y H oltún era el nombre putún de Puerto E scondido, en el brazo septentrional que encierra la Laguna de Términos. Zuiua es una palabra, según parece náhuatl, muy relacionada con los invasores mexicanos o mexicanizados que se decían de origen tolteca. $\mathrm{H}$ oltún zuiua parece indicar por eso un puerto en la Chontalpa, donde se encontraron las culturas mexicanas y putún.

A hora sabemos que en EI Tigre existió una importante ocupación en el Postclásico, pero también en el Clásico, como lo señalaran otros autores. Sin embargo, los asentamientos del lugar comienzan en el Preclásico superior, como lo demuestra la cerámica encontrada en el lugar durante las exploraciones realizadas en 1984 y en las temporadas de campo de 1998 y 1999, y sobre todo porque en la Estructura 2 se encontró una subestructura que en uno de sus lados presentó un mascarón (fotografía 3) y en la Estructura 1 se local izaron dos mascarones característicos de esa época en el Petén. EI M ascarón 1 (fotografía 4) es la cara de un individuo, que seguramente representa a un posible gobernante muerto, que con el tiempo sería sacralizado y podría representar el inicio de los grandes linajes que fueron característicos del área maya. En el M ascarón 3 (fotografía 5) se representan una posible iguana (itzam na), la serpiente, lazos de unión, orejeras y personajes que están viendo hacia el cielo; quizás también se trate del inicio de algunos aspectos religiosos importantes en el área maya como son la iguanacocodrilo, las serpientes, el jaguar y las aves.

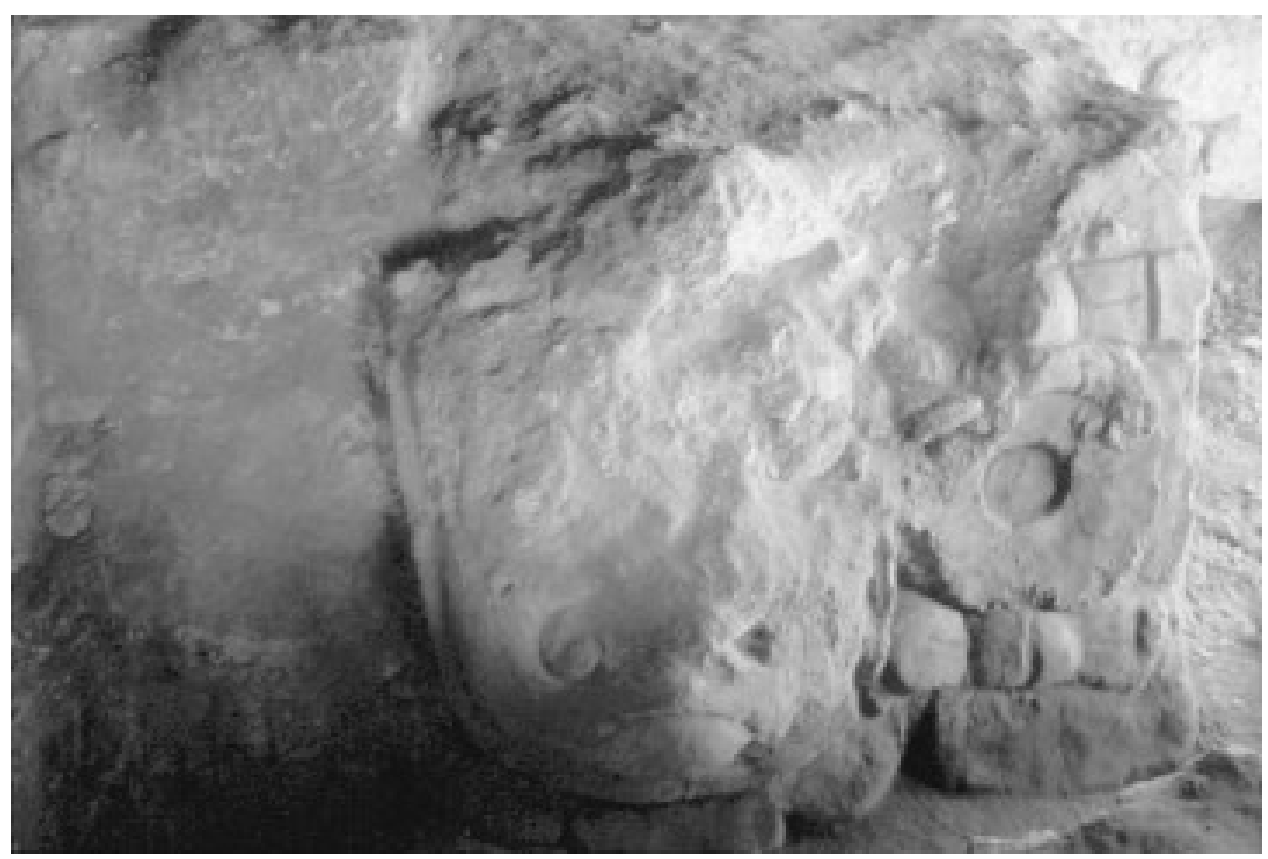

Fotografía 3. El Tigre, mascarón de la Estructura 2, trabajado en 1984. 


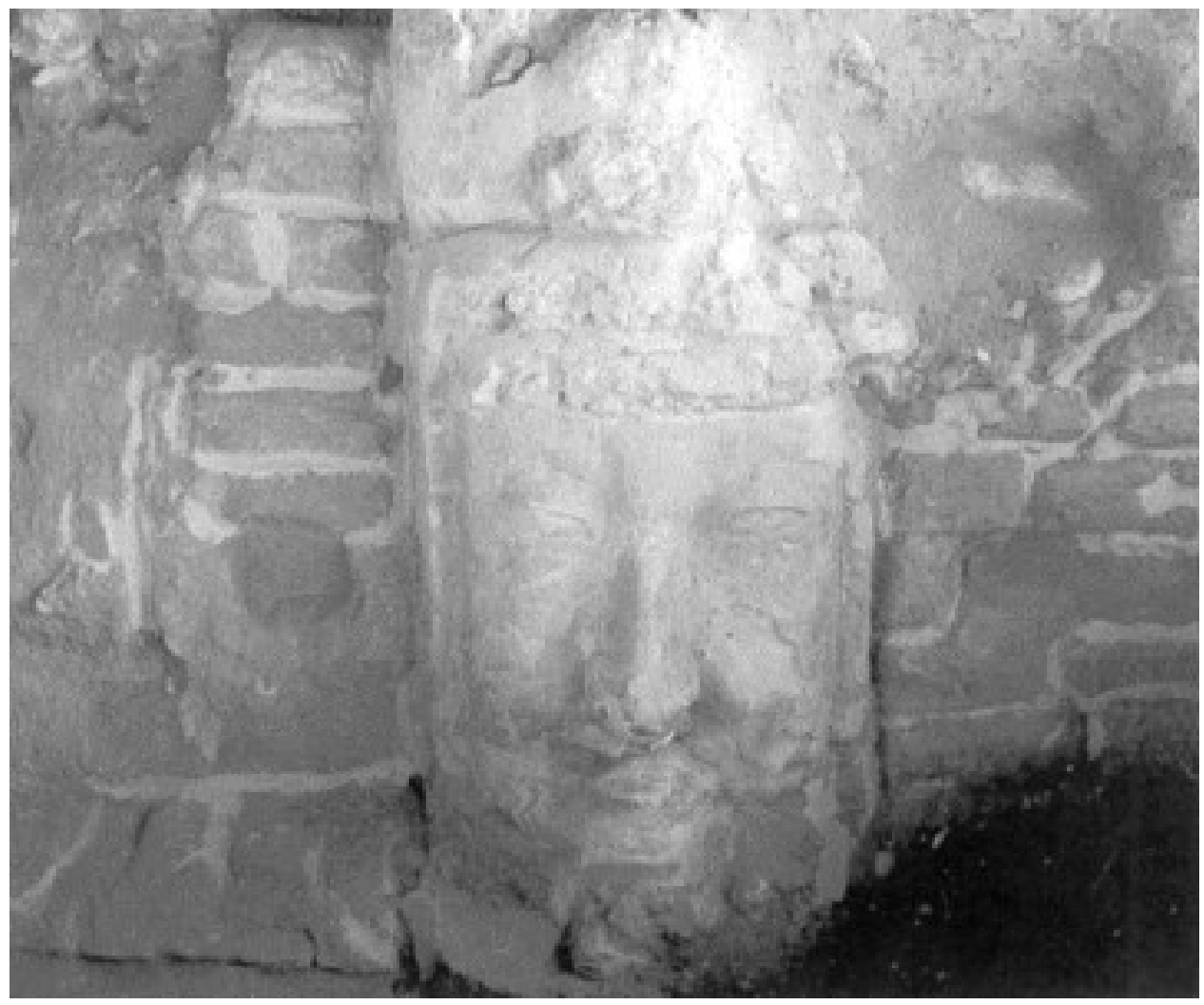

Fotografía 4. M ascarón N 0.1 de la Estructura 1.

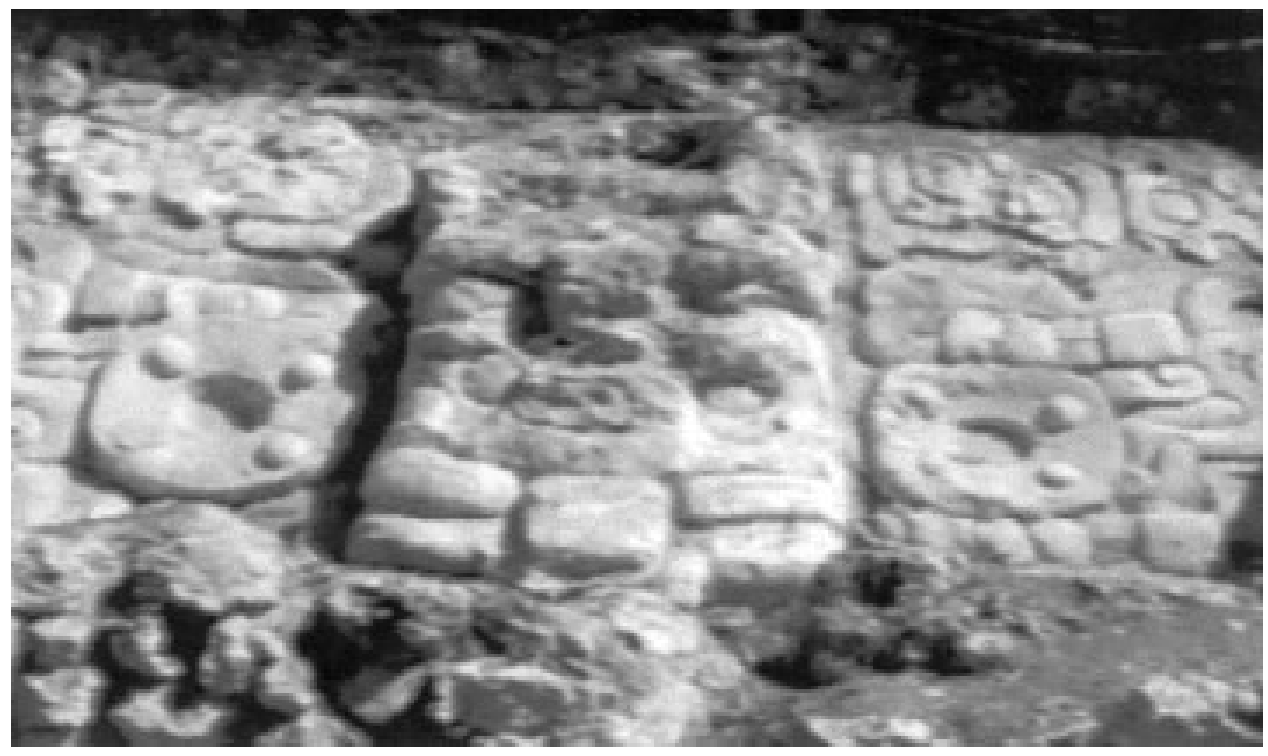

Fotografía 5. M ascarón N o. 3 iguana-cocodrilo. 
Estos datos confirman una de las hipótesis de Rands (1967), quien sostiene que dicha región, para esta época, estaba más íntimamente ligada al Petén. U n fenómeno parecido presenta la península de Xicalango en donde se hicieron trabajos arqueológicos tanto en el Aguacatal como en Santa Rita, los dos sitios más importantes.

D e acuerdo con los datos que tenemos en la actualidad, podemos concluir que los primeros grupos asentados en la región tienen como puntos de interés e innovación las Tierras Bajas centrales, y para el 400-200 aC la región claramente estaba orientada hacia las influencias que venían del Petén (cfr. H ernández 1981, Casasola 1979, O choa 1985).

EI Clásico temprano (200-600 dC) al parecer no es muy importante, la ocupación de áreas fue escasa, lo que suponemos se debió a una disminución de la población o a un desplazamiento del grupo hacia otras regiones, situación que se observa en otras áreas de las tierras bajas noroccidentales (cfr. Rands 1967, C asasola 1979). D urante el C lásico (600-800 dC), tanto en la sierra como en las orillas de los ríos, muchos sitios de la región llegan a su máximo esplendor (O choa y Vargas 1986, Vargas 1985, Vargas y H ernández 1979), algunos presentan escultura, arquitectura, inscripciones y estelas; Piña Chan reporta una para E I Tigre. Es entonces cuando podemos hablar del grupo chontal, pues según los lingüistas, hacia esa época se separa esta lengua de la cholana.

Sería demasiado extenso hablar del colapso maya, pero varios autores están de acuerdo (cfr. A dams 1973, Sabloff 1973, Casasola 1987) en señalar a este grupo como portador de una vigorosa tradición alfarera de Anaranjado y Gris fino, que se fue introduciendo gradualmente desde J onuta, pasando por Palenque, Piedras N egras y Yaxchilán, hasta llegar a Altar de Sacrificios y Seibal ya como chontales. Este último grupo dominó y controló las rutas de comercio y fue un factor de descontrol y desequilibrio en todos los sitios del U sumacinta y Pasión.

D urante el Clásico terminal (700-1000 dC), la población en la región alcanzó su máxima densidad. La economía se basó principalmente en el comercio y su poderío se extendió a gran parte del territorio actual de Tabasco y Campeche, dominando las rutas de comunicación con sitios tan importantes como Potonchán, Xicalango e Itzamkanac.

En el Postclásico (1100-1550 dC) se presenta una marcada disminución del material arqueológico, lo cual probablemente indica un abatimiento de la población o un desplazamiento hacia otras regiones de las Tierras Bajas, norte de Yucatán y costa oriental (cfr. Andrews 1978, Vargas 1987).

L as ocupaciones más evidentes se establecen en la zona del Bajo U sumacinta, probablemente en el río San Pedro y San Pablo, así como en la costa de Campeche y río C andelaria, en donde las actividades comerciales siguen teniendo gran importancia. 
Al compaginar toda esta información vemos que el florecimiento de los chontales se dio, según los conocimientos arqueológicos, en el Clásico terminal (700-1000 dC ); para ese momento las fuentes históricas de diferentes regiones hablan también de esta región. Por otra parte, no se ha encontrado una ocupación considerable para el Posclásico, por lo que suponemos que la región ya había vivido sus mejores años y en esa época se recordaban aquellas glorias.

Poder explicar todo este problema desde la perspectiva arqueológica e histórica abre grandes posibilidades, pero basándome en los C hilam Balam y en los Papeles de Paxbolom $\mathrm{M}$ aldonado sostengo que los chontales participaban de los conocimientos de la rueda de los katunes, influencia que seguramente recibieron de los itzaes, que permanecieron en Chakamputún 260 años, del 700 al $950 \mathrm{dC}$, y al parecer cambiaban de ciudad cada fin de katún 8 ahau .

Esta historia de la rueda de los katunes abarca un periodo de 1300 años y se puede reconstruir para la región de Acalan, ya que existen referencias a tres ruedas katúnicas: 8 ahau (9.13.0.0.0: 672-692 dC), abandono de Chichén I tzá y llegada a Chakamputún; (10.6.0.0.0: 928-948 dC) abandono de Chakamputún y hasta cierto punto de la región, la cual queda gobernada únicamente por chontales; 8 ahau (11.0.0.0.0: 1204-1224 dC) fin de baktún que coincide con el fin del katún 8 ahau, época en la que suceden grandes catástrofes y la destrucción de $\mathrm{C}$ hichén I tzá por $\mathrm{H}$ unac $\mathrm{C}$ eel. L a población huye de Yucatán y un grupo regresa a la provincia de Acalan, la cual conquistan con base en guerras y fundan nuevamente la gran capital de los acalanes o magtunes en Itzamkanac en el siguiente katún 8 ahau (11.12.0.0.0: 1441-1461 dC), gobernada por Paxbolom A cha.

Basándome en el cal endario, y específicamente en la rueda de los katunes, trataré de explicar el desarrollo de la región y de analizar el gobierno del mismo, que al parecer fue cuatripartito, según su propia cosmogonía.

Creo que ni la arqueología ni las fuentes históricas tienen la verdad, pero tampoco están equivocadas; ambas, como dijera Bernal, se complementan. A veces dedicamos nuestro esfuerzo a demostrar que la arqueología o las fuentes históricas están erradas en lugar de buscar una explicación a esas diferencias. En este trabajo trataré de explicar este interesante fenómeno que parecería mostrar que la información es contradictoria. Sin embargo, lo que nos ofrecen estas dos versiones es la posibilidad de comprender una visión cosmogónica de su mundo; es decir, que los putunes salieron de la región putún y regresaron a su lugar de origen después de haber permanecido en Chichén I tzá 260 años, y fundaron nuevamente I tzamkanac. 



\section{Capítulo ill Planteamiento del problema}

Para muchos arqueólogos la arqueología todavía se puede reducir al estudio de la cerámica, la lítica o a la aplicación de una serie de técnicas «novedosas», que son sin lugar a duda de gran importancia para la obtención de la información; pero esa no es la finalidad de esta disciplina. A mi modo de entender la arqueología debe estudiar las culturas prehispánicas como un todo. En la actualidad no se puede ignorar la divergencia adaptativa, la convergencia y la evolución paralela, tampoco la intensificación de la agricultura, el crecimiento de la población, la guerra, el comercio interregional y los patrones de asentamiento; todos estos factores, por sí mismos, son insuficientes para explicar la diversidad de las culturas; por lo tanto hay que ver a la sociedad desde varios ángulos.

El estudio de cualquier aspecto de la experiencia humana ha de ser, por necesidad, multifacético; a pesar de que se nos proponga reducir nuestra experiencia a sectores limitados del saber y sucumbamos a la tentación del pensamiento reduccionista, cuando no a una seudo-complejidad. M orin (1990), al hablar de la complejidad, nos dice cómo pensarla y da tres principios: el primero es el dialógico que nos permite mantener la dualidad en el seno de la unidad, asociando dos términos que son complementarios y antagónicos. El segundo principio es de recursividad organizacional, que es un proceso en el cual los productos y los efectos son al mismo tiempo, causa y efecto, producto de aquello que lo produce. Rompe con la idea lineal de causa/ efecto, porque to do lo que es producido vuelve a entrar en aquello que lo ha producido, en un ciclo autoconstitutivo, autoproductor. Y por último, el principio hologramático, en donde el todo contiene a las partes y las partes contienen al todo, pero el todo no es la suma de las partes.

Cada día se acepta más que el registro arqueológico es como un «texto » que hay que leer; sin embargo, para muchos arqueólogos los objetos son mudos; pero lo interesante de la arqueología es que los datos no se estudian aislados, sino dentro de un contexto, y lo que inferimos son conceptos públicos y sociales, reproducidos en la práctica de la vida cotidiana que queda plasmada en la cultura material. 
Como veremos más adelante, la visión cosmogónica queda plasmada en muchos hechos arqueológicos que se describen también en las fuentes históricas, y para los arqueólogos a veces son difíciles de comprender si no se buscan intencionadamente. U no de los objetivos de nuestro trabajo es presentar una propuesta alternativa a la concepción tradicional de la historia, en donde se incluya la idea de que las civilizaciones mesoamericanas necesariamente han pasado por periodos de desarrollo, apogeo y caída, en los cuales ha habido una sucesión ordenada e inevitable de acontecimientos. General mente no aceptamos la posibilidad de retrocesos, adaptaciones o modificaciones en la historia, sino sólo decadencias, lo cual implica una posición de casi fatalismo de la historia.

EI análisis histórico de ciclos de desarrollo resulta mucho más productivo, pues éstos dan vida y movimiento a la sociedad en su conjunto, la cual sufre constantes ajustes y desajustes que la vinculan y modifican a cada momento. En toda sociedad se producen expansiones y recesos, equilibrio y crisis, que a veces se convierten en puntos de expansión de un ciclo subsiguiente, o la llevan a la desaparición en algunos casos extremos.

Cuando se habla de crisis se trata de los procesos de transformación que sufrió la cultura maya en el transcurso del tiempo, por eso el término «colapso» no parece adecuado para la explicación de lo que sucedió en el área maya, ya que de alguna manera implica el fin de una cultura, lo cual no sucedió.

EI C hilam Balam, Landa, López de Cogolludo, fray Andrés de Avendaño y la E stela 31 de Tikal, primero con Sian C haan K'awil, 'Cielo Tormentoso', y después $\mathrm{H}$ asan $\mathrm{C}$ haan K'awil (A h Cacau), nos hablan del fatídico katún 8 ahau, en el cual se llevaron a cabo guerras y conquistas que implicaban cambios de asentamiento y modificaciones profundas en el antiguo sistema de los mayas; esto se daba cada 260 años de acuerdo con las cuentas de los katunes u kahlay katunob. Se tiene un registro de cinco katunes que abarcan 1300 años de historia. El primer katún 8 ahau que se registra en el C hilam Balam data del $435 \mathrm{dC}$ y corresponde a un fin de baktún, mismo que es consignado por el halach uinic Sian C haan K'awil, en la Estela 31 en Tikal. El último se registra en la época colonial con la caída de Tayazal, último reducto de los mayas itzaes.

El tiempo fue la obsesión de muchos pueblos antiguos, los mayas tuvieron mucho interés en desarrollar una filosofía para abarcar ese tema tan controvertido. I dearon diversos sistemas para computar el tiempo, registraron fechas y acontecimientos en estelas, códices y escritos posteriores a la C onquista, utilizando el tiempo como un recurso simbólico para sus fines político-sociales.

$\mathrm{N}$ o cabe duda que la presencia de los astros en el firmamento y la observación de sus movimientos, especialmente el Sol, la L una y Venus entre otros, tuvieron un impacto casi determinante en la mente del hombre maya, llevándolo a crear «ciencia» y a imaginar dioses y mitos al rededor de ellos. Es evidente que la concepción cíclica del mundo maya deriva directamente de la observación de la naturaleza. 
Posiblemente algunos acontecimientos no sucedieron exactamente en las fechas registradas y predichas, y además pueden existir vacíos significativos, y para llenarlos se registraron acontecimientos que no sucedieron; pero se hizo porque así lo señalaba su concepción cíclica del tiempo. Todo esto quizás se dio, aunque podemos detectar por medio de la arqueología la presencia del grupo en los diferentes lugares en donde ellos dicen haber estado, y si esto es cierto la fuente debe guardar algo de verdad. La magia de los números probablemente tenía más importancia para ellos que la ubicación exacta de los acontecimientos históricos, de allí lo interesante de intentar la posibilidad de corroborar las fuentes históricas con la arqueología.

En este trabajo pondremos a prueba la rueda de los katunes y trataremos de ver si verdaderamente los itzaes estuvieron en la región chontal en el periodo que ellos dicen, si los itzaes que llegaron a Chichén I tzá después de dejar Chakamputún Ilevaban elementos de la región putún; estas evidencias, si es que existen, deben quedar en restos arqueológicos, históricos y lingüísticos.

Básicamente nos interesa investigar los siguientes periodos: 1) $700 \mathrm{dC}$ al $950 \mathrm{dC}$. Cuando los itzaes estuvieron en Chakamputún, al parecer, tuvieron que realizar una serie de conquistas hasta asentarse en un lugar que supongo debió estar en la región de Acalan. 2) 950 al 1200 dC. Los itzaes salieron de C hakamputún hacia C hichén I tzá; se dice que este grupo pertenecía a una rama putún, lo cual demuestra que estuvieron en la región de los putunes. 3) 1200 al 1450 dC. Los magtunes llegan desde Cozumel; posiblemente se trataba de un grupo de itzaes que regresaba a su lugar de origen, la región putún; durante este periodo logran conquistar gran parte de su territorio y tienen conflictos con los otros grupos chontales. 4) $1450 \mathrm{dC}$. Poblamiento de Itzamkanac según los Papeles de Paxbolom $\mathrm{M}$ aldonado, y hegemonía de los magtunes.

EI primer gran reto que afrontamos en este trabajo es, precisamente, tratar de reconstruir la provincia de Acalan, que desapareció propiamente en 1557, cuando la población de I tzamkanac fue obligada a ir a Tixchel, por convenir a los intereses de los conquistadores. Con base en los trabajos realizados por Scholes y Roys desde 1948, nos dimos a la tarea de recorrer la región registrando todos los posibles vestigios arqueológicos que fuera posible visitar.

D urante varios años hicimos reconocimientos de superficie auxiliánd onos con los arqueólogos que habían trabajado en la región desde Andrewsıv. A partir de todos estos datos hemos dividido la provincia en la cabecera que debió regir el cuchcabal, y los batabilob y pueblos que la formaron. A través de los estudios arqueológicos nos dimos cuenta que el esplendor de la cultura de los putunes no solamente se dio en el Postclásico, sino que se mantuvo durante el Clásico terminal y el Preclásico.

Al hacer un estudio del pasado prehispánico es importante tomar en cuenta no sólo nuestros conceptos occidentales, sino también la perspectiva que los grupos en estudio tuvieron del concepto de territorialidad, de lo que es un pueblo, una provincia, etcétera, pues su visión del mundo era diferente a la nuestra. 
U tilizaremos los términos de cuchcabal, batabilob y cuchtel para definir la provincia de Acalan; describiremos el desarrollo, apogeo y decadencia de las unidades políticas. En ocasiones, una unidad política pudo haber comenzado su trayectoria como provincia subyugada por otra, liberándose posteriormente, para así empezar su propia historia de crecimiento, aumento de población e importancia; de esa manera llegaba a su apogeo y posteriormente sufría el mismo fin que las otras.

En los últimos años se ha escrito mucho sobre los estados centralizados y los segmentarios, se ha propuesto un antagonismo político entre los antiguos mayas. Existen varios planteamientos para diferenciar las entidades segmentarias de las centralizadas; esto será desarrollado posteriormente.

Es necesario resaltar la importancia que tiene en esta investigación la relación de la arqueología con las fuentes históricas, la iconografía, la epigrafía y la lingüística; gracias a todas ellas pude hacer una posible reconstrucción de la provincia de los acalanes y saber que la región fue más importante de lo que comúnmente se cree, pues de allí dicen venir varios grupos yucatecos: itzaes, xiues, cocomes, canules, cupules, etcétera, lo mismo que los quichés y cakchiqueles de Guatemala.

Por lo tanto, planteamos que en esta región la multietnicidad constituyó un factor importante que generó nuevas ideas y creencias que fueron determinantes en el periodo posterior. Como dijimos, también de aquí surgieron diferentes grupos o linajes que fueron protagónicos durante el Postclásico temprano.

Los putunes o chontales entraron en contacto con diferentes grupos del área maya y, posiblemente, también con grupos del Golfo de M éxico y del centro, lo cual hizo que recibieran diferentes influencias que los transformaron y, a la vez, los hicieron portadores de nuevas ideas. Fueron, como dice Thompson, los fenicios de A mérica, los grandes comerciantes que dominaron los ríos, lagunas y litorales del área maya. Posiblemente por esta característica, la provincia de Acalan y su cabecera, I tzamkanac vuelven una y otra vez al río, pues éste es vida y muerte, la columna vertebral, el camino principal de la provincia.

Vivieron al filo del agua, por lo tanto crearon toda una visión del mundo a partir del conocimiento del mundo natural y social en que vivieron: el agua y el río. Los chontales, igual que los otros grupos mayas, presentan una estructura del cosmos en dos planos: horizontal y vertical. L os ríos, el mar y el agua se encuentran en medio del territorio chontal.

C hicchan, la serpiente celeste que envía las lluvias, es el nombre del quinto día de los veinte signos del tzolkin, asociado con el rojo y el este. Es masculina y femenina, plural y singular, se le puede equiparar con Kukulcán.

A los itzaes se les conoce como los «brujos del agua»; entonces, no es extraño que estuvieran en Chakamputún, en la Provincia de Acalan y Xicalango, lugares de ríos, lagunas y pantanos, la región del agua. I tzamna fue 
su principal deidad; coincidencia o no, la cabecera de la provincia de Acalan Ileva el nombre de Itzamkanac, que bien pudiera significar «la segunda llegada de I tzam» a la región (comunicación personal de 0 tto Schumann).

Itzamna, el lagarto celeste y terrestre, era una deidad benévola, siempre amiga del hombre, aunque también se le asociaba con la destrucción o el desastre, era el patrono del día ahau, el último y más importante de los veinte días mayas. $D$ ios de los jerarcas, se le representa como un cocodrilo que flota en un enorme estanque de agua. En la Estructura 1 de EI Tigre hemos explorado el M ascarón 3 (véase fotografía 5, p. 57), que representa a una iguana-lagarto; posiblemente desde entonces el lagarto, el cocodrilo abundante en la región, es importante en la religión de los mayas yucatecos, pues se dice que era un dios no yucateco, llevado tal vez por los itzaes-putunes.

I xchel era la mujer y esposa de Itzamna, era la diosa de la Luna y del parto, se le relaciona con la fertilidad y el agua. Fue sin lugar a dudas una de las principales diosas de los putunes.

No deja de llamar la atención que los nombres de las dos ciudades más importantes de los putunes acalanes lleven el nombre de Itzamkanac y Tixchel. El primero localizado en el Alto $C$ andelaria y Tixchel localizado en la costa, casi en los extremos, como para abarcar to do el territorio de la provincia y de esa manera sacralizarlo, con dos de las principales deidades. Itzamkanac, podría significar 'la segunda casa de la I guana', se involucra con el nombre del dios principal de los yucatecos Itzamna; Tixchel, significa 'en el lugar de Ix Chel', la diosa mas importante de los putunes; se dice que uno de los principales santuarios estuvo en Cozumel, de donde venía el primer rey de los magtunes.

L os itzaes fueron portadores de la visión cíclica del tiempo, en la que el katún 8 ahau desempeñó un papel preponderante; ellos estuvieron allí entre el 700-950 dC y dejaron una huella profunda en sus habitantes: los chontales de Acalan. Posiblemente por ese mismo motivo los magtunes se asentaron en esa región cuando llegaron posteriormente de Cozumel.

Entre los factores que trataremos en este trabajo está precisamente el sistema de gobierno; no hay duda de que los itzaes llevaron a la península de Yucatán un sistema diferente, pues cuando ellos llegaron se formó el ah tepal, sistema de gobierno único que posteriormente cambió. Del mismo modo, pienso que la región de Acalan debió tener diferentes tipos de gobierno en el transcurso del tiempo. En un primer momento el gobierno fue lo que conocemos como una entidad segmentaria, posteriormente, un poder más centralizado, para llegar finalmente a un sistema de gobierno más parecido al cuchcabal. Veremos esto con detenimiento en los siguientes capítulos.

Aquí quedan planteados algunos de los problemas que nos interesan en el desarrollo de este trabajo y que trataremos de desarrollar a lo largo del mismo. 



\section{HISTORIA Y ARQUEOLOGÍA DE ACALAN}





\title{
Capítulo l \\ LA PROVINCIA DE ACALAN-TIXCHEL SEGÚN LAS FUENTES HISTÓRICAS
}

\author{
U BICACIÓN Y LÍMITES DE LA PROVINCIA
}

La historia del poblamiento de la región al sur de Campeche es complicada. Por los Papeles de Paxbolom M aldonado se sabe que tenía por lo menos 76 comunidades, la principal era I tzamkanac o H ueyacalan; casi todas están en la cuenca del río Candelaria, aunque posiblemente en el momento del contacto se extendieran hasta Laguna de Términos y hacia el norte hasta M amantel. En 1557 la población principal de I tzamkanac fue trasladada a Tixchel y el territorio desde entonces permaneció vacante; por tal motivo es difícil su localización al no aparecer registrado en ningún mapa; se utilizan general mente fuentes del siglo xvı. Para la localización de la provincia de Acalan, generalmente se utilizan Las C artas de R elación de Cortés, la obra de Bernal D íaz del Castillo y los Papeles de Paxbolom M aldonado.

Algunos autores situaban la provincia de Acalan en la confluencia de los ríos U sumacinta-San Pedro M ártir y otros en el C andelaria. Se sabía que se ubicaba en la ribera de un río que desembocaba en la L aguna de Términos, arriba de una serie de rápidos y cascadas que dificultaban su acceso.

Según las fuentes históricas, la provincia de Acalan abarcaría desde T ixchel, a orillas del mar, parte de la L aguna de Términos y toda la cuenca del río Candelaria, hasta por lo menos el río San Pedro M ártir. I tzamkanac fue la capital o cabecera de la provincia y ha sido identificada con el sitio arqueológico de EI Tigre (Scholes y Roys 1968, Piña Chan y Pavón Abreu 1959, O choa y Vargas 1986, Gerhard 1991, Vargas 1994).

L a mayoría de los primeros viajeros que llegaron a la provincia de A calan lo hicieron por tierra; baste citar a Cortés, quien llegó desde Tenosique pasando por el río San Pedro M ártir hasta I tzamkanac a orillas del río C andelaria; lo mismo hizo Alonso $D$ ávila, quien pasó años después por el puente que Cortés había construido sobre el San Pedro Mártir. Sin embargo, los frailes que viajaron de Tixchel a I tzamkanac y los mismos encomenderos que hacían ese viaje de ida y vuelta, ya sea a Tixchel o a Xicalango, nos dicen que el trayecto por río duraba varios días y la mayoría de ellos dan una im- 
portancia considerable a los rápidos que encontraron, aunque algunos no los mencionan; por lo tanto, parece seguro ubicar los principales asentamientos de Acalan arriba de Sal to G rande.

Según las fuentes históricas, la provincia de Acalan estaba muy poblada, comprendía 76 pueblos y aldeas que se mencionan en el texto chontal de Paxbolom $M$ aldonado y, según Bernal Díaz del Castillo, algunos de los pueblos estaban en tierra firme y otros so bre «algo a la manera de islas», él obtuvo 100 canoas cargadas de alimentos «[...] porque aquella poblazón de Acalan era sobre veinte poblezuelos, de ellos unos en tierra firme y otros en unas como isletas, y todo se andaba en canoas por ríos y esteros» ( $D$ íaz del Castillo 1974, II: 200).

Muchos de estos asentamientos son difíciles de identificar porque los nombres y datos de la mayoría de ellos se han perdido porque poco después de la conquista los pobladores de I tzamkanac y sus alrededores fueron trasladados a Tixchel. E n 1530 existían aproximadamente diez pueblos encomendados y en 1540 sólo una encomienda, I tzamkanac, ya que la población de la zona casi había desaparecido pues el comercio, que fue la actividad principal del lugar, quedó prácticamente desarticulado, al desaparecer los otros grandes puertos de comercio a larga distancia.

Acalan aparece como una entidad política distinta de Xicalango y Potonchán, las otras provincias chontales; tiene además un territorio con autonomía política y una cabecera bien identificada en las fuentes históricas: I tzamkanac.

Reuniendo la información de Scholes y Roys (1968), Piña C han y Pavón Abreu (1959), Andrews (1943), O choa y Vargas (1986), Pincemín (1993), M ario Ruz (1991) y Ana Luisa Izquierdo (1997) en la búsqueda de los límites de la provincia de Acalan podemos llegar a la conclusión de los primeros autores: «los más importantes asentamientos del cacicazgo, incluyendo la capital I tzamkanac, estuvieron situados a lo largo del curso superior del sistema del río $C$ andelaria, arriba de los rápidos y caídas que impiden el tráfico en esta corriente» (Scholes y Roys 1968: 410).

Para llegar a tal conclusión los autores toman en cuenta la información de Cortés, de los Pedimentos y probanzas, la $C$ arta de fray $L$ orenzo de Bienvenida, los Papeles de Paxbolom $\mathrm{M}$ aldonado, más otros muchos documentos históricos que se encuentran en archivos.

Los límites de la provincia de Acalan al momento del contacto español pudieron ser los siguientes, aunque debemos recordar que éstos variaron en las diferentes épocas de ocupación, pues los intereses comerciales también cambiaron conforme se aprecia en los materiales arqueológicos.

Los expedicionarios españoles que entraron con Cortés a la provincia de Acalan lo hicieron por el suroeste y salieron por el noreste, pasando por Itzamkanac su capital o cabecera. Cortés (1969: 125) narra el momento en que ingresaron a la provincia de Acalan: «[...] y dormí una noche en el monte y 
otro día poco más de mediodía allegué a las estancias y labranzas de la provincia de Acalan, y antes de llegar al primer pueblo della que se llama Tizatépetl [...]».

Izquierdo (1997: 51) piensa que Xacchute, presente en los Papeles de Paxbolom M aldonado (Scholes y Roys 1968: 373), puede ser el nombre chontal de Tizatépetl, pues dice: «salieron al principio de la tierra de Xacchuté». El lugar perteneció a la provincia de Acalan, ya que allí recibió la visita del hijo de Paxbolom Acha, señor de aquella provincia. De ahí, por consejo del cacique, Cortés (1969: 126) y sus soldados se fueron a un pueblo más grande, que también era suyo: «muy hermoso: Ilámase Teutiiacaa, tiene muy hermosas mezquitas, en especial dos, donde nos aposentamos y echamos fuera los ídolos [...]».

El texto chontal (Scholes y Roys 1968: 371) nos dice que después de tocar Xacchuté «llegaron a proveerse a Taxahhaa», por lo que ése podría ser el nombre en chontal de Teutiercas.

L a información sobre la frontera de la provincia hacia esa parte es interesante porque contamos con la C arta de R elación de $C$ ortés y los Papeles de Paxbolom, los cuales confirman que los primeros pueblos de la provincia debieron estar en el territorio localizado después del río San Pedro M ártir y por una gran parte de territorio despoblado. Sin embargo, en el mismo texto chontal se asienta que el primer rey magtún Auxaual, junto con otros principales, al llegar a la región chontal provenientes de Cozumel, lo primero que hicieron fue conquistar Tenosique y posteriormente la costa, es decir, la I sla del Carmen, Tixchel y por último Itzamkanac.

L os límites de la frontera sur de la provincia de A calan serían los poblados de Xacchuté y Taxahhaa, y desde allí hasta el río San Pedro M ártir sólo habrían montes deshabitados; sin embargo, hacia el río San Pedro, afluente del $\mathrm{C}$ andelaria, es donde existe la mayor concentración de sitios arqueológicos, lo que demuestra la vocación de la provincia hacia el comercio, pues ésa era la ruta fluvial importante hacia el Petén guatemalteco.

$\mathrm{H}$ acia el este, tomando como centro EI Tigre (I tzamkanac) el dominio de Acalan se extendería sobre todo por el río C aribe, afluente del C andelaria; más allá estarían los habitantes de la provincia de M azatlán o cehaches, rival es de los acalanes.

Las probanzas de Feliciano Bravo, fray Andrés de Avendaño y otros autores ubican la frontera de los cehaches al sur de C huntuquí.

La zona noroeste de la provincia de Acalan estaría ocupada por toda una serie de sitios que se relacionan con el río $\mathrm{M}$ amantel y C hivojá: entre los pueblos chontal es citados están los siguientes: C hivohá, Popolá, Chicbul, C hekubul, U sulabán, Tixchel, etcétera, pero cerca de ellos también existía una población cehache, como es el caso de Taquiache, que está a 4 ó 6 leguas al este de Popolá.

Los historiadores han hecho un magnífico trabajo de localización de muchos poblados de la región, pero en algunos no han podido precisar la 
diferencia entre la población chontal y cehache; sin embargo, lo que sí puede afirmarse es que la población chontal se asentó en la costa hasta unos 30 kilómetros tierra adentro.

Scholes y Roys (1968) e Izquierdo (1997), al hablar de la frontera de los chontales con los cehaches nombran varios poblados que sin lugar a duda eran cehaches: $\mathrm{N}$ acaukumil, que estaba localizado posiblemente entre el nacimiento del río $\mathrm{M}$ amantel y lo que hoy es Escárcega; Cheuzih, que al parecer fue un pueblo antiguo y de arraigo en la región en donde se congregaron los indios de I xmachich en 1609, localizado cerca de la laguna M ocú, C hacuitzil que se ubicaría entre E scárcega y M atamoros; y C hunhaz que estaría cerca de isla Pac.

Los historiadores están conscientes de que no son posibles las precisiones en su localización pues, desde el primer momento en que los españoles llegaron a ese territorio, las poblaciones empezaron a sufrir traslados por múltiples causas, sobre todo porque esa región se volvió un lugar de refugio para los indígenas que huían de la colonización; de esa manera se confundieron varios grupos mayas.

Pero esa indefinición de las fronteras de la provincia de Acalan con sus vecinos los cehaches no es sólo una característica de esta parte del área maya, sino que debemos pensar en un área amplia donde interactuaban los grupos y no de una línea fija como frontera. Además, se sabe que ese concepto de frontera rígida al parecer no existió, pues había enclaves de otros grupos dentro de un territorio, por ejemplo, Acalan. La multietnicidad parece ser una de las características de los grupos chontales, ya que sabemos que en la región de Tabasco convivían con nahuas, zoques y mixe, entre otros. $Y$ al parecer en Acalan también existieron varios grupos diferentes.

Al tratar de definir una frontera con las características antes descritas sólo pretendemos tener una guía para la arqueología, ya que partiremos de las fuentes históricas que hablan precisamente de la provincia de Acalan. Ésta pudo ocupar toda la cuenca del río Candelaria hasta la costa, gran parte de la L aguna de Términos e I sla del Carmen, el estero de Sabancuy en donde se localiza Tixchel y una faja importante del sur de Campeche (mapa 7).

En Tixchel se hablaba chontal en el siglo xvı, «los cuales hablaban una lengua diferente Ilamada putunthán» (Ciudad Real 1976, II: 356). Fue conquistada por los magtunes y gobernada por ellos hasta que conquistaron y habitaron Itzamkanac (Scholes y Roys 1968: 367). Por las mismas fuentes se sabe que en los alrededores de Tixchel existían varios poblados de habla chontal dependientes de él, por lo que es factible considerar todo el estero de Sabancuy como parte de la provincia de Acalan.

Putunthán significa 'la lengua de los putunes' y Chakamputún 'la sabana de los putunes'; al respecto, López de Cogolludo nos dice que Chakamputún es el mismo Champotón. Thompson identifica a Potonchán casi frente al poblado actual de Frontera sobre el río Grijalva. Al parecer el actual Cham- 


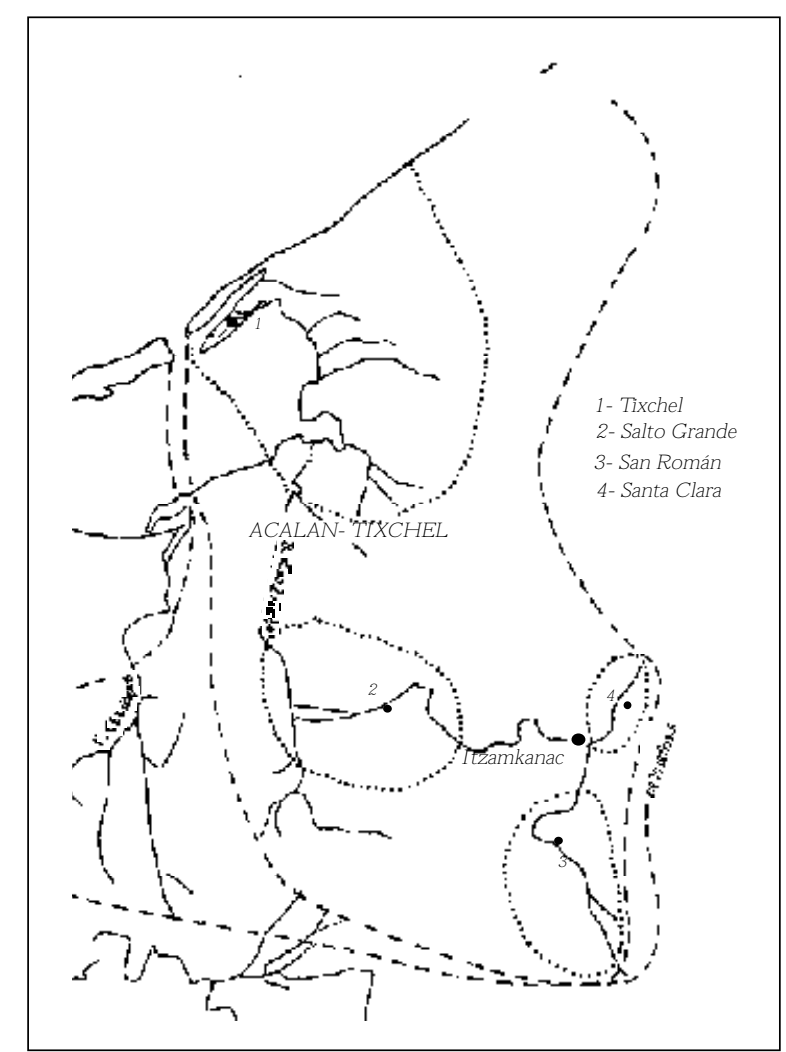

M apa 7. Provincia de Acalan según las fuentes históricas (modificado de Izquierdo 1997).

potón tenía dos sitios arqueológicos a las orillas del río, pero ambos son del Postclásico tardío y si aceptamos la descripción hecha por los C hilam Balam de $\mathrm{M}$ aní y el C humayel, sabemos que los itzaes estuvieron en Chakamputún un periodo de 260 años, que correspondería entre el 700 y 950 dC y por lo tanto no pudieron estar en el actual Champotón, pues su ocupación es muy tardía. Por ello pensamos que Chakamputún debió estar más al sur, posiblemente en la región de Acalan.

Siguiendo con la opinión de los autores citados (Scholes y Roys, Izquierdo) la frontera más norteña bajo el dominio de los acalanes fue $\mathrm{H}$ alail, posiblemente un poblado chontal con hablantes de maya yucateco. Se localizaba cerca de U sulubán y a orillas del río $\mathrm{H}$ olhá, que hoy recibe el nombre de La Malinche. O tro asentamiento fronterizo fue quizás Sahcabchén (fotografía 6), importante tanto durante la época prehispánica como colonial, pues los frailes lo escogieron como cabeza de doctrina, y además fue la puerta de entrada hacia la región cehache; se localiza a unos $35 \mathrm{~km}$ de C hampotón, aproximadamente; estos territorios de frontera se caracteri- 


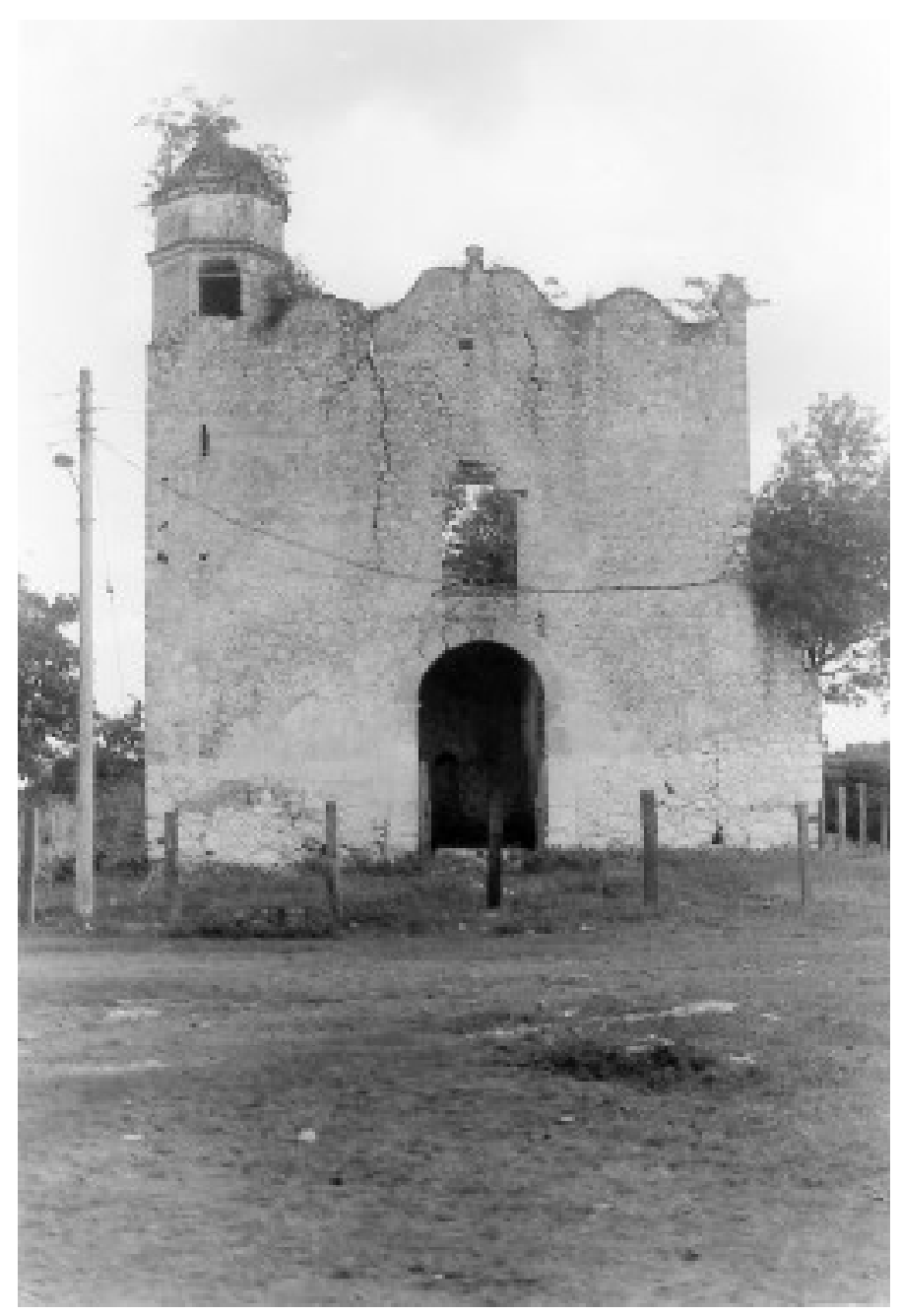

Fotografía 6. I glesia de Sahcahchén.

zan por la convivencia de diversos grupos; asentamientos mixtos, pueblos chontales y mayas yucatecos compartían el terreno.

\section{ITZAMKANAC CABECERA DE LA PROVINCIA}

Cuauhtémoc murió ejecutado en la provincia de Acal an el 28 de febrero de 1525. El misterio ha rodeado este hecho, bien porque existen diversas versiones sobre el acontecimiento o porque los restos de tan importante personaje han desaparecido; unos sostienen que se encuentra cerca del U sumacinta, otros en I tzamkanac y los más en I chcateopan. Al respecto se ha escrito bastante, pero se ignora en dónde fue ejecutado y, aun más, en 
dónde fueron depositados los restos óseos. Seguramente, como era costumbre en las exequias reales, debieron incinerar los cuerpos de los muertos; después de descolgarlos se les amortajó y quemó, y consumidos en la cremación, el atado fúnebre junto con ofrendas reales fueron depositados conforme sus costumbres, en tierras mayas, en I tzamkanac la capital chontal de Acalan.

Este hecho, documentado en diversas fuentes históricas del M éxico coIonial, puede tener una gran importancia en la vida de algunas comunidades. $\mathrm{N}$ o se sabe con exactitud dónde lo ejecutaron, pero sí se sabe que fue en la provincia de Acalan; por los indicios que tenemos ésta corresponde en términos generales al actual territorio del río Candelaria y EI Carmen. No sería nada extraño que al ser ejecutado Cuauhtémoc, tlatoani, señor de M éxico Tenochtitlan, se le rindieran homenajes importantes en la capital de la provincia y como tal se le erigiera un monumento póstumo como se acostumbraba en las exequias reales.

U n año después que los españoles y el Capitán del Valle estuvieron en Acalan, se fue Paxbolom A cha a otro pueblo llamado Tachacán, adonde murió, y los suyos le metieron en una canoa y lo trajeron a Acalan para enterrarlo (Papeles de Paxbolom M aldonado).

Sólo las investigaciones arqueológicas con el auxilio de especialistas y técnicas de fechamiento y análisis del ADN de los restos óseos podrían comprobar el hecho de que C uauhtémoc estuviera enterrado en I tzamkanac 0 Acalan. Estos son tan sólo algunos comentarios.

Estando en la provincia de Coazacoalco, Cortés nos dice que obtuvo mapas de los señores de Tabasco y Xicalango, y tomó la decisión de pasar por ahí (cfr. Becerra 1987, Scholes y Roys 1968, Piña Chan y Pavón Abreu 1959, Gurría Lacroix 1973, Catalán de Sánchez 1985). I nició su camino por la costa hasta $C$ upilco, que está a 35 leguas; tuvo que recorrer muchas ciénagas y ríos pequeños, construir puentes y utilizar canoas. D e Tonalá llegaron a los Agualulcos, distantes nueve leguas, y de allí cruzaron otro río en donde construyeron un puente de «novecientos y treinta y cuatro pasos», por el que pasaron caballos y gente, «fue una cosa bien maravillosa de ver». Bernal Díaz del Castillo dice que, luego de aquel gran puente, fue por unos poblezuelos hasta llegar a otro gran río que se dice M azapa, y de allí llegó a otro gran pueblo, Copilco.

Cortés, basándose en los dibujos que los de Tabasco y Xicalango le hicieron, debía llegar a otra provincia que se llama Zagoatán, después de pasar ciénagas y montañas muy cerradas, pues los de Xicalango no sabían cómo llegar por tierra sino sólo por agua (río); tuvieron que cruzar uno muy poderoso que se llamaba G uezalapa (posiblemente el Grijalva), uno de los brazos que entraba en el de Tabasco.

Cortés narra que los indios de Zagoatán huyeron y no encontró más que a «dos indios y ciertas mujeres», de los cuales dice: 
[...] pregunteles también por el camino para ir a la provincia de $C$ hilapan que según la figura que yo traía había de llevar aquella derrota, y jamás lo pude saber de ellos, porque decían que ellos no andaban por la tierra, sino por los ríos y esteros en sus canoas; y lo que más de ellos se pudo alcanzar fue señalarme una sierra que pareció estar hasta diez leguas de allí y decirme que allí cerca estaba la principal población de Chilapan, y que pasaba junto con ella un muy grande río que abajo se juntaba con aquel de Zagoatán.

Chilapan era de «muy gentil asiento y harto grande»; por medio de la captura de algunos indígenas supieron que debían pasar el río C hilapan y muy grandes ciénagas para ir a Tepetitán o Tamascatepeque, el cual hallaron también desierto y quemado. Desde allí se dirigieron a I xtapan, que estaba como a 15 leguas; este pueblo era muy grande y hermoso, se ubicaba en la margen izquierda del río U sumacinta, posiblemente cerca del actual Emiliano Zapata.

La provincia de Acalan, según los relatos de Cortés, estaba a 40 leguas del pueblo de I ztapan. Al salir de I ztapan llegaron a Tatahuital pán, situado a cinco leguas pasando seguramente el río Chacamax, pues no encontraban todavía el U sumacinta. De allí, y de acuerdo con sus mapas, debían ir a Ziguatecpan, río arriba, y O zumacintlan, que estaba antes; pero en medio de los montes y ciénagas se extravió la expedición.

Encuentran Ziguatecpan a orillas del río, quemada y abandonada. Al preguntar Cortés el camino que lo llevaría a Acalan, unos le respondieron que debía seguir río arriba, mientras otros dijeron que era dar mucho rodeo, que lo mejor sería pasar el río por aquel pueblo, ya que había una senda por donde ellos lo guiarían a Acalan. D esde allí envía en canoa a un español con gente de Ziguatecpan a la provincia de Acalan y posteriormente a otros cuatro españoles por tierra, para que supiesen si los españoles que debían ir con los bastimentos desde los bergantines habían llegado. Esta población podría ser identificada con la actual Tenosique en la margen izquierda del río.

L a descripción que hace C ortés acerca de su paso por el U sumacinta es breve, nos dice que lo cruzó con harto trabajo por ser ancho y corriente; continuaron tres días por montañas espesas hasta llegar a un gran estero 0 ancón, en donde construyeron un puente con más de mil vigas, la menor era casi tan gorda como el cuerpo de un hombre, y de nueve y diez brazas de largura, sin otra madera menuda que no tenía cuenta (mapa 8). Bernal D íaz del Castillo (1974) nos dice que Cortés: «[...] comenzó a caminar y en dos días llegó al gran río que ya otra vez he dicho. Y luego puso diligencias en hacer una puente y fue con tanto trabajo y maderos gruesos y grandes que después de hecha, se admiraron los indios de A cal an de verla [...]».

La información aportada por las fuentes históricas con respecto a Acalan es muy interesante, ya que nos señala que sus naturales eran enemigos de los de Ziguatecpan; que desde esa población a Acalan había cinco o seis días de despoblado, y el primer pueblo de Acalan era Tizatépetl, a día y medio del 


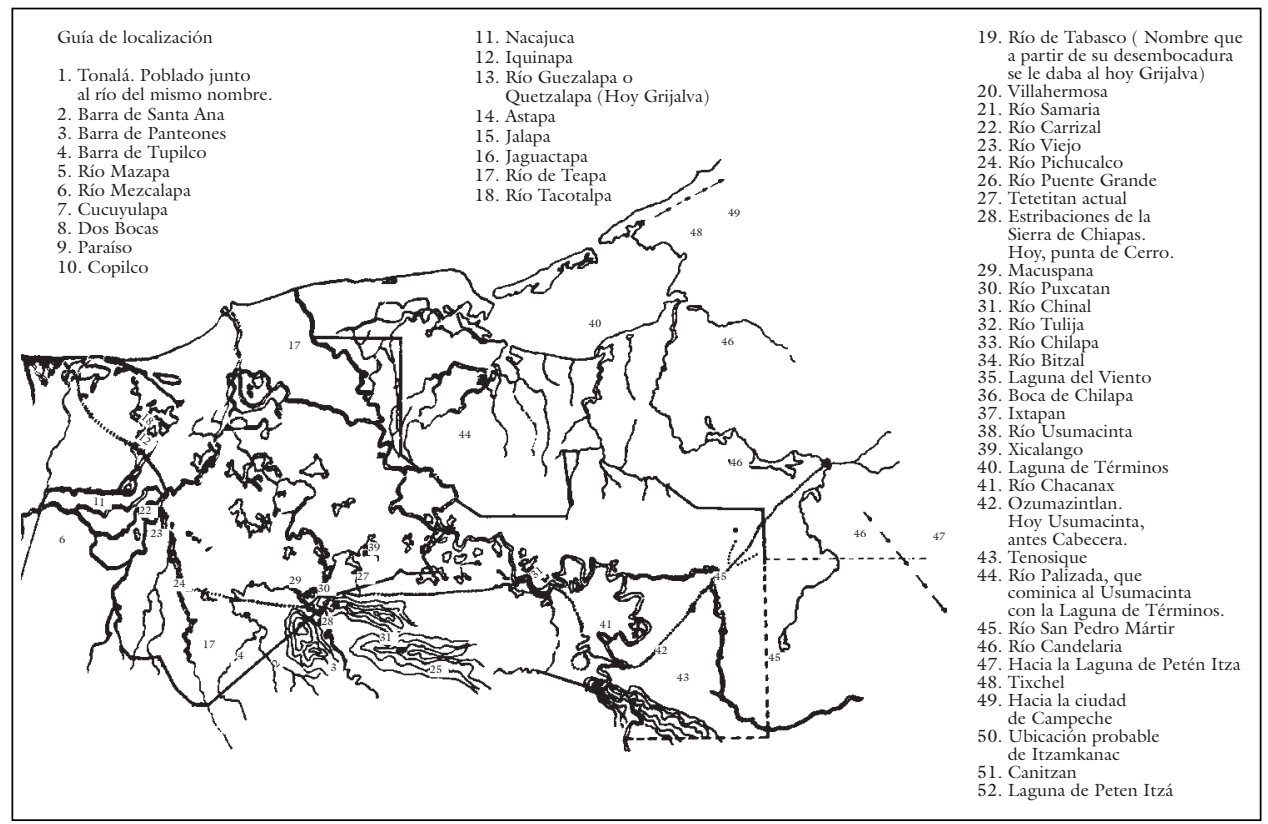

Mapa 8. Ruta de H. Cortés hacia Acalan, Itzamkanac (tomado de Catalán de Sánchez 1985).

puente construido por Cortés, y que seguramente dicho puente fue construido sobre el río San Pedro Mártir. Al referirse a Acalan dice que era una muy gran provincia en donde había mucha abundancia de bastimentos.

Así nos describen Cortés y Bernal Díaz del Castillo su llegada a Acalan; por otra parte, tenemos la información aportada por fuentes históricas de la región, la cual nos permite suponer que la localización de dicha provincia es correcta entre el río San Pedro Mártir y el Candelaria, ya que nos señalan algunas características muy propias de la región.

Por otro lado los Anales de Tlatelolco y el mismo Chimalpahin nos dicen que los chontales estaban emparentados con los nobles toltecas del centro de México y suponen que existieron guarniciones mexicas entre Xicalango y Acalan, es decir, al norte de Tabasco y sur de Campeche. Además los chontales se reconocieron súbditos de la gente de México: "Que venga el señor, nuestro amo y soberano. Que nos hagamos dignos de esta merced. Que nos trate a sus súbditos con clemencia. Porque si él nos impone algo, ya se encontrará de dónde tomarlo» (Toscano 1984: 230).

A la provincia de Acalan llegaban diversas rutas fluviales y terrestres, siendo la principal el río Candelaria, desde donde podían comerciar hacia el exterior llegando a Tixchel, Xicalango, Potonchán, y hasta Nito y Naco, en Honduras.

Estamos de acuerdo con la mayoría de los autores que han identificado a El Tigre con Itzamkanac, ya que las fuentes históricas describen con de- 
talle esa región por donde pasó Cortés y ejecutó al huey tlatoani Cuauhtémoc. 0 tras fuentes históricas, tanto regionales como generales, también Ilevan a pensar que I tzamkanac se localizaba a orillas de un gran río que no puede ser otro más que EI Candelaria, en donde se ubica EI Tigre. Tanto Bernal Díaz del Castillo como Cortés nos describen el paso de otro gran río después de su estancia en I tzamkanac.

Para la descripción de la muerte de C uauhtémoc nos basamos fundamentalmente en Cortés, Bernal D íaz del Castillo y en los Papeles de Paxbolom. Sin embargo, el lector interesado sería importante que confrontara a los siguientes autores (cfr. H ernán Cortés 1969: 260-3, Bernal Díaz del Castillo 1974, III: 43-8, A nales de Tlatelolco, Gonzalo Fernández de O viedo y Valdés 1851-5, Francisco López de Gómara 1965: 143-4, Fray Toribio de Benavente, M otolonía, Fray D iego D urán, Fray Juan de Torquemada, Fernando de Alva Ixtlilxóchitl, Fray Francisco de Aguilar, Cristóbal del Castillo, Fernando Alvarado Tezozómoc, Francisco de San Antón M uñoz Chimalpahin Cuauhtlehuanitzin, Códice Vaticano A 3438 o C ódice R íos: lámina Cxxxv, Códice A ubin, M apa de T epechpan: manuscrito núm. 40).

$\mathrm{N}$ uestro interés no se centra en la muerte de C uauhtémoc, sino en tratar de ubicar a través de ese desafortunado hecho a I tzamkanac, ya que las fuentes históricas en algunos casos dan indicios de su localización; como expresamos, Cortés no señala en dónde se le dio muerte, y en cambio los Papeles de Paxbolom son claros al decirnos que fue en un pueblo anterior a I tzamkanac, en Yaxzam; allí le cortaron la cabeza (figura 2), que clavaron en una ceiba delante de la casa de idolatría que había en ese lugar.

Cortés (1969) describe ampliamente los acontecimientos previos a la ejecución de Cuauhtémoc para justificarse, pero con respecto al lugar sólo nos dice que: «Aquí en esta provincia acaeció un caso que es bien que Vuestra M ajestad lo sepa»; agrega que fueron ahorcados los dos (Guatemucin y Tetepanquetzal) y que soltó a los otros.

Bernal Díaz del Castillo (1974) nos dice: «Y sin haber más probanzas, Cortés mandó ahorcar a Guatemuz y al señor de Tacuba, que era su primo [...]». N o añade ninguna información con respecto al lugar de la muerte de Cuauhtémoc, pero da juicios importantes y concluye: «Y fue esta muerte que les dieron muy injustamente, y pareció mal a todos los que íbamos».

Los Papeles de Paxbolom (Scholes y Roys 1968) nos narran lo siguiente: «Vinieron los españoles a esta tierra en el año de mil quinientos veinte y siete. El capitán se llamaba D on M artín Cortés. Q ue entraron por Tanoçic y pasaron por el pueblo de Taxich y salieron al principio de la tierra de Xacchuté y llegaron a proveerse en el pueblo de Taxaha».

Tiene algunos errores como son el año y el nombre de Cortés; sin embargo, con base en los Papeles de Paxbolom se sabe que el rey Paxbolom A cha estaba en Itzamkanac y fue llamado por Cortés desde el pueblo de 


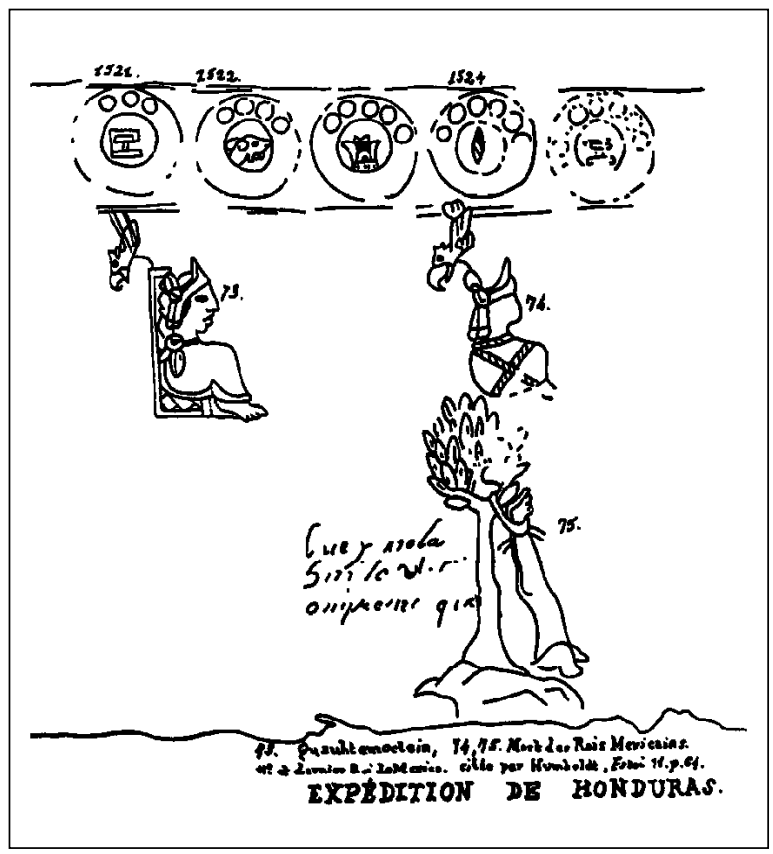

Figura 2. Muerte del tlatoani Cuauhtémoc.

Xachaa, en donde estuvo descansando 20 días. Siguiendo la fuente histórica, sería allí donde Quatemuc, rey de Tenochtitlan, sugirió a Paxbolom A cha que se unieran los indios magtunes chontales para matar a los españoles. Como Quatemuc siempre lo estaba importunando, se fue con el capitán D el Valle y le dijo que anduviera con cuidado con él, porque podría hacerle alguna traición. O ído esto, el capitán Del Valle lo prendió, echó en prisión y al tercer día le cortaron la cabeza, la cual fue clavada en una ceiba delante de la casa de idolatría que había en el pueblo de Yaxzam. En el listado de pueblos, donde se numeran 76, el 49 se llama Taxahá, y se anota que allí estuvo C ortés 20 días y fue el lugar en donde decapitaron al capitán mexicano Q uatemuco.

Y luego partió el capitán del Valle, y con él toda su gente y el Rey Paxbolom Acha con toda su gente, llegaron a la ciudad de Yzamcanac. Y estando allí, empezaron a trazar por qué parte se podía hacer puente para poder pasar el río con todo su ejército, que tendría una legua de travesía con sus bajíos; y así se empezó a henchir los bajíos y a hacer la puente, que se acabó dentro de dos días por la mucha gente que había (Scholes y Roys 1968).

Muchos son los cronistas e historiadores que hablan de la muerte de Cuauhtémoc; sin embargo, ninguno de ellos, sobre todo de los que estuvieron presentes, nos dice que Cuauhtémoc haya sido muerto en Itzamkanac. Gómara es el único que lo menciona como lugar de la ejecución. 
Cortés no señala un lugar específico, sino refiere el suceso como acontecido en la provincia de Acalan. Bernal Díaz del Castillo nos narra que la ejecución fue realizada en otro pueblo más adelante, sujeto al mismo Acalan. Chimalpahin menciona Acalan $\mathrm{H}$ ueymollan como provincia; Ixtlixóchitl cita el nombre azteca de la población Teotilac, dos jornadas más allá de Acalan; y el manuscrito chontal presenta a la población de Yaxzam. Si seguimos la descripción de Cortés, la ejecución de Cuauhtémoc debió realizarse en el pueblo anterior a Itzamkanac, Teutiercas según su relación, o Taxahá según los Papeles de Paxbolom.

En general, to dos los cronistas están de acuerdo en que C uauhtémoc y el señor de Tacuba fueron colgados de una ceiba (ixminche) o de un pochote (figura 3); sin embargo, existe la otra versión de que primero fueron decapitados y sus cuerpos suspendidos de los tobillos de las ramas de la ceiba, en tanto que las cabezas fueron clavadas en los muros del templo principal de Yaxzam (Taxahá).

A pesar de contar en fuentes históricas con referencias importantes relacionadas con la muerte de Cuauhtémoc sobre la existencia y localización de I tzamkanac, sigue siendo difícil ubicar su situación geográfica; pero estamos de acuerdo con Scholes y Roys (1968), Piña Chan y Pavón Abreu (1959), en que el sitio arqueológico de El Tigre podría ser Itzamkanac.

Como dijimos, la importancia de este sitio no es sólo por dicho acontecimiento, sino porque es un lugar a donde llegaban diversas rutas fluviales y terrestres, portando mercancías que pasaban a distintas partes de M esoamérica. Fue la capital de una de las provincias más ricas de la $\mathrm{C}$ hontalpa, como lo atestiguan las fuentes históricas. Por eso sería interesante conocer y entender las relaciones que mantuvo con otras áreas, sus características culturales y la relevancia económica que tuvo durante la época prehispánica,

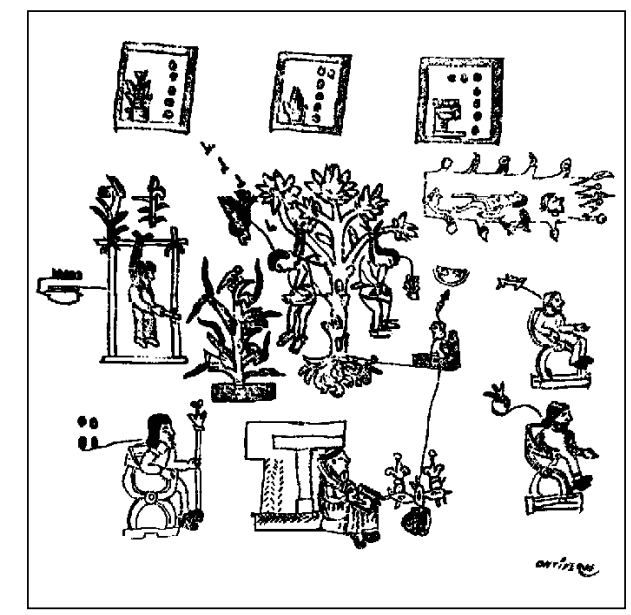

Figura 3. M uerte de Cuauhtémoc ( $C$ ódice Vaticano). 
para intentar una explicación de los procesos histórico-culturales que ahí ocurrieron.

C reemos que a pesar de la falta de conocimientos del área y del sitio en especial, la arqueología, las fuentes históricas y la misma tradición oral pueden ser factores importantes para reconstruir no solamente el hecho histórico de la ejecución del tlatoani Cuauhtémoc sino también la importancia de la región; si sus restos reposan o no allí, no aumenta ni disminuye su figura histórica.

LoS POBLAdores de LA PROVINCIA de ACALAN SEgún LAS FUENTES

\section{El Chilam Balam}

Barrera Vásquez y Rendón (1969: 21), en El Libro de los libros del C hiIam Balam, aclaran un punto importante al Ilamar C rónica $\mathrm{M}$ atichu a los textos del C hilam Balam de M aní, Tizimín y Chumayel, que habían sido tomados como tres crónicas distintas y los considera uno, el cual divide en cuatro partes.

$\mathrm{N}$ os interesa la parte I, que es la historia de las migraciones de los xiues, desde su salida de N onoual en el katún 3 ahau (10.2.0.0.0: 849-869 dC) hasta su establecimiento en Chacnabitón, y la parte ı, que es la historia itzá del descubrimiento de la provincia de Siyán $C$ an Bakhalal, el descubrimiento y abandono de Chichén Itzá en el katún 8 ahau (9.13.0.0.0: 672-692 $\mathrm{dC}$ ), el arribo a Chakamputún y su abandono en el katún 8 ahau (10.6.0.0.0: 928-948 dC), para establecer de nuevo sus hogares en Chichén I tzá después de 40 años de peregrinar.

Algunos otros pasajes del C hilam Balam nos interesan pues pensamos, como varios autores (cfr. Tozzer 1978, Barrera Vásquez y Rendón 1969, Piña C han 1980, Thompson 1975), que los itzaes y otros grupos de Yucatán eran chontales o se relacionaron íntimamente con ellos.

EI C hilam Balam es claro al citar un grupo maya que llega a la región de Bacalar (415-435 dC), costa oriental de Quintana Roo, que descubre Chichén Itzá (435-455 dC) y reina allí por diez veintenas de años, para luego abandonarla (672-692 dC). Posteriormente se estableció en Chakamputún, allí tuvo su hogar y después de 260 años lo abandonó para regresar nuevamente a Chichén I tzá. Este último momento es el que nos interesa.

O cho ahau. Fue abandonada C hichén I tzá, después de trece dobleces de katún. Y se establecieron en Chakam-putún, en sus casas, en el tiempo de este katún (672$692 \mathrm{dC}$ ).

Cuatro ahau. Fue conquistada por ellos la tierra de Chakamputún (711-731 dC). (C hilam Balam de C humaye). 
El C hilam Balam de Tizimín (Barrera V. y Rendón 1969) nos dice lo siguiente:

D iez veintenas de años reinaron en Chichén I tzá y fue abandonada (495-692 dC). Transcurrieron trece dobleces de katún (435-692 dC).

Y fueron a establecerse a C hakamputún.

Allí tuvieron su hogar los itzaes, hombres religiosos.

En el katún 6 ahau (692-711 dC), fue alcanzada la tierra de Chakamputún.

4 ahau (711-731 dC), fue alcanzada la tierra, por ellos, de Chakamputún.

L a fuente es clara cuando nos refiere que los itzaes abandonaron $C$ hichén Itzá y vivieron en Chakamputún, que se localizaba al sur de Campeche. D esgraciadamente no describe su estancia en Chakamputún; da información complementaria al decirnos que uno imix es el primer día del año y Chichén I tzá fue conquistada por los itzaes, quienes fueron creados por $M$ izcit A hau (el dioso señor M izcit que no es otro que N acxit, Kukulcán o Q uetzalcóatl), nombre maya-chontal por poner el título (ahau) después del nombre propio (Piña Chan 1980: 33). Los itzaes lo adoptaron en tierras mayas-chontales por el rumbo de la L aguna de T érminos y C hampotón, antes de ir a Yucatán, a esta región se le conocía con el nombre de Zuyúa y por eso se hicieron descender de él y lo llevaron a C hichén I tzá.

Los datos anteriores nos permiten estar de acuerdo con Piña C han (1980: 33-4) quien dice lo siguiente:

[...] los itzaes eran gente de habla maya-chontal y estuvieron en la región comprendida entre Xicalango y Champotón, Campeche, es decir, en tierras de Zuyúa (del poniente); tenían una cultura híbrida con elementos mayas chontales, del altiplano Central de M éxico, del Centro de Veracruz, de la H uasteca y aún de la costa del Pacífico de Guatemala [...] Esta cultura híbrida fue la que llevaron a Yucatán, cuando salieron de Chakamputún.

Siguiendo la descripción del $\mathrm{C}$ hilam Balam de $\mathrm{C}$ humayel sabemos que Ios itzaes conquistaron la tierra de Chakamputún o C hampotón, Campeche, en un 4 ahau (711-731 dC).

[...] 8 ahau (928-948 dC). Fue abandonado Chakam putún por los hombres itzaes. Y vinieron a poner sus casas otra vez. Trece dobleces de katún estuvieron establecidos en sus casas de Chakamputún. En este mismo katún fueron los itzaes a vivir bajo los árboles, bajo la ceniza, bajo su miseria.

Estuvieron en Chakamputún 13 dobleces de katún (260 años) y abandonaron el lugar para ir a Chichén Itzá.

C uatro ahau es el katún en que sucedió que buscaron C hichén I tzá. Allí fue compuesto lo maravilloso para ellos por sus padres. Cuatro partidas salieron. «L as cuatro divisiones de la tierra» se nombran. 
Cuatro ahau es el katún en que sucedió que invitaron a los de las $C$ uatro divisiones, nombradas $C$ antzuculcab, para que vinieran. Fueron «hechos padres» cuando vinieron a C hichén I tzá. I tzaes entonces se llamaron.

EI C hilam Balam de $C$ humayel es claro con respecto a la fundación de Chichén I tzá, que se inicia el uno imix, primer día del calendario ritual.

U no I mix, el día de alcanzar el cielo, va el rey al poniente del pozo, en donde abierto está el templo. El uno I mix es el día en que se dice en Chichén de los itzaes: ¿L legaron o estaban?

Para que lo entendáis. Dicen que fue creado de noche. ¿N osotros acaso nacimos? Se ha dicho que fuimos creados por M izcit Ahau.

En el peregrinar de los itzaes, el tiempo cíclico es fundamental, permanecen 260 años en Bacalar-Chichén, posteriormente pasan 260 años en Chakamputún, luego permanecen 40 años perdidos antes de llegar a Chichén en donde gobernaron otros 220 años. Parecerían seguir el registro de las cuentas de katunes (u kahlay uxocen katunob) de 260 años; pero, aún más, me atrevería a pensar que no sólo están regidos por el año ritual o tzolkin, sino por el ciclo de Venus que pasa por diferentes estadios, uno como estrella matutina, otro como estrella vespertina, ciclo de 90 días, ciclo de oscuridad y desaparición. Cada ciclo de katunes o ciclo ritual de 7200 días tenía una profecía específica relacionada sólo con ese periodo de tiempo.

Para comprobar dicha hipótesis veremos que los itzaes gobiernan en Chichén I tzá del 948 dC a 1204 dC que son los 260 años, cuando se da la traición de $\mathrm{H}$ unac $\mathrm{C}$ eel $\mathrm{C}$ auich y el gobernante de $\mathrm{C}$ hichén I tzá abandona el lugar para salir hacia la costa oriental de Q uintana Roo, Polé. "C uatro veintenas de años y diez más hace: El décimo tun del 8 ahau (10.18.10.0.0.0: $1194 \mathrm{dC}$ ), fue el año en que se dispersaron por causa de Ah Sinteut Chan, Tzontecum, Taxcal, Pantemit, Xuchueuet, I tzcuat, C acal tecat».

Es decir, los itzaes después del ataque sufrido por los de $M$ ayapán se dispersan, y posiblemente un grupo de ellos regresa a las tierras de Acalan, como veremos en los Papeles de Paxbolom. En ese katún 8 ahau se funda $M$ ayapán.

En el siguiente katún 8 ahau (11.12.0.0.0: 1441-1461 dC), según el mismo $C$ hilam Balam, fue «cuando se abandonó y destruyó I chpan-M ayapán por los de extramuros, los de atrás de la muralla, por causa del gobierno múltiple en el interior de M ayapán».

L os itzaes que gobernaron Tayazal, la última capital, según fray Andrés de A vendaño, se entregaron a los españoles en 1697, pues ellos sostenían que el tiempo había llegado para tal fin; esa fecha corresponde al katún 8 ahau (12.5.0.0.0: 1697-1717 dC).

Lo que hemos visto en el C hilam Balam es la repetición del katún 8 ahau a lo largo de cinco ruedas katúnicas que abarcan un perio do de 1300 
años, éstas son muy útiles para nuestros objetivos, pues registran una larga secuencia histórica de conquistas, de asentamientos y de abandonos alternativos de importantes sitios mayas (mapa 9).

El katún 8 ahan marcaba el fin de una era, fue tiempo de cambio, de gue-rras, inicio de otro ciclo. En el primer katún 8 ahau (9.0.0.0.0: 415$435 \mathrm{dC}$ ), se descubre Bacalar y posteriormente Chichén Itzá. En el segundokatún 8 ahau (9.13.0.0.0: 672-692 dC) abandonan Chichén, descubren Chakamputún y viven allí. En el tercer katún 8 ahau (10.6.0.0.0: 928-948 dC) dejan la región de Chakamputún y van hacia Chichén Itzá, donde se establecen por segunda ocasión. En el cuarto katún 8 ahau (10.19.0.0.0: 1185-1204 dC) destruyen Chichén Itzá y se asientan en Mayapán. En el quinto katún 8 abau (11.12.0.0.0: 1441-1461 dC) destruyen Mayapán y

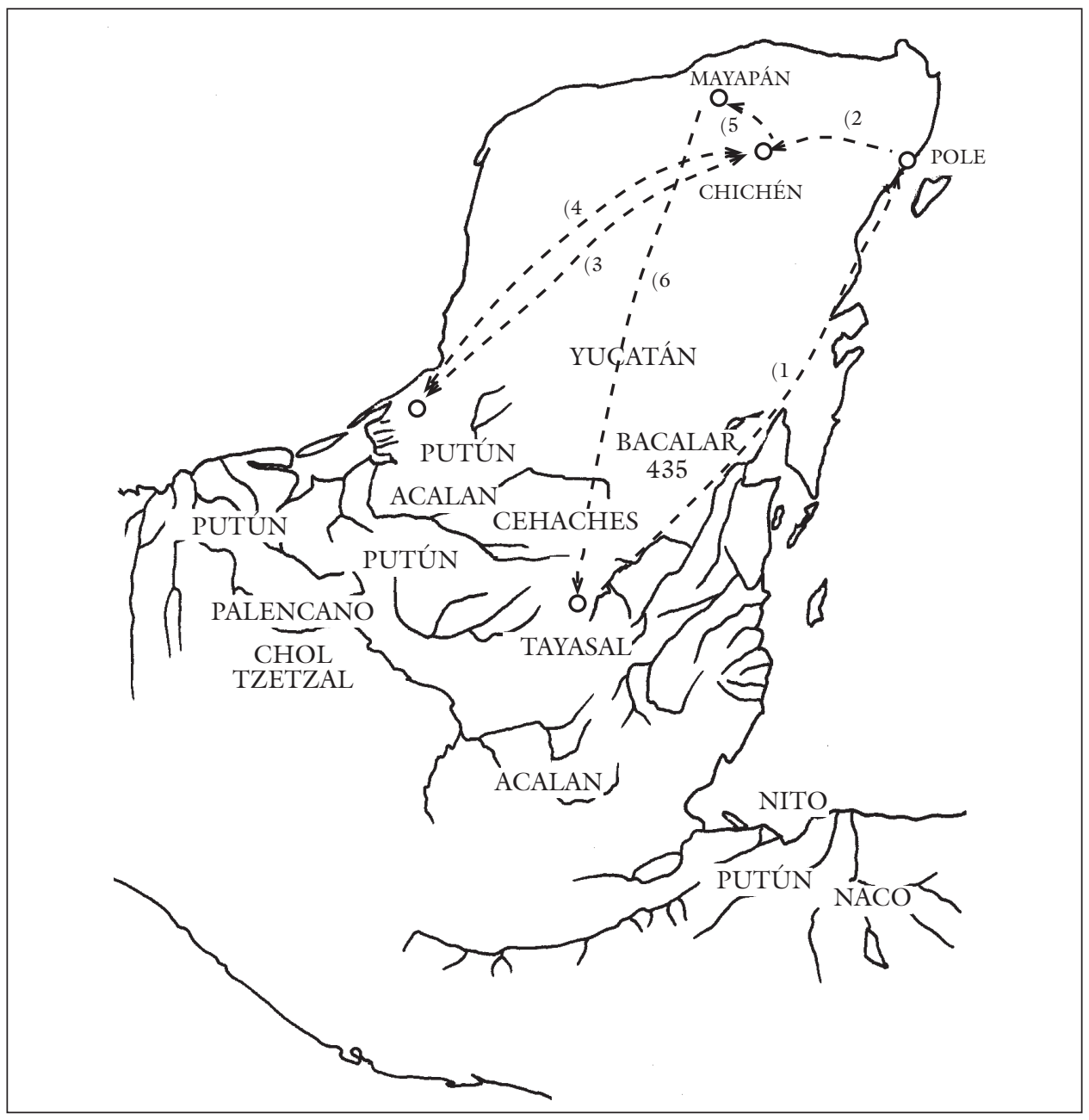

Mapa 9. Peregrinar de los itzaes según la rueda katúnica. 
se forman las diferentes provincias. En el sexto katún 8 ahau (12.5.0.0.0: 1697-1717 dC), conquistan Tayazal.

El katún 8 ahau para los itzaes y para otros grupos mayas debía ser de gran importancia, pero éste adquiría un papel de mayor trascendencia cuando coincidía con el fin de un baktún, que siempre fue catastrófico. Baste recordar el baktún 9.0.0.0.0., que coincide con la caída del ejército que había traído 'N ariz Rizada' a Tikal y que vence Sian C haan K'awil, 'C ielo Tormentoso'; y la narración del C hilam Balam se inicia precisamente con ese katún y baktún; y el baktún 11.0.0.0.0. que coincide con otro katún 8 ahau registra la conquista de $\mathrm{C}$ hichén I tzá por $\mathrm{H}$ unac $\mathrm{C}$ hel $\mathrm{C}$ auich.

EI C hilam Balam de $M$ aní dice con respecto a los xiues que llegan a Yucatán casi al mismo tiempo que los itzaes:

N onoual.

Este es el orden de los katunes desde cuando salieron de su tierra, de su hogar de

C uatro katunes estuvieron los tutul xiu (849-928 dC) al poniente de Zuyúa.

$\mathrm{L}$ a tierra de donde vinieron (es) Tulapan Chiconautlan.

Cuatro katunes caminaron hasta que llegaron aquí, en compañía del caudillo (H olón) Chan Tepeu y sus acompañantes.

En el katún 2 ahau (987-1007 dC) se estableció Ah Suytok Tutul Xiu en U xmal.

Lo más importante de resaltar es que tanto los tutul xiu, 'pájaros azules' (figura 4), como los itzaes salieron de la zona de Tabasco-Campeche, la región chontal. L os xiues partieron de Tulapan Chiconautlan, al parecer de la costa de Veracruz (Piña Chan 1980: 36); tuvieron sus hogares en la región de N onoualco (Tabasco), al poniente de Suyua (L aguna de Términos). L os itzaes conquistaron, ocuparon la tierra de Chakamputún en el 4 ahau (711-731 dC) y estuvieron allí hasta el 8 ahau (928-948 dC), es decir 11 dobleces de katún.

C ada katún tenía su asiento en la tierra, una ciudad era escogida para celebrarlo y por tal motivo alcanzaba poder y fuerza. Los itzaes, sabedores de la importancia de ese katún y como integrantes del grupo dirigente, buscaron afanosamente el asiento del katún 8 ahau en Chichén y lograron asentarse nuevamente en donde quizá llegaron a su máximo esplendor. Sin embargo, en el siguiente katún 8 ahau abandonaron Chichén I tzá y emigraron a M ayapán.

El abandono de C hichén I tzá se imputa a la traición de $\mathrm{H}$ unac $\mathrm{C}$ ed, ocurrida entre el 1185 y el 1204 de la era cristiana. «Trece dobleces de katún hacía que estaban establecidos (los itzaes) cuando se dispersaron por causa de H unac C eel, para darles lección a los itzaes» (987-1007 dC a 1224-1244 dC).

Basados en el Chilam Balam (Tizimín, Chumayel), proponemos que los itzaes provienen de la región central del Petén, porque la fecha más temprana a que hacen referencia es 415 dC y su llegada es a Balacar; de allí emigraron a Chichén Itzá y permanecieron hasta el inicio del siguiente katún 8 ahau, después se fueron a C hakamputún, la región de los chontales; 


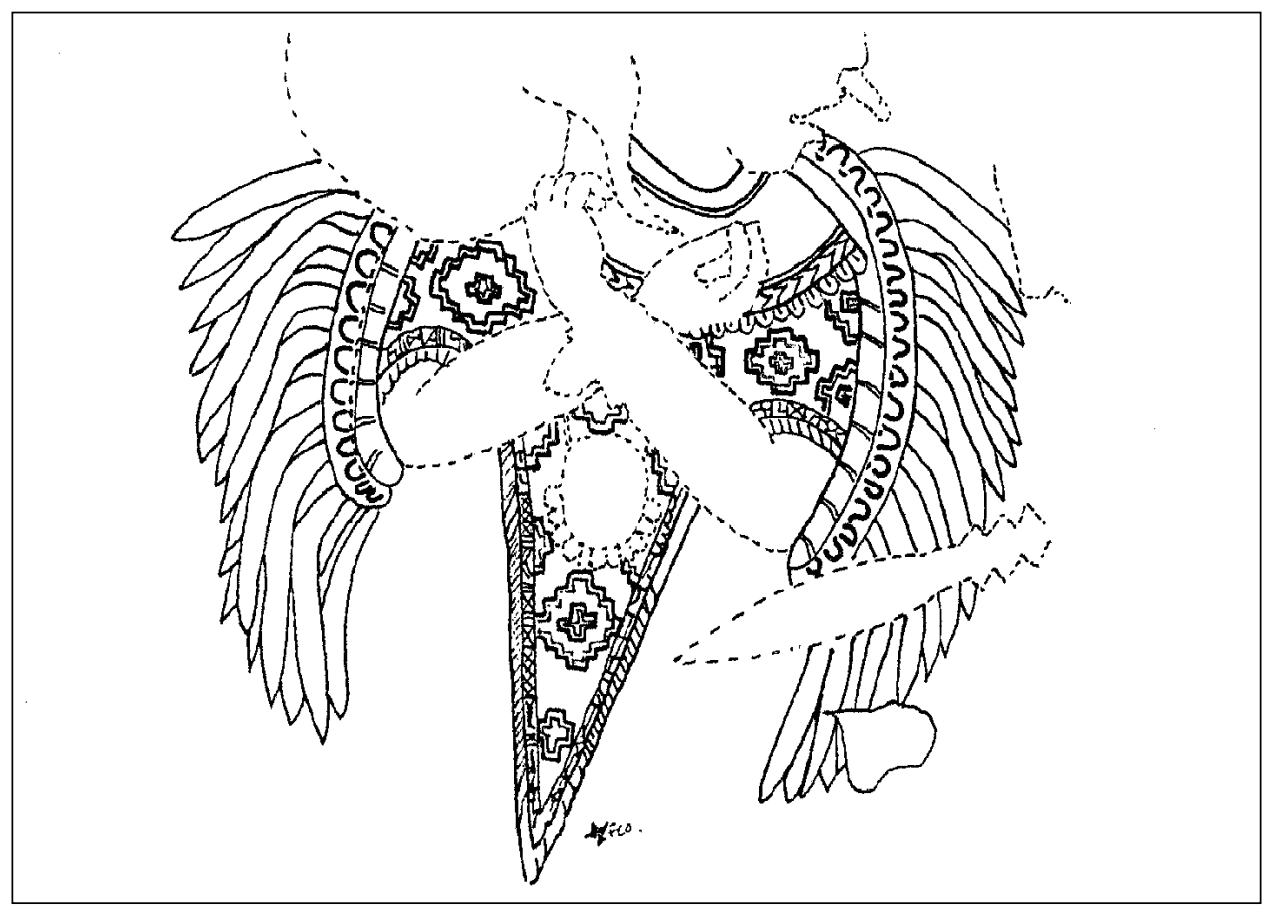

Figura 4. Los tutul xiu, 'Pájaros Azules'. (Foncerrada 1993, figura 23b).

permanecieron ahí otros 260 años y regresaron nuevamente a Chichén I tzá para refundarla. Esta es una rama de los mayas chontales o putunes, son putunes-itzaes que después de la caída de C hichén I tzá, ocurrida con la conquista de $\mathrm{H}$ unac $\mathrm{C}$ eel, regresaron a la región chontal como itzaes-putunes, y llegaron a ser los magtunes 0 acalanes.

L os putunes o mayas chontales se extendían desde C hampotón hasta el G rijalva-U sumacinta, eran expertos comerciantes en las vías fluviales y marítimas que controlaban la ruta alrededor de la península de Yucatán. Este último hecho queda corroborado por los textos que a continuación veremos de los Papeles de Paxbolom.

\section{Los Papeles de Paxbolom M aldonado}

Esta es la única fuente chontal que existe, por lo tanto es de gran importancia al ser la única que habla directamente de los chontales de Acalan y de la región, de allí la necesidad de realizar un análisis detallado. «En el principio Auxagual, rey, vino de Cozumel, y habiendo cogido los pueblos de aquí, fue a recoger el pueblo de Tanoçica y los grandes principales A vtha llamados y también los Paxoques y también los chacbalam, cuatro con los Paxmulú y estos llevó por compañeros» (Scholes y Roys 1968). 
EI rey A uxaual (halach uinic), y cuatro principales que venían de Cozumel, realizaron la conquista de toda la región.

Pachimal, hijo de Auxaual, fue el segundo rey; y Champel, el tercero, conquistó lo que actualmente son la L aguna de T érminos e I sla del Carmen.

El cuarto rey, Pexgua, fue quien pobló Tixchel por 60 u 80 años; sin embargo, los de Champotón, Xicalango, Pomeba y Tabasquillo le hicieron la guerra y tuvo que abandonar Tixchel rumbo a M agtún, que llamaban Acalan. Conquistó el pueblo de los quiaches y los de mezatecate y los zulob, y así fue señor de la tierra de Acalan.

El quinto rey se llamó Pachimalays y fue quien conquistó Chagtemal detrás de Bakhalal, al que le impuso tributo; no quiso partirlo con loszulob por lo que entró en guerra con ellos.

El sexto rey se llamaba Paxbolom A cha; éste fue el que pobló Acalan, y estando allí vinieron los españoles. Llama poderosamente la atención que hasta ese momento viniera la gente a Itzamkanac o Acalan, pues desde el cuarto rey se dice que «así fueron señores de la tierra de Acalan». Pienso que el grupo magtún o tamagtún había dejado Chichén I tzá obligado por el fin del katún 8 ahau y, al Ilegar a la región, lo que hizo fue reconquistarla, pero no fundó ninguna gran ciudad, sino hasta que se cumpliera la rueda katúnica de los 260 años que habría de ser durante el sexto rey Paxbolom A cha, que fue cuando se pobló I tzamkanac.

Un análisis breve nos hace ver que el primer rey magtún llegó de Cozumel y seguramente lo hizo después del katún 8 ahau, alrededor de 1204; su gente permaneció en la región habitando diferentes partes: Tenosique, Laguna de Términos, Tixchel y región de Acalan, hasta que Paxbolom A cha pobló esta última, precisamente cuando comenzaba el katún 8 ahau al rededor de 1441.

La fuente es rica no solamente por la información que nos da sobre el origen de los magtunes, sino también por otros aspectos, como la descripción de los 76 pueblos y la confirmación de que la cabecera de dicha provincia se llama I tzamkanac, lugar en donde vivía el rey Paxbolom A cha: «que la cabecera se llamaba Yxamhanac, y allí estaba el rey Paxbolom Acha, que así se llamaba, que éste era su reino, teniendo sus gobernantes, principales, M utuzin, rey, H inzuti, Pazayatonal y Cixún, que así se llamaban».

Esta manera de presentar el gobierno de la región se repite nuevamente cuando Cortés pasa por I tzamkanac: «R ey y señor, estás tú en tu reino y ciudad que yo quiero ir a ver lo que quieren los españoles. Y así fue con los demás principales que se llamaban Pazinchiquigua y Paxguaapuc y Paxchagchán, compañeros de Paloquem, en nombre del rey» (Scholes y Roys 1968).

\section{El Popol Vuh}

Por los C hilam Balam se sabe que los itzaes estuvieron en la región de Acalan entre el 700 y 950 dC, lo mismo que los xiues, quienes estuvieron 80 
años en $\mathrm{N}$ onoalco. Esta no es la única fuente que nos habla de la región chontal, pues el Popol Vuh también nos dice que la zona de Z uyúa se refiere al poniente, lugar situado entre Xicalango y Champotón, y en donde al parecer se concentraron varios grupos antes de dispersarse hacia varios rumbos para fundar sus pueblos y linajes ilustres. Al respecto, el Popol Vuh nos narra lo siguiente:

Tepeu, O lomán, Cohah, Quenech, Ahau, que así se llamaban esos hombres allí en el oriente, donde se multiplicaron. Y habiendo Ilegado a sus oídos la noticia de una ciudad se dirigieron hacia allá.

Ahora bien, el nombre del lugar a donde se dirigieron [...] eraT ulan-Zuivá, VucubPec, Vucub-Ziván. Este era el nombre de la ciudad a donde fueron a recibir a sus dioses.

N os separamos allá en Tulan, en Zuyvá, de allá salimos juntos y allí fue creada nuestra raza cuando vinimos, decían entre sí.

Carmack (1976: 74) dice que Zuiwá, lugar al oeste de Yucatán rodeado de agua, puede ser el antiguo nombre de Xicalango. Piña Chan (1980) piensa que Zuyúa o Zuivá es una región que correspondería al área de la L aguna de Términos. Por otra parte el mismo Carmack, sin dar mayores explicaciones, apunta que tamac-tun, el gentilicio utilizado para nombrar a los habitantes de la región de Acalan, es también empleado para designar a uno de los primeros asentamientos quichés de los altos de Guatemala: Amak'Tán.

Como se puede ver, la región es de gran importancia, ya que se nombra en diversas fuentes históricas indígenas.

\section{M emorial de Sololá o Anales de los cakchiqueles}

Entre los grupos que dicen venir de esa región están los quichés, cakchiqueles, itzaes y xiues: «D e cuatro (lugares) Ilegaron las gentes a TuIan. En oriente está una Tulan; otra en Xibalbay; otra en el poniente, de allí llegamos nosotros, el poniente; y otra donde está dios».

Por las citas en unciadas con anterioridad en el Popol Vuh y en el M emorial de Sololá, podemos decir que los cakchiqueles y los quichés abandonaron la 'Ciudad del Poniente' (Tulan Zuyvá) después de recibir a sus dioses; según Piña C han (1980: 35) se dirigieron a la costa del Golfo, en donde pelearon contra los nonoualcas de Tabasco y los xulpiti, que pudieron ser los xiues, puesto que éstos tuvieron su hogar también en N onoual co; pasaron a Zuyúa (Laguna de Términos), en donde fueron derrotados; de allí se dirigirían a Guatemala pasando por las montañas del Tacaná.

$\mathrm{H}$ ay guerra allá en el $\mathrm{O}$ riente, en el Ilamado Zuyúa ( $L$ aguna de Términos o H oltún zuyá); allá iréis a probar armas y vuestros escudos que os daré [...] Así se nos dijo [...] L uego llegamos a la orilla del mar. Allí estaban reunidos todas las tribus y los guerreros a la orilla del mar. 
Al parecer de allí se dirigieron hacia C oatzacalcos hasta llegar al sur de Veracruz y norte de Tabasco.

L uego nos juntamos y en seguida fuimos a hacer encuentro a una tribu enemiga, los N onoualcas, L os Xulpiti (sur de Tabasco), así llamados, que se encontraban a la orilla del mar y estaban en sus barcas.

En verdad fue terrible el disparar las flechas y la pelea. Pero pronto fueron destruidos por nosotros [...] y cuando ya se habían dispersado los nonoualcas y xulpitis, dijeron todos los guerreros: ¿Cómo atravesaremos el mar? [...] Y nosotros respondimos. En sus canoas pasaremos, sin que nos vean nuestros enemigos.

Así pues nos embarcamos en las canoas de los nonoualcas y dirigiéndonos al oriente pronto llegamos allí. Formidables eran de verdad, la ciudad y las casas de los de Zuyvá (Zuyúa o Laguna de Términos) allá en el oriente. Cuando hubimos llegado a la orilla de las casas nos pusimos a lancearlos, luego que llegamos [...] peleamos con sus perros, con sus aves de corral [...] atacamos una vez, hasta que fuimos derrotados ( $\mathrm{M} \mathrm{e}$ morial de Sololá 1950).

Piña C han (1991: 67-70) explica este pasaje diciendo que entre el 700 y 900 de nuestra era, varios grupos étnicos comenzaron a emigrar en busca de nuevas tierras donde asentar sus linajes y fundar pueblos, la región más favorecida fue la costa del Golfo; Ilevaban como caudillos a señores sacerdotes del culto a Q uetzal coatl.

En el capítulo 6 del M emorial de Sololá puede apreciarse claramente que sólo migraban la élite dominante y los guerreros que los acompañaban para concertar las alianzas o conquistar los territorios que se deseaban; posteriormente se mandaba por la población civil.

Los grupos que partían tenían que dar tributo: piedras preciosas, metal, guirnaldas cosidas con plumas verdes y azules, y ofrendaban flautas, canciones, cal endarios rituales y astronómicos, pataxte y cacao. E so mismo recibían en tributo cuando lograran asentarse en los lugares a donde iban.

Los quichés y cakchiqueles, al parecer, migraron conjuntamente para establecerse en el actual territorio de Guatemala; algo parecido a lo que sucedió con los xiues e itzaes, que se establecieron en Yucatán, aunque con 80 años de diferencia.

Los xiues conquistaron primero $\mathrm{Mul} \mathrm{Chic,} \mathrm{en} \mathrm{donde} \mathrm{sostuvieron} \mathrm{pe-}$ leas sangrientas que quedaron registradas en murales, pintados con gran dramatismo, y después conquistaron U xmal. Los itzaes antes de establecerse en $C$ hichén I tzá recorrieron gran parte de la península guerreando y conquistando pueblos; al final se asentaron en las orillas del pozo y ahí empezaron a recibir el tributo.

En los textos del M emorial de Sololá y el Popol Vuh se presenta una similitud en cuanto a los dioses creadores, a la espera del nacimiento de la luz o la aurora del sol, la entrega del fuego y la toma de posesión de la tierra que éstos les habían prometido en la mítica Tulan. Finalmente, cuando tienen cierta independencia y conforman una estructura de po- 
der, su cosmovisión se expresa en la estructura social y la misma división del poder en cuatro partes, lo que también vemos en la migración de los itzaes.

L lama poderosamente la atención que muchos de los grupos mayas del Postclásico temprano y tardío digan venir de la región del agua. Por otra parte a esta región del agua llegan grupos del centro de M éxico: olmecas xicalangas y posiblemente desde antes algunos grupos teotihuacanos.

\section{RECONSTRUCCION DEL ÁREA a PARTIR DE LAS FUENTES}

Por las fuentes históricas de origen indígena podemos decir que la provincia de Acalan fue muy importante, porque algunas de ellas la nombran como origen de los pueblos quichés, cakchiqueles, xiues e itzaes; los Papeles de Paxbolom citan por lo menos 76 pueblos. O tros documentos designan a I tzamkanac como su capital y otros muchos nos hablan de la existencia de otros pueblos; Díaz del Castillo refiere 20 pueblos para 1525 y Dávila diez para 1529.

D urante el Postclásico tardío seguramente la provincia fue relevante, pues tenemos la referencia de varias fuentes históricas; nosotros hemos insistido en que el Postclásico tardío no fue la etapa de mayor auge para los chontales, creemos que ésta se dio durante el Clásico terminal y que al final de ese periodo se pueden localizar las migraciones de los diferentes grupos a Yucatán y Guatemala. También durante el Preclásico superior hemos encontrado restos muy significativos que demuestran una ocupación densa en la región.

En este apartado intentaremos reconstruir la provincia de Acalan según los pueblos nombrados en los $P$ apeles de $P$ axbolom $M$ aldonado publicados por Scholes y Roys. O tto Schumann, M anuel Chávez y Fidencio Briceño (comunicación personal) tradujeron los nombres de todos esos poblados con la finalidad de buscarlos por medio de reconocimientos de superficie en el terreno; sin embargo, ha sido muy difícil localizarlos, pues su etimología no indica con exactitud en dónde están; algunos creemos haberlos localizado tentativamente.

1. A calan, Ilamado Itzamkanac, pueblo.

2. Tahobo, 'en el lugar del árbol hueco' (Schumann).

3. Tahcab o Tacacau, 'en la tierra, en la cuerda' (Schumann).

4. Tapib, 'en el horno' (Scholes y Roys).

5. Çacmunal (Zacmnal), 'en lo enterrado' (Schumann). 'Tumba blanca' (Scholes y Roys).

6. Tanauibcab, 'en la tierra parada' (C hávez).

7. Tauchcabal, 'tierra del zapote negro o del tlacuache' (Schumann). 
8. Tahkakalaez, 'en lo revuelto o en la quemazón' (B riceño y C hávez).

9. Tapacauichcab, 'en la tierra del arroyo de dos caras o del arroyo fal so' (Briceño y C hávez).

10. Txkancubim, 'en la acacia amarilla' (Scholes y Roys).

11. T anacomchutte, 'en la casa del árbol que contiene agua, en la casa que cuenta o almacena el agua' (Chávez).

12. Tahcehxuch, 'donde abreva el venado' (Briceño y C hávez).

13. T akunchelal, 'en los árboles kunche' (Scholes y Roys).

14. Tatok, 'en el pedernal' (Scholes y Roys).

15. Tamauitz, 'en el cerro de la guacamaya' (Schumann).

16. Peténmax, 'isla o territorio del mono' (Scholes y Roys).

17. T achakam (ahora llamado C hunab), 'en la sabana' (Scholes y R oys).

18. T ayel, 'en el lugar de los niños o de los huevos' (Schumann).

19. Temax, 'donde están los monos o los chiles' (Scholes y Roys).

20. Tahaalkantelal, 'entre los arroyos del árbol kante' (Schumann).

21. Tahmalín, 'donde las flores' (para hacer colchones o antorchas) (C hávez).

22. Tahkomtilal, 'en el valle sin dueño' (C hávez).

23. T ahaazcab, 'el lugar del amanecer o el lugar de la alborada' (Briceño).

24. Petenakú, 'isla o territorio sagrado o del templo divino' (C hávez).

25. UxPetén, 'isla o territorio sagrado o del templo divino' (Chávez).

26. U atunhobonnixtte, 'en el nixté inclinado' (Scholes y Roys).

27. Takoolkú, 'en el lugar del caldo sagrado o en el lugar de lo hábil y sagrado' (C hávez).

28. Tahchimaytún, 'piedra venado, en chontal' (Scholes y Roys).

29. Panuitzcab: Sobre la tierra o pueblo del cerro, la tierra del cerro quebrado ( $C$ hávez).

30. Tahçacab (Tahsacab): 'en la cantera de cal' (Scholes y Roys).

31. Tixmalindzunum, dzunum significa 'colibrí' (Scholes y Roys).

32. T ahbidzcabal, 'donde la tierra labrada' (C hávez).

33. T ançut (Tanzut), 'en la vuelta' (Scholes yRoys).

34. C hánhilix, 'varas pequeñas o palizadas' (C hávez).

35. T acantoppoltún, 'en donde brotan las piedras pequeñas' (C hávez).

36. H omolná, 'casa hundida o derrumbada' (Scholes y Roys, Briceño).

37. T aocabal, 'en el pie de la tierra'; 'en el soporte de la tierra' (Chávez).

38. Taulí, 'en el pie de la tierra'; 'en lo semejante'; 'en la entrada' (C hávez).

39. Ç acchuté (Zacchuté): 'cedro blanco' (Scholes y Roys).

40. Taniuitz, 'en la ladera del monte' (Scholes y Roys).

41. T appottelal, 'donde brotan los árboles' (C hávez).

42. Tapaxtoh, 'en el atabal del impuesto' (Chávez).

43. Tahchacchauac, 'en el lugar del gigante' (C hávez). 
44. T akuçaycab (T akuzaycab), 'en la sagrada tierra apelmazada o amontonada' (C hávez).

45. Palibpetetté, 'hendidura o arroyo en forma de frijol o forma redonda' (Chávez).

46. Tachiciua, 'en la oreja del maíz nuevo' (C hávez).

47. T ayaxttelal, 'donde las ceibas están' (Scholes y Roys).

48. T ayaxakcab, 'donde la tierra verde se une o mezcla' (C hávez).

49. Tuxakhá, 'donde el agua se mezcla'. Tal vez sea la confluencia de dos corrientes (Scholes y Roys).

50. Taypilal, '¿en las redes para lagartos?' (C hávez).

51. T ahbudzil, 'en la humareda' o 'donde hay humo' (Schumann).

52. H oknadzic, 'donde el humo está' (Scholes y Roys).

53. Tabidzcabal, 'en la tierra labrada' (C hávez).

54. Tanohún, 'en lo grande' o 'en lo viejo' (Chávez).

55. Kalum, 'tierra amarilla' (Scholes y Roys).

56. Tapaxua, 'En lo quebrado', 'donde el maíz quebrado', 'en lo dispersado' (asentamientos) (C hávez).

57. Y axhopat, 'cinco promontorios verdes' o 'espaldas verdes' (C hávez).

58. T apop, 'en los juncos' (Scholes y Roys); 'en las esteras' (Schumann).

59. Tabolay, 'donde el animal de rapiña está' (Scholes y Roys).

60. Tapom, 'en el árbol de copal' (Scholes y Roys).

61. Tapulemttelal, 'en la cresta de las aves' (C hávez).

62. T uholham, 'en el lugar de la tierra entre cada hueco' (Schumann).

63. T açachilal (Tazachilal), 'donde las calandrias' (C hávez).

64. Boteac, 'cañas o tallos del maguey', 'promontorio en agua estancada o mar tranquilo' (Chávez).

65. Tadzumuycab, 'en la tierra de las palomas' (Schumann).

66. Tamomoncab, 'la tierra de los momones' (Shumann).

67. Tahchimal, 'en el escudo' o 'en la defensa' (Scholes y Roys).

68. Y axahintún, 'piedra verde' o '¿Señor Piedra Verde?' (C hávez).

69. Tahkomcab, 'en el lugar de la tierra hundida' o 'de la hondonada' (B riceño y C hávez).

70. Temoch, 'árbol tullido' (C hávez y Briceño).

71. Taychilak, '¿en la lengua lastimada?' (C hávez).

72. Tachiicabal, 'en la tierra de los nances' (Schumann).

73. T uhol ham, '¿orilla limpia o abierta?' (C hávez).

74. Taykbalam, 'donde el tigre (jaguar) negro está' (Scholes y Roys, Schumann).

75. T anochich, 'donde la gran ave está' (Scholes y Roys).

76. Tamultún, 'en el túmulo de piedras' (Scholes y Roys, Schumann).

Estos son los 76 pueblos que nombran los Papeles de Paxbolom $\mathrm{M}$ aldonado; creemos que algunos de ellos necesariamente tienen que corres- 
ponder a los sitios arqueológicos reportados en los diferentes reconocimientos de superficie que se hicieron. D esgraciadamente no tenemos una cronología para la mayoría de ellos y, por lo tanto, no podemos decir con certeza cuáles son del Postclásico tardío, y con esto aproximarnos a su identificación con la lista que dan los Papeles de Paxbolom; sería interesante que con el tiempo pudiésemosidentificar alguno de ellos, pues el número de los sitios arqueológicos que se encuentran a la orilla del río es también de un poco más de 70 y, lógicamente, la mayoría debería tener una ocupación desde el Preclásico hasta el Postclásico. 



\section{Capítulo II \\ LA PROVINCIA DE ACALAN-TIXCHEL SEGÚN LA ARQUEOLOGÍA}

\section{Antecedentes arqueológicos}

E. W. Andrews Iv (1943) realizó trabajos en diversas partes de la zona maya y recalcó la existencia de una laguna de conocimientos, acerca de lo que hoy son los municipios de EI Carmen y Candelaria, al sur de $\mathrm{C}$ ampeche. En el invierno de 1939-1940 recorrió dicha área describiendo varias regiones (Pustunich, $M$ atamoros, Cilvituk, cuenca del Candelaria y la región al sur del $\mathrm{C}$ andelaria) y algunos sitios arqueológicos. Ya desde entonces señalaba la importancia de El Tigre, aunque no visitó todos los sitios de la cuenca del Candelaria.

Alberto Ruz recorrió la costa del estado de Campeche en 1943; no intentó penetrar en el interior, pero aportó datos importantes con respecto a numerosos sitios de la costa, y sobre todo, dio información sobre la cronología de la zona. En 1960 se publicó el A tlas A rqueológico de la República $\mathrm{M}$ exicana número 2 , que se refiere a $\mathrm{C}$ ampeche.

Para 1959 aparece una publicación de Piña Chan y Pavón Abreu sobre las ruinas de EI Tigre, en la que sostienen la hipótesis de que dicho sitio es I tzamkanac, la capital de la provincia de Acalan, lugar en donde fue muerto Cuauhtémoc por Cortés en el desafortunado viaje hacia las $\mathrm{H}$ ibueras.

En 1972 se publican los trabajos de Siemens y Puleston sobre los canales del río Candelaria y el primer croquis preliminar del sitio de El Tigre (figura 5). En 1978 aparecieron los trabajos del M iddle American Research Institute sobre la costa de Yucatán y C ampeche. A mbas obras son de gran importancia (Eaton 1978, Ball 1978).

Entre los meses de octubre y noviembre de 1983 se realizó un reconocimiento arqueológico en la cuenca del río Candelaria ( 0 choa y Vargas 1986), dividiéndose el área en siete secciones en donde se localizaron 33 sitios arqueológicos (mapa 10).

Bajo la dirección del doctor Román Piña Chan, se llevó a cabo en 1984 el Proyecto Arqueológico El Tigre, en éste se realizaron algunas explora- 
HISTORIA Y ARQUEOLOGÍA DE ACALAN

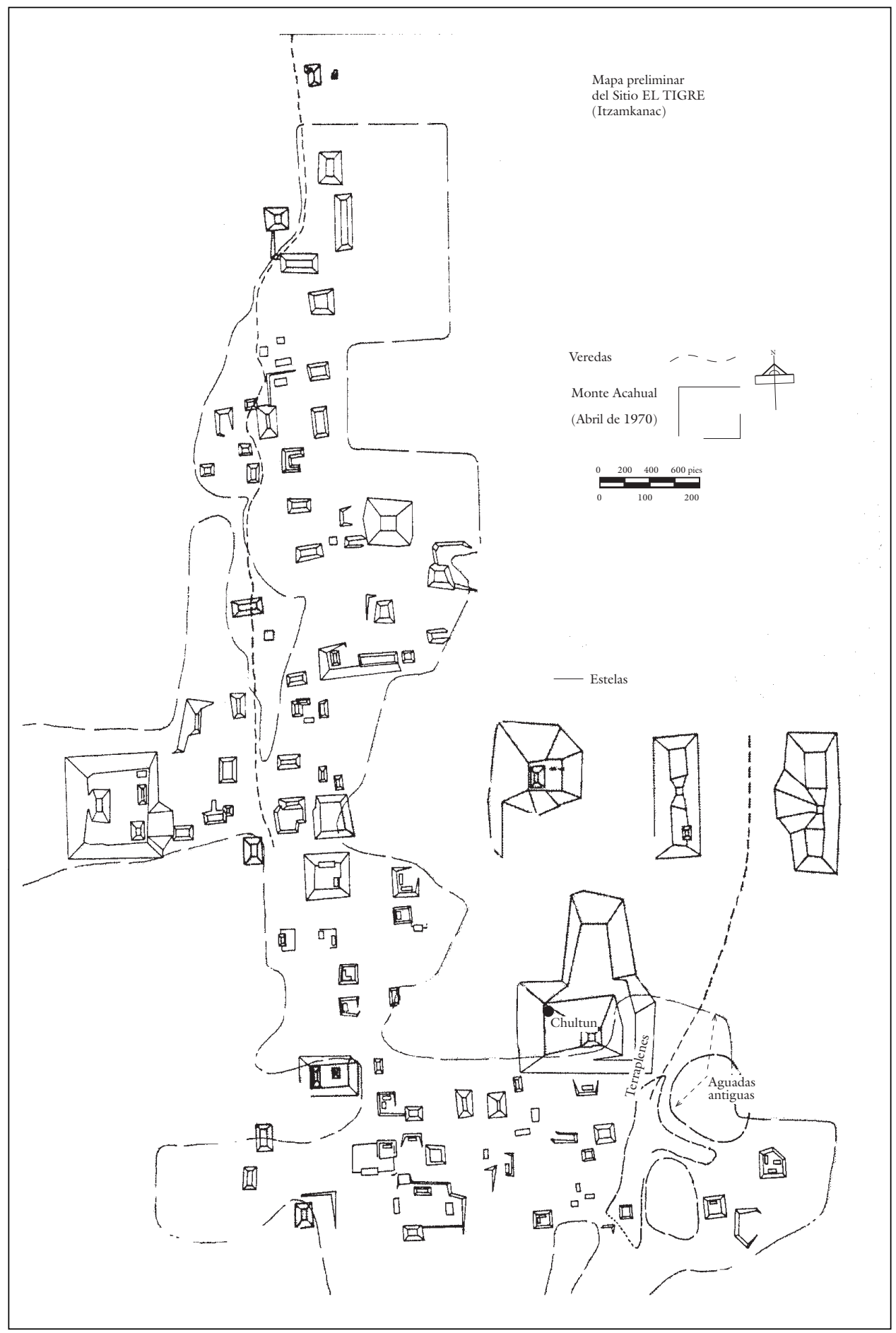

Figura 5. Plano El Tigre, según Puleston y A. Siemens (1972). 


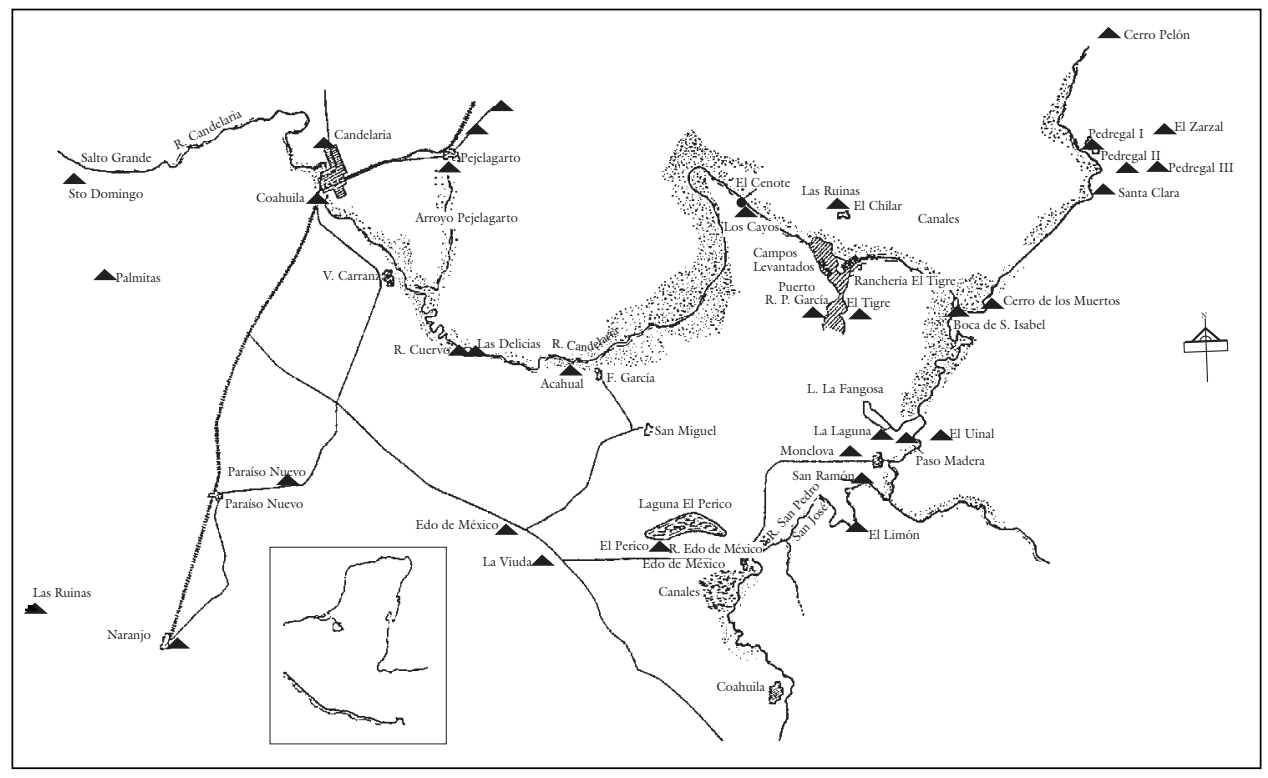

Mapa 10. Localización de sitios en la cuenca del río Candelaria.

ciones en zonas habitacionales y en dos de las estructuras principales del sitio. Desgraciadamente, el proyecto quedó inconcluso y la información también.

Pincemín planteó en 1985 un proyecto de reconocimiento en el valle del Candelaria (no existen valles en la región) y además de los informes obtuvo su tesis de doctorado. Hizo una tipología de los sitios y los clasificó de la siguiente manera: Al con una estructura, siete sitios; A2 con dos a ocho estructuras domésticas, 22; Bl con diez estructuras domésticas, cuatro; B2 con una o dos especiales, cuatro; clasifica 13 sitios como zonas domésticas y una especificada; y dos con 15 a 300 estructuras domésticas y especificadas. En total define 52 sitios, de los cuales la mayoría ya habían sido descritos por Ochoa y Vargas (1986); no aporta mayor información adicional pues lo poco que añade se refiere a sitios muy pequeños; tal vez lo más interesante de su trabajo sea el estudio de la cerámica, que con muy pocos tiestos pretende y logra hacer a su manera una cronología para «el valle» del Candelaria.

Como puede apreciarse, después de la realización de varios proyectos arqueológicos se desconoce propiamente el patrón de asentamiento de la región; también se ignora la cronología de los sitios, su arquitectura y su tipología cerámica.

Sin embargo, cada uno de los proyectos, independientemente de los logros, ha aportado algo de conocimiento sobre la región, que sin duda es de gran importancia, pues aparece citada en las fuentes históricas y los restos materiales arqueológicos son de gran relevancia. 


\section{El Preclásico. Primeras ocupaciones}

Poco era lo que se había estudiado del Preclásico en la zona maya, ya que lo que llamaba la atención era el Clásico. Paulatinamente se empezaron a hacer esfuerzos para entender el Preclásico medio (ciclo 6) y el Preclásico superior (ciclo 7, inicio del 8); así, se hicieron trabajos en Cerros, Cuello, EI M irador, Tikal, L amanai, U axactún, Komché, Edzná, Cobá y otros sitios que aportaron una gran cantidad de datos. É stos revelaron que el Preclásico superior en las tierras bajas se caracterizó por un nivel socio político muy elevado, con evidencias arqueológicas de arquitectura, artefactos líticos y cerámicos, asentamiento s habitacionales, organización socio política, arte e iconografía muy complejos.

Las investigaciones actuales no han podido determinar las causas del florecimiento de la cultura maya ni el proceso de sus orígenes en los tiempos preclásicos (ciclos 6 y 7).

La ocupación prehispánica de la región de Tabasco-Campeche se remonta a los tiempos de la cultura olmeca con el sitio de La Venta, que se encuentra a orillas del río Tonalá. En la parte media del U sumacinta existen restos arqueológicos en Tierra Blanca, Pomoca y L a Concepción, Ios cuales reflejan una cultura diferente que no puede clasificarse como olmeca, sino más ligada a una población autóctona.

\section{El Preclásico medio}

Los mejores estudios de este periodo en el área maya se realizaron en el Petén, lo más cercano a nuestro interés. Los primeros habitantes llegaron al área de $\mathrm{N}$ akbé hacia 1200 ó 1000 aC. La ocupación mayor se dio hacia el 1000 y 600 aC (F ase 0 x temprano), en donde aparentemente había una aldea o pueblo de tamaño considerable, la cerámica era excelente debido a la calidad, variedad y cantidad; también se han encontrado figurillas, pitos y ocarinas, todos diagnósticos del Preclásico medio de la fase Mamón en U axactún.

$\mathrm{H}$ ansen (1992: 83) propone que el desarrollo de $\mathrm{N}$ akbé hacia una cultura más compleja es multicausal, al detectarse desigualdad económica y jerarquía social con el establecimiento de una ideología religiosa manejada por una élite emergente, la cual es la responsable del florecimiento masivo de construcciones arquitectónicas. EI intercambio de larga distancia interregional, sobre todo de conchas y obsidiana, propició relaciones pacíficas con sociedades que controlaron las fuentes de los bienes importados, y la administración de importación y distribución propició una élite administrativa.

Parece que durante la fase $0 x$ tardío (600-300 aC) de $\mathrm{N}$ akbé se realizó una gran remodelación, se construyeron plataformas y edificios de 5 a 18 metros de altura. Q uizás durante esta fase no tuvieron escultura arquitec- 
tónica. El patrón de asentamiento consistió en la colocación de edificios mayores en un eje norte-sur y este- oeste sobre una plataforma; en U axactún se identifica en el Grupo $\mathrm{E}$; lo mismo se ha encontrado en N akbé y Güiro.

Con respecto a la escultura, se sabe que existen evidencias de ella y posiblemente se dio el inicio de la escritura en el área maya, pero aún falta mucho por investigar.

El único sitio arqueológico que podría pertenecer a esa fase en la región de Acalan es $\mathrm{N}$ ueva E smeralda, en donde se han encontrado figurillas (fotografía 7) y masas tipo olmeca (fotografía 8). También creemos haber identificado algunos tipos cerámicos pertenecientes al Preclásico medio en EI Tigre y una posible subestructura en la E structura 1 que puede apreciarse en el corte de un pozo estratigráfico (véase figura 7, p. 116).

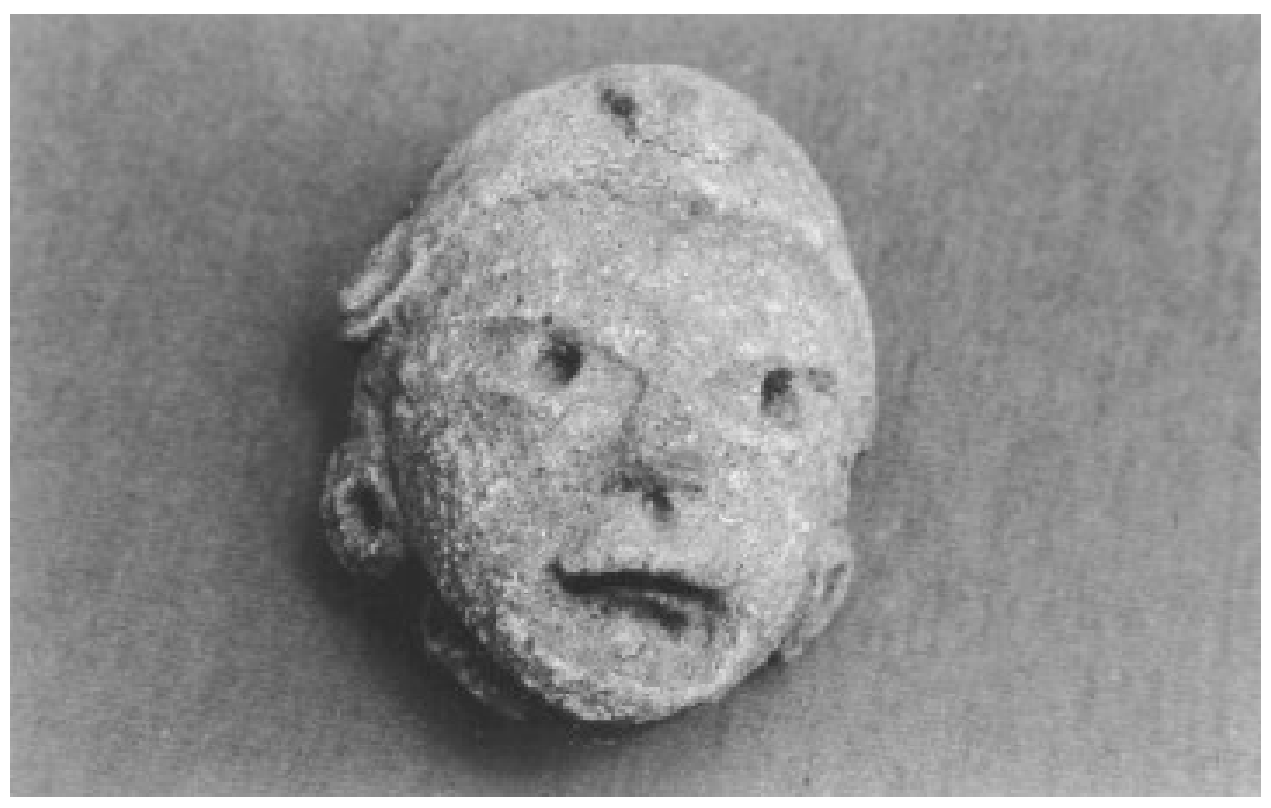

Fotografía 7. Figurilla del Preclásico medio. N ueva E smeralda.

\section{El Preclásico superior}

Al parecer, durante el Preclásico superior la ideología religiosa representó la cristalización de la autoridad absoluta de los soberanos mayas en el norte del Petén. Se construyeron edificios de patrón triádico y de un tamaño jamás repetido en el mundo maya, se realizaron construcciones a gran escala en el norte del Petén, $\mathrm{N}$ akbé, El M irador, Tintal y Güiro. É stas consisten en una plataforma que sostiene tres estructuras, la más grande es central y dos más pequeñas se encuentran una a cada lado del edificio central. 


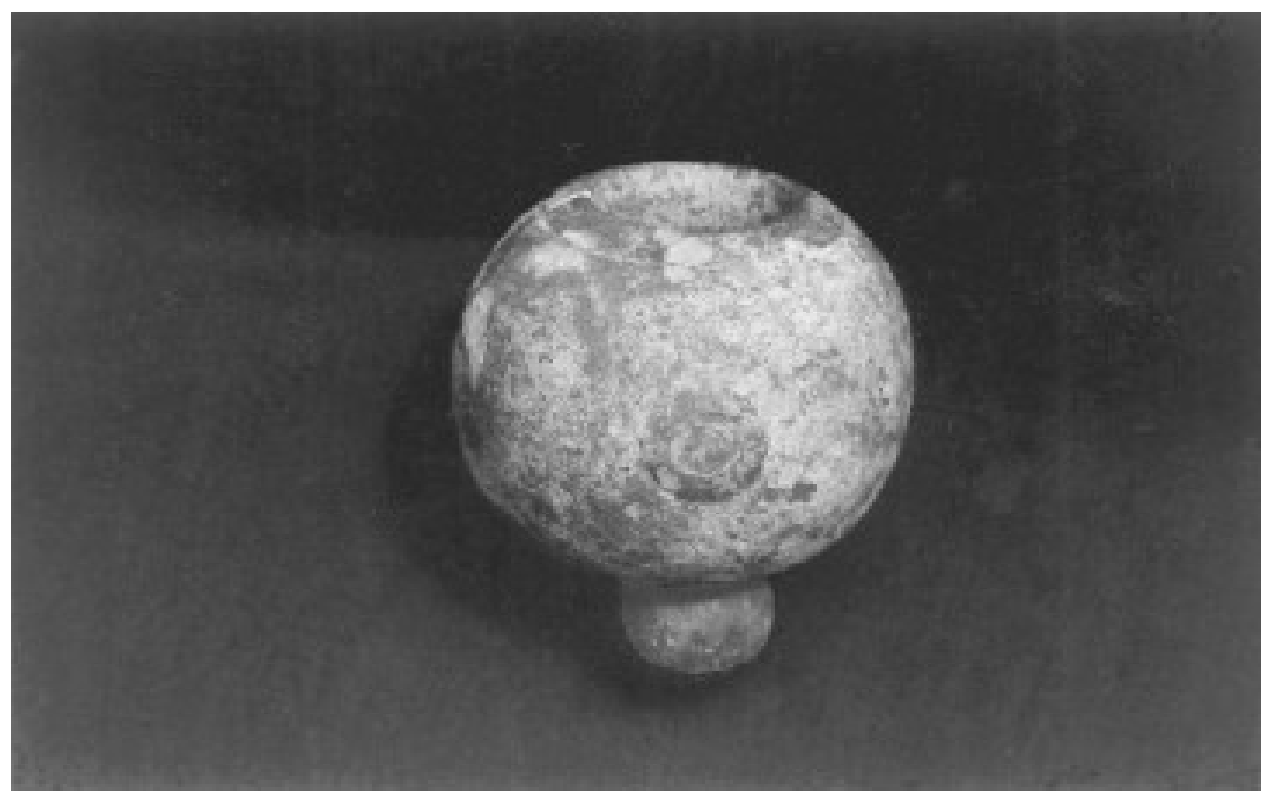

Fotografía 8. M asa tipo olmeca de $\mathrm{N}$ ueva E smeralda.

Los edificios triádicos alcanzan una al tura hasta de 45 metros y generalmente tienen mascarones y muchas veces cuatro escalinatas.

D urante el Preclásico superior los mayas formalizaron la construcción de tumbas, algunas de ellas tienen murales pintados en negro y azul sobre rojo, con evidencias de textos tempranos pintados en los muros.

Al parecer se dio un ascenso espectacular de los centros grandes que dominaron una región política y económica durante el Preclásico superior, como queda manifestado por el tamaño y cantidad de estructuras; sin embargo, al final del Preclásico ( $150 \mathrm{aC}-250 \mathrm{dC}$ ) se colapsaron todos estos centros y sus repercusiones se dejaron sentir en to da el área maya; seguramente éstos fueron los cimientos o antecedentes que sirvieron de base para el florecimiento de los grandes centros de la época Clásica en el Petén central.

En las pocas exploraciones realizadas en algunos lugares de la región chontal se han encontrado materiales del Preclásico. Por ejemplo, en EI Tigre se estudió en 1984 una subestructura (fotografía 9) que muestra un mascarón característico del Preclásico superior de la zona del Petén guatemalteco. En Xicalango, otro sitio importante de la región chontal, también se ha encontrado cerámica de ese periodo; en la cuenca del río U sumacinta medio, entre Tenosique y E miliano Z apata, y en la orillas del río San Pedro M ártir, también existen varios sitios de dicho periodo (cfr. H ernández y Álvarez 1978, H ernández 1981, 0 choa 1983 y 1985). 
Rands (1967) ya había propuesto que en estos lugares existía desde esa época una unión clara con el Petén. Dicha propuesta ha sido confirmada por los estudios que en el área se han realizado, encontrándose cerámica de las fases Premamón, M amón y Chicanel del Preclásico maya; parte de esa cerámica acusa un estilo local, lo cual indica que en la región existe una población autóctona de raigambre maya.

D urante esa época, en la región chontal, las poblaciones por lo general fueron pequeñas villas y aldeas sin templos ceremoniales, con la excepción de Povicuc, el cual tenía una plataforma o montículo que no fue utilizado con fines de habitación.

El patrón de asentamiento en ese momento se localizaba a lo largo de los ríos y orillas de las lagunas; para su subsistencia parece que dependían básicamente de la pesca, como lo indican los hallazgos de restos orgánicos de pescado, cocodrilo, tortuga y caracol. La cacería y la agricultura quizás fueron complementarias.

Es todavía difícil sacar conclusiones respecto a la organización social de esta etapa, pues los materiales arqueológicos no reflejan una marcada es-

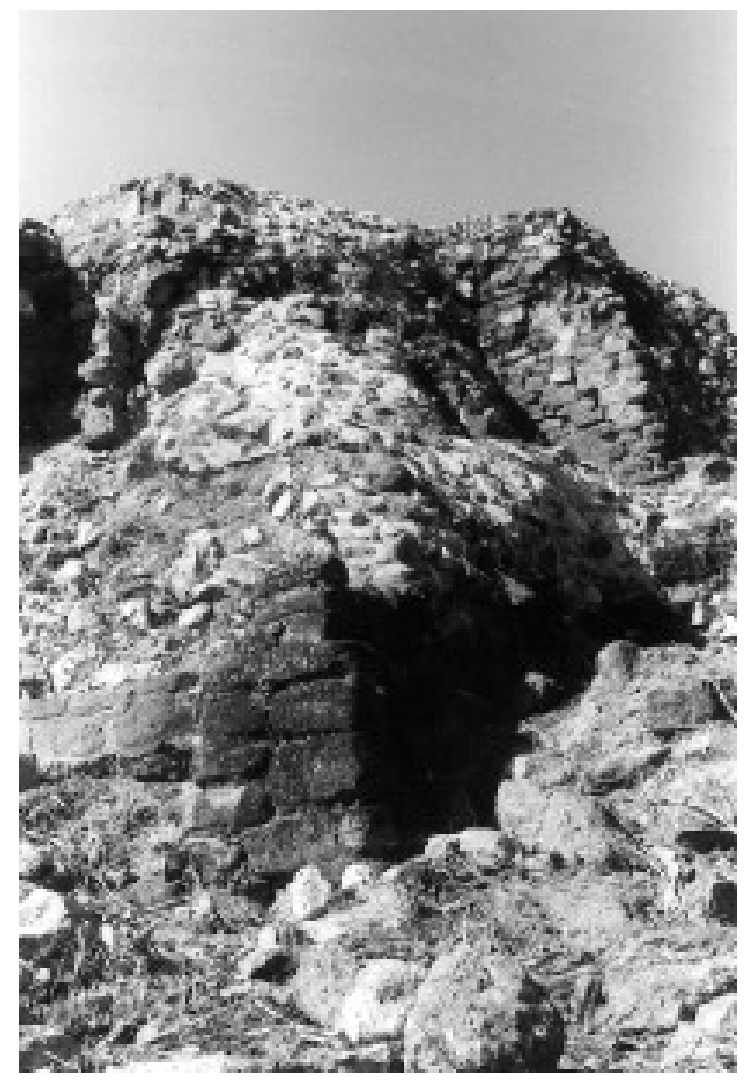

Fotografía 9. EI Tigre, subestructura de la Estructura 2. 
tratificación social, aunque se pueden apreciar ciertos indicios de una diferenciación.

A pesar de no existir estudios detallados de la región de Tabasco para el Preclásico, sostenemos que existe una presencia clara de los olmecas y una ocupación en toda la región que refleja una cultura diferente a la de éstos, así como relaciones con otras áreas.

D e acuerdo con los datos que tenemos en la actualidad, concluimos que los primeros grupos asentados en la región eran portadores de las tradiciones proto olmeca y olmeca. $\mathrm{H}$ acia el 800-400 aC al parecer las tierras bajas centrales constituyeron un centro de interés e innovación. Alrededor del $400 \mathrm{aC}-200 \mathrm{dC}$ la región estuvo claramente orientada hacia las influencias que venían del Petén (cfr. H ernández 1981, C asasola 1979, O choa 1985).

L a escasez de materiales arqueoló gicos impide sacar mayores conclusiones, pero apunta a señalar que la ocupación se inició durante el Preclásico temprano, aumentó durante el Preclásico medio y llegó a su apogeo durante el Preclásico tardío.

La región fue habitada desde entonces por una población autóctona que se asentó a lo largo de los ríos y a orillas de las lagunas; con lo que ese tipo de asentamiento, tan característico de los chontales, se remonta en la región a miles de años.

En contraposición con lo dicho sobre sitios de la región chontal, en EI Tigre se han excavado tres estructuras que denotan la importancia del sitio durante el Preclásico superior. Como dijimos, en 1984 se excavó la E structura 2 y se encontró un mascarón del tipo característico de U axactún, la estructura mide aproximadamente $20 \mathrm{~m}$; asociada con el mascarón se encuentra cerámica característica del Preclásico superior. En 1997-98 también se excavó la Estructura 1, en donde apareció la parte frontal de un edificio de esa época. Por otra parte, la cerámica encontrada, Sierra Rojo y los otros tipos característicos, corresponde claramente al Preclásico superior, lo que hace suponer que EI Tigre era ya una ciudad importante con edificios monumentales y grandes plazas, que dominó seguramente el comercio del río Candelaria, y para ese entonces se ligaba más con el Petén guatemalteco.

U na de las características de los sitios arqueológicos de los mayas del Petén central durante el periodo Preclásico superior ( $300 \mathrm{aC}$ a $250 \mathrm{dC}$ ) es la combinación de la escultura con la arquitectura en la decoración de las fachadas de los templos, con la representación de grandes mascarones modelados en estuco y pintados de varios colores (crema, rojo y negro). L as representaciones más favorecidas en ese tipo de mascarones se refieren a jaguares, serpientes, lagartos, aves y/ o una combinación de las mismas creando una especie de monstruos, que sin lugar a duda evocan a los ancentros comunes y deidades telúricas o del inframundo. 
En EI Tigre, la localización de mascarones en contextos ceremoniales de subestructuras, es decir, integrados a los templos piramidales, presupone su utilidad religiosa. La orientación de sus fachadas hacia el interior de los patios y la preferencia hacia los puntos específicos del horizonte resalta su importancia simbólica y cosmológica. Y la composición tripartita de los elementos constitutivos (orejera-rostro-orejera) que flanquean el acceso a los templos, es una tradición proveniente del Petén que se extiende hasta el norte de Yucatán. Por lo tanto, la particularidad de los mascarones debe ser vista como parte de un largo proceso de aceptación y profusión en el que los elementos constitutivos, la disposición y la escala de manejo, son variaciones de un mismo sistema de valores que se refleja también en una larga tradición alfarera (Vargas, D elgado y M ugarte 2000).

L a Plataforma $1 C$ sub, que es la que porta los mascarones, tiene un solo cuerpo o nivel y, al parecer, sólo tenía una escalinata en la fachada sur. Es difícil reconocer si los recintos fueron techados con mampostería o con palmas de guano debido a que sólo quedaron los pisos; sin embargo, es casi seguro, por la época a que nos referimos, que eran de materiales perecederos.

La reconstrucción de la Plataforma $1 C$ sub, en la Plataforma $1 C$, ilustra la situación de los mascarones y el estilo típico del Petén en los taludes y el remetimiento de las esquinas. Los mascarones están dispuestos a los lados de una escalinata central (figura 6).

L os mascarones 1 y 2 son contemporáneos con el M ascarón 3, pues los niveles de los pisos son los mismos; estos mascarones, como dijimos, son muy comunes en todo el Preclásico superior en casi toda el área maya de las tierras bajas. A parecen asociados con la cerámica Sierra R oja que es característica de ese periodo, pero no es un marcador seguro pues abarca tanto el Preclásico superior como el Protoclásico.

A partir de los estudios cerámicos realizados en EI Tigre hemos definido cinco complejos ( cuadro 1 ). L as evidencias más tempranas corresponden al Preclásico medio y principios del Preclásico superior, y lo hemos llamado Complejo Auxaual. Este complejo debe entenderse en principio como hipotético, porque por el momento no tenemos evidencias arquitectónicas, a no ser una subestructura en la E structura 1, que bien podría ser del Preclásico medio. Las evidencias cerámicas en que nos basamos para definirlo, numéricamente son poco representativas, sin embargo indican el comienzo de una ocupación importante en el sitio. Cerca de El Tigre se encontró material característico de este complejo en el sitio conocido como N ueva E smeralda, de allí proviene una figurilla y una «masa» típicamente olmeca.

Algunos de los tipos son: J uventud rojo: Jolote; D esvario chamfered: no especificada; Pital crema: Blotchy; Paso danto inciso: no especificada; pertenecientes a los complejos A cachén, San Félix y Chun Yaxchic, que se fechan por comparación con otros sitios tan tempranamente como el 600 


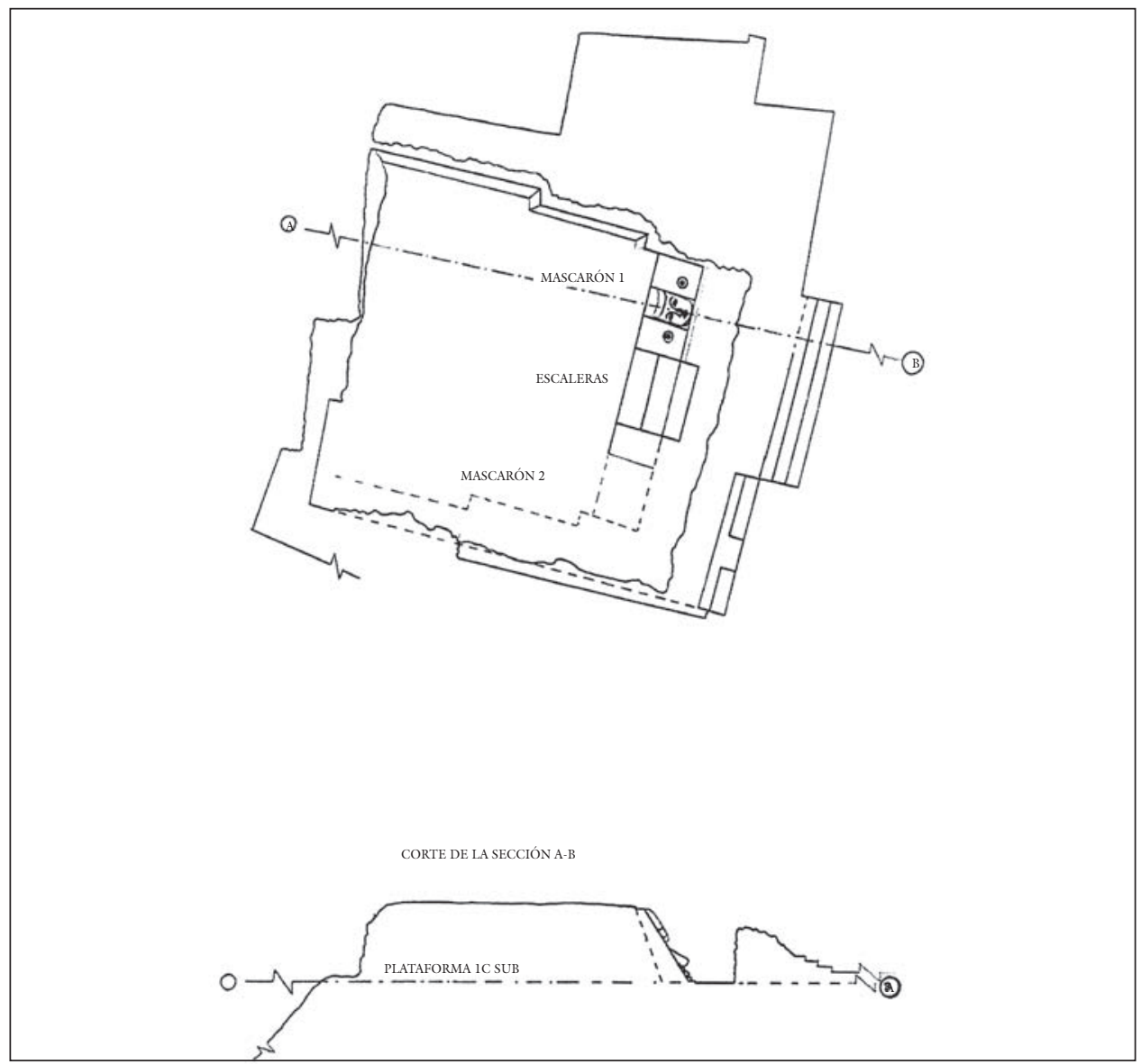

Figura 6. Planta y corte de la plataforma IC y lC Sub (J. Mugarte).

aC; por lo tanto suponemos que los primeros habitantes de El Tigre debieron haber llegado hacia esas fechas. Los otros tipos de este complejo pertenecen tanto al Preclásico medio como al Preclásico tardío.

El segundo complejo lo hemos llamado Pachimalays, y los materiales parecen representar dos facetas: la primera de ellas posiblemente arranca desde el Preclásico tardío y la segunda pertenece al Protoclásico. La primera faceta es plenamente identificable con los grupos cerámicos Sapote, Negro, Flor, Morfín y Sierra. Por ello, esta faceta debe entenderse como importante para El Tigre, pues no sólo existen los materiales cerámicos, sino también se tiene arquitectura monumental, perfectamente registrada en las estructuras 1 y 2 . En la primera hemos explorado parte de una sub-estructura que debió alcanzar $10 \mathrm{~m}$ de altura; mientras que en la segunda estructura se exploró una subestructura que apareció en la parte superior como consecuencia de un saqueo, mostrando restos de arquitectura y un mascarón característico del Petén guatemalteco. 
Cuadro 1. Cuadro cronológico.

\begin{tabular}{|c|c|c|c|c|c|c|c|}
\hline AÑOS & PERIODOS & EDZNÁ & BECÁN & CALAKMUL & EL TIGRE & COBÁ & ALTAR \\
\hline \multirow{11}{*}{\begin{tabular}{|l|}
1500 \\
1400 \\
1300 \\
1200 \\
1100 \\
1000 \\
900 \\
800 \\
700 \\
600 \\
500 \\
400 \\
300 \\
200 \\
100 \\
a.C. \\
d.C. \\
100 \\
200 \\
300 \\
400 \\
500 \\
600 \\
700 \\
800
\end{tabular}} & $\begin{array}{l}\text { Posclásico } \\
\text { tardío }\end{array}$ & Cuartel & Lobo & $?$ & \multirow[t]{2}{*}{$\begin{array}{l}\text { Paxbolom } \\
\text { Acha }\end{array}$} & {$\left[\begin{array}{l}--- \\
\text { Seco }\end{array}\right.$} & ? \\
\hline & $\begin{array}{l}\text { Posclásico } \\
\text { temprano }\end{array}$ & \multirow{2}{*}{ Catedral } & \multirow[b]{2}{*}{ Xcocom } & \multirow{3}{*}{$\mathrm{H}$ alibe } & & \multirow[b]{2}{*}{ Oro } & Jimba \\
\hline & Clásico & & & & \multirow{3}{*}{ Paxua } & & Boca \\
\hline & $\begin{array}{l}\text { terminal } \\
\text { Clásico }\end{array}$ & \begin{tabular}{|l} 
M uralla \\
Agua
\end{tabular} & \begin{tabular}{|l|} 
Chintok \\
\end{tabular} & & & & Chixoy \\
\hline & tardío & potable & Bejuco & $\mathrm{Ku}$ & & Palmas & Veremos \\
\hline & \multirow{2}{*}{\begin{tabular}{|l|} 
Clásico \\
temprano
\end{tabular}} & \multirow{2}{*}{ Poderes } & Sabucán & \multirow{2}{*}{ Kaynikte } & \multirow{2}{*}{ Champel } & Blanco & \multirow{2}{*}{ A yn } \\
\hline & & & Chacsik & & & \multirow{2}{*}{ Añejo } & \\
\hline & $\begin{array}{l}\text { Proto- } \\
\text { clásico }\end{array}$ & Cepos & \multirow[b]{2}{*}{ s Pakluum } & \multirow[b]{2}{*}{ Takan } & \multirow{2}{*}{$\begin{array}{l}\text { Pachi- } \\
\text { malays }\end{array}$} & & Salinas \\
\hline & $\begin{array}{l}\text { Preclásico } \\
\text { tardío }\end{array}$ & Baluartes & & & & - - - & Plancha \\
\hline & $\begin{array}{l}\text { Preclásico } \\
\text { medio }\end{array}$ & M alecón & \multirow{2}{*}{ Acachén } & Zihnal & Auxaual & & San Félix \\
\hline & $\begin{array}{l}\text { Preclásico } \\
\text { temprano }\end{array}$ & & & $?$ & $?$ & & $\mathrm{Xe}$ \\
\hline
\end{tabular}

Los habitantes de EI Tigre debieron ocupar el sitio desde entonces, para dominar, en primer lugar, un islote que no se inunda y, en segundo, gran parte del río Candelaria, ruta de comunicación importante para salir desde el Petén hacia el Golfo de M éxico. El sitio se localiza estratégicamente, para dominar el comercio hacia la Laguna de Términos, y tener el control de los ríos Caribe y San Pedro.

Por lo que sabemos hasta ahora, el sitio arqueológico, para esta primera faceta, estuvo más ligado al Petén que a la costa; hacemos esta inferencia apoyados en los mascarones y en la cerámica característica de dicha época, observación que con anterioridad había hecho $\mathrm{R}$ ands acerca de la región de Palenque.

En la faceta tardía el sitio siguió funcionando casi igual que en la anterior; ésta se sitúa entre finales del Preclásico tardío y principios del Clásico temprano, lapso que aso ciamos tentativamente con el Protoclásico. É ste se refiere al intervalo entre los años $100 \mathrm{aC}$ al $250 \mathrm{dC}$. Algunos autores lo asocian con el surgimiento del Clásico maya; y por último, otros lo definen como una moda cerámica caracterizada por los soportes mamiformes, técnica decorativa del negativo, cerámicas monocromas de color naranja e introducción de la policromía. 
Esta faceta se caracteriza por los grupos: Sierra, N olo, Caribal, Xanabá, Tolok y Sabán, pertenecientes a los complejos Pakluum, Plancha, Takán y Añejo, definidos para los sitios de B ecán, Altar de Sacrificios, C alakmul y Cobá (Vargas y D elgado 1999).

\section{EL CLÁSICO}

Los mayas, como otros pueblos de M esoamérica, llegaron a su esplendor durante el Clásico. En la región chontal de la sierra florecieron gran cantidad de sitios mayas, así como en la zona del U sumacinta medio, a orillas del río San Pedro M ártir, en la costa y en la cuenca del río Candelaria.

El uso de estelas con personajes y textos tiene sus antecedentes en lugares como A baj Takalik, Kaminaljuyú y EI Portón. En las tierras bajas, al parecer, se inició a partir del Preclásico superior, en monumentos como la Estela 1 de $\mathrm{N}$ akbé, fechada al rededor del año 300 aC; la Estela 2 de EI $\mathrm{M}$ irador, un poco más tardía y la Estela $\mathrm{H}$ auberg correspondiente al 197 $\mathrm{dC}$. Éstas se convirtieron hacia el $300 \mathrm{dC}$ en el lugar ideal donde los gobernantes se hacían admirar acompañados de dioses y antepasados, con gran alarde de su grandeza, su linaje y en algunas ocasiones también de su heroísmo guerrero.

Es importante señalar y aclarar desde ahora que durante la ocupación del Preclásico y Clásico no puede hablarse del grupo lingüístico chontal, porque no se había separado de la lengua cholana. También podemos decir que en las provincias de Tabasco, Xicalango y Acalan, casi no existen registros de fechas en estelas; ésta podría ser una característica de la región en contraposición con el Petén.

Durante el Protoclásico y Clásico temprano la ocupación del área es escasa, lo que señala quizás una disminución de la población. En el Petén guatemalteco el fenómeno es diferente; por ejemplo en la Estela 29 de Tikal (292 dC), que tiene la fecha de 8.12.14.8.15 (13 men 3 zip), aparece el glifo emblema en su forma habitual, lo cual da testimonio de la antigüedad de Tikal como capital de su provincia; no se han encontrado otros glifos emblemas en textos de ese periodo temprano.

L as estelas del C lásico temprano se conocen por su fino e inciso trabajo escultórico en sus cuatro caras. Éstas corresponden en Tikal al reinado de Sian C haan K'awil y de su sucesor inmediato Kan A k 'Jabalí Amarillo'; al parecer de algunos autores este perio do coincide con su «época de gloria». Sian $\mathrm{C}$ haan $\mathrm{K}^{\prime}$ awil, décimo primer soberano, fue sepultado en el entierro 48 descubierto dentro del Templo 33 de la Acrópolis N orte, al oriente de la tumba de su padre. El título de ahau se le confirió el 27 de noviembre del 411 , pero no llegó al trono sino hasta el 1 de febrero del 426, cuando accedió como nuevo soberano de Tikal, obteniendo así el título de chakte. Su 
gobierno alcanzó los 30 años de duración; murió en el 456 y aparece representado en las estelas 1, 2, 28 y 31 (Valdés, Fahsen y M uñoz 1997: 22); él registra el primer katún 8 ahau que corresponde a un fin de baktún.

La E stela 31 fue enterrada en la E structura 5D-33-2 y así se preservó de los el ementos natural es y de posibles daños perpetrados por el hombre; tiene uno de los textos más complicados en el corpus de inscripciones mayas. Tatiana Proskouriakoff (1996: 28-30) habla, entre otros muchos acontecimientos narrados en la estela, de la llegada de los extraños a Tikal y cita a dicha estela como prueba de ello. El individuo vestido lujosamente puede identificarse como un típico gobernante maya, mas los otros dos individuos armados con escudos, lanzadores y flechas visten lo que ha sido descrito como trajes «mexicanizados» o de «Teotihuacan». Algunos autores piensan en la subordinación entre grupos culturales o entre ciudades mexicanas y mayas (Coe 197: 99-102); otros han sugerido que un grupo cultural extranjero vino con el gobernante llamado ' $\mathrm{N}$ ariz C urva', padre de Sian $\mathrm{C}$ haan K 'awil, y ocupó Tikal (Coggins 1975: 140-5).

Todavía no se ha establecido con certeza la naturaleza exacta de los contactos entre estas áreas y culturas. D urante el periodo C lásico temprano había muchos elementos mexicanos en el área maya incluido Tikal, así como en Kaminaljuyú y en varios sitios de la costa del Pacífico, lo que hace suponer una fuerte influencia teotihuacana sobre el área maya. Al mandar hacer la Estela 31, Sian C haan K'awil trató de legitimar su poder a través de una conexión ancestral y de la imitación de un antecesor, más que por la fuerza militar o de la conquista.

Parecería que la estela representa ese contacto entre las dos culturas, pero quedan muchas preguntas sin respuestas, como ¿quiénes eran esos extranjeros?, ¿desde cuándo estaban en el Petén? A nosotros nos interesan los hechos descritos en la Estela 31, pues a partir de allí se introduce la práctica, muy común entre los itzaes, de conmemorar el acontecimiento del katún 8 ahau.

Proskouriakoff (1996: 34-6) opina que posiblemente después de la muerte del rey extranjero ('¿N ariz Rizada?') su ejército se rindió al nuevo monarca Sian Chaan K'awil. En Tikal el reinado de Sian Chaan K'awil cubrió el cambio de ciclo (9.0.0.0.0; $435 \mathrm{dC})$, en donde se aprecia un cambio de política y de actitud del arte oficial. Todo parece indicar giros muy profundos que no se pueden explicar adecuadamente a menos de que se diera una revolución en la estructura del poder central (ibidem: 41).

Al final del gobierno de Kan A k en Tikal algunas ciudades lejanas empezaron a erigir su primeras estelas, por ejemplo, Caracol, Yaxchilán con la Estela 27 y Calakmul, todas posteriores al ciclo (9.4.0.0.0), lo cual puede indicar que aunque no tuvieran un gobierno central, sí reconocían la unidad de sus tierras y de su pueblo (ibidem: 51 ). 
D espués del reinado de Sian C haan K'awil, que llevó a la ciudad de Tikal a un esplendor importante, empezó un periodo de decadencia al que Proskouriakoff llama «tiempos difíciles»; en éste no se construyeron edificios, ni tumbas ricas, ni monumentos; sin embargo, esto no significa que la ciudad estuviera abandonada. Pareció hundirse en una oscuridad relativa entre la comunidad de ciudades mayas que surgieron en regiones periféricas. Con base en los textos jeroglíficos disponibles actualmente, ninguna ciudad en las tierras bajas menciona a Tikal entre los años 507 y 652 ( $M$ arcus 1976: 71). A partir de esas fechas se da un gran crecimiento y expansión, ciudades como C alakmul, que dominó el sur de Campeche, llegó por estos tiempos a su pleno florecimiento. Posiblemente su ubicación estratégica, con acceso a la $L$ aguna de Términos por el río $C$ andelaria, haya contribuido sustancialmente a su prosperidad, pues era una ruta comercial importante que cayó bajo su poderío.

Por lo poco que se sabe de Acalan, se nota que el Clásico temprano (200$600 \mathrm{dC}$ ) no fue muy relevante. Sin embargo, hacia el final de este perio do se inició la manufactura de la cerámica de pasta fina Belisario Anaranjado sobre Crema y Barí Bicromo, en varios sitios de las tierras bajas noroccidentales (C asasola 1979: 8). Rands (1967) da cuenta en Trinidad, hacia esa época, de los tipos de pasta fina. Se trata de cerámicas de pasta color crema que anteceden a los tipos de los grupos Altar y Tres $\mathrm{N}$ aciones, que son característicos de los chontales arqueológicos; por lo tanto, proponemos que los chontales debieron estar ahí desde mucho antes, es decir, desde el Clásico por lo menos.

$\mathrm{L}$ a restauración de Tikal como gran centro religioso de las tierras bajas mayas fue un acontecimiento de enorme importancia y está marcado por la subida al poder de H asaw C haan K'awil (Ah Cacau). Su coronación fue el 6 de marzo del $682 \mathrm{dC}(9.12 .9 .17 .16)$, diez años después del comienzo de un nuevo katún 8 ahau que, de acuerdo con las profecías, debía ser un periodo de revitalización con la introducción de líderes carismáticos que llevaran a la prosperidad y al éxito a Tikal. $\mathrm{H}$ asaw $\mathrm{C}$ haan $\mathrm{K}$ 'awil realizó victoriosas batallas y alianzas matrimoniales, y de esa manera aseguró su poder para después desplegar un ostentoso ritual nativista, durante el cual se restableció la práctica de erigir estelas esculpidas y altares ( $D$ ahlin 1986: 94-97).

$\mathrm{H}$ asaw $\mathrm{C}$ haan K'awil tenía el gran compromiso de celebrar los ciclos históricos y proféticos señalados por los finales de katún 8 ahau; estas prácticas las hizo más espectaculares, como para que certificaran pública y periódicamente sus derechos; así construyó los complejos de pirámides gemelas, la Estela 30 que lo representa y el Altar 14 que lleva el final 9.13.0.0.0 katún 8 ahau $8 \mathrm{U}$ o (692 dC). Estas prácticas no son iniciadas por este ahau, sino son introducidas con la llegada de 'N ariz Rizada' a Tikal.

Sian C haan K'awil, uno de los principales señores de Tikal, había subido al poder en el katún 8 ahau anterior, es decir 260 años antes; para enfatizar su identidad, $\mathrm{H}$ asaw $\mathrm{C}$ haan $\mathrm{K}$ 'awil mandó registrar en el $\mathrm{D}$ intel 3 del 
Templo । el aniversario del décimotercer katún de una fecha desconocida, pero obviamente importante, que estaba registrada en la Estela 31; allí fue enterrado, en el propio centro de la vida pública ritual de Tikal. M urió en el $734 \mathrm{dC}$ después de haber mejorado y restablecido el poderío de Tikal que había tenido una larga decadencia. Este fortalecimiento siguió adelante con su hijo, aunque la decadencia cultural en todos los aspectos de la vida se hizo evidente cerca de 75 años posteriores a su muerte y, aproximadamente en otros 20 años, se puede decir que Tikal estaba en situación de colapso (Culbert 1973: 89).

Según el D intel 3 del Templo । de Tikal, $\mathrm{H}$ asaw $\mathrm{C}$ han $\mathrm{K}$ 'awil, mandó a grabar una inscripción que se ha leído como la captura y sacrificio de Yukom Y ich'ak K'ak' 'Garra de Jaguar', uno de los gobernantes más connotados del reino de la Cabeza de Serpiente, C alakmul. El año 695 (Carrasco y Boucher 1999: 1-15) fue testigo de la guerra entre Tikal y Calakmul: se enfrentaron Y ukom Y ich'ak K 'ak', que había subido al trono 4 años después que su rival, y $\mathrm{H}$ asaw $\mathrm{C}$ han $\mathrm{K}$ 'awil (9.12.13.17.7, abril 6 del 686); al parecer el primero fue capturado y sacrificado por $\mathrm{H}$ asaw $\mathrm{C}$ han K'awil.

$L$ as exploraciones realizadas por $C$ arrasco et al. en $C$ alakmul han podido identificar que Y ukom Y ich'ak K'ak' está enterrado en la Tumba 4 de la Estructura 2; y que el texto del Dintel 3 del Templo । de Tikal narra la derrota del linaje de la casa real de Calakmul, mas no su muerte. El glifo emblema de la Cabeza de Serpiente deja de registrarse en los textos de otros sitios que fueron sus aliados y su política se reorienta hacia el norte de las Tierras Bajas M ayas, principalmente hacia sus vecinos del área Río $\mathrm{Bec}$, que en ese momento estaba en pleno auge. Estos acontecimientos sin lugar a duda debieron afectar la región de Acalan.

D urante el Clásico tardío (600-850 dC), tanto en la sierra como a orillas del río San Pedro M ártir, en la costa y sobre el río C andelaria se llega a un gran esplendor. Muchos fueron los asentamientos en el área. Algunos de ellos presentan escultura, arquitectura, inscripciones y estelas como El Tortuguero, EI A renal, R eforma, Santa Elena y EI Tiradero. En estos lugares como en otros muchos puede apreciarse la relevancia que tuvo la cultura maya.

Para esa época la importancia de la región chontal era periférica, pues el mayor desarrollo se había dado en el Petén con sitios tan importantes como Tikal, Calakmul, U axactún y EI M irador. En la zona chontal se iniciaba la elaboración de la cerámica anaranjada fina, precursora de los tipos Balancán, Altar y Tres $\mathrm{N}$ aciones, que después fueron característicos de ese grupo.

EI Clásico temprano se encuentra representado pobremente en EI Tigre y lo hemos nombrado como Complejo Champel, los tipos que lo determinan son: Triunfo estriado: Aliso; Candelaria aplicado: N o especificado y Balanza negro: Balanza; pertenecen al Complejo Chacsik definido para Becán, que corresponde a la fase inicial del Clásico temprano. 
Los tipos Triunfo estriado, Aguila naranja, Pucté café y Quintal sin engobe, son característicos del Clásico temprano; mientras que los tipos Sabán burdo, Pucté café, Balanza negro, F alcón towny brown, M una pizarra, Subín rojo y Tinaja rojo son propios del Clásico temprano y algunos de ellos son más importantes durante el siguiente complejo.

En el Complejo Champel encontramos dos fases, una temprana y otra tardía, con la característica, de que al parecer, la región para esos momentos no tiene una ocupación importante. $\mathrm{H}$ asta ahora, no hemos explorado ningún resto arquitectónico característico del Clásico temprano.

Los grupos cerámicos descritos para este complejo son: Blanco, Ayn, Kaynikté, Chacsik, Sabucán, Bejuco, Chintok, Veremos, Chixoy y Pasión, definidos para los sitios de Becán, Cobá, Altar de Sacrificios y Calakmul (Vargas y D elgado 1999).

\section{El Clásico terminal. El auge de la región chontal}

Este momento es de singular relevancia en el proceso de desarrollo cultural de la región, ya que durante éste y el siguiente periodo se alcanzó la máxima densidad de población, surgió toda una serie de tipos cerámicos e inició una tradición cultural que caracteriza al grupo chontal. E sta etapa se encuentra asociada con la llegada de los itzaes a C hakamputún, por el 700; la caída de Calakmul; y los grupos de linaje que salieron posteriormente de la C hontalpa hacia Guatemala y Yucatán.

Por la cerámica se puede inferir que estos grupos fueron portadores de una vigorosa tradición alfarera de anaranjado fino y gris fino, que se fue introduciendo gradualmente desde J onuta, pasando por Palenque, Piedras N egras y Yaxchilán, hasta Ilegar a Altar de Sacrificios y Seibal. Este nos indica el gradual control de las rutas comerciales en todas estas zonas por grupos que pueden ser caracterizados como chontales (Casasola 1987: 305).

D urante el Clásico terminal aparecieron por primera vez los tipos de pasta fina de los grupos A Itar, T res $\mathrm{N}$ aciones, A chote y Balancán (fotografía 10); a medida que avanzó este periodo, dichos grupo s cerámicos se generalizaron en toda la región y algunos sitios alcanzaron un gran desarrollo; tal es el caso de N ueva Esperanza, Povicuc, El Arenal, O axaca, EI Encanto, EI Pájaro y Allende, entre otros. EI uso generalizado de esta cerámica se dio en el bajo y medio U sumacinta, L a Chontalpa, Sierras Bajas, zona del río San Pedro Mártir y área del San Pedro y San Pablo, Xicalango y río C andelaria.

Muchos de los habitantes de las grandes ciudades como Palenque y algunos de las sierras salieron hacia las orillas de los ríos y la costa, rutas comerciales conocidas desde antes. Aquí cabe resaltar que estos grupos llegaron a la región desde finales del Clásico tardío y tuvieron su máximo 


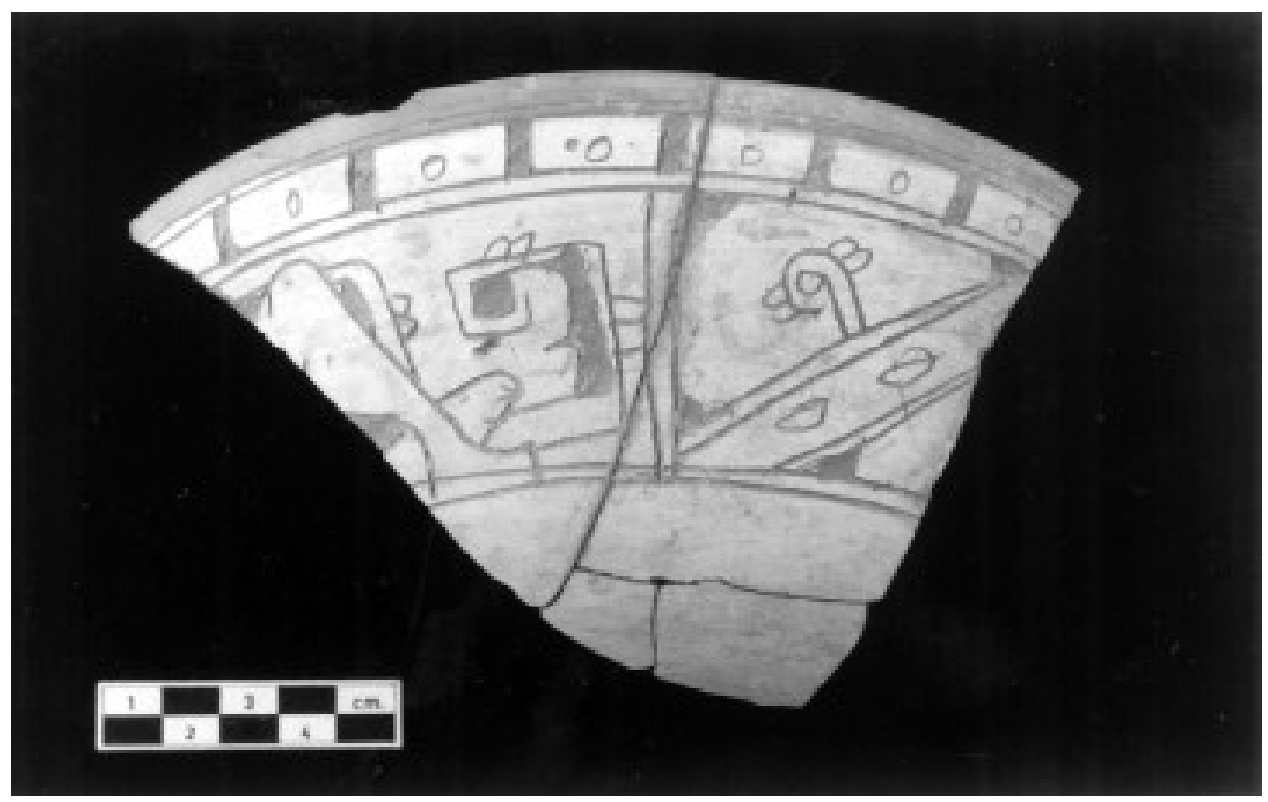

Fotografía 10. Cerámica chontal.

florecimiento durante el Clásico terminal: asimismo se dio un cambio de orientación en el patrón de asentamiento, consistente en el abandono masivo de su población para establecerse en las orillas de los ríos y dominar las rutas fluviales.

Por medio de reconocimientos de superficie que se hicieron en dichos ríos se ha podido constatar que la llegada de esos grupos coincide con un aumento de las actividades constructivas en esa zona; aparece la cerámica anaranjada fina tipo Balancán y Altar, Ias figurillas de un estilo característico de la región y las inscripciones generalmente en la cerámica; no se vuelve a realizar su talla en estelas.

En toda la región de ríos y lagunas se construye una serie de ciudades, unas más grandes que otras, las cuales prueban que esa zona adquirió gran importancia durante este periodo, después de la caída de Palenque o hacia el final de su florecimiento cuando aún estaba ocupado. Entre estos sitios se pueden nombrar Comalcalco, El Pájaro, Allende, EI Encanto, O axaca, J onuta y otros muchos más, cuyas características son las construcciones de ladrillo y la cerámica anaranjada fina y gris fino.

Su economía se basó principalmente en el comercio y su poderío se extendió a gran parte del territorio actual de Tabasco y Campeche, y debió llegar hasta $\mathrm{N}$ aco y $\mathrm{N}$ ito, en $\mathrm{H}$ onduras, como nos lo dicen las fuentes históricas.

Por ser el comercio su principal actividad, contó con puertos tan importantes como Itzamkanac a orillas del río Candelaria, Tixchel a orillas del estero de Sabancuy, Xicalango y Potonchán, este último a o rillas del río 
Grijalva. Estos fueron sin lugar a duda, los puertos principales de los chontales en la región.

Poco es lo que se ha explorado. EI único ejemplo que se conoce de este estilo arquitectónico es Comalcalco (fotografía 11), pero suponemos que las demás ciudades tenían características similares, como son las construcciones de ladrillo para los templos palacios, muchos de ellos con bóveda; el uso del estuco para la construcción de pisos y paredes; la escultura a base de estuco; y ausencia de estelas e inscripciones al estilo clásico.

En la actualidad se han hecho varios trabajos en EI Tigre, y se ha explorado parte de las estructuras 1 y 2 , más dos estructuras habitacionales, Io que nos muestra que existen otras características propias de la región de la provincia de Acalan, ya que allí hay piedra y no se encuentra la arcilla para la construcción de ladrillos; posiblemente con el tiempo se pueda definir un estilo arquitectónico propio del río $\mathrm{C}$ andelaria.

Entre el 700-950 dC es cuando se da la mayor ocupación en la Provincia de Acalan; se registraron unos 180 sitios arqueológicos, ubicados en lugares estratégicos para controlar el comercio. D urante esa época disminuyó el comercio con el Petén y se acrecentó con la $L$ aguna de Términos y Yucatán; se dio un cambio de orientación en sus intereses.

El complejo Paxua señala la virtual desaparición de la influencia del Petén en la alfarería de EI Tigre. A partir de entonces empezó a desarrollarse la cerámica originaria de la región de los ríos y lagunas de TabascoC ampeche, aunque se haya iniciado anteriormente.

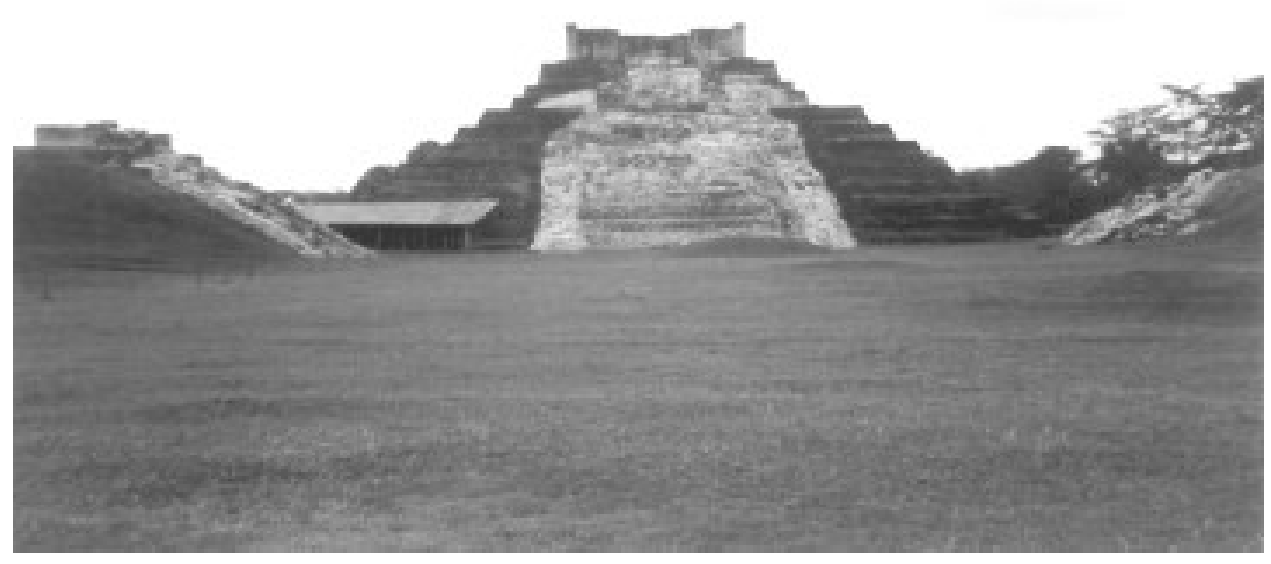

Fotografía 11. Comalcalco. 
Los marcadores más significativos de este complejo son las cerámicas Altar, Balancán y Tres $\mathrm{N}$ aciones, entre otras, caracterizadas por las pastas finas y su color naranja. También encontramos algunas cerámicas características de Yucatán, lo que podría interpretarse como nexos de la región chontal con la península.

Este complejo, que corresponde al J onuta definido por Berlin, abarca del $700 \mathrm{dC}$ hasta por lo menos el $950 \mathrm{dC}$; en él creo que pueden distinguirse tres facetas: la primera, relacionada con el Clásico tardío maya, está poco representada en el sitio; la segunda corresponde a aquellos tipos característicos del Clásico tardío y Clásico terminal y, por último, la tercera se relaciona con los tipos cerámicos Altar y Balancán, característicos del Clásico terminal. E stas tres facetas son de gran importancia porque se puede apreciar la evolución del grupo chontal en la región: vemos en primer lugar cerámica maya del Clásico asociada con cerámica fina que posteriormente fue característica de los chontales. Poco a poco se hizo más característica la cerámica anaranjada fina, que es la que distingue a los chontales de la región de Tabasco-Campeche.

Este complejo arranca desde el Clásico tardío. Al principio es poco representativo, pero más tarde llega a ser el más importante de la región. Los tipos que forman la fase más temprana de este complejo, asociado lógicamente con algunos de los tipos de la siguiente fase, son: Batres rojo, Corona rojo, grupo Corona; Grupo D zitbalché, N anzal y Blanquillo; Encanto estriado: Alambre y Pepino; Tinaja rojo: Paso R eal; todos característicos del Clásico tardío.

La segunda fase se caracteriza por aquellos tipos cerámicos pertenecientes tanto al Clásico tardío como al Clásico terminal, entre ellos están: Grupo Coyoc, Grupo Cuyero, varios tipos del Grupo Encanto, Grupo Tres $\mathrm{N}$ aciones, Grupo Balancán, Grupo Achote, Altar y Cambio sin engobe.

Los que forman la tercera fase son: el Grupo Tinaja, el C edro Acanalado del Grupo Altar, el Cumtún compuesto del Grupo Cambio y el Grupo D zibal.

El complejo Paxua es el más característico de la región, pues en esta etapa se construyen los principal es edificios de los sitios arqueológicos chontales, por lo tanto, lo que se ha explorado posiblemente pertenece a ese complejo (Vargas y D elgado 1999).

\section{EL PoSTCLÁsICO}

Este periodo presenta una marcada disminución de material arqueológico en comparación con el anterior, lo que probablemente indique un abatimiento de la población o desplazamiento hacia otras regiones de las Tierras Bajas M ayas. 
D urante el Postclásico, como lo señalan las fuentes históricas, el apogeo de esta zona se dio en la costa, en las provincias de Tabasco, Xicalango y Acalan. Los datos arqueológicos no demuestran auge en estos sitios durante este periodo; algunos florecen durante el Clásico terminal y tienen una ocupación desde el Preclásico. Solamente en Champotón se ha encontrado mayor ocupación durante el Postclásico. Los cronistas, al referirse a ésta, la mencionan como una población de mucha importancia. Sin embargo, los restos arquitectónicos no son muy significativos, aunque se obtuvo copioso material cerámico que denota un asentamiento muy denso.

La ocupación postclásica en el U sumacinta medio no va más allá del Postclásico temprano. Se ha hallado cerámica del grupo M atillas. Lo más tardío que se ha encontrado en la cuenca del río San Pedro data del Postclásico temprano (H ernández y Álvarez 1978, Vargas y H ernández 1979). En el bajo U sumacinta y en la cuenca del río San Pedro y San Pablo la ocupación durante este periodo también es mínima. Según las fuentes históricas, en la costa, la cuenca del río Candelaria y la península de Xicalango, es donde las actividades comerciales llegaron a tener mayor auge en este periodo.

Las fuentes históricas son un auxiliar muy importante para entender esta región durante el Postclásico tardío, pues registraron nombres de ciudades que seguramente funcionaban todavía en esa fecha. El aspecto cronológico es determinante, porque su desconocimiento ha provocado una mala interpretación y un desfasamiento que causan graves problemas para la comprensión en la historia. L as fuentes históricas del siglo Xvı afirman que la población era escasa, sin embargo, algunos autores sostienen que la región tenía mucha importancia para el Postclásico tardío; tal es el caso de Eric Thompson (1975: 167-8), quien al hablar de Xicalango dice que era uno de los mayores centros comerciales de América antigua, a donde acudían los mercaderes aztecas.

Con lo anterior no se quiere negar que Potonchán, Xicalango y Acalan coexistieran al momento del contacto y siguieran jugando un papel relevante en la zona, sólo hemos querido demostrar que el auge de la región de ríos y lagunas de Tabasco-C ampeche se dio durante el Preclásico y Clásico terminal. En el Postclásico temprano, posiblemente la desocupación de la región fuera bastante grande, mientras que para el Postclásico tardío empezó nuevamente a tener cierta importancia, recordando a la que había sido en tiempos anteriores.

Con la llegada de los magtunes a la región putún durante el Postclásico, ésta entra en una gran inestabilidad, los conflictos bélicos, al parecer, son frecuentes y se dan uniones transitorias para defender sus territorios; se crean nuevas organizaciones y otras desaparecen. Los acalanes conquistan Tenosique, la zona de la L aguna de Términos y Tixchel; posteriormente son obligados a salir del estero de Sabancuy y fundar I tzamkanac río arriba.

El complejo Paxbolom Acha marca el último periodo de ocupación prehispánica en la región de EI Tigre, y se halla estrechamente relacionado 
con la tradición de las cerámicas chontales finas del grupo $M$ atillas, alfarería característica del Postclásico tardío.

Lo que puede apreciarse a través de este análisis preliminar es que después del Clásico terminal, durante el Postclásico temprano, existió una aparente desocupación y en el Postclásico tardío se volvió a ocupar, concordando con las fuentes históricas que narran la llegada de los magtunes a la región, los cuales conquistaron primero Tenosique, después I sla del Carmen y Tixchel, en donde se asentaron por espacio de 80 años; de ahí fueron sacad os por los de Tabasco, Xicalango y C hampotón, viéndose obligados a poblar I tzamkanac, localizado río arriba.

La fecha que se establece para el abandono de Itzamkanac es 1557, cuando los pobladores fueron obligados por los frailes a abandonar el lugar para asentarse nuevamente en Tixchel.

Este complejo también tiene dos fases, una temprana y otra tardía. La primera está relacionada con la cerámica Altar que es de la fase anterior, pero al parecer algunos tipos de ese grupo sobreviven; mientras la segunda se caracteriza por la cerámica M atillas, que es del Postclásico tardío, y corresponde a la ocupación y auge de los acalanes (Vargas y D elgado 1999).

\section{Síntesis de la arqueología de la provincia de Acalan}

En la región chontal se registra una posible ocupación desde el Preclásico medio, siendo más clara en el Preclásico superior tanto a orillas del río C andelaria como en la costa. D el sitio arqueológico de N ueva Esmeralda proceden varias figurillas y un instrumento de piedra propios del Preclásico medio y posiblemente algunos materiales de EI Tigre también sean de esa época; además, al excavar un pozo estratigráfico en la Estructura 1 se localizó una plataforma a gran profundidad, que debe ser anterior al Preclásico tardío (figura 7). Como dijimos, el Preclásico superior es plenamente identificable en la región, pues tenemos arquitectura en las estructuras 1 y 2 ; en esta última se exploró parte de un mascarón característico de U axactún y Tikal; las estructuras arquitectónicas alcanzan una altura de hasta 20 metros, lo que nos indica su importancia.

La cultura chontal floreció desde el final de la ocupación de Palenque y llegó a su máximo esplendor durante el 800 dC hasta el Postclásico temprano. Su economía se basó principalmente en el comercio y su poderío se extendió a gran parte del territorio actual de Tabasco y Campeche, debió llegar hasta $\mathrm{N}$ aco y $\mathrm{N}$ ito, en $\mathrm{H}$ onduras, como nos lo dicen las fuentes históricas.

E $n$ la literatura histórica y antropológica se sostiene que el grupo chontal de Acalan es característico del Postclásico tardío y se cita como su gran capital a Itzamkanac. En este trabajo no se niega la ocupación del Postclásico, sin embargo se postula que esta gran capital prehispánica fue cons- 


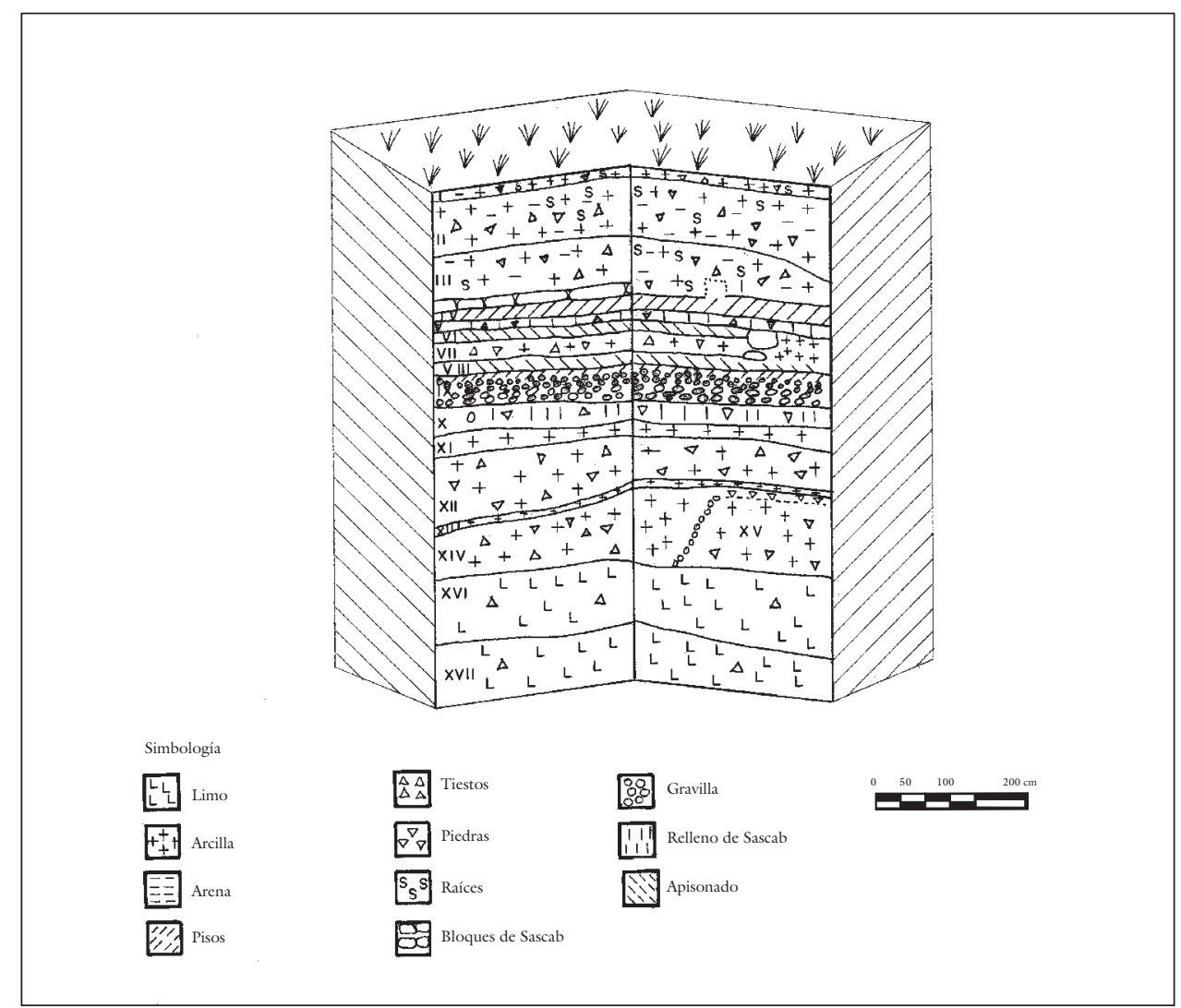

Figura 7. Pozo estratigráfico en la Estructura l (A. Delgado).

truida en el Preclásico, llegó a su máximo esplendor durante el Clásico terminal (700-1000 dC); y perduró hasta la llegada de los conquistadores. Por lo tanto, en este trabajo sostenemos que hacia 1525 los chontales ya habían perdido su grandeza y poderío de otros tiempos, y posiblemente hacía apenas unos 60 años que la gran capital de Itzamkanac estaba adquiriendo nuevamente fuerza y poderío.

Con respecto a la temporalidad, apoyados en los datos arqueológicos y lingüísticos (Schumann 1978 y 1985) podemos postular que la lengua chontal se separó de la cholana a finales del Clásico tardío (600-800 dC). Sin embargo, la tradición cerámica de pasta fina que antecede a los tipos de los grupos Altar, Balancán y Tres Naciones, entre otros, que es característica de la región y cristaliza en el Clásico terminal (800-1100 dC), se inicia desde antes.

Durante el Clásico terminal (800-1100 dC) se alcanza la máxima densidad de población en la región. Desde el punto de vista de la cerámica, existe una continuidad con respecto al complejo anterior y aparecen por 


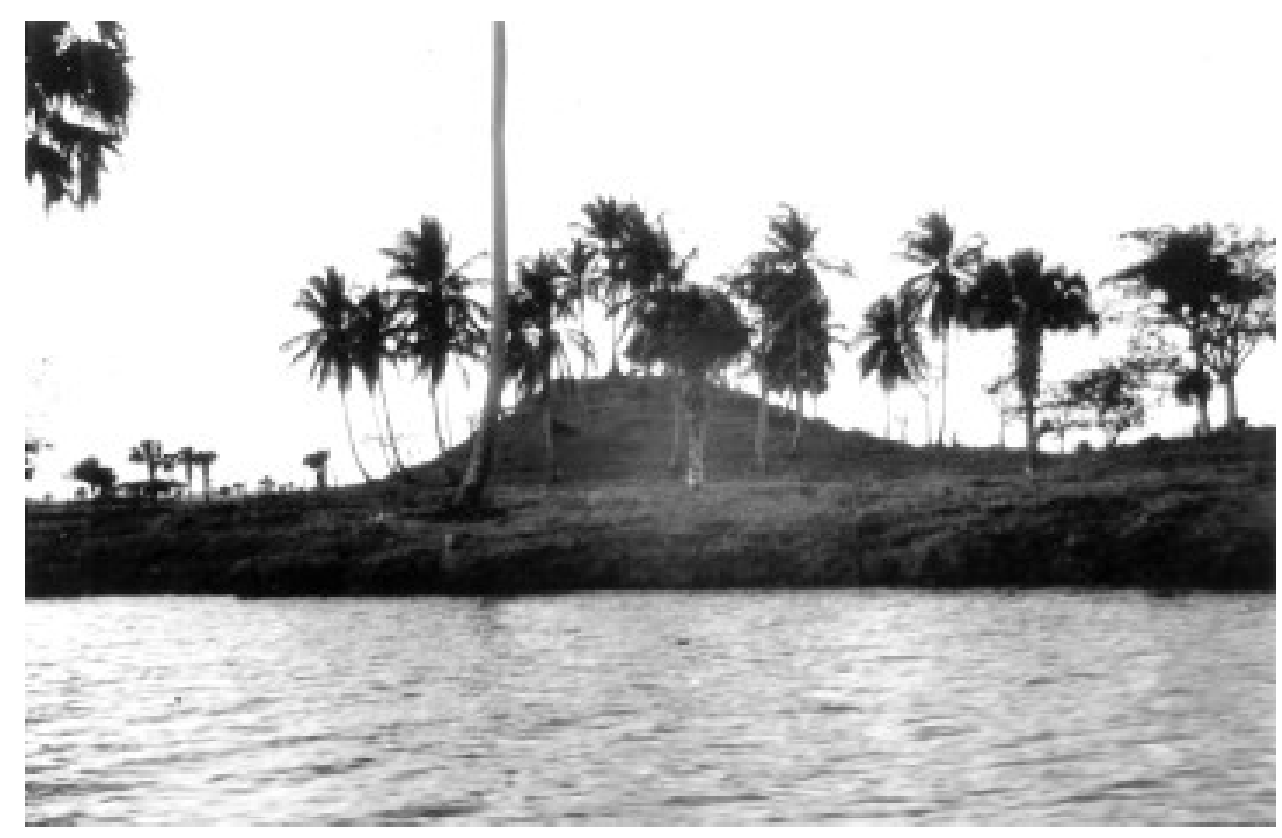

Fotografía 12. Río San Pedro y San Pablo, sitio construido con ladrillos.

primera vez los tipos de pasta fina de los grupos Altar, Tres $\mathrm{N}$ aciones, A chote y Balancán. A medida que avanza el Clásico terminal, estos grupos cerámicos se generalizan en toda la región y algunos sitios logran un gran desarrollo, todos estos son construidos con ladrillos y se localizan a orillas del río San Pedro y San Pablo (fotografía 12). El uso generalizado de esa cerámica se da en el bajo y medio U sumacinta, la C hontalpa, Sierras Bajas, zona del río San Pedro M ártir y el área del San Pedro y San Pablo, Xicalango y río $C$ andelaria.

A manera de conclusión, diremos que el análisis de las cerámicas arqueológicas de EI Tigre muestra una ocupación continua en la región, que se inicia a principios del Preclásico medio, es más importante en el Preclásico superior, disminuye hacia el Clásico temprano y tardío, aumenta considerablemente al final del Clásico tardío y llega a su máximo explendor durante el Clásico terminal. EI Postclásico temprano es pobre en ocupación, pero parecería que durante el Postclásico tardío, Acalan recupera importancia. 



\section{EL RÍO Y LA PROVINCIA DE ACALAN}





\section{Capítulo i \\ El Río Candelaria, ordenamiento Y PLANEACIÓN}

ORdENAMIENTO DEL ESPACIO Y PLANEACIÓN DE LOS POBLADOS

L os procesos de colonización en los tiempos prehispánicos dejaron vestigios regulares en el paisaje cultural. C on base en eso hechos hemos podido estudiar el ordenamiento de los asentamientos urbanos y rurales en el espacio, y su posición en relación con un lugar principal y con puntos específicosdesu entorno natural, como es, en primer lugar, el río; pero esto obedece, en gran medida, a la organización político-territorial de la sociedad magtún.

D a la impresión de que la mayoría de los sitios hubieran sido escogidos conscientemente por ser lugares destacados y estratégicos, con visibilidad sobre la mayor parte del río. La importancia de un lugar era sin duda mayor si a partir del mismo se podían dominar los meandros y otros sitios.

L a Chontalpa está surcada por innumerables ríos, pantanos y lagunas (fotografía 13) y expuesta a inundaciones por el desbordamiento de sus corrientes fluviales. Sus habitantes se asentaron en los bordos de terreno más consistentes y pronto se familiarizaron con los fenómenos meteorológicos característicos del área, de tal suerte que conociéndolos pudieron desarrollarse; no se aferraron a las limitaciones del lugar, ni se levantaron superando las carencias, sino que reconocieron su posición geográfica como lugar de ríos y lagunas, rodeados de riquezas no agrícolas que compensaron grandemente las muchas otras deficiencias de su territorio.

A esta área se le llamó la región de ríos y lagunas, es un enclave especial pues allí se encuentran dos de los más grandes ríos del sureste mexicano, el G rijalva y el U sumacinta, y la zona que ocuparon los chontales se caracteriza por ser de tierras bajas anegadizas, en donde se forma gran cantidad de lagunas, ciénagas y pantanos.

Esta característica es de singular importancia, ya que involucró a sus habitantes en una peculiar forma de aprovechamiento y utilización de los ríos como vías de comunicación; muchos de los sitios arqueológicos se localizan en sus márgenes a pocos metros del cauce, al filo de las aguas. 


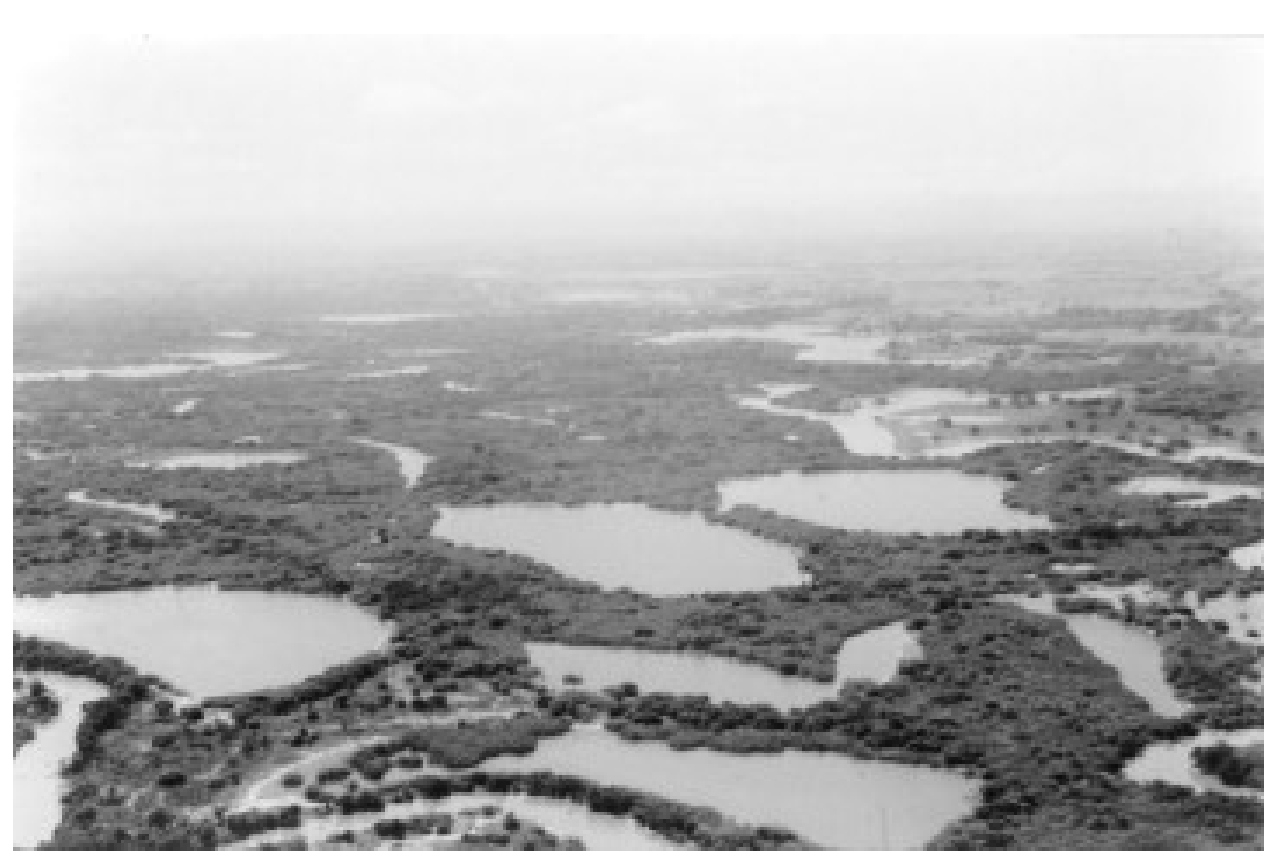

Fotografía 13. Región de los ríos, lagunas y pantanos.

La situación geográfica estratégica de los chontales les permitió aprovechar un vasto sistema de rutas fluviales a través de los ríos $\mathrm{G}$ rijalva, U sumacinta, Chacamax, San Pedro Mártir, San Pedro y San Pablo, Palizada, Chumpán y Candelaria, entre otros, hasta la Laguna de Términos, lo que fue de vital importancia para su expansión e intercambios comerciales y culturales con otras partes del área maya, y su caracterización como comerciantes por excelencia.

El área se localiza en el sureste de la R epública M exicana, abarca parte del estado de Campeche y una mínima porción de Tabasco, tiene una extensión aproximada de $19817 \mathrm{~km}^{2}$ y está comprendida en las regiones hidrológicas G rijalva-U sumacinta y Yucatán, oeste-C ampeche, respectivamente.

El clima predominante es cálido subhúmedo y se localiza en las porciones central y este, aumenta su grado de humedad hacia el oeste, en donde es cálido húmedo; la precipitación total anual varía entre $1100 \mathrm{~mm}$ en el este y $1600 \mathrm{~mm}$ en el oeste; la temperatura media anual oscila al rededor de los $26^{\circ} \mathrm{C}$.

L as rocas que afloran son sedimentarias del terciario: secuencias cal cáreas y dolomíticas, y depósitos clásticos del $C$ uaternario. $L$ a formación $C$ hichén I tzá del E oceno ocupa la mayor parte del área, consiste en calizas compactas de color blanco amarillento en estratos medianos a gruesos y ocasionalmente masivos.

Pertenece a la provincia fisiográfica de la planicie costera del Golfo y está dentro de la porción suroeste de la plataforma de Yucatán. Caracteri- 
zada por tener una laguna costera, separada por una isla, se comunica con el mar por medio de las bocas del Carmen y Puerto Real, formándose en esta última un delta de flujo de marea que se desarrolla hacia el interior de la laguna.

La zona continental periférica a la laguna está formada por extensas planicies de inundación, con pantanos y concentración de manglares. Las corrientes principales que drenan en el área son los ríos Palizada, EI Este, Chumpán, C andelaria, M amantel y C hivojá, que depositan considerables cantidades de terrígenos en la L aguna de Términos.

Existen dos unidades geomorfológicas con características bien definidas. La primera ocupa la porción occidental, está formada por la Laguna de Términos, separada por la I sla del Carmen, y conformada por «bajos». $L$ a segunda unidad se encuentra hacia el oriente y está constituida por una planicie rocosa sin plegamientos, consiste en su mayor parte en calizas que a menudo tienen cavernas y hundimientos.

En esta área afloran sedimentos que corresponden a unidades geológicas cuya edad varía del Terciario inferior al reciente. Q ueda comprendida dentro de dos zonas estructurales distintas. La porción occidental se encuentra en el oriente de la cuenca de $M$ acuspana- $C$ ampeche, cuyo origen se relaciona con los disturbios tectónicos atribuidos a la orogenia $L$ aramide.

La región es una unidad formada por calizas de ambiente nerítico, de color claro, con macrofauna de gasterópodos y pelcípodos, así como microfósiles tintinnidos y algunos ostracodos; probablemente pertenezcan a la formación Carrillo Puerto (M ioceno superior, Plioceno inferior). Forma pequeños lomeríos y aflora en la porción austral del área. Es una unidad poco consolidada, formada por gravas, arenas, limos y arcillas, esta última con propiedades plásticas y cierto contenido de materia orgánica. O cupa extensos valles fluviales.

E I clima predominante es cálido subhúmedo y se localiza en las porciones central y este, aumenta su grado de humedad hacia el oeste, en donde es cálido húmedo; la precipitación total anual varía entre $1100 \mathrm{~mm}$ en el este y $1600 \mathrm{~mm}$ en el oeste; la temperatura media anual oscila alrededor de $\operatorname{los} 26^{\circ} \mathrm{C}$. La evaporación media anual varía de 1400 en el Candelaria a 1520 en I sla Aguada.

El escurrimiento se genera sobre to do en las cuencas de los ríos Palizada y Candelaria, se reduce hacia la cuenca del Champotón y es casi nula hacia la península de Yucatán.

La división hidrológica ubica el área en la región Grijalva-U sumacinta y Yucatán, o este- $C$ ampeche, que pertenecen a la vertiente oriental. Está constituida por los ríos perennes: Palizada, E I E ste, C humpán, C andelaria, M amantel y Chivojá, que escurren por la llanura costera y desembocan en la laguna anexa a la de Términos. EI río Candelaria es el más importante del área, nace en Guatemala y tiene un recorrido de 150 km hasta su des- 
embocadura directa en la laguna de Panlao, e indirecta en la de Términos a través de la boca de Pargos; es un río de planicie con numerosos meandros, zonas de inundación e incluso, en algunas partes, invierte prácticamente su dirección; su principal afluente es el río Caribe proveniente del este. El río $\mathrm{M}$ amantel es una pequeña vía fluvial que desemboca en la laguna de Panlao; el Chivojá llega a la L aguna de Términos, al norte del anterior, en el este de dicha laguna. EI río U sumacinta se aprecia en la esquina suroeste.

L as condiciones de humedad del área han dado lugar a la formación de gran número de lagunas, entre las que destacan la de Términos, cuya área aproximada es de $1500 \mathrm{~km}^{2}$; en sus al rededores se encuentran las de Puerto Rico, Carlos, EI Este, EI Vapor, Sitio Viejo, Chocajito, Panlao, EI Pujo y Ensenada $G$ rande. En el sureste se localizan las de L agón D ulce, Colorada, Palmasola, los J uanitos y otras, en una extensa zona sujeta a inundaciones. Ahí existe un sinnúmero de pequeños cuerpos de agua.

Son abundantes los terrenos inundables y los pantanos; la excesiva descarga pluvial y las condiciones topográficas propician este fenómeno que se extiende en los alrededores de la L aguna de Términos, hacia la zona de la desembocadura del U sumacinta, tramos de los ríos Candelaria y Caribe, y extensas áreas del sureste donde los bajíos se inundan periódicamente, siendo más significativos los de Cilvituc, Tres Aguadas, EI Tigre, El Burro, La H uerta, La Venada, La E speranza y La Abundancia.

La información hidrométrica se reduce a la obtenida en la estación $C$ andelaria; el volumen medio anual escurrido en este lugar en el periodo de 1953-1973 fue de 1405 millones de metros cúbicos, lo que representa un gasto medio de $44.5 \mathrm{~m}^{3} / \mathrm{seg}$.; el máximo caudal se aforó en octubre de 1963, y fue de $408 \mathrm{~m}^{3} / \mathrm{seg}$.

L a provincia lingüística chontal coincide casi exactamente con una zona que forma una entidad geográfico-cultural caracterizada por tierras bajas pantanosas, anegadas una gran parte del año y con un sistema hidrográfico único, compuesto por multitud de ríos y estuarios, abundantes lagunas y salidas al litoral marino. Sus habitantes se adaptaron a los recursos naturales del trópico húmedo del sureste de M éxico, dando soluciones específicas y creando un conocimiento propio de su medio ambiente.

La ocupación humana data de los tiempos preclásicos mesoamericanos hasta la actualidad; durante ese largo perio do hubo fluctuaciones de población, aumentos y disminuciones. La información disponible sugiere que existen diferentes orientaciones ocupacionales en las diferentes épocas.

Los putunes se comunicaron a través de las lagunas y ríos en cuyas o rillas se local izó un gran número de sitios arqueológicos, to dos ellos colocados estratégicamente en lugares que dominan entradas y salidas. $\mathrm{H}$ acia la costa hay varios jilones (caminos), al gunos de ellos se extienden por varios kilómetros. Del río San Pedro y San Pablo se podía pasar a Xicalango por tres diferentes vías: la primera, posiblemente la menos utilizada por los 
peligros que se tenían que afrontar, costeaba por la orilla del mar. La segunda llegaba al último sitio arqueológico localizado sobre el río San Pedro y San Pablo, el camino se hacía a pie hasta la costa. La tercera, tal vez la más usada, sobre todo en la época de aguas, era la que entraba al arroyo ColoradoL aguna Colorada-río Colorado y posteriormente, a las lagunas de Pom y A tasta y al río Sierra. Estas rutas eran las más viables para llegar al gran centro de comercio de Xicalango, desde allí se podía acceder a Tixchel e Itzamkanac.

La documentación que se refiere a Xicalango como uno de los mayores puertos de comercio es numerosa (Scholes y Roys 1968, Cardós 1959, C hapman 1957, Thompson 1975, O choa y Vargas 1979). Se dice que llegaban allí los comerciantes desde Yucatán, $\mathrm{H}$ onduras, C hiapas y el Golfo de M éxico. El lugar fue despoblado poco antes de 1579 y su población trasladada a J onuta, otro pueblo chontal enclavado en las márgenes del U sumacinta.

El enclave estratégico de Itzamkanac (EI T igre) es claro, pues se localiza sobre unas lomas desde donde se domina gran parte del río Candelaria (fotografía 14); tiene estructuras que sobrepasan los $20 \mathrm{~m}$ de altura (fotografía 15) y varias calzadas. Su ocupación data del Preclásico superior, sin embargo, pensamos que su periodo de auge fue el Clásico terminal y llegó hasta el Postclásico tardío, como lo demuestran los hallazgos realizados en la parte superior de dos edificios excavados. I tzamkanac o EI T igre está río adentro, bien protegido y lo suficientemente alejado de Xicalango como para no entrar en conflicto, ya que desde allí se podía ir fácilmente a la L aguna de Términos, por el río $C$ aribe se llegaba a $C$ alakmul y por el $C$ andelaria o río San Pedro hasta el Petén, rutas que sirvieron para transportar mercancías locales e importadas desde el Petén hacia la costa.

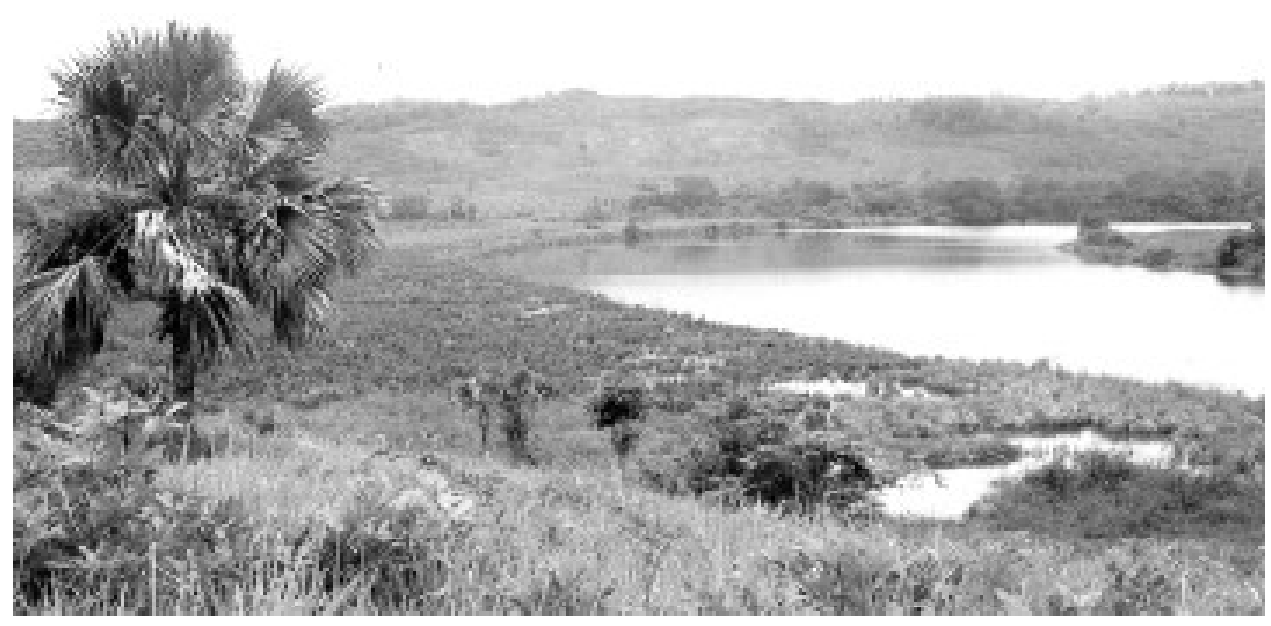

Fotografía 14. Sitio estratégico que domina gran parte del río. 


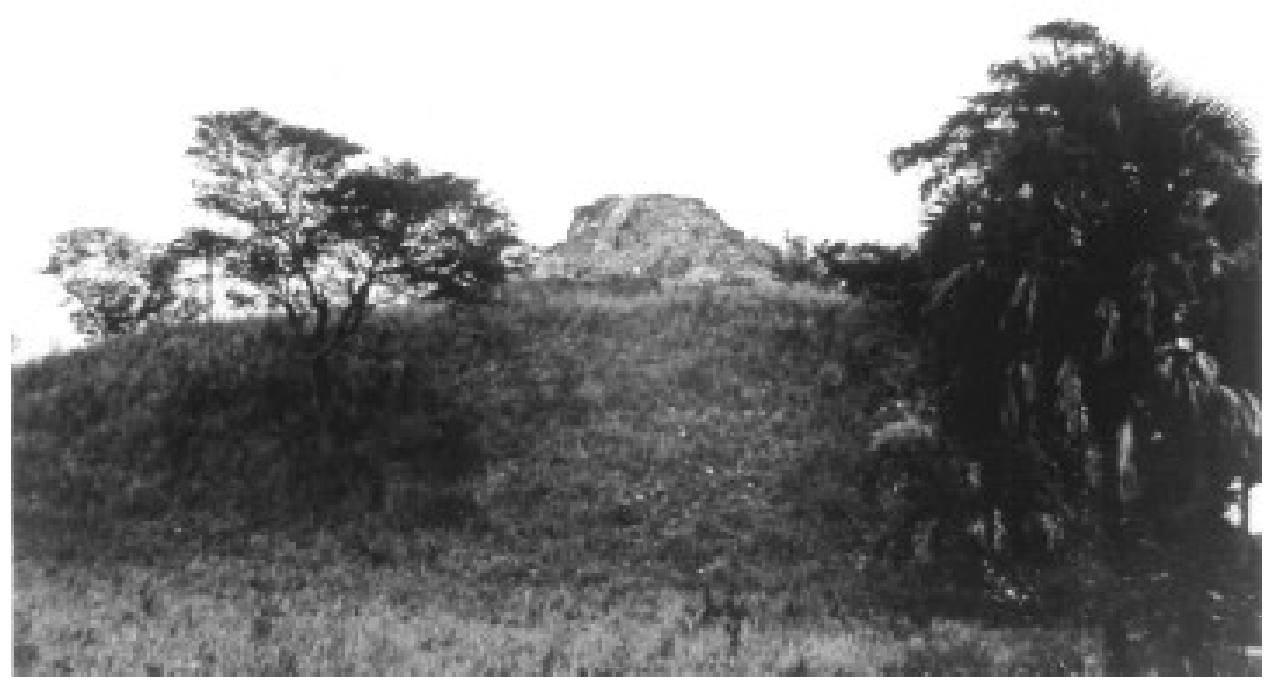

Fotografía 15. El Tigre, Estructura 2.

Los Papeles de Paxbolom M aldonado describen la llegada de los magtunes 0 acalanes y la conquista que realizaron en la región. Vinieron de Cozumel, según dice la fuente, y lo primero que hicieron fue tomar Tenosique (Tanocida) y otros pueblos; posteriormente ocuparon Laguna de Términos y Tixchel en la costa, se apo deraron de la tierra de los cehaches y conquistaron $C$ hagtemal (Chetumal) y Balancán. El sexto rey fue Paxbolom $A$ cha quien pobló Acalan, y estando allí vinieron los españoles.

Lo que pretendían los acalanes era dominar las rutas de comunicación tanto del río Candelaria, como del U sumacinta y las lagunas que dan hacia la costa, ya que de esa manera controlarían el comercio; sin embargo, los de Tabasco y Xicalango se unieron para defender el dominio que también ejercían sobre las rutas de comunicación en la costa y lagunas; por ello obligaron a los acalanes a desocupar T ixchel y asentarse en I tzamkanac, que estaba río arriba del Candelaria.

La capital de los acalanes cayó también poco después de la conquista española, al romperse la estructura del comercio a larga distancia, y la población fue trasladada a Tixchel en 1557.

L os mayas chontales tuvieron varios centros de comercio, localizados en lugares bien protegidos, como para ofrecer la seguridad necesaria de un puerto de intercambio; ellos fueron: Potonchán, Xicalango, T ixchel e I tzamkanac. $D$ e estos puertos partían los mercaderes hacia diversos puntos del sur, norte y centro de M esoamérica; rutas que sirvieron para transportar mercancías local es e importadas. Por el momento no sabemos cómo se interrelacionaban las tres unidades políticas chontales para asegurar el comercio que dominaron por varios siglos. 


\section{El Río CandeLARIA}

A la investigación de los restos arqueológicos a lo largo del río se añadió la valoración de las variaciones en el paisaje, que fue la clave para buena parte del análisis; así fue posible distinguir con claridad tierras con colinas, llanuras anegadas por los ríos, tierras inundables, dunas, etcétera.

Topográficamente, la zona puede dividirse en dos sectores: los pantanos y las lomas bajas; el primero abarca las orillas del río y casi todas sus desembocaduras, cubriendo además gran parte de L aguna de Términos y el estero de Sabancuy. EI segundo comprende aquellos lugares que apenas llegan a los 100 metros sobre el nivel del mar.

El sistema intensivo de agricultura en tierras inundables que existía en esta zona antes de la conquista otorga especial importancia a la investigación sobre la subsistencia en las tierras bajas tropicales. Scholes y R oys han demostrado que ésta fue una vez la provincia maya de Acalan, una región aparte, la base de los mayas putunes, expansionistas, viajeros y comerciantes. En el siglo anterior a la conquista estaba densamente poblada y tenía una imponente capital, I tzamkanac. Todo esto coincide más o menos con la cuenca de desagüe de una red navegable de cursos acuáticos, detrás de una serie de rápidos sobre el canal principal del Candelaria, lo cual contrasta agudamente con lo que puede verse hoy en día.

EI C andelaria superior tiene tierras inundables y tierra firme; en esta última siempre han estado las poblaciones y también se ha hecho la agricultura de roza y quema. L as tierras inundables siempre han tenido mala fama, pues se les asocia con criaderos de mosquitos y de insectos y con la putrefacción, de ahí que recientemente en to do el mundo se hagan grandes obras de drenado en esos lugares. En los últimos años se han realizado magníficos estudios en tierras inundables de $M$ esoamérica y, al parecer, los mayas que se asentaron en esos lugares tuvieron una actitud positiva, pues aún están surcadas de canales de irrigación o desagüe y de campos levantados para la agricultura intensiva. Q uizás el pantano no fue tan mortífero como lo es ahora.

Gunn et al. (1994: 174) crearon un modelo climático global, combinando la descarga del río Candelaria, con las estadísticas del Balance Global de Energía, para así crear un modelo de relaciones climáticas global regional. El modelo indica que un periodo de sequía acaeció en la época del colapso de EI M irador, que las descargas máximas corresponden a las más altas temperaturas y que a una precipitación menor corresponden temperaturas más bajas. Para hacer dicho modelo analizan 26 años de descarga fluvial en la historia del sistema del río C andelaria.

Algunas de las conclusiones a las que llegaron dichos investigadores sobre aumento y disminución del caudal de agua, coinciden con lo que nosotros planteábamos sobre el aumento y disminución de la población en la región; seguramente estos cambios climáticos afectaron a los habitantes que vivían en las orillas de las lagunas y del río C andelaria (figura 8). 
Estimación de variaciones climámticas. Río Candelaria, Campeche, México.

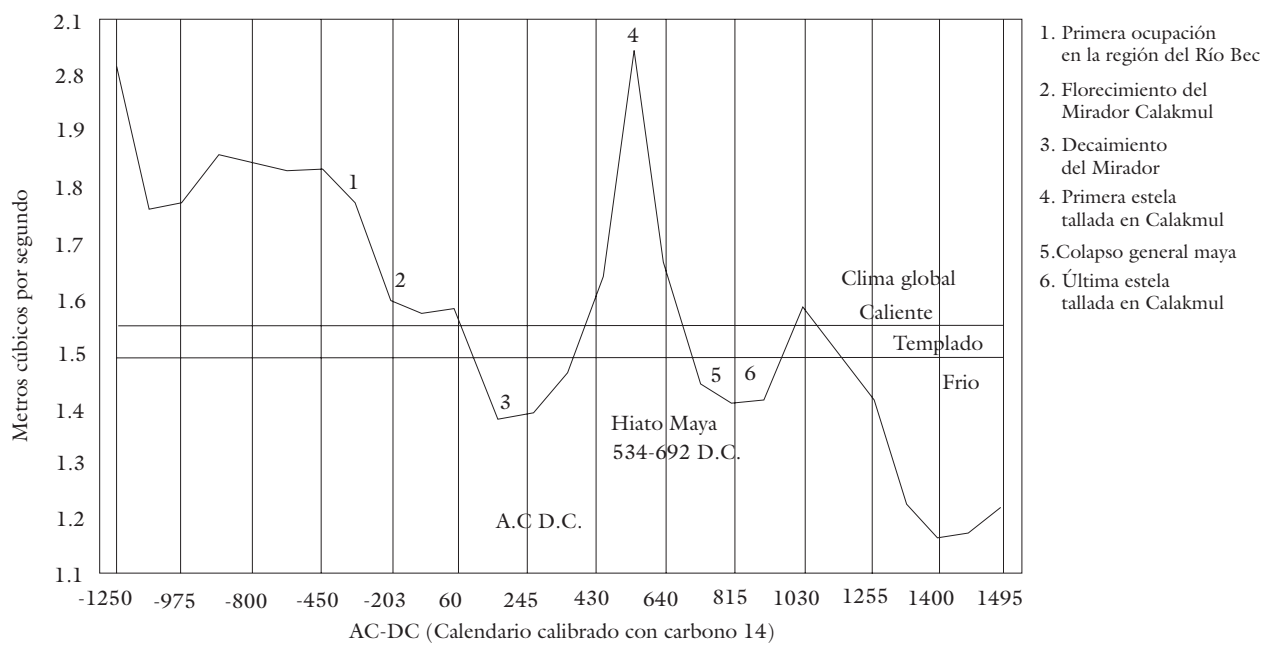

Figura 8. Estimación de variaciones climáticas en el Río Candelaria, Campeche, México. Tomado de Gunn, Folan y Robichaux 1994.

\section{Generalidades}

Al hacer una revisión de los mapas de la región se ve claramente que el río, en la mayoría de ellos, ni siquiera se registra, en otros está mal localizado y en los que aparece se consigna con diferentes nombres. En el mapa de 1579, Melchor de Alfaro Santa Cruz lo llama río de Zapotitlán (mapa 11); en otros textos es registrado como afluente del Usumacinta, es llamado río Hosvinil, Batcab o Bateab, río Pacaitun, río Isabel, Concepción y finalmente Candelaria. Su ubicación no fue muy exacta, ya que varió desde el Chumpán hasta el río Mamantel.

Entre los principales afluentes que tiene el río están El Mango, El Pacaitún, El Pejelagarto, La Esperanza, Las Golondrinas, El Caribe que a su vez tiene otros afluentes y además los manantiales de Miguel Hidalgo que son bellísimos.

El río tiene una longitud algo mayor a los $200 \mathrm{~km}$, sus afluentes principales son el San Pedro y el Caribe, los cuales se unen en Boca Santa Isabel para formar propiamente el Candelaria, que nace por lo tanto en Guatemala, y pasa frente a El Tigre. De un poco más de $100 \mathrm{~m}$, de anchura en él se forman varios meandros hasta llegar a Salto Grande, que dista unos $66 \mathrm{~km}$.

A partir de Salto Grande, el río se divide en numerosos brazos de anchura variable, formando muchos caudales en donde se conocen más 60 saltos y rápidos. Scholes y Roys (1968: 49) citan a Pawling, quien cuenta un total de 21 saltos; Acevedo (citado en Scholes y Roys 1948) asegura que hay más de 40; y 


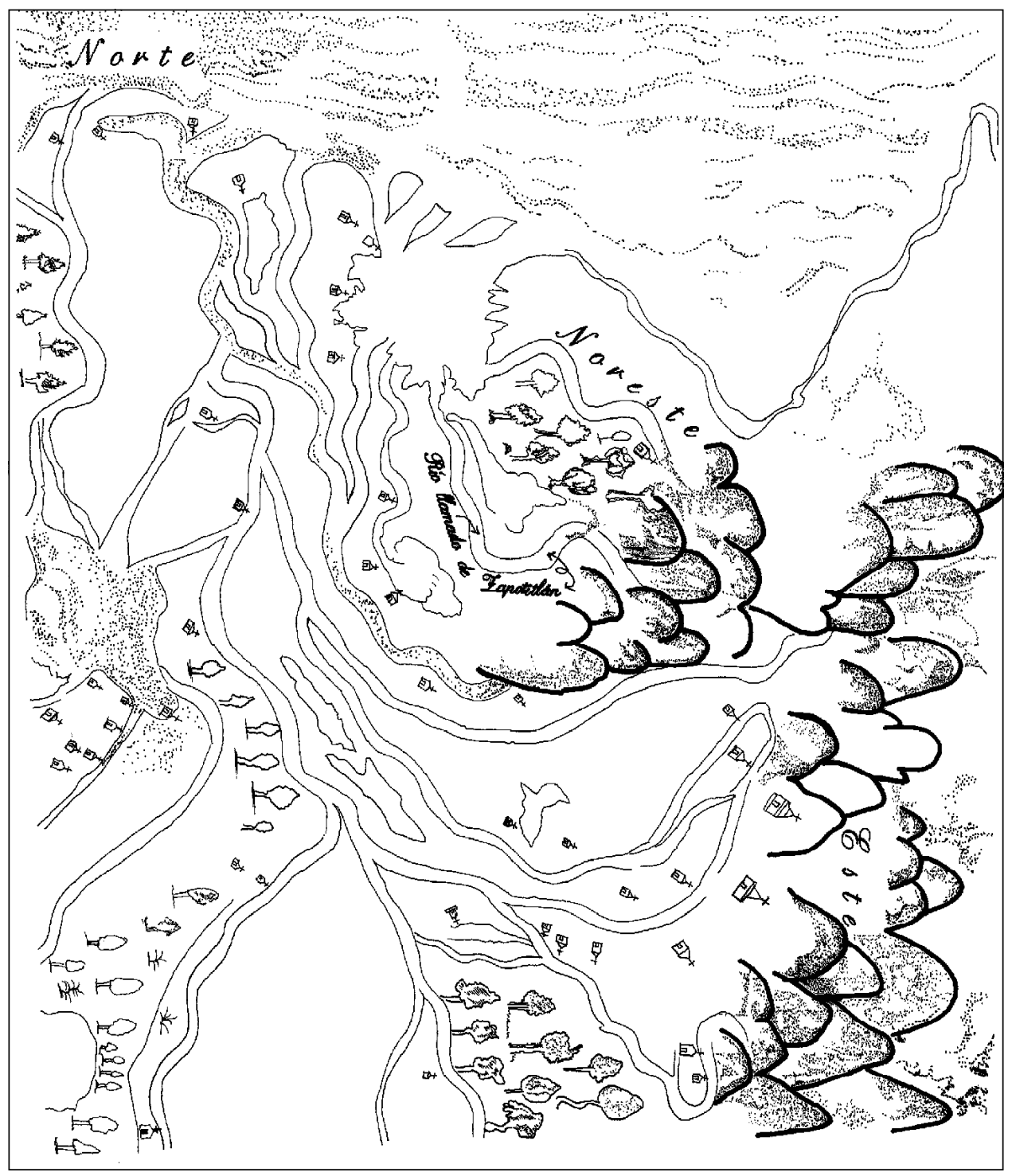

$M$ apa 11. D etalle del mapa de Alfaro Santa Cruz, que llama Z apotitlán al río de $\mathrm{C}$ andelaria. Tomado de las $\mathrm{R}$ elaciones $\mathrm{H}$ istórico-geográficas de la gobenación de Y ucatán.

José L uis Cervera (1870) enumera 68, algunos de los cuales habían sido dinamitados para facilitar el tránsito. Estos sal tos están compuestos por grandes rocas calcáreas constituidas por la acumulación de los sedimentos acarreados por el río.

En un recorrido que hicimos en julio de 1996 desde el ejido I gnacio Zaragoza hacia Salto Grande, que tendrá unos $50 \mathrm{~km}$ de largo, en total contamos 35 boquetes. L legamos sólo hasta la mitad, pues un árbol caído 
con abejas africanas nos impidió el paso para terminar la exploración. Con un buen lanchero conocedor de los pasos se pueden sortear sin ningún problema dichos boquetes. Esto nos lleva a plantear la factibilidad de dicho paso durante la época prehispánica, posiblemente no pasaron por los rápidos sino que buscaron pasos alternos que permiten arrastrar con cuerdas un cayuco de ciertas dimensiones.

Al año siguiente hicimos el descenso desde Salto Grande hacia I gnacio Zaragoza. La experiencia fue muy interesante pues pudimos recorrer parte de lo que habíamos hecho con anterioridad y parte de lo que nos faltó en el recorrido anterior, contamos 36 boquetes más, todos de menor tamaño que los anteriores a excepción de Salto G rande. Sin embargo, las corrientes son fuertes para un cayuco que bien puede aminorar la velocidad con los remos y ramas de la orilla, aunque el caudal es angosto y a veces peligroso.

Además en ambas orillas se encuentran localizados algunos sitios arqueológicos, el paso fue lento y seguramente estos lugares ofrecían descanso y seguridad a los comerciantes que transitaban por el lugar. Asimismo, topográficamente esta parte del río controlaba de forma natural el tránsito de personas y mercancías.

A partir del boquete de EI Burro, que se encuentra poco antes de I gnacio Zaragoza, el río adquiere otra vez su anchura de hasta $150 \mathrm{~m}$, sus aguas se vuelven salobres y en las orillas se aprecian los manglares hasta la desembocadura del río en la laguna de Panlao, que se comunica a su vez con la de Términos por la Boca de los Pargos.

A partir de allí se puede seguir la travesía a T ixchel rodeando la L aguna de Términos, en la cual se localizan varios pequeños sitios arqueológicos que llevan directo al estero de Sabancuy, en donde también se registraron otros sitios. D esde la boca de los Pargos se atraviesa la L aguna de Términos para llegar a la península de Xicalango, entrar a la red de lagunas que se unen para acceder hasta el sitio de Santa Rita, que bien podría ser el Xicalango de la fuentes.

L a travesía de la L aguna de T érminos puede ser peligrosa por los vientos fuertes, pero si se toma en calma es rápida y segura. EI trayecto de la laguna de $\mathrm{Pargos}$, la entrada del río $\mathrm{C}$ and elaria hasta los primeros boquetes también es una travesía muy tranquila. La dificultad se presenta al pasar los boquetes, pues al gunos de ellos son peligrosos cuando forman rápidos; sin embargo, se sabe que existen arroyos alternos que bien cuidados y limpios facilitan dicha travesía. D espués de Salto $\mathrm{G}$ rande el río vuelve a ser manso y tranquilo y la navegación se facilita hasta llegar a EI Tigre y demás sitios de los afluentes Caribe y San Pedro, por donde podía navegarse hasta Calakmul y el Petén guatemalteco.

Las fuentes históricas narran el trayecto que hacían los indios de Itzamkanac a Xicalango, el cual duraba tres días en cayuco (fotografía 16). El fraile Bienvenida nos dice que para llegar desde Tixchel a Itzamkanac 


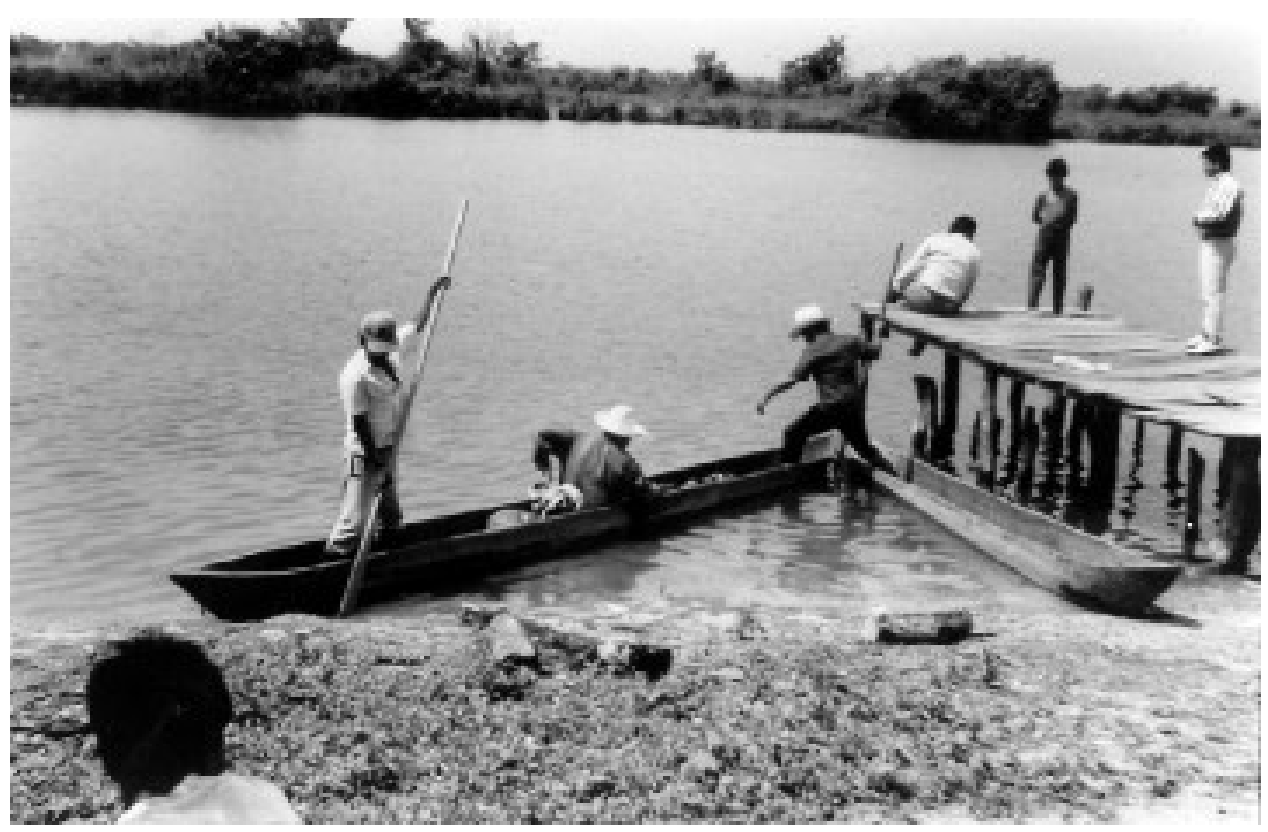

Fotografía 16. Cayucos, medio de transporte en el río Candelaria.

había que pasar varios saltos. Esa fue, sin lugar a duda, una vía normal de comunicación durante la época prehispánica hasta principios de siglo xx.

\section{El alto, medio y bajo $\mathrm{C}$ andelaria}

Para la descripción del río Candelaria, que es el más largo del estado de C ampeche, podría dividirse en tres zonas topográficas bien diferenciadas: alto, medio y bajo $C$ andelaria. Sin embargo, he preferido añadir también a esta división algunos aspectos culturales para que se integren ambos: los topográficos y los culturales.

D ebemos recordar que Acalan fue una provincia y como tal debió tener un territorio que dominó y controló; además, sabemos que existió una capital o cabecera y por lo menos 76 pueblos con sus respectivos jefes o batab.

A continuación hacemos una descripción geográfica del río, señalando la presencia de sitios arqueológicos o construcciones que la hacen interesante; algunos de ellos indiscutiblemente formaban concentraciones semiautónomas, que en el contexto general de la geografía política de Acalan eran batabilob dentro del cuchcabal de Acalan. Esto será tratado con más detalle en el capítulo siguiente. 


\section{L aguna de Panlao}

Es una pequeña laguna separada de la de Términos por una serie de isl etas - tres en total-, que ocultan o camuflan la desembocadura de los ríos $\mathrm{C}$ andelaria y $\mathrm{M}$ amantel, pues éstos no desembocan directamente en la $\mathrm{L}$ aguna de Términos.

Panlao tiene entre 5 y $6 \mathrm{~km}$ de longitud por unos 4 de anchura. Se tiene noticias de la existencia de tres sitios arqueológicos en sus orillas: L a Sirena, La D esembocadura y EI O stional. Es digna de notarse la presencia de un camino que atraviesa la laguna de Panlao y comunica los sitios de $L$ a $D$ esembocadura y EI O stional; tiene una distancia de 2500 m con una anchura de $4 \mathrm{~m}$ y con dos boquetes que fueron ampliados para que pasaran embarcaciones de mayor calado; cada uno fue construido para dejar paso libre hacia los ríos M amantel y C andelaria (fotografía 17).

La construcción de dicho camino pudo ser artificial, está hecho con concha de ostión, y su profundidad máxima quizá fue de $2 \mathrm{~m}$. Tal vez lo más interesante del trabajo fue el control que ejercieron en la laguna de Panlao para vigilar el paso de embarcaciones hacia los ríos y viceversa.

Sin lugar a duda, la construcción de ese camino pudo deberse a fenómenos naturales, quizás fue utilizado por los mayas, ya que tenía la doble función de comunicar los sitios que se encuentran en ambas orillas y controlar el paso de las embarcaciones que transitaban por allí hacia los ríos

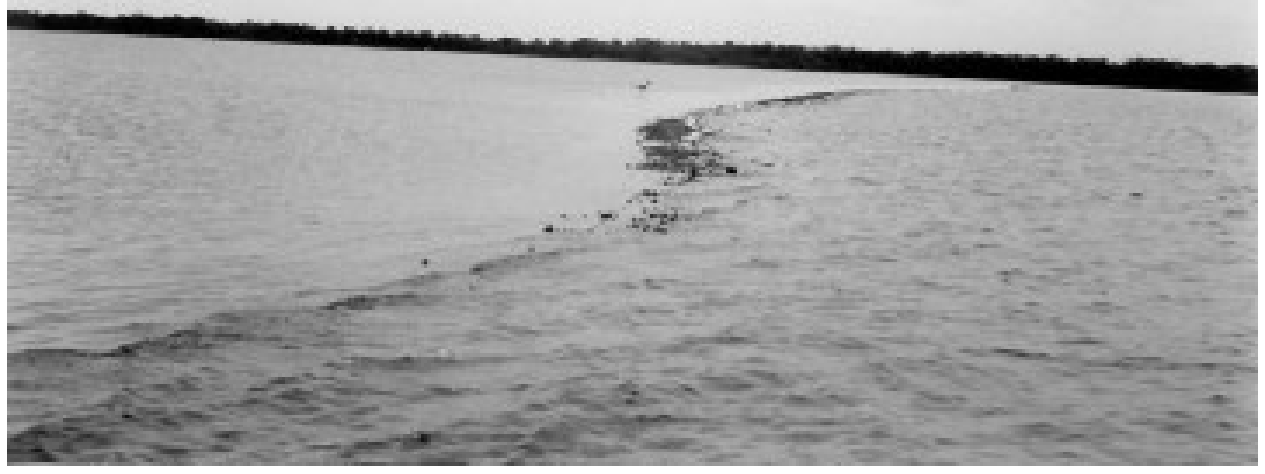

Fotografía 17. Posible camino (sacbe) en la laguna de Panlao. 


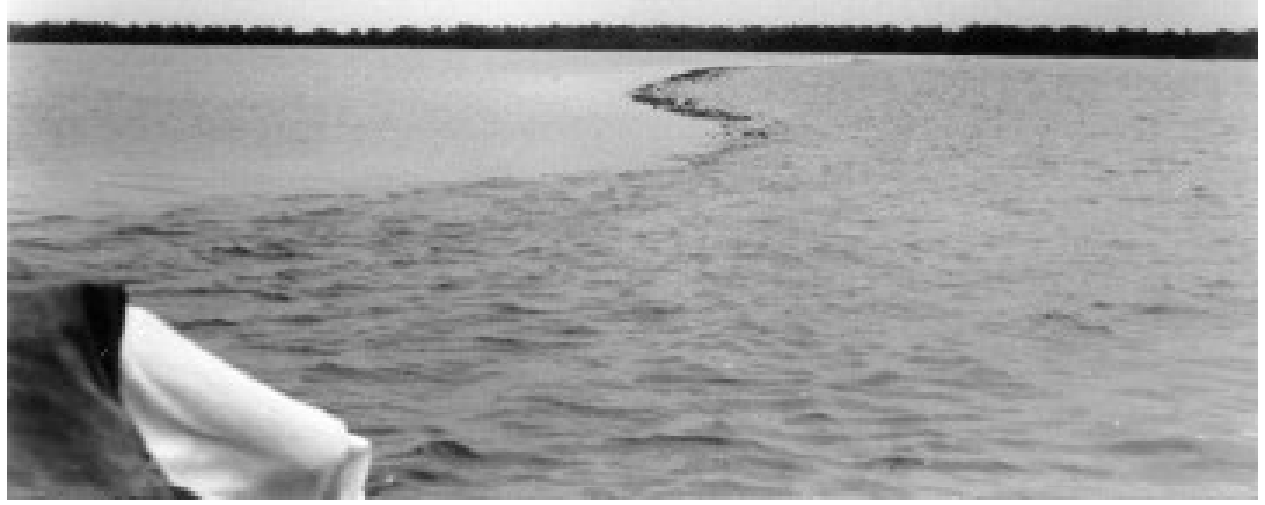

Fotografía 18. Boquetes del posible camino sobre laguna de Panlao.

$\mathrm{C}$ andelaria y $\mathrm{M}$ amantel, por donde se hizo un intenso comercio hasta principios de siglo (fotografía 18). Parece ser una muralla artificial, construida para la defensa, pues sabemos por las fuentes históricas que la región estuvo expuesta a invasiones y ataques de grupos ajenos a la región.

\section{Bajo Candelaria}

Lo hemos definido a partir de la desembocadura del río en la laguna de Panlao hasta el primer boquete 0 sal to. M ide aproximadamente $50 \mathrm{~km}$ de longitud, sus aguas son mansas y tranquilas, lo que hace un trayecto fácil de navegar. La margen izquierda se caracteriza por terrenos pantanosos y sujetos a inundaciones, la vegetación en general es de manglares y la salinidad de sus aguas aumenta a medida que uno se acerca a la laguna (fotografía 19). L a margen derecha es un poco más alta y está cubierta de vegetación densa. En el curso del río existen varias islas, meandros, la laguna $L$ as $M$ aravillas y se registraron dos afluentes, EI M ango y $\mathrm{EI}$ M onterrey; no se reportó ningún sitio arqueológico, seguramente porque el bajo $C$ andelaria era un tramo que se hacía sin escalas.

\section{M edio C andelaria}

A partir de Salto Grande, el río se divide en numerosos brazos de anchura variable, formando diferentes caudales y muchos saltos rápidos (fotografía 20), de los cuales algunos han sido dinamitados para facilitar el tránsito. 


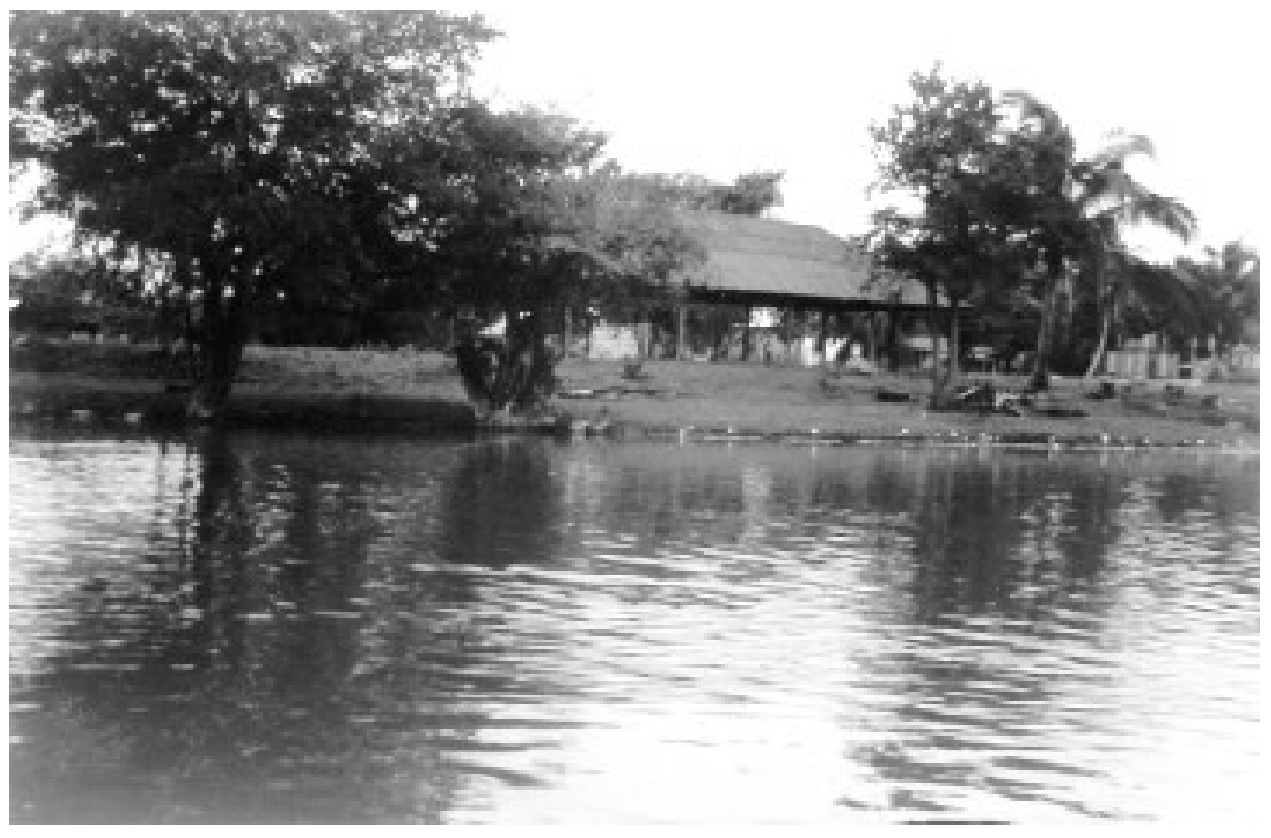

Fotografía 19. Vista del bajo Candelaria.

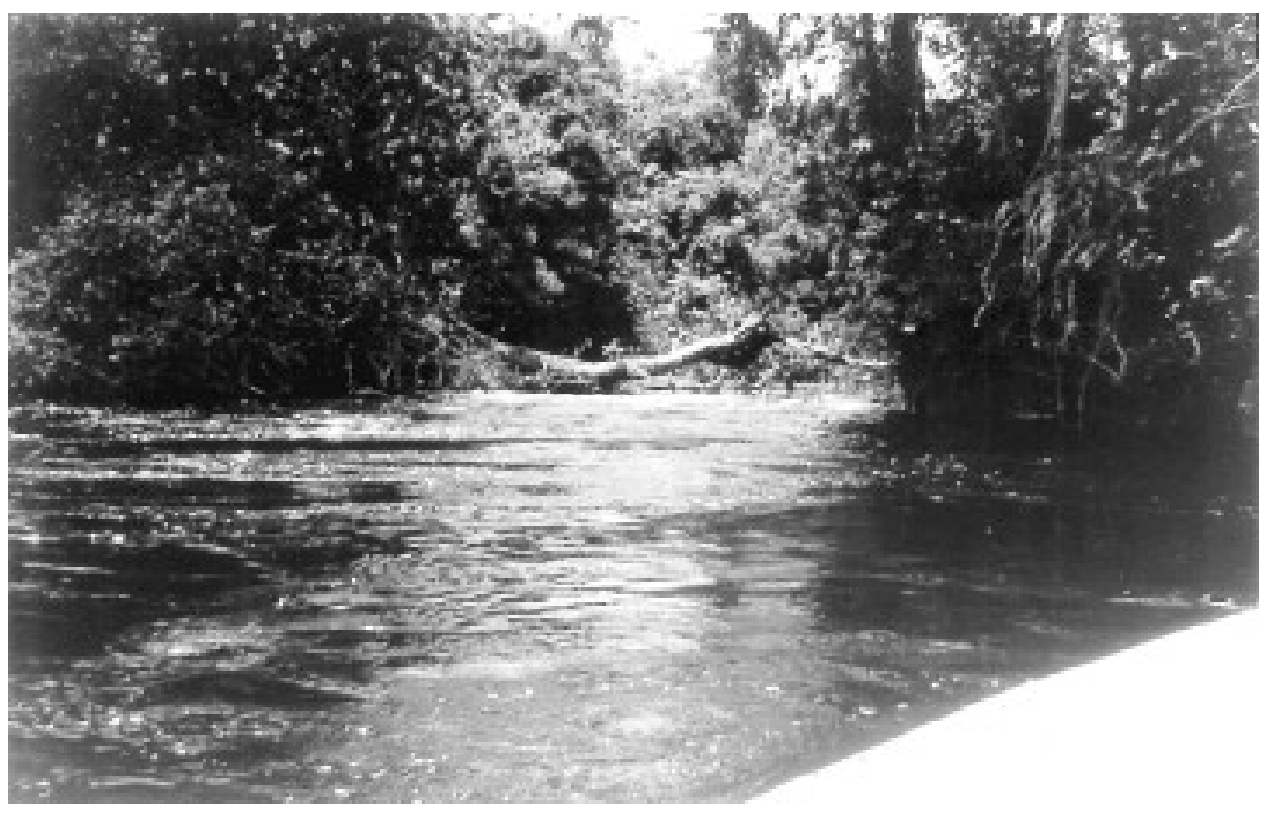

Fotografía 20. Salto de agua en el C andelaria medio. 
En un recorrido por esta sección del río que es de $50 \mathrm{~km}$ de largo, contamos 35 saltos, algunos de ellos tienen caídas más pequeñas como sucede con el boquete denominado el $\mathrm{H}$ uarichoche; creo que esto es lo que hace la gran disparidad en su número, ya que algunos han descrito más de 60 saltos (fotografía 21); además, por la cantidad de raudales puede haber más de un camino, dependiendo siempre del tamaño de la embarcación con la que se transita, que en nuestro caso era lancha de fibra de vidrio con un motor fuera de borda de 55 caballos.

En el recorrido que hicimos en julio de 1996 desde el ejido Ignacio Zaragoza hacia Salto Grande pasamos los siguientes boquetes o saltos.

1. Salto Grande

2. La Zanja del Toro

3. La Chaqueta

4. La Tranca

5. Buenavista

6. EI Rey

7. Sin Nombre

8. EI J urel

9. El Príncipe

10. El Tinto

11. EI Guano

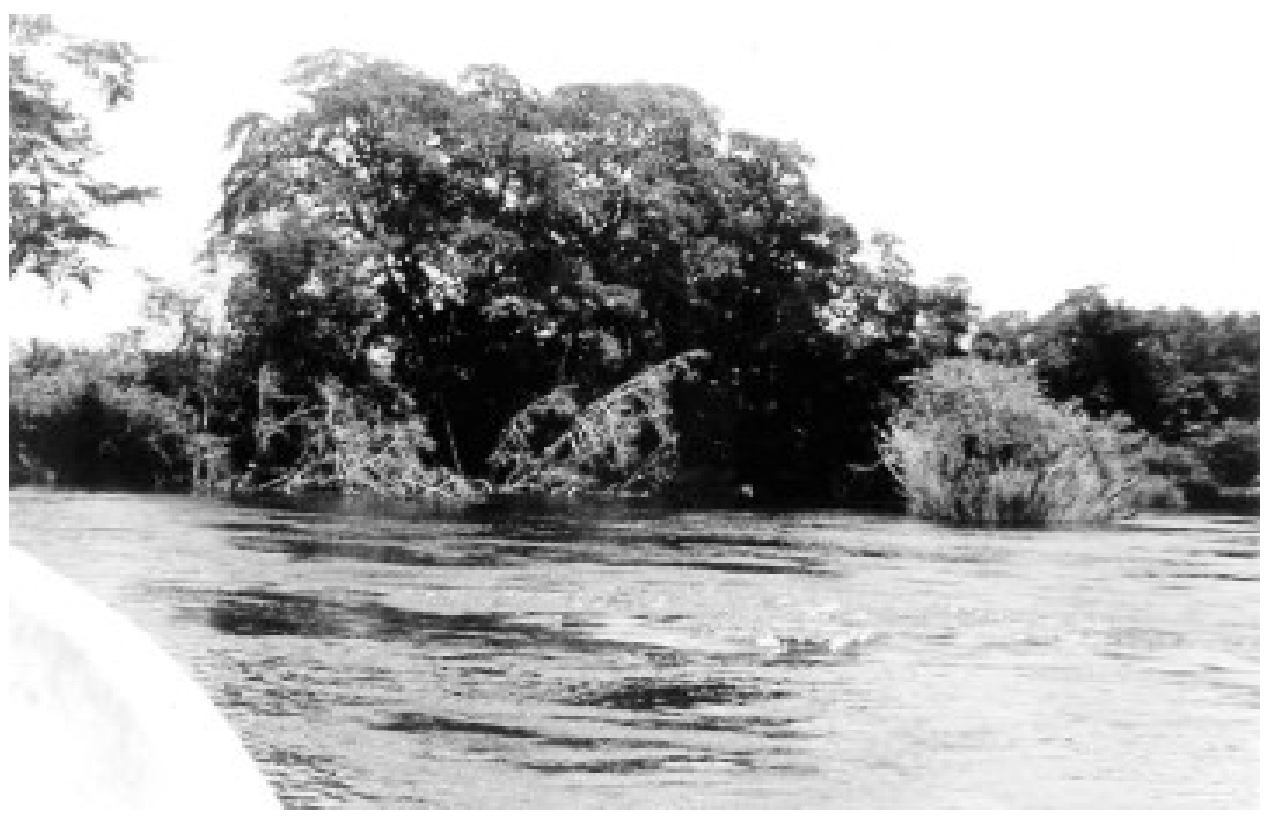

Fotografía 21. Salto de agua en el Candelaria medio. 
12. El G uacamayo

13. L os Salames (Tres Chiquitos)

14. EI Guau

15. Servilleta

16. El Camiseta (por el arroyo M amey, donde hay otro montículo)

17. La M ontera (rancho de San I sidro, hay montículos)

18. EI Chechén (hay dos montículos)

19. Los M elchores (dos cuyos)

20. Los Tigres (son tres boquetes: EI Tigre, La Tigra y EI Tigrito con ruinas)

21. El Sábalo (por el arroyo del Sábalo)

22. EI Zapatero

23. Ánima Sola

24. La Paloma

25. La Palomita (rancho La Paloma)

26. La D ama (rancho La D ama de los Gallegos)

27. EI Valiente (después del rancho de J acinta de $\mathrm{N}$ avarro)

28. EI Valiente $\mathrm{C}$ hico

29. El H uarichoche (tres caídas seguidas más o menos pequeñas)

30. EI I caco

31. El Burro

Como ya señalamos, contamos 31 boquetes, algunos posiblemente tienen más de un nombre, como sucede con el de L a Escuadra, llamado también de Las Escaleras y que nuestro guía no citó. En ese recorrido ya no pudimos seguir; sin embargo, al año siguiente hicimos la travesía de Salto $G$ rande hacia el boquete en donde no habíamos podido pasar y contamos 36 que en total suman 67, la mayoría no tiene nombre o si lo tuvo ya no se recuerda a no ser el de los más importantes.

En un análisis preliminar hemos propuesto que esta sección del río, bien pudo funcionar como un batabilob dependiente de Itzamkanac, ya que en ella existen por lo menos 20 sitios arqueológicos, el más importante de ellos Salto Grande (fotografía 22), que funcionaría como cabecera del batabilob magtún. Tamagtún quiere decir «el lugar de la puerta de piedra», seguramente recibió ese nombre por la cantidad de boquetes que existen en esa sección.

\section{Alto C andelaria}

Después de Salto Grande la navegación del río Candelaria se vuelve tranquila y apacible, abarca $60 \mathrm{~km}$ hasta boca de Santa I sabel, en donde se forma propiamente el río C andelaria. Tiene dos afluentes importantes: $\mathrm{EI}$ Pacaitún y E I Pejelagarto; en cada uno de ellos se localizan sitios arqueológi- 


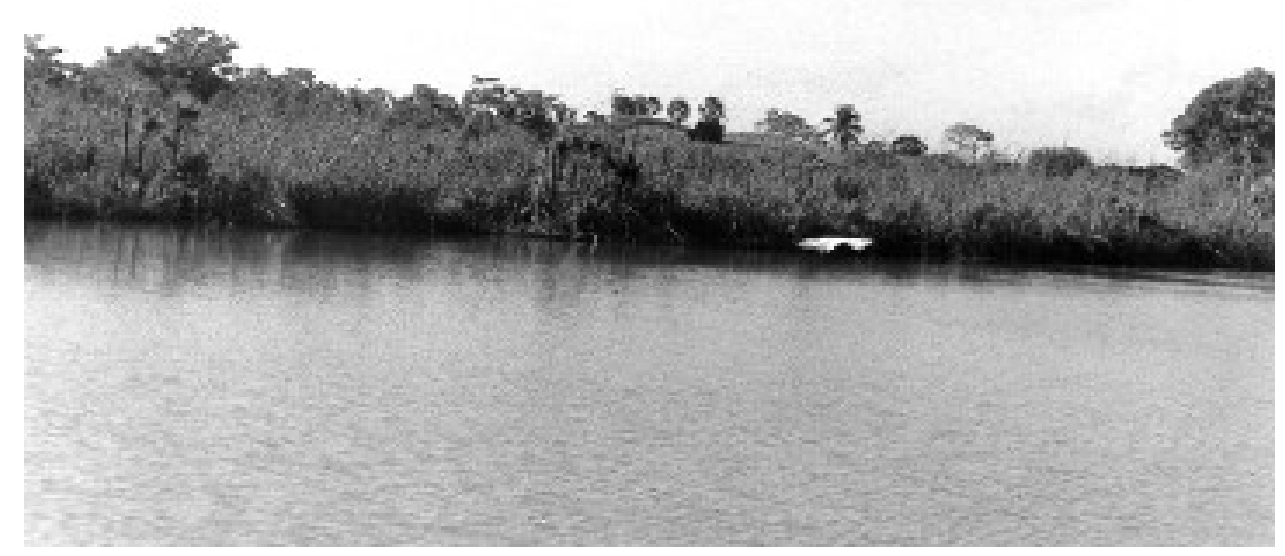

Fotografía 22. Sitio arqueológico de Salto Grande.

cos de cierta importancia, lo que sugiere que controlaban parte de la tierra no inundable y su vía de acceso era a través de los afluentes al río.

En el tramo de Salto Grande a Candelaria Ángel Soler, persona interesada en la arqueología y magnífico conocedor del río, localizó lo que llama las compuertas: se trata de auténticos diques, muros de piedra que atraviesan el río; en algunos de ellos se puede fácilmente caminar por la parte superior sin hundirse y así atravesar el río. En total son ocho compuertas (mapa 12), la primera muy cerca del poblado de Candelaria, la segunda se Iocaliza en Salto A hogado, en la orilla izquierda, y junto a su arranque, hay vasijas en el fondo del río; la tercera, cuarta y quinta se encuentran antes de llegar al afluente llamado Pacaitún y cerca de sitios arqueológicos, lo que indicaría la posibilidad de una construcción prehispánica. Poco antes de ensancharse el río y junto al sitio arqueológico de Paso Real se halla la sexta compuerta, al estrecharse nuevamente el río está la séptima y poco después la octava compuerta.

Lógicamente, habría que comprobar si verdaderamente estas compuertas no son naturales e indagar si fueron construidas por los mayas. En la actualidad, se piensa que las grandes inundaciones que se dan año con año son causadas en parte por estas compuertas y por los saltos que no permiten que el agua circule libremente. Algunos ingenieros de R ecursos $\mathrm{H}$ idráulicos han propuesto que se dinamiten para dejar pasar libremente el agua y de esa manera remediar las inundaciones. 


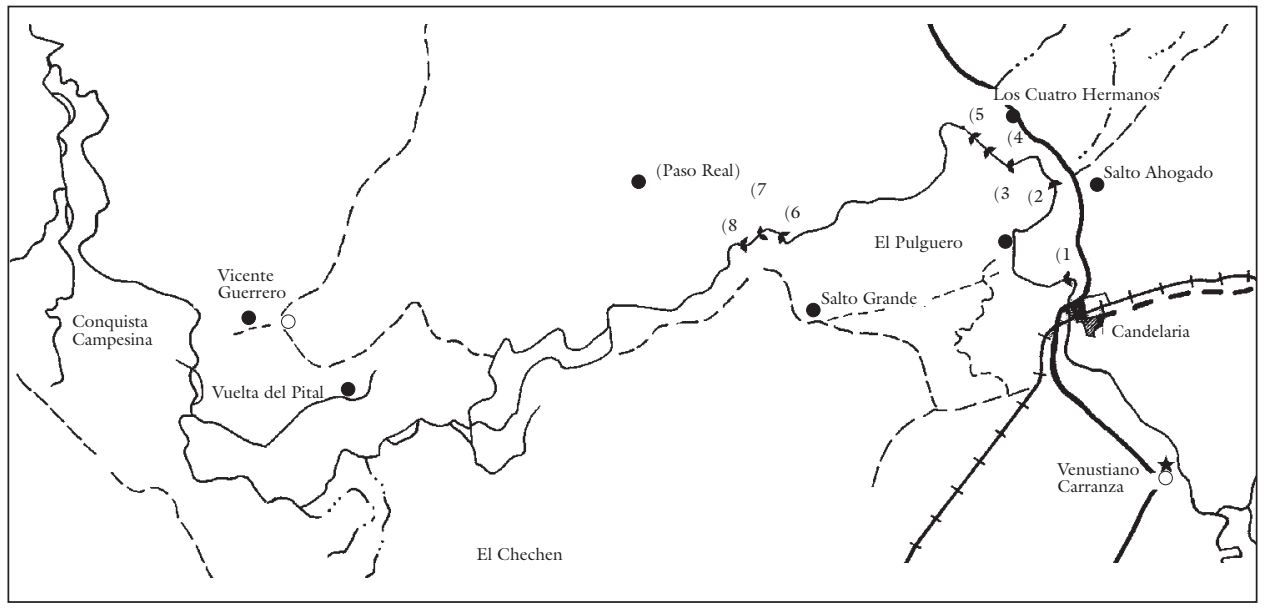

Mapa 12. Localización de las 8 compuertas en el alto Candelaria.

Si esto fuera verdad, sería interesante registrarlo y estudiarlo pues nos demostraría el gran control que del río tuvieron los acalanes de Itzamkanac. Por otra parte, los materiales cerámicos que se han obtenido al parecer son del Clásico terminal; se sabe que hacia esa época, alrededor del $800 \mathrm{dC}$, algo ocurrió en la civilización del Clásico Maya. Diferentes autores han proporcionado información fresca relacionada con los cambios climáticos en la región, que fueron un factor clave en la decadencia de algunos centros rectores mayas.

Los factores que influyeron en el colapso maya, según la mayoría de los autores incluyen el crecimiento de la población, la degradación del medio ambiente y conflictos internos, entre otros. En la región de ríos y lagunas, y en el norte de las tierras bajas, se incrementaron y florecieron ciudades, lo mismo que algunas de las poblaciones del sur asentadas en condiciones ventajosas; otras no lograron sobrevivir. La llegada de regímenes de sequías pudo tener una situación de arriesgada agudeza, causando con ello un gran descontento en la población, el cual provocó la caída de la élite en el poder; se dio entonces el abandono de centros urbanos e importantes cambios demográficos y económicos en el sur y norte de las tierras bajas. Las continuas sequías en dos siglos, como sugieren los resultados de Hodell et al. (1995), debieron afectar considerablemente algunas poblaciones.

Sin lugar a duda, la adaptación de los chontales a este medio ambiente tropical fue exitosa, por muchos siglos superaron numerosos problemas y alcanzaron niveles poblacionales que exceden a los modernos en la misma área. Ciertamente se dio un periodo de sequía en toda el área maya, el agua disminuyó considerablemente según algunos autores, y esto hizo que las poblaciones disminuyeran o crecieran en diferentes parte de la zona. 
Entonces, no sería nada ilógico pensar que ante la necesidad de conservar el agua del río los magtunes construyeran esos diques o compuertas (fotografía 23), que servirían para aumentar o disminuir el nivel del río. E stas son tan sólo algunas consideraciones que podrían tomarse para hacer un estudio de dichas formaciones. También tenemos que recordar que precisamente la mayor ocupación de la región se dio en el Clásico terminal, cuando muchos otros centros de las tierras bajas del sur estaban en su decadencia.

En el alto Candelaria se dio la mayor ocupación y se localizó la capital de los magtunes, I tzamkanac. Frente al sitio arqueológico y en tres lugares específicos se encuentran vasijas en el fondo del río, que pudieron ser ofrendas a los dioses del agua. Algunos piensan que fueron arrastradas por la corriente; yo me inclino a creer que sí han sido movidas por la corriente del agua, pero se hallan justo en los lugares en donde fueron arrojadas, ya que su relación con la ocupación en tierra es evidente. Varios pescadores han sacado en EI Tigre un poco más de 25 vasijas, al sumergirse para realizar su pesca (fotografía 24). É stas se han encontrado exactamente frente al sitio, en lugares que tienen que ver con el puerto o recodos del río.

En el alto Candelaria la concentración de sitios arqueológicos se da en el tramo comprendido entre Salto Grande y los diques o compuertas; ahí se encuentra otro de los sitios interesantes por su distribución, sus características y su cercanía con Pacaitún y Pejelagarto. U no de los sitios más hermosos está en el paraje de San J uan; éste es un sitio mediano que no se ve desde el
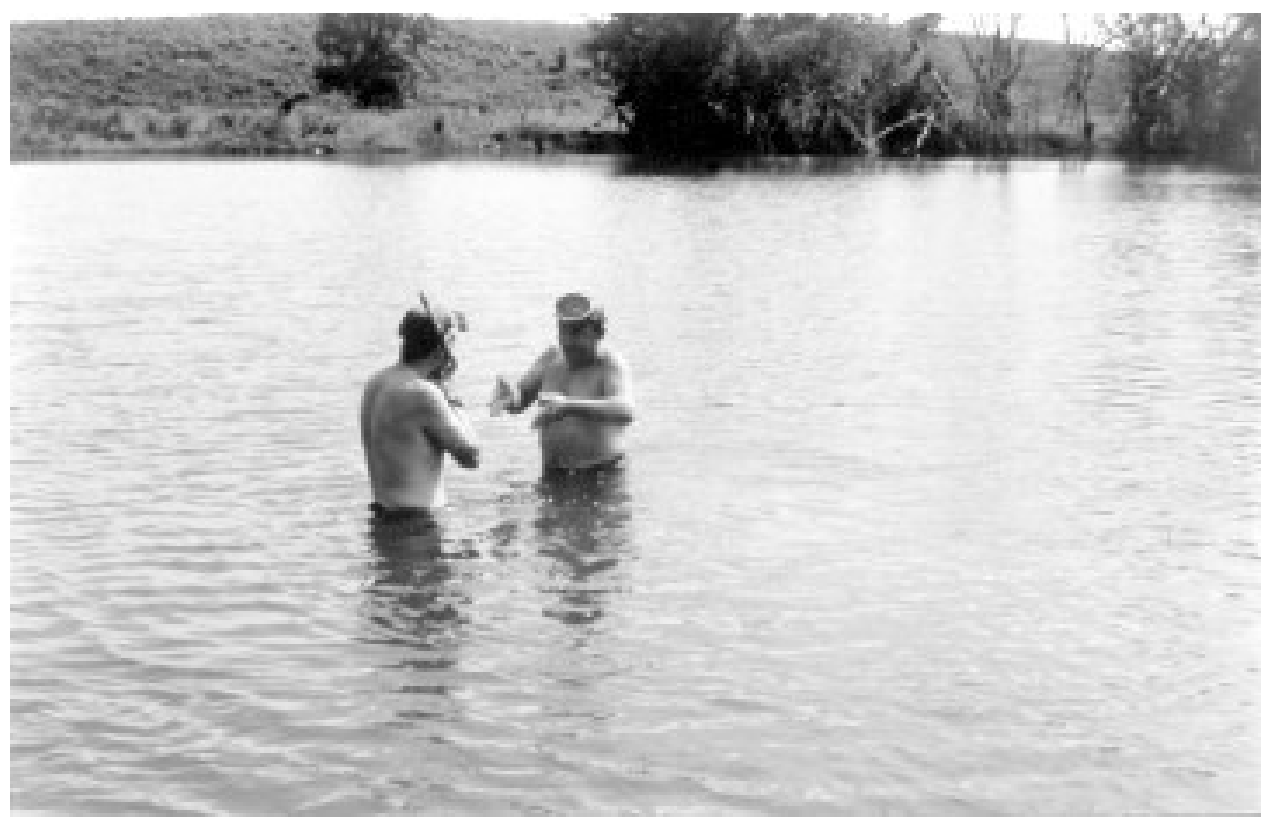

Fotografía 23. Compuerta que atraviesa el río C andelaria (Ángel Soler). 


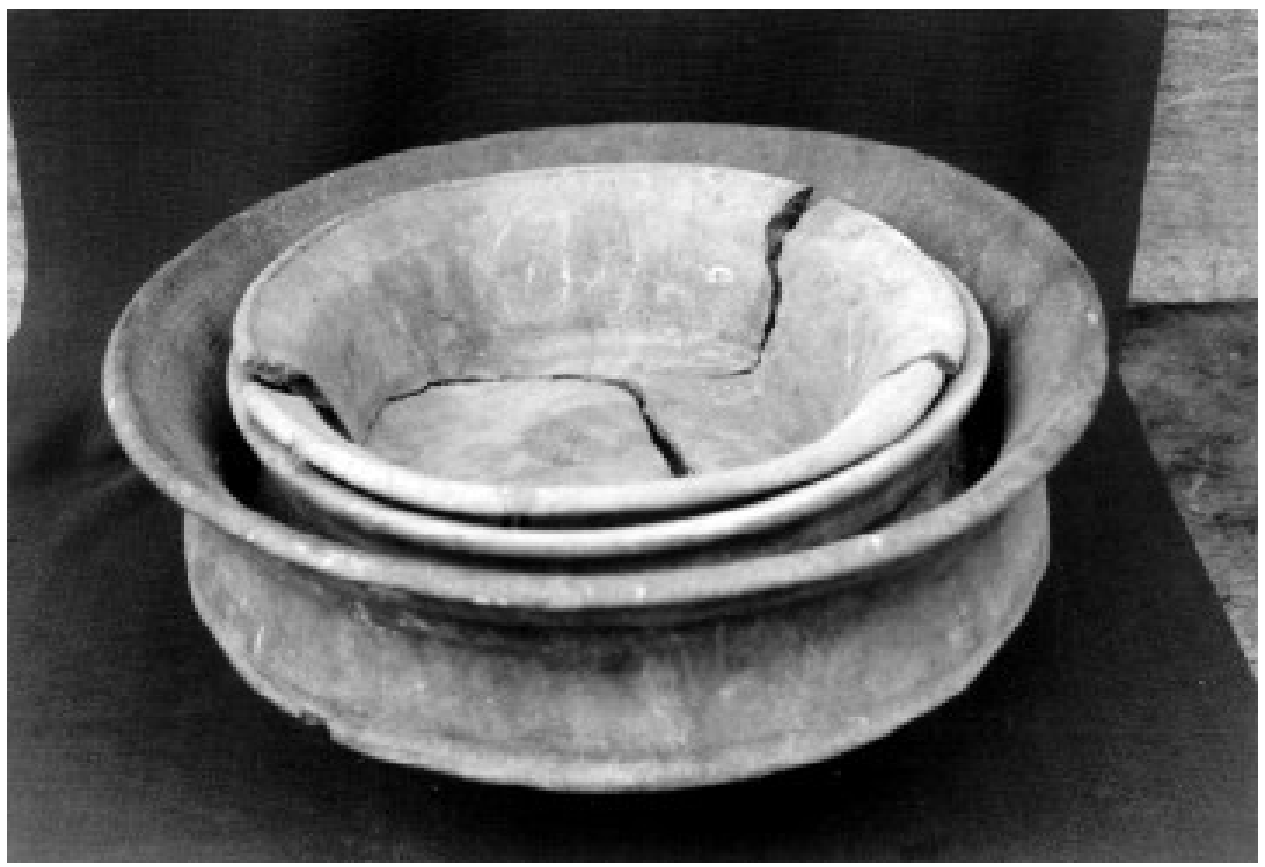

Fotografía 24. Vasijas que fueron sacadas del fondo del río.

río pero lo controlaba perfectamente. En ese tramo del río sólo hay tres sitios antes de llegar a EI Tigre. La población que se asentó en el alto Candelaria, el Caribe y el San Pedro bien podría llamarse los acalanes, diferenciándose así de los magtunes y de los xicalancas.

\section{Control y manejo del río}

También dentro del agua los pescadores localizaron dos montículos, los cuales están separados entre sí por unos $12 \mathrm{~m}$, la piedra es caliza y bien pudo venir del sitio. Este hallazgo, que no es nuevo pues se conocía por lo menos hace diez años, es muy interesante, porque podría ser la base que sostuviera los troncos utilizados para la construcción del puente que hizo C ortés (1969: 236) después de permanecer por varios días en I tzamkanac; de allí pasó el río, siguió los bajos y se dirigió a la región de los cehaches: «[...] ]llegaron a la ciudad de Yzamcanac. Y estando allí, empezaron a trazar por qué parte se podía hacer puente para poder pasar el río con todo su ejército, que tendría una legua de travesía con sus bajíos[...]».

Y si esto no fuera cierto, podría existir la posibilidad de que fuera la base de un puerto. Me inclino por la primera ya que, basado en los estudios de Gunn, Folan y Robichaux (1994 185), el Candelaria tiene su más bajo nivel de aguas hacia $1400 \mathrm{dC}$ y apenas se estaría recuperando de la gran sequía cuando Cortés pasó por I tzamkanac en 1525; por lo tanto, la cons- 
trucción del puente (mapa 13) no debió ser tan complicada como lo hubiera sido si el nivel de río estuviera en los límites más altos.

El Candelaria se conoce mundialmente por los hallazgos de los canales y campos elevados, reportados por Siemens y Puleston en diferentes publicaciones. Desde entonces se han copiado y difundido ampliamente sus trabajos, algunos han sostenido que se trata de canales prehispánicos, caminos o atajos, pues su trazo es perpendicular al río y "parecían ser las huellas de antiguos canales de acceso entre el río y las casas o milpas» (Siemens y Puleston 1972: 235).

Estudios recientes han demostrado que no todos los canales son prehispánicos, algunos fueron construidos en siglo XIX para sacar el palo de tinte en canoas (Millet 1984). Sin embargo, hay que seguir aceptando, mientras no se haga un estudio detallado, que algunos de los canales sí son prehispánicos (fotografía 25), pues muchos de ellos llegan a sitios arqueológicos, otros pudieron servir para irrigación, drenaje y también, como lo plantea Thompson (1974: 279), ser viveros.

En cuanto a los campos elevados (fotografía 26), no solamente se encuentran alrededor del sitio de El Tigre, sino que llegan casi hasta la población de Candelaria; los más conocidos son los que están frente al sitio, pero también se registran hacia el oeste y cerca de un gran meandro que forma El Candelaria.

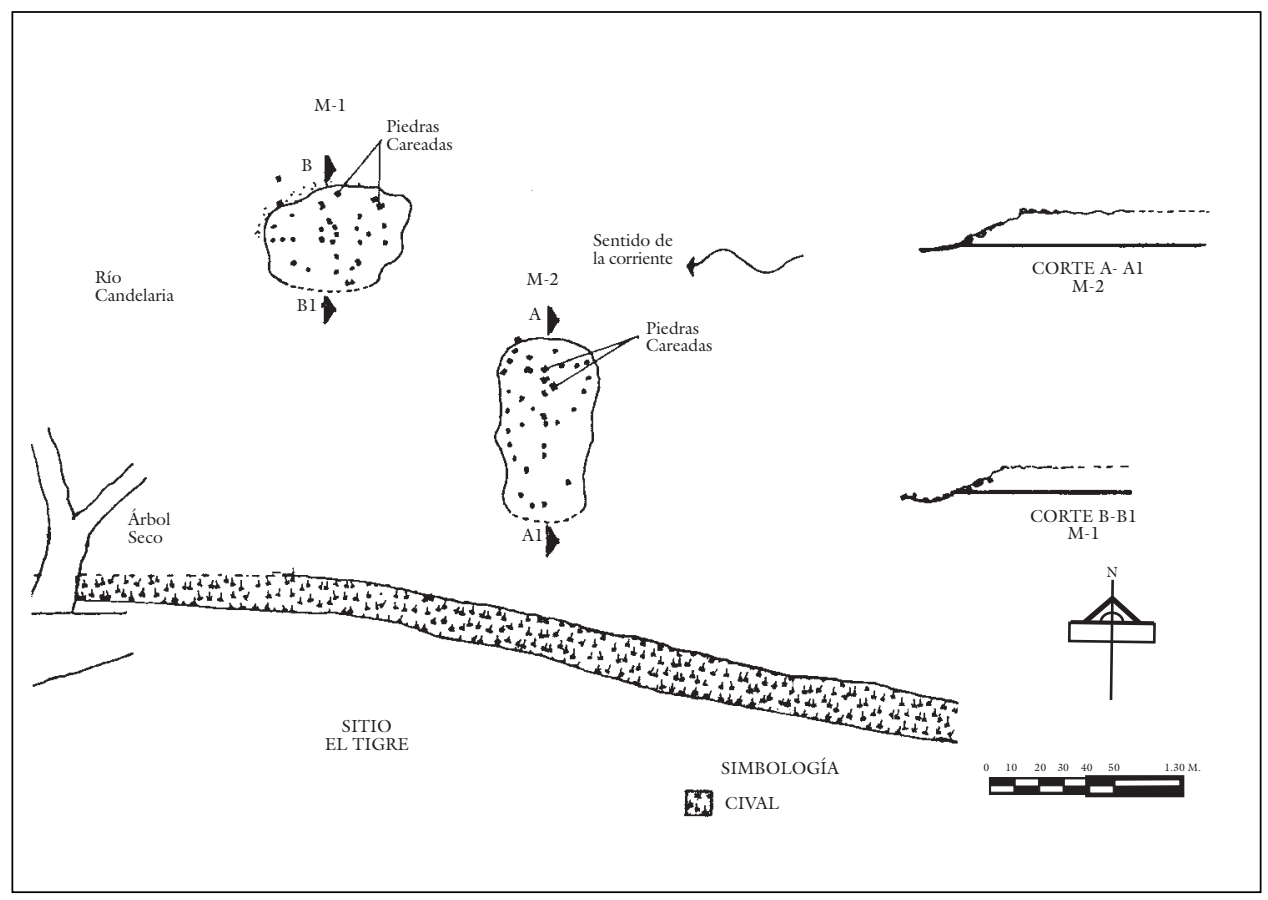

Mapa 13. Localización del posible puente (S. Analco). 


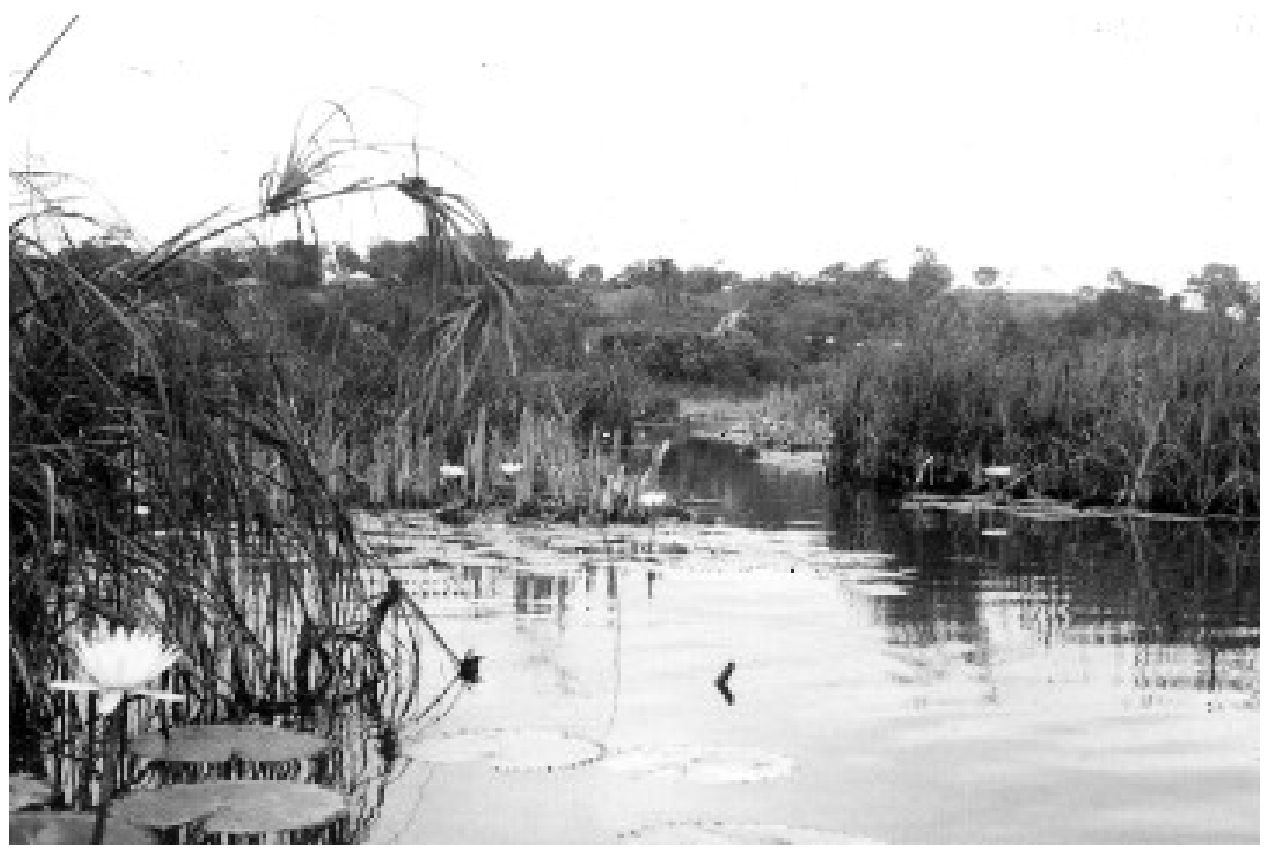

Fotografía 25. Canales del río C andelaria, frente a EI Tigre.

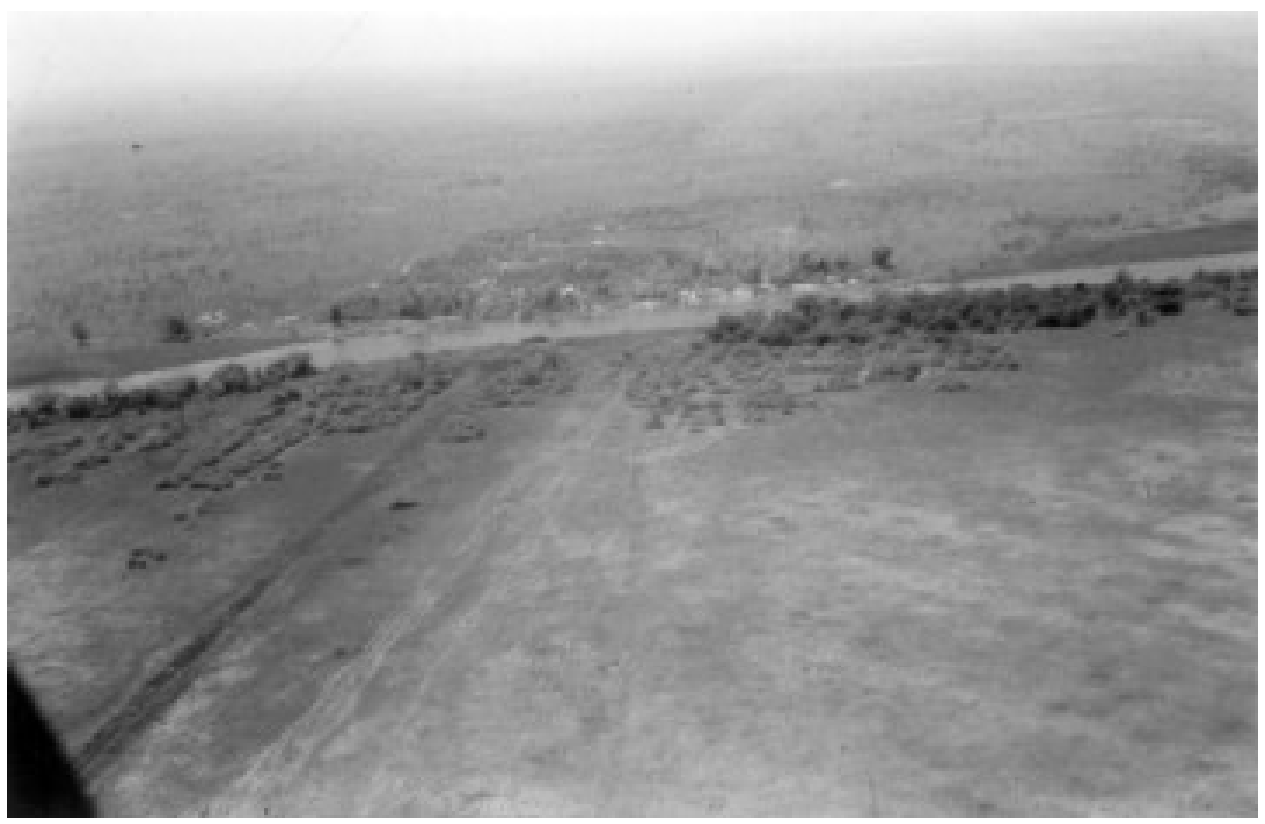

Fotografía 26. Campos levantados cerca de la población de EI Tigre. 
Siemens, en los años de 1995 y 1996, ha seguido con los estudios de los campos elevados; sus trabajos están en proceso.

La extensión de los campos elevados puede ser de 300 hectáreas; son sistemas de cultivo en las tierras pantanosas por medio de procedimientos semejantes a los que se emplean en las tierras altas (Palerm y Wolf 1973: 28-9), así como sistemas de plataformas de cultivo rodeados por canales de 1 a $2 \mathrm{~m}$ de anchura. Se ha propuesto que pudo cultivarse maíz, gramíneas, algodón, cacao y raíces comestibles, entre otros (Siemens 1989: 71-80). Con una prueba del carbono 14 se pudo inferir que la construcción data de alguna época del periodo Protoclásico final ( $50 \mathrm{aC}$ al $250 \mathrm{dC}$ ) en adelante (ibidem: 79). Es interesante señalar también que hacia esa época se dio una de las menores descargas del río C andelaria (Gunn et al. 1994: 185), por lo tanto, la invención y construcción de los campos elevados fue seguramente necesaria para responder a un momento de mayor sequía, y de esa manera asegurar la alimentación, ya que el agua para regadío pudo ser extraída directamente de los canales y ser conducida a los campos.

EI sitio arqueológico de EI Tigre está delimitado al norte por el río C andeIaria, al oeste por lo bajos, al sur por la laguna del Pato y al este por bajos. Podemos decir que el sitio está rodeado de agua y para salvar la comunicación, sobre todo por el lado oeste, tuvieron que construir caminos sacbeob (fotografía 27) sobre los bajos, que tuvieron la finalidad de comunicar el sitio con otra sección; al sur sucede lo mismo, pero estos sacbeob tal vez tuvieron la doble función de comunicar y separar el nivel del agua. Los

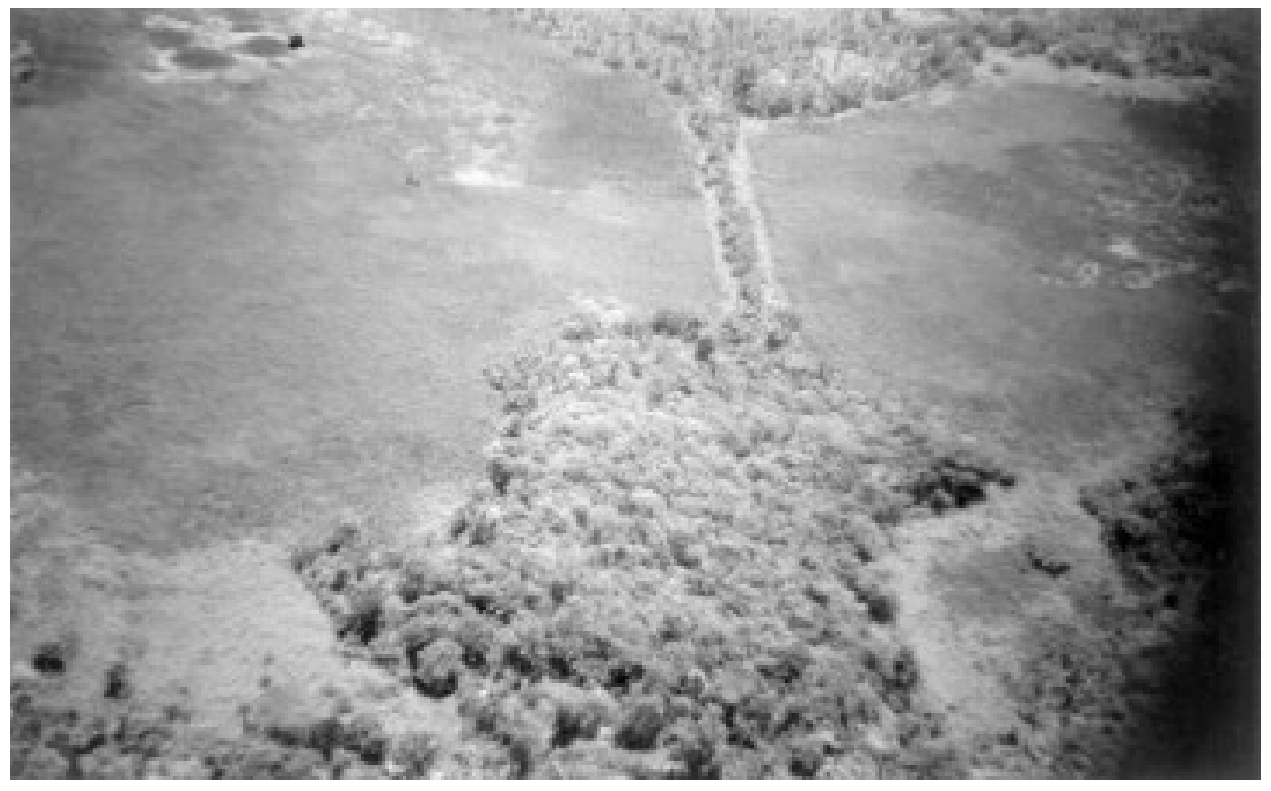

Fotografía 27. Sacbe construido sobre los bajos. 
acalanes controlaron dicho nivel por medio del sacbe que funcionó como dique, ya que es una barrera artificial y sólo dejaba una comunicación estrecha por medio de un puente. Se han localizado tres sacbeob, pero pueden existir más, pues en los últimos años la destrucción ha sido muy grande. $D$ entro del sitio también se han encontrado varios caminos, que comunican la parte central con los bajos y hacia el río.

La ciudad tenía un sistema hidráulico muy bien planificado y diseñado para permitir el escurrimiento controlado del exceso de agua de lluvia, mientras captaba la cantidad de agua necesaria para su sobrevivencia y sus más de 15000 residentes. J usto al lado y atrás de la E structura 1 se encuentran varias aguadas (fotografía 28); al parecer, cuando una de éstas alcanzaba su límite de capacidad, el exceso de agua seguía un nivel menor que la transportaba hacia otra aguada localizada más abajo.

L os bajos determinan los límites de EI Tigre, que parece fueron considerados importantes como tierras de cultivo por los antiguos mayas, quienes practicaron una forma de horticultura que incluía dos cosechas de maíz, una temprana y otra tardía.

L os mayas fueron hidrólogos altamente capacitados; sin embargo, cualquier cambio significativo en el patrón de lluvias a lo largo de varios años pudo haber tenido un efecto contundente sobre determinados lugares.

No obstante, si estos cambios se prolongan y se generalizan sobre la mayor parte del área maya, podrían causar el derrumbe de los E stados y las regiones. Por esto se sugiere la hipótesis de que los E stados anteriores, re-

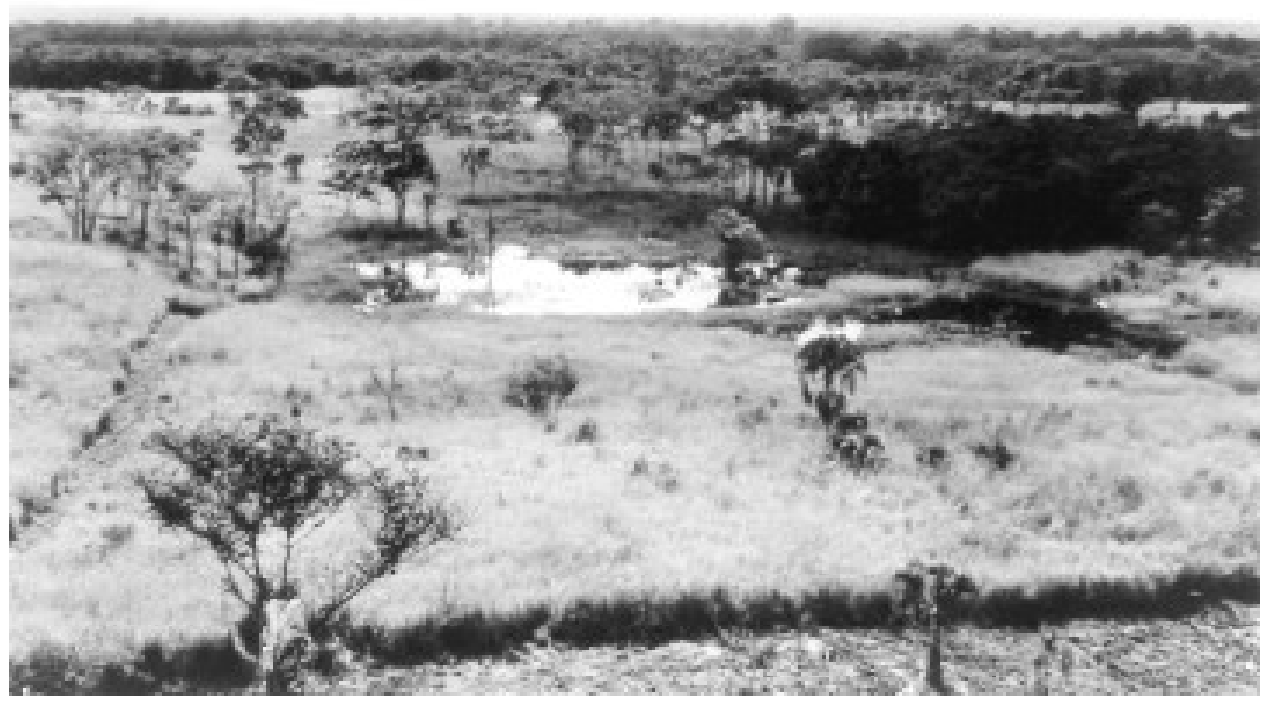

Fotografía 28. U na de las aguadas más grandes de EI Tigre. 
gionales como Calakmul, sufrieron serios reveses durante el siglo Ix, por ejemplo, debido a las escasas Iluvias que disminuyeron los nacimientos y forzaron a la mayor parte de la población a movilizarse hacia otras áreas que tenían los beneficios de las grandes lagunas, ríos y otra clase de aguas superficiales permanentes que no se encontraban en el Petén del norte (Folan 1994: 66).

Los acalanes dependían del agua, tanto la escasez como la abundancia fueron maléficos, pero sin lugar a duda lograron adaptarse, aunque en ocasiones sufrieron los estragos del agua.

\section{Los afluentes: el Caribe y el San Pedro}

El río Caribe es uno de los brazos que al juntarse con el San Pedro en boca de Santa I sabel forman el río C andelaria. Remontando éste seguramente se puede llegar hasta la laguna de Cilvituc, también hasta Concepción y desde allí, por medio de otros bajos, a Calakmul. Según algunos mapas, este río nace en la vecina R epública de Guatemala. En lo personal, sólo he llegado hasta L as Palomas, desde allí el río empieza a estrecharse considerablemente hasta la laguna de Salsipuedes. La información que tengo es que sí hay un sitio arqueológico en Salsipuedes y otro en el arroyo Selva N egra; al parecer, éste es bastante más grande; otro que se llama Las Ruinas, se localiza como a $4 \mathrm{~km}$ de Torres Burgo, es bastante grande y pienso que pertenece más al estilo Petén, está en los límites de lo que es la Provincia de Acalan. En un trayecto de un poco más de $20 \mathrm{~km}$ no hay sitios arqueológicos, por lo tanto pienso que desde el Pedregal para arriba podemos considerarlo como tierra de nadie o cehache - por lo menos no es tierra de los chontales acalanes-; esta apreciación se basa en que la cerámica ya no es anaranjada, las construcciones arquitectónicas se relacionan más con el Petén que con el Tigre y empiezan a aparecer inscripciones como en el caso de Las Ruinas.

En los recorridos arqueológicos por el río Caribe se han localizado siete sitios; Ios más importantes son Cerro de los M uertos y Santa Clara (fotografía 29), ambos localizados en la margen izquierda del río. Podemos pensar que C erro de los M uertos es más temprano, pues sus materiales cerámicos en superficie corresponden al Preclásico y Clásico temprano; mientras que Santa Clara se identifica con el Clásico terminal, tiene algunas estructuras muy parecidas a EI Tigre y desde allí se pueden ver las principales pirámides de éste. L os otros sitios son menores, con excepción de El Zarzal, que puede clasificarse como sitio de segundo o tercer orden y también corresponde al Clásico terminal. Boca de Santa I sabel es un sitio pequeño, que se localiza casi en la confluencia de los dos ríos; su papel debió ser muy importante porque desde allí se alcanza cualquiera de las dos orillas. 


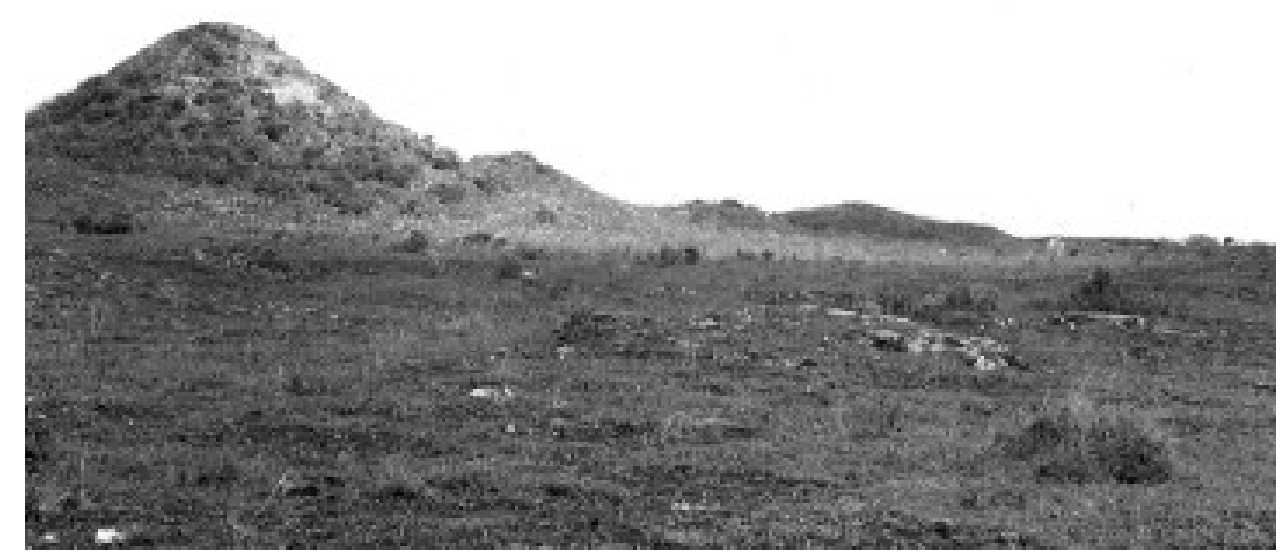

Fotografía 29. Santa Clara, localizado a orillas del río Caribe.

En la margen derecha del río Caribe también se localizan los canales; éstos son más abundantes frente a los sitios de Cerro de los M uertos y Santa Clara y llegan hasta el Pedregal.

\section{Río San Pedro}

A orillas del río San Pedro también se ha localizado un buen número de sitios arqueológicos, aproximadamente siete. É stos son medianos y dominan gran parte de la corriente fluvial; allí se ha encontrado una buena concentración de canales y también cerca de Monclova se hallaron vasijas prehispánicas en el río (fotografía 30). También son dignos de mencionar los manantiales de $\mathrm{M}$ iguel $\mathrm{H}$ idalgo que alimentan al río San Pedro.

La mayor concentración de sitios arqueológicos se da entre M onclova y Estado de M éxico. Éste río tiene gran relevancia, porque al parecer se interna hasta Guatemala, muy cerca de Tikal. El afluente de N ueva Esperanza también tiene una dirección que va hacia el Petén guatemalteco. En un recorrido por lancha no localizamos ningún sitio arqueológico, aunque su navegación se dificulta por ser estrecho y tener en la actualidad mucha palizada en sus aguas a consecuencia de los huracanes; es posible que fuera navegable en cayuco durante la época prehispánica. 


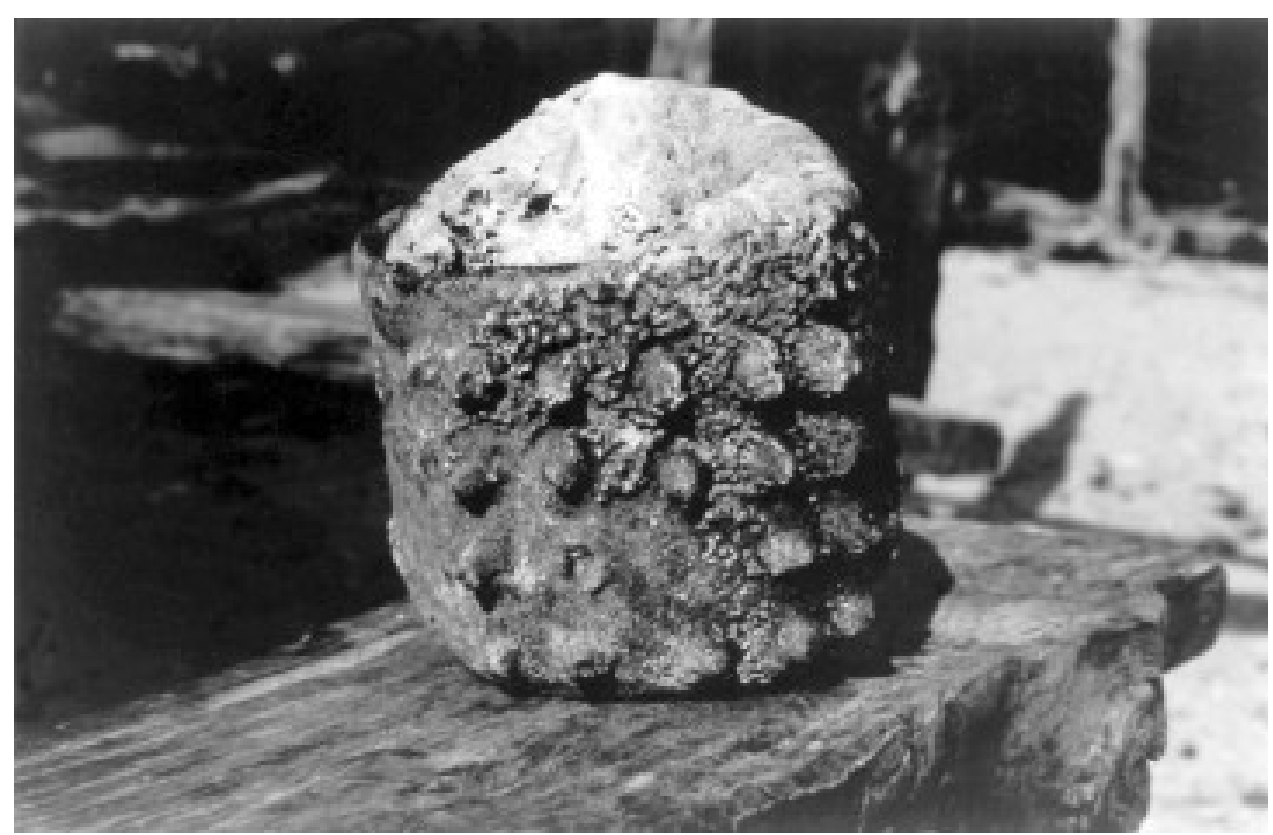

Fotografía 30. Vasija encontrada por los pescadores en el río San Pedro.

EL AGUA EN LA COSMOVISIÓN MAYA-CHONTAL

Los chontales o putunes vivieron al filo del agua para bien o para mal, y mucho tiempo de su vida giraba alrededor de ella. Su cosmovisión - un concepto que hace referencia al conjunto de ideas que tiene un individuo 0 un grupo con respecto al mundo que lo rodea- debe reflejar ese contacto íntimo entre el hombre y el agua. El estudio de las concepciones indígenas debe partir del conocimiento de las sociedades que las crean y tiene que dar debida cuenta del mundo natural y social en que los creadores han vivido (López Austin 1984: 7; Broda 1991: 461-500).

Los chontales, al igual que los otros grupos mayas, presentan la misma estructura del cosmos. El universo está integrado por tres niveles o planos en una dimensión vertical: a) en medio se encuentra el territorio chontal, tierra, ríos y el mar; b) abajo está el mundo subterráneo o inframundo; y c) arriba se halla el cielo.

Según la visión chontal del mundo, el territorio se encuentra en un plano horizontal cubierto por una media esfera -el cielo-, por la que transitan el sol, la luna y las estrellas. En los confines del mundo, el cielo toca al mar (Vásquez et al. 1994).

Arriba de la tierra se encuentra el cielo, capa donde se localizan los astros. Al Sol se le considera de sexo masculino y es el dador de fuerza y calor. La L una es la gemela, la esposa del Sol, y sus atributos son el agua, la Iluvia, la vegetación y la fertilidad, se le relaciona con Ix Bolom. 
La L una vivió entre los chontales y, según una versión, se dice que existió una anciana que moraba en el río y la gente la llamaba Bolom. La viejecita se bañaba en el río los jueves y los sábados, y en una ocasión la gente de Tucta fue a verla, pues se perdían con frecuencia niños en el pueblo. Al espiar a Bolom, notaron que era una mujer muy bonita de cabello largo; al voltear ella su cabeza pudo ver que la observaban. No pasó mucho tiempo cuando la anciana desapareció del lugar. Esto hizo que el río se cerrara... (Pérez 1968).

Para los chontales de Vicente Guerrero, Bolom es la dueña de los mares, en los cuales habita en una casa de chapopote (I ncháustegui 1987). Bolom significa nueve y es un número ritual para los chontales en relación con el inframundo.

El inframundo era un lugar oscuro y frío dentro de la tierra, a donde iban la al mas de los muertos. En la mitología maya, los dioses del inframundo regían la lluvia y la fertilidad; habitaban las cuevas, lugares de transición entre día y noche, vida y muerte, representaban las fauces abiertas de la tierra.

Para los chontales y para los mayas yucatecos, el número nueve tenía connotaciones acuáticas, frías, de inframundo. En Comalcalco se encuentran nueve efigies estucadas en bajorrelieve, que se pueden relacionar con los señores de la noche; lo cual nos permite inferir que el inframundo estaba gobernado por los Bolom T iku o nueve señores de la noche, descritos en el Chilam Balam de C humayel.

El dios del número nueve era conocido como C hicchan, la serpiente celeste que envía las lluvias, y se le representaba como un joven con manchas de jaguar. Chicchan es el nombre del quinto día de los veinte signos del tzolkin, asociado con el rojo y el este, correspondiente a serpiente.

Entre los chortis de G uatemala todavía perdura la deidad de los chicchanes (Wisdom 1961: 444), de la cual se piensa es una serpiente gigantesca, la más importante; es masculina y femenina, plural y singular y puede equivaler al Kukulcán de los mayas yucatecos. «Los chichanes del cielo provocan la mayoría de los fenómenos celestes, son cuatro. Cada uno vive en una de las direcciones (o puntos cardinales) del mundo, en el fondo de un gran lago. El del norte es el jefe y da órdenes a los otros tres, que son sus ayudantes».

L os chubascos y tormentas son causados por el paso veloz de una chicchan (deidad femenina) por el cielo. El arco iris es el cuerpo de un chicchan extendido en el cielo. El trueno es el grito de un chicchan a sus compañeros que están al otro lado del firmamento; sus respuestas producen un trueno continuo.

Se piensa que en los ríos, fuentes o depósitos de agua vive un chicchan, y cuando se secan se debe a que éste ha muerto y por lo tanto ha perdido el espíritu o esencia. También se cree que las crecientes son causadas por una serpiente que desciende del cielo y vive en una fuente; al morir ésta el río se 
seca. D urante la estación de lluvias habitan en los ríos, durante la de secas en las colinas, y en el mar y los lagos durante to do el año.

Los chicchanob, conforme se acerca la estación de secas, remontan el curso de los ríos para ir a pasarla cerca de las fuentes. Al advenimiento de la estación de lluvias, descienden de las colinas y penetran en los cursos de los ríos, haciendo subir su caudal por efecto del desplazamiento del agua que sus cuerpos provocan. Si son muchos los que nadan al mismo tiempo río abajo, las aguas se desbordan y causan inundaciones.

A veces los chicchanob se desplazan de un arroyo a otro y provocan aludes y destrucciones, por eso cuando ha habido un huracán se dice que un chicchan ha pasado.

Cuando los ríos disminuyen gradualmente se cree que los chicchanob los están abandonando para trasladarse a sus fuentes de origen. E n conclusión, nos dice Wisdom (ibidem: 447), los chicchanob son responsables de los estados benéficos y perjudiciales de la tierra y del cielo.

El Popol Vuh (Recinos 1964) en su primera parte describe la creación, el origen del hombre y los varios ensayos infructuosos. En el capítulo primero nos dice que la faz de la tierra no se manifestaba, sólo estaba «el agua en reposo, el mar apacible. N o había nada dotado de existencia». Según el libro sagrado de los quichés, la tierra, los valles y las montañas surgieron del agua, estaban sumergidas dentro de ella y así fue como «se dividieron las corrientes de agua, los arroyos se fueron corriendo libremente entre los cerros y las aguas quedaron separadas cuando aparecieron las altas montañas».

H uracán, Tepeu y Gucumatz, el creador, el formador y los progenitores hicieron de lodo la carne del hombre, pero vieron que no estaba bien porque dentro del agua se deshacía y no podía sostenerse. Entonces desbarataron y deshicieron su obra y su creación. Y en seguida dijeron: ¿cómo haremos para perfeccionar, para que salgan bien nuestros adoradores, nuestros invocadores?

Después de una consulta el creador y el formador labraron muñecos de madera, los cuales se parecían al hombre, pues hablaban como él y poblaron la superficie de la tierra. Existieron y se multiplicaron; sin embargo, poco después ya no se acordaron del corazón del cielo y por eso cayeron en desgracia. Fueron aniquilados, destruidosy deshechos los muñecos de palo, y recibieron la muerte. U na inundación fue producida por el corazón del cielo; se formó un gran diluvio que cayó como castigo sobre las cabezas de los muñecos de palo.

La tercera creación también fue infructuosa; "como no pensaban, no hablaban con su creador y su formador, que los habían hecho, que los habían creado», fueron muertos y anegados; el agua nuevamente fue el factor destructor de la humanidad. En el texto del Popol Vuh, del agua nacen los valles, las montañas y la tierra, pero el agua también destruyó las tres frustradas creaciones del hombre.

La existencia de ríos no sólo se da en la tierra sino también en el inframundo. EI Popol Vuh describe cuatro que tienen que pasar $\mathrm{H}$ un-H unahpú 
y Vucub-H unahpú; el primero de ellos corría rápidamente entre los barrancos llamados $\mathrm{N}$ u ziván cul y Cuziván. Luego pasaron por el río que fluía entre jícaras espinosas. D espués fueron a la orilla de un río de sangre y lo atravesaron sin beber su líquido. L legaron a otro río solamente de agua y no fueron vencidos. Siguieron adelante hasta acercarse al lugar en que se juntaban cuatro caminos y allí fueron vencidos.

H unahpú e Ixbalanqué, al ir al Xilbalbá, pasaron por varios ríos y barrancas: uno de «podre» y otro de sangre; sobrevivieron a todas las pruebas que les impusieron los señores de X ibalbá mostrando absoluto dominio tanto en las ceremoniales, como en las de ingenio y perseverancia.

Sin embargo, llegó el momento de la muerte en el que los gemelos debían morir; para ellos era claro que también la resurrección se daría en el elemento que propiciaba la fertilidad y la vida: el agua.

H unahpú e Ixbalanqué dejaron instrucciones a Xulú y Pacam de lo que debían hacer después de su muerte. A mbos se lanzaron a la hoguera en forma voluntaria, frente a los señores de Xibalbá, y murieron de esa manera ante el júbilo de los señores, a pesar de que nunca habían sido derrotados por la fuerza.

Y cuando por tercera vez os digan: ¿Será bueno que arrojemos sus huesos al río?; si así os fuere dicho por ellos: Así conviene que mueran - diréis-; luego conviene moler sus huesos en la piedra, como se muele la harina de maíz; que cada uno sea molido [por separado]; en seguida arrojadlos al río, allí donde brota la fuente, para que se vayan por to dos los cerros pequeños y grandes (Recinos 1968).

D e esta manera los gemelos establecieron claramente al elemento agua como el apropiado para la resurrección; permanecerían en el fondo de río para luego resucitar. Sus huesos no fueron muy lejos, pues se asentaron en el fondo del río y se convirtieron en hermosos muchachos: «Al quinto día volvieron a aparecer y fueron vistos en el agua por la gente. Tenían ambos apariencia de hombres-peces cuando los vieron los de Xibalbá, después de buscarlos por todo el río».

H unahpú e I xbalanqué son deidades pluviales, Gucumatz, serpientes que viven en fuentes de agua. EI renacimiento se daal quinto día, que a su vez está relacionado con Chicchan, que es el quinto día del mes. Se le ve con la apariencia de hombre-pez en el río, porque es hijo de Gucumatz, la gran serpiente emplumada cósmica y del lagarto terrenal, su compañero, ambos acuáticos.

$\mathrm{El}$ dios «D » era el lagarto celeste y también terrestre: una deidad benévola, siempre amiga del hombre. $\mathrm{N}$ unca se ve asociado su nombre con la destrucción o el desastre, tampoco aparece en los códices acompañado de los símbolos de la muerte. Era el señor de los cielos, de la noche y del día.

Itzamná (figura 9) al parecer no es originario de Yucatán, fue traído de alguna otra parte, posiblemente haya sido transplantado del Petén, pues 


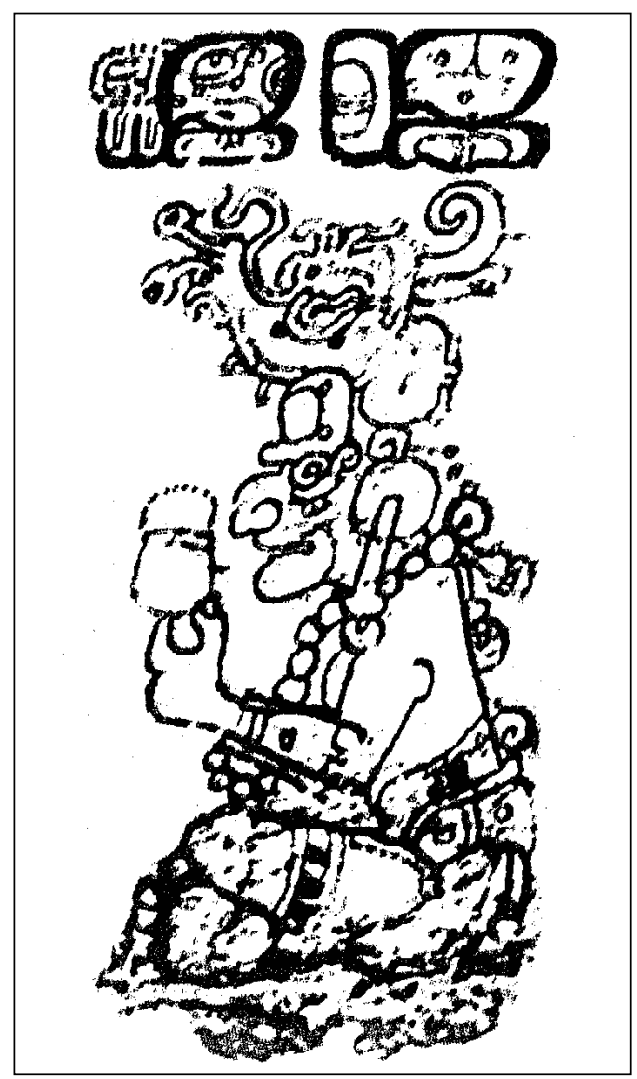

Figura 9. I tzamná, C ódice de D resde.

fue el primer sacerdote y el inventor de la escritura que se desarrolló primero en la época Clásica en el Petén. Su nombre tiene dos jeroglíficos, uno puede ser una representación convencional de su cabeza y el otro contiene como elemento principal el signo del día ahau «rey, monarca, gran señor»; de manera que el segundo de los jeroglíficos de I tzamná declara su posición como jefe del panteón maya yucateco, era el patrono del día ahau, el último y más importante de los veinte días mayas.

Itzam $\mathrm{Na}$, (C asa de I guanas). Itzamná era ante todo el dios de los jerarcas, mientras que los chacs eran los favoritos de los campesinos; este culto posiblemente desapareció rápidamente al hundirse la antigua élite gobernante después de la conquista hispana. Los nobles llegaron a considerarlo durante el Clásico como el único dios, y los demás seres sus criados o inferiores. Al terminar el Clásico ese monoteísmo que postula Thompson (1975: 286) caducó; tal vez por ser un culto demasiado abstracto, no gustó a los campesinos. Fue el dios máximo de los mayas yucatecos, pero en algunos aspectos era el más confuso, porque incorporaba en él muchos elementos de otros dioses. Aunque posiblemente su característica más im- 
portante fue que concebía la superficie de la tierra como un cocodrilo que flotaba sobre un enorme estanque, por lo que I tzam $\mathrm{N}$ a fue en efecto una representación del universo maya.

EI M ascarón 3 explorado en EI Tigre corresponde al Preclásico superior, bien podría ser la representación temprana de un lagarto (Itzamná), y este dios, como lo dijera Thompson, fue introducido a Yucatán de otra región. Por lo tanto su origen se podría localizar en el territorio de Acalan, lugar en donde abunda el lagarto.

Ixchel (figura 10), la esposa de Itzam $\mathrm{N}$ a, era también la diosa de la luna, diosa del parto y, entre otras, se relaciona con la fertilidad y el agua.

Ixchel tenía grandes santuarios en Cozumel e I sla M ujeres; probablemente los itzaes putunes introdujeron su nombre en Yucatán cuando conquistaron Chichén I tzá y posteriormente C ozumel, pues Ixchel era una de las principales divinidades de los putunes.

D os de las grandes ciudades de los putunes acal anes fueron I tzamkanac y Tixchel. La primera bien podría significar «en la segunda casa de la I guana». O tto Schumann sugiere que quizá sea «en la segunda cintura de la iguana», es decir, que el nombre involucra a este dios principal de los yucatecos, I tzam $\mathrm{Na}$, y nos da a entender que la segunda casa de la I guana-cocodrilo también podría significar que está a la mitad de una región, lo cual es cierto pues se

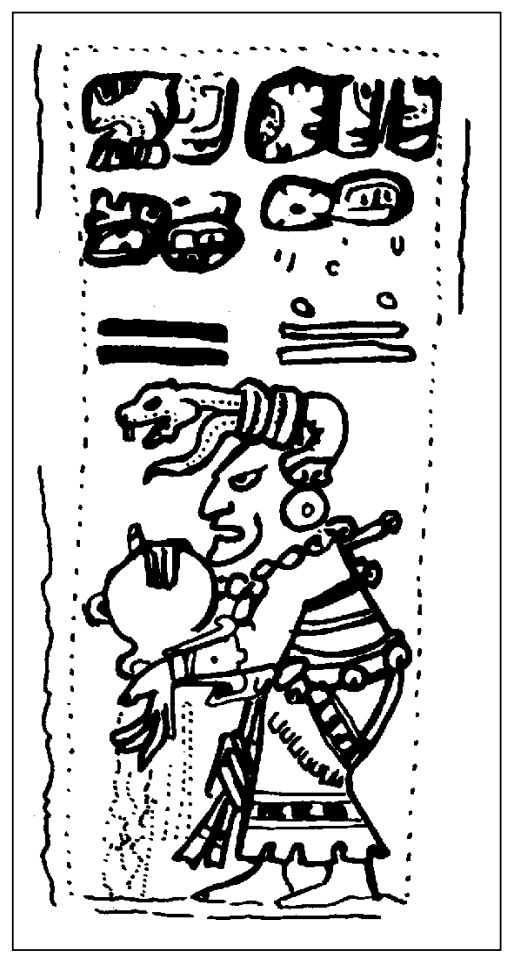

Figura 10. La diosa Ixchel, esposa de Itzamná. 
encuentra casi en el centro de la región del río Candelaria. L a otra traducción nos indicaría que Itzamkanac fue la segunda casa de los itzaes.

Tixchel significa «en el lugar de Ix Chel», recordemos que el primer Señor de los magtunes vino de Cozumel, su hijo Pachimal consolidó el gobierno y Champel, nieto de Auxaual, conquistó la Laguna de Términos, Boca N ueva y Puerto Escondido. El cuarto rey Paxgua cambió la capital a Tixchel: «este rey fue el que pobló a Tixchel».

Los pueblos vecinos de Champotón, Xicalango y Tabasco hicieron la guerra contra los intrusos, quienes tuvieron que ir a otro lado, I tzamkanac. «Y así dejaron Tixchel despoblado y se fueron a magtún que llaman Acalan» (Scholes y Roys 1968).

Pasaron varios reyes o señores y le to có a Paxbolom A cha establecer su capital en Acalan-I tzamkanac: «este era el rey que pobló Acalan». Su nombre, como dijimos con anterioridad, tiene que ver con la guerra; Pax era el mes en que se celebraban ceremonias en pro de la guerra y bolom está relacionado con la luna y con el número nueve, que a su vez se relaciona con el inframundo, y lógicamente con I xchel.

$\mathrm{L}$ os Papeles de $\mathrm{P}$ axbolom $\mathrm{M}$ aldonado (ibidem) son muy claros al respecto, ya que nos dicen que los pobladores de Tixchel son los descendientes del primer rey magtún que llegó de Cozumel, en donde sabemos que estuvo el principal santuario de Ix Chel, quien a su vez fue una de las diosas principales; sin lugar a duda el nombre de I tzamkanac está muy relacionado con I tzamná, que es otro de los dioses importantes de los mayas yucatecos, y posiblemente su nombre se deba a la permanencia de los itzaes en la región de Acalan desde por lo menos el 700 dC.

\section{LAS CATÁSTROFES}

L a provincia de Acalan, por ser una región de ríos, lagunas y pantanos, estuvo sometida a momentos críticos y problemáticos por las sequías y la abundancia de agua a consecuencia de los huracanes. E ra además la puerta de entrada al área maya y seguramente ése fue otro factor importante de perturbación, pues allí llegaron diferentes grupos que provocaron inestabilidad y conflictos.

Los mejores estudios sobre cambios climáticos fueron realizados en el Petén; por ejemplo, en EI M irador hay un descenso y abandono súbito alrededor del año de $150 \mathrm{dC}$ y corresponde a un periodo seco ( $M$ atheny 1987: 321). El M irador llegó a ser uno de los más grandiosos centros mayas durante el Preclásico; sin embargo, murió abruptamente coincidiendo con condiciones climáticas de suma sequía ( $D$ ahlin 1983: 251). Por medio de una prueba con carbono 14 , se puede inferir que la construcción de los campos levantados de EI Tigre datan de alguna época del periodo que va 
desde 50 años aC hasta el año $250 \mathrm{dC}$, que coincide plenamente con lo planteado por Gunn, Folan y Robichaux (1994: 174-96). Los campos levantados habían sido construidos por la necesidad de asegurar la producción de alimentos en un periodo de sequía. Se sabe que ese periodo corresponde a una de las menores descargas del río Candelaria y por lo tanto los niveles del río estarían entonces muy por abajo de los actuales.

Al hacer una simple correlación de las estimaciones de la descarga de aguas en el río Candelaria, se aprecia claramente que hacia el $535 \mathrm{dC}$ se dieron las mayores descargas del río, lo que indica que los niveles debieron estar por lo menos a 9 m sobre el nivel actual, motivo por el cual sus habitantes lo abandonaron durante ese periodo y lo repoblaron hacia el 700 dC-950 dC, cuando ocurrió un periodo tibio, acompañado de precipitación moderada. Alrededor del $800 \mathrm{dC}$ las ciudades de las tierras bajas del sur y áreas adyacentes empezaron a declinar y seguramente la población buscó condiciones climáticas más seguras; por tal motivo la región de ríos y lagunas de Tabasco-C ampeche fue ampliamente favorecida. Los niveles más bajos de humedad se dieron alrededor de 1400 dC y prevalecieron hasta casi la conquista; por ello no es difícil pensar que en 1525, cuando Cortés pasó por I tzamkanac, el río $\mathrm{C}$ andelaria estuviera en sus niveles más bajos y la construcción de un puente no hubiera sido tan problemática como cuando estaba en sus niveles más altos.

E ste modelo (G unn, Folan y R obichaux 1994) lógicamente tendrá que ser mejor estudiado y deberá refinarse; sin embargo, la propuesta hecha por ellos y la arqueológica presentada por varios investigadores que han trabajado el área, coinciden de manera general, pues se sabe que existió una ocupación importante durante el Preclásico superior, una disminución de población hacia el Clásico tardío, una mayor ocupación en el Clásico terminal, una desocupación parcial hacia el Postclásico temprano y una reocupación durante el Postclásico tardío. Las explicaciones que se han dado a esto simplemente se refieren a que en momentos determinados los intereses comerciales se dirigían hacia el Petén y en otros hacia Yucatán. Ahora estamos en la posibilidad de pensar que obedecieron a otros factores como los climáticos, que lógicamente deben ser explicados de alguna manera y allí entrarían los cosmogónicos, como la concepción del tiempo cíclico, el katún 8 ahau, que es catastrófico y seguramente debe combinarse con eventos astronómicos y naturales, además de calamidades y guerras como la sostenida en el $695 \mathrm{dC}$ por Calakmul y Tikal, en donde ésta última salió vencedora, creando lógicamente una inestabilidad en la región del río $C$ andelaria y permitiéndole cierta independencia, porque al parecer ésta se relacionaba en gran medida con Calakmul.

$L$ as ofrendas encontradas en el río y fechadas alrededor del 950 dC fueron consagradas a éste, ya que en ese momento las descargas de agua eran menores y tenían que ofrecerle ollas como acto ritual para asegurar 


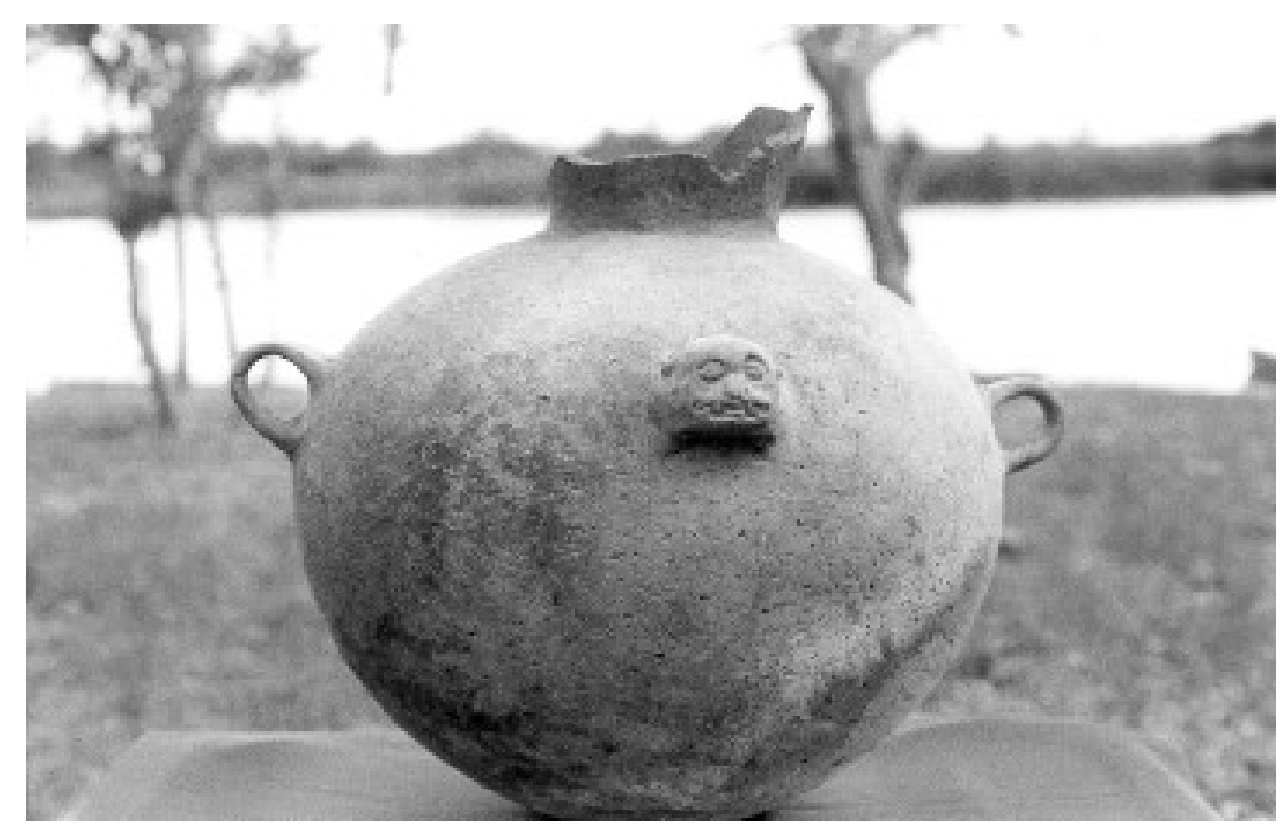

Fotografía 31. O frendas de cántaros en el río C andelaria.

de alguna manera el flujo del preciado líquido (fotografía 31). La construcción de los diques, que podría fecharse alrededor del 900 dC, sin lugar a duda obedece a una forma práctica de resolver el problema del nivel del río.

Acceder a las grandes capitales chontales, Potonchán, Xicalango y AcaIan, al parecer no fue tan fácil, se necesitaba un sistema de control y no todos podían llegar al centro; seguramente también había un sistema de comercialización muy bien organizado, como insinúa el registro de sitios en los mapas, en donde se localizan algunos de diferentes categorías, que debieron tener diversas funciones y en los periodos de sequía o sobreabundancia de agua sufrieron los efectos de manera catastrófica. 



\title{
Capítulo II \\ ITZAMKANAC CABECERA \\ DE LA PROVINCIA DE ACALAN
}

\author{
La Provincia de Acalan
}

Frontera y extensión de la provincia

Contamos con información histórica que describe la llegada de los primeros españoles a I tzamkanac desde diferentes puntos por el U sumacinta o por el río C andelaria; gracias a ello podemos local izar la capital de los acalanes. Cortés se presentó en 1524, Alonso Dávila fundó Salamanca de I tzamkanac pocos años después, los encomenderos también describieron el trayecto que hacían de I tzamkanac a Xicalango y, al respecto, no hay duda de que todas esas fuentes históricas se refieren al río C andelaria y a EI Tigre como la capital de Acalan.

Según las fuentes históricas, la provincia de Acalan abarca desde Tixchel a orillas del mar, parte de la Laguna de Términos y toda la cuenca del río C andelaria hasta por lo menos el río San Pedro M ártir. I tzamkanac fue la capital o cabecera de la provincia y ha sido identificada con el sitio arqueológico de El Tigre (Scholes y R oys 1968, Piña C han y Pavón Abreu 1959, O choa y Vargas 1986, Gerhard 1991, Vargas 1994).

La provincia de Acalan estaba muy bien poblada, comprendía 76 pueblos y aldeas que se mencionan en el texto chontal de Paxbolom $M$ aldonado y, según Bernal Díaz del Castillo (1974), algunos de los pueblos estaban en tierra firme, otros sobre «algo a la manera de islas»; él obtuvo 100 canoas cargadas de alimentos de «ciertos [pueblos] situados entre algunos ríos».

M uchos de estos asentamientos son difíciles de identificar, pues los nombres y datos de la mayoría se han perdido en el tiempo, porque poco después de la conquista los pobladores de I tzamkanac y sus alred edo res fueron trasladad os a Tixchel.

En 1530 existían aproximadamente diez pueblos encomendados y en 1540 sólo una encomienda: I tzamkanac; la población de la zona casi había desaparecido, pues el comercio, que fue la actividad principal del lugar, quedó prácticamente desarticulado al desaparecer los otros grandes puertos de intercambio a larga distancia. 
Los límites de la provincia de Acalan en el momento del contacto español pudieron ser esos, aunque debemos recordar que variaron en las diferentes épocas de ocupación, pues los intereses comerciales también cambiaron conforme se aprecia en los materiales arqueológicos.

Los expedicionarios españoles que entraron con Cortés a la Provincia de Acalan lo hicieron por el suroeste y salieron por el noreste, pasando por I tzamkanac su capital o cabecera. Cortés (1969: 125) narra el momento en que ingresaron a la provincia de Acalan de la siguiente manera: «[...] y dormí una noche en el monte y otro día poco más de mediodía allegué a las estancias y labranzas de la provincia de Acalan, y antes de llegar al primer pueblo della que se Ilama Tizatépetl».

Es un lugar que perteneció a la Provincia de Acalan pues en él recibió la visita del hijo de Paxbolom A cha, señor de aquella provincia. De allí, por consejo del cacique, Cortés (ibidem: 126) y sus soldados se fueron a un pueblo más grande que también era suyo: «muy hermoso: Ilámase Teutiaca, tiene muy hermosas mezquitas, en especial dos, donde nos aposentamos y echamos fuera los ídolos [...]».

El texto chontal (Scholes y Roys 1968: 371) nos dice que después de to car Xacchuté «llegaron a proveerse a Taxahá», por lo que ése podría ser el nombre en chontal de Teutierca.

Los primeros pueblos de la provincia debieron estar en el territorio que se localiza después del río San Pedro M ártir y por una gran parte despoblada. Sin embargo, los límites podrían ser mayores pues al llegar el primer rey magtún A uxaual, junto con los principales a la región chontal, provenientes de Cozumel, lo primero que hicieron fue conquistar Tenosique y posteriormente la costa, es decir, I sla del Carmen, Tixchel y por último I tzamkanac.

L os límites de la frontera sur de la Provincia de Acalan serían los poblados de Xacchuté y Taxahá; desde allí hasta el río San Pedro Mártir sólo habrían montes deshabitados; hacia el río San Pedro, afluente del Candelaria, se da la mayor concentración de sitios arqueológicos, lo que demuestra la vocación de la provincia hacia el comercio, pues ésa era la ruta fluvial importante hacia el Petén guatemalteco; ese sería un batabilob dependiente de I tzamkanac.

$\mathrm{H}$ acia el este, tomando como centro a EI Tigre (I tzamkanac), el dominio de Acalan se extendería sobre todo por el río Caribe, afluente del $C$ andelaria; más allá estarían los habitantes de la Provincia de M azatlán 0 cehaches, rivales de los acalanes.

La zona noroeste de la Provincia de Acalan estaría ocupada por una serie de sitios que se relacionan con los ríos $M$ amantel y Chivojá; entre los sitios chontales que se citan están los siguientes: C hivo há, Popolá, C hicbul, Chekubul, U sulabán y Tixchel entre otros; pero cerca de ellos también existía una población cehache, como es el caso de la población de Taquiache, que está a 4 ó 6 leguas al este de Popolá. 
Scholes y Roys (1968) hicieron un magnífico trabajo de localización de muchos de los poblados que registraron en la región, pero en algunos casos no han podido precisar la diferencia entre la población chontal y cehache; sin embargo, lo que sí se puede afirmar es que la población chontal se asentó en la costa hasta unos $30 \mathrm{~km}$ tierra adentro.

Las precisiones en la localización de algunos pueblos no son posibles, porque desde el primer momento en que los españoles llegaron a ese territorio las poblaciones empezaron a ser trasladadas a otros lugares por múltiples causas, sobre to do porque esa región se volvió un lugar de refugio a donde los indígenas huyeron de la colonización. D e esa manera se confundieron varios grupos mayas.

L as fronteras de la Provincia de A calan con sus vecinos los cehaches no pueden ser precisadas, no es sólo una característica de esta parte del área maya; sino que «las fronteras» se deben pensar como un área amplia donde interactuaban los grupos. Además, se sabe que el concepto de frontera rígida, al parecer, no existió, pues había enclaves de otros grupos dentro de un territorio que se decía, por ejemplo, Acalan. La multietnicidad quizá fue una de las características de los grupos chontales, pues sabemos que en la región de Tabasco convivían con nahuas, zoques y mixes, entre otros. Posiblemente en Acalan existieron también varios grupos diferentes, los magtunes, cehaches y los dzulob.

El tratar de definir una frontera con las características descritas sólo pretende ser una guía para la arqueología; así partimos de las fuentes históricas que hablan precisamente de la provincia de Acalan, la cual seguramente ocupó toda la cuenca del río Candelaria hasta la costa, gran parte de la Laguna de Términos e Isla del Carmen, el estero de Sabancuy, en donde se localiza Tixchel, y una faja importante del sur de Campeche.

\section{La estructura de la Provincia de A calan}

Con base en la descripción hecha por Scholes y Roys (1968) para la Provincia de Acalan, nos dimos a la tarea de hacer un reconocimiento de superficie, que abarcó caminar por tierra, brechas y caminos recién abiertos, navegar en lancha por lagunas y ríos casi intransitables, llenos de belleza y misterio. En el área registramos aquellos vestigios arqueoló gicos que pudimos identificar, utilizamos la fotografía aérea, mapas topográficos y espacio mapas para el mejor registro de los sitios, lo mismo que GPS.

EI análisis de los patrones arqueológicos de asentamiento ha llevado a que el término «unidad política» se convierta en un concepto muy popular dentro de la literatura especializada, y que designe libremente un amplio rango de entidades territoriales con distintas extensiones, niveles de complejidad sociopolítica y ubicación temporal. 
A nivel regional las unidades políticas no existen en aislamiento, sino que siempre aparecen acompañadas por otras de configuración semejante. Cuando éstas establecen una relación permanente de interacción se conforma lo que denominamos «esfera política», que puede identificarse por los siguientes elementos: mismo complejo cultural, una interacción permanente a todos los niveles, un mismo grado de complejidad política y una relación constante que tiende a ser paritaria, pero no excluye la posibilidad de conflicto. La esfera política en la región estaría formada por Xicalango, Potonchán y Acalan (mapa 14), ya que las tres participaban de los mismos elementos culturales.

Por lo tanto, la unidad política o provincia para los mayas la constituía «un espacio territorial donde se encuentra un conjunto de pueblos cuyos gobernantes están enlazados, con aquellas relaciones tan complejas de índole político-religioso, por el poder que reside en un pueblo y en ésta el vínculo personal determinado por la relación política entre gobernante y gobernados [...]» (Okoshi 1994: 282-3).

Partiendo de esta interpretación, las provincias de Yucatán no poseían una frontera bien definida ni tenían un trazo lineal; Acalan tampoco. Además, el vínculo político-religioso-económico entre gobernantes y gobernados cobraba un valor trascendental en los conceptos mayas de pueblo, jurisdicción

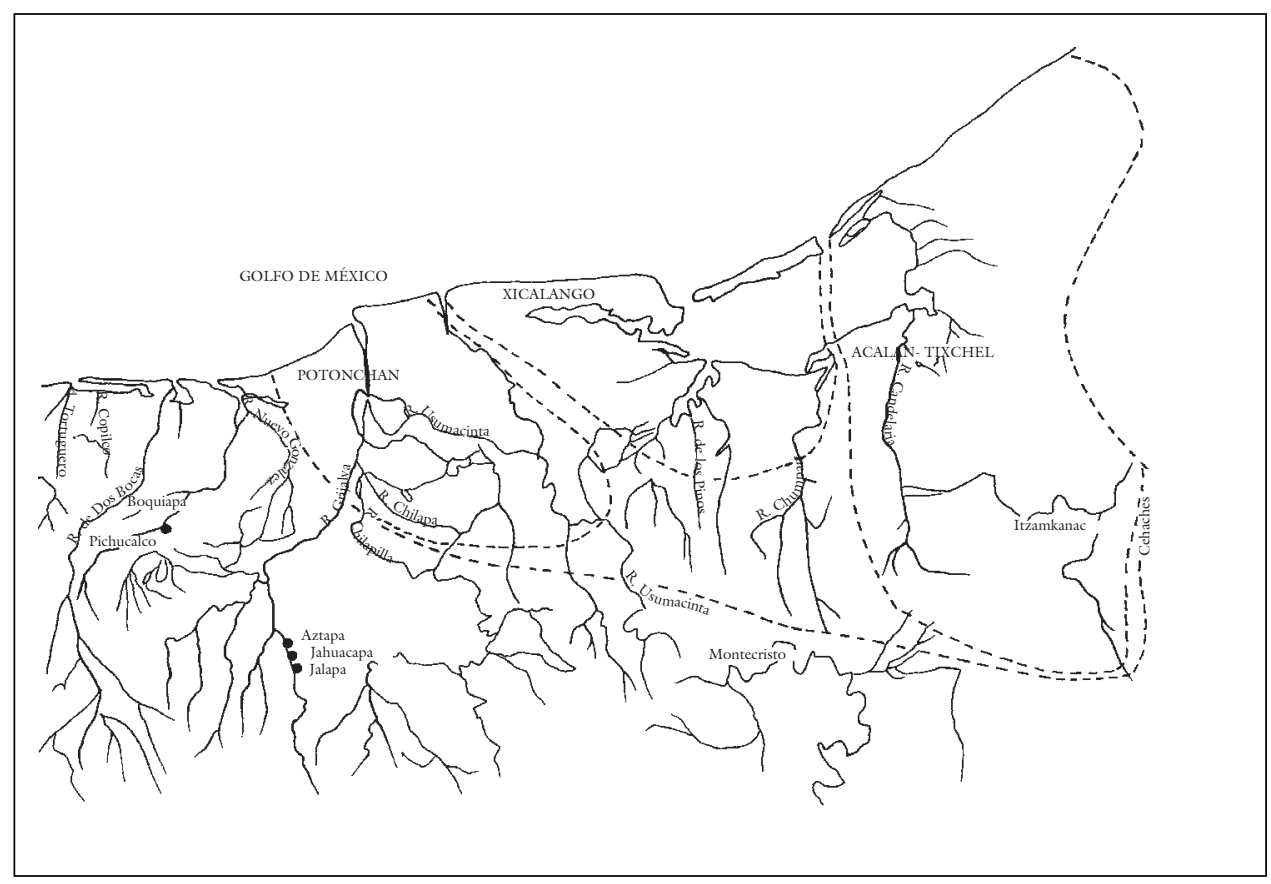

Mapa 14. Esfera política formada por Potonchán, Xicalango e Itzamkanac (modificado de Izquierdo 1997). 


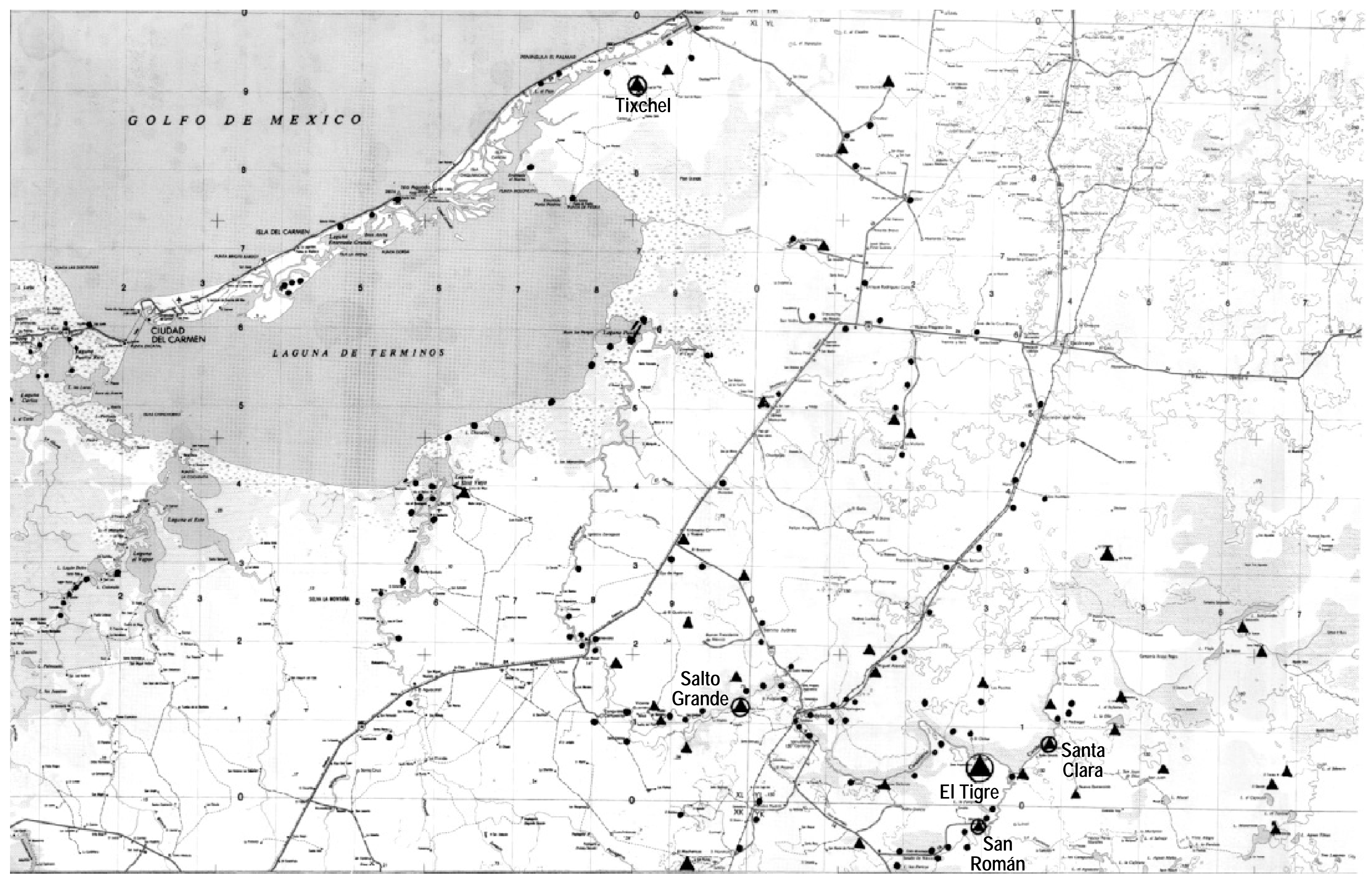

M apa 15. Localización de sitios en la Provincia de Acalan. 
y provincia que así lo entendían: «[...] conjunto de pueblos cuyos gobernantes están enlazados, con aquellas relaciones tan complejas de índole político religiosa, por el poder que reside en la jurisdicción, por lo que los españoles Ilamaron cabecera y los a él subordinados como sujetos» (0 koshi 1994: 267).

Los Papeles de Paxbolom $M$ aldonado, al describir algunos acontecimientos de la región en el momento de la llegada de Cortés narran que Paxbolom A cha era el Señor Supremo, es decir, el halach uinic de la región; pero también nos hablan de cuatro señores que fueron convocados para tomar la decisión de ir con Cortés. En los mismos papeles se habla de cuatro divinidades que existían en I tzamkanac, Io cual refleja la concepción cuatripartita que los mayas tenían del universo, y conforme a la cual construyeron su «mundo». Sacralizaron la región con dos de las más importantes deidades mayas: I tzamna y Tixchel. EI primero al poniente y la segunda al oriente.

Los magtunes posiblemente no dividieron «su mundo» físicamente conforme a la idea cuatripartita (norte, sur, este, oeste y centro), pues su sistema de distribución obedeció en gran medida a su medio geográfico, que fue el río, obligándolos a adaptarse; por lo tanto, se conformó a la distribución caprichosa del río; pero sí manejaron el concepto.

Itzamkanac se localizaba en el alto Candelaria, no lo rodeaban muchos sitios y estaba donde se forma propiamente el río por el C aribe y el San Pedro; ésa es la cabecera o capital de la Provincia de Acalan, que como su nombre lo indica era el lugar de las canoas; en ella hemos localizado aproximadamente 150 sitios (mapa 15); aunque creemosque nos faltan muchos, con ese recorrido tenemos un panorama aproximado del cuchcabal de los magtunes.

En el río Caribe, que nace en el gran bajo de Calakmul, se localizan diez sitios. Al decir de algunos autores éste adquirió gran importancia debido a que a través de él I tzamkanac tuvo la posibilidad de conectarse con el Golfo de M éxico a través del río Candelaria, factor esencial para su auge; además, pudo conectarse con la laguna de Cilvituc por medio de riachuelos y lagunas, dándole a esa región una salida franca al mar.

Sobre el río Caribe existen dos sitios de importancia, uno es Cerro de los M uertos, cuyo material localizado en superficie parece indicar que fue muy relevante durante el Preclásico superior; el otro es Santa Clara, en cuya superficie se encuentra gran cantidad de cerámica tipo Balancán y Altar, lo que indica una ocupación durante el Clásico terminal. Por su ubicación y temporalidad creo que Santa Clara fungió como sitio rector en el control del tráfico sobre el río C aribe, funcionando como un batabilob dependiente de I tzamkanac. Los otros sitios, algunos de ellos menores, bien pudieron ser pueblos dependientes de Santa C lara.

El mismo fenómeno se da sobre el río San Pedro, en donde se localizan varios sitios arqueoló gicos de diferentes niveles; el más importante de ellos es San Román, ubicado casi al frente del arroyo La Esperanza, que debió 
funcionar como sitio rector o batabilob con los pueblos aledaños distribuidos en los bajos y a orillas del río.

El tercer batabilob estaría formado por unos 25 sitios arqueológicos que se localizan en los saltos del río C andelaria; el más importante es Salto Grande, que está muy cerca del lugar en donde empiezan los sal tos, lo que sugiere que ejercieron control en el paso de las mercancías por esos lugares peligrosos, 0 en las que llegaban desde la Laguna de Términos e iban hacia Itzamkanac, pues de allí el viaje era tranquilo hasta su destino. Este batabilob puede ser Ilamado sin problemas tamagtun 'lugar o puerta de entrada' a A calan. Seguramente el nombre que reciben en la fuente histórica se debe a que se asentaron en ese lugar o más arriba, en I tzamkanac, pues A calan es el lugar de las canoas.

El cuarto batabilob sería Tixchel, 'el lugar de Ixchel', que dominaba to do el comercio del estero de Sabancuy, el oriente de la L aguna de Términos y la entrada a los ríos de Chumpán, C hivojá, M amantel y Candelaria. Batabilob de gran importancia para I tzamkanac pues de esa manera se aseguraban las mercancías desde Tixchel hasta la cabecera. El agua fue el camino, la columna vertebral del comercio en la región y qué mejor que asegurarla en todo el trayecto.

Este cuarto batabilob estaba formado por sitios con diferentes características; en total podemos hablar de unos 20, algunos de ellos, como Tixchel, eran sitios de cierta importancia; lo otros eran estructuras solas que sirvieron de señalamiento en el terreno para dirigir el tránsito seguro de las embarcaciones que llevaban las mercancías de un lugar a otro. É stos también pudieron funcionar como puertos de control.

\section{LA CABECERA DE LA PROVINCIA. ITZAMKANAC}

EI sitio de EI Tigre colinda al norte con el río C andelaria, al sur, este y o este con el ejido Pablo García. En términos generales, la ocupación del sitio se había definido hasta los bajos, ocupando los terrenos del ejido El Tigre. Se calculaba una superficie de 350 hectáreas, sin embargo, en la actualidad sabemos que la extensión es de aproximadamente 500 hectáreas, extendiéndose sobre todo al este y oeste.

El sitio se localiza en la margen izquierda del río, sobre un lomerío natural que no excede los $100 \mathrm{msnm}$, es una zona de lomas bajas que en otra época correspondió a una selva subperennifolia y actualmente es de pastizales debido a la deforestación; aunque al este se conserva todavía parte de esa selva con la fauna característica de la región.

En 1996 se realizó el levantamiento planimétrico del sitio arqueológico EI Tigre. Se trabajó por medio de una cuadrícula que cubrió toda el área que nos habíamos propuesto levantar. N os auxiliamos con la fotografía aérea, las escalas fueron: 1:50000 y una ampliación que se mandó a hacer a 1:5000. 
El levantamiento topográfico se inició con la búsqueda del punto «0» que nos sirviera de arranque; después de recorrer varios puntos escogidos con anterioridad en la fotografía aérea llegamos a la conclusión de que uno de los más factibles para hacer la cuadrícula era el extremo sureste del poblado, que se aprecia fácilmente en la fotografía aérea y no será movido con facilidad, porque a los habitantes del lugar les interesa conservarlo y está allí hace 25 años.

La cuadrícula se trazó con una desviación de $5^{\circ}$, que tiene la línea que nos serviría de eje norte-sur y es el límite este del poblado. Se trabajaría por medio de cuadrantes que fueron definidos como I, II, III y IV. Podía usarse indistintamente cualquiera de ellos siempre y cuando se trabajara de manera sistemática hasta agotar toda la información existente en dicho cuadrante. Para el registro de cada uno se utilizaron números romanos, letras mayúsculas y números arábigos. L as letras estuvieron registradas en el eje este-oeste y los números en los norte-sur.

Cada cuadrante se dividió en cuadros de 100 por $100 \mathrm{~m}$, que a su vez se subdividían en otros de 50 por $50 \mathrm{~m}$ para el registro de todos los elementos arqueológicos, ya fueran arquitectónicos, escultóricos, talleres, caminos, afloramientos de piedra, petroglifos, etcétera. Estos fueron registrados en papel milimétrico a una escala de 1:1000 y posteriormente vaciados en el cuadrante correspondiente a una escala 1:2000; de esta manera se tiene el registro de cada uno de los cuadros de 100 por 100 m, separados con un registro más detallado de los edificios y una descripción general del cuadro, que nos permitió hacer la concentración del cuadrante y la descripción general.

Como puede verse, el levantamiento topográfico es bastante exacto pues creamos una retícula en el sitio, la cual nos permitió el registro de todos los elementos arqueológicos visibles; de ese modo lo hemos entendido mejor, ya que hemos encontrado grandes conjuntos arquitectónicos, calles y caminos, el área del puerto y las relaciones que éstas podían tener con las estructuras principales; en fin, el análisis que podremos hacer será de gran ayuda para realizar exploraciones en el futuro, ya que sabemos el funcionamiento que tuvo el sitio en términos generales; posteriormente, por medio de las excavaciones, se podrán afirmar o desechar algunas de las propuestas que se harán mediante el levantamiento topográfico.

Por ser EI Tigre uno de los sitios más grandes localizados a orillas del Candelaria, hemos creído que se trata de la capital o cabecera de la provincia de Acalan y por tal motivo presentamos una descripción detallada del lugar.

\section{Cuadrante।}

El Cuadrante I se localiza hacia el sureste del punto «0», tiene una extensión hacia el este de 1100 m y hacia el Sur de 1600 m. La mayor concentración de montículos se da en los primeros $600 \mathrm{~m}$ en el eje este-oeste y en el eje norte-sur de los 200 a 1300 m (mapa 16). 


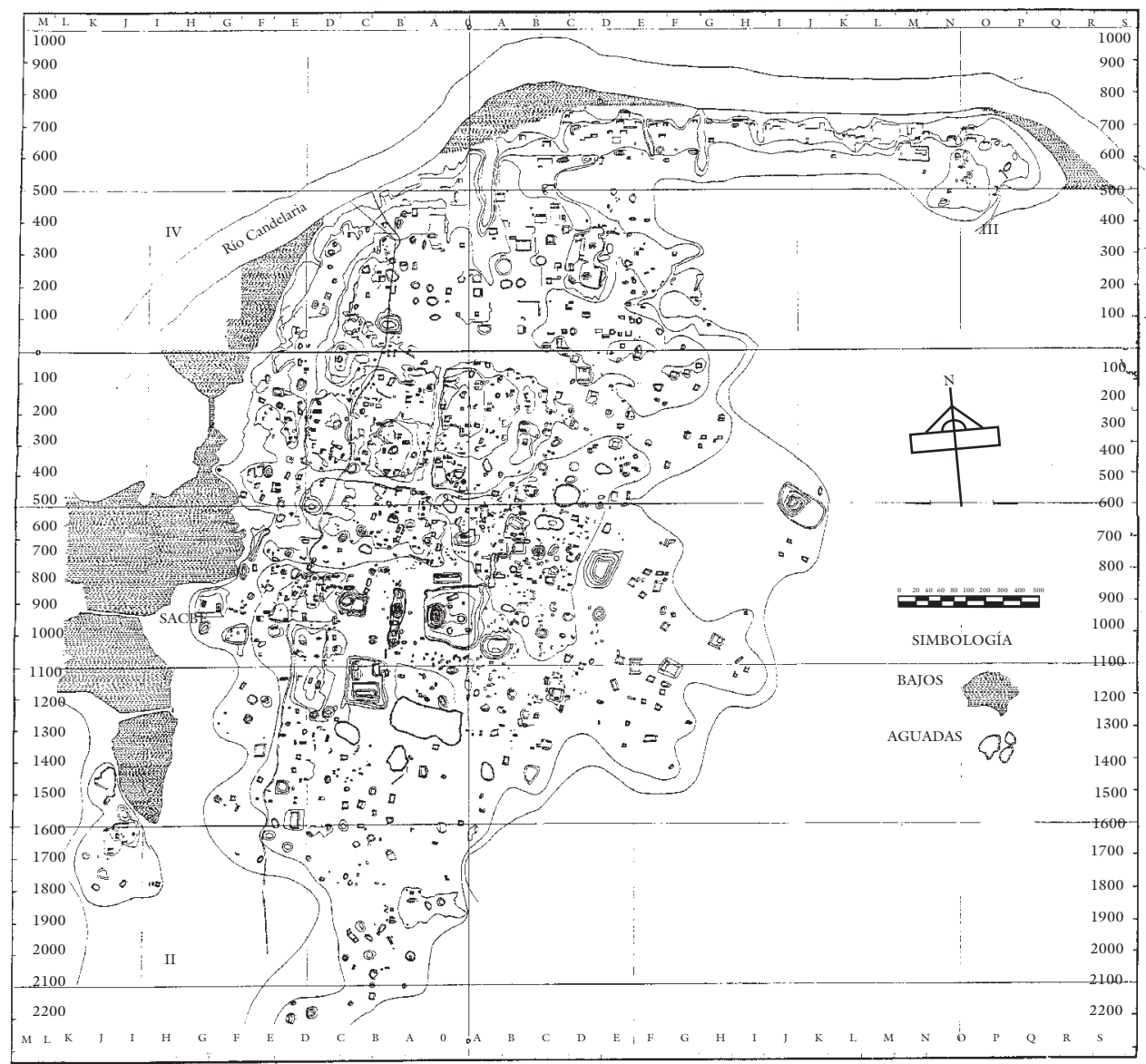

Mapa 16. Levantamiento topográfico de El Tigre.

La ocupación prehispánica es muy clara, existen plataformas, pirámides, aguadas y posiblemente hasta un juego de pelota; parte de este cuadrante queda enmarcado dentro de lo que puede llamarse el área central del sitio; sin embargo, hacia el este desde el Centro Ceremonial de El Tigre, a medida que se aleja uno, se encuentran dos estructuras muy grandes: una a $400 \mathrm{~m}$ de la Estructura 4 y la otra como a $1 \mathrm{~km}$, exactamente a orillas de los bajos; se sale totalmente de la formación general del sitio y mira hacia el este, formando por lo tanto un conjunto aparte.

El terreno desciende gradualmente hasta los bajos, muchas partes del lado este son casi imposibles de visitar en tiempos de agua; también hacia ese lado del sitio se conserva todavía la selva y existe la fauna característica de la región.

Este cuadrante tiene características muy interesantes, pues en él se localiza gran número de estructuras redondas, conjuntos, 13 aguadas de diferen- 
tes dimensiones, un grupo de chultunes, restos de estelas y un posible juego de pelota; el cuadrante tiene aproximadamente 500 estructuras.

Todas éstas por lo general son plataformas que no alcanzan gran altura, aunque algunas son relativamente amplias. Casi a la mitad del cuadrante existen cuatro aguadas, como puede apreciarse en el plano topográfico: dos de ellas son muy grandes, una está casi azolvada y en la otra todavía se aprecia su profundidad pese a estar en vías de desaparecer (fotografía 32); junto a esta aguada se local izan al gunas estelas y varios montículos relativamente grandes.

Al sureste de las aguadas se encuentra uno de los dos montículos más grandes del cuadrante y el otro está exactamente hacia el este. Los demás montículos localizados en la parte baja del cuadrante son pocos pero relativamente grandes; por otro lado la tierra de ese lugar es muy húmeda y negra, posiblemente muy productiva en la época prehispánica.

La Estructura 4 es la más grande de to do el sitio; su orientación hacia el este, tiene unos $200 \mathrm{~m}$ de frente por otros 200 hacia los lados, la altura promedio de la plataforma es de unos $10 \mathrm{~m}$ y con una máxima de $30 \mathrm{~m}$ (fotografía 33). Frente a esa estructura existen dos aguadas relativamente pequeñas y al lado sur está otra estructura de dimensiones considerables, muy parecida a la Estructura 4; to das las demás son más pequeñas.

Al sur, a partir de la Estructura 4, el sitio sigue teniendo una ocupación considerable, sin embargo, termina a los $500 \mathrm{~m}$, ya que el bajo se acerca mucho al área de ocupación. C reemos que el sitio debe seguir un poco más

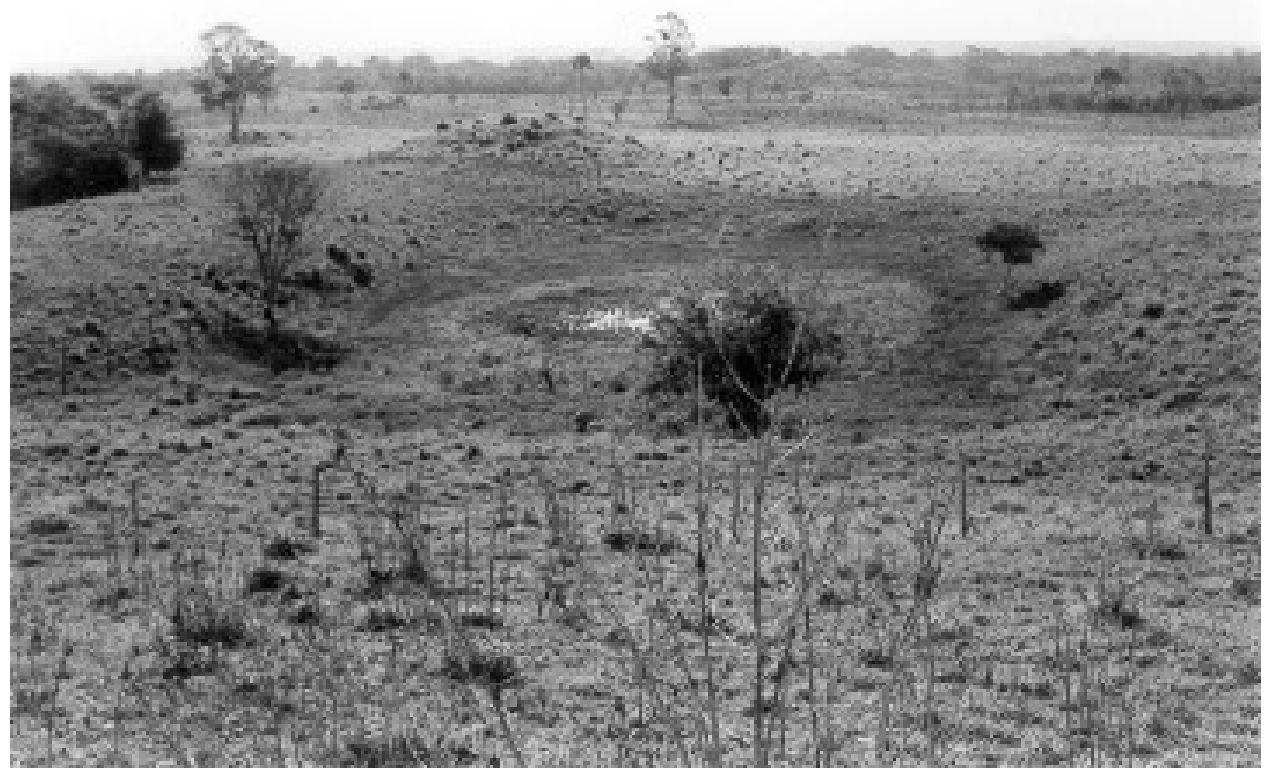

Fotografía 32. Aguada localizada en el Cuadrante ı. 


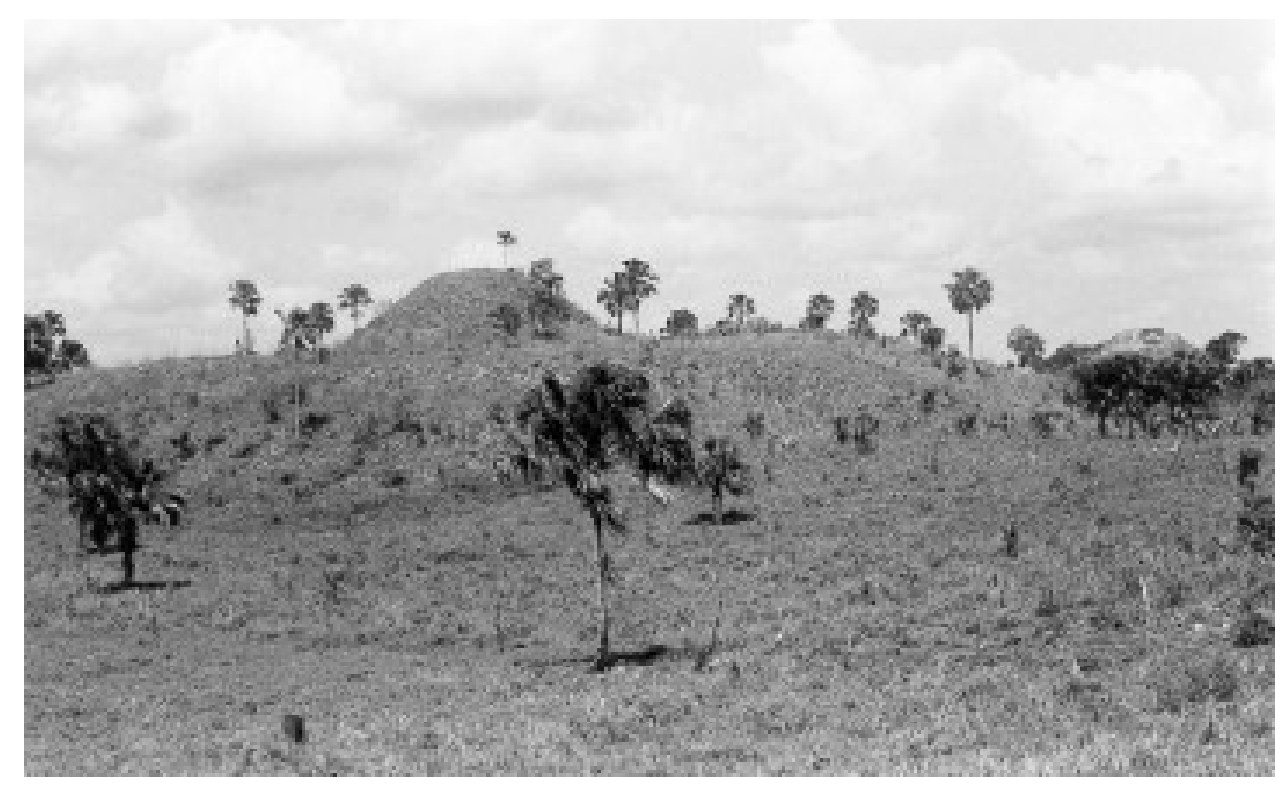

Fotografía 33. Estructura 4.

allá de donde lo dejamos, pero por ahora es difícil localizar todos los restos arqueológicos pues disminuyen.

\section{Cuadrante ॥}

El Cuadrante $\|$ se localiza hacia el suroeste del punto «0» y queda delimitado hacia el norte por el Cuadrante IV, al este por el Cuadrante I, en el oeste por los bajos y hacia el sur por la laguna de EI Pato. EI cuadrante abarca una extensión de $2200 \mathrm{~m}$ al sur por un promedio de $900 \mathrm{~m}$ hacia el oeste (mapa 16).

Es el cuadrante más importante del sitio, porque en él se encuentran el Centro Ceremonial y las principales vías de comunicación: los sacbés y los caminos. También allí se registran estelas, chultunes y petroglifos. Empezaremos por describir los caminos. El primero de ellos se inicia casi en el punto «0» tiene una orientación norte-sur y una longitud de $700 \mathrm{~m}$ (fotografía 34); forma parte de la construcción de ese camino una hondonada artificial a la que le construyeron al gunos edificios a los lados para encauzar al visitante hacia la parte central del sitio. O tro de los caminos es aquel que se junta al anterior y tiene una orientación este-oeste; el sistema constructivo al parecer es el mismo, se forma por un encaño y en las partes altas se construyen las estructuras. C omo rasgo característico también existen rampas de acceso desde los bajos hacia los niveles más altos; asimismo, se registraron otros caminos que tienen la misma orientación de los bajos hacia el centro del sitio.

EI sacbe (fotografía 27) de EI Tigre es ampliamente conocido por diversas comunicaciones. Es una construcción artificial sobre el pantano, que sirvió para 
comunicar la parte central del sitio con un anexo en donde se construyeron más de 60 estructuras. Como particularidad el sacbe tiene al centro un paso que se cubría seguramente con un puente de madera, que a su vez permitía el cruce de embarcaciones pequeñas y el flujo del agua. Siemens piensa (comunicación personal) que el sacbetenía otra función además de comunicar: retener agua en los momentos que fue necesario, ya que en esa parte del sitio también existen campos elevados. Pasar el sacbe y pretender ir al centro ceremonial del sitio es relativamente fácil, pues existe un camino formado por las plataformas que dirige al visitante hacia la gran plaza que forman en el centro las estructuras 1, 2 y 3.

Al este y sur de la Estructura 1 se encuentran tres grandes aguadas. La mayor tiene $200 \mathrm{~m}$ de longitud por 100 de anchura y todavía en la actualidad permanece por varios meses con agua; existe además todo un sistema de nivelación para llevar el agua de una aguada a otra.

$\mathrm{H}$ acia el sur, detrás de la Estructura 1 , el sitio arqueológico disminuye considerablemente, los conjuntos se vuelven mejor estructurados y dejan grandes espacios en algunas partes.

EI Centro Ceremonial está compuesto por cuatro grandes estructuras y seis de dimensiones menores, dos plazas, 13 altares, tres estelas y las vías de acceso al sitio.

Lo importante del levantamiento topográfico del centro ceremonial no son tanto los detalles arquitectónicos que pueden apreciarse en el levantamiento, sino más bien la relación que guardan las estructuras entre sí; de esta manera se aprecia la distribución y disposición de los grandes edificios de EI Tigre (figura 11).

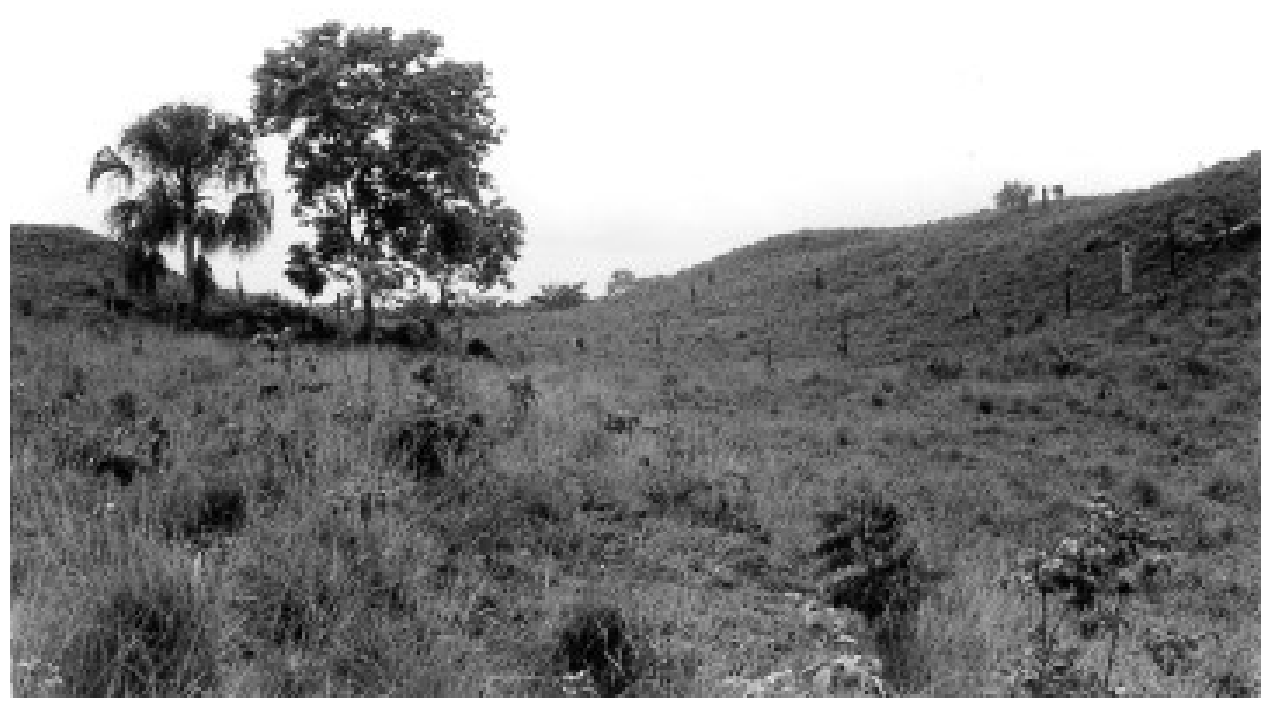

Fotografía 34. Camino formado por plataformas. Éstas llevan al centro ceremonial. 


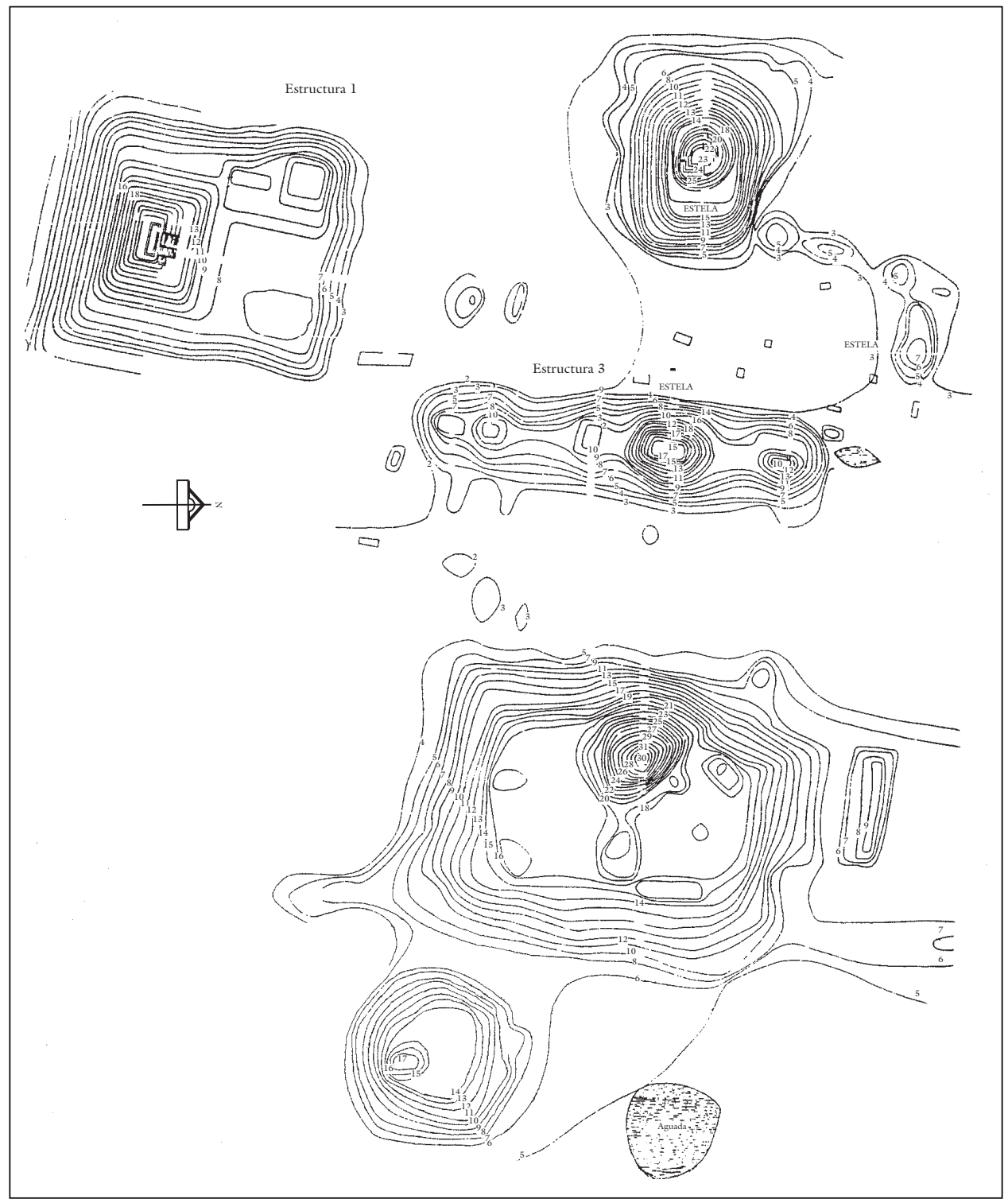

Figura 11. Centro ceremonial de El Tigre.

Llama la atención la forma de las grandes estructuras, pues generalmente en cualquier sitio se puede ver un «estilo» propio de la región. En El Tigre las estructuras principales son totalmente diferentes, ninguna se parece entre sí; sin embargo, existe una armonía, una planeación de la parte central, aunque en un principio pensábamos que la Estructura 3 era una inclusión en la gran plaza. La Estructura 1 cierra la gran plaza hacia el sur, y las 2, 3, y 4 están perfectamente orientadas al este conformando las dos grandes plazas. 
Asimismo atrae la atención la Estructura 3, cuya forma no es común en el área maya, aunque en varios lugares de la zona chontal se encuentran edificios parecidos a ése. En cuanto a la Estructura 4, es interesante señalar que dentro del mismo sitio existen otros tres ejemplos, pero de menores dimensiones, pues debemos recordar que ésa es la estructura más grande del sitio.

L a Estructura 1 fue llamada así porque en un principio creímos era la más importante del sitio, pues junto con la 2 y la 3 forman una gran plaza que tiene unos 300 m de longitud por 150 de anchura. Se localiza al sur de la gran plaza y está conformada por una gran plataforma de aproximadamente 149 m de longitud en el eje norte-sur y por $132 \mathrm{~m}$ de anchura en el eje esteoeste. La altura de la gran plataforma es de casi $9 \mathrm{~m}$ y sobre ella existen cuatro montículos, de los cuales dos dan al frente, y al fondo de dicha estructura se levanta una pirámide que tiene una al tura aproximada de $23 \mathrm{~m}$. Se logra ascender a dicha plataforma por medio de una escalinata que da acceso a la parte superior en donde se encuentran esas dos estructuras, y para llegar hasta ahí se sube también por medio de otras escaleras sin alfardas (figura 12).

L as exploraciones realizadas en 1984 comprendieron sólo la parte superior, en donde se excavó una estructura que presenta tres puertas, dos fueron tapiadas y una quedó abierta, la del centro.C omo detalle arquitectónico se aprecian unas molduras en la parte inferior.

La piedra está muy bien tallada, aunque en la actualidad se destruye fácilmente por estar expuesta al fuego cada año.

L a estructura piramidal está compuesta en su parte superior por tres 0 cuatro cuerpos, con muros rectos (fotografía 35). Al frente unas escaleras amplias, sin alfardas, sobresalen de los cuerpos de la estructura y al llegar a la parte superior existe un descanso para subir al cuarto superior, formado rectangularmente y construido a base de bloques de piedra caliza.

L as exploraciones que se realizaron en 1997-98 han aportado nuevos datos; por ejemplo, fue interesante darnos cuenta de que en las escal inatas se podía apreciar una etapa constructiva que perteneció a la última ocupación del sitio, es decir, al Postclásico tardío (1200-1557 dC). Esta etapa constructiva estaba muy destruida, por lo tanto se realizó una excavación más detallada en aquellos lugares en donde no se apreciaba su presencia. Como a unos $0.80 \mathrm{~cm}$ de profundidad se encontró la otra etapa constructiva, que debió pertenecer al Clásico terminal (700-950 dC), y en algunos lugares puede apreciarse muy bien, mientras que en otros gran parte de la escalinata está destruida, sin embargo ésta es la que hemos explorado más. Existe una tercera etapa más profunda, como a metro y medio, tapada por escombro y en muy buen estado de conservación; de ella no nos ocuparemos porque significaría mover una gran cantidad de escombro, lo cual es casi imposible; su época de construcción debió ser del Preclásico superior, unos 200 años antes de C risto.

L a excavación se realizó de tal manera que cuando se hizo la consolidación se mostraron las tres diferentes etapas constructivas (figura 13). A los 


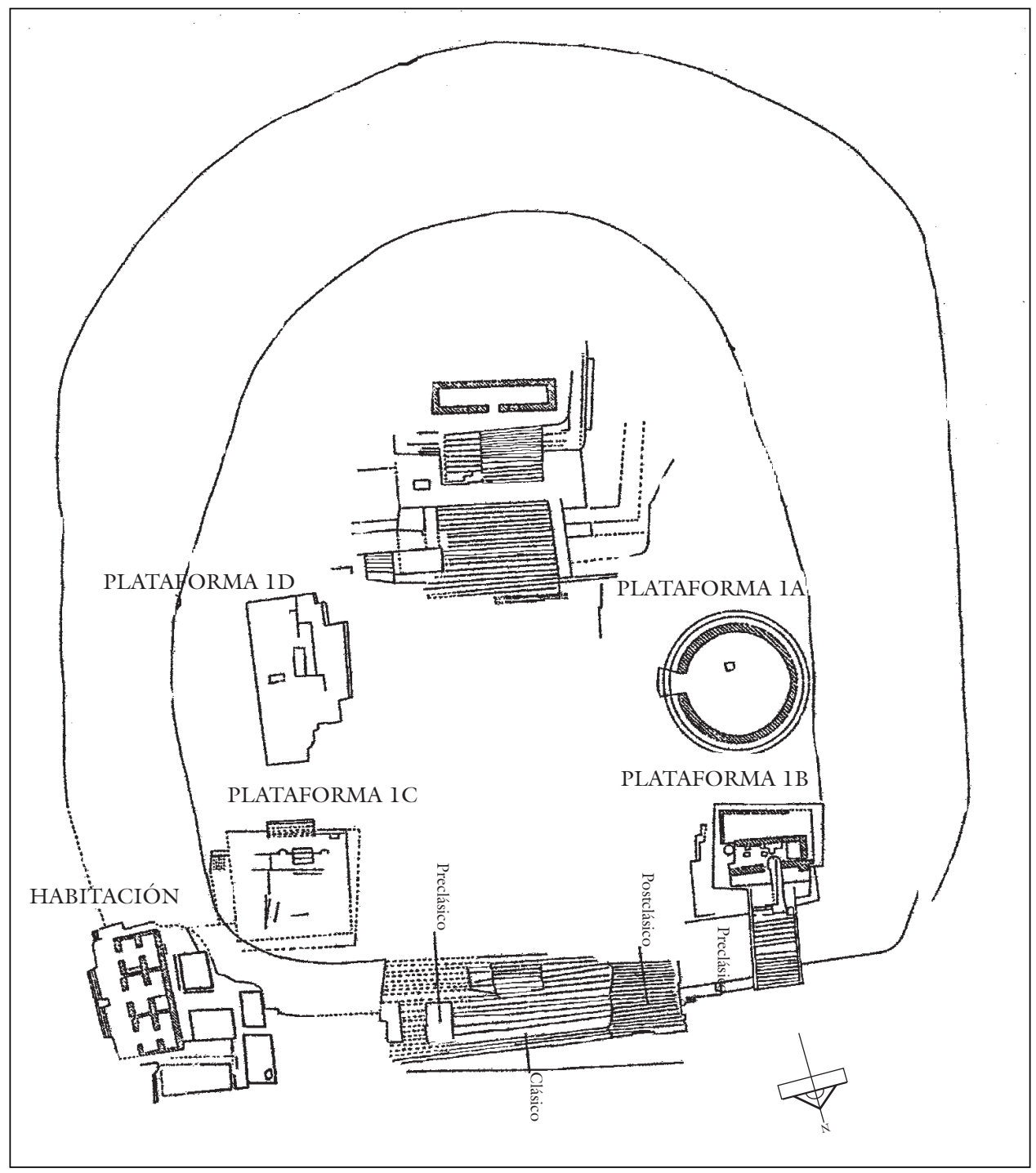

Figura 12. Plano de la Estructura 1.

lados de las escalinatas se han encontrado las paredes que la delimitan (fotografía 36); un detalle interesante es que los muros no llegan hasta abajo, sino que están en talud.

$\mathrm{Al}$ frente de los cuerpos de esta parte de la Estructura 1 se ha encontrado gran cantidad de restos cerámicos que denotan que el lugar fue reutilizado; además, se han explorado por lo menos 11 entierros. Al parecer, los cuerpos que la formaron estuvieron construidos con un relleno de sascab, se recubrieron de pequeñas piedras y sólo en la parte superior se utilizaron piedras bien cortadas que formaron únicamente una hilada colocada en la parte superior. 


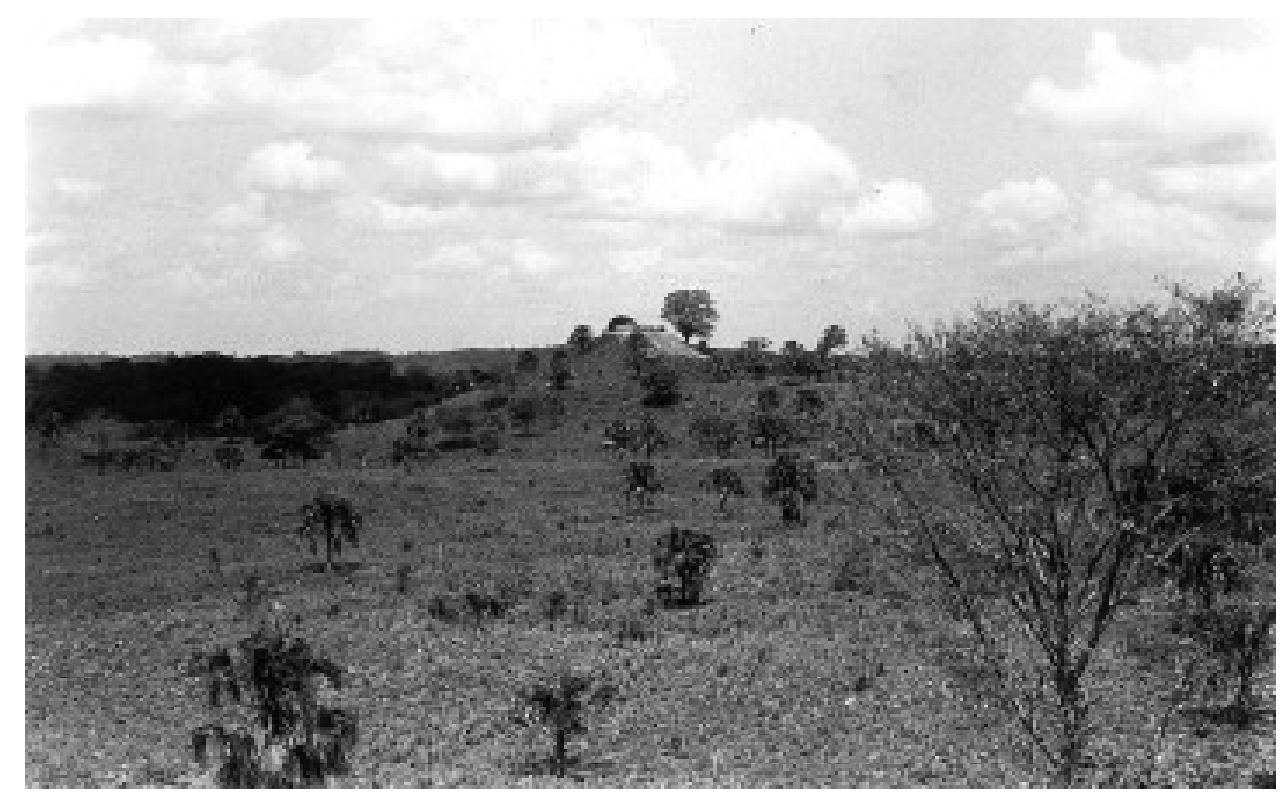

Fotografía 35. Vista general de la Estructura 1.

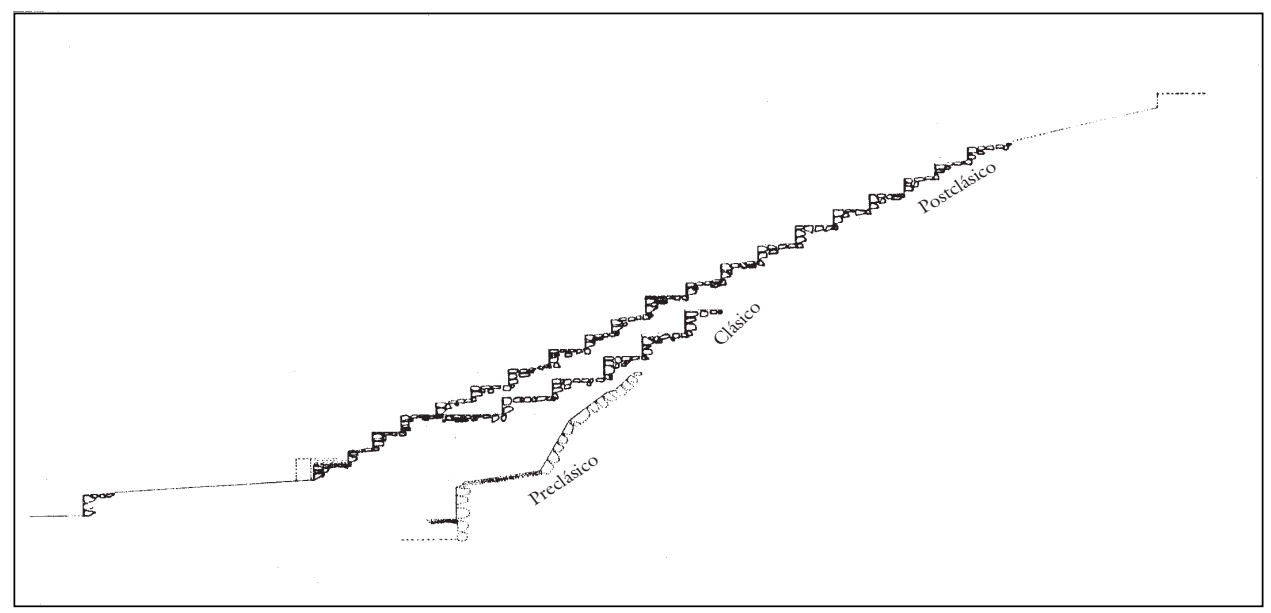

Figura 13. Tres etapas constructivas en la Estructura l (Brizuela A.).

Asociados con la Estructura 1 y con la estructura habitacional se encuentran cinco altares (fotografía 37) orientados de norte a sur, se elevan aproximadamente $0.75 \mathrm{~cm}$ de altura y generalmente tienen una pequeña moldura en la parte inferior del muro, de donde sale otro muro recto. El sistema constructivo es de pequeñas piedras que fueron pegadas con argamasa. 


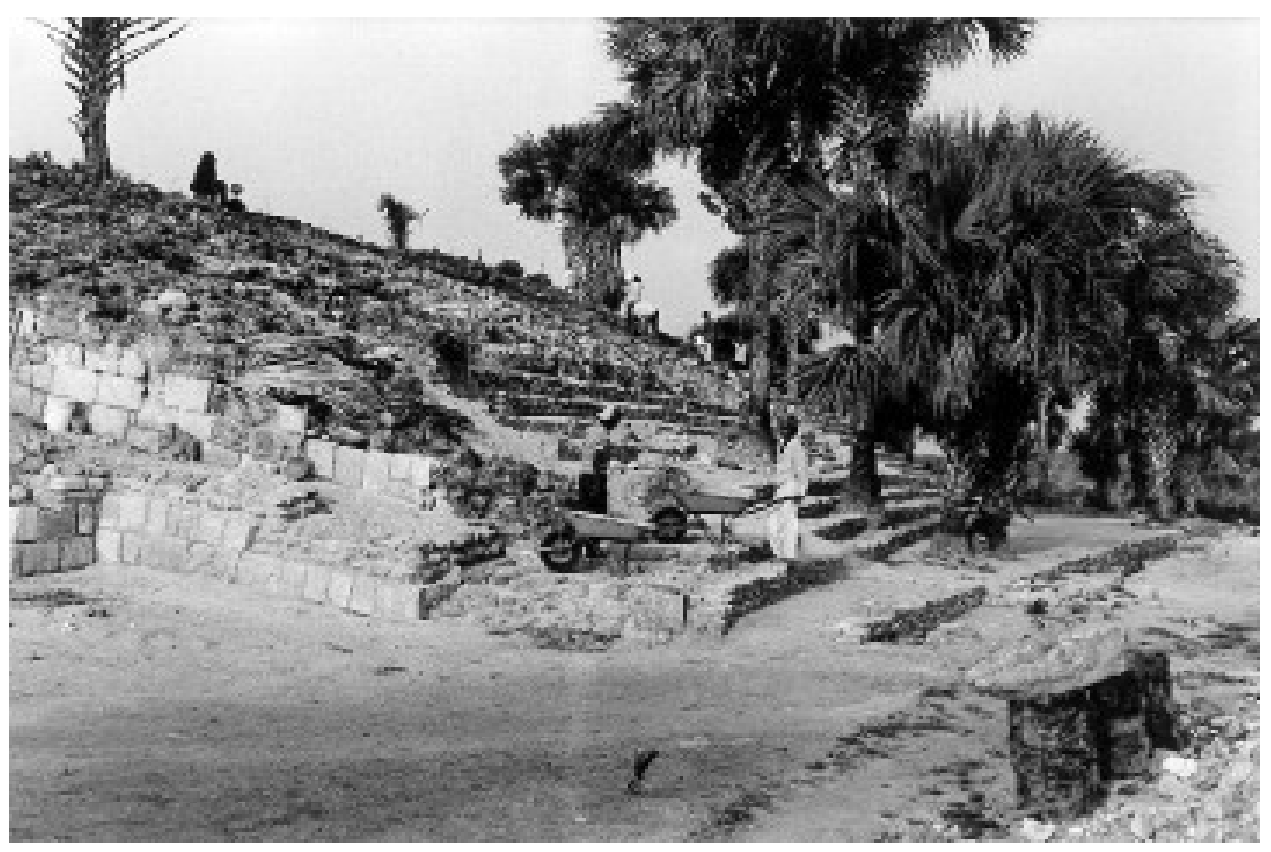

Fotografía 36. Lado de la escalinata de la E structura 1.

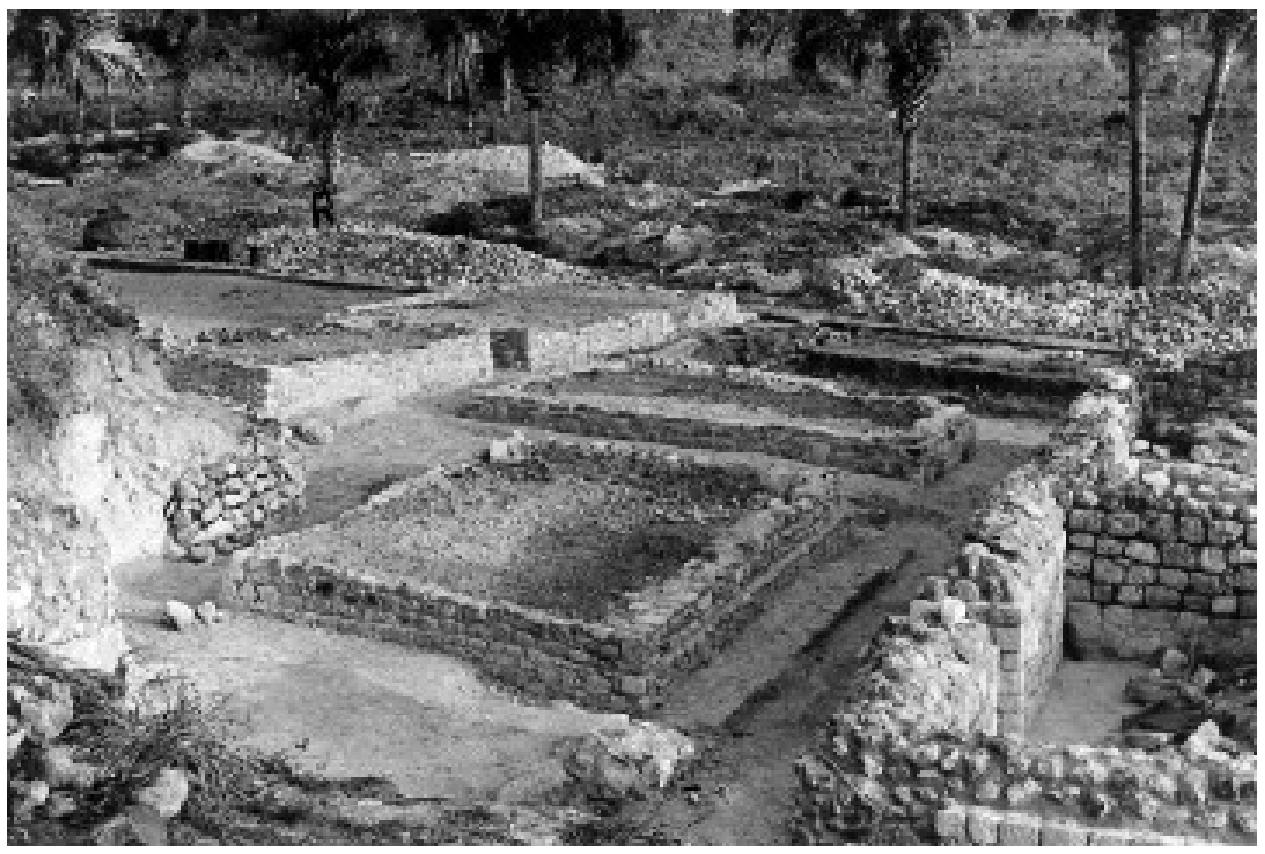

Fotografía 37. Altares frente a la Estructura 1. 
Es difícil determinar su función pero bien podrían ser altares o tumbas, ya que al parecer su construcción es posterior a la estructura habitacional y aun a la Estructura 1. N o tienen acceso a la parte superior, ni se encontró piso en ésta; sin embargo, están bien orientadas conforme a la estructura habitacional. Entre los cinco altares existen pasillos relativamente angostos que seguramente sirvieron para caminar entre ellos.

Para acceder a la parte superior de la estructura se tiene que subir por la escal inata que está al frente; la al tura aproximada es de $10 \mathrm{~m}$. Al llegar a esa zona de la estructura puede verse una gran plaza y a los lados de la misma se aprecian cuatro plataformas que tienen diferentes formas y alturas. Al fondo hay otra escalinata que sirve para subir al templo principal, que está en la parte superior de la estructura a una altura de $23 \mathrm{~m}$.

Se decidió realizar la exploración en una de las plataformas de la parte superior, a la que se llamó Plataforma $1 \mathrm{~A}$. Tiene la característica singular de ser redonda (fotografía 38) y estar compuesta por un muro redondo que seguramente cedió por el peso del techo plano y parte de los muros se derrumbaron hacia afuera. En el interior de la plataforma hemos encontrado el techo que tenía un grosor aproximado de $15 \mathrm{~cm}$; gracias a éste el piso de la estructura se conservó muy bien (figura 14). La única puerta de entrada está orientada hacia el este y desde allí se inició la consolidación.

E n 1984 se había iniciado la exploración de la Plataforma 1C; sin embargo, nunca se terminó, y algunas partes exploradas quedaron sin consolidar, motivo por el cual el deterioro había hechos estragos en algunos muros.

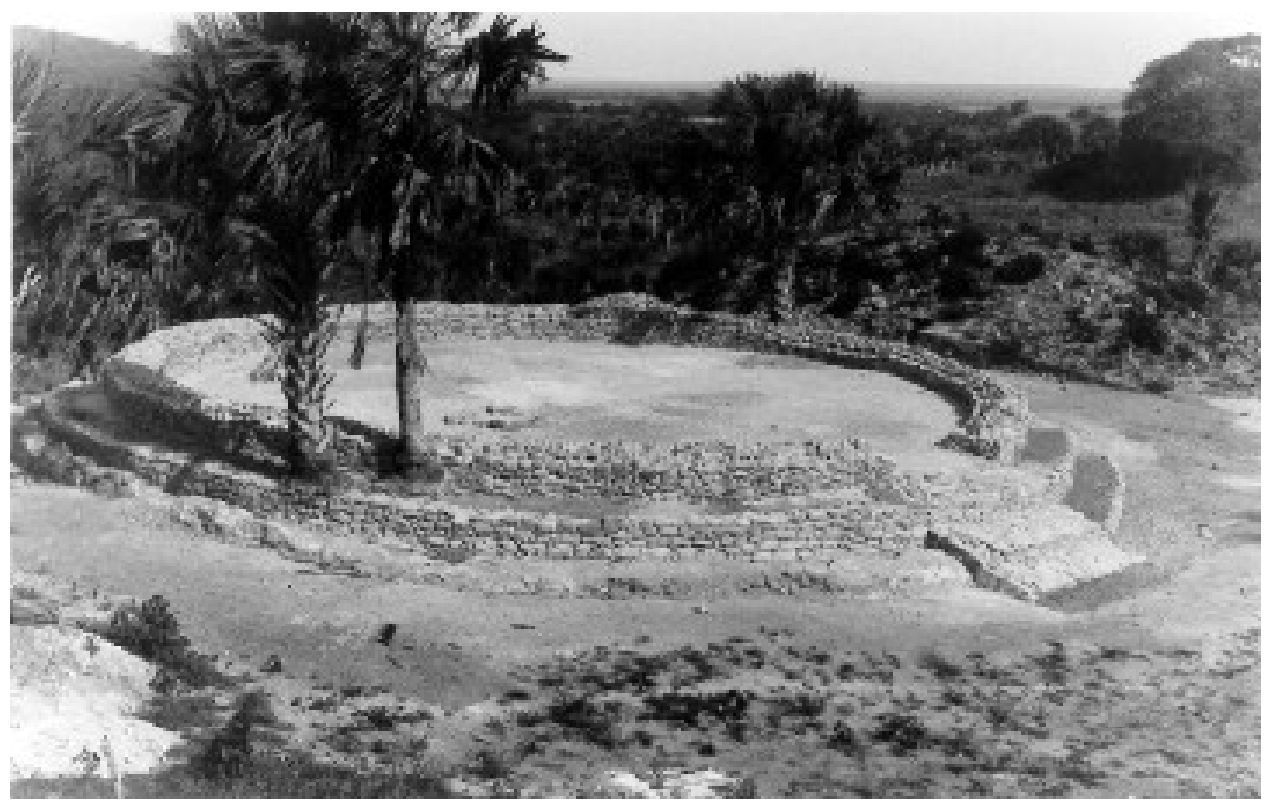

Fotografía 38. Plataforma 1A, que se localiza en la Estructura 1. 


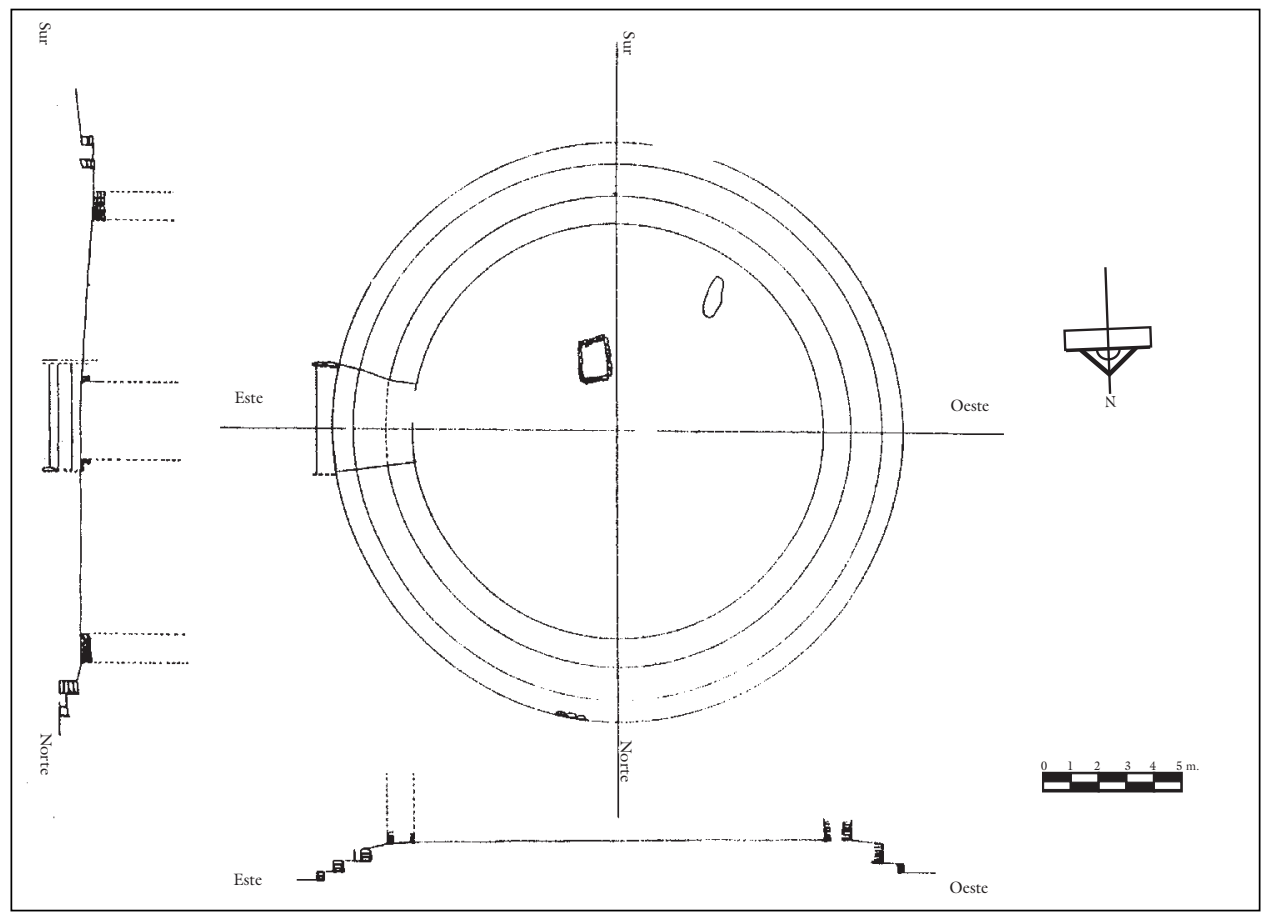

Figura 14. Planta y corte de la Plataforma lA.

Se procedió a la limpieza y excavación de esta plataforma; de inmediato nos dimos cuenta de que algunos muros habían sido consolidados de manera errónea, y partes de otros también fueron añadidas. Por lo tanto, nos concentramos en la exploración de la parte exterior. Nos dimos cuenta de que había muros que correspondían a otra etapa constructiva que al explorar nos permitieron encontrar uno de los hallazgos más interesantes de la última temporada de campo: dos mascarones que representan el rostro humano (fotografía 39).

Al este de la Estructura l se excavó un palacio habitacional, que sigue esa orientación general y se asienta sobre una plataforma con escaleras al frente; sus dimensiones son $1.16 \mathrm{~m}$ de anchura y tiene escalones de entre 0.30 y $0.40 \mathrm{~cm}$ de altura.

Sobre la plataforma encontramos una serie de cuartos en los cuales se pueden observar dos etapas constructivas y tienen como característica las esquinas redondeadas. Sus puertas están orientadas en línea recta con las es-caleras de la plataforma y los muros tienen un promedio de 0.50 a $0.70 \mathrm{~cm}$. Como elemento arquitectónico la fachada del primer cuarto presenta un friso, que se encuentra regularmente a $0.20 \mathrm{~cm}$ del suelo, con un espesor de $7 \mathrm{~cm}$ aproximadamente. La puerta tiene de anchura $1.80 \mathrm{~m}$. En el interior del cuarto encontramos todos sus muros cubiertos con el mismo sistema usado en el exterior.

Para entrar al segundo cuarto encontramos otro escalón de la misma naturaleza que el del cuarto anterior, sigue la dirección de la puerta anterior, la cual tiene de ancho $1.70 \mathrm{~m}$. De igual forma, presenta recubrimien- 


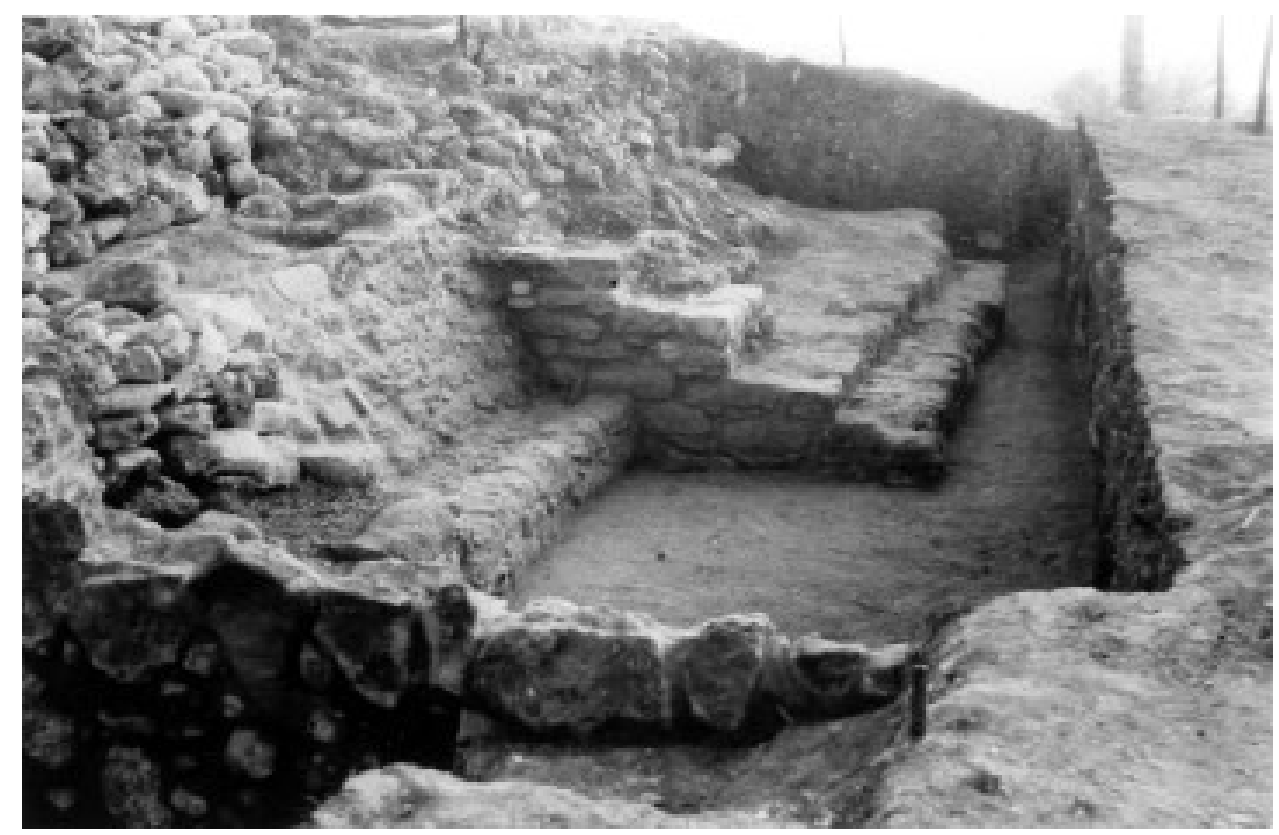

Fotografía 39. Vista general de la Plataforma 1C.

to en todos sus muros y como característica principal encontramos una especie de banqueta localizada al norte del cuarto.

L a segunda etapa constructiva se caracteriza por sus esquinas redondeadas y se tratatambién de dos cuartos localizadosal norte dela plataforma, cuyas entradas tienen la misma orientación hacia el este. U na característica de estas etapas constructivas es que el muro que las separa y las une a la vez tiene en promedio de $0.38 \mathrm{~cm}$ de anchura, mientras que los otros muros llegan a 0.80 ó $0.90 \mathrm{~cm}$.

El primer cuarto de esta etapa se encuentra a 3.20 m de distancia del punto en que la plataforma comienza a descender; se tiene acceso a él por un escalón de $0.30 \mathrm{~cm}$ y una puerta de $2 \mathrm{~m}$ de anchura. Las dimensiones del cuarto son 5.20 por $2.12 \mathrm{~m}$. En los muros exteriores encontramos, al igual que en los cuartos anteriores una decoración con frisos, los cuales están antes del escalón de unos $7 \mathrm{~cm}$ de altura, después presenta un sistema de lajas de 0.20 por 0.30 $\mathrm{cm}$ y nuevamente un friso de las mismas dimensiones (figura 15).

En general, Ias lajas que recubren los muros de esta etapa constructiva son de menores dimensiones que las de la etapa anterior. E $n$ el interior del cuarto encontramos muros con recubrimientos de laja de piedra caliza. EI acceso al siguiente cuarto es a través de un escalón de $0.30 \mathrm{~cm}$ y una puerta de $1.52 \mathrm{~m}$. Las dimensiones del cuarto son 5.24 por $1.84 \mathrm{~m}$. Los muros internos sur, este y oeste presentan el mismo recubrimiento que el cuarto anterior. La fachada tiene el sistema friso-muro-friso.

Parte de ésta había sido trabajada en la temporada de campo de 1984. D urante el mes de diciembre de 1997 se siguió la exploración y se delimitó 


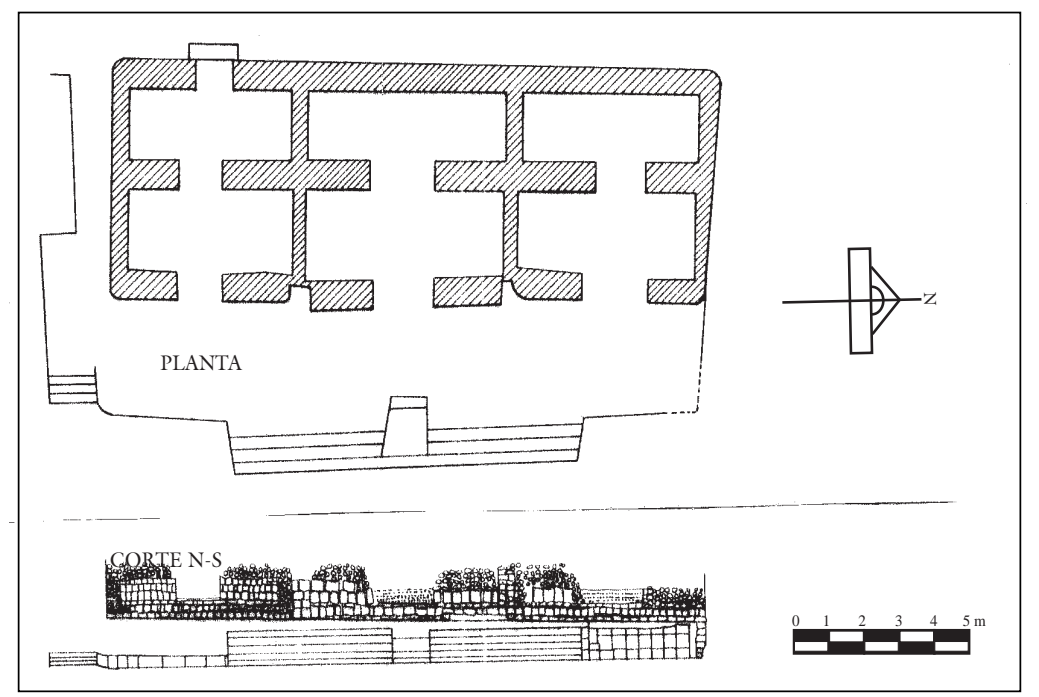

Figura 15. Planta y corte de la Estructura habitacional.

en su parte sur y oriente, dejando libre otro cuarto y las escalinatas (fotografía 40) que se encuentran en el lado frontal, es decir hacia el oriente. El trabajo es muy interesante, ya que está formado por piedras pequeñas muy bien trabajadas y en la base tiene una moldura típica del estilo arquitectónico Río Bec. Como característica relevante encontramos que el tercer cuarto tiene tres puertas, una mira hacia el oriente, otra en el centro y comunica a los dos cuartos, la tercera da hacia el poniente y tiene una pequeña banqueta que sirve para indicar que allí está la entrada de la habitación.

La Estructura 2 está orientada hacia el este y forma la gran plaza junto con las estructuras 1 y 3 . Es la estructura más pequeña de las cuatro enumeradas, mide menos de $100 \mathrm{~m}$ y su altura promedio es de $25 \mathrm{~m}$ (figura 16). Ésta se compone por una gran plataforma de aproximadamente diez metros de altura, a la que se llega por medio de una escalinata factible de apreciar en algunas partes; no tiene alfarda. Una vez que se está en la parte superior de la plataforma existe una superficie plana, en donde hay una estela que en la actualidad está tirada y fragmentada, pero todavía se localiza el lugar de donde proviene, está muy erosionada.

Para llegar a la parte superior de la estructura se sube por otra escalinata, de la cual no se aprecian los escalones y se llega a otro descanso en cuyo final sí pueden verse los restos de una escalera de cuatro peldaños que pertenecieron a la subestructura tapada por un muro en forma de talud. Existe otro pequeño descanso y por medio de 13 escalones se llega hasta la parte superior que debió tener un templo. Dicha escalinata está flanqueada por una alfarda ancha. Esta última parte de la estructura estaba formada por cuatro cuerpos compuestos de muros rectos. 


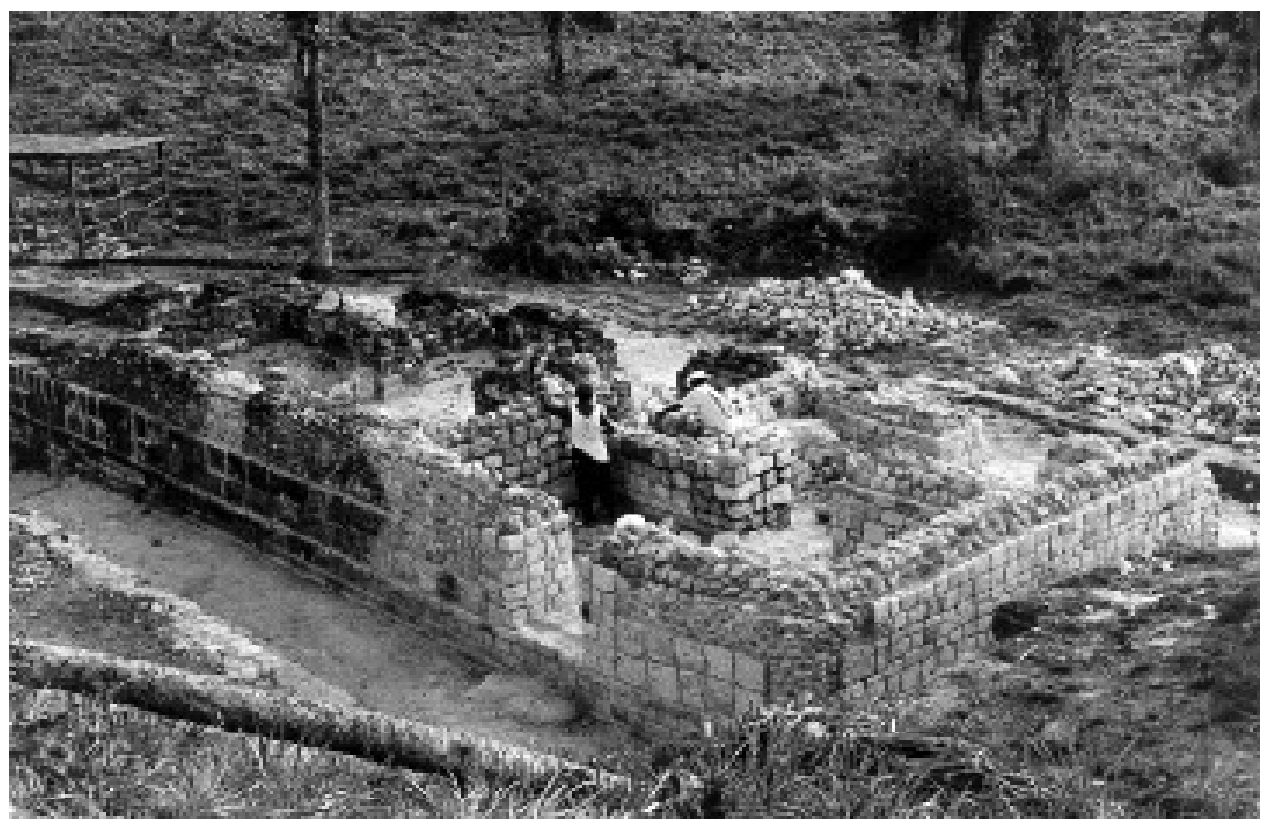

Fotografía 40. Estructura habitacional.

El costado norte de la estructura y casi todo el lado central de la misma presentan un profundo hoyo de saqueo, que destruyó gran parte de la última época. En 1984, ante la posibilidad de destrucción que presentaba dicha estructura, se decidió intervenirla con el propósito de darle una mayor solidez; sin embargo, transcurridos más de diez años, la estructura presenta al sur un profundo asentamiento y en el lado norte, en donde está el hoyo de saqueo, a pesar de haber sido explorado y consolidado, se ha desplomado parte del muro de contención que se había construido y ha quedado un hoyo debajo de las escaleras por lo cual es urgente volver a consolidarla.

EI hoyo de saqueo dejó al descubierto tres etapas constructivas (fotografía 41) y posiblemente una cuarta; también se pueden apreciar varios pisos. En el plano topográfico quedan representados los pisos y las etapas constructivas.

D e esta estructura se ven las escalinatas que quedaron al descubierto desde los tiempos en que fue reportada por Piña Chan y Pavón Abreu y por las exploraciones hechas en 1984. También llamó la atención desde entonces por tener la única estela reportada en el sitio. Por los reconocimientos preliminares que se han realizado, actualmente podemos hablar de varias estelas en EI Tigre.

En la etapa más antigua de esta estructura se aprecia un trabajo en piedra de muy buena calidad, presenta muros en talud y otros rectos con ceja y esquinas redondeadas. Casi en la esquina de esta estructura, al hacer los trabajos de consolidación, se encontró un mascarón parecido a los de $U$ axactún y Tikal del Preclásico, y al revisar la cerámica asociada con dicha estructura se verificó ese posible fechamiento. 
EL RÍO Y LA PROVINCIA DE ACALAN

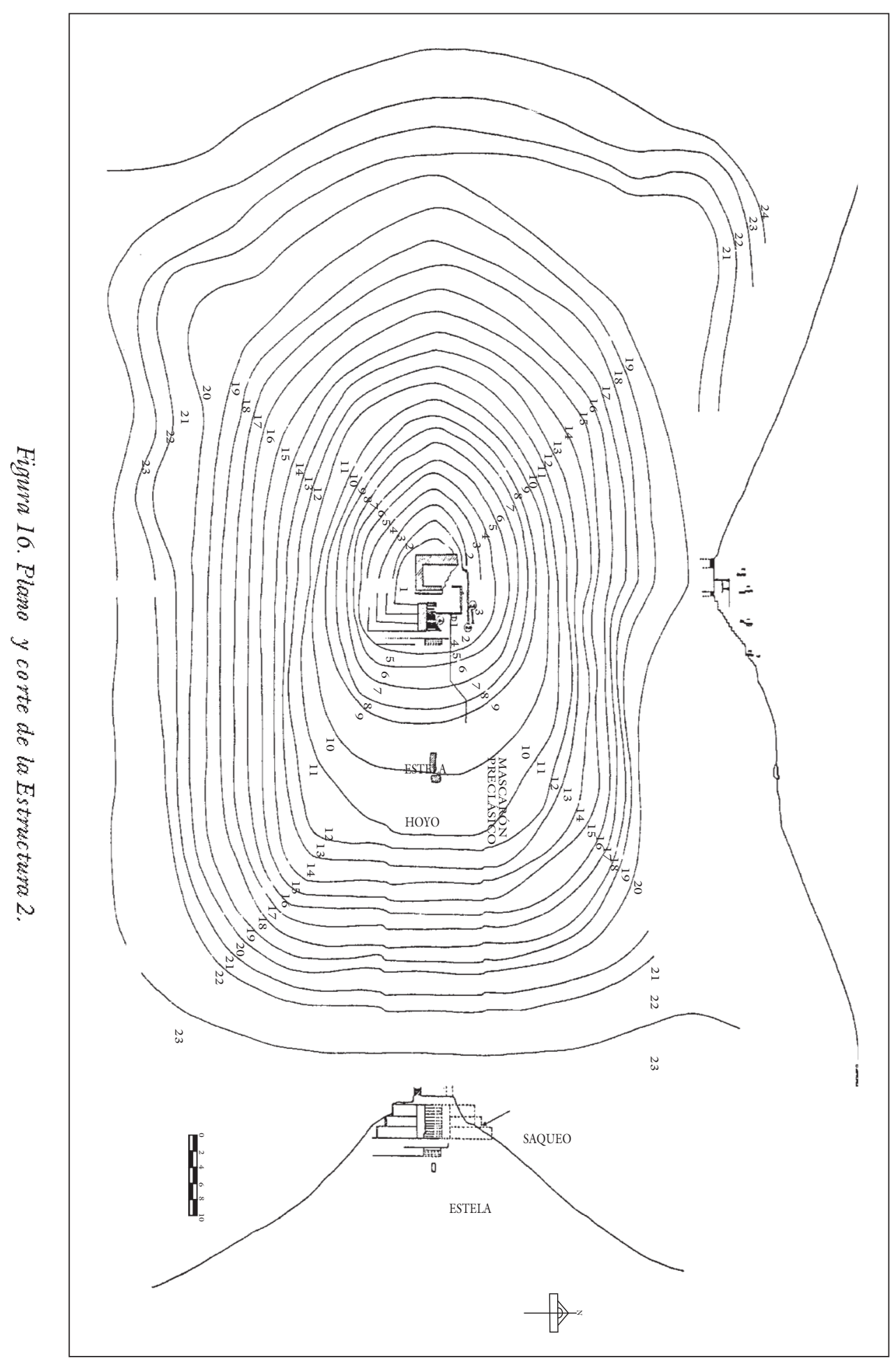




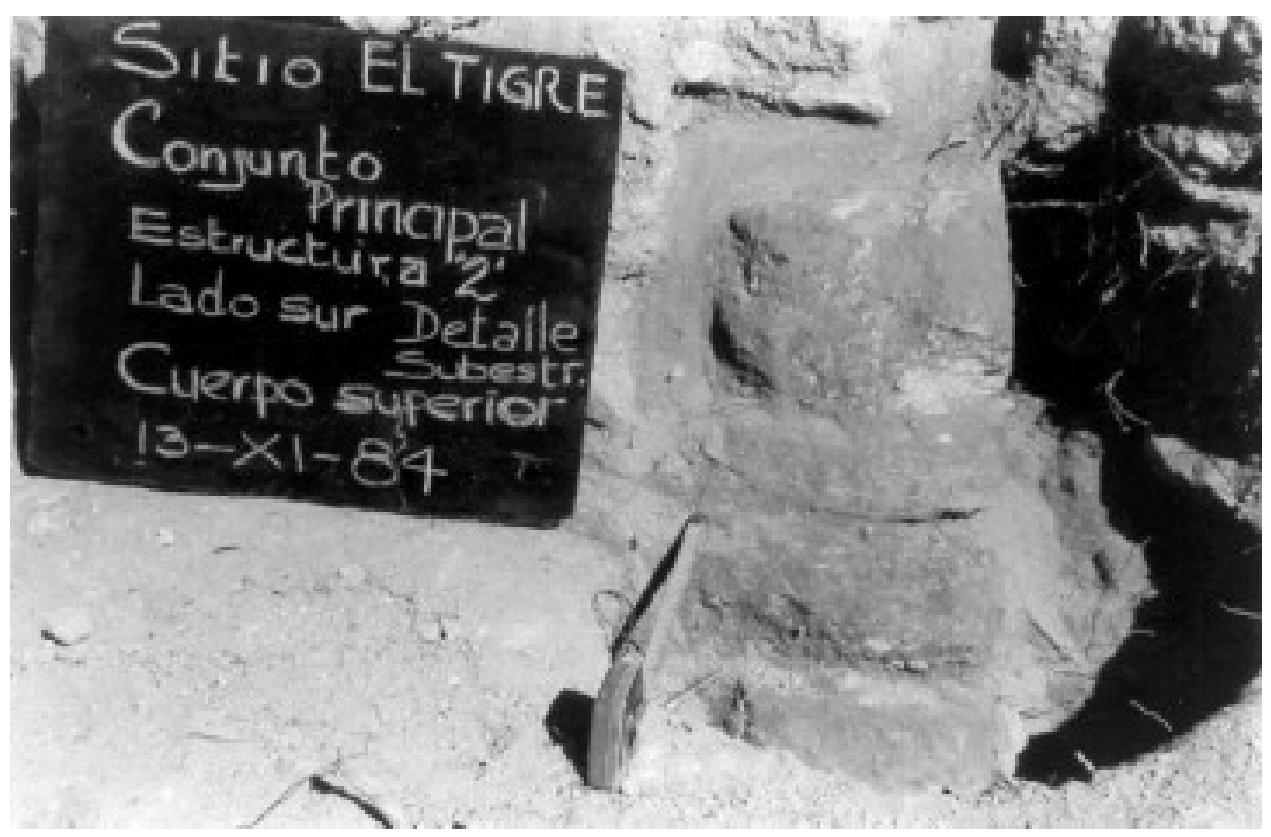

Fotografía 41. D etalle de la subestructura de la Estructura 2.

L a E structura 3 no es característica de la zona maya, los conocimientos que se tienen sobre ésta son escasos, sólo se reportan en la región chontal de Tabasco y ésta de El Tigre. Con el levantamiento topográfico y los perfiles que se hicieron, hoy podemos dar una descripción y posible función de la misma (figura 17).

Se localiza entre las estructuras 2 y 4 , forma las plazas 1 y 2 , y tiene una longitud de $206 \mathrm{~m}$ por 50 de anchura aproximadamente; se compone de cinco montículos unidos entre sí. Antes del levantamiento topográfico pensábamos que había sido construida después de la planeación de la gran plaza, sin embargo, por la disposición de los accesos y posibles escalinatas vemos que los montículos $A$ y $C$ tienen sus escaleras hacia el oeste, es decir, forman la gran plaza con la E structura 2, mientras que los montículos D y $E$, aunque son más pequeños, tienen acceso por el este y forman la gran plaza junto con la Estructura 4. EI M ontículo B, al parecer, tiene dos accesos: uno al norte y otro al sur; por ahora no podemos decir cuál pudo ser la función de dicha estructura.

EI M ontículo A de la Estructura 3 está constituido por una plataforma de aproximadamente $6 \mathrm{~m}$ de altura, al subirla hay un descanso, y se continúa por una escalinata hasta los $4 \mathrm{~m}$ para llegar a la parte superior, en donde existe un plano que debió tener una construcción habitacional de materiales perecederos. La al tura aproximada es de $11 \mathrm{~m}$ y está orientado hacia el oeste.

EI M ontículo B es una estructura piramidal con una altura de casi $20 \mathrm{~m}$, las escalinatas debieron estar hacia el oeste, o posiblemente tuvieron doble 


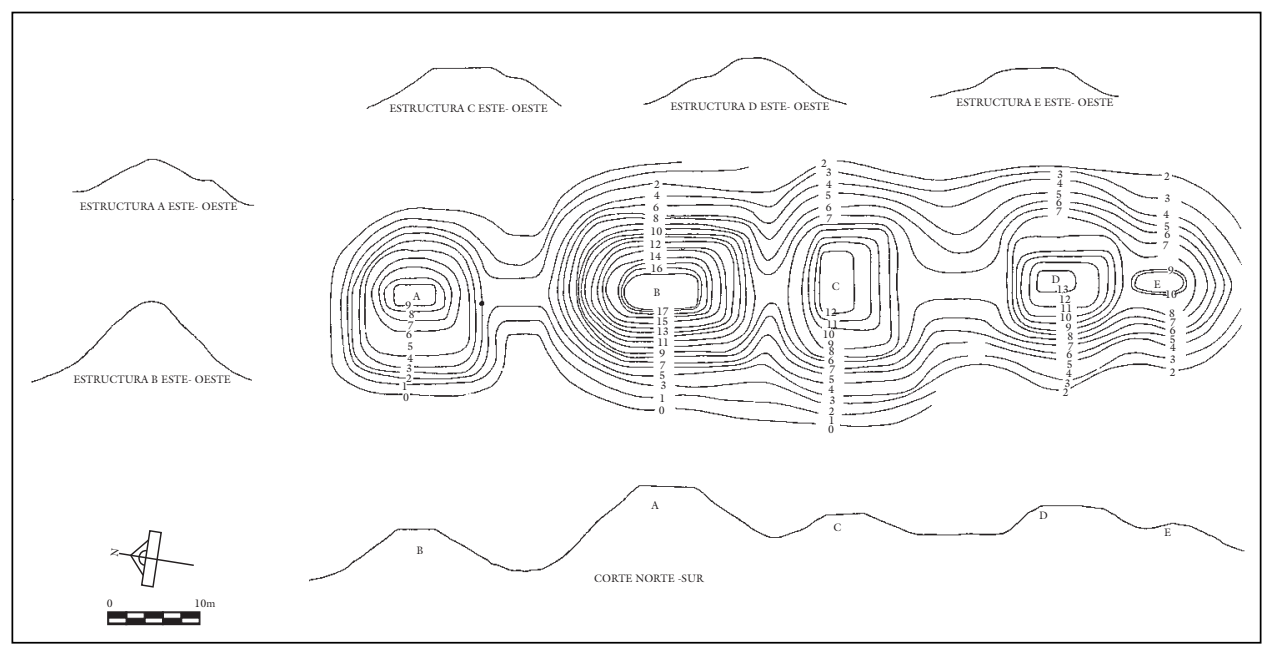

Figura 17. Planta y corte de la Estructura 3.

acceso: uno por el norte y otro por el sur. La parte superior presenta un plano que debió tener una construcción de materiales perecederos ya que no se observan restos de muros o hiladas de piedra. Sin lugar a duda, es el montículo principal de la Estructura 3; además, se alinea con las estructuras 2 y 4 .

El Montículo C es el tercero en importancia de la Estructura 3, tiene acceso por el oeste, frente a la gran plaza; lo mismo que el montículo A, cuenta con una plataforma a la que se asciende por escalinatas y se llega a un descanso para posteriormente, por medio de otra, subir aproximadamente 3 $\mathrm{m}$ y acceder a la parte superior; allí se aprecia una nivelación en donde debió estar la construcción con materiales perecederos.

El D es el cuarto de los montículos de la Estructura 3, su altura promedio es de aproximadamente $8 \mathrm{~m}$ y su entrada da al este, frente a la segunda plaza.

El Montículo E es el más pequeño de los cinco, su acceso también parece ser hacia el este. Aunque los hemos descrito por separado, todos forman una unidad (fotografía 42).

La Estructura 4 es la más grande del sitio, mide casi $200 \mathrm{~m}$ de longitud por otro tanto de anchura, su forma es cuadrangular, aunque en una de sus esquinas, la noroeste, está conformada por una división extraña de donde sale otro montículo menor; esto mismo sucede en las esquinas sureste y noreste, aunque hacia el norte presenta un pequeño montículo paralelo. La gran estructura, que se eleva aproximadamente unos $10 \mathrm{~m}$ sobre el nivel de la plaza, forma una planicie en la parte superior en donde se asientan siete plataformas de diferentes tamaños y formas (figura 18). El montículo principal alcanza una altura de $28 \mathrm{~m}$ sobre el nivel de la plaza y arranca desde la base misma de la estructura, posiblemente es el montículo más alto del sitio. Su orientación es hacia el este, aunque no se aprecian las escalinatas para poderlo confirmar; sin embargo, se alinea con 
ITZAM KANAC CABECERA DE LA PROVINCIA DE ACALAN

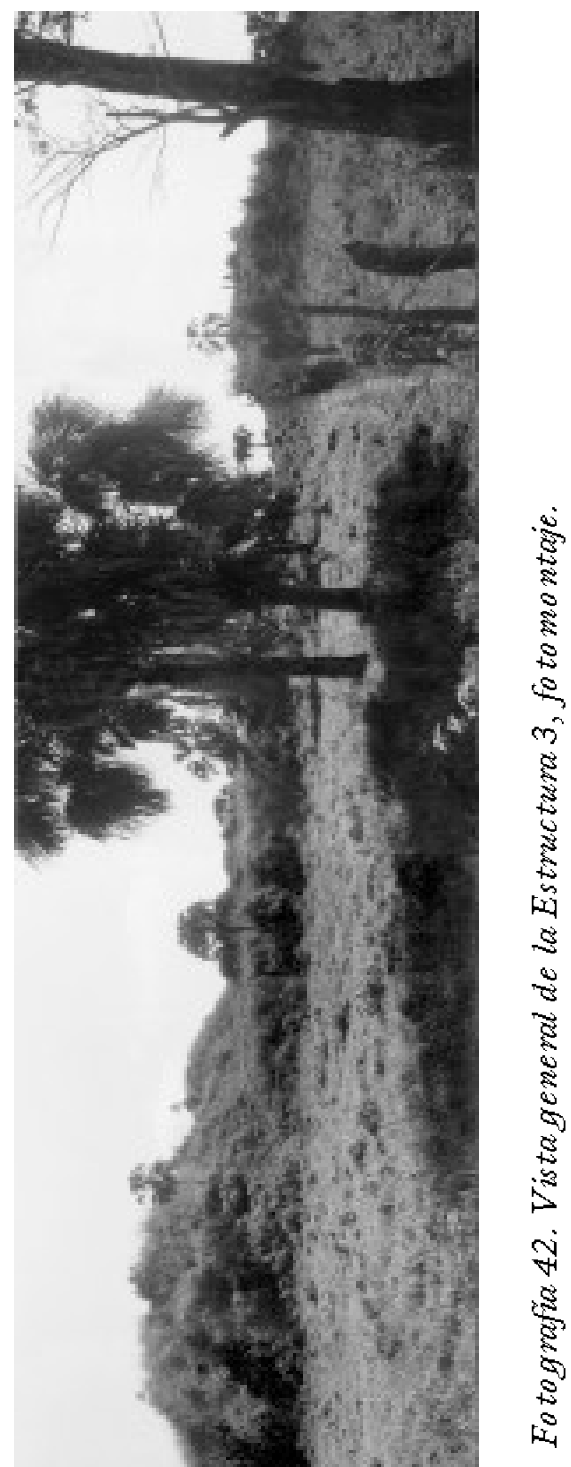




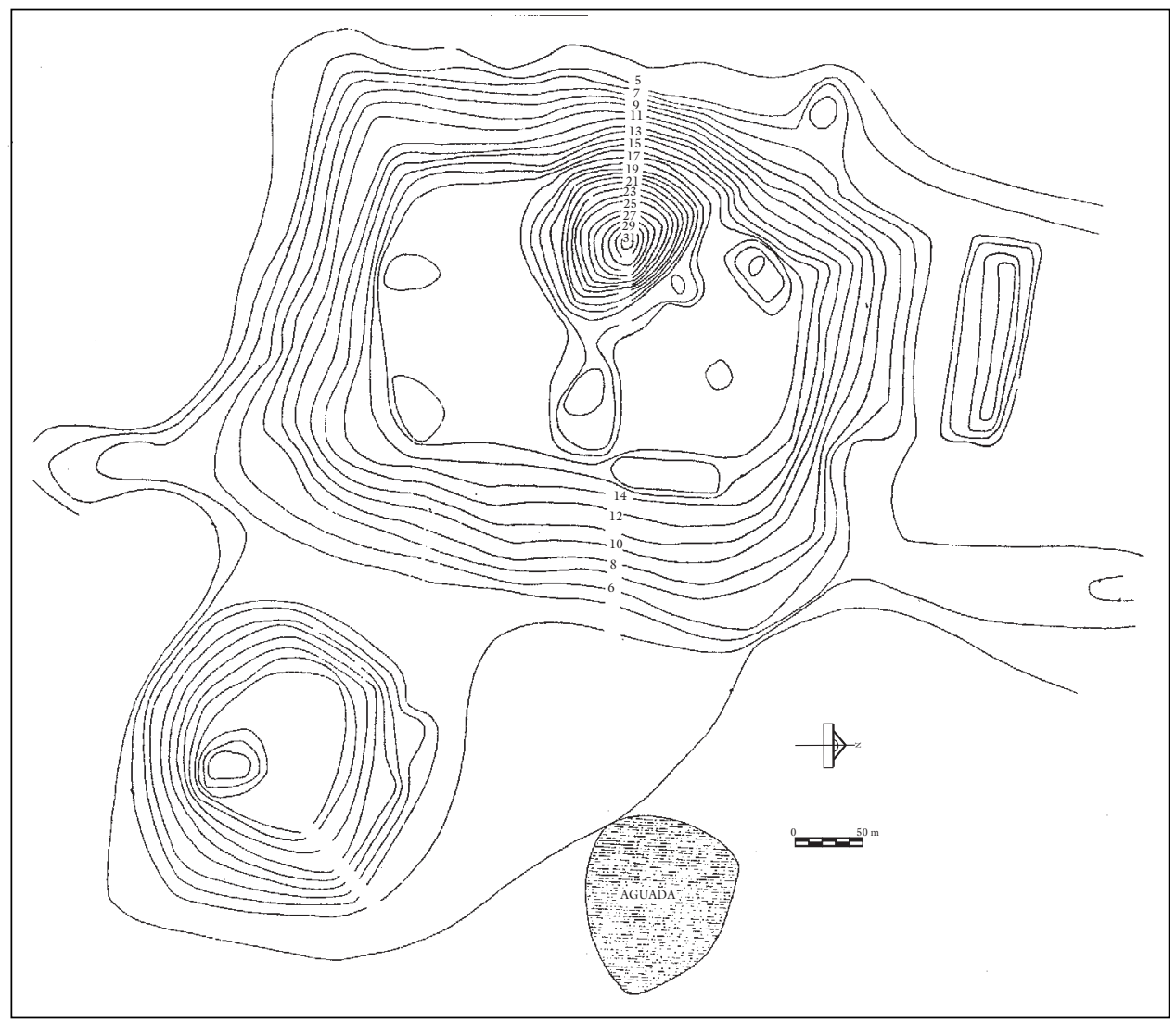

Figura 18. Planta de la Estructura 4.

los otros montículos de las estructuras 2 y 3 . Se eleva $15 \mathrm{~m}$ sobre la base de la gran plataforma y ocupa el centro; al frente existe otro de menor dimensión que alcanza una altura de $3 \mathrm{~m}$ sobre el nivel de la misma. Tanto hacia el sur como hacia el norte se encuentran otras elevaciones. Las más importantes son las del norte, que llegan a medir hasta $3 \mathrm{~m}$, mientras que los restos de las del sur se encuentran apenas delimitados; lo mismo sucede con las del noroeste, en donde se puede ver hasta los restos de la base.

Posiblemente esta estructura tenga más de un acceso, pues en la gran plataforma se encuentran algunos remetimientos que bien pudieran indicar escalinatas. Al frente se halla una gran aguada que abre una enorme plaza delimitada por otras estructuras.

Es interesante añadir que esta estructura es única, no característica de la zona maya; sin embargo, al hacer los reconocimientos de superficie en el sitio hemos encontrado por lo menos tres estructuras que podrían parecérsele, por lo tanto podría constituir un estilo río Candelaria. En la esquina noreste se encontró una gran piedra que quizás sea un fragmento de estela. 


\section{Cuadrante III}

Este cuadrante, como los anteriores, tiene sus propias y muy peculiares características. En primer lugar colinda con la actual población de EI Tigre por el oeste - o sea con el C uadrante IV-, por el norte con el río Candelaria, por el este con los bajos que rodean al sitio, y por el sur con el Cuadrante । (véase mapa 16, p. 164).

Al Cuadrante III, como al IV, por estar a la orilla del río Candelaria, podemos considerarlos como el puerto natural del sitio, ya que las plataformas en algunas partes llegan hasta la orilla del río. Seguramente cuando funcionó el sitio gran parte de las orillas eran arregladas y cuidadas para que los cayucos o embarcaciones pudieran Ilegar hasta la ribera. N o descartamos tampoco que hubiesen muelles de madera, o sistemas de canales para acercarse hasta el borde. Lo más relevante de este cuadrante es precisamente la gran cantidad de plataformas que se registraron a la orilla del río, localizadas a pocos metros y a muy poca altura del nivel de agua.

En otro nivel superior al descrito anteriormente, como a $5 \mathrm{~m}$ de altura sobre el nivel del río y a unos $50 \mathrm{~m}$, existen algunos montículos que tienen una elevación mayor, posiblemente de 5 a $10 \mathrm{~m}$; al parecer, controlaban desde la parte superior las plataformas anteriores. Este sistema de control, dependía, a su vez, de otro mayor.

Este otro sistema se localiza como a $500 \mathrm{~m}$ de la orilla del río y está asentado sobre un tercer nivel natural que debe estar a unos $20 \mathrm{~m}$ sobre el nivel del río; este conjunto de estructuras mayores debió controlar todo el comercio que llegaba por el este, es decir río arriba.

0 tro aspecto importante de este cuadrante son los restos arqueológicos registrados dentro del mismo río. Por los pescadores sabíamos de la existencia de vasijas dentro del lecho del río; con la ayuda de los informantes localizamos varios puntos importantes, el primero de ellos frente al paraje conocido como Santa A melia y el otro en la curva que se registra en el plano topográfico de este cuadrante. También sabíamos de la existencia de dos montículos dentro del río, en el lugar que se conoce como «C uyos», que bien pudieron ser las bases del puente que Cortés mandó construir en febrero y primeros días de marzo de 1525, y utilizó después de la ejecución de C uauhtémoc para salir de I tzamkanac; o quizás un muelle prehispánico; sólo con excavaciones subacuáticas podría determinarse esto.

D urante los levantamientos to pográficos que se hicieron del cuadrante pudimos observar una diferencia muy notable en el campo: la concentración del material. Al parecer, en éste se pueden ver más cerámica y sílex que en el C uadrante ıv; también en el río se localizaron más vasijas y restos arqueológicos en piedra que en el IV. En cambio, en este cuadrante se observa una mayor cantidad de material de concha y coral, piedras semipreciosas y objetos más acabados, lo que puede señalar una diferencia 
importante ya que dentro del mismo Itzamkanac debieron existir otros puertos o lugares especializados en donde se comerciaba con determinados productos. Esto es, por ahora, sólo una observación de campo, falta hacer un reconocimiento exhaustivo de superficie y lógicamente excavaciones que nos permitan obtener materiales que lo confirmen.

El comercio que se concentraba en esta parte del sitio seguramente fue el que venía del Petén, ya fuera por el río San Pedro o por Caribe. Recordemos que existen otros sitios río arriba que seguramente controlaban el paso de embarcaciones y comerciantes que llegaban a la cabecera, I tzamkanac.

EI C uadrante III tiene una longitud de $1800 \mathrm{~m}$ por unos 800 de anchura hacia el este, posteriormente el asentamiento se estrecha y únicamente se registra en los 150 m cercanos al río, para terminar en la localidad conocida como Santa Amelia, en donde se vuelve a ensanchar a unos $300 \mathrm{~m}$.

$\mathrm{H}$ aremos una descripción general del cuadrante desde el este hacia el oeste. EI paraje de Santa Amelia debió ser muy importante, ya que se localiza en el extremo este del sitio, domina una pequeña curva del río y seguramente era el lugar a donde llegaban los mercaderes que venían del Petén hacia I tzamkanac y Xicalango. Allí se da una concentración de montículos (fotografía 43) que no alcanzan una altura mayor a los $8 \mathrm{~m}$, pero se encuentran localizados estratégicamente para dominar gran parte del río y para evitar las posiblesinundaciones en época de lluvias. También en este lado se conoce desde hace algunos años una concentración de chultunes (fotografía 44) que han sido tapados para evitar que el ganado sufra accidentes. Asimismo frente al paraje se localizó, en el fondo del río, gran cantidad de vasijas cerámicas que bien pudieron ser depositadas en el lugar como ofrendas, o producto de algún accidente 0 naufragio.

Santa Amelia debe tener unas 70 estructuras, la mayoría son plataformas que se acomodan a la configuración del terreno y unos diez montículos semiredondos que alcanzan una altura de 5 a $8 \mathrm{~m}$; su localización es estratégica porque dominan parte del río y/ o una serie de plataformas justo al este.

$\mathrm{H}$ acia el oeste el sitio se estrecha y se observan solamente plataformas que se construyeron acondicionando las irregularidades del terreno; ésta es una faja que se extiende por aproximadamente $1 \mathrm{~km}$. En la parte más alta existe un terreno plano con tierra negra, lo extraño es que no se registra ningún tipo de ocupación prehispánica.

A los $700 \mathrm{~m}$ desde el eje norte-sur y a $750 \mathrm{~m}$ del eje este-oeste se localizan dos montículos de piedra en el fondo del río; en un principio se pensó en la posibilidad de que fueran los restos del puente construido por Cortés en 1525. Debemos recordar que el nivel del río, según algunos estudios, debió estar muy bajo, ya que en ese momento se registraba una de las mayores sequías que han ocurrido en el área maya.

El terreno en esta parte del sitio sube suavemente hasta alcanzar una al tura de $10 \mathrm{~m}$ sobre el nivel del río y forma pequeñas ondulaciones en donde se localizan los restos arqueológicos. En algunas partes se hacen verdaderas trans- 


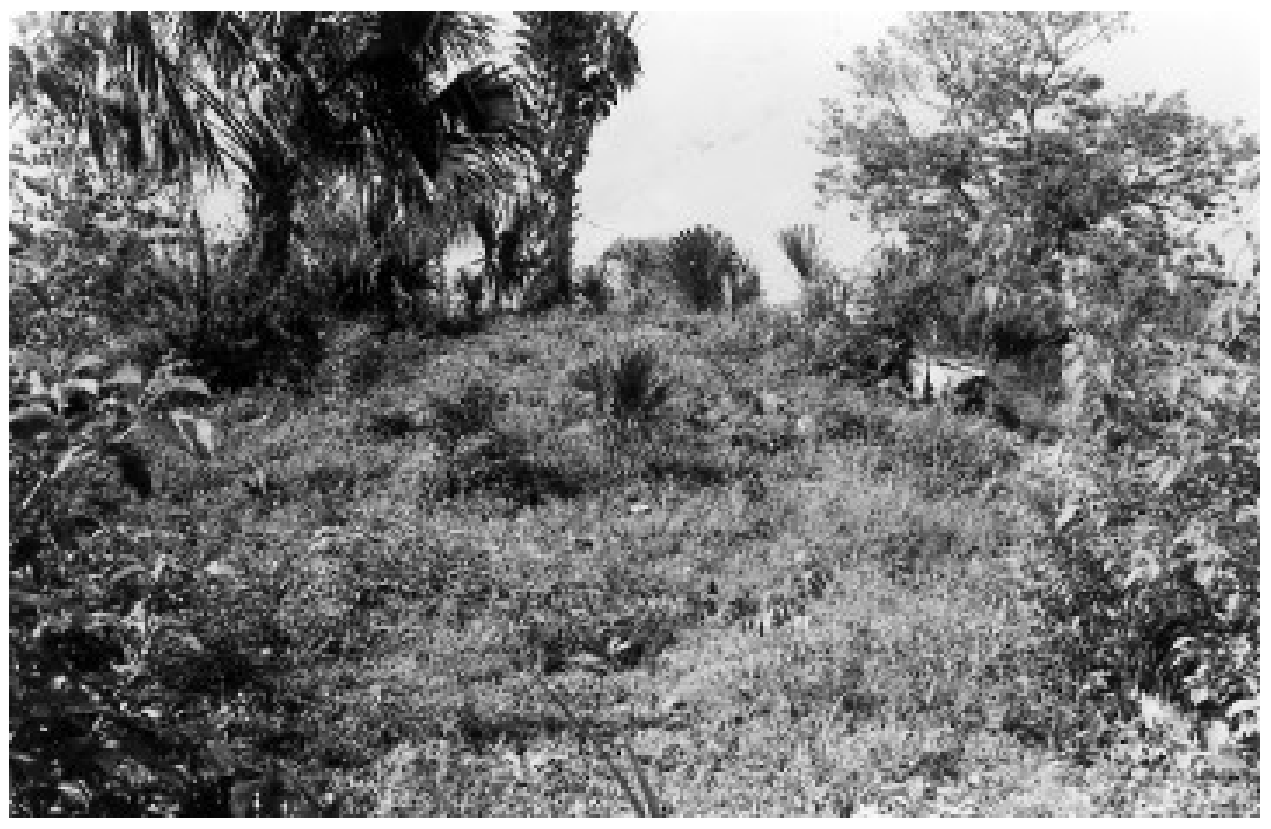

Fotografía 43. Paraje de Santa Amelia.

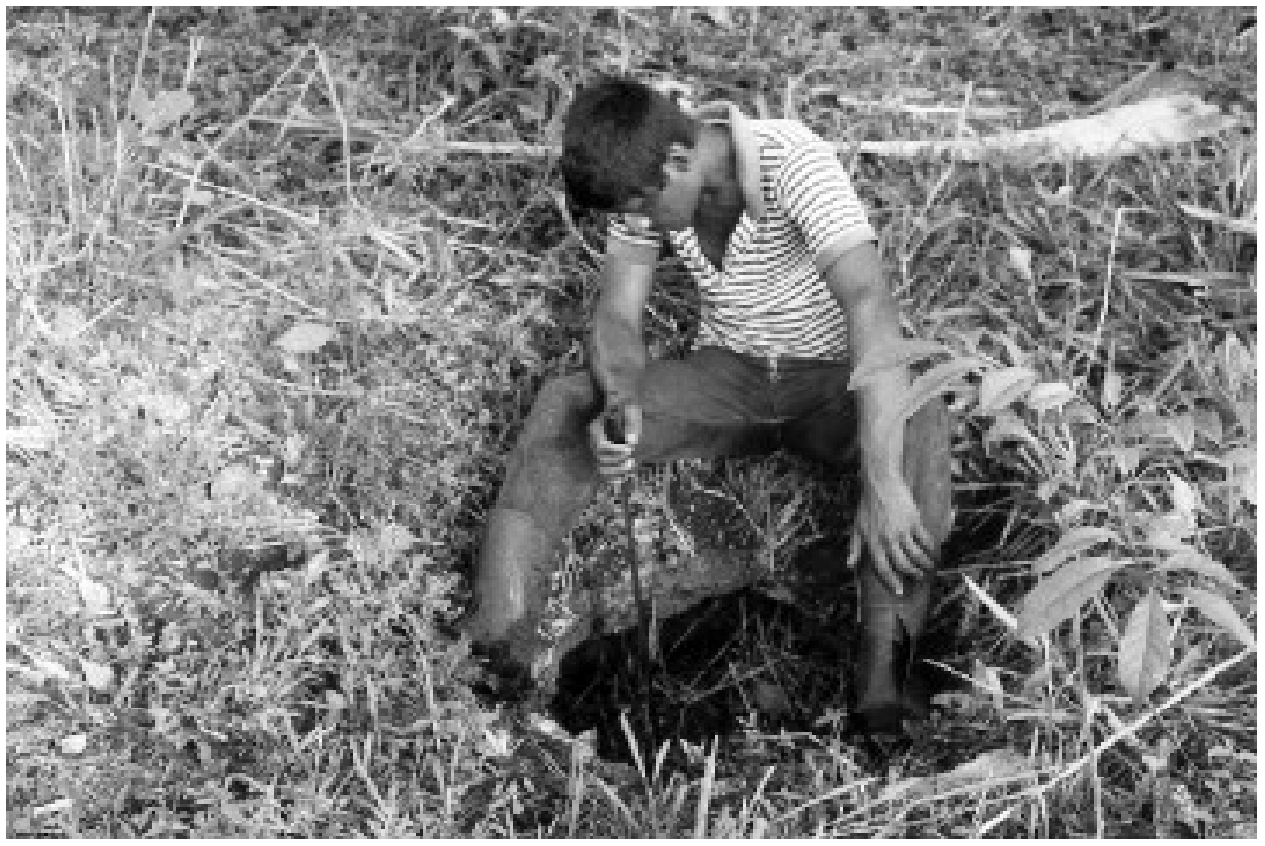

Fotografía 44. Chultunes de El Tigre. 
formaciones para llegar a la orilla del río, como sucede en el lugar en donde creemos estuvo uno de los puertos del sitio; allí se rellenó la zona pantanosa y se construyó una pequeña plataforma casi al borde mismo del río (fotografía 45). Sería interesante excavar tanto en tierra firme como en la ribera.

En esta parte del cuadrante se nota claramente una gran concentración de plataformas, montículos, edificios pequeños y de medianas dimensiones. En los cuadros 3 y 4 D se localiza la estructura más grande del cuadrante, mide aproximadamente $200 \mathrm{~m}$ de longitud (norte-sur) por 100 de anchura (este-oeste), su orientación es hacia el este y la altura promedio es de $13 \mathrm{~m}$; por sus dimensiones creemos que fue muy importante, quizá allí llegaban primero los artículos que traían las embarcaciones por el río San Pedro y EI Caribe, que son las conexiones hacia el Petén-Calakmul.

El Cuadrante ıII es, sin lugar a dudas, el más importante para realizar excavaciones con la intención de buscar datos relacionados con el comercio, pues se encuentran plataformas construidas en las orillas del río y montículos medianos que debieron ser utilizados para controlar el tráfico de ciertos productos, todos ellos supervisados por esa gran estructura que domina el cuadrante. Allí se registró un total de 300 estructuras, aproximadamente.

\section{Cuadrante Iv}

Es el más pequeño de los cuatro, colinda por el norte con el río, por el este con los bajos o pantanos, por el oeste con el Cuadrante III y por el sur con el ॥ (véase mapa 16, p.164).

Su característica principal es que por el norte colinda con el río y frente a éste están los campos levantados y algunos de los canales de irrigación

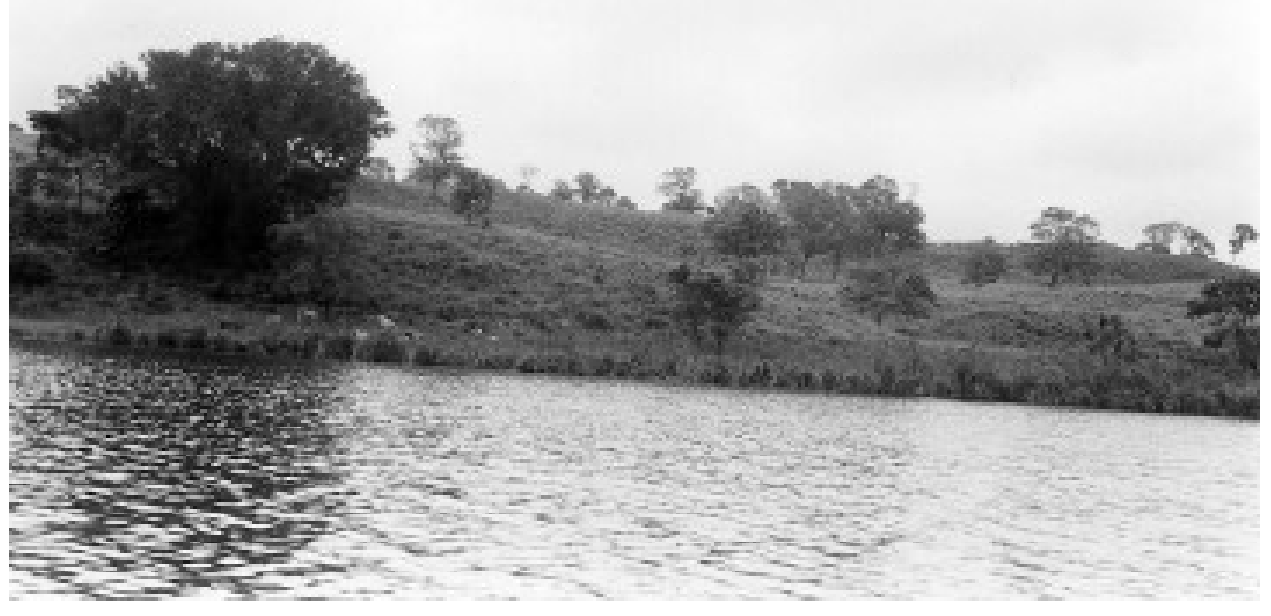

Fotografía 45. Plataformas a orillas del río C andelaria. 
que han hecho famoso a EI Tigre, a través de las publicaciones de Siemens y Puleston. También en este cuadrante se localiza la actual población de EI Tigre que cuenta con unos 150 habitantes.

Cerca del río se localizan plataformas iguales a las del cuadrante anterior; como el poblado se asienta sobre el sitio, éstas han sido destruidas o rebajadas dejando al descubierto parte de las estructuras, por lo cual es frecuente encontrar enterramientos en fosas redondas, también cerámica de todos los tipos, materiales que no son de la región, como concha, coral, obsidiana y piedra verde entre otras; lo que nos indica que el lugar debió participar del intenso comercio que se desarrolló en el sitio durante la época prehispánica.

Aquí existen tres o cuatro niveles artificiales hechos por los habitantes prehispánicos que vivieron en esta parte del sitio; las nivelaciones fueron intencionales y sobre éstas se construyeron algunas plataformas y estructuras menores. La cerámica encontrada en superficie es abundante y generalmente de los grupos Altar, Balancán y M atillas.

Seguramente parte de estas plataformas, como las que se encuentran en los bajos hacia el sacbe, sirvieron a sus habitantes para controlar el comercio que llegaba de Xicalango y T ixchel por la L aguna de Términos y río $C$ andelaria hasta el sitio de Itzamkanac. Estos bajos se encuentran muy abiertos hacia el oeste del sitio; también allí se han encontrado abundantes muestras cerámicas y vasijas enteras en el río, lo que podría indicar un comercio intensivo, u ofrendas que fueron depositadas al lí para pedir un buen viaje y mejor retorno.

Esta parte de los bajos es muy amplia, pero se estrecha hacia adentro del sitio; se abre nuevamente hasta llegar al sacbe que impide el acceso de cualquier tipo de embarcación por más pequeña que sea, ya que éste tenía a la mitad una especie de puente que seguramente sirvió para dejar pasar el agua y pequeñas embarcaciones.

En este lugar, que se estrecha a ambos lados, tanto en el actual ejido de EI Tigre como hacia el ejido Pablo García, existen algunas plataformas, las cuales seguramente sirvieron para controlar el paso de las embarcaciones que se introducían hacia el sitio arqueológico. El conjunto de edificios que se localiza en esa parte fue de gran importancia, pues está formado por caminos y estructuras que bien pueden significar un estatus especial de los comerciantes que controlaban este lugar específico.

E I poblado se asienta a orillas del río (fotografía 46) y está expuesto a las inundaciones que año con año causan problemas a la población. Topográficamente se aprecian tres grandes niveles y en todos existen restos arqueológicos que generalmente son plataformas bajas.

En la actualidad se construyeron la escuela y la casa médica en la parte superior; allí están todavía 30 estructuras, una de las cuales fue explorada durante las intervenciones de 1984. La exploración de una plataforma 


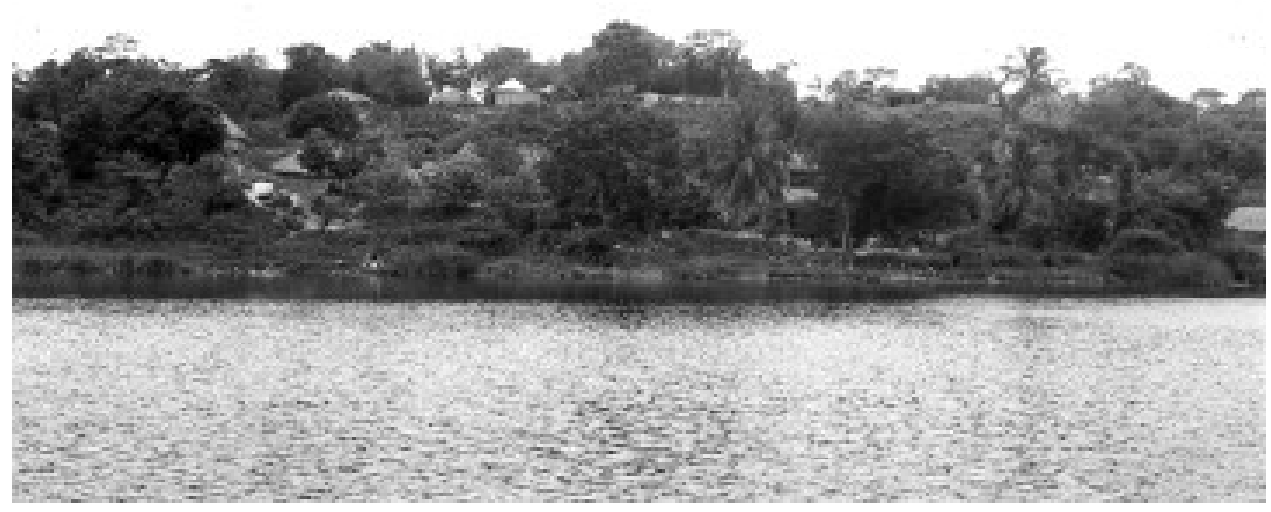

Fotografía 46. Poblado ejido EI Tigre.

habitacional mostró varias etapas constructivas y poseer en su interior un gran cuarto, mientras que en el exterior se puede observar un espacio abierto que sirvió de antesala (fotografía 47).

El trabajo en piedra es bueno y se aprecia una moldura en la parte inferior de los muros que formaron las paredes de dicho cuarto. Pudo tener techo plano de mampostería o posiblemente de materiales perecederos; sin embargo, me inclino por la primera posibilidad, ya que se encontró gran cantidad de material en su interior.

La plataforma es rectangular, de frente mide $24 \mathrm{~m}$ por 14 de anchu$\mathrm{ra}$, aprovecha un afloramiento de roca caliza adosado al oeste de la estructura. En su fachada tiene una amplia terraza o patio de 6 por $21.75 \mathrm{~m}$ de frente, sobre cuya porción este y norte, existe una secuencia de escalones alineados. Se presenta la planta del edificio y dos cortes con una posible reconstrucción (figura 19).

La estructura habitacional descrita aquí pertenece a un conjunto mayor formado por varias estructuras y plazas; ésta domina gran parte del río y su función estuvo relacionada con el comercio. Por el análisis cerámico se sabe que tiene una ocupación que se remonta al Preclásico superior pasando por el Clásico hasta llegar al Postclásico, lo que nos indica que el conjunto desempeñó un papel importante en el comercio por largo tiempo (Vargas y D elgado 1999).

EI C uadrante Iv domina gran parte de una curva que da el río $C$ andelaria, al parecer por allí se entraba hacia el centro ceremonial; en la actualidad los bajos han sido invadidos por zacatales que hacen casi imposible el paso de cayucos. En esa vuelta del río también se han encontrado varias vasijas de barro en el fondo. 


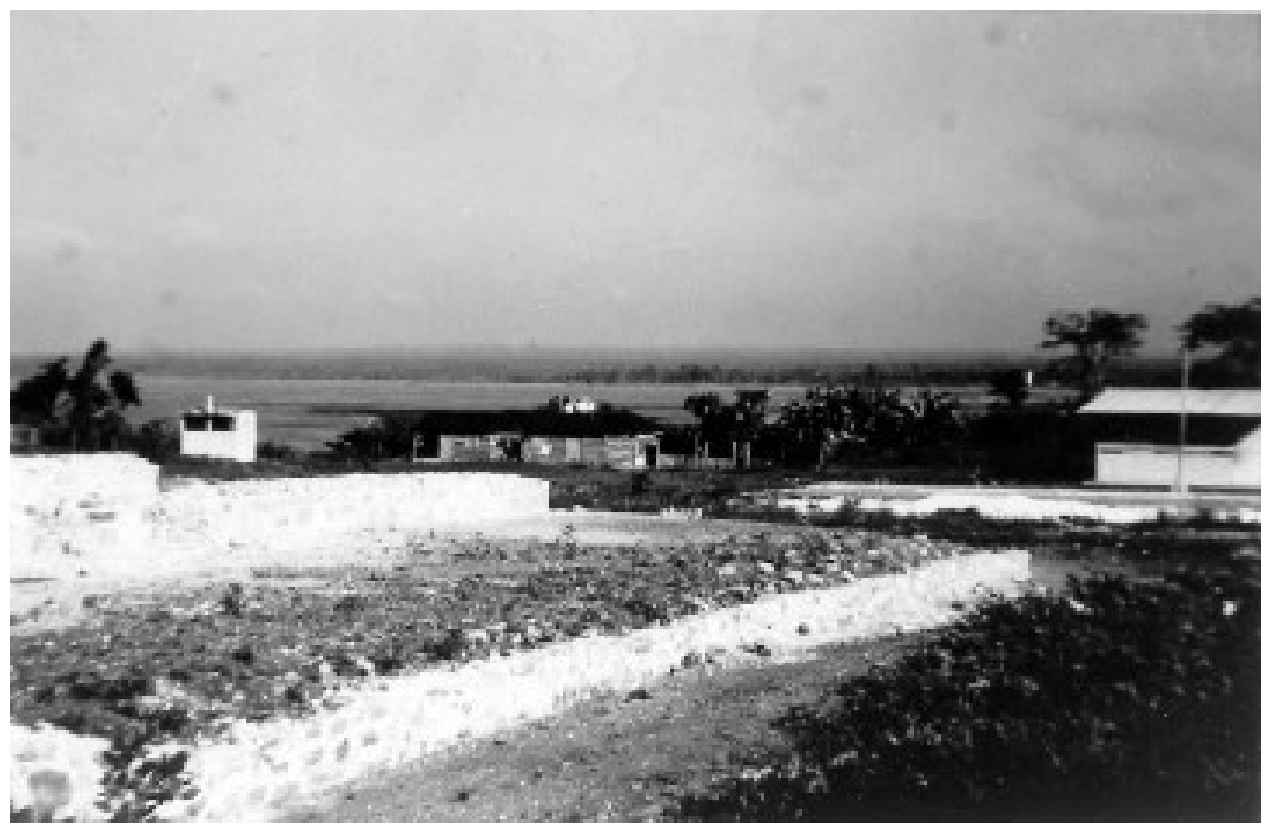

Fotografía 47. Plataforma habitacional cerca de la escuela.

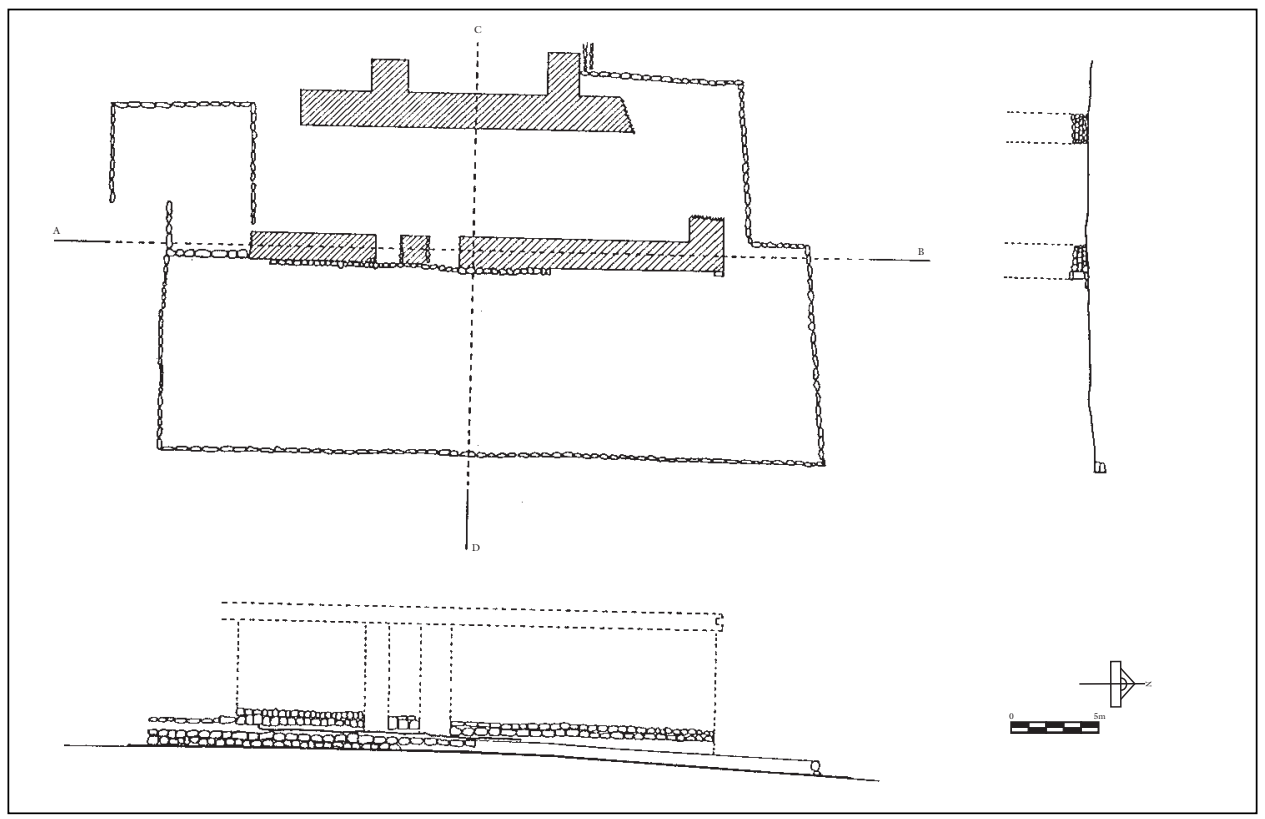

Figura 19. Planta y corte de la plataforma habitacional de la Escuela. 
En el nivel medio de la elevación se encuentran hacia el oeste varios montículos más o menos grandes, que dan testimonio de la importancia de esa parte del sitio; en total debieron ser un poco más de 20, lógicamente los más importantes eran los localizados hacia el oeste y en la parte alta del cuadrante. A orillas del río y de los bajos sólo se encuentran plataformas que llegaban hasta el borde y seguramente en tiempos de aguas quedaban inundadas; existen algunos restos visibles, aproximadamente 15. El total de estructuras localizadas en este cuadrante fue de casi 90 .

Al frente de este cuadrante y de la población actual se extienden los campos levantados que dan fama al sitio; también allí se localiza uno de los canales más importantes (véase fotografía 25, p.142).

\section{Itzamkanac. El Tigre}

El levantamiento topográfico del sitio no cubre el $100 \%$, ya que sólo se cubrió lo que es el ejido de El Tigre y parte de lo que es el ejido Pablo García hacia el este y sur; falta to do lo que se extiende hacia el oeste, pasando el sacbe y los bajos (figura 20).

En esa área del sitio se registraron alrededor de 65 estructuras en un croquis preliminar y en un reconocimiento para detectar la ocupación se caminó por espacio de $3 \mathrm{~km}$; la zona habitacional sigue y posiblemente llegue cerca del poblado de Pablo García. También se detectaron varios fosos, algunos podrían ser naturales pero otros sí son artificiales, lo que demuestra una construcción defensiva hacia esa parte del sitio y que la región se vio envuelta en conflictos bélicos.

H acia el sur la ocupación sigue hasta la carretera, que está como a 9 km del río; sin embargo, creo que la ocupación del sitio debe terminar por la laguna del Pato; en el levantamiento que presentamos falta como $1 \mathrm{~km}$ para llegar a dicha laguna, y la ocupación se hace cada vez menor a medida que uno se aleja del Centro Ceremonial de El Tigre; por falta de tiempo no realizamos todo el registro de restos arqueológicos.

En el Cuadrante I, que se localiza hacia el este, también se registraron casi todas las estructuras arqueológicas visibles; sin embargo, igualmente tuvimos que dejar todas aquellas que se encuentran en los bajos, pues en otro recorrido hecho hacia esa parte del sitio se detectaron restos arqueológicos por el este hasta el río San Pedro.

En cuanto al Cuadrante III, se registraron todos los restos arqueológicos que se han localizado cerca del río Candelaria y los bajos. U na parte importante de este cuadrante no tiene restos materiales visibles, por lo que suponemos fue un área de bosques o de cultivos en la que los habitantes del lugar no construyeron nada a propósito. C reemos que lo que se conoce como Santa A melia, puede pertenecer al momento del florecimiento de EI Tigre y posiblemente la ocupación humana llegue hasta el Postclásico. 


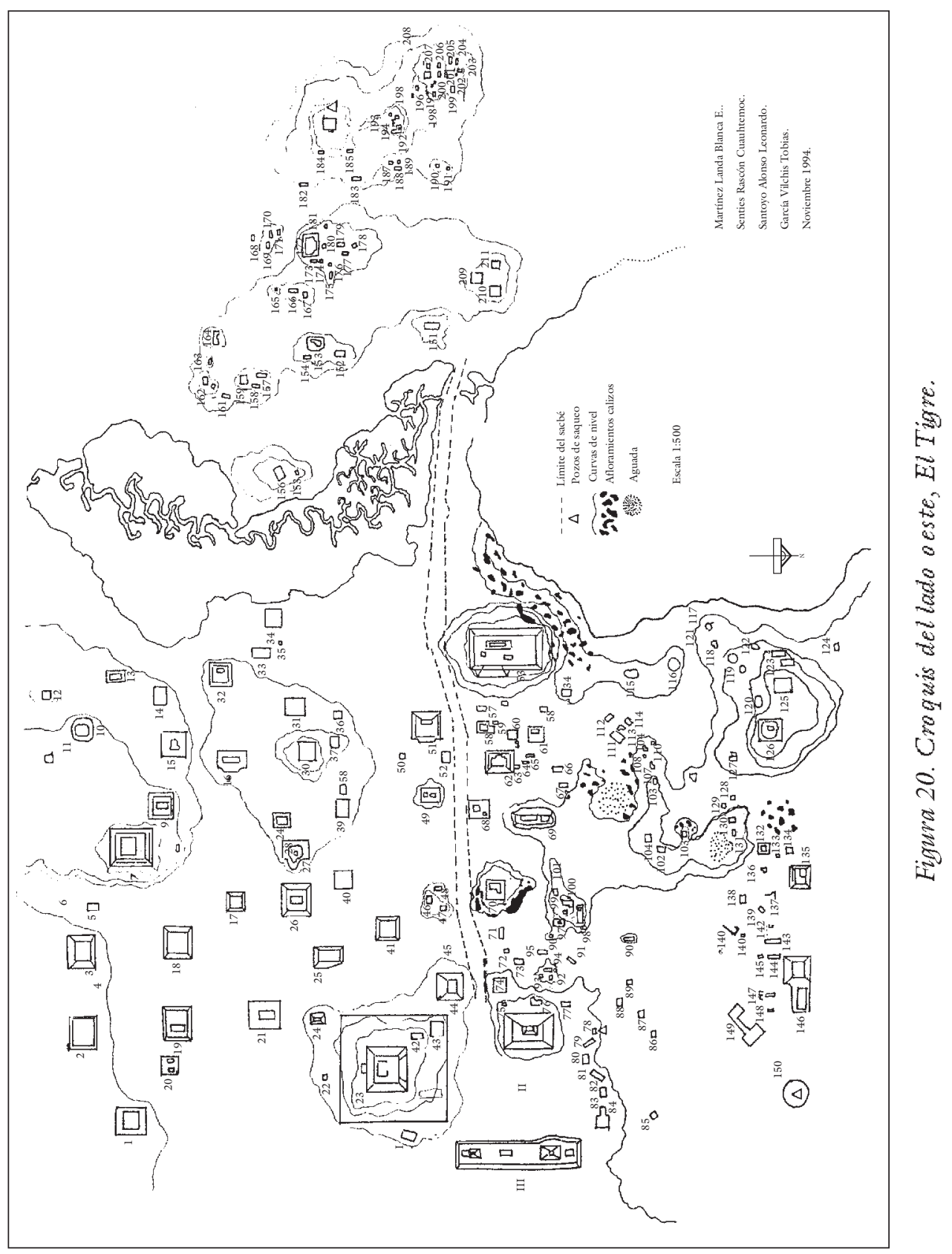


EI Cuadrante Iv no presenta ningún problema en cuanto a sus límites, éstos son: al norte el río, al oeste los bajos, y al este y sur los extremos del poblado, cubriéndose de esa manera to do el cuadrante.

En una valoración preliminar creemos que EI Tigre es el sitio más grande de todo el río Candelaria; le sigue en importancia Cerro de los M uertos y Santa Clara sobre el río Caribe, afluente del C andelaria. También ha de nombrarse el sitio de San Enrique, conocido en la actualidad como Las Campanas, registrado por nosotros como Las Pozas y localizado cerca del río Pejelagarto, afluente del Candelaria; más abajo se halla otro sitio de cierta importancia llamado Salto G rande, que también muestra enormes edificios.

$\mathrm{H}$ emos calculado la extensión del sitio en unos $5 \mathrm{~km}$; sólo se presenta el levantamiento topográfico de lo que es el ejido EI Tigre y parte del ejido Pablo García; se cubren 3200 m en el eje este-oeste y 2200 m en el eje norte-sur (véase mapa 16, p.164).

En total se registraron aproximadamente 500 estructuras en el Cuadrante I, 750 en el Cuadrante II, 300 en el Cuadrante II y 90 en el Cuadrante Iv; hacen un total de 1640 estructuras, más 64 que hay pasando el sacbe.

Según 0 viedo, Itzamkanac tenía entre 900 y 1000 casas, su población total habría sido de 4000 a 4500 habitantes, tomando como base 4.5 personas por familia y sólo una familia por casa. De haber muchas casas con familias extensas, la cifra podría ser considerablemente mayor; sin embargo, es imposible calcular el número de dichas casas. M ás aún, este factor puede ser erróneo, ya que O viedo toma la información de Alonso Luján quien pudo a su vez exagerar el tamaño de la población o no apreciarlo bien.

$\mathrm{N}$ o tenemos datos para calcular la población de los 76 pueblos mencionados en los Papeles de Paxbolom $M$ aldonado, tampoco tenemos mayor información sobre los 20 pueblos nombrados por Bernal Díaz del Castillo; sin embargo, Cortés y sus 3000 auxiliares, en 1525, se abastecieron en la población de Acalan y él mismo sostuvo que era muy importante al decir que era un «lugar grande con muchos templos».

En E I Tigre se registraron al rededor de 1700 estructuras; no to das son casas habitación, muchas de ellas son templos; otras, diversos elementos arqueológicos; posiblemente otras muchas no pertenezcan al Postclásico tardío; sin embargo, es interesante verlo en conjunto, porque El Tigre es el lugar más grande de todo el Candelaria, y bien podría identificarse con el I tzamkanac de las fuentes históricas.

L os sacbeob en EI Tigre se conocen desde hace muchos años, sobre todo el número 1, que en fotografía aérea es claramente visible. Tiene $300 \mathrm{~m}$ de longitud y fue construido sobre bajos para poder comunicar el sitio con el lado oeste; tal vez lo más relevante de este sacbe sean las divisiones que los mayas dejaron para que el agua pudiera circular. L a anchura del sacbe es de aproximadamente $25 \mathrm{~m}$, en la actualidad está en malas condiciones por el paso de ganado y caballos. Continúa hacia el centro ceremonial del sitio y se 
forma por las estructuras que se van distribuyendo de tal manera que delimitan una especie de calle que llega a la plaza principal, su longitud es de $1061 \mathrm{~m}$.

Poco antes de llegar a los bajos hay una serie de estructuras perfectamente distribuidas y al otro lado del pantano existe otro sacbe en malas condiciones debido a que el guano y otras plantas casi lo han destruido, el cual llega hasta un montículo natural muy alto.

En un principio creímos que la construcción del sacbe obedecía al hecho de que allí se obtenía la piedra, es decir, la cantera del lugar; sin embargo, en la ocasión que tuvimos la oportunidad de caminar observamos por lo menos 61 estructuras, algunas de ellas de gran tamaño y otras menores, por lo tanto pensamos que es una parte importante del sitio que está relacionada también con el comercio y el centro ceremonial.

EI sacbe 3 se localiza al sur de la E structura 1, en los bajos de la laguna del Pato como a unos $3 \mathrm{~km}$; tiene una modalidad muy peculiar, ya que al parecer construyeron una base de piedra sobre los bajos, formando un piso consistente y duro que permite utilizar la vara para mover el cayuco y, en la actualidad, en tiempos de secas pasan por allí los caballos sin problema alguno. Esta construcción llega a una plataforma que sirvió seguramente de embarcadero, pues está en la orilla; allí se localizaron diez estructuras.

Faltan por analizar todos los sistemas de comunicación entre los diferentes conjuntos, ya que existe una serie de nivelaciones y sistemas de conducción hacia diferentes partes del sitio; esto todavía no ha sido trabajado ni siquiera a nivel de croquis.

En EI Tigre no se han encontrado inscripciones, pero sí estelas. La 1 se localiza en la E structura 2 y está reportada desde los tiempos de Piña C han y Pavón Abreu. Todavía hace algunos años se hallaba in situ, sobre la gran plataforma, pero fue sacada de su lugar y quebrada allí mismo; sin embargo, se sabe en dónde estuvo pues todavía se conserva el hoyo original. No puede especularse si algún día tuvo inscripciones ya que está demasiado deteriorada.

La Estela 2 no existe físicamente, pues fue saqueada de EI Tigre por dos individuos (J osé Alejos Correa y Agustín Pérez D amián) a quienes se apresó y llevó a la cárcel de Candelaria, el 10 de septiembre de 1966. En este lugar está el acta, pero no existe ninguna descripción de dicha estela, que al decir de algunos informantes, permaneció ahí por dos o tres meses y después, a petición de las autoridades se envió a C ampeche, en donde se pierden las pistas. Por gente que conoció la pieza tuve la oportunidad de visitar el lugar y fotografiar la espiga de la estela.

$L$ a descripción que algunos hacen de la estela es muy interesante, dicen que tenía un águila cayendo y un personaje a caballo y estaba labrada en ambas caras. Los informantes que la vieron afirman que sí estaba grabada; lógicamente hay que tomar la descripción con muchas precauciones.

La E stela 3 se localiza al sur de la primera plaza y frente a la Estructura 14 del croquis; tampoco tiene restos de inscripción y está fragmentada en dos partes, una de ellas permanece en su lugar. 
La Estela 4 todavía permanece enterrada en esa misma plaza, al este y frente a la Estructura 3.

La Estela 5 no tiene problemas de identificación, porque se encuentra fragmentada en dos y todavía se aprecia parte in situ. N o conserva ningún resto de inscripción y está al centro de una pequeña plaza.

La E stela 6 se localiza sobre una de las estructuras de la calzada, la espiga todavía está en su lugar.

L as otras estel as localizadas en los reconocimientos de superficie bien pudieran serlo o no, ya que en el lugar se encuentra gran cantidad de piedras grandes en proceso de deterioro; pensamos que por lo menos tres de estas grandes lajas pudieran ser estelas, pero habría que hacer una limpieza detallada para poderlas definir.

En el mapa preliminar de EI Tigre, realizado por Siemens en abril de 1970, se localiza un chultún detrás de la Estructura 1. En 1984 visitamos los chultunes que son ampliamente conocidos por los habitantes del ejido $y$, sobre todo, por el dueño del paraje conocido como Santa Amelia.

En los reconocimientos de superficie real izados durante esta temporada de campo se localizaron nuevos chultunes, algunos de ellos en muy buen estado de conservación, otros en cambio fueron tapados por representar un peligro para el ganado.

En fin, creemos que después de esto podemos estar de acuerdo con los planteamientos realizados por Scholes y Roys, Piña C han y Pavón Abreu de que EI T igre es la famosa capital de los acalanes, el I tzamkanac de las fuentes históricas; sin embargo, falta mucho por investigar y trabajar en la zona.

El sitio tiene un centro ceremonial muy bien definido, con estructuras grandes, sacbeob que lo comunican, rampas de acceso, estelas, áreas de posibles puertos, muelles, campos elevados, canales de irrigación, chultunes, grandes aguadas, etcétera, que hacen del lugar una gran ciudad que debe corresponder seguramente a la cabecera de una importante provincia. Además concuerda con la descripción de H ernán Cortés y Alonso D ávila, quienes recorrieron la región viniendo desde el río San Pedro M ártir; también cioincide con la descripción que hacen los frailes, los encomenderos y los Papeles de Paxbolom $M$ aldonado, que señalan el trayecto ya sea desde Xicalango y/ o Tixchel, pasando por los saltos hasta Itzamkanac. H emos localizado, asimismo, el posible puente construido por C ortés para pasar el río, después de la muerte de C uauhtémoc.

Al describir I tzamkanac, los Papeles de Paxbolom dicen que la estructura principal tenía cuatro templos dedicados a las cuatro principales divinidades y que una de ellas era Kukulcán. En lasúltimas exploraciones realizadas en la Estructura 1 hemos excavado un templo redondo que, sin lugar a duda, estaba dedicado a esa divinidad maya, Kukulcán. Por lo tanto, se puede pensar que EI Tigre fue el I tzamkanac de las fuentes históricas, pues éstas concuerdan con la localización y los datos arqueológicos. 


\section{Capítulo III \\ Los putunes de Acalan y los itzaes}

LOS ITZAES Y LOS PUTUNES

Sabemos por las fuentes históricas, en especial por el Chilam Balam, que los itzaes estuvieron en la región de Chakamputún, 'la sabana de los putunes', y que de alguna manera dejaron su huella en la población. Permanecieron 260 años y después salieron hacia C hichén I tzá llevando el culto de Kukulcán. Los «brujos del agua», como se llamaron a sí mismos, conquistaron e impusieron un sistema de gobierno diferente, el ah tepal, centralizado bajo el dominio de los guerreros itzaes. Las fuentes históricas narran estos acontecimientos y las evidencias arqueológicas los corroboran, como lo veremos en el desarrollo de este capítulo.

Tozzer y Barrera Vásquez sostenían en acotaciones y notas de sus trabajos que los itzaes no parecían haber sido mexicanos, sino mayas de habla chontal, más relacionados con los magtunes de Acalan y proponían su filiación putún. Posteriormente, Thompson, Ruz L. y Piña C han, entre otros, identificaron con bases históricas e información arqueológica a los itzaes como putún-itzaes.

É ste tema, a pesar de ser ampliamente tratado en diferentes investigaciones, todavía sigue siendo problemático; muchos lógicamente no están de acuerdo con ese planteamiento y se sigue sosteniendo la vieja idea de que los itzaes eran toltecas y no mayas putunes, como señalan las fuentes históricas mayas y al gunos investigadores. Con esto no pretendemos negar que los chontales hayan tenido una fuerte mezcla con un pueblo de habla náhuatl, como lo indican algunos nombres de personas.

Los chontales ocuparon un enclave especial en M esoamérica, lo que los obligó a entrar en contacto con otros grupos y su territorio constituyó una entrada estratégica a la zona maya. D esde allí pudieron llegar por mar a toda la península de Yucatán y a Centroamérica.

Existen referencias históricas del centro de M éxico que aluden a esta región, lo mismo que fuentes históricas de Yucatán y Guatemala que mencionan las planicies de Tabasco-C ampeche. J iménez M oreno (1976 ) y otros autores (cfr. Foncerrada 1983) al hablar de los nonoualcos y olmecas 
xicalancas dicen que pudieron venir de Tabasco-Campeche, la región de ríos y lagunas. EI C hilam Balam, Landa y López de Cogolludo, entre otros historiadores de Yucatán, narran que los itzaes salieron de Chichén I tzá y fueron a Chakamputún, y después de permanecer allí algún tiempo regresaron nuevamente a Chichén I tzá. Los xiues, cocomes, cupules, canules y cheles, grupos importantes que estaban en Yucatán durante el Postclásico tardío, dicen venir de Tabasco, lugar al que no quieren regresar por ser una región de pantanos y mosquitos. Además, en varias fuentes se encuentran citas en donde ellos se acusan entre sí de ser extranjeros en Yucatán. Los Papeles de Paxbolom $\mathrm{M}$ aldonado narran claramente cómo el primer halach uinic de los magtunes viene de Cozumel, y el mismo documento cita la conquista de $C$ hetumal por ese grupo.

L os quichés y cakchiqueles, grupos mayas importantes de Guatemala, en sus crónicas narradas en el Popol Vuh y en los A nales de los $C$ akchiqueles, dicen venir de una región de ríos y lagunas, que bien pudiera identificarse con una parte del territorio tabasqueño-campechano. Carmack (1981) liga al grupo de los quichés con I tzamkanac.

E stas son citas que, de una u otra manera, señalan la importancia de la región durante ese momento de perturbación en M esoamérica que se conoce con el nombre de Epiclásico para el centro de M éxico y Clásico terminal para la zona maya, en el que, al parecer, el grupo chontal desempeñó un papel más importante del que comúnmente se le atribuye.

L os itzaes no parecen haber sido mexicanos, sino mayas de habla chontal, más relacionados con los magtunes de Acalan; en cambio, los ah canules y otros grupos mayas de la península de Yucatán procedían de Tabasco y se les relaciona más con los mexicanos.

Eric Thompson (1975), en su obra H istoria y R eligión de los M ayas, trata ampliamente el tema de los putunes e identifica a un grupo itzá como putún; da a conocer la patria de origen de los itzaes al decir que vienen de las tierras bajas noroccidentales de Tabasco y Campeche. Posteriormente Piña Chan (1980) en su libro C hichén Itzá. La ciudad de los brujos del agua, toma en cuenta a los chontales de T abasco-C ampeche para explicar a los itzaes de C hichén. Existen otros trabajos como los de L. M illet (1989: 157-158), quien pretende demostrar que Edzná es la casa de los itzaes y los trabajos de Peniche R ivero $(1990,1994)$, quien Ilevando «a sus últimas consecuencias los descubrimiento de Thompson» nos habla de dos ramas itzaes: la yucateca de C hichén I tzá y la campechana de Acalan.

EI tema no es nuevo, sin embargo casi todos los trabajos que se han realizado se han basado en las investigaciones de Scholes y Roys, en el texto Chontal publicado por esos autores y en fuentes históricas de Yucatán, como son los textos del C hilam Balam, López de Cogolludo y Lizana. A continuación haremos un resumen de lo que han expuesto algunos investigadores mayas al respecto (Tozzer 1978, Barrera Vásquez 1969, Thompson 
1975 y Piña C han 1980, entre otros) y en este trabajo trataremos de ver la presencia itzá en la región chontal, así como la chontal en la península de Yucatán, a través de las fuentes históricas y de las evidencias arqueológicas.

PRESENCIA YUCATECA EN LA REGIÓN CHONTAL. EVIDENCIAS HISTÓRICAS Y ARQUEOLÓGICAS

L as primeras evidencias histó ricas que tenemos de estos contactos de la península de Yucatán con la costa de C ampeche-Tabasco se refieren precisamente al pasaje del C hilam Balam de C humayel, que narra la salida de los itzaes de $C$ hichén hacia $C$ hakamputún: «4 ahau. Fue conquistada por ellos la tierra de Chakamputún» (711-731 dC).

Este acontecimiento se detalla mejor en los C hilam Balam de $\mathrm{M}$ aní y el de Tizimín, correlacionados por Barrera Vázquez y S. Rendón (1969), al decir lo siguiente:

D iez veintenas de años reinaron en Chichén I tzá y fue abandonada (495-692 dC). Transcurrieron trece dobleces de katún (435-692 dC) y fueron a establecerse a Chakamputún. En el katún 8 ahau (692-711), fue alcanzada la tierra de Chakamputún. 4 ahau (711-731 dC) fue alcanzada la tierra por ellos, de Chakamputún.

Es decir, al guna gente abandonó Chichén I tzá para ir a Chakamputún, en donde se establecieron, "allí tuvieron su hogar los itzaes, hombres religiosos». E sta es la primera llegada de los itzaes a la región chontal, en la que permanecieron una rueda de katunes, o sea, aproximadamente 260 años. Evidencias de tal presencia se puede inferir por los restos cerámicos Pizarra y Sotuta encontrados tanto en la costa como en EI Tigre, además de material de coral proveniente de la costa oriental de Quintana Roo.

Los Papeles de Paxbolom M aldonado, único documento chontal, son de gran importancia por su contenido histórico al hablar del origen de los magtunes o tamagtunes: «En el principio Auxaual, rey, vino de Cozumel, y habiendo cogido los pueblos de aquí, fue a recoger el pueblo de Tanocica y los grandes principales[...]».

Tanto los itzaes como los tamagtunes vinieron desde la península de Yucatán a la región chontal, los primeros llegaron hacia el $700 \mathrm{dC}$ y permanecieron hasta el $950 \mathrm{dC}$; y los magtunes debieron llegar hacia el 1200 $\mathrm{dC}$; ambas migraciones corresponden con el fatídico katún 8 ahau, que marcaba el abandono y la conquista de nuevos territorios.

En la región chontal se ha reportado cerámica de Yucatán que bien puede corresponder a los diferentes momentos de esa presencia itzá en la región. En el sitio arqueológico de Santa Rita, Campeche, lugar que creemos sea el Xicalango de las fuentes históricas (O choa y Vargas 1989), se hallaron cuentas 
de coral que posiblemente procedan de la costa oriental de Q uintana R oo, Io que nos indica una ruta de intercambio entre las dos regiones, como además lo demuestran algunas cerámicas procedentes de Yucatán encontradas en Tixchel e I sla del Carmen (Ball 1978) y por nosotros en EI Tigre.

La situación ecológica tan característica de la costa oriental de Q uintana Roo propició que se desarrollara un comercio que facilitara la adquisición de los productos que no tenían y la exportación de los que en su región se producían, como la sal, que al parecer empezó a exportarse desde el Formativo tardío (300-100 aC .; Andrews 1983: 7); la miel y la cera, que también producían en abundancia y exportaban en canoas desde Yucatán hasta Tabasco para intercambiar por cacao y productos de C hiapas y M éxico (Scholes y Roys 1968: 244).

El algodón fue otro producto muy abundante en Yucatán y su elaboración en tejidos era muy famosa, ya que se exportaban hacia M éxico, H onduras y Tabasco.

Es grandísima la cosecha de algodón de que se hacen diversos tejidos y telas muy buenas que corren por toda la N ueva E spaña, y muchos hilados, que teñidos de diversos colores, sirven para labrados de ropa, que se hacen muy vistosos y de gran primor» (López de Cogolludo 1957, t. ।, cap. I: 227).

El pescado, que es tan abundante en las costas del mar $C$ aribe, fue otro producto de gran importancia para el comercio, ya que se salaba y podía transportarse a grandes distancias ( $L$ ange 1971); también se llevaban dientes de tiburón y agujas de mantarraya para los sacrificios ceremoniales 0 autosacrificios, caparazones de tortuga como instrumentos musicales y conchas como ornamentos, collares, pulseras, etcétera.

En los Papeles de Paxbolom se señala la relación de los putunes con los habitantes de Cozumel, ya que el primer halach uinic de los magtunes llegó de la isla y, después de ser refundada Itzamkanac y tener todo el territorio controlado, conquistó C hetumal; además, debemos recordar que Cozumel está muy cerca de Bakhalal (Bacalar), lugar de donde provienen sus antepasados según el C hilam Balam.

M ayapán comenzó su hegemonía después de que $\mathrm{H}$ unac $\mathrm{C}$ eel $\mathrm{C}$ auich conquistó Chichén Itzá. EI C hilam Balam de C humayel dice: «EI trece ahau (1007-1027 dC) es el katún en que fundaron la ciudad de M ayapán. $\mathrm{H}$ ombres mayas se llamaron».

Acerca de esto Landa (1978: 16-7) nos dice que un grupo de mercenarios fue introducido a M ayapán, desde Xicalango y Tabasco por un gobernante cocón: «Q ue el gobernador Cocón entró en cudicia de riquezas, y que para esto trató con la gente de guarnición que los reyes de M éxico tenían en Tabasco y Gicalango, que les entregaría la ciudad, y que así trujo gente mexicana a M ayapán, y oprimió a los pobres y hizo muchos esclavos[...]». 
H unac $C$ eel Cauich de Mayapán inició la conquista de Chichén Itzá hacia los años de 1185-1204 de la era cristiana; venció a C hac Xib C hac, A h Tepal de Chichén Itzá, con la ayuda de siete capitanes mayapanenses (figura 21); también peleó contra los de I zamal, aliados de Chichén, obligando a huir al gobernante del lugar en compañía de algunos itzaes, hacia 1204-1244 de la era cristiana; posteriormente se dirigió hacia Polé, en la costa oriental.

D e allí regresó para conquistar M ayapán y la destruyó, según la C rónica M atichu y el C hilam Balam, en 1441-1461 dC, "para vaciar de la ciudad de M ayapán al poder amontonado en ella».

En M ayapán residieron los cocomes, se establecieron los xiu, los cheles, los tzeh, los canules, los cupules y posiblemente los linajes de los Puit, Pech y los Cochuah (Roys 1972: 32-7). Roys piensa que los canules se asentaron en la región noroccidental de la península, en la provincia que llama Ah Canul, y allí permanecieron unos 250 años, integrándose a los mayas yucatecos hasta la llegada de otro grupo proveniente de Tabasco.

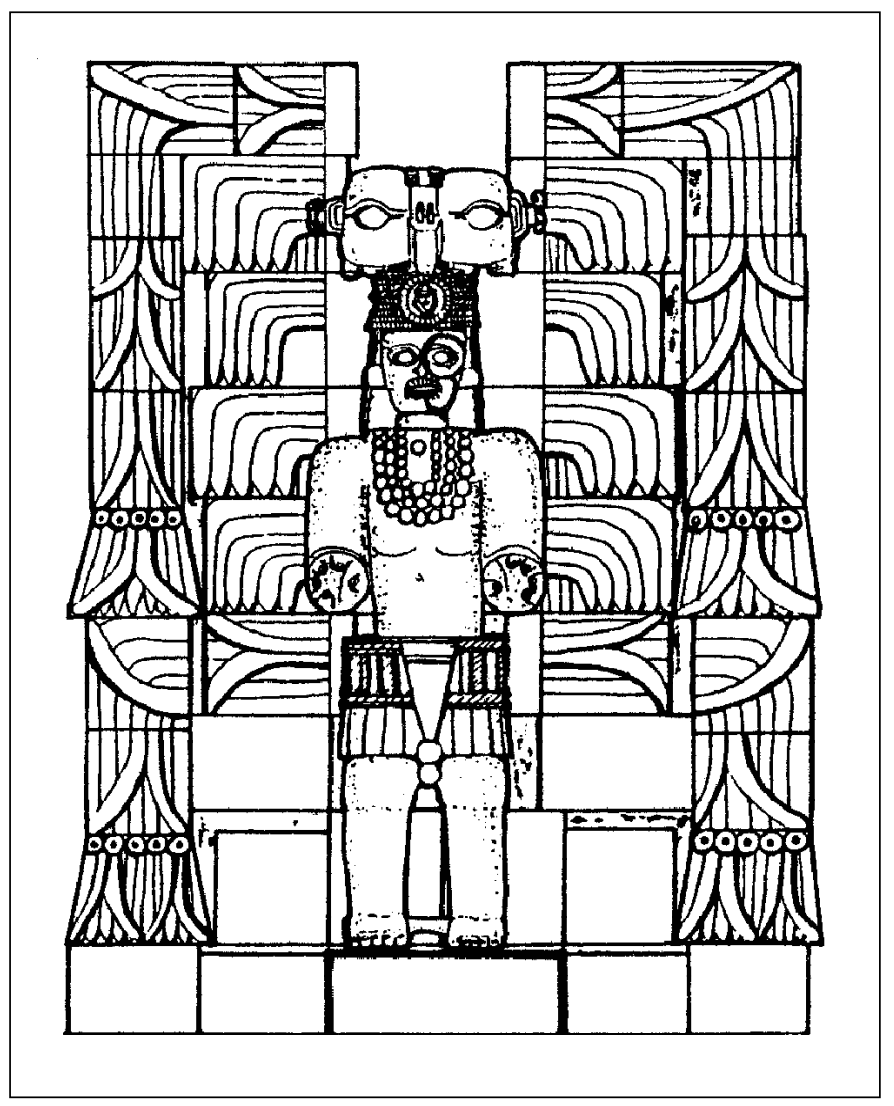

Figura 21. Capitán mayapanense de Kajab (J. Ligorred 1993). 
Según Landa (1978: 18), les estaba prohibido contraer matrimonio con los mayas yucatecos, pero no quisieron regresar a las lagunas y mosquitos de Tabasco.

O tro punto que debe tenerse en cuenta, aunque es difícil determinar su valor, es que el vocablo itzam de Itzamkanac, la capital de los putunes acalanes, es muy parecido a I tzá. I tzam es parte del nombre de unos de los dioses principales yucatecos: I tzamná 'La casa de la iguana'. Según comunicación personal de $\mathrm{O}$ tto Schumann Itzamkanac podría significar «L a segunda llegada de los I tzam»; con lo que se corroboraría la primera llegada de los itzaes hacia el $700 \mathrm{dC}$ y la segunda con los magtunes a la región alrededor del $1200 \mathrm{dC}$.

\section{Presencia putún en la Península de Yucatán. EVIDENCIAS HISTÓRICAS Y ARQUEOLÓGICAS}

La cultura chontal alcanzó su máximo esplendor desde el 700-950 dC hasta el Postclásico temprano; su economía se basó principalmente en el comercio y su poderío se extendió a gran parte del territorio actual de Tabasco, Campeche y debió llegar hasta $\mathrm{N}$ aco y $\mathrm{N}$ ito en $\mathrm{H}$ onduras, como nos lo dicen las fuentes históricas.

Por ser el comercio su principal actividad, contó con puertos importantes como Itzamkanac a orillas del río Candelaria, Tixchel a orillas de la L aguna de Términos, Xicalango y Potonchán, este último a orillas del río Grijalva.

En términos generales, el periodo que va del 700 al $950 \mathrm{dC}$ corresponde al auge de la región de ríos y lagunas, conocida generalmente como tierras bajas noroccidentales del área maya. El siguiente periodo, que correspondería del 950 al $1250 \mathrm{dC}$, se caracteriza básicamente por una ocupación que presenta una marcada disminución del material arqueológico, lo que probablemente indica un abatimiento de la población o desplazamiento hacia otras regiones de las tierras bajas mayas. L a ocupación mayor se da en el Postclásico tardío (1250 a 1550 dC) en la costa, en las provincias de Tabasco, Xicalango y Acalan.

Arqueológicamente estos sitios no presentan auge durante el Postclásico, algunos de ellos florecen en el Clásico terminal y la mayoría tiene una ocupación importante desde el Preclásico superior. Los putunes eran comerciantes y al mismo tiempo expansionistas que penetraron en muchas partes del territorio maya, avanzaron por el U sumacinta, el Pasión y también por el $\mathrm{C}$ andelaria. Estos grupos, al parecer, se relacionaron con los mexicanos (Teotihuacan, toltecas) y además fueron vecinos de grupos de habla mexicana; por eso podían desempeñar el papel de transmisores. Fueron grupos doblemente aculturados, pues eran receptores y a la vez 
promotores del replanteamiento cultural después de la caída del Clásico maya. M aterial cerámico (Altar, Balancán, Tres N aciones, etcétera) proveniente de la región chontal o putún se encuentra en diferentes partes, como Yaxchilán, Seibal, Altar de Sacrificio y en la costa oriental de Quintana Roo.

Roys (1933: 114-6) cita a los putunes en la traducción del Chilam Balam de C humayel de la siguiente manera: « $i Q$ uien soy yo entre el pueblo de los putunes?», y Thompson (1975: 33) nos dice que el contexto implica que los putunes eran los conquistadores de Chichén I tzá.

Es bien sabido que los itzaes, cocomes, xiues, canules y cheles no eran mayas yucatecos. EI C hilam Balam (Barrera Vázquez y Rendón 1969) dice que los itzaes reinaron en C hichén I tzá y la abandonaron para establecerse después en Chakamputún; allí tuvieron su hogar. «8 ahau (928-948). Fue abandonado Chakamputún por los hombres itzaes. Y vinieron a poner sus casas otra vez. Trece dobleces de katún estuvieron establecidos en sus casas de $C$ hakam putún. En este mismo katún fueron los itzaes a vivir bajo los árboles, bajo la ceniza, bajo su miseria».

Piña Chan (1980: 37), interpretando varios textos del Chilam Balam de Chumayel, dice que en el katún 4 ahau (968-987 dC) prácticamente nacieron al salir de Champotón rumbo a Yucatán, junto con el dios Kukulcán ( $M$ izcit A hau), que los había creado, hecho ver la luz; sus señores eran los pauah o dioses de las cuatro direcciones del mundo que penetraron por el poniente (Gran Bajada); aunque también en un 4 ahau (1224-1244 dC) llevaron a cabo una penetración por el oriente (Pequeña Bajada).

Estos hechos muestran la llegada, conquista y dominación de grupos extranjeros en Yucatán. Pero ¿quiénes fueron los itzaes? Según las fuentes históricas, un grupo maya de Tabasco, tal vez chontal, como lo han planteado algunos investigadores. Se dice también que fue un grupo que recibió una doble aculturación al ser receptor y promotor del replanteamiento cultural de M esoamérica, que con el tiempo fue absorbido por la población mayoritaria maya yucateca.

Los xiues y los canules, entre otros grupos que se encuentran durante la época postclásica y principios de la conquista española en Yucatán, vienen de la región de los chontales o putunes. Algunos de ellos dicen llegar del poniente de Suyúa, que se localizaría en la región de Tabasco-C ampeche; allí estuvieron cuatro katunes, o sea 80 años, se despidieron de su hogar $\mathrm{N}$ onoual, del que procedieron. Entre los documentos de la familia xiu que se conservan en la $\mathrm{U}$ niversidad de $\mathrm{H}$ arvard existen tres de suma importancia: un mapa, un tratado de tierra y uno sobre el árbol genealógico de la familia. Al pie de éste está sentado $\mathrm{H}$ un U itzil C hac T utul Xiu, el fundador de U xmal, y se registra la fecha de su fundación a un lado del abanico que este primer xiu lleva en la mano izquierda y data del katún 2 ahau (987-1007 dC). 
Thompson al hablar de los acalanes, dice que es una rama de los putunes o chontales y al referirse a los itzaes también señala que eran de origen putún. Los argumentos propuestos por ese investigador de que los itzaes tienen un origen putún son los siguientes:

1. A Chichén Itzá llegaron dos grupos. Los itzaes debieron hacerlo desde Cozumel hacia el 918 de nuestra era, cruzaron el estrecho y llegaron a Polé y desde allí avanzaron a tierra firme. Ya establecidos en Chichén I tzá reciben a Q uetzalcóatl-Kukulcán probablemente en el 987 dC. E se grupo entró por el oeste y llevaba influencias mexicanas mas fuertes (Thompson 1975: 21-2).

2. Landa y Lizana registran en sus obras la Gran Bajada y la Pequeña Bajada que hablan de una invasión en gran escala desde el oriente y una más pequeña desde el occidente.

3. A estos que llegan se les identifica como putunes, por los nombres que se les dan, putún y ah nun, y por la estrecha relación con C hakamputún, su tierra de origen; lo cual queda registrado en los murales (figura 22), en donde se recrea, según Thompson, una invasión por mar.

4. Ix C hel ha sido identificada como una diosa de los putunes y uno de los puntos importantes de la región de Acalan es Tixchel, 'el lugar de la diosa I xchel'; fue además una diosa importante de Cozumel e I sla M ujeres a donde llegaban a venerarla los comerciantes desde Tabasco-C ampeche.

5. Chakamputún, 'sabana de los putunes o pradera de los putunes', está íntimamente relacionado con los itzaes, de allí salieron hacia $C$ hichén

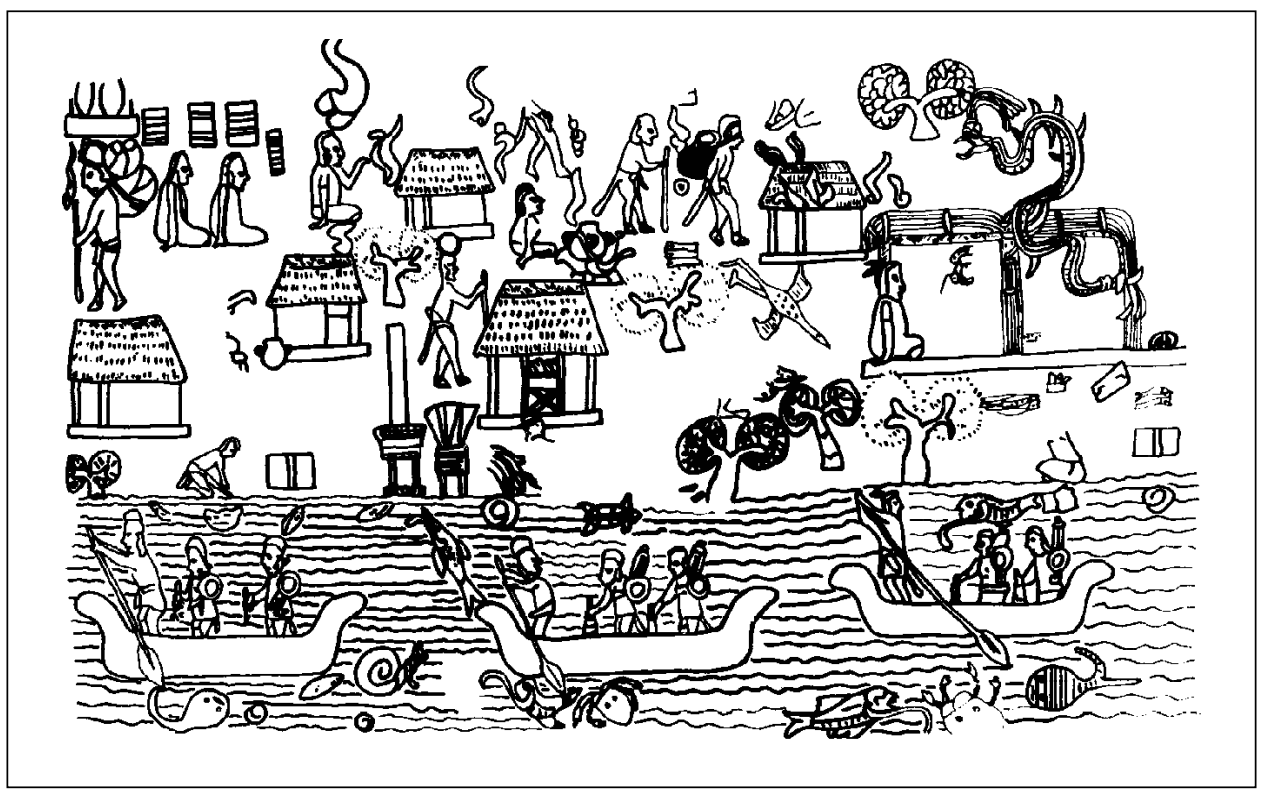

Figura 22. M ural de Chichén Itzá, viaje de los putunes. 
I tzá según nos dice el C hilam Balam. Esta puede ser una prueba interesante de que los itzaes eran putunes, ya que procedían de esa provincia.

6. Thompson (1975: 36) nos dice que a los itzaes con frecuencia se les denomina ah nunob, 'Ios que no saben el lenguaje de la tierra, Ios tartamudos o balbucientes'. En putún existe la palabra nunum 'vagabundo, el que no tiene domicilio fijo', el que 'siempre estaba corriendo por acá, corriendo por allá, sin que nadie sepa por qué ni para dónde'. Según el C hilam Balam los itzaes cada 260 años, al final del katún 8 ahau, tenían que abandonar su ciudad e ir a otro lugar.

7. Los mayas yucatecos ponían el título de ahau delante del nombre A hau Pech, mientras que los putunes acalanes ponían ahau detrás del nombre del jefe, Palocen A hau, M izcit A hau.

8. L as chozas pintadas en el mural de los guerreros en C hichén I tzá tienen las puertas no en el centro de la fachada, como es la costumbre en todo Yucatán, sino a un lado. Existe un ejemplo en el $\mathrm{N}$ aranjal cerca de $\mathrm{El}$ Tigre, que bien pudo ser el Itzamkanac, capital de los acalanes (Andrews 1943: figura 25b).

9. Thompson (1975: 37) al referirse al mural que se encontró en Chichén I tzá, nos dice que bien pueden ser guerreros putunes navegando frente a un poblado costero localizado en alguna parte del litoral de Tabasco y C ampeche: «Q uizá represente la escena la salida de los guerreros putunes para su largo viaje, que debía terminar con la conquista de C hichén I tzá y otros lugares de Yucatán».

10. Para Thompson, éstas son pruebas de que los itzaes eran putunes 0 de algún grupo meridional emparentado con ellos; controlaban una enorme extensión, la de los ríos y lagunas de Tabasco y Campeche más todo el litoral marino, probablemente con varias capitales: Potonchán, Xicalango, I tzamkanac y Tixchel. Ese dominio ejercido sobre un gran territorio facilitó el comercio y la llegada de nuevas ideas religiosas, como es el culto a Kukulcán.

11. O tra de las características de los itzaes eran sus prácticas eróticas. En el C hilam Balam (Barrera Vásquez y Rendón 1969) se les reprueba continuamente como «los lascivos, desenfrenados» y «los extranjeros que [...] trajeron consigo cosas vergonzo sas cuando vinieron. Perdieron su inocencia en el pecado carnal».

Al respecto Fernández de 0 viedo (1851-55, libro 17, cap. 17) dice lo siguiente: «Entre ídolos de barro y braseros hallados en lo que es ahora I sla del Carmen, había dos figuras de madera, una de ellas representaba a dos hombres dedicándose a la sodomía y otra a un hombre que sostenía sus genitales con ambas manos» (citado en Thompson 1975: 42).

Entre las evidencias arqueológicas están todos aquellos restos materiales de importación, que necesariamente tuvieron que pasar por la región de los putunes hacia la península de Yucatán; ellos fueron intermediarios entre el centro de M éxico y la península. 


\section{La obsidiana}

Existen dos rutas principales de comercio de este artículo, una tenía su origen en el centro de M éxico y otra por los altos de Guatemala. Esta última se dirigía hacia el norte de la península de Yucatán (I chpatún, Tulum, M ayapán), su origen probable es la región del río M otagua (Rovner 1976: 44). La obsidiana del valle de M éxico proviene de las canteras de Pachuca, $\mathrm{H}$ idalgo y Michoacán (ibidem: 45). En Tancah se encontraron 21 hojas parcialmente rotas; éstas son de dos tipos: gris opaco veteado y gris con ligero matiz rosado (M iller 1977: 103); además de varios núcleos y puntas de flecha. En C an C un hay abundancia de obsidiana gris y sílex, predominando la primera principalmente en artefactos completos o parte de ellos, puntas de proyectil y navajas ( $M$ ayer 1977: 210). En Tulum se ha encontrado gran cantidad de ese material, sobre todo navajas prismáticas, puntas de proyectil, núcleos, etcétera, al parecer traída de las tierras altas de Guatemala y M éxico, que tenía que pasar por la región putún.

$$
\text { El jade }
$$

En Cozumel se encontró un pendiente olmeca elaborado en el Preclásico pero en contexto Clásico tardío, lo cual podría señalar que desde esa época, y quizás desde antes, la isla no era un lugar apartado sino que estaba ligado por mar, mediante el intercambio a larga distancia (Rathje et al. 1973). En Tancah se encontró un jade o piedra que apareció en las plataformas tempranas de la Estructura 44, y que a su vez provenía de las tierras altas (M iller 1977: 130). En C an C un y Tulum se hallaron varios entierros con la cuenta de jade en la boca; en Cozumel se localizaron más de 100 hachas, al guna de jadeita, procedentes de las rocas vol cánicas de los al tos de G uatemala (Sabloff et al. 1975). En EI Tigre también se han encontrado varios objetos (fotografía 48) de ese material que llegaba por intercambio.

\section{L as plumas de quetzal, guacamayo y la piel de conejo}

Se han encontrado tres diferentes especies de guacamayos, una del sur de M éxico que no se encuentra en la península de Yucatán; un guacamayo verde (ara militaris) del norte de M éxico; y otra especie diferente a las anteriores: hueso de un periquillo (aratinga sp) que no es la especie común de Yucatán (aratinga astec) (H amblin y Rea 1979: 26-7).

La piel de conejo (tuchumite) utilizada en diseños de ropa era importada desde Tabasco, a donde quizá la habían llevado los comerciantes aztecas desde M éxico (Chapman 1957: 136). 


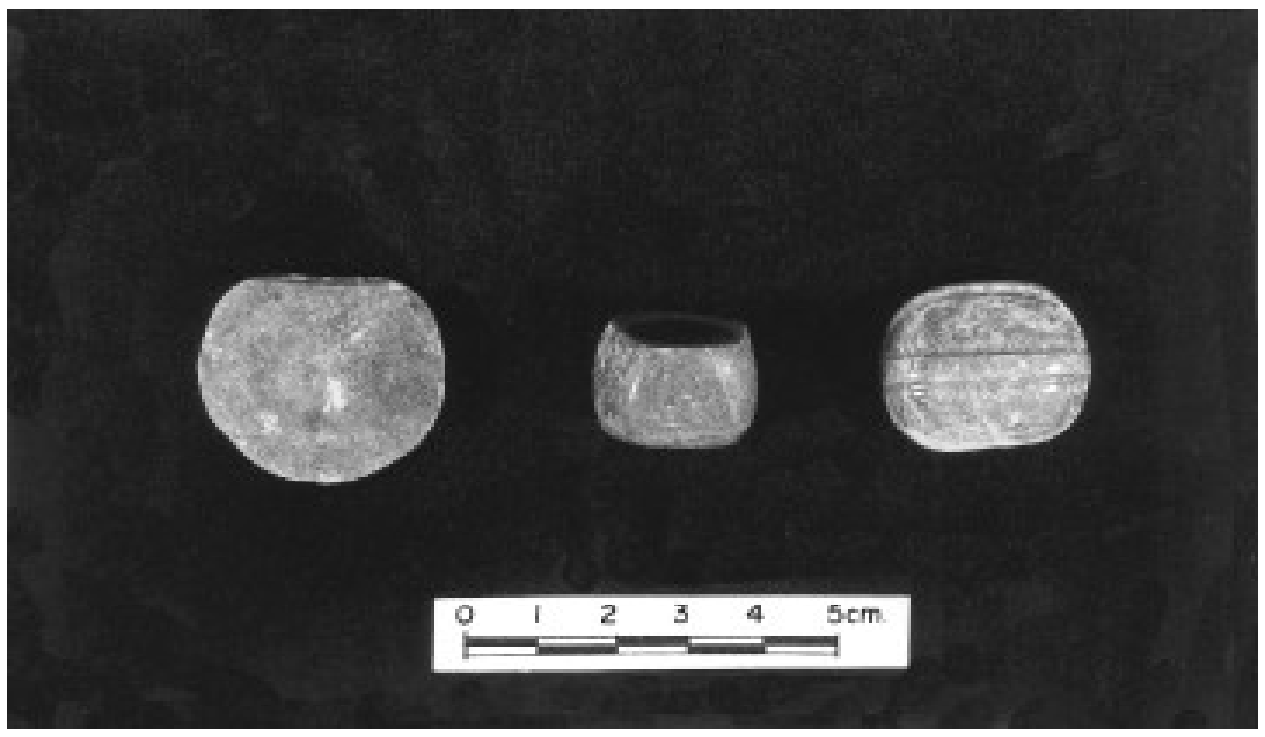

Fotografía 48. J ades de EI Tigre.

\section{El cacao}

Además de utilizarse como medio de cambio, constituía también una bebida y se importaba desde Tabasco, H onduras y Guatemala (Thompson 1975: 163-4).

\section{La cerámica}

Entre los tiestos cerámicos que se encontraron en Tulum están los que provienen de la región chontal (fotografía 49) y de M ayapán. De los primeros tenemos las cerámicas anaranjadas finas, cuyos grupos cerámicos más característicos son el Altar, con los tipos Trapiche inciso acanalado, variedad Trapiche, la variedad Altar; también se encuentra el grupo M atillas, con las variedades $M$ atillas y V illahermosa, cuyo lugar de origen podría ser Tabasco (de los sitios EI Coco, Juárez, Las M inas, Tamulté y Atasta, Campeche). Este tipo de tiestos se ha encontrado en Tulum (Vargas 1985), Tancah, EI M eco, Can C un y San M iguel, en Cozumel (Robles 1980: 279). O tra cerámica característica de la costa de Campeche es la del grupo Silhó, que se ha encontrado en Chichén Itzá y San M iguel en Cozumel.

\section{Los metales}

D esde esta región se han reportado los siguientes metales: oro, cobre, plata, estaño y las aleaciones de oro-plata-cobre, cobre-oro, cobre-estaño y cobreplomo (Castillo 1977: 93), que provienen de la región de M ichoacán y otras. 


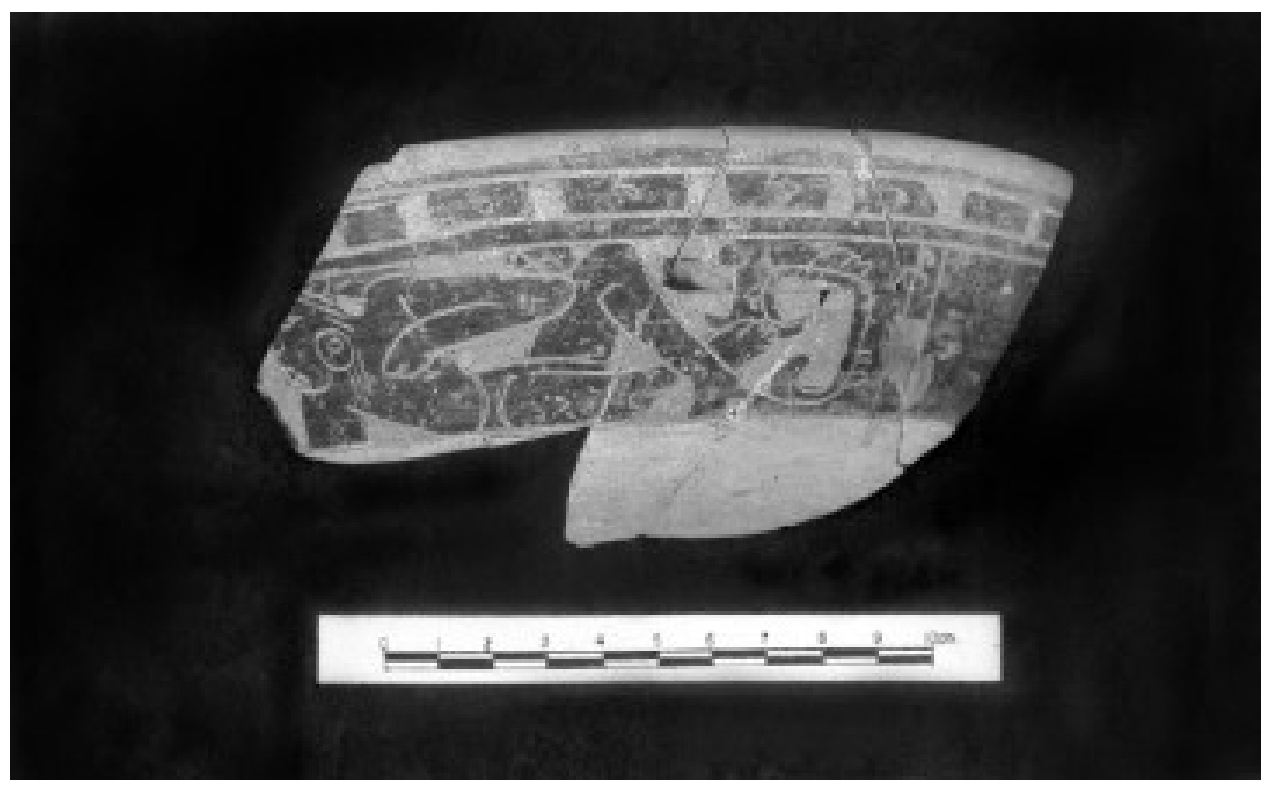

Fotografía 49. Cerámica putún de El Tigre.

En Can Cún se encontraron piezas en forma de cascabel, unas pinzas para depilar, una pequeña hacha de cobre (M ayer 1977: 211). En Tulum se mencionan anillos, hachuelas, agujas de cascabeles. Para Cozumel se reportan campanas de cobre (Sabloff et al. 1975). La fuente probable de estos metales puede localizarse en M éxico y en la frontera de lo que hoy es Guatemala y H onduras (Flores 1977: 73; Lothrop 1952).

\section{El coral}

Tanto en Xicalango como en EI Tigre se han encontrado piezas de coral que seguramente provienen de la costa oriental de Quintana Roo (fotografía 50). Benavides (1995: 524) habla de la presencia chontal en E dzná y dice encontrarla al terminar el Clásico con los cambios en las estelas, la presencia de la cerámica Sotuta y los rasgos propios de la arquitectura de esa época.

[...] E sta situación sólo sería revertida, por última vez, durante el C lásico terminal y el Postclásico temprano, cuando las sociedades chontales irrumpieron en el mundo maya yucateco y renovaron las diversas esferas de actividad humana en buena parte de la península. En cuanto a Edzná, sugerimos que los cambios cerámicos, escultóricos y arquitectónicos ocurridos entre los siglos I x y xı fueron realizados por mayas chontales que aprovecharon el papel previo de Edzná como capital regional e impulsaron desde ahí su penetración y dominio hacia el norte y el oriente de la península yucateca. 


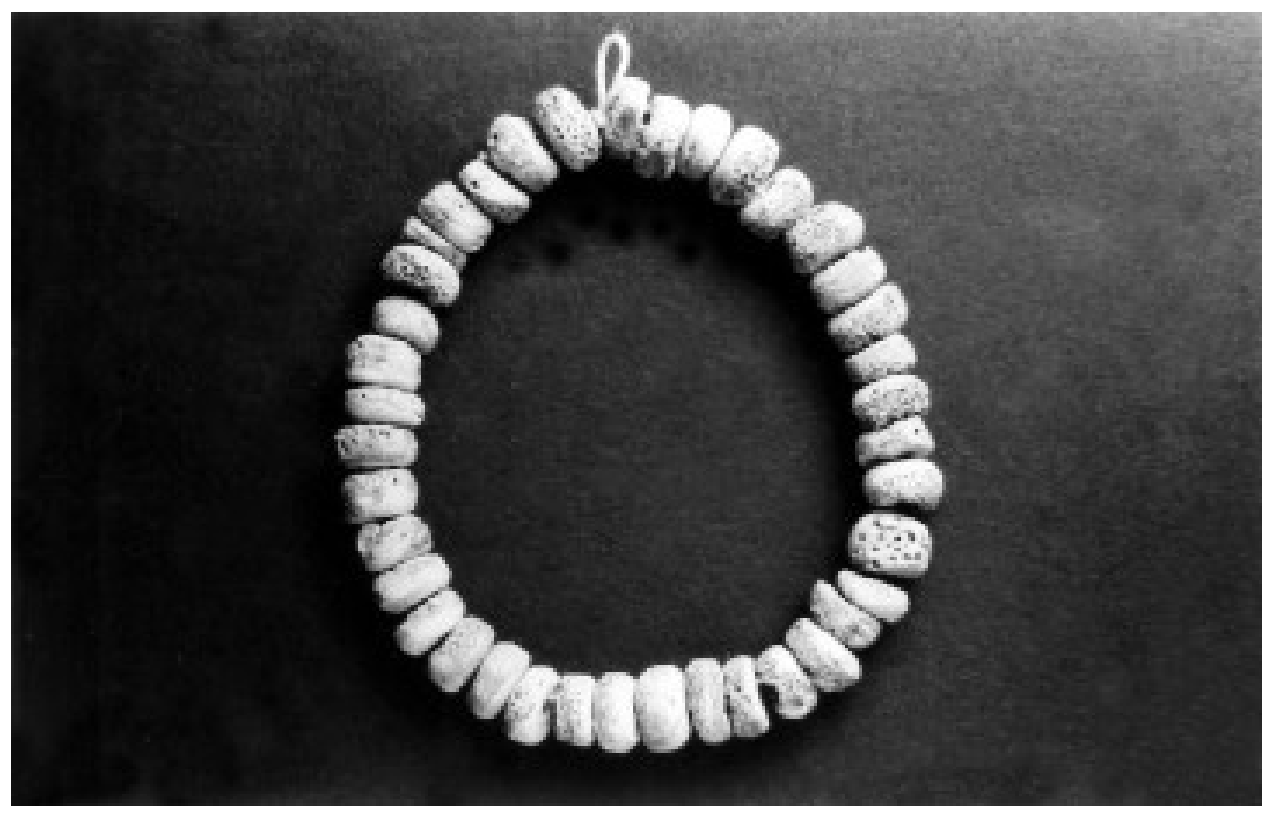

Fotografía 50. Corales encontrados en la región chontal.

COMENTARIO

Por las fuentes históricas podemos concluir que varios de los grupos de Yucatán y Guatemala provienen de la región de la Chontalpa. Generalmente pensamos que la región que trabajamos, siempre es la base de todos los grupos; sin embargo, en este caso es interesante señalar que ésta es casi inhóspita, difícil de vivir y, a pesar de ello, las fuentes históricas del centro de M éxico, Yucatán y Guatemala hacen referencia a ella; no deja de ser importante tal reflexión, ya que ésta podría ser más relevante de lo que hemos pensado.

En la actualidad se cree que esa región de ríos, lagunas, pantanos y mosquitos es casi imposible de habitar y es difícil pensar que allí se asentaron grupos humanos; sin embargo, existen evidencias arqueológicas que demuestran lo contrario.

Al relacionar las fuentes históricas con la arqueolo gía vemos que existe una concordancia, los chontales según la lingüística se separan de las lenguas cholanas a finales del C lásico tardío (600-800 dC) y arqueológicamente durante esa época se inicia la tradición de las cerámicas de pasta fina que anteceden a los tipos de los grupos Altar, Balancán y Tres $\mathrm{N}$ aciones, característicos de la región, que cristalizan en el siguiente periodo del Clásico terminal (800-1100 dC).

D esde hace algunos años, Tozzer, Barrera Vázquez, Thompson, Piña Chan, Ruz L. y otros han tomado en cuenta a los chontales de Tabasco- 
Campeche, para explicar que los itzaes, xiues, cocomes y otros grupos de la península de Yucatán provenían de esa región y que no parecen haber sido mexicanos, sino mayas chontales más relacionados con los magtunes de Acalan, que fueron grupos doblemente aculturados, pues eran receptores y a la vez promotores del replanteamiento cultural después de la caída del C lásico maya, en donde en medio de un caos se forman y cristalizan los nuevos grupos mesoamericanos.

Correlacionar fuentes históricas, lingüística y arqueo logía es importante, pues nos ayuda a entender el pasado prehispánico; juntas nos sirven para ver algo de lo mucho que sucedió en ese pretérito difícil de enfocar.

D e todo lo anterior, resal to la posibilidad de comprobar a través de la arqueología y de las mismas fuentes históricas la presencia de los itzaes en la región chontal así como la de los putunes en la península de Yucatán.

Existen tres posibilidades de análisis para la región chontal. La primera es la presencia de los itzaes en Chakamputún que temporalmente corresponde al katún 8 ahau (698 al 948 dC). L as referencias y evidencias arqueológicas que tenemos son la cerámica maya yucateca y parte de la arquitectura. En El Tigre hemos encontrado cerámica yucateca de los tipos Pizarra y Sotuta, algunas muestras podrían ser itzaes de C hichén. Ball y Eaton, desde 1978 habían hecho una observación parecida a la que presentamos aquí, lo que confirmaría la presencia itzá en la región entre el 700 y 950 d C. Además, tenemos la referencia del C hilam Balam que cita a los itzaes viviendo en Chakamputún.

Para el periodo siguiente no podríamos analizar la presencia de los itzaes en la región chontal, sino más bien sería al revés, es decir, la presencia de los chontales en Yucatán. L as evidencias que han aparecido recientemente nos indican que sí existe tal posibilidad; tanto en Chichén Itzá como en otros sitios de la península y la costa de Yucatán se ha encontrado material de la zona chontal, básicamente cerámica Tres N aciones, Balancán y Altar.

EI tercer periodo se refiere al apogeo de M ayapán que abarcaría de 1224 a 1444, y seguramente corresponde a la trayectoria seguida por los magtunes para conquistar el territorio de los chontales hasta la fundación de la ciudad de I tzamkanac por Paxbolom A cha. L as fechas no son exactas, pero bien podría pensarse que la llegada del primer rey magtún, que vino de Cozumel, haya sido después de la caída de Chichén I tzá y al Ilegar a la región chontal tuvo que conquistarla, pues existían otros grupos que ya estaban asentados allí. Antes de quedarse en Acalan, tuvieron que conquistar la región.

El cuarto periodo corresponde desde 1444 hasta 1557, que sería el abandono de I tzamkanac por los acalanes y su traslado a Tixchel. Aquí nos basamos en las fuentes históricas que narran algunos acontecimientos de ese momento.

Como puede apreciarse, los focos de interés y desarrollo van variando con el tiempo; al parecer, después del llamado «colapso maya» se observa 
un gran desarrollo en toda la región de Tabasco-C ampeche. En este periodo los chontales dominan toda la red de ríos y lagunas. Durante el Postclásico temprano el desarrollo costero se da hacia el norte de Campeche y Yucatán (Andrews 1978), y en el Postclásico tardío en la costa oriental de Q uintana R oo. Los pobladores de esas regiones pudieron ser chontales o putunes, dada la evidencia cerámica encontrada en dichos lugares; o por lo menos la élite pudo pertenecer a ese grupo de comerciantes, o como se ha señalado, pudiera darse la existencia de dos grupos étnicos en la región (Vargas 1994: 64).

Este tipo de contactos no solamente se puede percibir a través de la arqueología y de las fuentes históricas, sino también de la lingüística, ya que normalmente se ha pensado que los códices (T rocortesiano 0 de $\mathrm{M}$ adrid, D resde, París y Grolier) son yucatecos; sin embargo, Wald (citado en $L$ acadena 1997) en su investigación sobre el C ódice $D$ resde pone en evidencia que la lengua escrita en al gunas de sus secciones no es el yucateco, sino del grupo de idiomas cholanos, y Lacadena (1997) plantea el bilingüismo en el $C$ ódice $M$ adrid y lo relaciona con el grupo de idiomas cholanos.

Por lo tanto, tenemos evidencias arqueológicas, histó ricas y lingüísticas de la gran comunicación que se dio entre los chontales e itzaes; falta comprobar si también la relación humana es la misma, para eso será necesario hacer una investigación más detallada en los entierros de ambas regiones, y así demostrar si los itzaes son una rama de los putunes, como lo han planteado varios investigadores y como las evidencias históricas y arqueológicas nos lo hacen suponer. 



\section{TIEM POS DE CRISIS ANTICIPANDO EL FUTURO}





\section{Capítulo I ANTICIPANDO EL FUTURO}

N uestro objetivo es presentar una propuesta alternativa a la concepción tradicional de la historia, en donde se incluye la idea de que las civilizaciones mesoamericanas necesariamente han pasado por periodos de desarrollo, apogeo y caída, dentro de los cuales ha habido una sucesión ordenada e inevitable de acontecimientos. N o se acepta la posibilidad de retrocesos, adaptaciones o modificaciones de la historia, sino sólo decadencias, lo cual implica una posición de casi fatalismo de la historia.

Esta forma de hacer la arqueología resulta insuficiente para entender los procesos y la dinámica de muchos pueblos mayas prehispánicos y no logra explicar lo que ellos vivieron. El análisis histórico de ciclos de desarrollo resulta mucho más productivo, ya que da vida y movimiento a la sociedad en conjunto, puesto que está en constantes ajustes y desajustes que la vinculan y modifican a cada momento.

Tales ajustes y desajustes Ilevan a que al interior de la sociedad, se produzcan expansiones y recesos, crisis, expansiones y equilibrios, que se convierten a su vez, en puntos de expansión de un ciclo subsiguiente, o que lleva a una desaparición en casos extremos (Velázquez y López 1995: 27 ).

Los C hilam Balam nos hablan de guerras, conquistas, cambios que sucedían cada katún 8 ahau, e implicaron necesariamente modificaciones parciales o generales; evidentemente se conservan muchos elementos pertenecientes al antiguo sistema, pero se dan innovaciones y/ o la asimilación de otros nuevos. Los momentos de crisis, vistos como periodos de desorden y caos, son muy importantes para entender la estructura social; la crisis no tiene que ser entendida como una situación repentina, sino como el resultado de un proceso. Todo esto nos lleva a pensar que los itzaes tenían una cosmovisión muy estructurada, que establecía fuertes vínculos con el pasado y el futuro, y de alguna manera ellos intervenían en los acontecimientos de su pueblo para que la historia se cumpliera.

El término de colapso no parece adecuado para la explicación de lo que sucedió en el área maya, pues de alguna manera implica el fin de una cultura, lo cual no ocurrió. C uando se habla de crisis se trata de los procesos de transformación que sufrió la cultura maya en el transcurso del tiempo; un 
ejemplo del tiempo cíclico queda descrito en el $C$ hilam Balam y por fray Andrés de Avendaño en donde se narra el abandono de Chakamputún en el $948 \mathrm{dC}$, después de haber permanecido allí por espacio de 260 años, la caída de Chichén I tzá en 1220 dC y M ayapán en 1444 dC, y la conquista de Tayazal en 1697.

De todo lo anterior me interesa resaltar la posibilidad de comprobar a través de la arqueología y de las mismas fuentes históricas la presencia de los itzaes en la región chontal, y que estos abandonaban sus capitales al fin de cada katún 8 ahau que sucedía cada 260 años. En este sentido creo pueden analizarse estos momentos históricos mediante el estudio del patrón de asentamiento, la arquitectura y la cerámica; la iconografía y la epigrafía son también de gran valor.

Existen tres posibilidades de análisis para la región chontal. La primera es la presencia de los itzaes en C hakamputún, que temporal mente corresponde del 682 al 948 dC. No tenemos mayores referencias a respecto, pero sí podríamos tener evidencias arqueológicas como las cerámicas mayas yucatecas y parte de la arquitectura y la lingüística.

Para el periodo siguiente no podríamos analizar la presencia de los itzaes en la región chontal, sino más bien sería al revés, es decir, tendríamos que ver a los chontales en Yucatán. L as evidencias que han aparecido recientemente nos indican que sí existe tal posibilidad, tanto en Chichén I tzá como en otras regiones de la península de Yucatán.

EI tercer perio do se refiere al apogeo de M ayapán que abarca de 1190 a 1450 y seguramente corresponde también a la trayectoria seguida por los magtunes para conquistar el territorio de los chontales hasta la fundación de la ciudad de Itzamkanac por Paxbolom A cha.

El cuarto periodo corresponde de 1444 hasta 1557, cuando abandonan I tzamkanac y son trasladados a Tixchel.

\section{TIEMPOS DE CRISIS}

Los mayas creían que los acontecimientos de un ciclo se repetían en todos los sucesivos y que por lo tanto el calendario podía usarse para predecir hechos futuros, de esa manera anticipaban el porvenir; en el $C$ hilam Balam aparece ilustrada la reiteración cíclica de la historia.

Presentamos una propuesta alternativa en donde la idea del tiempo cíclico desempeña un papel importante, pues en toda sociedad existe la posibilidad de retrocesos, adaptaciones o modificaciones y no sólo decadencias, lo cual implica una posición de casi fatalismo de la historia.

La observación de la naturaleza influye en la concepción cíclica de los pueblos; recordemos que los mayas tenían un culto al tiempo, pues estaba presente en los rituales y en casi todas las actividades humanas. La tie- 
rra presenta distintos aspectos de acuerdo con las estaciones: mucha agua y vegetación en tiempos de lluvias, y en tiempos de secas lo contrario. Conocían los ciclos biológicos de la tierra, plantas, animales y personas. L as actividades relacionadas con la agricultura, la materia prima se regía por ciclos, pues debían tener un conocimiento preciso de cuándo, dónde y cómo utilizar y conservar la materia prima que la naturaleza proporcionaba.

En cuanto a la presencia de los astros en el firmamento y la observación de sus movimientos, especialmente el Sol, la L una, Venus y las estrellas, debieron haberlos impactado, llevándolos a imaginar dioses y a crear mitos.

Ellos describieron su historia en ciclos; por lo tanto el análisis histórico de ciclos de desarrollo resulta mucho más productivo para el conocimiento de la cultura maya, ya que éstos dan vida y movimiento a la sociedad en conjunto, puesto que la sociedad está en constantes ajustes y desajustes que la vinculan y modifican a cada momento. En toda sociedad se producen crecimientos y recesos, equilibrio y crisis, que a veces se convierten en puntos de expansión del ciclo subsiguiente.

Cuando se habla de crisis se trata de los procesos de transformación que sufrió la cultura maya en el transcurso del tiempo, por eso el término de «colapso» no parece el término adecuado para la explicación de lo que sucedió en algunas partes del área maya, ya que ese concepto implica el fin de una cultura, lo cual no sucedió con la maya.

E mpeñados en registrar el paso del tiempo idearon varios sistemas: el de la cuenta larga, que al canza gran difusión en el C lásico y en todas las tierras bajas del área maya. En lo alto de la inscripción aparece un gran jeroglífico, el Ilamado "glifo introductor»; en seguida leyendo de izquierda hacia derecha y continuando de arriba abajo aparecen las distintas unidades: primero los baktunes (ciclos de $360 \times 20 \times 20$ días $=144000)$; luego los katunes $(360 \times 20$ días = 7 200); los tunes ( 360 días); Ios uinales (20 días); y los kines ( 1 día).

Los tunes 0 años de 360 días, los años de 365 días llamados haab, las lunaciones y las revoluciones sinódicas de los planetas, se coordinaban con la cuenta de 260 días, generalmente conocida como tzolkin.

La cuenta larga es sustituida posteriormente por la llamada u kahlay katunob 'cuenta de los katunes', periodos de 20 años, en que con un sólo jeroglífico podía expresarse la fecha del día en que concluía el correspondiente perio do o katún; este daba marco a su afán profético y astrológico.

También se interesaron por conocer el año trópico que calcularon en 365 2420; y conocieron con precisión la duración de los ciclos lunares; en el Códice $D$ resde se tiene una importante información en la «tabla lunar», en donde relacionan los ciclos lunares con la cuenta de 260 días.

Conocieron el ciclo de noh ek, 'Ia gran estrella', como queda testimonio en el Códice de D resde (46-50), y lo correlacionaron con el tzolkin o cuenta de 260 días. Computaron la revolución sinódica de Venus en 584 días; en la actualidad se sabe que es de 583.92, es decir, tenían un error de 
adelanto. Teeple nos dice que si al final de 61 años de Venus se le sustraen 4 días, con esto se logra hacer divisible por 260 o sea por el número de días del tzolkin, el total de los transcurridos en esos años de Venus. Así podía alcanzarse la primera forma de correlación entre ambas cuentas.

Se preocuparon por conocer los misterios del universo y de la naturaleza, y por tal motivo trataron de precisar el significado y la medida de sus ciclos; los enmarcaron con infatigable anhelo de exactitud, desde diferentes puntos de vista: astronómico, cronológico y matemático. N uestro propósito es destacar algo muy conocido entre los mayas: los ciclos debieron regirlos en muchas de sus actividades.

L os mesoamericanos al parecer, dejaban desfasar el cal endario, porque cualquier intercalación habría variado las coincidencias cíclicas de los period os de 260, 360 y 584 días. Según Graulich (1990: 348-9) los sacerdotes reforzaban su papel sobre la masa de agricultores por ese motivo; los campesinos estaban obligados, entonces, a dirigirse a los sacerdotes para saber en qué momento debían proceder a la siembra o comenzar la recolección. El mismo autor afirma que el desfasamiento del calendario daba como resultado un gran ciclo de 1460 años imprecisos, al término del cual el año ritual y el año solar coincidían de nuevo.

El 682 se hallaba en el inicio de un ciclo de éstos, y corresponde en el área a la mitad de un katún 8 ahau, katún en que sube al trono de Tikal uno de los principales halach uinic, $\mathrm{H}$ asan $\mathrm{C}$ han $\mathrm{K}$ 'awil (A h C acau); por otra parte corresponde con la migración de lo itzaes hacia C hakamputún. En el 682 coinciden el año trópico y el año ritual, lo que significaba un nuevo principio. O tros sucesos del área maya son la muerte de Pacal en el año 683; en Yaxchilán el gran conquistador 'Escudo Jaguar' reinó a partir del año 682 y parece haber sido uno de los más importantes de la ciudad.

Jiménez M oreno había señalado ya desde 1959 la necesidad de definir un periodo intermedio entre el Clásico y el Postclásico, que explicara los cambios acontecidos entre el 600-700 dC. Se ha insistido desde hace muchos años en el cambio que se dio durante ese periodo intermedio: surgimiento de nuevos centros (Xochicalco, Teotenango, Cacaxtla, Tula, EI Tajín), migraciones y sobre todo la propagación del culto a Q uetzalcóatl.

Con la caída de Teotihuacan se inicia una gran inestabilidad política, lo que propicia migraciones y surgimiento de nuevas élites de comerciantes, guerreros, sacerdotes y go bernantes. «U na gran crisis sacude a M esoamérica del uno al otro confín y en medio del caos se incuba un mundo nuevo. $\mathrm{H}$ ay un cambio profundo de orientación cultural, en el que naufragan las viejas culturas milenarias y dominan las gentes que proceden de áreas periféricas 0 rezagadas» (Jiménez M oreno 1976).

Piña Chan (1977: 43) al referirse a ese periodo nos dice que coincide con el inicio de la propagación de la religión y el culto a Q uetzacóatl, que 
se observa un marcado espíritu guerrero y ello va acompañado del comercio con lugares alejados que permite la divulgación de ideas, estilos artísticos, objetos, materias primas; éxodo de grupos que andan en busca de nuevos centros; dispersión de sacerdotes-caudillos que llevan el nombre de Q uetzacóatl. Algunas formas de organización y de pensamiento son compartidas por las élites de varios grupos mesoamericanos, que pretenden imponer por la fuerza ese culto.

L a región de Acalan pasó por diferentes etapas, unas fueron prósperas y otras de abandono; éstas se debieron a diferentes razones: factores ambientales, conflictos entre grupos humanos, llegada de nuevos grupos a la región, factores externos, etcétera. Sin embargo, la presencia itzá en la región marca la llegada de ideas cosmogónicas particulares; ellos llegaron en un katún 8 ahau después de abandonar C hichén I tzá, y al cumplirse la rueda katúnica regresan de Chakamputún Ilevando el culto de Kukulcán; son portadores de nuevas ideas, las cuales imponen por la fuerza guerrera que los impulsaba. En la E structura 1 de EI Tigre localizamos una plataforma circular que se relaciona con la introducción de ese nuevo culto que llega a la región y posteriormente se difunde en gran parte del área maya.

L a expectación del katún 8 ahau estaba muy difundida entre los mayas, aparece por primera vez en la Estela 31 (figura 23) mandada a hacer por

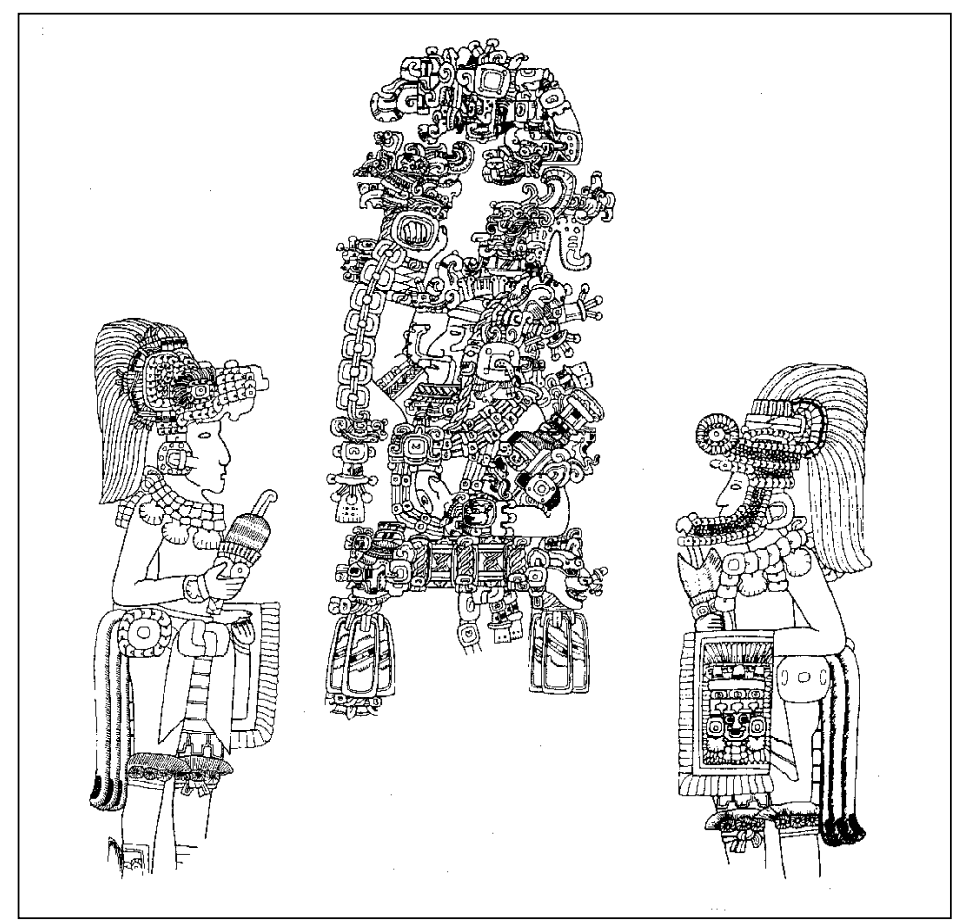

Figura 23. Estela 31 de Tikal, Sian Chan K'awil 'Cielo Tormentoso'. 
Sian C han K'awil 'Cielo Tormentoso' (435 dC) y la celebración del siguiente ciclo corresponde a H asan C han K'awil (A h C acau, 692 dC). Estos dos katunes aparecen citados en el Chilam Balam, y posteriormente se registran los siguientes que coinciden con la caída de Chichén Itzá y $M$ ayapán. Estos últimos son descritos por los principales historiadores de la península de Yucatán, L anda y López de Cogolludo. La caída de Tayazal, último reducto de los itzaes, también coincide con un katún 8 ahau, es tratado por Avendaño y Villagutiérrez Sotomayor. La historia del katún 8 ahau abarca 1300 años de los mayas.

L a información disponible es muy diversa, proviene de estelas, fuentes indígenas y otras de origen español; por lo tanto, no parece que se trate de una coincidencia. Debido a esta creencia, $\mathrm{H}$ asan $\mathrm{C}$ han K'awil logró tener éxito en Tikal al demostrar que su linaje y sus conexiones con el gobernante legendario Sian Chan K'awil eran casi de orden divino, es decir, utilizó para su beneficio las expectativas del katún 8 ahau, la historia y las profecías.

Su coronación fue en el 680 dC, ocurrió diez años después del comienzo de un nuevo katún 8 ahau. Primero aseguró su poder y después desplegó un ostentoso ritual asegurándose que pasara a la posteridad. No seguiremos hablando de $\mathrm{H}$ asan $\mathrm{C}$ han $\mathrm{K}$ 'awil sin señalar que un grupo de itzaes llegó por esas fechas a la región de Chakamputún. Según el C hilam Balam permanecieron allí 260 años y salieron posteriormente hacia $C$ hichén. Los Papeles de Paxbolom $M$ aldonado narran la llegada de los magtunes a la región de Acalan en el Postclásico y las conquistas que tuvieron que realizar antes de asentarse en I tzamkanac. Antes conquistaron Tenosique, I sla del Carmen y Tixchel.

$\mathrm{H}$ asan $\mathrm{C}$ han $\mathrm{K}$ 'awil es un buen ejemplo de manipulación de la concepción del tiempo cíclico para legitimar la pretensión de ser un gran profeta en el trono de Tikal; retomó una parte significativa de la cosmovisión de los antiguos mayas y utilizó para su beneficio la relación del tiempo cíclico y el concepto maya de la historia y la profecía.

Los astrónomos mayas concebían el tiempo como algo sin principio ni fin, lo que hacía posible proyectar cálculos acerca de momentos alejados en el pasado sin alcanzar más un punto de partida (Thompson 1960: 149). Pero junto a esa concepción de un tiempo sin límites en el pasado y en el futuro (Thompson 1954: 23), los mayas establecen un punto de referencia, especie de principio de su era cronológica. $Y$ es así como casi todas las inscripciones cal endáricas de sus estelas se computan en función de la cuenta larga que sitúa el momento de partida hacia 3113 aC. Por otra parte el katún 8 ahau encaja perfectamente en el engranaje de la cuenta larga maya, pues la inician con el fin del baktún 9.0.0.0.0. en Sian Chan Bakalar, lugar mítico pero también real, del oriente, de donde provienen los itzaes. 


\section{EL katún 8 ahau}

Para los itzaes y posiblemente para otros grupos mayenses, entre los que están los putunes, el katún 8 ahau era el de la guerra, la conquista y el cambio (Thompson 1975). C ada trece dobleces de katún, según el C hilam Balam, sucedía algún acontecimiento importante entre los itzaes. Para muchos autores esto es un mito, sin embargo, para otros el mito puede constituir una teoría de la historia.

Para realizar la conquista del I tzá, fray Andrés de A vendaño (R elación de las dos entradas que hice a la conversión de los gentiles itzaes y cehaches, paleografía E. Vargas 1997) puso especial interés en entender la concepción cíclica del tiempo y el contenido de las profecías katúnicas; intentó por ese medio convencer a los itzaes de que había llegado el tiempo de que fueran cristianos. Estos se convirtieron entre los mayas en los promotores de la resistencia cultural y política. D esde Tayazal se difundieron las profecías de los katunes que desarrollaban los sentimientos antiespañoles y levantamientos indígenas (G. J ones 1989: 6-11).

Entre los franciscanos el tema de las profecías es tratado ampliamente primero por Lizana, López de Cogolludo y A vendaño, posteriormente también por Villagutiérrez Sotomayor. Según Roys (1972: 185-6), estas profecías tenían que ver con el regreso de Kukulcán y los primeros misioneros vieron en ellas el anuncio de la llegada de los españoles y del cristianismo a la región maya; de allí que elaboraran todo un discurso en donde intervieniese $D$ ios $y$, según sus designios, los itzaes se convertirían sin resistencia al cristianismo y se entregarían al dominio de los españoles.

La visión que se formaron los frailes sobre la historia indígena se ajustó a sus patrones culturales, pues privilegiaron el regreso de Kukulcán; por eso no pudieron entender el significado que estos grupos le daban a su historia, dejando a un lado la relación que existía entre la concepción cíclica del tiempo y la organización política de los itzaes.

$L$ as explicaciones del mundo fueron importantes en M esoamérica; en este trabajo veremos cómo los itzaes construyeron un sistema perfectamente bien estructurado; cómo el katún 8 ahau coincide con el inicio del baktún 9.0.0.0.0 y como muchos de los finales de los katún 8 ahau también tienen coincidencia con fenómenos astronómicos.

Los estudios arqueoastronómicos han tenido un gran desarrollo en los últimos 20 años, han reunido una gran cantidad de información que demuestra que los mayas hacían complejas observaciones atronómicas estableciendo una rica tradición a través de los siglos. E se conocimiento fue la base para la construcción del calendario, además fue utilizado ampliamente en la orientación de los edificios y de sitios, lo cual obedecía al deseo de establecer una concordancia entre el orden humano y el cosmos, y de crear un orden ideal según los cánones de la cosmovisión (Broda 1992, 1993). Crearon un 
cuerpo de conocimientos exactos en la observación de los astros y también tuvieron la capacidad tecnológica y arquitectónica que les permitió la construcción de estas estructuras y ciudades «cósmicas» (Broda 1989, 1991).

\section{R elación del katún 8 ahau con el baktún, los eventos astronómicos y naturales.}

El maya, además de sus logros en arquitectura, escultura, cerámica, artes lapidarias, trabajos en pluma y textiles, obtuvo avances intelectuales de gran importancia, como son: la invención de las matemáticas de las posiciones y su concomitante desarrollo del cero, la construcción de una compleja cronología con un punto fijo de inicio, el uso de un conteo del tiempo tan exacto como nuestro actual calendario, e ideó varios sistemas en las técnicas calendáricas que le permitieron concebir un elaborado concepto del cómputo del tiempo «la cuenta larga» y la «cuenta corta».

Los mayas tenían un concepto cíclico del tiempo que expresaban por medio del sistema calendárico constituido por tres ciclos temporales interrelacionados: el tzolkin de 260 días, el tun de 360 días y el haab de 365. Cada día tenía un número (del 1 al 13) y un nombre (tomado de una serie constituida por 20 nombres), esta serie se repetía continuamente de tal manera que la combinación del número con el nombre del día también se repetía una única vez cada 260 días, siendo esta la base del tzolkin.

El tun estaba constituido por 18 meses y 20 días, y 20 tunes formaban el katún. L os coeficientes numéricos de los días en que concluían los katunes ocurrían según una secuencia regular y éstos se repetían una vez transcurridos trece katunes, dando por resultado un ciclo de 260 tunes, lo que equivalía aproximadamente a 256 años solares (Edmonson 1982: 713). El periodo de 360 días fue escogido porque los mayas querían tener un año formal que invariablemente comenzara en imix y terminara en ahau.

L a rueda calendárica consistía en que un día dado coincidía con el primer día del año una vez cada 52 años; cinco ruedas calendáricas corresponden a un periodo de 260 años, el cual nos interesa tratar en este trabajo que llamaré rueda de los katunes.

Casi todos los pueblos han tenido un punto de partida para computar sus eras cronológicas; los mayas no utilizaron un acontecimiento histórico, sino al parecer escogieron como punto de partida una fecha más antigua, en donde se supone la creación del mundo o puede pensarse en el nacimiento de sus dioses; la cuestión no ha podido ser resuelta. Su inicio o cero de la edad de los mayas es 13.0.0.0.0 4 ahau 8 cumhu, que corresponde al año $3113 \mathrm{aC}$. Arochi (1991: 101) propone como inicio y cero la fecha del baktún 12, katún 19, tun 0, uinal 0, kin 0, que correspondería al 18 de diciembre de 3133, un katún antes de la tradicional fecha, de esa manera se relacionaría con un acontecimiento astronómico: un solsticio de invierno. 
El final de los 13 ciclos de baktunes terminará con el baktún 12 en el año 2012, abarcando un periodo de 5200 años; los baktunes, como dijimos, son periodos de 400 años que fueron ampliamente utilizados y registrados por los mayas.

En los libros de los $C$ hilam Balam se registra el cómputo de los katunes desde la aparición de un grupo maya en las costas de Bacalar, hasta la caída de C hichén I tzá primero y después de M ayapán. Sin embargo, en otros textos como los de fray Andrés de A vendaño se trata la conquista de Tayazal en un katún 8 ahau, que corresponde a 1697 dC; abarcó un periodo desde el 417 hasta el 1697, que son 1280 años, es decir cinco ruedas de katunes. EI sistema de la rueda de los trece katunes (figura 24) fue utilizado por los mayas para el cómputo del tiempo, sobre todo durante el Postclásico, pero existen referencias desde el Clásico temprano en la Estela 31 de Tikal.

En un principio se habla de la manifestación de los trece espíritus de los katunes; es decir, la presencia de los espíritus mayas influía periódicamente en el mundo representando cada katún. El creador labró la primera piedra preciosa y de gracia que representa el primer katún y, cuando terminó de labrar las otras piedras de los katunes, sus espíritus quedaron suspendidos en el espacio y les advirtió que les dejaba en sus manos las cosas del mundo (Montoliú 1989: 29-30).

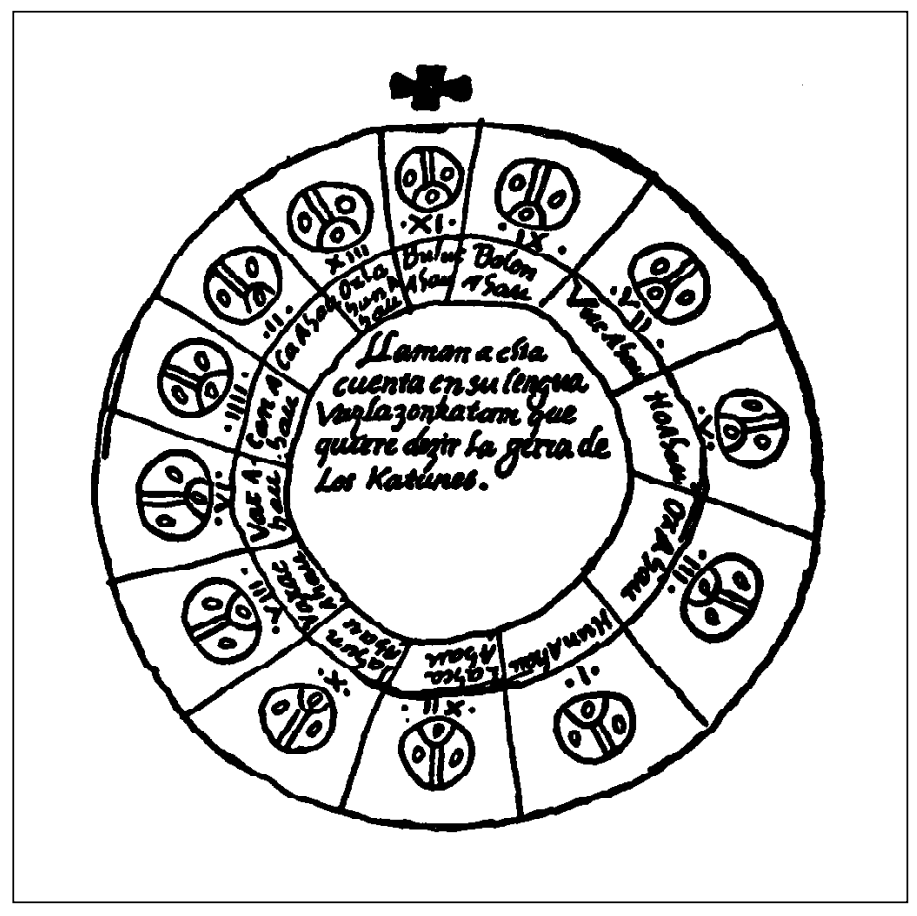

Figura 24. Señores de los trece katunes. 
EI nacimiento de los katunes implica en el texto el comienzo de la cuenta del tiempo relacionado con el desarrollo del maíz. En la lámina 26c del C ódice D resde, se observa que este árbol mítico llamado primer-árbol-delmundo nace del signo tun, semilla y año en este contexto, o piedra preciosa.

López de Cogolludo incluye en su manuscrito la imagen de una ceiba nacida de un cuerpo geo métrico rectangular, que es la tierra con sus cuatro esquinas. Alrededor de la ceiba se encuentran los rostros de los señores de los trece katunes (figura 25).

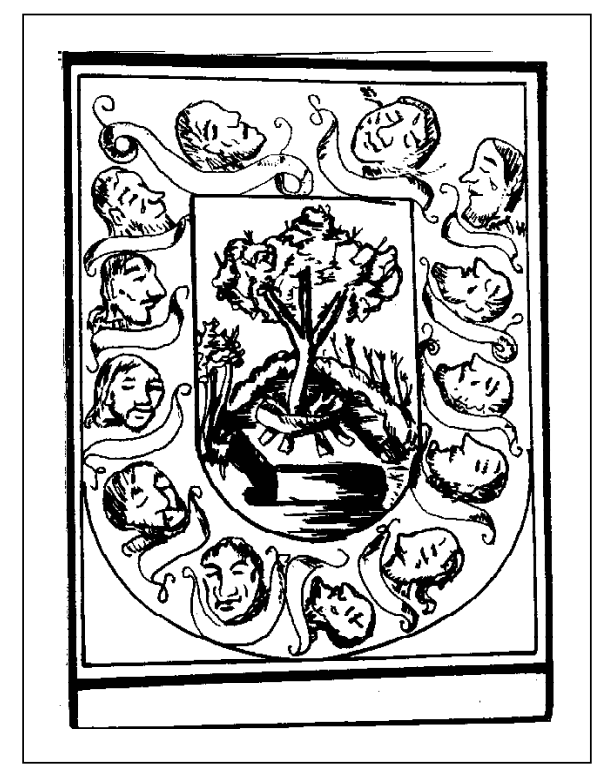

Figura 25. Señores de los trece katunes.

Sánchez de Aguilar (1937: 15-122) menciona que los mayas pegaban piedras unas sobre otras para registrar el paso de los katunes. L anda (1978: 17) nos dice que en M ayapán había siete $u$ ocho piedras de diez pies de largo cada una, redondas y bien labradas, y piensa que eran memoria de la fundación y destrucción de aquella ciudad. O tras están en la costa y los naturales al ser preguntados respondieron que acostumbraban erigir de 20 en 20 años una piedra de aquéllas. También $L$ anda, en otro pasaje, señala que solían hacer cuatro montones de piedra, una por cada rumbo del universo, ya que los años tienen sus orientaciones específicas.

Fray Andrés de Avendaño menciona que se veneraba a $Y$ ax ceel cab, árbol que suponían crecía en el centro de la Tierra, cuyas ramas traspasaban los cielos.

Basados en la tradición indígena que se describe en los C hilam Balam de C humayel, Tizimín y M aní, Ios itzaes llegaron a la península de Yucatán 
y descubrieron Sian C han Bacalar y posteriormente Chichén Itzá en el katún 8 ahau (415-435 dC); reinaron diez veintenas de años y la abandonaron para ir a C hakamputún. Allí permanecieron trece vientenas de años y transcurrido ese tiempo regresaron nuevamente a C hichén I tzá.

Poco antes habían llegado los xiues a la península de Yucatán, lucharon en $\mathrm{M}$ ul Chic y después se asentaron en $U$ xmal; más tarde los itzaes conquistaron y ocuparon Chichén I tzá y finalmente los cocomes se asentaron en M ayapán; existen además otros grupos que salieron de Tabasco y C ampeche a la región de Yucatán, por eso todos ellos se acusaban entre sí de ser extranjeros. Venían de la región de Zuyúa, lugar mítico y a vez real, algunos lo identifican con T abasco- $C$ ampeche, otros se contentan sencillamente con remitirlo al ámbito del mito; es decir, lo excluyen del proceso de la historia material.

Chichén I tzá gobernó y dominó gran parte de la península de Yucatán; Roys (1972) plantea que C hichén logró avasallar Cozumel y a los pueblos que se ubicaban alrededor de la Laguna de Términos; además, ejerció un control comercial sobre algunos lugares de Tabasco y las H ibueras. Sin embargo, otros autores (Robles y Andrews 1986: 84-86) sugieren que su territorio era más restringido, pues en su proceso conquistador encontraron resistencias y fueron incapaces de dominar la región que abarca desde Yaxuná hasta Cobá.

El ímpetu conquistador de los itzaes fue grande, pues pronto llegó a ser el centro político de un vasto territorio y, a raíz de los procesos de consolidación política y de expansión, se convirtió en la sede del ah tepal, es decir, en el lugar de residencia de un único señor o soberano, el $\mathrm{A}$ hau $\mathrm{H}$ alach $\mathrm{U}$ inic.

El katún 8 ahau era el de la guerra, la conquista y el cambio; cada 260 años era abandonada o destruida una ciudad, el pueblo itzá era arrancado de sus hogares, no importaba dónde estuvieran viviendo en ese momento. A final es del siglo vII dC fueron expulsados de C hichén luego de su primera ocupación. A mediados del Ix se les sacó de Chakamputún.

En las postrimerías del siglo xII fueron nuevamente desalojados de $C$ hichén por $\mathrm{H}$ unac $\mathrm{C}$ eel. Alrededor de la mitad del xv M ayapán fue saqueada y destruida y nuevamente durante un katún 8 ahau, a finales del xvII, los españoles conquistaron el último baluarte itzá de Tayazal (Roys 1933: 136).

$L$ a rueda de los katunes constituía la unidad principal del tiempo cíclico e histórico, y al darse la hegemonía de Chichén Itzá se instauró una cosmovisión particular y una forma de gobierno que fue el ah tepal o imperio. C on el surgimiento de M ayapán, como la nueva capital de las tierras bajas del norte de Yucatán, se dan cambios y redefiniciones tanto políticos como territoriales. A diferencia de $C$ hichén I tzá, su esfera de influencia fue más reducida (R oys 1972: 32-7). A simismo, en contraste con C hichén que logró ser la sede de un soberano único, M ayapán se constituyó posteriormente en un multepal, es decir, de un gobierno confederado. 
A mediados del siglo xv, a raíz de las pugnas entre los xiues y cocomes, $M$ ayapán fue destruida y el multepal se desintegró, quedando un vacío de poder y formándose los cuchcabalob o provincias. A la caída de M ayapán las provincias vivieron un periodo dinámico de reordenamiento político y territorial debido sobre to do a las guerras intestinas, fue una época turbulenta, en la que algunos territorios desaparecieron, otros se redujeron y seguramente surgieron nuevas entidades.

Existían por lo menos 16 entidades en donde residía un halach uinic 0 un batab que gobernaba un cuchcabal o provincia. La estructura territorial del cuchcabal estaba constituida por la capital y su área dependiente, después había el batabil regido por el batab, que ejercía un dominio político administrativo sobre un territorio, y por último estaba el cuchteel que era la unidad básica de la estructura territorial del cuchcabal.

Los sucesos de cada ciclo tenían una estructura similar, los individuos que participaban en ellos no eran los mismos, ni tampoco esos hechos sucedían en los mismos lugares; lo predecible en cada ciclo era solamente la estructura de los acontecimientos, por eso Bricker (1989: 29) denomina historia a estas crónicas de katún.

Algunos autores sostienen que los mayas intervinieron en la historia para hacer que los acontecimientos coincidieran con sus profecías. El ejemplo mejor conocido fue la conquista de la última capital itzá en Tayazal, que había resistido a varios intentos por convertirla al cristianismo sobre la base de que el momento profetizado ya había llegado; el hecho sucedió hasta 1697, año en que los itzaes por fin fueron conquistados por los españoles, y coincidió con un nuevo katún 8 ahau.

En 1618 los itzaes hicieron correr la noticia de que estaban dispuestos a convertirse al cristianismo, y por ello enviaron mensajeros a M érida para entregarse; sin embargo, no sucedió lo que supuestamente ellos habían ofrecido y los acusaron de mentirosos y engañadores. EI hecho parecería no tener ninguna importancia, ya que posteriormente los padres F uensalía y O rbita fueron al Itzá y no obtuvieron tal conversión. Pero la fecha de 1618 corresponde con el final del baktún 11 y principio del 12, mas no con el término del katún 8 ahau; aquí debió suceder un error de sus dirigentes, pues seguramente creyeron que los hechos fatídicos sucedían también al fin del baktún, y por eso corrigieron el error y siguieron siendo guerreros e infieles. D ebemos recordar que el inicio del ciclo de la rueda de los katunes se da en el baktún 9.0.0.0.0 (415-435 dC) que coincidió con el katún 8 ahau; cuando hay coincidencia entre ambos es catastrófico, como sucedió con el baktún 11.0.0.0.0 (1184-1204), que según el C hilam Balam corresponde a la caída de $\mathrm{C}$ hichén I tzá, cuando $\mathrm{H}$ unac $\mathrm{C}$ el $\mathrm{C}$ auich conquistó al halach uinic del lugar, C hac X ib C hac, y fundó la ciudad de M ayapán.

Para muchos autores el mito es la antítesis de la historia, pero para otros constituye una teoría de la misma (ibidem: 21-2); es posible que esos 
acontecimientos no sucedieran exactamente en las fechas predichas y que existan vacíos significativos; sin embargo, es probable que, aunque un acontecimiento no sucediera, fuera registrado como tal con el propósito de cumplir con los requisitos de su concepción cíclica de la historia. La magia de los números quizá tenía más importancia para ellos que la ubicación exacta de los acontecimientos históricos.

Señalo lo anterior porque esos 13 dobleces de katunes constituían las unidades principales del tiempo histórico o de la profecía en Yucatán. Al instaurarse la hegemonía de Chichén I tzá se impuso una forma de gobierno particular: el ah tepal o imperio. Al caer Chichén I tzá y surgir $M$ ayapán como la ciudad principal el sistema de gobierno fue el multepal o gobierno confederado y al caer M ayapán la península de Yucatán se dividió en 16 provincias o cuchcabalob; la historia se repite, pero de diferente manera.

$\mathrm{N}$ o hay duda de que el mito de la región zuyúa existe, pero tampoco hay duda de que en su tiempo la región ostentó la sacralidad mítica que legitimó el gobierno político; los gobernantes llevaron el nombre de los personajes míticos y actuaron fundados en su representación.

No existe la confusión entre lo humano y lo divino, lo humano utiliza lo divino para justificar sus actos terrenales, ya que de esa manera legitima su actuar, por lo tanto, el mito justifica el poder; y los hechos acaecidos no son un mito, están apoyados en él, pues algunos de ellos pueden verificarse gracias al mito. 



\section{Capítulo II \\ LA GEOGRAFÍA POLÍTICA Y EL ESPACIO SAGRADO EN ACALAN}

En términos generales, las sociedades mesoamericanas de la última época antes de la conquista se caracterizaron por la gran complejidad de su organización económica y social: la producción rendía excedentes apreciables, había una marcada división del trabajo, la distribución de recursos económicos tenía lugar mediante mercados locales, intercambios a larga distancia y un complicado sistema tributario.

Con respecto a la organización social, había una pronunciada estratificación, una política centralizada, con gran importancia tanto material como ideológica de la guerra, del comercio y de los aspectos religiosos.

Como ya dijimos, una de las características fundamentales de estas sociedades es la estrecha interrelación que presentan en todos sus aspectos, de allí que si se estudia la economía o el gobierno, siempre tendrán que ligarse a los aspectos de la vida social en forma más directa de lo que acontece con las sociedades modernas.

0 tra de las características importantes de la sociedad maya era el reconocerse como perteneciente a un grupo por línea materna o paterna; los mayas lo consideraban y llamaban linaje y hasta tenía sus propios dioses patronos, varios de los cuales parecen haber sido ancestros deificados (Roys 1933: 147, Scholes y Adams 1938: 153). La sociedad maya estaba dividida en dos grandes estratos: la gente común y la nobleza; entre las dos existía cierta movilidad social, es decir, en ciertos casos podía pasarse de una categoría a otra; sin embargo, no era tan fácil, ya que existían mecanismos controladores para poder conservar el poder entre aquellos que lo detentaban, este era el tzucub, que al parecer fue muy importante entre los mayas yucatecos del momento anterior a la conquista.

El grupo dominante o noble recibía en maya yucateco el nombre de almehen; no era un grupo homogéneo, sino que dentro de él existían diferentes rangos y niveles; por ejemplo, el ah tepal, 'soberano', tenía bajo su mando varios reinos y sus señores, y dominaba un vasto territorio, pero sólo se dio en Chichén Itzá. El halach uinic obedecía las órdenes del soberano y durante el sistema de los cuchcabalob fue la máxima autoridad. Los batab estaban abajo 
del halach uinic, eran los jefes de pueblos menores, aunque también fueron los principales de algunos cuchcabalob, ya que dichas entidades no podían tener un halach uinic por ser extranjeras en Yucatán. En el desempeño de sus funciones los auxiliaban los ah cuch cab, Ilamados también u noox batab, 'la cuña del batab', porque eran los soportes que lo mantenían.

Todos los al tos cargos, tanto civiles como religiosos y militares, eran hereditarios y se proveían de los miembros de una familia en la nobleza; dado que la dirección de las múltiples actividades de los grandes centros ceremoniales del Clásico y Postclásico debió ser tan compleja como dirigir la política, tuvieron que convertirse en hábiles administradores, sabios eminentes, astrónomos y matemáticos, además de sus atribuciones religiosas o militares.

El grueso de la población estaba formado por los comuneros o plebeyos (que eran trabajadores libres), campesinos, artesanos, pescadores y comerciantes menores, eran la gran masa del pueblo con cuyo trabajo se sostenían los señores del lugar y los sacerdotes. Además, fueron los constructores de los grandes centros ceremoniales y las grandes calzadas (sacbeob).

Cada uno de esos grupos po día nombrarse e identificarse cultural, social y económicamente (Carmack 1976). Los señores nacían de los dioses y a su vez podían ser dioses, participaban de ellos; la gente común, en cambio, nacía de los señores. E n cuanto a lo económico, existía una marcada división entre las actividades de los señores y las de los vasallos. L os señores trabajaban casi exclusivamente en la administración de los asuntos de las provincias, ya fuera política, religiosa o militarmente. Los vasallos aportaban el trabajo físico requerido, era su obligación producir alimentos; fabricar ropa, instrumentos y armas; edificar estructuras y caminos; pelear en la guerra y servir a los señores, entre otras muchas cosas.

Algunos oficios se combinaban entre los señores y los vasallos; lógicamente estos últimos ocupaban las posiciones más bajas en las artesanías, comercio y guerra.

\section{EL ESPACIO POLÍTICO}

La idea de espacio de una sociedad está fundamentada en su propia concepción del mundo; ésta forma parte de las representaciones colectivas, inconscientes que pertenecen a dicha socied ad. Estas representaciones colectivas inconscientes vueltas conscientes son las que llamamos «creencias», que se reflejan en un territorio con sus formas de asentamiento, organización política, social y económica, es decir, que permean todos los aspectos del grupo (Bonfil 1987: 25).

El grupo concreta estas ideas subjetivas en la realidad, ya que to das las instituciones sociales y políticas se adecuan formal y funcionalmente al 
modelo que representan. La relación entre las cosmovisiones y su reflejo en la organización territorial, política, económica y social de una sociedad, y en concreto de la maya ha sido tratada por diferentes autores (cfr. M ontoliú 1989, León Portilla 1968, Rivera D orado 1986, Vargas P. 1993). De allí la importancia de conocer como arqueólogos la cosmovisión del grupo que estudiamos, para entender la íntima unión que existe entre esta cosmovisión, la organización social y el manejo del espacio en donde se desarrolla la sociedad en estudio.

El altar, la casa, los templos, palacios y aun las mismas ciudades se encuentran situadas en un solo y mismo punto común, el centro del universo. Se trata de un espacio trascendente, de una estructura totalmente diferente del espacio profano, compatible con una multiplicidad e incluso con una infinidad de centros (Eliade 1986: 339). La idea espacial de un cuadrilátero con cuatro puntos que marcan sus esquinas y entradas, que es la visión cuatripartita del universo maya, el patrón cósmico de cinco puntos, etcétera, está íntimamente ligada a la organización espacial de varias ciudades mayas y al sistema de gobierno de algunos grupos, entre ellos los itzaes y chontales; tema éste por demás importante ya que en el mundo prehispánico maya no podían separarse tan fácilmente los aspectos religiosos, sociales y económicos, todo era una unidad. Así como es el cielo, así es la tierra, nos dicen los C hilam Balam.

La provincia de Acalan se localiza en la región de ríos, lagunas y pantanos, lo que determinó una organización muy particular a lo largo del río $C$ andelaria, sus afluentes y Laguna de Términos. $\mathrm{N}$ o siempre tuvo el mismo sistema de gobierno, pues en momentos determinados constituyó una entidad segmentaria formada por agregados y en otros fue una poderosa entidad centralizada que controló el comercio de la región formando una «unidad política» que a su vez conformó en ocasiones una «esfera política».

En la literatura arqueológica el término «unidad política» se ha vuelto un concepto muy popular, es empleado para designar libremente un amplio rango de entidades territoriales con distintas extensiones, niveles de complejidad sociopolítica y ubicación temporal (M arcus 1976, 1983, H odge 1984, Renfrew y Level 1984, H ammond 1991, Velázquez M orlet y López de la Rosa 1995).

Por eso la definimos como una unidad analítica, entendida como la entidad territorial fundamental a partir de la cual se organiza la subsistencia económica, política y social de un segmento poblacional bien definido, y restringimos el término al ámbito de las sociedades complejas poseedoras de un sistema político bien desarrollado (Velázquez M orlet y López de la Rosa 1995: 96).

Este tipo de unidades políticas se caracteriza por presentar cohesión política, identidad territorial, autonomía política, un patrón de asentamiento 
con jerarquía y un liderazgo bien consolidado. A nivel regional estas unidades políticas no existen en aislamiento, sino que siempre aparecen acompañadas por otras de configuración semejante. Cuando un grupo de unidades establece una relación permanente de interacción, se conforma lo que se denomina «esfera política», que para nuestro caso estaría definida por Xicalango, Potonchán y Acalan.

A través de la arqueología es difícil acceder a todos esos elementos, pero es interesante notar que pueden aparecer en algunos casos de manera independiente y autónoma, ya sea antes o después del surgimiento o rompimiento de un sistema centralizado, o como una forma de organización territorial totalmente ajena a éste; como parte de una organización mayor, dentro de la cual las distintas unidades mantienen los mismos componentes culturales generales (arquitectura, cerámica, etcétera); y como componente de un sistema mayor, altamente centralizado y de carácter expansionista y tributario.

En el desarrollo, apogeo y colapso de estas «unidades políticas» mesoamericanas existían ciclos. M uchas veces, una nueva «unidad política» comenzaba su trayectoria como provincia subyugada por otra; al liberarse empezaba su propia historia de crecimiento, aumentando en población e importancia; y, al fin, la nueva «unidad política» Ilegaba a su apogeo y sufría el mismo destino de las otras, pues comenzaba a perder sus provincias lejanas y llegaba así al término de ese poder centralizado ( $\mathrm{M}$ arcus 1973, 1976).

En los últimos años también se ha escrito mucho sobre los estados centralizados y los segmentarios, proponiendo un antagonismo entre ambos en el antiguo mundo maya, con énfasis en los diferentes tipos de organización que debieron existir entre el Clásico y el Postclásico. Se habla que fueron sociedades hidráulicas con un urbanismo bien desarrollado y una compleja adaptación al medio ecológico; se caracterizaban también por tener una densa población con una estratificación social y diferentes actividades económicas, entre otras (Fox et al . 1996: 797).

Laporte (1996: 26) plantea seis puntos para diferenciar las entidades segmentarias de las centralizadas. En primer lugar, dice que una entidad segmentaria está formada por un agregado de sitios, los cuales son réplica unos de otros en su estructura política y aun física, están en competencia en cuanto a la autoridad y reconocen la soberanía territorial, lo que indica un bajo grado de centralización. Las relaciones políticas de estas entidades se basan en la adscripción y el parentesco. En este tipo de unidades la autoridad es delegada de las bases hacia el centro, mientras que en las entidades centralizadas la autoridad final o legítima es retenida por los gobernantes centrales, y porciones de ésta son transmitidas hacia los delegados en los otros sitios. Como cuarto punto, Laporte añade que en las entidades segmentarias los puestos políticos son autosuficientes, de solidari- 
dad mecánica y débil integración entre quienes los ocupan; las entidades centralizadas se caracterizan por los regímenes jerárquicos, con puestos políticos diferenciados, interdependientes y con solidaridad orgánica.

O tro factor descrito por L aporte es el económico; señala que la economía de las entidades segmentadas es de autosuficiencia, con un intercambio limitado y la interdependencia de las áreas es menos solidaria y cohesiva; en contraposición, las unidades centralizadas, muestran una economía especializada entre las diferentes áreas y el intercambio es extensivo e interdependiente.

Como último punto, añade que las entidades segmentarias son consideradas como relativamente inestables, con tendencia a la separación de sus componentes. $L$ as centralizadas son relativamente estables, con componentes políticamente interdependientes y como parte de un régimen jerárquico.

L a organización del gobierno variaba de una región a otra. En las fuentes históricas existen abundantes referencias sobre un go bierno centralizado que abarcó gran parte de la provincia; al parecer, la entidad centralizada fue una de sus características, sin embargo creemos que la región de Acalan perteneció en algunos momentos al Petén guatemalteco dependiente de Tikal y en otros a C alakmul, lo que lógicamente trajo gran inestabilidad a la región. También podría pensarse que Acalan no tuvo un poder central que lo rigiera, sino que éste quizás fue ejercido por varios grupos de linaje, 0 tal vez por diversos grupos étnicos. Al final, poco antes de la conquista española, me inclino a pensar que el poder pudo ser confederado, pues al parecer hubo una alianza clara, entre dos de las principales ciudades, Itzamkanac y Tixchel.

Muchos autores han pretendido ver este fenómeno como un proceso de desintegración del poder, ya que pasó de uno central a otro confederado y posteriormente a un desmembramiento en provincias gobernadas cada una por un señor principal. Pero se olvidan de que para el caso de Yucatán, la fundación tanto de Chichén I tzá como de Mayapán fue hecha por extranjeros, itzaes y cocomes que llegaron tardíamente a la península; por lo tanto, cuando desaparecieron esos sistemas de gobierno, posiblemente se regresó al que tenían los mayas yucatecos con anterioridad.

\section{U nidad política dependiente del Petén (Preclásico)}

En el Preclásico superior el sistema de gobierno de la región de Acalan varió: la cuenca del río $C$ andelaria perteneció al gran desarrollo que se dio en el Petén, quedando dentro de la esfera de EI M irador; esta posibilidad se infiere por la arquitectura, la cerámica y los mascarones. I tzamkanac fue desde entonces un lugar relevante para el control del comercio por el río C andelaria hacia el Petén. 
En EI Tigre se han excavado tres estructuras que denotan la importancia del sitio durante el Preclásico superior. En 1984 se excavó la Estructura 2, en donde se encontró un mascarón parecido a los de $U$ axactún; asociada con el mascarón se encuentra la cerámica característica del Preclásico superior. En 1997-98 se excavó la Estructura 1, en donde apareció la parte frontal de un edificio y cerámica del Preclásico superior, el Sierra Rojo y los otros tipos en abundancia, lo que hace suponer que EI Tigre era ya una ciudad importante con edificios monumentales y grandes plazas que dominó el comercio del río Candelaria, y para ese entonces se ligaba más con el Petén guatemalteco. Esta tradición arquitectónica junto con los mascarones proviene del Petén y se extiende hasta el norte de Yucatán.

Al final del Preclásico superior el centro de importancia pasó a Tikal que durante el C lásico temprano llegó a un gran desarrollo; el área de C andelaria quedó marginada, seguramente se integró a una ruta importante de comercio para el Petén pero no tuvo una ciudad que lo controlara. Posteriormente sirvió para el desarrollo de Calakmul.

\section{Gobierno centralizado de A calan (C lásico terminal)}

Durante el Clásico terminal la provincia de Acalan adquirió aún más importancia y fue quizá una entidad centralizada en donde la economía se muestra especializada y el intercambio es extensivo e interdependiente; se apoya en un fuerte aparato militar.

EI poder centralizado formó varios centros de cierta importancia conformándose una nueva organización política que debió representar una verdadera innovación, pues dado su carácter de centralista se debió establecer un conjunto de alianzas y de sometimiento entre los señores que la constituyeron.

Lo anterior se infiere por el patrón de asentamiento característico de la región y porque ese sistema de gobierno fue el que llevaron los itzaes a C hichén I tzá. EI ah tepal fue un sistema de gobierno centralizado; antes de asentarse en el lugar lo conquistaban y empezaban a ejercer el poder por medio de un único señor o soberano. L legaban desde la región de C hakamputún y seguramente ése era el sistema de gobierno que conocían y ejercían en aquel territorio.

En las fuentes históricas se dice que los itzaes no estaban allí, sino que llegaron y conquistaron Chichén I tzá a fines del Clásico mesoamericano, después del 950 de la era cristiana; decían haber sido creados por A hau (señor M izcit), identificado con N acxit, Kukulcán o Q uetzalcóatl (Piña Chan 1980: 32-7).

U na vez conquistada Chichén, los itzaes procedieron a ordenar el lugar, medir la tierra, ordenar los poblados y, según la misma fuente, la población aumentó considerablemente. Por otro lado, el C hilam Balam termina 
esa parte de la narración escuetamente diciendo que el tributo empezó a entrar a Chichén.

Esto puede interpretarse de la siguiente manera: Ios itzaes al Ilegar a la península de Yucatán primero que nada tuvieron que someter a la población que existía en la región y, una vez vencida y pacificada, le empezaron a cobrar el tributo.

Roys (1972) plantea que C hichén logró dominar Cozumel y los pueblos que se ubicaban al rededor de la L aguna de Términos, además ejerció control comercial sobre algunos lugares de Tabasco y las $\mathrm{H}$ ibueras. Sin embargo, otros autores (Robles y Andrews 1986: 84-6) sugieren que su territorio fue más restringido, pues en su proceso conquistador encontró resistencia y fue incapaz de dominar la región que abarca desde Yaxuná hasta Cobá.

El ímpetu conquistador de los itzaes fue grande pues pronto llegó a ser el centro político de un vasto territorio y, a raíz de esos procesos de consolidación política y de expansión, se convirtió en la sede del ah tepal, es decir, en el lugar de residencia de un único señor o soberano, el ahau halach uinic.

Surgió entonces una estructura política compleja en las tierras bajas del norte de Yucatán que, entre otras cosas, implicaba una recomposición política, en donde el soberano de Chichén Itzá empezó a intervenir en las sucesiones de la élite maya y el poder, pues tuvo dos orígenes distintos: por una parte perduró el sistema preexistente y por otra se incorporaron aquellos que aceptaron al nuevo soberano, al nuevo sistema. Chichén I tzá impuso a la población un conjunto de funcionarios con el fin de controlarlos y adquirir el tributo; de esta manera la ciudad adquirió un gran esplendor arquitectónico y se convirtió en una de las más prósperas.

Asociada con todo lo anterior estuvo la imposición de dioses y ritos nuevos que debió ser impactante, ya que significaba incorporar a sus creencias deidades desconocidas y lógicamente se introdujo una cosmovisión diferente que ha quedado plasmada en el orden divino, social y espacial (Broda 1991, 1994). Esa cosmovisión los afectó en sus costumbres y en el arte mismo.

Entre el 700-950 dC fue cuando se dio la mayor ocupación en la Provincia de Acalan; se registraron unos 180 sitios arqueológicos, ubicados en lugares estratégicos para controlar el comercio. D urante esa época disminuyó el comercio hacia el Petén y su importancia se acrecentó hacia la L aguna de T érminos y hacia Yucatán; se dio un cambio de orientación en sus intereses.

El complejo Paxua señala la virtual desaparición de las influencias del Petén en la alfarería de EI Tigre; y a partir de entonces empieza a desarrollarse la cerámica originaria de la región de los ríos y lagunas de TabascoCampeche, aunque se inició con anterioridad. L osmarcadores mássignificativos de este complejo son las cerámicas Altar, Balancán y Tres $\mathrm{N}$ aciones entre otras, caracterizadas por las pastas finas y su color naranja. También encontramos cerámica característica de Yucatán, lo que podría interpretarse como posibles nexos de la región chontal con la península. 
Creo que pueden distinguirse tres facetas: la primera relacionada con el C lásico tardío maya, poco representada en el sitio, la segunda corresponde a aquellos tipos característicos del C lásico tardío y Clásico terminal y por último, la tercera se relaciona con los tipos cerámicos Altar y Balancán, característicos del Clásico terminal. Estas tres facetas son de gran importancia porque se puede apreciar la evolución del grupo chontal en la región: vemos en primer lugar cerámica maya del Clásico asociada con cerámica fina que posteriormente fue característica de los chontales.

Este complejo arranca desde el Clásico tardío, al principio es poco representativo, pero llega a ser el más importante de la región chontal.

$$
\text { Gobierno confederado (T abasco, Xicalango y C hampotón) }
$$

Entre el 900 y 1000 dC varios de los grupos principales de Yucatán y G uatemala salieron de la región de A calan-Xicalango, de la región de Zuyúa; eran guerreros que iban a conquistar nuevas tierras llevando a sus sacerdotes y dioses que impusieron después.

Landa (1978) dice que «los de M ayapán tomaron mucha amistad con ellos y que así estos de Tutul Xiu se sujetaron a las leyes de Mayapán y emparentaron unos con otros»; o sea, como interpreta Piña Chan (1980: 41), se estableció una alianza entre M ayapán, U xmal y Chichén Itzá, Io cual permitió el engrandecimiento y embellecimiento de sus respectivos centros.

Piña Chan (1980: 67), interpretando varios pasajes del C hilam Balam de $C$ humayel, concluye que el halach uinic de $M$ ayapán vence, con la ayuda de siete capitanes mayapanenses, a $\mathrm{C}$ hac $\mathrm{X}$ ib $\mathrm{C}$ hac, ah tepal de $\mathrm{C}$ hichén (fotografía 51), éste fue obligado a abandonar, con su pueblo, la ciudad y de ese modo iniciaron un éxodo hacia diferentes partes de la zona maya; uno de esos grupos migrantes podría ser el de los magtunes.

El surgimiento de M ayapán (fotografía 52) como la nueva capital de las tierras bajas del norte de Yucatán trajo consigo cambios y redefiniciones, tanto políticas como territoriales. A diferencia de C hichén I tzá su esfera de influencia fue más reducida (Roys 1972: 32).

L os cocomes desempeñaron un papel dominante en esta organización política, pero sin lograr concentrar el poder; sólo formaron un gobierno confederado (multepal), con el cual reinaron de manera conjunta, ya que eran vigilados por los otros grupos. Para gobernar los pueblos se vieron obligados a delegar cierto tipo de responsabilidades en los batab; no se sabe con exactitud cuáles fueron las funciones así del egadas.

Piña Chan (1980: 69), citando a L anda, dice que los señores acordaron que para que la república durara, el mando principal lo tuviera la casa de los cocomes, por ser la más antigua y más rica, y por ser el hombre que la regía entonces el de más valor. 


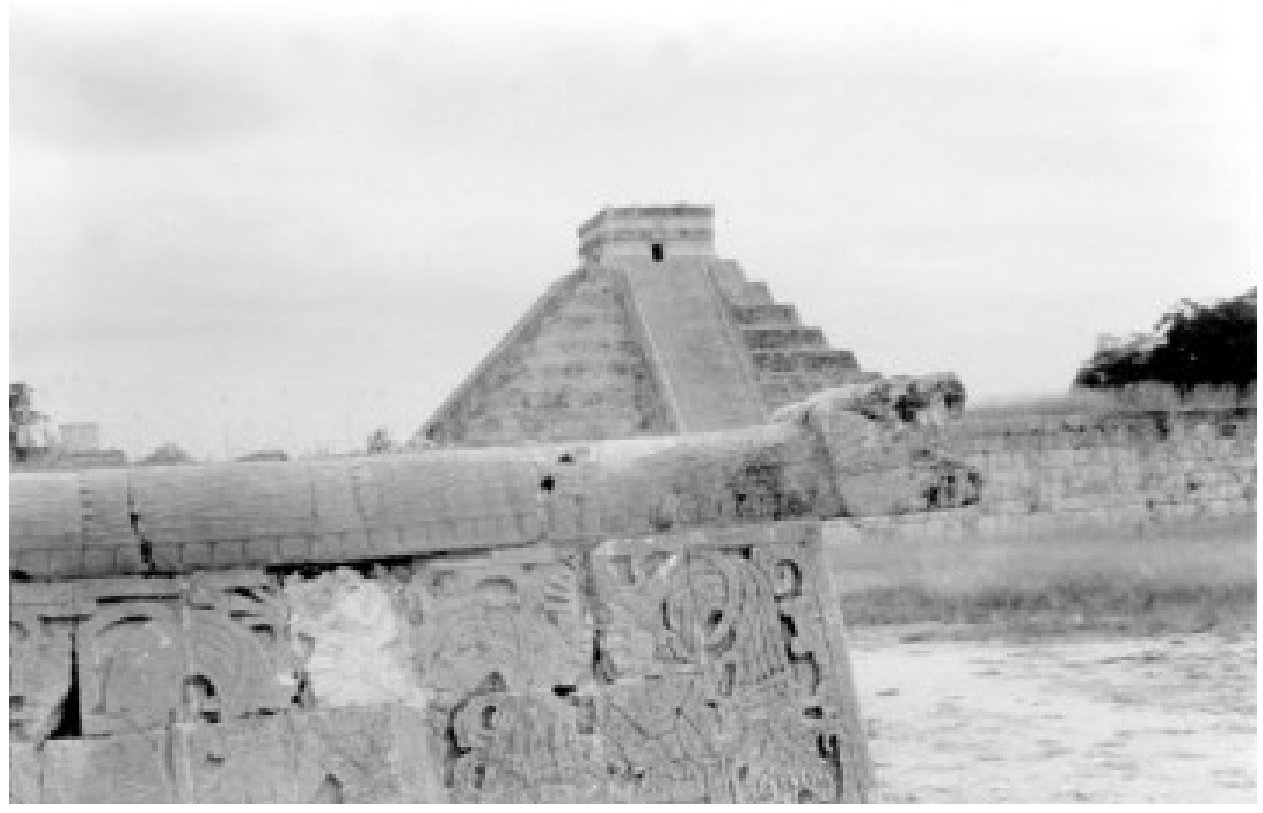

Fotografía 51.C hichén Itzá, EI C astillo.

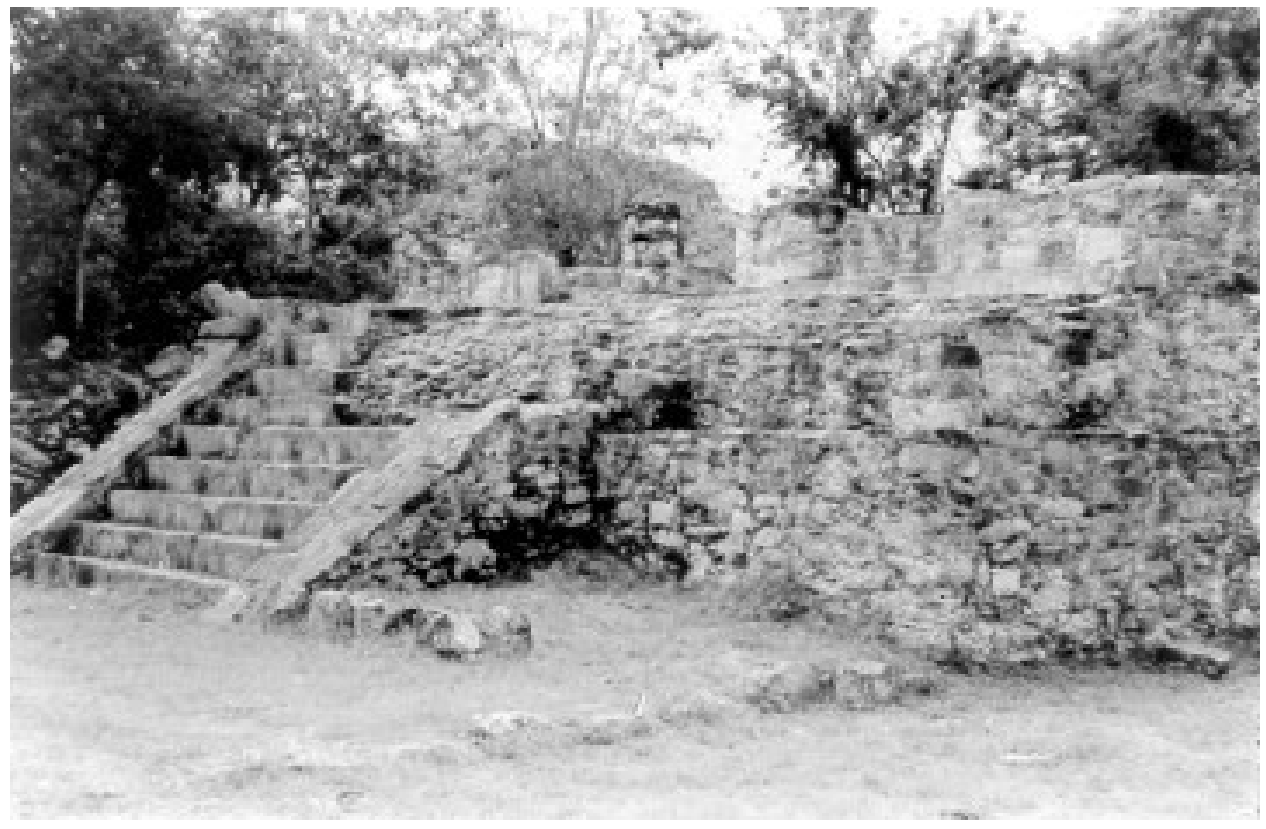

Fotografía 52. Estructura de M ayapán. 
Sin embargo, a mediados del siglo xv, a raíz de las pugnas entre los xiues y cocomes, M ayapán fue destruida y el multepal se desintegró, dejando un vacío de poder que favoreció la formación de los cuchcabalob o provincias. «8 ahau (1441-1461) fue cuando se abandonó y destruyó I chpa-M ayapán por los de extramuros, los de atrás de la muralla, por causa del gobierno múltiple en el interior de M ayapán».

L anda (1978) agrega que una vez destruida M ayapán los señores se fueron cada uno a su tierra; es de suponerse que los linajes prominentes se habían integrado en el multepal y regresaron como halach uinic a regir sus territorios; a esa asociación entre el lugar en donde establecieron su residencia y el territorio gobernado por esos señores se les denominó cuchcabalob.

En la región chontal el sistema de gobierno confederado no debió ser de gran importancia, pues son pocas las referencias que hay acerca de él. Los magtunes pelearon contra los de Champotón, Xicalango y Tabasco, esas pudieron haber sido las tres ciudades que controlaban el comercio por la costa y a su vez se unieron para sacarlos del Tixchel.

\section{Cuchcabal o provincias}

Al llegar los magtunes a la región, durante el Postclásico, conquistaron primero Tenosique y parte del U sumacinta, posteriormente se dirigieron hacia I sla de $C$ armen y T ixchel, de donde fueron expulsados por los de C hampotón, Xicalango y Tabasco, y después sometieron a la población de Itzamkanac, río arriba.

Paxbolom A cha fue quien consolidó I tzamkanac como cabecera de la provincia de Acalan, su advocación es eminentemente guerrera, Pax es el mes de la guerra en Yucatán, bolon es nueve, pero está relacionado también con el inframundo. É l logra establecer al comercio como la actividad principal de los acalanes y a I xchel e I tzamná como símbolos religiosos, como dioses que unieron la gran provincia, pues la religión es un arma fundamental para la cohesión de un territorio.

A la caída de M ayapán los cuchcabalob vivieron un periodo dinámico de reordenamiento político y territorial debido sobre todo a las guerras intestinas; fue una época turbulenta en la que algunos territorios desaparecieron, otros se redujeron y seguramente surgieron nuevas entidades.

Q uezada (1993: 53-6) dice que existían dos tipos de gobierno y no tres, como sostenía Roys (1957). En la primera forma nos señala que el halach uinic concentraba ciertas funciones y otras las ejercía de manera mediada. En la cabecera residía lógicamente el gran señor y el poder era hereditario por línea paterna. $L$ as funciones que manejaba por su cargo eran religiosas, militares, judiciales y políticas. Al parecer, uno de los aspectos clave para entender qué tan centralizado estaba el poder en un cuchcabal se refiere a la capacidad 
del halach uinic para imponer al batab, o sea, a la cabeza del segundo nivel, pues en muchos casos era puesto por los principales del batabil.

En la segunda forma de gobierno centralizado (Q uezada 1993: 56-61) las funciones básicas del poder se depositaban en personajes diferentes; éstos residían en la capital o cabecera del cuchcabal y uno de ellos era el halach uinic.

La posibilidad de análisis que nos ofrecen estos estudios es de gran importancia, ya que a través de los patrones de asentamiento podemos delimitar los territorios ocupados por diferentes linajes.

Roys propuso la organización político-territorial de los mayas con base en el término de provincia; pero en realidad Q uezada (1993: 61) nos dice, que este término fue utilizado en tres asociaciones distintas: una en conexión con el topónimo de cierto lugar en donde residía un poder que gobernaba determinado territorio; la segunda en relación con el patronímico de un linaje gobernante; y finalmente la usaron para referirse al conjunto de pueblos ubicados en un área con cierta característica natural.

Ciertamente cuando el halach uinic fue el personaje que dio unidad y cohesión a un territorio, y poseyó una estructura administrativa clara para gobernarlo, allí sí existió un cuchcabal; mientras que en los otros tipos de organización en los que se daban alianzas para evitar ser sometidos por sus vecinos mejor organizados no existía un territorio político, ya que dichas alianzas eran coyunturales y pasado el peligro desaparecía la unidad; es decir, fueron incapaces de generar un gobierno central con una administración política unificada.

Los españoles, desde un principio, emplearon el término provincia con los diferentes matices: uno para referirse a Yucatán y otro para indicar las subdivisiones internas. D espués aplicaron ese término en varios contextos: uno para referirse a un área con cierta característica natural, otro en concesión al patronímico de un halach uinic, y lo usaron también asociado con topónimo del lugar.

L as tres instituciones mayas más importantes durante el Postclásico fueron el cuchcabal, el batabil y el cuchteel. El cuchcabal era el espacio territorial donde se encontraba un conjunto de pueblos cuyos gobernantes estaban enlazados política y religiosamente por el poder que residía en un lugar llamado cabecera o capital; como entidad político territorial se caracterizó por tener un punto central que, además de ser un núcleo poblacional y posiblemente centro económico y religioso, en él se ejercían también funciones políticas.

Las funciones políticas, rituales y ceremoniales del batab convirtieron al batabil en una institución de naturaleza política y administrativa; en la figura que unía y vinculaba a la población sujeta en torno a él; en un todo orgánico y cohesionado (Q uezada 1993: vi). O koshi (1993: 192-3) nos dice que batab tendría la acepción de: «el de la autoridad o el primer personaje que concierta o arregla asuntos del pueblo». Su función básica era administrativa, judicial y militar. El batabil formaba parte del cuchcabal, la 
institución de carácter político y territorial más importante de los mayas yucatecos a la llegada de los españoles a la península. El halach uinic era el que la gobernaba y el batab dependía directamente de este funcionario, puente de unión entre la población sujeta y el poder central.

El cuchteel era la unidad básica, en él estaban integrados los grupos de familias extensas; Roys tradujo este término como barrio y para él fue la unidad política mínima de las provincias prehispánicas, pues estaba integrado por casas que al bergaban grupos de familias extensas, es decir, parientes consanguíneos que reconocían a un jefe familiar. El cuchteel era una unidad básica residencial localizada, así como una unidad administrativa y de trabajo.

El batabil, del que ya hemos hablado, se componía por un conjunto de unidades sujetas a un batab y puede ser interpretado como el espacio territorial bajo el dominio y dependencia del batab, en donde ejercía su poder; al parecer, tal entidad no tenía límites precisos. El batabil aparece como un centro rector, hacia él fluían los excedentes tributarios, se organizaba la energía humana para las diversas actividades religiosas y de guerra; era el lugar que vinculaba con la cabecera o capital. El batab no ejercía sus funciones de una manera vertical, pues existía un consejo integrado por los ah cuch cab, o sea, los representantes de cada uno de los cuchteelob que componían el batabil, quienes eran nombrados por el batab y representaban los intereses económicos, políticos y militares de la élite gobernante de esas unidades básicas.

EI cuchteel y el batabil formaban el cuchcabal con su capital o cabecera y su área dependiente, o provincia, como lo llamaron los españoles. El halach uinic era el personaje que cohesionaba y daba sentido a esta entidad, que a su vez era la más compleja de la organización indígena; el poder supremo era el halach uinic que residía en la cabecera.

La Provincia de Acalan estuvo formada por cuatro batabilob y una cabecera, Itzamkanac; en ésta existió un poder central que fue gobernado por un halach uinic, Paxbolom A cha. Se propone tentativamente a EI Tigre como la cabecera de la provincia; a Santa Clara sobre el río C aribe, como el centro de un batabil dependiente de I tzamkanac, que controlaba todo el comercio por ese río; lo mismo que al sitio arqueológico de San Román sobre el río San Pedro que controlaba el comercio hacia el Petén y a Salto Grande sobre la margen del río $C$ andelaria, lugar de rápidos y con tránsito lento y difícil. El cuarto batabilob dependiente de I tzamkanac fue Tixchel, lugar de la diosa Ixchel, que regía parte del estero de Sabancuy y parte de la Laguna de Términos a donde desembocan los ríos C hivojá, $M$ amantel, Candelaria y Chumpán.

La estructura del cuchcabal fue compleja y claramente se ve la importancia del halach uinic y del batab, que como personajes principales dominaron y controlaron la vida política y administrativa de la provincia, ellos fueron parte integrante de la nobleza y como tales eran reconocidos. 


\section{EL ESPACIO SAGRADO}

Para los mayas el universo está formado por tres grandes planos cósmicos: el cielo, la tierra y el inframundo. Para el hombre religioso, el cielo se muestra como un espacio inaccesible, inmutable, eterno, escenario de múltiples fenómenos que consideran como manifestaciones de lo sagrado: la presencia cotidiana del sol y la oscuridad, los ciclos de lluvias, los truenos, la periodicidad de la luna o el curso inalterable de las estrellas son algunos factores que los impactaron.

La concepción geométrica del plano terrestre reúne múltiples significaciones, ya que cada región presenta valencias simbólicas peculiares, origina un espacio donde lo sagrado, con sus diversas cargas, rodea al hombre. El plano terrestre para el maya era una superficie plana y cuadrada, dividida en cuatro grandes sectores situados al rededor de un punto denominado el centro del mundo.

La imagen cuatripartita del universo está todavía hoy en día profundamente arraigada, casi como lo estuvo durante la época prehispánica (Villa R ojas 1968). Para los mayas, la superficie terrestre está dividida en cuatro grandes sectores que, a partir de un centro imaginario, se extienden hacia los cuatro rumbos del compás. Cada uno de ellos tiene sus propios dioses, colores e influencias y además conexiones específicas con los diversos ciclos que forman el cal endario aborigen. Su réplica se encuentra en la forma de muchos pueblos, en la milpa, en el altar de ceremonias del $\mathrm{C}$ hac $\mathrm{C}$ haac y en el calendario del año sagrado de 260 días, formado por 13 uinales y los periodos de 20 días. La gente común debe haber conocido el año sagrado de 260 días, el tzolkin, era la pauta de su vida ceremonial. El año sagrado no estaba dividido en meses, era una sucesión de 260 días que se formaban anteponiendo los números del 1 al 13 a los veinte jeroglíficos de los días mayas. El año civil o haab se componía de 18 meses de 20 días cada uno y 1 mes adicional de 5 días, lo que da un total de 365 posiciones que los días podían ocupar en los meses de dicho año calendárico.

Los mayas concibieron la tierra en función de un extraordinario complejo de símbolos: la imagen de los monstruos de los que brota la vida; la distribución cuatripartita que a partir de un centro extiende la realidad entera por los rumbos de colores, poblados de dioses y fuerzas primigenias, de aves y árboles cósmicos y también de los humanos que allí viven y mueren.

Pero el universo horizontal no alcanza en sí mismo su más pleno sentido, su existencia se explica por el fluir incesante del tiempo y por la presencia de los dioses que moran en los planos superiores e inferiores que completan la imagen del espacio universal.

H asta aquí nos hemos ocupado de la concepción horizontal del universo; ahora revisaremos la que corresponde a la imagen vertical del mismo, con sus trece cielos y sus nueve planos inferiores. Existen dos versiones cosmogónicas con respecto a la disposición de los trece planos celestes: la 
primera, dispuesto de modo estrictamente vertical, uno sobre otro; y la segunda, que sugiere Thompson (1954: 225), en forma de escalera, con seis escal ones ascen dentes del lado del poniente y otros seis del oriente, correspondiendo al cenit el décimotercer escalón que unía ambos lados.

M ucho se ha escrito sobre la relación espacio y tiempo, existen evidencias en las estelas, códices, fuentes históricas y en la tradición de los pueblos mayas actual es. L os mayas antiguos seguramente dieron una significación cosmogónica a la planeación de sus ciudades. El antiguo patrón cósmico de cinco puntos proviene del concepto de las cuatro esquinas del mundo que correspondían aproximadamente a los puntos intercardinales (Villa Rojas 1968: 43). Estos puntos solsticiales ocuparon un lugar principal en las observaciones de los astrónomos mayas.

Los itzaes en su peregrinar recrearon su visión del mundo, nacieron, al venir de Sian Chan Bakalar, en el oriente, en sian chan, 'cielo ofrendado', 'cielo linaje'; Chichén Itzá estaba al centro, de allí fueron después de permanecer un ciclo de 260 años al poniente ( $Z$ uyúa, 'entrada al inframundo') a C hakamputún, de donde regresaron otra vez a $C$ hichén y al caer ésta migraron hacia el norte, a M ayapán de donde salieron después de otro ciclo de 260 años hacia Tayasal, al sur. Su desplazamiento fue del oriente al centro, del centro al poniente, del poniente al centro, del centro al norte y del norte al sur; se desplazaron hacia los cuatro rumbos del mundo, permaneciendo 260 años en cada uno de esos lugares, y en cada uno de éstos se repitió el acto de nacer, desarrollarse y morir.

El cosmos necesita renovarse periodicamente y el tiempo cíclico manifestado por la rueda katúnica representa el orden cósmico, contiene una creación, una existencia y un retorno al caos; estos factores son una necesidad del universo para dar lugar a un nuevo orden cósmico y, con ello, a otro periodo del mundo (Farris 1985: 55 ).

O koshi (1997: 184-187) opina que estos periodos de tiempo fueron indispensables antes de establecerse en un nuevo centro político ceremonial. Y al analizar el orden del recorrido de los itzaes desde Polé hasta C hichén I tzá dice: «A simple vista uno se percata de que la ruta del recorrido reconstruido toma el patrón del sentido contrario al del movimiento de las manecillas del reloj. Se sabe que este modelo es el equivalente horizontal de la diaria trayectoria vertical del sol, "que se sigue al hacer referencia al espacio sagrado por excelencia, el cosmos" ».

Los itzaes en su recorrido hacia Chichén Itzá se desarrollan en un espacio cósmico, obedeciendo al ciclo katúnico y siguiéndolo en sus cuatro etapas: nacimiento relacionado con el oriente, crecimiento, apogeo y decadencia con el norte; muerte (o retorno al caos) con el poniente, pruebas y obtención de la sabiduría con el sur. Los itzaes emplearon toda esta estructura ideológica para legitimar su poder político en cada uno de los cíclos katúnicos. 
Como dijimos, en cada katún se daba todo el proceso, igual que en cada uno de los cinco grandes periodos. En el primer katún 8 ahau nacieron en el oriente, en Sian C han Bakalar y fueron hacia el norte, a C hichén Itzá, el centro, en donde se desarrollaron; el siguiente katún 8 ahau lo pasaron en el poniente, en Zuyúa, lugar relacionado con el inframundo para renacer con la sabiduría y el poder político que ejercieron en Chichén I tzá en el siguiente ciclo katúnico. Chichén fue el centro de su universo y a su al rededor se extendía el mundo, allí se daba la comunicación entre las regiones cósmicas gracias a la existencia de un eje, de un axismundi. En $M$ ayapán, que puede relacionarse con el norte, se desarrolló el siguiente katún 8 ahau, que en sus creencias era de muchas miserias, falta de agua y, por lo general, negativo pues vendrían «discordias y guerras entre sí propios o con otros pueblos [...]». En Tayazal, localizado al sur, se desarrollaría el siguiente ciclo katúnico que se puede considerar bueno.

La asociación del inframundo con el poniente, el cual pudiera localizarse en esta parte de Tabasco-C ampeche, no es mala, pues recordemos que el inframundo además es un lugar de sabiduría y renacimiento necesario para la existencia del cosmos.

Carmack (1976: 74) dice que Tulan-Zuiwá, lugar al oeste de Yucatán rodeado de agua, puede ser el antiguo nombre de Xicalango. Piña Chan (1980) piensa que Zuyúa o Z uivá es una región que corresponde al área de la Laguna de Términos. Por otra parte el mismo Carmack, sin dar mayores explicaciones apunta que Tamac-Tún, el topónimo empleado para designar a los habitantes de la región de Acalan, es también usado para nombrar a uno de los primeros asentamientos quichés de los altos de Guatemala: A mak'Tán.

Como puede verse, la región es de gran importancia, ya que se nombra en diversas fuentes históricas indígenas.

Entre los grupos que dicen venir de esa región están los quichés, cakchiqueles, itzaes y xiues: «D e cuatro [lugares] Ilegaron las gentes a Tulan. En oriente está una Tulan; otra en Xibalbay; otra en el poniente, de allí llegamos nosotros, el poniente; y otra donde está dios».

Por las citas enunciadas con anterioridad en el Popol Vuh y en el $\mathrm{Me}$ morial de Sololá, podemos decir que los cakchiquel es y los quichés abandonaron la 'Ciudad del Poniente' (Tulan Zuyvá) después de recibir a sus dioses; según Piña C han (1980: 35) se dirigieron a la costa del Golfo, en donde pelearon contra los nonoual cas de Tabasco y los xulpiti, que pudieron ser los xiues, puesto que éstos tuvieron su hogar también en Nonoualco; pasaron a Zuyúa (Laguna de Términos), en donde fueron derrotados; de allí se dirigieron a Guatemala pasando por las montañas del Tacaná.

Piña C han (1991: 67-70) explica este pasaje diciendo que entre el 700 y 900 de nuestra era, varios grupos étnicos comenzaron a emigrar en busca 
de nuevas tierras donde asentar sus linajes y fundar pueblos, la región más favorecida fue la costa del Golfo; Ilevaban como caudillo a un sacerdote del culto a Q uetzalcoatl.

En el capítulo 6 del M emorial de Sololá se puede apreciar claramente que sólo una pequeña porción de la población, la élite dominante y los guerreros que los acompañaban para concertar las alianzas, eran quienes partían a conquistar los territorios que se deseaban; posteriormente se mandaba por la población civil.

Los quichés y cakchiqueles, al parecer, realizaron conjuntamente la migración que los conduciría a establecerse en el actual territorio de Guatemala; algo parecido a lo que sucedió con los xiues e itzaes que se establecieron en Yucatán, aunque con 80 años de diferencia.

Los xiues conquistaron primero $\mathrm{M} \mathrm{ul} \mathrm{Chic,} \mathrm{en} \mathrm{donde} \mathrm{sostuvieron} \mathrm{pe-}$ leas sangrientas que quedaron registradas en dramáticos murales y de ahí pasaron a conquistar $U$ xmal. L os itzaes, por su parte, antes de asentarse en C hichén I tzá recorrieron gran parte de la península guerreando y conquistando pueblos; al final se asentaron en las orillas del pozo y ahí empezaron a recibir el tributo.

En los textos del M emorial de Sololá y el Popol Vuh se presenta una similitud en cuanto a los dioses creadores, a la espera del nacimiento de la luz o la aurora del sol, la entrega del fuego y la toma de posesión de la tierra que éstos les habían prometido en la mítica Tulan. Finalmente, cuando tienen cierta independencia y conforman una estructura de poder, se expresa su cosmovisión en la estructura social con la misma división del poder en cuatro, lo que también vemos en la migración de los itzaes.

L lama po derosamente la atención que muchos de los grupos mayas del Postclásico temprano y tardío digan venir de la región del agua; por otra parte ahí llegan grupos del centro de M éxico: olmecas xicalangas y, posiblemente desde antes, algunos grupos teotihuacanos.

Thompson (1975: 44) dice que los itzaes llegaron de cuatro lugares y uno de ellos estaba en el oeste; Holtún Zuiua era el nombre putún de Puerto Escondido, en el brazo septentrional que encierra la Laguna de T érminos. 


\section{Capítulo ill COMENTARIO FINAL}

Los estudios que actualmente existen sobre lo político-territorial nos permiten delimitar, a través de los patrones de asentamiento, los territorios ocupados por diferentes linajes. Acalan parecería estar fuera, pues no se le considera dentro de las 16 provincias; sin embargo, participó de manera muy particular en los acontecimientos que se daban en la península de Yucatán.

En términos generales, las sociedades mesoamericanas de la última época antes de la conquista se caracterizaron por la complejidad de su organización económica y social: la producción rendía excedentes apreciables, había una marcada división del trabajo, la distribución de recursos económicos tenía lugar mediante mercados locales, intercambios a larga distancia y un complicado sistema tributario.

Con respecto a la organización social había una pronunciada estratificación y un orden político centralizado, que ponía énfasis en la guerra, el comercio y los aspectos religiosos. Como ya dijimos, una de las características fundamentales de estas sociedades es la estrecha interrelación que presentan en todos sus aspectos, de allí que si se estudia la economía o el gobierno, siempre tiene que ligarse con los aspectos de la vida social en forma más directa de lo que acontece en el caso de las sociedades modernas.

\section{ACALAN E ITZAMKANAC}

A nivel regional, la existencia de la unidad política de Acalan es difícil de documentar en periodos tempranos, debido, a que carecemos de fechamiento para muchos sitios registrados en superficie.

L as primeras evidencias consistentes proceden del Preclásico superior, del cual se encuentra cerámica, arquitectura y escultura en bajorrelieve. Al parecer, se dio un crecimiento espectacular en el tamaño de los centros y la cantidad de las estructuras que los formaban; dichos centros dominaron una región política y económicamente extensa. Al final del Preclásico superior ( $150 \mathrm{aC}$ a $250 \mathrm{dC}$ ) se colapsaron casi todos y sus repercusiones en toda el área maya seguramente fueron el cimiento o 
antecedente para el florecimiento de los grandes centros de la época C lásica, fenómeno que quizás no se dio en Acalan, ya que el desarrollo de la región fue periférico.

La región del río Candelaria y posiblemente toda la costa sur de Campeche se integró al desarrollo que se dio en ese momento en la parte norte del Petén ( $N$ akbé, EI M irador, Tintal y Güiro).

D urante el Clásico temprano y tardío el desarrollo en la región del río Candelaria fue pobre, no se aprecia mucha cerámica característica de la época y tampoco a nivel de la arquitectura se registra el gran auge del Petén. J. M arcus (1995: 200) dice que para los siglos vil y vilı, Ias fronteras de Tikal se redujeron considerablemente, aunque la ciudad siguió creciendo. Calakmul, entre los siglos vı y vı tenía una zona de influencia política igual o mayor que la de Tikal; en ese momento el Candelaria debió depender de C alakmul y empezó a tener cierta autonomía.

Si tomamos en cuenta los cál culos de descarga de agua del río C andelaria estimados por $\mathrm{G}$ un et al. (1994: 185) para los años del 430 al $650 \mathrm{dC}$ los promedios son mayores, por lo que seguramente hicieron imposible la vida en dicha región.

Aproximadamente a partir del 700 dC la situación se normalizó y la descarga del río disminuyó, con la consecuente factibilidad de ocupación. Esto es corroborado ampliamente por la arqueología, ya que se encuentra gran cantidad de restos cerámicos de esa época; lo mismo sucede con las construcciones; dicho periodo corresponde del 700 al $950 \mathrm{dC}$; estamos hablando ya de una provincia que domina to do el río Candelaria hasta la L aguna de Términos; son putunes o chontales, que tenían relaciones con otras provincias, formando de esa manera una «esfera» política que controlaba todo el comercio de la costa y de los ríos.

$D$ urante ese perio do se da la mayor actividad constructiva alrededor de Ios ríos Candelaria, San Pedro y San Pablo, río U sumacinta, Grijalva, Laguna de Términos. Los restos de cerámica tipo Altar, Balancán y Tres N aciones son abundantes en toda la región. Se puede decir que éste es el periodo de mayor ocupación, el auge de los chontales.

Como acontecimiento importante se registra la captura del halach uinic 'Garra de Jaguar' de C alakmul por el rey de Tikal, dejando seguramente un vacío de poder en el dominio territorial de Calakmul, que llegaba por lo menos hasta el río Candelaria (Marcus y Folan 1994: 23, M arcus 1995: 205).

D urante el tiempo comprendido entre el 950 y el $1200 \mathrm{dC}$ el nivel de descarga del río C andelaria aumenta y, al parecer, el centro de interés se desplaza hacia Yucatán, siendo C hichén I tzá el gran centro. Por otra parte, la región chontal no parece tener mayor importancia durante este periodo, pues según algunos autores dependió de Chichén; el material cerámico y los restos arqueológicos encontrados son escasos. 
A partir del 1200 hasta el 1400 se da la menor descarga del río y empieza a recuperarse a partir de esa fecha; pero lo interesante es que la región vuelve a tener cierta importancia desde entonces. Los diferentes halach uinic magtunes conquistan Tenosique, la región de la L aguna de T érminos y el río C andelaria. El rey A uxaual vino de Cozumel y conquistó el pueblo de Tanocica, acompañado por los cuatro principales. El tercer rey conquistó lo que ahora es Términos, Boca N ueva y Puerto E scondido. El cuarto rey pobló Tixchel, pero tuvo guerras con los de Champotón, Xicalango y Tabasco, por lo que hubo de abandonarlo e irse hacia M agtún, 'Iugar de la piedra que tapa', que debe ser el Candelaria medio, en donde están los rápidos y la navegación fluvial se hace difícil. Pexgua, halach uinic de los magtunes, conquistó a los quiaches, los mazatecas y a los zulob, y «así fueron señores de la tierra de Acalan».

En tiempos del quinto rey, que se llamó Pachimalays, se conquistó C hagtemal y se tuvieron guerras con los zulob quienes tomaron Balancán y pretendieron que los acalanes dividieran el tributo de los pueblos, como éstos se negaron, hubo guerras y regresaron a Acalan.

EI sexto rey se llamaba Paxbolom A cha; en su tiempo se pobló Acalan; éste «era su reino» que estaba conformado por 76 pueblos y la cabecera I tzamkanac, a donde llegó Cortés.

Los magtunes o tamagtunes al parecer conquistaron y dominaron la región media del Candelaria, ya que ellos se asentaron en toda esta parte de los rápidos, que es 'el lugar de la piedra que tapa' ( 0 tto Schumann comunicación personal). Además, se construyó y se utilizó una especie de defensa natural para vigilar la entrada hacia los ríos C andelaria y $\mathrm{M}$ amantel; dicha construcción es un camino en la laguna de Panlao, que permite el acceso a dos de los sitios arqueológicos y el control sobre la entrada a los ríos.

Paxbolom A cha murió dos años después de que pasó Cortés por I tzamkanac y le sucedió otro de sus hijos, posiblemente Pachimalays, quien a su vez fue sucedido por don Luis Paxua que huyó a Chiua; le siguió su segundo hijo llamado Lamaateazel, padre de don Pablo Paxbolom, quien asumió el gobierno en 1566 tras la muerte de su primo, y quedó como el único heredero legítimo del cacicazgo de Acalan; éste se inspiró en el ejemplo de su abuelo para reconstruirlo desde Tixchel. Ya como cacique y gobernador de Acalan-Tixchel fue reconocido por diversas poblaciones de diferente manera; al gunas comunidades le expresaron su interés por comerciar y pagarle tributo, mas no querían tener nada con ningún español. En otros lugares fue aceptado por los indígenas para ser instruidos en la fe cristiana; y a otros grupos los asentó en su jurisdicción; así, en 20 años logró reorganizar la región de Tixchel, por lo que las condiciones fueron favorables tanto para él como para los pueblos indígenas bajo su protección.

La historia de Itzamkanac puede apoyarse sobre datos más o menos concretos, los que tenemos son escasos para reconstruir el contexto regional, por lo que aún queda mucho por hacer. 
La selección del lugar sobre el cual se habría de construir la gran ciudad de Itzamkanac no fue producto de la casualidad: se ubica en una zona muy rica en suelos cultivables, suficientemente cercana al río como para utilizarlo como vía de comunicación fluvial, un área donde la materia prima para construcción es abundante y de buena calidad; por otra parte, es evidentemente una región con una excelente ubicación geográfica, que resultó estratégica para un control político y económico excepcional.

La primera característica notable radica en que su zona nuclear -de hecho la porción en que se ha documentado la ocupación más antiguaestá en el centro físico del asentamiento y en lo más alto del lugar que sirvió desde entonces para dominar gran parte del río Candelaria. De ahí creció gradualmente hacia el este y el sur, quedando el núcleo del sitio muy bien protegido de cualquier ataque y de las inundaciones.

No hemos hecho el levantamiento topográfico de todo el sitio, sin embargo, la delimitación que proponemos implica una extensión de casi $30 \mathrm{~km}^{2}$ y se presume que durante el Clásico terminal el acceso a la ciudad era a partir del sacbe que se localiza hacia el oeste, pero también se podía llegar por otros caminos que se encuentran al norte, los cuales comunicaban el centro con el puerto que estaba a orillas del río.

La ciudad tuvo diferentes dimensiones a lo largo del tiempo; no podríamos en estos momentos hacer un análisis de los cambios, pues la información de que disponemos todavía es muy fragmentaria.

Itzamkanac, como cualquier otra ciudad, tuvo modificaciones a través del tiempo, lo que implica sin duda transformaciones políticas de importancia. Sin embargo, hay que dejar claro que estos vaivenes en la distribución interna del poder no eliminaron al lugar como el punto más importante de la región, de tal manera que hoy en día sigue siendo un lugar relevante.

Por las fuentes históricas sabemos que I tzamkanac se relacionaba comercialmente con Xicalango y Tixchel; con la primera seguramente tuvo que entrar en conflictos, pero lograron resolverlos desarrollánd ose como capitales independientes. Con Tixchel fue diferente, pues también dependía de I tzamkanac y la relación no sólo fue controlar el comercio hacia la península de Yucatán, sino que lo religioso debió desempeñar un papel importante, ya que tanto I tzamná como I xchel fueron dioses esenciales en el mundo maya.

Por ahora, como dijimos, no nos interesa la esfera política de los chontales, sino la «unidad política de Acalan», que debió tener su cabecera en EI Tigre (I tzamkanac), dominando el río $C$ andelaria y los afluentes $C$ aribe y San Pedro, que forman el Alto C andelaria. Los saltos, aproximadamente 70 , son una barrera natural del río y forman el Candelaria medio; allí también se localizó gran cantidad de sitios arqueológicos que seguramente controlaban la travesía lenta y pesada; formaban una unidad a nivel regional, posiblemente un batabilob dependiente de la cabecera. Además, la entrada hacia los ríos $C$ andelaria y $M$ amantel también fue controlada, pues se 
construyó una especie de camino que atravesaba la laguna de Panlao dejando dos boquetes que permitían el acceso hacia los ríos.

É sta, de ninguna manera es un propuesta acabada, está sujeta a modificaciones a partir de la nueva información que se genere con otras exploraciones y conocimientos sobre la región.

\section{EL SISTEMA DE GOBIERNO}

En los Papeles de Pablo Paxbolom M aldonado se dice que su abuelo Paxbolom A cha era el halach uinic de la provincia de Acalan y to do lo tenía que consultar con sus cuatro gobernadores (M utuzin, rey, $\mathrm{H}$ inzuti, Pazayaatomal y Cixun) que estaban en sus respectivos pueblos (Taxunum, C habte, A tapan y T atzanto), «porque no se podía hacer cosa sin dar parte a estos principales». Cuando A uxaual llegó desde Cozumel, vino con los cuatro principales: «estos llevó por compañeros»; y cuando salen de C hakamputún: «C uatro partidas salieron. Las cuatro divisiones de la tierra se nombran [...] en que sucedió que invitaron a los de las cuatro divisiones, nombrados $C$ antzuculcab, para que vinieran. Fueron hechos padres cuando vinieron a C hichén I tzá. I tzaes entonces se llamaron».

La Provincia de Acalan estuvo formada por cuatro batabilob y una cabecera; en ésta existió un poder central que fue gobernado por un halach uinic. Se propone tentativamente a EI Tigre como la cabecera de la provincia; a Santa Clara, sobre el río C aribe, como el centro de un batabil dependiente de Itzamkanac, que controlaba todo el comercio por ese río; lo mismo que al sitio arqueológico de San Román sobre el río San Pedro que controlaba el comercio hacia el Petén y a Salto Grande sobre la margen del río Candelaria, lugar de rápidos y con tránsito lento y difícil. El cuarto batabilob dependiente de I tzamkanac seguramente también se ligaba por los aspectos religiosos: Tixchel, era el lugar de la diosa I xchel, que regía parte del estero de Sabancuy y parte de la Laguna de Términos a donde desembocan el río de C hivojá, M amantel, C andelaria y Chumpán.

Los chontales que habitaron la región de ríos y lagunas no sólo tuvieron una cabecera o capital, sino se habla de por lo menos tres: Potonchán, Xicalango y Acalan. U na de tantas dudas es ¿cómo funcionaron estas tres capitales, que seguramente también tuvieron un territorio determinado (provincia o cuchcabal), como se desprende de las fuentes históricas y de la misma arqueología? Esto, por ahora, es sólo un planteamiento; una posible explicación sería la utilización del concepto de «unidad política» y de «esfera» que, como dijimos, se da cuando un grupo de unidades políticas establecen una relación permanente de interacción, y estas entidades, para desarrollarse, necesariamente tuvieron que establecer interacciones permanentes que las obligaron a darse seguridad y prosperidad. 
L os diferentes autores que se citan en el texto se refieren por lo general a «unidades políticas», a estados centralizados, estados segmentarios y a los cuchcabalob, término ampliamente utilizado por Roys para Yucatán durante el Postclásico.

Por la información que se tiene sobre la región de Acalan (mapa 17) podemos concluir que para el Preclásico superior ésta debió permanecer bajo la esfera de dominio del Petén, y tanto EI Tigre (Itzamkanac) como Santa Rita (Xicalango) fueron lugares estratégicos para el comercio, pues desde entonces controlaron las rutas de ríos y lagunas.

Las inundaciones provocaron que durante el Clásico medio la región se abandonara y posiblemente disminuyera su importancia, ya que fueron las mayores de todas las épocas, lo que hizo imposible la permanencia en los sitios por ser una zona de bajos.

Sin embargo, alrededor del $700 \mathrm{dC}$ las condiciones ambientales cambiaron y el lugar se volvió atractivo para seguir dominando las rutas de comunicación que controlaban el comercio de la costa con el Petén y Yucatán. A demás, la situación que reinaba en el Petén, tanto en Tikal como en $C$ alakmul, indica que dejaron un vacío de poder a nivel regional, lo que favoreció el surgimiento de estos sitios y provincias que llegaron a tener un control casi

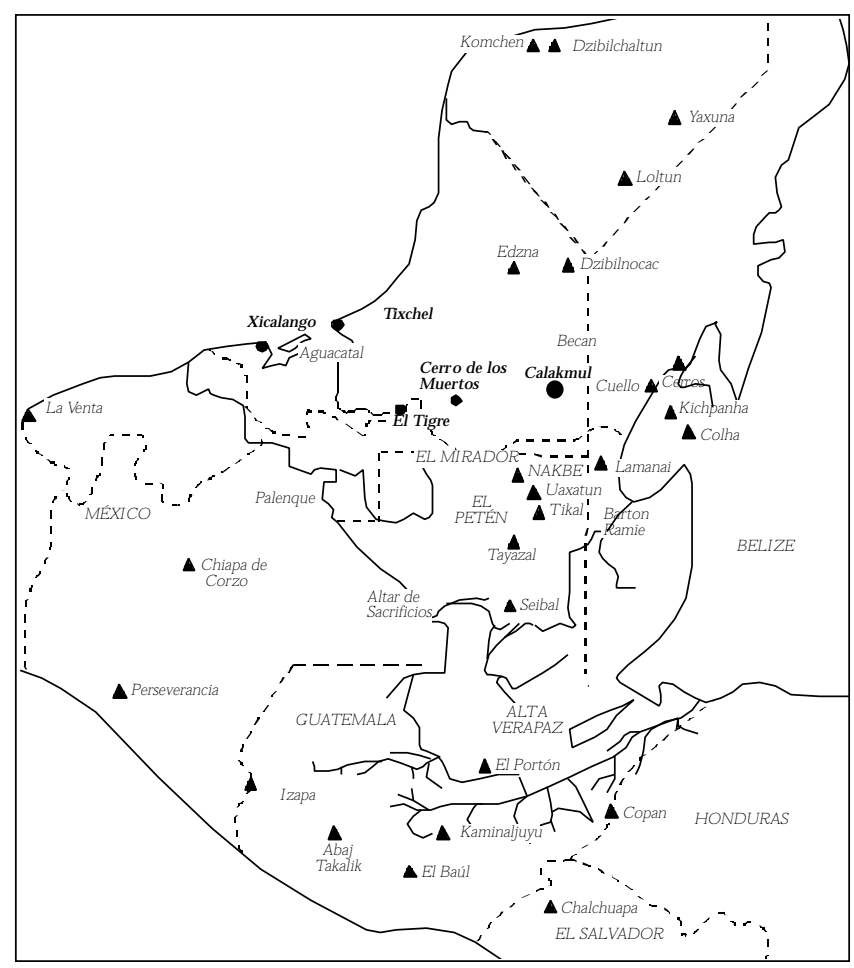

M apa 17. Acalan y el Petén. 
absoluto sobre las rutas fluviales. Debieron de surgir hasta esferas de control sobre esta región que fue la puerta de entrada al área maya, y de esa manera podría explicarse el surgimiento de las tres grandes capitales chontales o putunes: Potonchán, Xicalango e Itzamkanac.

A partir del $950 \mathrm{dC}$ la región parece haber sido abandonada nuevamente, pues los restos materiales a nivel cerámico y arquitectónico disminuyen considerablemente y resurgen durante el Postclásico tardío, sobre todo en la costa y en las orillas del río Candelaria.

Básicamente nos ha interesado investigar los siguientes periodos (cuadro 2 ), que no creemos haber agotado, sólo ha sido un planteamiento para ser retomado por futuras investigaciones:

1. $700 \mathrm{al} 950 \mathrm{dC}$. Los itzaes al parecer realizaron una serie de conquistas hasta asentarse en Chakamputún.

Cuadro 2. Periodificación de El Tigre Campeche.

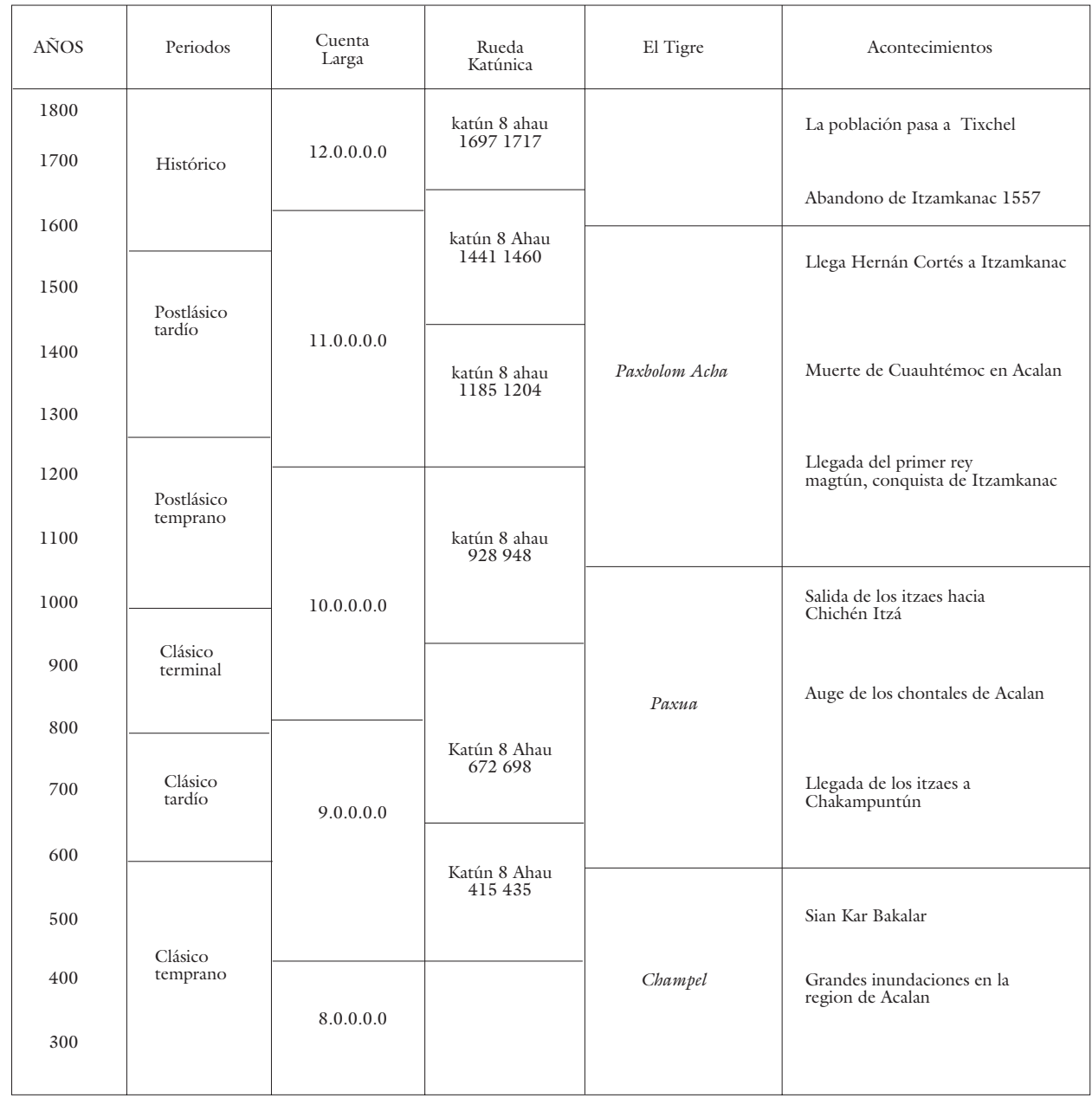


2. 950 al 1200 dC. Los itzaes salen de C hakamputún hacia C hichén I tzá; se dice que pertenecen a una rama putún. EI C hilam Balam narra la conquista que hacen, hasta asentarse en el pozo, en donde les empiezan a tributar.

3. 1200 al $1450 \mathrm{dC}$. Llegan los magtunes desde Cozumel, posiblemente es un grupo de itzaes que regresan al lugar de origen, a la región putún; durante este perio do logran conquistar gran parte de su territorio y tienen conflictos con los otros grupos chontales.

4. 1450 dC. Poblamiento de Itzamkanac según los Papeles de Paxbolom $M$ aldonado y hegemonía de los magtunes en el río $C$ andelaria.

El primer gran reto que afrontamos en este trabajo, fue tratar de reconstruir la provincia de Acalan para la época prehispánica, con base en los trabajos realizados por Scholes y Roys desde 1948. Recorrimos la región registrando y visitando todos los posibles vestigios arqueológicos. Ésta, por ser una región de ríos, lagunas y pantanos estuvo sometida a momentos críticos provocados por las sequías y por la abundancia de agua a consecuencia de los huracanes. Fue la puerta de entrada al área maya y, seguramente, ese fue otro factor importante de perturbación, pues allí llegaron diferentes grupos que suscitaron inestabilidad y conflictos, baste recordar a los magtunes.

\section{EL TIEMPO Y EL ESPACIO SAGRADO}

Los itzaes en su recorrido hacia Chichén Itzá se movieron en un espacio cósmico, obedeciendo los ciclos katúnicos y siguiéndolos en sus cuatro etapas: nacimiento relacionado con el oriente; crecimiento, apogeo y decadencia con el norte; muerte (o retorno al caos) con el poniente; pruebas y obtención de la sabiduría con el sur. L os itzaes emplearon esta estructura ideológica para legitimar su poder político en cada uno de los ciclos ka-túnicos. En cada katún se da todo el proceso, mismo que se repite en cada uno de los cinco grandes periodos.

La asociación del inframundo con el poniente y el que esta región pudiera localizarse en esta parte de Tabasco-Campeche, no es una idea mala, pues el inframundo es además un lugar de sabiduría y renacimiento, necesario para la existencia del cosmos. Tulan-Zuiwá, es un lugar al oeste de Yucatán rodeado de agua, puede ser el antiguo nombre de Xicalango. Para otros autores Z uyúa o Zuivá es una región que se encuentra en el área de la Laguna de Términos.

Entre los grupos que dicen venir de esa región están los quichés, cakchiqueles, itzaes y xiues: «D e cuatro (lugares) llegaron las gentes a Tulan. En oriente está una Tulan; otra en Xibalbay; otra en el poniente, de allí llegamos nosotros, el poniente; y otra donde está dios».

Entre el 700 y 900 de nuestra era, varios grupos étnicos comenzaron a emigrar en busca de nuevas tierras donde asentar sus linajes y fundar pueblos, la región más favorecida fue la costa del Golfo; llevaban como caudillo a señores sacerdotes del culto a Q uetzalcóatl. 
Thompson (1975: 44) nos dice que los itzaes llegaron de cuatro lugares y uno de ellos fue del oeste, $\mathrm{H}$ oltún Zuiua era el nombre putún de Puerto Escondido, localizado en el brazo septentrional que encierra la $L$ aguna de T érminos.

Se dio la relación del tiempo cíclico con los fenómenos naturales y astronómicos muestra de ello son los periodos que quedaron marcados con la llegada de los itzaes a la región de Chakamputún, hacia el $682 \mathrm{dC}$ que coinciden, al decir de Graulich, con el tzolkin, el tun y el año astronómico. Esa fecha es además un katún 8 ahau. C on la simple correlación de las estimaciones de la descarga de aguas del río Candelaria, se aprecia claramente que hacia el $535 \mathrm{dC}$ fue cuando se dio la mayor descarga y la ocupación habitacional de la región fue muy baja, reiniciándose hacia el 700 al $950 \mathrm{dC}$ cuando ocurrió un periodo generalmente tibio, acompañado de precipitación moderada. Alrededor del 800 dC las ciudades mayas de la zona central empezaron a declinar, y seguramente, mucha de la población buscó condiciones climáticas más seguras y por tal motivo la región de ríos y lagunas de Tabasco- $C$ ampeche fue favorecida. $D$ esde $1400 \mathrm{dC}$ las condiciones de baja humedad prevalecieron hasta casi la conquista, por tal motivo no es difícil pensar que cuando pasó C ortés por I tzamkanac, el río C andelaria estuviera en sus niveles más bajos y la construcción de un puente no hubiera sido tan difícil, como cuando estaba en sus niveles más altos.

La expectación por el katún 8 ahau estaba muy difundida entre los mayas, aparece por primera vez en Tikal en la Estela 31, mandada a hacer por Sian C han K'awil 'C ielo Tormentoso' (435 dC) y posteriormente por $\mathrm{H}$ asan $\mathrm{C}$ han K'awil (A h C acau) (692 dC) en el siguiente katún 8 ahau. Estos dos katunes aparecen citados en el C hilam Balam, posteriormente se citan los siguientes, que coinciden con la caída de Chichén Itzá y M ayapán. Estos últimos son descritos por los principales historiadores de la península de Yucatán. La caída de Tayazal, último reducto de los itzaes, que coincide con un katún 8 ahau, es tratada por Avendaño y Villagutiérrez Sotomayor. La historia del katún 8 ahau abarca 1300 años de la vida de los mayas.

La información disponible es muy diversa, proviene de estelas, fuentes indígenas y fuentes de origen español; por lo tanto no creo que se trate de una coincidencia. La creencia en los ciclos katúnicos estaba muy difundida, el mejor caso lo tenemos con $\mathrm{H}$ asan $\mathrm{C}$ han $\mathrm{K}$ 'awil que logró tener éxito en Tikal al demostrar que su linaje y sus conexiones con el gobernante legendario 'C ielo Tormentoso' eran casi de orden divino. U tilizó para su beneficio las expectativas del katún 8 ahau, la historia y las profecías.

Los chontales, igual que algunos otros grupos mayas, tenían la misma estructura del cosmos. A rriba de la tierra se encontraba el cielo, capa donde se localizan los astros. AI Sol se le consideraba de sexo masculino y era el dador de fuerza y calor. L a L una era la gemela, la esposa del Sol y sus atributos son el agua, la lluvia, la vegetación y la fertilidad; se le relacionaba con Ix Bolon. 
El inframundo era un lugar oscuro y frío que se encuentra dentro de la tierra y a donde iban las almas de los muertos. En la mitología maya, los dioses del inframundo regían la lluvia y la fertilidad, habitaban las cuevas. L ugares de transición entre día y noche, vida y muerte, representaban las fauces abiertas de la tierra.

Itzamkanac bien podría significar 'en la segunda casa de la iguana'. O tto Schumann, dice que podría significar 'en la segunda cintura de la iguana', es decir, que el nombre involucra a este dios principal de los yucatecos I tzam $\mathrm{N}$ a, y nos da a entender que es la segunda casa de la iguana; también podría significar que está a la mitad de una región, lo cual es cierto, pues se encuentra casi al centro de la región del río Candelaria. La otra traducción significaría que I tzamkanac fue la segunda casa de los itzaes.

Tixchel significa 'en el lugar de Ix Chel'. Recordemos que el primer señor de los magtunes vino de Cozumel, su hijo Pachimal consolidó el gobierno, y C hampel, nieto de A uxaual, conquistó la Laguna de Términos, Boca N ueva y Puerto Escondido. El cuarto rey Paxgua, cambió la capital a Tixchel, «este rey fue el que pobló a Tixchel». Los pueblos vecinos de Champotón, Xicalango y Tabasco guerrearon contra los intrusos quienes tuvieron que ir a otro lado, Itzamkanac. «Y así dejaron Tixchel despoblado y se fueron a magtún que llaman Acalan».

D espués de varios reyes o señores le tocó a Paxbolom A cha establecer su capital en Acalan-Itzamkanac, «este era el rey que pobló Acalan». Su nombre, como dijimos con anterioridad, tiene que ver con la guerra; Pax era el mes en que se celebraban ceremonias en pro de la guerra y bolon está relacionado con el nueve y la luna, Ixchel.

Los pobladores de Tixchel eran los descendientes del primer rey mag-tún que llegó de Cozumel, en donde, sabemos, estaba el santuario de I xC hel, que a su vez fue una de las diosas principales. Sin lugar a duda el nombre de I tzamkanac está muy relacionado con I tzamná, que es otro de los dioses importantes de losmayas yucatecosy, posiblemente, su nombre se deba a la permanencia de lositzaes en la región de Acalan. En el lugar se ha encontrado un mascarón con la posible representación de Itzam, el cocodrilo-lagarto.

Los mayas concibieron la tierra en función de un extraordinario complejo de símbolos: la imagen de los monstruos de los que brota la vida; la distribución cuatripartita, que a partir de un centro extiende la realidad entera por los rumbos de colores, poblados de dioses y fuerzas primigenias, de aves y árboles cósmicos y también de los humanos que allí viven y mueren.

D ebemos sumerginos en el conocimiento de la cultura e historia de los mayas, nos dice Sir E ric Thompson, debemos tratar de mirar su cosmovisión con ojos no europeos. Sólo entonces comenzaremos a «entrar dentro de la piel » del sacerdote-astrónomo-matemático, sólo entonces entenderemos algo de ese pasado maravilloso que ha quedado en la penumbra de los siglos. 


\section{BiBLIOGRAFÍA}

Adams, Richard E. W.

1973 «M aya Collapse: Transformation and Termination in the Ceramic Sequence at Altar de Sacrificios», en Patrick Culbert (ed.), The $\mathrm{C}$ lassic $\mathrm{M}$ aya $\mathrm{C}$ ollapse, Albuquerque, $\mathrm{U}$ niversity of $\mathrm{N}$ ew $\mathrm{M}$ exico Press, pp. 133-163.

AdAMS, RICHARD E. W. (cOMP.)

1977 The O rigins of $\mathrm{M}$ aya C ivilization, Albuquerque, $U$ niversity of $\mathrm{N}$ ew M exico Press.

AdAm S, ROBERT MCC.

1974 «Anthropological Perspectives on Ancient Trade», C urrent A nthropology, no. 15, pp. 239-258.

Álvarez, Carlos, y luis Casasola

1985 Las figurillas de J onuta, T abasco, M éxico, Instituto de Investigaciones Filológicas, Centro de Estudios Mayas, unam.

Andrews, Anthony P.

1977 «R econocimiento arqueológico de la costa norte del estado de Campeche», Boletín de la Escuela de C iencias A ntropológicas de la U niversidad de Y ucatán, M érida, Yucatán, año 4, no. 24, pp. 64-77.

1978a «Breve adenda al reconocimiento arqueológico de la costa norte del estado de Campeche», Boletín de la Escuela de C iencias A ntropológicas de la U niversidad de Y u catán, M érida, Yucatán, año 6, no. 33, pp. 40-43.

1978b «Puertos costeros del Postclásico temprano en el N orte de Yucatán», Estudios de Cultura M aya, M éxico, Centro de Estudios Mayas-UNAM, vol XI, pp. 75-93.

1983 M aya Salt Production and Trade, Tucson, A rizona, The U niversity of Arizona Press.

1984 «The Political Geography of the Sixteeth C entury Yucatan M aya: Comments and Revisions», J ournal of A nthropological R esearch, XL (4), pp. 589-596. 
ANDREWS, E. WYLLYS

1941 «An Ethnological N ote from Cilvituk, Southern Campeche», N otes on $M$ iddle A merican A rchaeology and ethnology, vol. 1, no. 5, pp. 22-23.

1943 The A rchaeology of Southwestern C ampeche, Washington, C arnegie Institutions Contributions to American Anthropology and $\mathrm{H}$ istory no. 40.

Anglería, Pedro Mártir de

1964-5 D écadas del N uevo M undo, M éxico, Biblioteca J osé Porrúa E strada de $\mathrm{H}$ istoria M exicana, no. 6, 2 vols.

AROCHI, LUIS ENRIQUE

1991 «C oncordancia cronológica arquitectónica entre C hichén Itzá y M ayapán», en J. Broda, S. I waniszewski y L. M aupomé, (eds.), A rqueoas-tronomía y etnoastronomía en M esoamérica, M éxico, I nstituto de Investigaciones H istóricas-UNAM, pp. 97-112.

A tlas arqueológico de la R epública M exicana

1939 Formado por el I nstituto $\mathrm{N}$ acional de Antropología e H istoria, presentación de I gnacio M arquina, M éxico, Publ. 41 del Instituto Panamericano de Geografía e H istoria.

Avendaño y Loyola, Andrés de

1696 R elación de las dos entradas que hize a la conversión de los gentiles Y tzaes y cehaches, ms. 1040, C hicago, Edward E. A yer Collection, N ewberry Library, paleografía de $E$. Vargas $P$.

Aveni, Anthony F. (comp.)

1980 A stronomía en la A mérica A ntigua, M éxico, Siglo xxı editores, col. N uestra América.

BALL, J OSEPH W.

1978 «Archaeological Pottery of the Yucatan-C ampeche C oast», en J. D. Eaton y J. W. Ball (eds.), Studies in the A rchaeology of Coastal $\mathrm{Y}$ ucatan and $\mathrm{C}$ ampeche, $\mathrm{N}$ ew $\mathrm{O}$ rleans, $\mathrm{M}$ iddle American R esearch Institute, 46, pp. 69-146.

1985 «The Postclassic Thompson Wasn Tabasco: The Thirteenththorough Seventeenh-century Archaeology of Central Eastern C ampeche, M exico», The L owland M aya Postclassic..., pp. 73-84.

Barrera Vásquez, Alfredo

1974-5 «La ceiba-cocodrilo», A nales del INAH, época 7a., pp. 187-208.

Barrera Vásquez, Alfredo, y Silvia Rendón

1969 El libro de los libros del C hilam Balam, 4a. ed., M éxico, Fondo de Cultura Económica, Colección Popular no. 42. 
Becerra, M arcos E.

1987 Por la ruta histórica de M éxico, C entroamérica i las Antillas, Villahermosa, Gobierno de Estado de Tabasco.

Benavides C., Antonio

1991 Geografía Política de Campeche en el sigloxvı, M éxico, Serie H istoria, INAH.

1995 «Edzná, su arquitectura y los chontales», M emorias del Segundo $C$ ongreso Internacional de $M$ ayistas, $M$ éxico, Centro de Estudios M ayas-UNAM, pp. 515-529.

Benavides C., Antonio, y Anthony P. Andrews

1979 Ecab: Poblado y Provincia del Siglo xvi en Yucatán, M éxico, IN AH.

BERLIN, H EINRICH

1953 «Archaeological Reconnaissance in Tabasco», C urrent R eports, Washington, Carnegie Institutucion of Washington, no. 7, pp. 102-136.

1956 «L ate Pottery H orizons of Tabasco, M éxico», C ontribution to A merican A nthropology and $\mathrm{H}$ istory, Carnegie Institution of Washington, Publicación 59, pp. 95-153.

BERNAL, I GNACIO

1960 Bibliografía de arqueología y etnografía, M esoamérica y norte de M éxico. 1514-1960, M éxico, INAH .

BINFORD, L. R.

1967 «Smudge Pits and $\mathrm{H}$ ide Smoking: The $U$ se of A nalogy in Archaelogical Reasoning», A merican A ntiquity, no. 32, pp. 1-12.

BOnFIL, GuilLeRmo

1987 «L a encrucijada latinoamericana: ¿encuentro o desencuentro con nuestro patrimonio cultural?», Boletín del INAH, M éxico, vol. 13, suplemento.

BRICKER, VICTORIA R.

1981 The Indian C hrist, the Indian King: The H istorical Substrate of $M$ aya $M$ yth and $R$ itual, Austin, $U$ niversity of Texas Press.

1989 El C risto indígena. El rey nativo, M éxico, Fondo de Cultura Económica.

Brito SAnsores, William

1991 «Interpretación de un calendario sagrado del Códice Madrid», en J. Broda, S. I waiszewski y L. M aupome (eds.), A rqueoastro- 
nomía y etnoastronomía en M esoamérica, M éxico, Instituto de I nvestigaciones H istóricas-UNAM, pp. 145-152.

BRODA, JOHANNA

1989 «G eografía, clima y observación de la naturaleza en la M esoamérica prehispánica», en Ernesto Vargas P. (ed.), La cueva de Santa A na Teloxtoc, M éxico, I nstituto de I nvestigaciones Antropológicas-U NAM , pp. 35-51.

1991 «Cosmovisión y observación de la naturaleza: el ejemplo del culto de los cerros», en J. Broda, S. I waniszewski y L. M aupomé (eds. ), A rqueoastronomía y etnoastronomía en M esoamérica, M éxico, Instituto de Investigaciones H istóricas-un AM , pp. 461-500.

1992 «I nterdisciplinariedad y categorías culturales en la arqueoastronomía de $M$ esoamérica», C uadernos de arquitectura M esoamericana, M éxico, unam, no.19, pp. 23-44.

1993 «Astronomical Knowledge, Calendrics, and Sacred Geography in Ancient M esoamerica», en L. Clive N. Ruggles y N icholas J. Saunders (eds.), A stronomies and Cultures, N iwot, U niversity Press of Colorado.

1994 «Algunas reflexiones acerca de las continuidades culturales en la historia de M éxico», C uicuilco, M éxico, ENAH, nueva época, vol. 1 , no. 1, pp. 27-37.

Cabrera Bernat, Ciprián

1982 Temas de la historia prehispánica de T abasco, M éxico, C onsejo Editorial del Gobierno del Estado de Tabasco.

Cardós de Méndez, Amalia

1959 «El comercio de los mayas antiguos», A cta A ntropológica, M éxiCO, ENAH, vol. 2, no. 1.

CARMACK, Robert M.

1976 «L a estratigrafía quicheana prehispánica», en Pedro Carrasco y Johanna Broda (eds.), Estratificación social en la M esoamérica prehispánica, M éxico, Centro de I nvestigaciones Superiores, SEPINAH, pp. 245-277.

1981 The Quiche M ayas of $U$ tatlan: the Evolution of a $H$ ighland Guatemala Kingdom, N orman, U niversity of O klahoma Press.

Carrasco, Pedro

1978 «La economía del M éxico prehispánico», en Pedro Carrasco y Johanna Broda (eds.), Economía política e ideología en el M éxico prehispánico, M éxico, Editorial N ueva I magen, pp. 13-76. 
Carrasco, Ramón, y Sylviane Boucher

En prensa «U na revisión histórica sobre Garra de Jaguar, Gobernante de Calakmul en el siglo séptimo», en E rnesto Vargas P. (ed.), IV C oloquio de A rqueología, Pedro Bosch Gimpera. La arqueología mexicana, M éxico, Instituto de Investigaciones AntropológicasUNAM.

CASASOLA, LUIS

1979 «L a cerámica del M edio U sumacinta y sus relaciones con otras áreas de las T ierras Bajas $\mathrm{N}$ oroccidentales», $\mathrm{M}$ éxico, manuscrito.

1987 «El colapso maya y la zona del U sumacinta M edio», R evista M e xicana de Estudios A ntropológicos, M éxico, t. xxxıII, vol. 2, pp. 303-306.

Castillo, Noemí

1977 «Presencia del metal en el área maya», Procesos de cambio en $M$ esoamérica áreas circunvecinas, xv $M$ esa Redonda, $M$ éxico, Sociedad M exicana de Antropología y U niversidad de Guanajuato, t. II, pp. 71-77.

Ciudad Real, Antonio de

1976 T ratado curioso y docto de las grandezas de la N ueva E spaña: relación breve y verdadera de las muchas que sucedieron al Padre Fray A lonso Ponce en las provincias de la N ueva España, siendo comisario general de aquellas partes, M éxico, unAm, 2 vols.

CLARK, J.G. D.

1939 A rchaeology and Society, L ondres, M ethuen.

CoBos, RAFAel

1994 «Katún and Ahau: Dating the End of Chichén Itzá», Paper presented in the Symposium: Chronological Framewordks for A ncient $M$ aya D evelopment: $N$ ew Eviden ce from $N$ or theaster $n$ Y ucatan, 93rd Annual M eeting of the A merican Antrhropological Association, Atlanta, D ecember 2.

COE, MICHAEL

1966 The M aya, Londres, Thames and H udson.

Coe, William R.

1967 Tikal: guía de las antiguas ruinas mayas, Filadelfia, U niversity of Pennsylvania. 
Coggins, Clemens

1975 Painting and Drawing Styles at Tikal: An Historical and I conographic R econstruction, PhD dissertation, D epartment of Fine Arts, Ann Arbor, M ichigan, $\mathrm{H}$ arvard U niversity, $\mathrm{U}$ niversity Microfilms, no. 76-3783.

Collingwood, R. G.

1946 The I deal of H istory, O xford, O xford U niversity Press.

CORTÉs, H ERNÁN

1969 Cartas de R elación, M éxico, Porrúa, C ol. «Sepan C uántos...» no. 7.

Culbert, Patrick

1973 The Classic M aya C ollapse, Albuquerque, U niversity of $\mathrm{N}$ ew M exico Press.

Chamberlain, Robert

1974 C onquista y colonización de Y ucatán 1517-1550, M éxico, I ntroducción y notas de I gnacio Rubio M añé, Biblioteca Porrúa (57).

Chapman, AnN

1957 Puertos de intercambio en M esoamérica prehispánica, M éxico, traducción de Felipe M ontemayor, Serie H istórica, INAH, I nstituto Indigenista I nteramericano.

Chase, Arlen y Diane Z. Chase

1996 «M ore than kin and king. Centralized Political O rganization Among the Late Classic M aya», Current A ntrhropology, vol. 37, no. 5, pp. 803-810.

Chávez, José M.

1996 La custodia de San Carlos de Campeche. Intención franciscana de evangelizar entre los mayas rebeldes. Segunda mitad del siglo XVII, tesis de licenciatura en historia, M éxico, Facultad de Filosofía y Letras-UNAM.

DAHLIN, BRUCE H.

1983 «Climate an Prehistory on the Yucatan Peninsula», Climatic Change, no. 5 vol. 3, pp. 245-263.

1986 «Los rostros del tiempo: un movimiento revitalizador en Tikal durante el periodo Clásico tardío», M esoamérica, La Antigua, Guatemala, CIRMA, no.11, pp. 79-112. 
D AVOUST, M .

1980 «L es premiers chefs mayas de Chichén I tzá», M exicon II, no. 2, mayo.

Díaz del Castillo, Bernal

1974 H istoria verdadera de la conquista de la N ueva España, M éxico, Editorial Porrúa, Col. «Sepan Cuántos...» no. 5.

EATON, JACK D.

1978 A rchaeological Survey of the Yucatan-Campeche C oast, $\mathrm{N}$ ew $O$ rleans, $\mathrm{M}$ iddle A merican R esearch I nstitute, Tulane U niversity, Publication 45.

EDMONSON, MUNROS.

1982 The A ncient Future of the Itzá: The Book of C hilam Balam of Tizimín, Austin, U niversity of Texas Press.

ELIADE, MIRCEA

1986 Tratado de historia de las religiones, M éxico, Biblioteca ERA.

FARRISS, N ANCY M.

1980 «Propiedades territoriales en Yucatán en la época colonial: algunas observaciones acerca de la pobreza española y la autonomía indígena», $\mathrm{H}$ istoria mexicana, no. 18, 30(2), pp. 153-208.

1984 M aya Society under C ol onial R ule: The Collective Enterprise of Survival, N ew Jersey, Princeton U niversity Press.

1985 «Recordando el futuro, anticipando el pasado; tiempo histórico y tiempo cósmico entre los mayas de Yucatán», La memoria y el olvido: Segundo Simposio de H istoria de las M entalidades, M éxico, IN AH, pp. 47-60.

Fernández de O Viedo y Valdés, Gonzalo

1851-5 H istoria general y natural de las Indias, islas y tierra firme del mar océano, M adrid, 4 vols.

1959 H istoria general y natural de las Indias, islas y tierra firme del mar océano, M adrid, España, Biblioteca de autores españoles.

FLANNERY, K. V.

1972 «The Cultural Evolution of Civilizations», A nnual R eview of Ecology and Systematics, no. 3, pp. 399-426.

1976 The Early M esoamerican Village, N ueva York, Academic Press.

FLORES, LORENZA

1977 «C ontactos del área maya con otros pueblos de M esoamérica a través de los metales», L os procesos de cambio en M esoamérica y áreas 
circunvecinas, xv M esa redonda, M éxico, Sociedad M exicana de Antropología, U niversidad de G uanajuato, t. ı, pp. 71-77.

FLoRESCANo, EnRIQUE

1994 «La nueva interpretación del pasado mexicano», El historiador frente a la historia, M éxico, Instituto de Investigaciones $\mathrm{H}$ istóricas-unam, Serie de divulgación, pp. 7-27.

FOLAN, WILLIAM

1994 «Calakmul, C ampeche, M éxico. U na megalópolis maya en el Petén del Norte», en W. Folan H. (coord.), C ampeche M aya Colonial, Campeche, U niversidad Autónoma de Campeche, Colección Arqueología, pp. 55-84.

FONCERRADA DE M OLINA, M ARTA

1982 «Signos glíficos relacionados con T láloc en los murales de la batalla en Cacaxtla», A nales del Instituto de I nvestigaciones Estéticas, M éxico, Instituto de Investigaciones Estéticas-unAM, vol. 13(50), pp. 23-33.

1983 «L os murales de Cacaxtla: muerte en la guerra», Jahrbuch für Geschichte von Staat, W irtschaft und Geselleschaft Lateinamerikas, Alemania, t. 20.

FOX, JAMES

1984 «Polyvalance in M aya $\mathrm{H}$ ieroglyphic Writing», en J ohn J usteson y $\mathrm{L}$ yle $\mathrm{C}$ ampbell (eds.), P honeticism in $\mathrm{M}$ ayan $\mathrm{H}$ ieroglyphic $\mathrm{W}$ riting, I nstitute for mesoamerican Studies, State U niversity of N ew York, pp. 17-76.

Fox, JOHN W.

1987 M aya Postclassic States F ormation. Segmentary Lineage M igration in A dvancing Frontiers, Cambridge U niversity Press.

Fox, John, Garrett W. Cook, Arlen F. Chase y Diana Z. Chase 1996 «Q uestions of Political and E conomic I ntegration. Segmentary versus $C$ entralized States among the Ancient $M$ aya», $C$ urrent $A n-$ thropology, vol. 37, 5, pp. 795-801.

García de León, Antonio

1985 R esistencia y utopía. M emorial de agravios y crónicas de revueltas y profecías acaecidas en la provincia de $C$ hiapas durante los últimos quinientos años de su historia, M éxico, Ediciones Era, 2 tomos. 
Garza, Mercedes de LA

1975 La conciencia histórica de los antiguos mayas, M éxico, C entro de Estudios M ayas-unAM, C uaderno 11.

Gerhard, Peter

1991 La frontera sureste de la N ueva España, M éxico, Instituto de Investigaciones $\mathrm{H}$ istóricas e I nstituto de Geografía-u NAM .

GRANT D. JONES

1989 M aya R esistance to Spanish Rule: Time and history on a C olonial Frontier, Albuquerque, U niversity of $\mathrm{N}$ ew M exico Press.

Graulich, MICHEL

1990 M itos y rituales del M éxico antiguo, España, Colegio U niversitario, E diciones I stmo.

Grube, Nikolai y David Stuart

1987 «O bservations on T 110 at the Syllable ko», R esearch R eports on A ncient $M$ aya $W$ riting, Washington, D.C. Center for $M$ aya R esearch, no. 8, pp. 1-14.

Gunn, Joel D., William J. Folan y Hubert R. Robichaux

1994 «Un análisis informativo sobre la descarga del sistema del río $C$ andelaria en Campeche, M éxico: reflexiones acerca de los paleoclimas que afectaron a los antiguos sistemas mayas en los sitios de Calakmul y EI M irador», en W. Folan H ., (coord.), C ampeche $M$ aya $C$ olonial, $C$ ampeche, $U$ niversidad A utónoma de $C$ ampeche, Colección Arqueología, pp. 174-196.

GURRÍA LACROIX, JORGE

1973 I tinerario de H ernán Cortés, E diciones Euroamericanas, M éxico.

Guzmán Bockler, Carlos y Jean L oud Herbert

1970 Guatemala: una interpretación histórico social, M éxico, Siglo Xxı editores.

H Amblin, N AnCy y Amadeo Rea

1979 «L a avifauna arqueológica de C ozumel», Boletín de la Escuela de C iencias A ntropológicas de la U niversidad de Y ucatán, M érida, año 7, no. 37, pp. 21-49.

H AMMOND, N ORMAN

1991 «I nsidetheBlack Box: D efining M aya Polity», en T. P. Culbert (comp.), Classic $M$ aya Political $H$ istory: $H$ ieroglyphic and A rchaeological Evidence, Cambridge, Cambridge $U$ niversity Press, pp. 253-284. 
H ANSEN, RICHARD D.

1990 Excavations in the Tigre C omplex, EI M irador, Peten, Guatemala, Papers of the N ew World Archaeological Foundation, Provo, U tah, Brigham Young U niversity, no. 62.

1992 «El proceso cultural de Nakbé y el área del Petén N or-Central: Las épocas tempranas», v Simposio de I nvestigaci ones A rqu eológicas en Guatemala, 15-18 de julio de1991, Guatemala, M useo N acional de Arqueología y Etnología, M inisterio de Cultura y Deportes, Instituto de Antropología e H istoria, Asociación Tikal, pp. 81-96.

H ernández Ayala, Martha I von

1981 C ronología y periodificación de la región del río San Pedro M ártir, Tabasco, tesis profesional, M éxico, ENAH.

H ernández, Martha, y Carlos Álvarez

1978 «N otas sobre las ocupaciones en el área del río San Pedro», Estudios preliminares sobre los mayas de las Tierras Bajas $\mathrm{N}$ oroccidentales, M éxico, Centro de Estudios M ayas-unam, pp. 45-70.

HODDER, I AN

1991 Interpretación en A rqueología. Corrientes actuales, Barcelona, España, Ed. Crítica.

H ODdER, IAN, y CLIVE ORTON

1990 A nálisis espacial en arqueología, Barcelona, España, Ed. C rítica.

H ODGE, MARY G.

1984 «Aztec City-States», Studies in Latin A merican Ethnohistory and A rchaeology, vol. 13, M emoirs of the M useum of Anthropology, 18, Ann Arbor, U niversity of M ichigan.

H odell, David A., Jason H. CuRtis y Mark Brenner

1995 «Posible Role of Climate in the Collapse of Classic M aya Civilization», Nature, no. 375, pp. 391-394.

I NCHÁUSTEGUI, CARLOS

1987 Las márgen es de T abasco chontal, Villahermosa, Tabasco, M éxico, I nstituto de Cultura de Tabasco.

I ZQUIERdo, ANA LUISA

1978 «L as influencias nahuas entre los chontales», Estudios preliminares sobre los mayas de las T ierras Bajas $\mathrm{N}$ or occidentales, M éxico, Centro de Estudios M ayas-unAM, pp. 71-90. 
1984 «L a visión geográfica de la chontalpa en el siglo XVI», Estudios de Cultura $M$ aya, $M$ éxico, Centro de $E$ studios $M$ ayas-Instituto de I nvestigaciones Filológicas-un AM, vol. xv, pp. 143-176.

1997 A calan y la chontalpa en el siglo xvı. Su geografía política, M éxico, C entro de Estudios M ayas-I nstituto de I nvestigaciones FilológicasUNAM.

Jiménez M oreno, Wigberto

1976 «Síntesis de la historia pretolteca de M esoamérica», Esplendor del M éxico A ntiguo, M éxico, C entro de I nvestigaciones Antropológicas de M éxico, pp. 1019-1108.

Jiménez Valdés, Gloria Martha

1984 La arqueología de la península deX icalango, tesis profesional, M éxiCO, ENAH .

Jones, Grant D.

1989 M aya resistance to spanish R ule:T Time and $\mathrm{H}$ istory on a Colonial Frontier, Albuquerque, $U$ niversity of $\mathrm{N}$ ew M exico Press.

KELLY, D AVID

1968 «Kakupacal and the itzas», Estudios de Cultura M aya, M éxico, Centro de Estudios M ayas-unAM, vol. vII, pp. 255-268.

1976 D esciphering the M aya Script, Austin, U niversity of Texas Press.

1982 «N otes on Puuc I nscriptions and H istory», en L awrence M ills (ed.), The Puuc: N ew Perspectives: Papers Presented at the Puuc Symposium, Pella, Iowa, Central College, M ay 1977, Supplement, Central College.

KOWALSKI, JEFF KARL

1985 «L ords of the N orthern M aya: Dynastic H istory in the Inscriptions», Expedition, 27 (3), pp. 50-60.

1989 «Who Am I Among the Itza?: Links between N orthern Yucatán and the Western M aya L owlands and $\mathrm{H}$ ighlands» en Richard D iehl y J anet Berlo (eds.), M esoamerica after the D ecline of T eotihuacán, A.D. 700-900, Washington, D.C., Dumbarton Oaks Research Library and Collection, pp. 173-186.

Lacadena, Alfonso

1997 «Bilingüismo en el Códice de M adrid», Los investigadores de la cultura maya, Campeche, M éxico, U niversidad Autónoma de Campeche, no. v, pp. 184-204. 
LANDA, FRAY DIEGO DE

1978 R elación de las cosas de Yucatán, M éxico, Biblioteca Porrúa no. 13.

LANGE, FEDERICK

1971 «M arine Resources: a Viable Subsistence Alternative for the Prehistoric L owland M aya», A merican A nthropologist, 73, 3, pp. 619-639.

Laporte Molina, Juan Pedro

1996 «El concepto de entidad segmentaria en la historia arqueológica del noroeste de las montañas mayas», M ayab, M adrid, España, U niversidad Complutense, no.10, pp. 25-32.

León Portilla, Miguel

1968 Tiepo y realidad en el pensamiento maya, M éxico, Ensayo de acercamiento, Serie Culturas M esoamericanas, Instituto de Investigaciones $\mathrm{H}$ istóricas-UNAM .

Ligorred P., José de C.

1993 La Escultura Puuc: A nálisis iconológico del C odz Pop de Kabah, tesis profesional, M éxico, ENAH .

LiNCOLN, ChARLESE.

1990 Ethnicity and Social O rganization at C hichén Itzá, Y ucatan, $\mathrm{M}$ exico, tesis doctoral presentada en la U niversidad de $\mathrm{H}$ arvard.

1993 «Structural and Philological Evidence for Divine Kingship at Chichén Itza, Yucatan, $\mathrm{M}$ exico», en $\mathrm{H}$ ans Prem (ed.), $\mathrm{M}$ aya A rchaeology of the N orth-W estern Y ucatan Peninsula, Germany, $\mathrm{H}$ idden Among $\mathrm{H}$ ills, Acta mesoamericana, vol. 7, Verlag von Flemming, Möckmühl, pp.164-196.

López Austin, Alfredo

1984 T extos de medicina náhuatl, Instituto de I nvestigaciones $\mathrm{H}$ istóricas-unam, M éxico.

López de Cogolludo, Diego

1957 H istoria de Y ucatán, M éxico, 5a edición, Colección de Grandes Cronistas M exicanos, Academia literaria.

López de Gómara, FRANCISCO

1965 H istoria general de las I ndias, España, Artes Gráficas R afael Salvá, 2 vols. 
LóPEZ de VeLASCo, JuAN

1994 Geografía y descripción universal de las indias recopiladas por el cosmógrafo-cronista Juan López de Velasco desde el año de 1571 al de 1574, M adrid, Tipográfico de Fortanet.

Lothrop, SAMuel

1952 M etals from the $C$ enote of Sacrifice $C$ hichén I tzá, $Y$ ucatan, C ambridge, $\mathrm{H}$ arvard $\mathrm{U}$ niversity, $\mathrm{M}$ emoirs of the Peabody $\mathrm{M}$ useum of Archaeology and Ethnology, vol. X, 2.

MARCUS, JOYCE

1973 «Territorial O rganization of the Lowland Classic M aya», Science, no. 180, pp. 911-916.

1976 E mblem and State in the C Iassic M aya Lowlands, Washington, D.C., D umbarton $\mathrm{O}$ aks.

1983 «L owland M aya Archaeology at the C rossroads», A merican A ntiquity, no. 48, pp. 454-488.

1992a «D ynamic C ycles of M esoamerican States», N ational G eographic R esearch \& Exploration, Washington, D.C., 8 (4), pp. 392-411.

1992b M esoamerican W riting Systems: Propaganda, M yth, and H istory in Four A ncient C ivilizations, $U$ niversity of Princeton Press, $\mathrm{N}$ ew J ersey.

1993 «Ancient M aya Political O rganization», en Jeremy A. Sabloff y J ohn S. H enderson (eds.), Lowland $M$ aya $C$ ivilization in the Eigth C entury A.D., Washington, D.C., D umbarton O aks R esearch Library and Collection, pp. 111-183.

1995 «Patrones comunes en varios estados M esoamericanos», I nvestigadores de la cultura maya, Campeche, U niversidad de $C$ ampeche, 3, t. I, pp.186-214.

MarCus, JoyCE, y W. Folan

1994 «U na estela más del siglo v y nueva información sobre Pata de J aguar, gobernante de Calakmul en el siglo viı», Gaceta U niversitaria, M éxico, U niversidad Autónoma de Campeche, año IV, pp. 15-16.

MathenY, RAY R.

1970 «The ceramics of Aguacatal, C ampeche, M exico», Papers of the $\mathrm{N}$ ew W orld A rchaeological Foundation, Provo, U tah, Brigham Young U niversity, 27.

1987 «El M irador», N ational Geographic, vol. 172, 3, septiembre, pp. 316-339. 
1971-1960 «Investigations in Campeche, M exico», C erámica de C ultura M aya, Philadelphia, Penn., 7, pp. 1-15,

M AYER, PABLO

1977 «Can C un: informe preliminar», Los procesos de cambio en M esoamérica y áreas circunvecinas, xv M esa Redonda, M éxico, Sociedad M exicana de Antropología y U niversidad de Guanajuato, t. II, pp. 207-213.

MEDINA, ANDRÉS

1994 «L a etnografía como una reflexión en torno a la nación», M irada A ntropológica, Puebla, U niversidad Autónoma de Puebla, vol. I, 1.

Memorial de Sololá o Anales de los Cakchiqueles

1950 Traducción, introducción y notas de Adrián Recinos, M éxico, Fondo de Cultura Económica, Biblioteca Americana, Serie de Literatura indígena, no. 11.

Miller, Arthur

1977 «The M aya and the Sea: Trade and Cult at Tancah and Tulum, Q uintana Roo, M exico», en Elizabeth Benson (ed.), The Sea in the Precolumbian $\mathrm{W}$ orld, Washington, Trustees for $\mathrm{H}$ arvard $\mathrm{U}$ niversity, pp. 97-140.

MILLET, LUIS

1984 «L os canales de la costa de Campeche y su relación con la industria del palo de tinte», M esa R edonda de la Sociedad M exicana de A ntropología, C hiapas, M éxico, 17 (2), pp. 237-245.

1989 «Edzná, Campeche: una revaloración de su historia», M emorias del Segundo Coloquio I nternacional de $M$ ayistas, $M$ éxico, Centro de Estudios M ayas-UNAM , 1981, 1, pp. 517-521.

MONTOLIÚ, MARÍA

1989 C uando los dioses despertar on. C on ceptos cosmol ógi cos de los antiguos mayas de Y u catán, estudiados en el C hilam Balam de C humayel, M éxico, Instituto de Investigaciones Antropológicas-un AM.

MORIN, EDGAR

1990 Introducción al pensamiento complejo, Barcelona, España, Gedisa Editores.

OCHOA, LORENZO

1985 «O rigen, desarrollo y decadencia de la cultura maya en Tabasco», en Lorenzo O choa (coord.), OImecas y mayas en Tabasco. C inco 
acercamientos, Villahermosa, Tabasco, M éxico, Gobierno del Estado de Tabasco, pp. 73-92.

OCHOA, LORENZO Y ERNESTO VARGAS

1979 «EI colapso maya, los chontales y Xicalango», Estudios de C ultura M aya, M éxico, Centro de Estudios M ayas-unAM, vol. XII, pp. 61-91.

1986 «I nforme del reconocimiento arqueoló gico realizado en la cuenca del río Candelaria, Campeche», Estudios de Cultura M aya, M éxico, Centro de Estudios M ayas-unAM, vol. xvı, pp. 325-377.

1989 «Xicalango, puerto chontal de intercambio: mito y realidad», Comercio, comerciantes y rutas de intercambio en el $M$ éxico antiguo, M éxico, Secretaría de Comercio y Fomento I ndustrial, pp. 203-219.

O KOSHI H ARADA, TSUBASA

1993 L os canules: análisis etnohistórico del Códice de C alkiní, tesis doctoral en $\mathrm{H}$ istoria, M éxico, UnAm .

1994 «E cab: una revisión de la geografía política de una provincia maya yucateca del Postclásico tardío», M emoria del Primer Congreso Internacional de $M$ ayistas, $M$ éxico, Centro de $E$ studios $M$ ayas-I nstituto de Investigaciones Filológicas-U N AM, pp. 280-287.

1995a «Tenencia de la tierra y territorialidad: conceptualización de los mayas yucatecos en vísperas de la invasión española», en Lorenzo O choa (ed.), C onquista, transculturación y mestizaje. Raíz y origen de M éxico, M éxico, unAM, pp. 81-94.

1995b «Gobierno y pueblos entre mayas yucatecos postclásicos», R evista U niversidad de M éxico, M éxico, no. 534-535, pp. 22-27.

1997 «T iempo de los I tzaes y de los Cocom», en M arie-O dile M arion (coord.), Simbológicas, M éxico, CONACYT, 1, pp. 81-190.

O koshi H arada, Tsubasa y Sergio Quezada

1990 «T zucub y cuchcabal: dos términos para entender la organización territorial de los mayas yucatecos en el tiempo de la invasión española (el caso de la llamada provincia de los cupules)», en Yoko Sugiura y M ari Carmen Serra (eds.), Etnoarqueología: Primer Coloquio Bosch-Gimpera, M éxico, unAM, pp. 363-369.

Palerm, Ángel, y Eric Wolf

1973 O bras hidráulicas prehispánicas en el sistema lacustre del valle de M éxico, M éxico, INAH. 
Peniche Rivero, Piedad

1990 Sacer dotes y comerciantes. El poder de mayas e itzaes. Y ucatán en los siglos vII-XVI, M éxico, F ondo de Cultura E conómica.

1994 «Q uetzalcóatl, la moneda cacao y los itzaes: la integración de los mayas de Yucatán, $\mathrm{H}$ onduras y $\mathrm{G}$ uatemala con el Altiplano de M éxico», en William Folan $\mathrm{H}$ iggins (coord.), Campeche maya colonial, Campeche, U niversidad Autónoma de Campeche, Colección Arqueología, pp. 162-173.

Pérez González, B.

1968 «La fundación de Tuxta, una leyenda chontal», T lalocan, M éxico.

PIGOTT, S.

1959 A pproach to A rchaeology, C ambridge, M assachusetts, $\mathrm{H}$ arvard U niversity Press.

Pincemín Deliberos, Sophia

1993 R emontando el río..., Campeche, M éxico, U niversidad Autónoma de Campeche, Colección Arqueología.

PIÑa Chan, ROMÁN

1977 C ampeche, durante el periodo colonial, M éxico, INAH .

1980 C hichén Itzá. La ciudad de los brujos del agua, M éxico, Fondo de Cultura Económica.

1985 C ultura y ciudades mayas de C ampeche: C alakmul, Edzná, Becan X puhil, Jaina, Gobierno del Estado de Campeche, Campeche.

1991 El Puuc. U na tradición cultural maya, M éxico, Citibank.

Piña Chan, Román y Raúl Pavón Abreu

1959 «Fueron las ruinas EI Tigre, Itzamkanac?», El M éxico A ntiguo, M éxico, t. xı, pp. 473-481.

PROSKOURIAKOFF, TATIANA

1963 «H istorical Data in the Inscriptions of Yachilan» (part I), Estudios de Cultura M aya, M éxico, 3, pp. 149-167.

1996 H istoria maya, M éxico, Siglo xxı editores, Colección América N uestra, no. 42.

Quezada, Sergio

1993 Pueblos y caciques yucatecos, 1550-1580, M éxico, El Colegio de M éxico. 
RANDS, ROBERT L.

1967 «Cerámica de la región de Palenque, M éxico», Estudios de C ultura M aya, M éxico, Centro de Estudios M ayas-un AM, vol. vı, pp. 111-147.

Rathje, William, Jeremy A. Sabloff y David A. Gregory

1973 «El descubrimiento de un jade olmeca en la isla de Cozumel, Q uintana Roo, M éxico», Estudios de C ultura de M aya, M éxico, Centro de Estudios M ayas-UNAM, Ix, pp. 85-9.

RECINOS, AdRIÁN

1964 Popol Vuh. Las antiguas historias del Quiché, M éxico Fondo de Cultura E conómica, Colección Popular.

1983 [1898] Relaciones H istórico Geográficas de la Gobernación de Y ucatán, 2 vols, M ercedes de la Garza et al. (eds.), paleografía de $M$ a. del Carmen León, M éxico, C entro de Estudios M ayasI nstituto de Investigaciones Filológicas-u nam, Serie Fuentes para el Estudio de la Cultura M aya no. 1.

Renfrew, Colin y Eric V. Level

1984 «Exploring dominance: Predicting Polities from Centers», A pproaches to Social A rchaeology, E dimburgo, E dinburgh U niversity Press, pp. 54-77.

Rivera Dorado, Miguel

1986 La religión maya, M adrid, Alianza Editorial.

ROBLES, FERNANDO

1980 «La secuencia cerámica de la región de Cobá, Q uintana Roo», M éxico, In AH, Colección Científica, Serie Arqueología.

Robles, Fernando y Anthony Andrews

1986 «A R eview and Syntesis of R ecent Postclassic Archeology in N orthern Yucatan», en J. A. Sabloff y W. W. Andrews V. (eds.), Late $L$ owland $\mathrm{M}$ aya $\mathrm{C}$ ivilization, Albuquerque, $\mathrm{U}$ niversity of $\mathrm{N}$ ew $\mathrm{M}$ exico Press, pp. 53-98.

ROVNER, I RWIN

1976 «A M ethod for $D$ etermining $O$ bsidian Trade $P$ atterns in the $M$ aya Lowlands», Katunob, vol. Ix, 1, pp. 43-50.

ROYS, RALPH L.

1933 The Book of C hilam Balam of C humayel, Washington, Carnegie Institution of Washington, publ. 438. 
1943 The Indian Background of C olonial Y ucatan, U niversity of O klahoma Press.

1957 The Political G eography of the Y ucatan M aya, Washington, cıw, Publ. 613.

1972 The Indian Background of C olonial Yucatan, U niversity of O klahoma Press.

Ruz L., Alberto

1945 «C ampeche en la arqueología maya», A cta antropológica, M éxico, INAH, vol. 1 (2-3), 18.

1969 L a costa de C ampeche en los tiempos prehispánicos, M éxico, Serie Investigaciones del INAH no.18.

1971 «I nfluencias mexicanas sobre los mayas», D esarrollo cultural de los mayas, M éxico, Centro de Estudios M ayas-unAM, pp. 203-241.

RUZ, MARIO H UMBERTO

1991 L os linderos del agua. Francisco de M ontejo y los orígenes de T abasco colonial, paleografía y estudio, Gobierno del Estado de Tabasco.

Sabloff, Jerem

1973 «C ontinuity and D isruption during Terminal L ate Classic Times at Seibal: C eramic and other E vidence», en T. P. Culbert (comp.), The $\mathrm{C}$ Iassic $\mathrm{M}$ aya $\mathrm{C}$ ollapse, Albuquerque, $\mathrm{U}$ niversity of $\mathrm{N}$ ew M exico Press, pp. 107-131.

Sabloff, Jeremy y William Rathje (eds.)

1975 «A Study of Changing Precolumbian Commercial Systems: the 1972-1973 Seasons at Cozumel, M exico», M onographs of the Peabody M u seum, Cambridge, M ass., $\mathrm{H}$ arvard U niversity, no. 3.

Sahagún, Fray Bernardino de

$1975 \mathrm{H}$ istoria general de las cosas de N ueva España, M éxico, Editorial Porrúa, Col. «Sepan cuántos...» 300.

Sánchez Caero, Ó scar F.

1979 Excavaciones arqueológicas en la zona de J onuta, T abasco, tesis profesional, M éxico, ENAH.

Sánchez de Aguilar, Pedro

1937 Informe contra I dolorun C ultores, 3a. edición, M érida, M éxico.

SCHELE, Linda y DaVid Freidel

1990 A F orest of Kings: The U ntold Sotry of the A ncient M aya, N ew York, Q uill William M orrow. 
SCHOLES, F. y AdAMS

1938 D on D iego Quijada, alcalde mayor de Y ucatán, 1561-1565, M éxico, Biblioteca $\mathrm{H}$ istórica M exicana, vols. 14-15.

SCHOLES, F. y R. ROYS

1968 The M aya C hontal Indians of A calan-T ixchel, N orman, U niversity of O klahoma Press.

1997 Los chontales de A calan-Tixche, M ario H. Ruz y Rosario Vega (trads.), $M$ éxico, Centro de Estudios M ayas-un AM y Centro de Investigaciones y Estudios Superiores en Antropología Social.

SCHUMANn, OtTo

1978 «C onsideraciones sobre el idioma chontal de Tabasco», en L orenzo $O$ choa (ed.), Estudios preliminares sobre los mayas de las tierras bajas noroccidentales, M éxico, Centro de Estudios M ayas-UnAM, pp. 91-105.

1985 «C onsideraciones históricas acerca de las lenguas indígenas de Tabasco», en Lorenzo O choa (coord.), O Imecas y mayas en T abasco. C inco acercamientos, Villahermosa, M éxico, Gobierno del Estado de Tabasco, pp. 113-128.

Siemens, Alfred

1966 N ew A gricultural Settlement along M exico's C andelaria R iver, Inter-American E conomic Affaiirs, 20-23-39.

1989 Tierra Configurada, M éxico, conACULTA.

Siemens, Alfred y Dennis E. Puleston

1972 «Ridged fields and associated features in Southern C ampeche. N ew Perspectives on the Lowland M aya», A merican A ntiquity, 37 (2), pp. 228-239.

SMALIUS, O RTWIN

1975 El maya-chontal de A calan. A nálisislingüístico de un documento de losaños 1610-1612, M éxico, Centro de Estudios M ayas-I nstituto de Investigaciones Filológicas-unam, Serie de Cuadernos no. 9.

Sotelo Santos, Laura Elena

1988 Lasideas cosmológicas mayas en el siglo xvı, M éxico, Centro de Estudios M ayas-unAM, C uaderno no. 19.

THOMPSON, ERIC

1954 The R ise and Fall of $M$ aya C ivilization, $\mathrm{N}$ orman, U niversity $\mathrm{O}$ klahoma Press. 
1960 M aya $\mathrm{H}$ ieroglyphic W riting, N orman, U niversity of O klahoma Press.

1974 «C anals of the Rio C andelaria B asin, Campeche, M exico», en N. $\mathrm{H}$ ammond (ed), M esoamerican A rchaeology $\mathrm{N}$ ew A pproaches, Austin, U niversity of Texas Press, pp. 297-302.

$1975 \mathrm{H}$ istoria y religión de los M ayas, Félix Blanco (trad.), M éxico, Siglo xxI editores.

TORRES, FRAY TOMÁS DE LA

1945 D esde Salamanca España hasta C iudad R eal, C hiapas. D iario del viaje 1544-1545, Frans Blom (prol.), M éxico, Editora C entral.

Toscano, Salvador

1984 C uauhtémoc, M éxico, Fondo de Cultura Económica, Secretaría de Educación Pública, L ecturas M exicanas, no. 20.

Tozzer, Alfred M.

1978 Landa's R elacion de las C osas de Y ucatan. A translation, N ew York, Kraus R eprint $\mathrm{C}$ o., $\mathrm{H}$ arvard U niversity, Papers of the Peabody $\mathrm{M} \mathrm{u-}$ seum of American Archaeology and Ethnology, vol. XvIII.

TRIGGER, BRUCE G.

1978 Time and Traditions: Essays in A rchaeological Interpretation, Edimburgo, E dinburgh U niversity Press.

$1992 \mathrm{H}$ istoria del pensamiento arqueológico, Barcelona, E ditorial C rítica.

Valdés, Juan Antonio, Federico Falsen y Gaspar Muñoz C.

1997 Estela 40 de Tikal. H allazgo y lectura, Guatemala, Instituto de Antropología e H istoria de Guatemala, A gencia E spañola de C ooperación Internacional, Ministerio de Cultura y Deportes de Guatemala.

Vargas Pacheco, ERnesto

1983 «L os mayas chontales de Tabasco», en L orenzo O choa y Thomas Lee Jr. (eds.), A ntropología e historia de los mixe-zoque y mayas, M éxico, UnAM, Brigham Young U niversity, pp. 271-302.

1985 «A rqueología e historia de los mayas-chontales de Tabasco», en L. O choa (coord.), O Imecas y mayas en T abasco. C inco acercamientos, Villahermosa, M éxico, Gobierno del Estado de Tabasco, pp. 93-112.

1987 «H istoria y antropología. Algunas enseñanzas del doctor R. Piña Chan», H omenajea R omán Piña, M éxico, unAm, pp.131-145.

1991 «I nvasiones, influencias, contactos y conquistas durante la época prehispánica. Algunas reflexiones», Seminario Internacional de 
Pueblos Indios, Guatemala, EI v Centenario del D escubrimiento de América, CEMCA, pp. 11-18.

1993 «El espacio sagrado en Tulum», Iv M esa R edonda de la Sociedad Española de Estudios M ayas. R eligión y Sociedad en el Á rea M aya, $M$ adrid, España, U niversidad Complutense.

1994a «Síntesis de la historia prehispánica de los mayas chontales de TabascoCampeche», A mérica Indígena, M éxico, no. 1-2, pp. 15-61.

1994b Proyecto arqueológico «EI Tigre» I tzamkanac, cabecera de la Provincia deAcalan, manuscrito, presentado al Consejo deArqueología del INAH , M éxico.

1996 «Entidades político territorial de los mayas antiguos de Yucatán», R evista de A rqueología A mericana, M éxico, I nstituto Panamericano de Geografía e H istoria, no. 10, pp. 101-119.

Vargas, ERnesto, y Angélica Delgado

1999 «D escubrimientos recientes en "EI T igre" », L os investigador es de la cultura maya, Campeche, U niversidad Autónoma de Campeche, manuscrito.

Vargas, Ernesto, Angélica Delgado y Jacobo Mugarte

2000 «I conografía de los mascarones pleclásicos de EI Tigre», Ix Encuentro L os Investigador es de la C ultura M aya, Campeche, M éxico, U niversidad Autónoma de Campeche.

Vargas, ERnesto, y Martha I. Hernández

1979 «N otas sobre el sitio arqueológico de R eforma, Balancán, Tabasco», R evista M exicana de Estudios A ntropológicos, M éxico, Sociedad M exicana de Antropología, t. xxv, pp. 47-71.

VARGAS, ERNESTO, Y LORENZO OCHOA

1982 «N avegantes, viajeros y mercaderes: N otas para el estudio de la historia de las rutas fluviales y terrestres entre la costa de TabascoCampeche y tierra adentro», Estudios de C ultura M aya, M éxico, Centro de Estudios M ayas-unAM, vol. XIv, pp. 59-119.

Vargas, ERnesto, y Kimiyo Teramoto

1996 «L as ruinas arqueológicas de EI T igre, C ampeche. ¿l tzamkanac?», M ayab, M adrid, España, Sociedad Española de Estudios M ayas, no. 10, pp. 33-45,

1997a Tulum. Organización político-territorial de la costa oriental de Quintana R 00, M éxico, I nstituto de I nvestigaciones Antropológicas-U NAM . 
1997 b « so, manejo y dominio de los recursos fluviales. El caso del Candelaria», Los investigadores de la cultura maya, C ampeche, U niversidad Autónoma de Campeche, no. 5, pp. 432-445.

1997c «El Katún 8 ahau», en M arie-O dile M arion (coord.), Simbológicas, M éxico, CONACYT, pp. 191-198.

s/ f «L as L lanuras intermedias», Estudios de C ultura M aya, M éxico, Centro de Estudios M ayas-UNAM .

Vásquez Dávila, Marco Antonio, y Enrique Hipólito H.

1994 «La cosmovisión de los chontales de Tabasco: notas preliminares», A mérica Indígena, M éxico, Instituto Indigenista I nteramericano, vol. LIV, 1-2, pp. 149-168.

Velázquez Morlet, Adriana y Edmundo López de la Rosa

1995 a «L a región y la ciudad: dinámica de los patrones de asentamiento en el occidente de Yucatán», en E. Vargas (comp.), Seis ensayos sobre antiguos patrones de asentamiento en el área maya, M éxico, Instituto de Investigaciones Antropológicas-un AM, pp. 93-112.

1995b «Tiempos difíciles: consideraciones sobre la crisis general de los siglos Ix y x en Yucatán», M emorias del Segundo C ongreso Internacional de $M$ ayistas, $M$ éxico, Centro de Estudios $M$ ayas-Instituto de I nvestigaciones Filológicas-un AM , pp. 225-238.

Villagutierre, JuAn de

1985 «H istoria de la conquista de Itzá», C rónicas de A mérica, España, $\mathrm{H}$ istoria 16.

Villa Rojas, Alfonso

1968 «Los conceptos de espacio y tiempo entre los grupos mayances contemporáneos», en M iguel León Portilla (ed.), T iempo y realidad en el pensamiento maya, M éxico, Instituto de I nvestigaciones H istóricas-un Am, Serie de C ulturas M esoamericanas no. 2.

1985 «L a tenencia de la tierra entre los mayas de la antigüedad», Estudios etnológicos: los mayas: M éxico, unAM, pp. 23-45.

VOGT, EVON Z.

1964 «The genetic model and M aya cultural development», en E. Z. Vogt y A. Ruz R. (eds.), D esarrollo cultural de los mayas, M éxico, Seminario de Cultura M aya, un Am, pp. 9-48.

W ASSERSTON, ROBERT

1989 Clase y sociedad en el centro de C hiapas, M éxico, Fondo de Cultura Económica. 
Willey Gordon, R., y W. R. Bullard J R.

1953 Prehistoric Settlements in the Viru Valley, Peru, en R. Wauchope y R. Willey (eds.), Bureau of M iddle American Indians, Austin Texas Press, vol. 2.

WISDOM, CHARLES

1961 Loschortís de Guatemala, G uatemala, Editorial del M inisterio de E ducación Pública «J osé de Pineda I barra».

ZAVALA, SILVIO

1992 «A preciación sobre el historiador frente a la historia», El historiador frentea la historia, M éxico, Instituto de Investigaciones H istóricas-U NAM, Serie de Divulgación, pp. 47-56. 


\section{Itzamkanac y Acalan}

Tiempos de crisis anticipando el futuro

Editado por el Instituto de Investigaciones Antropológicas de la Universidad Nacional Autónoma de México, la versión electrónica se terminó en el mes de junio de 2015. La corrección estuvo a cargo de Adriana Incháustegui y Omar Marín; su composición se hizo en el IIA por Lourdes Aznavwrian Salas y Martha González en tipo Galliard 11:13, 13:13 y 18:20 puntos y la fotografía por Rafael Reyes. La edición estuvo al cuidado de Juan Antonio Perujo. 


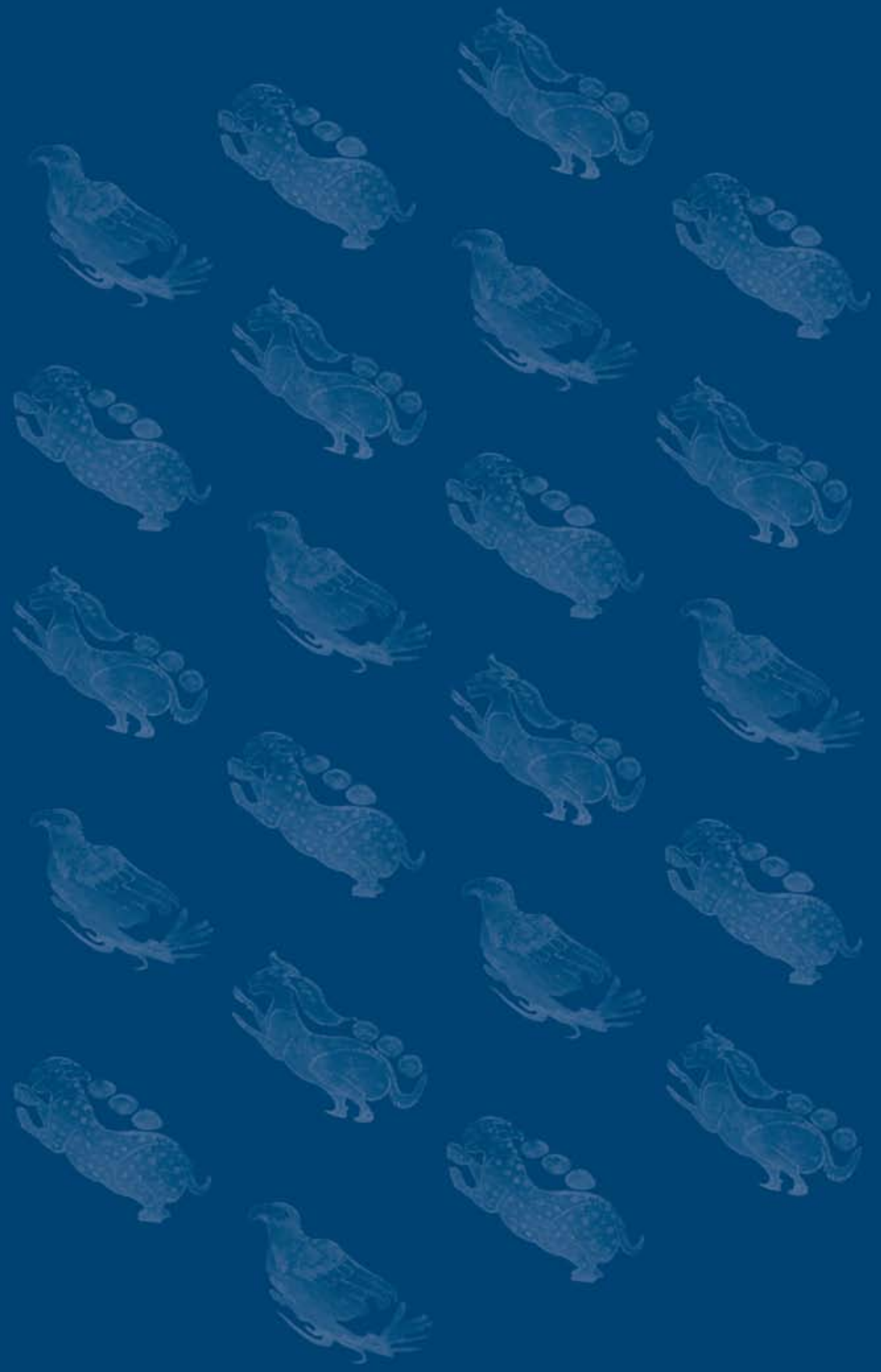

